\title{
1988 Wet Deposition Temporal and Spatial Patterns in North America
}

\author{
J. C. Simpson \\ A. R. Olsen \\ E. A. Bittner
}

March 1992

Prepared for

the U.S. Environmental Protection Agency

under a Related Services Agreement

with the U.S. Department of Energy

Contract DE-AC06-76RLO 1830

Pacific Northwest Laboratory

Operated for the U.S. Department of Energy

by Battelle Memorial Institute 


\title{
DISCLAIMER
}

This report was prepared as an account of work sponsored by an agency of the United States Government. Neither the United States Government nor any agency thereof, nor Battelle Memorial Institute, nor any of their employees, makes any warranty, expressed or implied, or assumes any legal liability or responsibility for the accuracy, completeness, or usefulness of any information, apparatus, product, or process disclosed, or represents that its use would not infringe privately owned rights. Reference herein to any specific commerclal product, process, or service by trade name, trademark, manufacturer, or otherwise does not necessarily constitute or imply its endorsement, recommendation, or favoring by the United States Government or any agency thereof, or Battelle Memorial Institute. The views and opinions of authors expressed herein do not necessarily state or reflect those of the United States Government or any agency thereof.

\author{
PACIFIC NORTHWEST LABORATORY \\ operated by \\ BATTELLE MEMORIAL INSTITUTE \\ for the \\ UNITED STATES DEPARTMENT OF ENERGY \\ under Contract DE-ACO6-76RLO 1830
}

Printed in the United States of America

\begin{abstract}
Available to DOE and DOE rontractors from the
Office of Scientific and Technical Information, P.O. Box 62, Oak Ridge, TN 37831; prices available from (a15) 576-8401. FTS 626-8401.
\end{abstract}

Available to the public from the National Technical Information Service,
U.S. Department of Commerce, 5285 Port Royal Rd., Springfield, VA 22161. 
PNL- -8049

DE92 011509

1988 WET DEPOSITION

TEMPORAL AND SPATIAL PATTERNS

IN NORTH AMERICA

J. C. Simpson

A. R. 01 sen

E. A. Bittner

March 1992

Prepared for

the U.S. Environmental Protection Agency

under a Related Services Agreement

with the U.S. Depariment of Energy

Contract DE-AC06-76RLO 1830

Pacific Northwest Laboratory

Richland, Washington 99352 
Although the research described in this report has been funded wholly or in part by the inited States Environmental Protection Agency, it has not been subjected to Agency review and therefore does not necessarily reflect the views of the Agency and no official endorsement should be inferred. 


\section{ABSTRACT}

The focus of this report is on North American wet deposition temporal patterns from 1979 to 1988 and spatial patterns for 1988. It is the third in a series of reports that investigate the patterns of annual precipitationweighted average concentration and annual deposition for nine ion species: hydrogen, sulfate, nitrate, ammonium, calcium, chloride, sodium, potassium, and magnesium. The data in the report are from the Acid Deposition System (ADS) for the statistical reporting of North American deposition data which includes the National Atmospheric Deposition Program/National Trends Network (NADP/NTN), the MAP3S Precipitation Chemistry Network, the Utility Acid Precipitation Study Program (UAPSP), the Canadian Precipitation Monitoring Network (CAPMON), and the daily and 4-weekly Acidic Precipitation in Ontario Study (APIOS-D and APIOS-C).

Mosaic maps, based on surface estimation using kriging, display concentration and deposition spatial patterns of $\mathrm{pH}$, hydrogen, sulfaie, nitrate, ammonium, and calcium ion species for 1988 annual, winter, and summer periods. For all these ion species the highest concentrations or depositions primarily occur in the northeastern part of the United States and/or the southeastern part of Canada. The western United States has much lower concentrations and depostions for all the ion species except calcium.

Temporal pattern analyses use a subset of 35 sites over a 10-year (1979-1988) period and an expanded subset of 137 sites, with greater spatial coverage, over a 7-year (1982-1988) period. The 10-year period represents the longest period with wet deposition monitoring data available that has a sufficient number of sites with data of known quality to allow a descriptive summary of annual temporal patterns. Sen's median trend estimate and Kendall's seasonal tau (KST) test are calculated for each ion species concentration and deposition at each site in both subsets. For both subsets the deposition trend estimates of all the ion species are decreasing for more than $50 \%$ of the sites. The concentration trend estimates of all the ion species, except nitrate, are decreasing for almost $50 \%$ of the sites. For the 1979-1988 subset, the sulfate concentration is decreasing for over $75 \%$ of the sites and the sulfate deposition is decreasing for over $90 \%$ of the sites. 
Kendall seasonal tau (KST) tests found that all ion species have significantly $(p<0.05)$ decreasing trends at one or more sites. In particular, $17 \%$ and $29 \%$ of the 35 sites in the 1979-1988 subset have significant decreases for sulfate concentration and deposition, respectively. Additionally, greater than $17 \%$ of the sites also have significant decreases for calcium, chloride, sodium, potassium and magnesium concentration and deposition. Nitrate, ammonium and hydrogen ion have the fewest sites with significant trends. 


\section{ACKNOWLEDGMENTS}

The preparation of this report has relied heavily on the expertise and assistance of many other individuals. Derrick Bates, the current project manager, and Pat Titzler maintained the data and provided input for this report. Kevin Adams implemented the computer graphics algorithms to produce the spatial mosaic maps of precipitation chemistry. Darlene Winter, DeeAnn Peterson and Debbie Smith used their expertise to help organize the report, especially the preparation of the figures.

This research has been funded as part of the National Acid Precipitation Assessment Program by the U.S. Environmental Protection Agency. 


\section{CONTENTS}

ABSTRACT . . . . . . . . . . . . . . . . . . . . . . 1 . . 1 . . ACKNOWLEDGEMENTS . . . . . . . . . . . . . . . . . . . . V

1.0 INTRODUCTION. . . . . . . . . . . . . . . . . . . 1.1

1.1 PRIOR SPATIAL PATTERN AND TREND STUDIES. . . . . . . . . . . . 1.1

1.2 SPATIAL INTERPOLATION METHODOLOGY REVIEW . . . . . . . . . 1.5

1.2.1 Categories of Alternative Techniques. . . . . . . . 1.6

1.2.2 Expert Judgment and Deterministic Technique Applications. 1.7

1.2.3 Stochastic Technique Applications . . . . . . . . . 1.9

1.2.4 Issues Related to Spatial Interpolation . . . . . . . 1.12

1.3 TREND ANALYSIS METHODOLOGY REVIEW. . . . . . . . . . . . . 1.14

1.3.1 Trend Methods for a Single Site........... . 1.15

1.3.2 Trend Assessment for Networks of Sites. . . . . . . . 1.17

2.0 DATA PREPARATION AND ANALYSIS METHODOLOGY . . . . . . . . . . . . . 2.1

2.1 SOURCES OF WET DEPOSITION DATA . . . . . . . . . . . 2.1

2.2 DATA QUALITY AND SUMMARIZATION PROCEDURES. . . . . . . . . 2.4

2.3 SELECTION OF SITES FOR SPATIAL AND TEMPORAL PATTERIN ANALYSES . 2.8

2.3.1 Temporal Pattern Sites.............. 2. . . .

2.3.2 Spatial Pattern Sites .............. 2.11

2.4 SPATIAL ESTIMATION METHODOLOGY . . . . . . . . . . . . . 2.11

2.5 TEMPORAL PATTERN METHODOLOGY ................. 2.13

3.0 INDIVIDUAL ION SPATIAL AND TEMPORAL PATTERNS. . . . . . . . . . . . 3.1

3.1 EMISSION TEMPORAL PATTERNS 1978-1988.............. . . 3.2

3.2 1988 SPATIAL PATTERNS. . . . . . . . . . . . . . . . 3.2

3.2.1 pH and Hydrogen ................ 3.6 


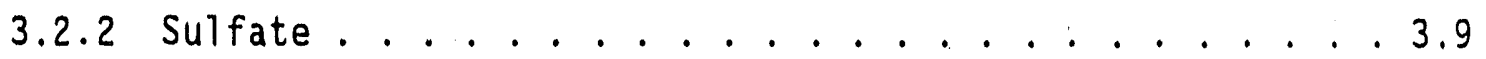

3.2.3 Nitrate................ . . 3.12

3.2 .4 Ammonium. ................. 3.15

3.2.5 Calcium . . . . . . . . . . . . . . . 3.18

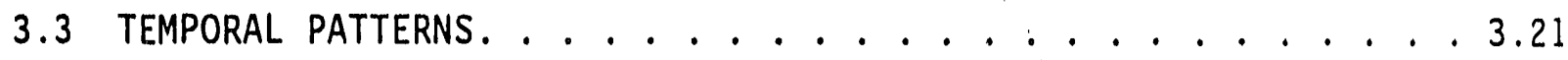

3.3.1 Hydrogen, $\mathrm{pH}$ and Precipitation. . . . . . . . 3.22

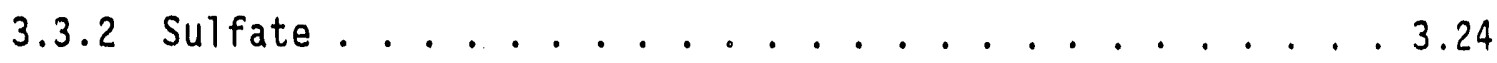

3.3.3 Nitrate ................. . . 3.26

3.3 .4 Ammonium. . . . . . . . . . . . . . . 3.27

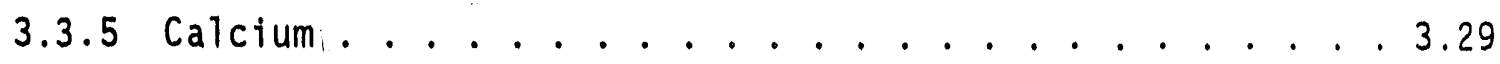

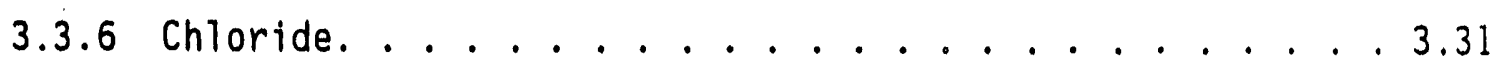

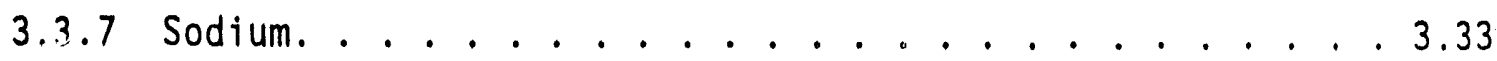

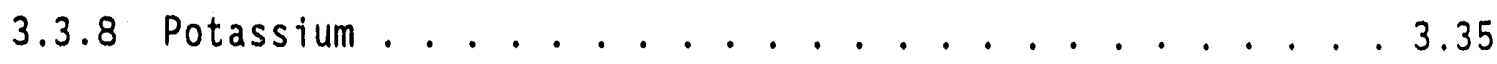

3.3.9 Magnesium ................. . . . . . . . . . . .

$4, \therefore$ MULTIVARIATE TEMPORAL PATTERNS. . . . . . . . . . . . . . . . . . . 4.1

4.1 MULTIVARIATE TEMPORAL PATTERN CONSISTENCY ACROSS ION SPECIES . . 4.1

4.1.1 Concentration Multivariate Patterns . . . . . . . 4.2

4.1.2 Deposition Multivariate Patterns. . . . . . . . . . 4.7

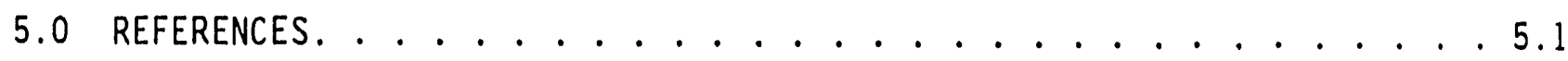




\section{FIGURES}

2.1 Geographic Location of Sites in 1988 Operating a Fu11

Year and the Subset of Sites Meeting Annual UDDC

Criteria for Sulfate. . . . . . . . . . . . . . . 2.5

2.2 Locations of Sites Included in Trend Subsets

for 1979-1988 and 1982-1988 . . . . . . . . . . . . . . 2.10

2.3 Definition of Boxplot Display . . . . . . . . . . . 2.15

3.1 National Trend in Total Suspended Particulate Emissions, 1978-1988. . 3.3

3.2 National Trend in Sulfur Oxide Emissions, 1978-1988........ . 3.3

3.3 National Trend in Nitrogen Oxide Emissions, 1978-1988....... . 3.4

3.4 National Trend in Volatile Organic Compound Emissions, 1978-1988. . . 3.4

4.1 Estimated 1988 Ion Species Concentration for 1979-1988

Trend Sites and 1982-1988 Trend Sites . . . . . . . . . . 4.8

4.2 Ion Species Concentration Trend Estimates for 1979-1988

Trend Sites and 1982-1988 Trend Sites............. . 4.9

4.3 Distribution of Ion Species Concentration Trend Estimates

as Percent of Estimated 1988 Annual Concentration for

1979-1988 Trend Sites and 1982-1988 Trend Sites.......... . 4.10

4.4 Estimated 1988 Ion Species Deposition for 1979-1988

Trend Sites and 1982-1988 Trend Sites . . . . . . . . . . . . . 4.11

4.5 Ion Species Deposition Trend Estimates for 1979-1988

Trend Sites and 1982-1988 Trend Sites .. . . . . . . . . . 4.12

4.6 Distribution of Ion Species Deposition Trend Estimates

as Percent of Estimated 1988 Annual Deposition for

1979-1988 Trend Sites and 1982-1988 Trend Sites . . . . . . . . . . 4.13

A.l Annual 1988 Spatial Distribution of Precipitation-weighted

$\mathrm{pH}$ and Hydrogen Ion Deposition. . . . . . . . . . . . . . . . A.l

A.2 Winter 1988 Spatial Distribution of Precipitation-weighted

$\mathrm{pH}$ and Hydrogen Ion Deposition. . . . . . . . . . . . . . . A.2

A.3 Summer 1988 Spatial Distribution of Precipitation-weighted

$\mathrm{pH}$ and Hydrogen Ion Deposition. . . . . . . . . . . . . . . A.3

A.4 Annual 1988 Spatial Distribution of Sulfate Precipitation-

weighted Concentration and Deposition. . . . . . . . . . . . . A.4 
A.5 Winter 1988 Spatial Distribution of Sulfate Precipitationweighted Concentration Deposition ...............5

A.6 Summer 1988 Spatial Distribution of Sulfate Precipitationweighted Concentration and Deposition ............. A.6

A.7 Annual 1988 Spatial Distribution of Nitrate Precipitationweighted Concentration and Deposition ..............7

A.8 Winter 1988 Spatial Distribution of Nitrate Precipitationweighted Concentration and Deposition ............. A.8

A.9 Summer 1988 Spatial Distribution of Nitrate Precipitationweighted Concentration and Deposition .............9

A.10 Annual 1988 Spatial Distribution of Ammonium Precipitationweighted Concentration and Deposition..............10

A.11 Winter 1988 Spatial Distribution of Ammonium Precipitationweighted Concentration and Deposition ...............11

A.12 Summer 1988 Spatial Distribution of Ammonium Precipitationweighted Concentration and Deposition ...............12

A.13 Annual 1988 Spatial Distribution of Calcium Precipitationweighted Concentration and Deposition ...............13

A.14 Winter 1988 Spatial Distribution of Calcium Precipitationweighted Concentration and Deposition ...............14

A.15 Summer 1988 Spatial Distribution of Calcium Precipitationweighted Concentration and Deposition ..............15

A.16 Temporal Pattern of Annual Precipitation and Annual Precipitation-weighted $\mathrm{pH}$ for 1979-88 Trend Subset. . . . . . . . . . A.16

A.17 Temporal Pattern of Annual Precipitation and Annual Precipitation-weighted $\mathrm{pH}$ for 1982-88 Trend Subset. . . . . . . . . A.17

A.18 Temporal Pattern of Annual Precipitation-weighted Hydrogen Ion Concentration and Annual Hydrogen Ion Wet Deposition for 1979-88 Trend Subset. . . . . . . . . . . . A.18

A.19 Temporal Pattern of Annual Precipitation-weighted Hydrogen Ion Concentration and Annual Hydrogen Ion Wet Deposition for 1982-88 Trend Subset. . . . . . . . . . . . . . . . . . A.19

A.20 Trend Estimates of Annual Precipitation and Annual Precipitation-weighted pH for 1979-88 Trend Subset. 
A.21 Trend Estimates of Annual Precipitation and Annual

Prectpitation-weighted pH for 1982-88 Trend Subset. . . . . . . A.21

A.22 Trend Estimates of Annual Precipitation-weighted Hydrogen Ion Concentration and Annual Hydrogen Ion Wet Deposition for

1979-88 Trend Subset. . . . . . . . . . . . . . . . A.22

A.23 Trend Estimates of Annual Precipitation-weighted Hydrogen Ion

Concentration and Annual Hydrogen Ion Wet Deposition for

1982-88 Trend Subset. . . . . . . . . . . . . . A.23

A.24 Temporal Pattern of Annual Precipitation-weighted Sulfate Ion

Concentration and Annual Sulfate Ion Wet Deposition for

1979-88 Trend Subset. . . . . . . . . . . . . . . . . . A.24

A.25 Temporal Pattern of Annual Precipitation-weighted Sulfate Ion

Concentration and Annual Sulfate Ion Wet Deposition for

1982-88 Trend Subset. . . . . . . . . . . . . . . A.25

A.26 Trend Estimates of Annual Precipitation-weighted Sulfate Ion

Concentration and Annual Sulfate Ion Wet Deposition for

1979-88 Trend Subset. . . . . . . . . . . . . . . . . . A.26

A.27 Trend Estimates of Annual Precipitation-weighted Sulfate Ion

Concentration and Annual Sulfate Ion Wet Deposition for

1982-88 Trend Subset.

A.28 Temporal Pattern of Annual Precipitation-weighted Nitrate Ion

Concentration and Annual Nitrate Ion Wet Deposition for

1979-88 Trend Subset. . . . . . . . . . . . . . . . A.28

A.29 Temporal Pattern of Annual Precipitation-weighted Nitrate Ion

Concentration and Annual Nitrate Ion Wet Deposition for

1982-88 Trend Subset. . . . . . . . . . . . . . . . . . A.29

A.30 Trend Estimates of Annual Precipitation-weighted Nitrate Ion

Concentration and Annual Nitrate Ion Wet Deposition for

1979-88 Trend Subset.

A.31 Trend Estimates of Annual Precipitation-weighted Nitrate Ion

Concentration and Annual Nitrate Ion Wet Deposition for

1982-88 Trend Subset.

A.32 Temporal Pattern of Annual Precipitation-weighted Ammonium Ion

Concentration and Annual Ammonium Ion Wet Deposition for

1979-88 Trend Subset. . . . . . . . . . . . . . . . . A.32

A.33 Temporal Pattern of Annual Precipitation-weighted Ammonium Ion

Concentration and Annual Ammonium Ion Wet Deposition for

1982-88 Trend Subset. 
A.34 Trend Estimates of Annual Precipitation-weighted Ammonium Ion Concentration and Annual Ammonium Ion Wet Deposition for

1979-88 Trend Subset.

A.35 Trend Estimates of Annual Precipitation-weighted Ammonium Ion

Concentration and Annual Ammonium Ion Wet Deposition for

1982-88 Trend Subset.

A.36 Temporal Pattern of Annual Precipitation-weighted Calcium Ion Concentration and Annual Calcium Ion Wet Deposition for

1979-88 Trend Subset.

A.37 Temporal Pattern of Annual Precipitation-weighted Calcium Ion

Concentration and Annual Calcium Ion Wet Deposition for

1982-88 Trend Subset.

A.38 Trend Estimates of Annual Precipitation-weighted Calcium Ion

Concentration and Annual Calcium Ion Wet Deposition for

1979-88 Trend Subset.

A.39 Trend Estimates of Annual Precipitation-weighted Calcium Ion

Concentration and Annual Calcium Ion Wet Deposition for

1982-88 Trend Subset.

A.40 Temporal Pattern of Annual Precipitation-weighted Chloride Ion

Concentration and Annual Chloride Ion Wet Deposition for

1979-88 Trend Subset.

A.41 Temporal Pattern of Annual Precipitation-weighted Chloride Ion

Concentration and Annual Chloride Ion Wet Deposition for

1982-88 Trend Subset.

A.42 Trend Estimates of Annual Precipitation-weighted Chloride Ion

Concentration and Annual Chloride Ion Wet Deposition for

1979-88 Trend Subset. . . . . . . . . . . . . . . . A.42

A.43 Trend Estimates of Annual Precipitation-weighted Chloride Ion

Concentration and Annual Chloride Ion Wet Deposition for

1982-88 Trend Subset.

A.44 Temporal Pattern of Annual Precipitation-weighted Sodium Ion

Concentration and Annual Sodium Ion Wet Deposition for

1979-88 Trend Subset.

A.45 Temporal Pattern of Annual Drecipitation-weighted Sodium Ion

Concentration and Annual Sodium Ion Wet Deposition for

1982-88 Trend Subset.

A.46 Trend Estimates of Annual Precipitation-weighted Sodium Ion

Concentration and Annual Sodium Ion Wet Deposition for

1979-88 Trend Subset. 
A.47 Trend Estimates of Annual Precipitation-weighted Sodium Ion Concentration and Annual Sodium Ion Wet Deposition for 1982-88 Trend Subset. . . . . . . . . . . . . . . . . . A.47

A.48 Temporal Pattern of Annual Precipitation-weighted Potassium Ion Concentration and Annual Potassium Ion Wet Deposition for 1979-88 Trend Subset. ................. A.48

A.49 Temporal Pattern of Annual Precipitation-weighted Potassium Ion Concentration and Annual Potassium Ion Wet Deposition for 1982-88 Trend Subset. . . . . . . . . . . . . . . . A.49

A.50 Trend Estimates of Annual Precipitation-weighted Potassium Ion Concentration and Annual Potassium Ion Wet Deposition for 1979-88 Trend Subset.

A.51 Trend Estimates of Annual Precipitation-weighted Potassium Ion Concentration and Annual Potassium Ion Wet Deposition for 1982-88 Trend Subset.

A.52 Temporal Pattern of Annual Precipitation-weighted Magresium Ion Concentration and Annual Magnesium Ion Wet Deposition for 1979-88 Trend Subset. . . . . . . . . . . . . . . A.52

A.53 Tomporaï Pattern of Annual Precipitation-weighted Magnesium Ion Concentration and Annial Magnesium Ion Wet Deposition for 1982-88 Trend Subset. . . . . . . . . . . . . . . . A.53

A.54 Trend Estimates of Annual Precipitation-weighted Magnesium Ion Concentration and Annual Magnesium Ion Wet Deposition for

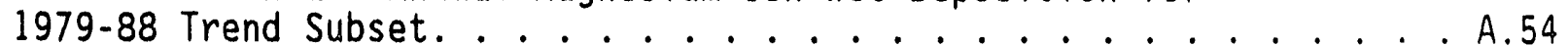

A.55 Trend Estimates of Annual Precipitation-weighted Magnesium Ion Concentration and Annual Magnesium Ion Wet Deposition for 1982-88 Trend Subset. 


\section{TABLES}

2.1 Wet Deposition Monitoring Networks in the United States

and Canada that Contributed Data to the ADS. . . . . . . . . . 2.3

2.2 Number of Sites Operated, by Network, from 1979 to 1988. . . . . . . . 2.4

2.3 Number of Sites, by Network, that Monitored Precipitation

More than 90 Percent of Year from 1979 to 1988 . . . . . . . . . . . 2.4

2.4 Number of Sites, by Network, Meeting the Unified Deposition

Database Committee Annual Summary Data Completeness Criteria

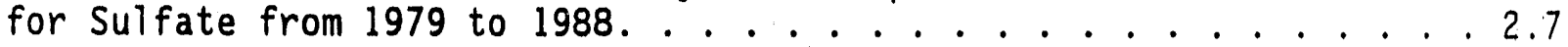

4.1 Change per Year ( $\mu$ eq/1/year) of Precipitation-weighted

Annual Mean Concentration for 1979-1983 Trend Sites. . . . . . . . . . 4.14

4.2 Change per Year ( $\mu$ eq/1/year) of Precipitation-weighted

Annual Mean Concentration for 1982-1988 Trend Sites. . . . . . . . 4.14

4.3 Number and Percent of Significantly $(p<0.05)$ Decreasing

and Increasing Trend Est:mates by Ion Species for

Concentrations at 1979-1988 and 1982-1988 Trend Sites. . . . . . . . 4.15

4.4 Ranks by Ion of Annual Concentration Temporal

Change for 1979-1988 Trend Sites . . . . . . . . . . . 4.16

4.5 Percent Change per Year of Precipitation-weighted Annual

Mean Concentration for 1979-1988 Trend Sites . . . . . . . . . . . . 4.17

4.6 Percent Change per Year of Precipitation-weighted Annual

Mean Concentration for 1982-1988 Trend Sites . . . . . . . . . . 4.17

4.7 Change per Year (meq/ $/ \mathrm{m}^{2} /$ year) of Annual Deposition

for 1979-1988 Trend Sites. . . . . . . . . . . . . . . . . . 4.18

4.8 Change per Year (meq/ $\mathrm{m}^{2} /$ year) of Annual Deposition

for 1982-1988 Trend Sites. . . . . . . . . . . . . . . . 4.18

4.9 Number and Percent of Significantly $(p<0.05)$ Decreasing

and Increasing Trend Estimates by Ion Species for

Deposition at 1979-1988 and 1982-1988 Trend Sites. . . . . . . . . . 4.19

4.10 Ranks by Ion of Annual Deposition Temporal

Change for 1979-1988 Trend Sites . . . . . . . . . . . . . . 4.20

4.11 Percent Change per Year of Annual Deposition for 1979-1988

Trend Sites. . . . . . . . . . . . . . . . 4.21 
4.12 Percent Change per Year of Annual Deposition for 1982-1988

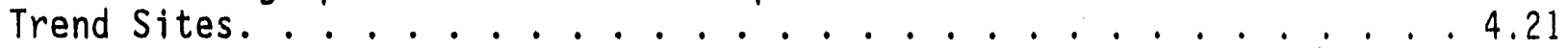

A.1 1979-1988 Trend Sites Ordered by Sitename. . . . . . . . . . . . . . A.56

A.2 1982-1988 Trend Sites Ordered by Sitename. . . . . . . . . . . . . A.57

A.3 1988 Frequency Distribution Percentiles for Annual and

Seasonal Ion Species Precipitation-weighted Concentration. . . . . . . A.60

A.4 1988 Frequency Distribution Percentiles for Annual

and Seasonal Ion Species Deposition. ................61

A.5 Summary of 1979-1988 Trend Sites Annual

Precipitation-weighted Concentration by Year . . . . . . . . . . . A.62

A.6 Summary of 1979-1988 Trend Sites Annual Deposition by Year . . . . A.65

A.7 Summary of 1982-1988 Trend Sites Annual

Precipitation-weighted Concentration by Year ............68

A.8 Summary of 1982-1988 Trend Sites Annual Deposition by Year. . . . . A.70

A.9 Frequency Distribution Percentiles of Estimated Concentrations

( $\mathrm{mg} / 1$ ) at the Center of 2670 Squared Kilometer Hexagons in

Eastern North America $(n=1833)$ and Western $(n=1875)$ United States. . A.72

A.10 Frequency Distribution Percentiles of Estimated Deposition

$(\mathrm{kg} / \mathrm{ha})$ at the Center of 2670 Squared Kilometer Hexagons in

Eastern North America $(n=1833)$ and Western $(n=1875)$ United States. . A.73

A.11 Minimum and Maximum Annual, Winter, and Summer

Precipitation-weighted $\mathrm{pH}$ and Total Hydrogen

Deposition Observed at ADS Sites in 1988 by Region. . . . . . . . . A.74

A.12 Minimum and Maximum Annual, Winter, and Summer Sulfate

Precipitation-Weighted Concentrations and Total

Deposition Observed at ADS Sites in 1988 by Region . . . . . . . . . . A.75

A.13 Minimum and Maximum Annual, Winter, and Summer Nitrate

Precipitation-Weighted Concentrations and Total

Deposition Observed at ADS Sites in 1988 by Region . . . . . . . . . . A.76

A.14 Minimum and Maximum Annual, Winter, and Summer Ammonium

Precipitation-Weighted Concentrations and Total

Deposition Observed at ADS Sites in 1988 by Region . . . . . . . . . . A.77

A.15 Minimum and Maximum Annual, Winter, and Summer Calcium

Precipitation-Weighted Concentrations and Total

Deposition Observed at ADS Sites in 1988 by Region . . . . . . . . . A.78 


\subsection{INTRODUCTION}

The focus of this report is on the temporal and spatial patterris of wet deposition occurring in the United States and southeastern Canada. The report gives a descriptive statistical summary of wet deposition in terms of ion species concentration and deposition. Mosaic maps display 1988 annual and seasonal (winter and summer) spatial patterns for $\mathrm{pH}$, hydrogen, sulfate, nitrate, ammonium, and calcium wet deposition. The intent of the mosaic maps is to give a general overview of regional differences in wet deposition. Descriptive graphical displays of annual wet deposition at monitoring sites and Kendall seasonal tau statistical trend analyses provide information on the temporal patterns that existed during two time periods. The 1979-1988 time period is the longest continuous period when a reasonable number of wet deposition sites operated in the United States and southeasiern Canada to enable temporal patterns to be examined. The shorter 7-year time period, 1982-1988, is used to expand the spatial coverage of the sites included in the temporal pattern analyses.

The report consists of four sections and an extensive appendix. Section 1 gives an introduction to the report and reviews related studies. Section 2 describes the sources for the wet deposition data, the data quality and summarization procedures applied, the selection of sites included in the spatial and temporal pattern analyses, the spatial estimation methodology used, and the temporal pattern methodology used. Section 3 describes annual temporal patterns for nine ion species observed during the 10-year and 7-year periods and the spatial pattern in 1988 for five of the ion species. In this section, the ion species are considered one-at-a-time. Because the number of tables and figures used is large, they are placed together in the appendix. Section 4 contains a study of ion species temporal patterns based on a modified Kendall seasonal tau analysis of four-weekly data. In this section, the nine ion species are considered simultaneously.

\subsection{PRIOR SPATIAL PATTERN AND TREND STUDIES}

Several studies have examined current spatial and temporal patterns. Each of these studies used different data screening and statistical analysis 
techniques. A brief summary of the results and conclusions of each of these studies is presented below.

In a National Research Council (NRC) (1986) study, data were obtained from 12 National Atmospheric Deposition Program/National Trends Network (NADP/NTN) sites from 1979 through 1982, and from several Canadian Network for Sampling Precipitation and the Canadian Air and Precipitation Monitoring Network (CANSAP and APN) sites from 1980 to 1982. The data record available to the NRC (1986) study was too short to permit a quantitative analysis; only a qualitative description of temporal pattern tendencies is given. Despite the relatively sparse data available, their observations and conclusions have been largely supported by more recent and comprehensive studies. The NRC consistently noted the similar behavior of year-to-year changes in sulfate concentration with that of ions not considered to have anthropogenic origins, e.g., calcium. Decreasing calcium concentrations were as prevalent as decreasing sulfate concentrations. For most of the 12 sites studied in the eastern United States, the concentration of most ions was higher in 1980 and 1981, and lower in 1979 and 1982. Canadian sites had similar multi-year patterns; however, year-to-year changes at some sites were different from neighboring sites.

Schertz and Hirsch (1985) examined 19 sites from NADP/NTN over the period 1978 through 1983. They used the Kendall seasonal test (Hirsch et al. 1982) to determine if a temporal change had occurred during the period covered in their study. They found decreases in ionic concentration were more common than increases for the 19 NADP/NTN sites. Of all the ions examined, sulfate had the largest decreases in concentration per year. Rates of change in concentration, significant at the $5 \%$ leve1, ranged from -0.20 to -0.48 $\mathrm{mg} / 1 /$ year. When Schertz and Hirsch analyzed weekly ionic concentrations that were adjusted to account for variation in precipitation amount, even more sites showed significant decreases in concentration over the 1978 to 1983 period. All sites in Ohio, Pennsylvania, and West Virginia showed significant decreases in sulfate and nitrate concentration.

Dana and Easter (1987), analyzing the MAP3S Precipitation Chemistry Network (MAP3S/PCN) data from 1976 through 1983, found that sulfate concentrations decreased about $2 \%$ per year at most all sites. However, these 
temporal changes were not statistically significant. Their analyses were based on a regression model applied to individual sample data that accounted for seasonal behavior through a phase-shifted sine wave and dependence on time assumed linear. The coefficient of the linear time term of the regression model is the parametric estimate of the rate of change in the period.

Barchet et al. (1987a) undertook an analysis of the temporal patterns at sites in the NADP/NTN, Utility Acid Precipitation Study Program (UAPSP), MAP3S/PCN, Acid Precipitation in Ontario Study (APIOS), and CAPMON/APN networks for the period 1980 through 1984. They present results for monthly changes in precipitation weighted mean concentration and deposition of seven ions. Their analyses are based on 48 sites that met a common data screening criteria applied to monthly summaries. The NADP/NTN weekly sampling network provided 28 sites; daily sampling networks provided 17 sites (eight from MAP3S/PCN, five from UAPSP, and four from CAPMON/APN); three sites came from the APIOS monthly cumulative network. Most of the sites studied by Schertz and Hirsch (1985) and by Dana and Easter (1987) are among the sites selected for this study. They used both the Kendall seasonal test and seasonal regression model in the statistical analysis. All estimates of change are based on the linear time coefficient of their regression model. Barchet et a1. (1987a) found that decreases in concentration dominate the temporal pattern during the period for most ions. The median annual change for sulfate concentration at all eastern sites (44 sites) was estimated as -0.11 $\mathrm{mg} / 1 /$ year. Changes in concentration for the other ions tended to be downward but did not display as strong a pattern as for sulfate. Temporal changes in deposition over the period were not nearly as uniformly downward as for concentration. This appeared to be related to an increase in precipitation amount during the latter part of the period that counteracts the decrease in concentration at many sites.

Endlich et al. (1988) investigated the spatial and temporal pattern of three daily sampling networks that included the UAPSP, the MAP3S, and the Wisconsin Acid Deposition Monitoring Program (WADMP). The study spanned the period 1979-1983, with the combined UAPSP and MAP3S sites numbering 6 to 20 for any one year. In 1982, the WADMP added three more sites to the pooled data. Data were screened to create a single, uniform daily data set by 
examining data quality flags and codes, with the UAPSP screening program as the standard for data acceptance. Kriging was used for spatial analysis as discussed by Eynon (1988). On the basis of the fitted semi-variograms, kriging interpolation plots were produced for $\mathrm{pH}$, sulfate, nitrate, and ammonium for 1979-1983. In the northeast where most monitoring sites were located, the region of highest acidity (lowest pH) for 1982 extended from approximately St. Louis, along the Ohio River Valley, across Pennsylvania and New York, and to New England. The patterns in other years were similar. For 1982 (and other years), sulfate and nitrate patterns were quite similar to those for hydrogen ion. The patterns for nitrate had the highest values in the northwest part of the region and extending southward toward the Ohio River Valley and eastward over the Great Lakes.

Seilkop and Finkelstein (1987) provided precipitation chemistry patterns and trend for eastern North America (roughiy east of the Mississippi) for 1980-1984. Data were obtained from the Acid Deposition System (ADS) data summaries for the NADP/NTN, MAP3S, CANSAP, APN, UAPSP, and APIOS wet deposition networks. Data were screened using the data completeness measures described in Section 2 for annual summaries. However, no quarterly criteria were applied and a $75 \%$ criteria was required rather than $60 \%$. Isopleth maps were used to provide characterizations of concentrations and wet deposition of sulfate, nitrate, and hydrogen ion. The authors used simple kriging to interpolate site values for isopleths. The individual annual sulfate spatial maps for the study period showed that the isopleths generally had a SW to NE major axis with a maximum centered between northern Ohio and souther:i Ontario, in the vicinity of Lake Erie. The spatial plots also showed a slight locrease in sulfate deposition between 1980 and 1983, with a slight increase in 1984 . Both the peak levels and the generally higher levels around the peak decreased by about $15 \%$ in 1980-1983. The authors noted that levels far from the peak (considered background) did not seem to change from year to year. Except for 1984, the sulfate concentration patterns were quite consistent with deposition patterns for all years. This consistency between deposition and concentration was also evident for hydrogen ion and nitrate. The nitrate patterns were generally quite similar to those of sulfate, but smoother. During the 1980-1983 period, nitrate also decreased by $15-20 \%$ in areas of high deposition 
and concentration. However, the nitrate maximum was displaced slightly east and north of the sulfate maximum. The hydrogen ion deposition maps showed the same general shape and temporal change as sulfate, but the maxima were shifted south and east of both the sulfate and nitrate maxima. The authors discussed the observed trend with regard to precipitation and emission trend. The absence of a precipitation-based explanation for deposition decreases does lend support to a hypothesized relationship between observed decreases in hydrogen ion, sulfate, and nitrate during 1980-1983 with reported reductions in emissions. However, the 15-20\% reduction in ion concentrations must be viewed with caution, as the authors pointed out, because in a large part of the area of maximum deposition, the coefficient of variation (related to the location of isopleth lines) was approximately $15 \%$ in 1982 and $20 \%$ in 1980 .

\subsection{SPATIAL INTERPOLATION METHODOLOGY REVIEW}

Wet deposition researchers use several different methods of spatial interpolation to investigate wet deposition spatial patterns. A major objective is the production of a map display that allows the visualization of the spatial pattern. Geographic mapping is one way to summarize data collected at geographically dispersed monitoring sites, to graphically "extend" the data, and to enhance qualitative assessment of the pattern. Three types of map display predominate in the literature for displaying the results: isopleth maps, mosaic maps, and 3-D perspective maps. The display choice is not dependent on the interpolation technique (with the possible exception of hand-drawn maps) but does involve a choice on what is the best display to convey the information on the spatial pattern. The choice depends on the intended purpose for the display.

Bilonick (1985) gives his view on criteria that may be expected for any reasonable spatial interpolation technique. "The method should (1) provide estimates that are "close" to the actual (unknown) intersample values, (2) provide some idea of the reliability of its estimates, (3) incorporate as much objective information as possible (both directly and from the sample data and other sources) in producing the estimates, (4) be consistent (everyone using the technique with the same assumptions should produce essentially the same map) and (5) not be too costly." It is difficult, if not impossible, for 
any current technique to satisfy completely all of the criteria. These criteria should be kept in mind when techniques are discussed or are claimed to be optimal in some sense.

\subsubsection{Categories of Alternative Techniques}

The number of alternative techniques available for spatial interpolation is large and it is convenient to categorize them into three classes (following Burrough 1986): subjective or expert judgment, deterministic, and stochastic. Creutin and obled (1982) use an alternative classification system. Their categories are named nearest neighbor, arithmetic mean, spline-surface fitting, so-called optimal interpolation, kriging method, and interpolation based on empirical orthogonal functions. In addition, they present terms inat help distinguish essential characteristics of interpolation. These are statistical versus deterministic, spatial versus clinatological, interpolation versus smoothing, and local versus global methods. Although these distinctions are useful, they are discussed only peripherally here.

Subjective or expert judgment interpolation results in generation of isopleth maps by visually interpolating point values on a mapped surface by generating lines associated with values of equal magnitude on the surface. Cartographers have used this procedure as early as in the 1920s. The "quality" of the interpolated surface depends upon the skill of the person generating the map and their ability to qualitatively incorporate their knowledge of concomitant information into the placement of the isopleth lines.

Deterministic techniques arose from surface fitting techniques, typically from the field of numerical analysis. The number of deterministic procedures is large and computer algorithms for their implementation are readily available. Deterministic techniques fit the data exactly, implying that each datum is known exactly, i.e., no sampling or estimation error for datum is present. Techniques include assignment of nearest neighbor (also termed proximal or Thiessen polygon), bilinear interpolation, quadratic interpolation, spline fitting, local moving average, inverse distance-squared weighting (and other distance weighting functions), trend surface fitting, and many others. Typically, these procedures are easily computerized and require minimal computing resources. Hence they are convenient for quick preparation 
of interpolated surfaces and their subsequent display. Contouring algorithms rely mainly on one or more of these techniques. Trend surface fitting techniques do accommodate interpolation when data is known with error but they do not incorporate information on any spatial correlation structure, hence they are considered deterministic.

Stochastic techniques incorporate information on the stochastic structure of the data and typically use empirically determined spatial correlations (or their equivalent). Optimal interpolation developed by Gandin (1965) uses spatial covariance or correlation as the basis for interpolation. The fitted theoretical spatial correlation function is used to produce a weighting function for each point to be estimated such that the mean square error of the estimate is minimized. Optimal interpolation has been developed mainly by researchers in meteorology and is suggested for use by the World Meteorological Organization (1970). Additional research in this area has been done by Rodriquez-Iturbe and Mejia (1974) and Lenton and Rodriquez-Iturbe (1977). Kriging, developed by Matheron (1971), is a spatial interpolation technique used extensively in geostatistics and relies on the concept of spatial variance (equivalent in concept to spatial covariance). It results in a system of simultaneous equations whose solution produces interpolation weights based on a model of the covariance structure associated with the data. The spatial variance function is known as the semi-variogram and a unified, consistent methodology exists for fitting theoretical semi-variograms to empirical semi-variograms. In most cases, kriging is applied locally by using a globally defined semi-variogram and a local neighborhood of data points for the interpolation. Under assumptions that include the "intrinsic hypothesis", the kriging estimator is the best linear unbiased estimator. The simple, linear kriging method has been extended to handle trends (universal kriging) and non-linear estimation problems (conditional expectation and disjunctive kriging). Details may be found in David (1977), Journel and Huijbregts (1978), 01ea (1975), Ripley (1981), and Clark (1979).

\subsubsection{Expert Judgment and Deterministic Technique Applications}

Spatial patterns of wet deposition over areas of North America have been developed using expert judgment or deterministic techniques by several researchers. Cogbi11 and Likens (1974) produced a 1955-1956 map of 
volume-weighted, annual data on hydrogen ion concentration and a 1965-66 map of precipitation pH. Subsequently, Stensland and Semonin (1982) re-examined the data for 1955-56, prepared another isopleth map, and compared it with a map based on 1978-1980 data from the NADP network. Although not stated, it appears the latter maps were generated by a deterministic-based computer algorithm. Likens and Butler (1981) summarized prior work by preparing modified maps and compared it to the spatial pattern over eastern North America for 1975-76. They state the latter map was essentially the same whether based on computer drawn map using a surface fitting algorithm or based on subjectively drawn contours. Barrie and Hales (1984) developed hand-drawn isopleth maps of the mean annual concentration and deposition of hydrogen, sulfate, nitrate and ammonium ions in precipitation in North America for 1980 based on Canadian and U.S. monitoring network data. They describe the process used in developing the location of the hand-drawn contours and give a qualitative analysis of their uncertainty. Munger and Eisenreich (1983) produced computer interpolated maps of average sulfate concentration over the U. S. and Canada for 1970-80. No attempt was made to determine map reliability. Galloway and Whelpdale (1980) developed an isopleth map of 1977 average sulfate deposition for eastern Canada but did not state how the map was generated. Pack (1980) prepared hand-drawn contours for average sulfate concentration for the perrod August 1978 to June 1979. The isopleths are based on 17 sites from two networks (EPRI/SURE and MAP3S) and an attempt was made to statistically justify combining the two networks. Zemba, Golomb, and Fay (1988) consider the spatial pattern of four-year (1982-85) averaged wet sulfate and nitrate deposition over eastern North America. Their patterns are depicted as contour maps produced by the NCAR computer graphics software (McArthur 1983). The algorithm interpolates irregularly spaced data to an internal grid from which it uses splines under tension to construct contours. The NADP network prepares an annual data summary report (e.g., NADP 1991) that includes isopleth maps prepared using a distance weighted interpolation algorithm. The algorithm, and its user-determined parameters, was selected only after the computer generated contours were qualitatively compared with hand-drawn contours prepared by network staff (Bowersox, personal communication). 
It is apparent from the number of papers discussed, and many additional papers not discussed, that subjective and deterministic interpolation methods are widely used in presenting wet deposition patterns over North America. This may in part be attributed to the little to moderate effort required to prepare an isopleth map. Another factor may be related to the amount of information the authors desired to convey. Typically the discussion of the information content of the maps emphasized the broad general features of the spatial pattern displayed and not its detafled structure. Only broad qualitative comparisons among alternative maps were presented. Without direct discussions with the authors, it is not possible to determine if the level of information content was sufficient for their planned intentions or if the subjective quality of the maps limited their ability to give detalled spatial interpretations or coinparisons.

\subsubsection{Stochastic Technique Applications}

Most applications of stochastic techniques to spatial interpolation of wet deposition data have used kriging. One exception is Gatz and Naiman (1980) who used the optimal method developed by Lenton and Rodriquez-Iturbe (1977). They examined the spatial variability of rain water impurities in mesoscale events. Finkelstein (1984) and Eynon and Switzer (1983) published two early applications of kriging methodology to wet deposition data.

Finkelstein (1984) used annual average precipitation-weighted concentrations from July 1979 to June 1980 to investigate the application of simple kriging to wet deposition. Using polynomial functions as models for fitting semi-variograms to the annual data and addressing the behavior of the semi-variogram at distances near zero by analyzing a second small scale research network, isopleth maps for hydrogen and sulfate ions were presented. The uncertainty in the location of the isopleth line was expressed by presenting upper and lower "confidence isopleths" derived by adding and subtracting the estimated kriging variance from the estimates and contouring the results. Subsequently, Seilkop and Finkelstein (1987) applied the same simple kriging procedures in a study of wet deposition patterns and trends in eastern North America from 1980 to 1984. In both cases, kriging was applied locally with a globally determined semi-variogram. Journel and Hutjbregts 
(1978) state that estimation bias is not serfous under moderate spatial trends.

Eynon and Switzer (1983) using daily data from the EPRI/SURE nine station network developed a spatio-temporal stochastic model that included deterministic components for spatial, temporal, and measurement variation. The fitted autocorrelation structure was then used as a semi-variogram in kriging to produce isopleth maps of seasonal and rainfall adjusted yearly average $\mathrm{pH}$ over the eastern United States.

Bilonick $(1983,1985)$ studied the spatial and temporal patterns of hydrogen and sulfate ions in the northeastern United States based on bulk precipitation samples collected by the U.S. Geological Survey from 1965-1979. His approach for hydrogen ion was to estimate semi-variograms for each month from 1965-1979 and then pool the monthly semi-variograms to produce average monthly semi-variograms. The latter was necessary due to limited data available each month. Rather than applying kriging to obtain point estimates to contour, he applied kriging to produce monthly block estimates for $80 \mathrm{~km}^{2}$ blocks. These estimates and estimation variances are combined to form yearly block estimates and variance estimates. Although the possible impact of spatial anisotropy was recognized, insufficient data was available to segregate the data to produce directional semi-variograms. Theoretical spherical semi-variograms with a "nugget" effect were empirically fit. The block spatial estimation resulted in a rectangular array of 12 block estimates that were displayed by presenting a numerical value of the estimate. This is a simplified version of a mosaic map display. The subsequent paper studied sulfate concentration and deposition space-time patterns by estimating a joint space-time semi-variogram. Because of limited number of sites, a threedimensional semi-variogram that accommodated spatial anisotropy was simplified to a two-dimensional spatially isotropic model. The model included additive terms for a nugget effect, a cosine model for seasonal effect, a spherical model in time for small distances and a linear model in space. Simple kriging was then used to obtain block estimates as before. The spatial pattern was displayed used gray-scale shading of the block estimates superimposed over a gnomonic projection of the northeast. Using a second data set demonstrated the use of universal kriging when drift (spatial trend) is present. The 
resulting block estimates are displayed as a mosaic and qualitatively compared to a previously prepared hand-drawn isopleth map (Peters and Bone11i 1982). Bilonick concludes that the universal kriging and hand-drawn maps agree in broad outline with respect to the general level of sulfate deposition and tendency for deposition to increase from north to south. Differences are attributed to use of different map display techniques and different initial data screening. Additionally some smoothing appeared to also have been caused by kriging.

A series of reports (01sen and Watson 1984; 01sen and Slavich 1985, 1986; Sweeney and 01sen 1987, 1989; Erb et a1. 1989) from the Acid.Deposition System (Watson and 01 sen 1984) include annual precipitation-weighted concentration and deposition isopleth maps for hydrogen, sulfate, nitrate, ammonium, and calcium ions over North America. Each isopleth map is developed (1) using a common data screening criteria to determine which sites are included, (2) a theoretical isotropic semi-variogram (typically spherical with nugget effect) fitted to empirical semi-variogram, and (3) local simple kriging to produce point estimates on a dense regular grid ( $80 \times 80 \mathrm{~km}$ for earlier years and $40 \times 40 \mathrm{~km}$ in later years). The estimates on the regular grid were then contoured using a simpie bilinear interpolation, with the final maps edited for unrealistic contouring edge effects. Isopleth maps presented by Barchet et al. (1987b) were prepared by the same group and followed the same procedures.

Endlich et al. (1986) and Eynon (1988) estimated the spatial pattern of precipitation chemistry over the eastern United States. Their studies relied on data from three daily networks: UAPSP, MAP3S, and WADMP (Wisconsin). To perform their kriging analysis, they used the availability of multiple years of data to first remove long-term spatial and temporal trends from year-to-year fluctuations. The least squares fitted function used was a quadratic spatial polynomial plus a linear trend versus time. The residuals from the fitted surface were then used in developing the kriging semi-variogram. They found that a simple linear semi-variogram with a nugget adequately described the spatial covariance structure and that an isotropic form was sufficient. The final estimated surface is constructed by adding the fitted trend surface to the estimated kriging surface from the residuals. 


\subsubsection{Issues Related To Spatial Interpolation}

Prior studies lead to the identification of a number of issues that must be considered when wet deposition data are spatially interpolated and displayed. The issues are related to characteristics of wet deposition occurring in North America.

Fundamental to any application of an interpolation technique is the selection of data to be used in the analysis. This selection depends on the representativeness of the site and the completeness of the data for the period of interest. Criteria for selection have been developed by the Unified Deposition Database Committee (01sen et al. 1990). When several maps based on the same time period of data are compared, a major reason for qualitative differences is the selection of different subsets of data by the researchers. Simpson and 01 sen (1990) completed a study on the effect of using different data completeness criteria on isopleth maps. They concluded that the overall general regional patterns are reasonably insensitive to changes in criteria but that local features can be highly sensitive. In most cases, change= in criteria do not change the estimated conceiitration or deposition at a site but do impact whether a site is included in the analysis.

Simple kriging essentially requires an assumption of stationarity of the mean and spatial covariance. The spatial patterns of precipitation chemistry in North America have a persistent spatial trend (non-stationary mean). Most researchers have used local application of simple kriging to address the issue. Venkatram (1988) questions the applicability of simple kriging to the spatial analysis of wet deposition data. He concludes that a primary assumption in kriging of a stationary mean is invalid when looking at wet deposition over eastern North America. Other researchers have also noted the violation and have concluded that the presence of non-stationarity, although limiting, does not preclude the use of simple kriging locally to obtain? essentially unbiased estimates. Venkatram states that the local density of sites is likely to be insufficient for such local estimation. He proposes an alternative procedure to deal with non-stationary mean: application of a simple semi-empirical lagrangian model to estimate the non-stationary mean, followed by simple kriging of residuals from the model and observed data. In addition to removing non-stationarity of the mean, the spatial anisotropy 
observed by others is also likely to be removed. His preliminary study (Venkatram 1989) shows that the use of a deterministic model is likely to improve (smaller error variance) upon simple kriging without the model. Enyon (1988) removes non-stationarity of the mean by fitting spatial quadratic polynomials and then applying simple kriging to the residuals. Venkatram's approach of using other information to remove non-stationarity of the mean and other approaches such as Eynon's deserve additional study.

Annual mean (or median) precipitation chemistry values at a monitoring site are estimates that have an associated variance. Typically, applications of simple kriging have related this error to the nugget in the semi-variogram. Inclusion of a nugget does not explicitly incorporate the known measurement error at the monitoring site, since the kriging estimate at a monitoring site remains the measured value. If spatial correlation is present then nearby sites contain information that should be incorporated into the kriging estimate at the monitoring site. Monitoring site measuremient error is included in kriging analyses used for preparing the spatial maps presented in Section 3.

Several researchers (e.g., Granat 1978, Bilonick 1985, Guertin et al. 1988, Vong et a1. 1989, Wampler and 01sen 1987) have questioned the appropriateness of direct spatial interpolation of precipitation-weighted mean concentration and deposition. One issue centers on the non-additive character of precipitation-weighted means when the volume of precipitation is not constant over the area being estimated. Guertin et al. argue that deposition and precipitation amount should be spatially interpolated and then derive precipitation-weighted mean concentration by dividing the interpolated deposition by the interpolated precipitation amount. Others argue that the concentration field has smaller spatial variation than deposition and precipitation. Hence its spatial interpolation should have smaller variance estimates. The greater spatial variation of precipitation is addressed by using the greater number of precipitation monitoring stations, rather than relying solely on precipitation amounts from precipitation chemistry monitoring sites. Deposition is obtained by multiplying the interpolated concentration and precipitation amount. Vong et a1. (1989), in a review of existing literature and available empirical evidence, conclude that the latter 
approach appears to be preferred when North American regional patterns are of interest. Further research is required, especially if local features in a spatial pattern are of interest.

Current state-of-the-science spatial interpolation methods applied to precipitation chemistry data have produced spatial isopleth or mosaic maps that have similar broad regional patterns but that differ in representation of local features. Knowledge is insufficient at present to identify a single best spatial interpolation procedure or to provide reliable quantitative associated variance estimates. Further studies are required to address the issues of data selection, non-stationarity of mean and variance, isotropy versus anisotropy, incorporation of measurement uncertainty, and direct versus indirect interpolation of deposition.

\subsection{TREND ANALYSIS METHODOLOGY REVIEW}

An objective of regional and national network monitoring in North America is the detection and assessment of wet deposition irends. The monitoring network would, optimally, provide a long unbroken series of measurements, made using the same methods, at regionally representative sites. The record of data would be sufficiently long to cover the time period of interest. For wet deposition, the time period of interest starts in the ea.ly 1900 s until the present. An extended time period would aid in drawing conclusions by minimizing the likelihood of being misled by short-term trends or drifts in the data series. Using the same methods for measurement, minimizes introduction of uncertainties at discrete time points due to changes in protocols. Documentation of changes and overlap of data collected under new and old procedures are essential. Inference that trends found at a site apply to a larger area require careful study, especially in assessing the regional representativeness of the site. Preferably, several regionally representative sites are available within the same region to enable an assessment of the consistency of their trends to be made.

Trend analyses have used a number of alternative methodologies and data sets. Investigators have used several alternative methods for trend analysis at a site, e.g., graphical plots, regression models, time series models, and nonparametric models. Those investigators who considered trends at multiple 
sites used several alternatives for combining information from the sites, e.g. comparison of spatial patterns across years, comparison of time plots combining sites, and empirical assessment of trend results. Investigators have used alternative measures for precipitation chemistry: concentration, deposition, or change in relationship between concentration and precipitation amount (all over some averaging period).

A difficulty in comparing availabie trend analyses occurs as a result of differences in how investigators selected sites for study, the time period included, the trend analys is methodology, and the selected measure for precipitation chemistry. This section gives an overview of some of the alternative trend analysis methodologies.

\subsubsection{Trend Methods for a Single site}

Trend graphical plots are an important component of trend analys is for almost all investigators. Plots enable an investigator to visually assess the temporal pattern of the data, either leading to a more formal model or to a qualitative statement about the presence of a trend. Trend plots may be based on individual wet deposition samples or averaged over a common time (monthly, quarterly, annual). Plots based on time averaged values reduce the visual impact of the typical large variation of individual samples, hence increasing the ability to see seasonal and longer term trends. An alternative to plotting averaged values is to enhance time series plots of individual samples by adding a smoothed model (e.g., lowess nonparametric smooth or regression model) to the plot to aid the visual detection of a pattern. Schertz and Hirsch (1985) make effective use of lowess plots to assess trend patterns at individual sites. Oehlert (1984), also summarized in NRC (1986), used deseasonalized time series plots of monthly volume-weighted concentration and deposition to investigate trends at Hubbard Brook from 1964 to 1979.

A widely used technique for trend analys is is linear regression modeling on individual samples, monthly averages, or annual averages. Typically, the regression model includes terms for a linear long term trend, a cyclic seasonal trend, and a term that adjusts for a postulated effect due to precipitation volume. Each investigator determines whether to include these effects and, if so, how complicated the model term will be. For example, Dana 
and Easter (1987) analyzed trends for the MAP3S sites from 1976-1983 using both a simple linear and a simple linear plus a simple sine periodic function for seasonal effect. Their analyses are applied to individual sample concentrations which are transformed by taking logarithms, to account for the tendency toward log-normal distributions of individual sample concentrations. Linear trends are determined from the regression coefficient for long-term trends, with its significance based on the t-test for the coefficient. Likens et al. (1984) apply simple linear regression on annual volume-weighted averages to the Hubbard Brook data. The trend is computed as the change in annual weighted average, and standard errors for the trends are computed without accounting for autocorrelation between years. Oehlert (1985) notes that multiple regression analyses typically ignore autocorrelation, resulting in standard errors being calculated without appropriately modeling the error structure.

Time series techniques model the data as in regression, but the residuals are allowed to be autocorrelated. Hidy et al. (1984) estimated parametric autoregressive moving average (ARMA) models for lag twelve differences in monthly concentrations for trend analyses of the USGS precipitation chemistry network in New York. Differencing by lag twelve removes seasonality and the residuals are modeled as a constant plus an ARMA process residual, the constant being the average trend per year. Oehlert (1984) investigated trends for Hubbard Brook monthly volume-weighted average concentrations and deposition. Seasonal influences were eliminated by subtracting from each monthly value the mean of the time series for that month. Trends were determined (essentially) by ordinary least squares regression, but the standard errors of the trends are adjusted for the presence of autocorrelation in the residuals. Bilonick and Nichols (1983) approach trend analysis of the USGS data by concentrating on finding a stationary autoregressive integrated moving average model that adequately describes the data. If one can be found, the data are assumed to be stationary and the mean is determined to be a constant, i.e., no trend is present. Oehlert (1985) has criticized this approach.

Schertz and Hirsch (1985) introduced a nonparametric trend analysis method, termed Kendall seasonal tau (KST), in their analysis of trends in 
weekly NADP/NTN wet deposition data from 1978-1983. Hirsch et a1. (1982) and Hirsch and S1ack (1984) developed the method for examining trends in surface water quality. The method has two parts, a test for trend based on Kendal1's tau and an estimate for trend based on Sen's median slope estimator. The trend estimate is very resistant to outliers and can be estimated in the presence of missing values. The original KST method does not account for autocorrelation, but the modified test does. The latter requires a longer time series (approximately 10 years of monthly data) and autocorrelation that is not too strong. Barchet (1987) presented a trend analysis based on KST for sites operating during 1978-1984 from several North American wet deposition networks. Recently, similar analyses have been completed by 01 sen (1989) and Simpson and 0lsen (1990) and form the basis for the trend analysis in this report.

\subsubsection{Irend Assessment for Networks of Sites}

Determination of trends at individual sites is only one aspect of trend assessment for North America. Individual sites may reflect influences of local impacts (e.g., changes near the site in emissions or land use) and not reflect trends in the surrounding regional area. Current wet deposition networks have time series data for many sites available for assessment of regional and national trends. Investigators have used several alternative methodologies to assess regiorial trends: changes in distribution of annual concentration for a set of sites, comparison of annual spatial patterns, and qualitative analysis of trend results from a set of individual sites.

Rodhe and Granat (1984) summarized more than 25 years of data on sulfate in precipitation from the European Air Chemistry Network for assessment of seasonal and long term trends. With data available from 50 to 100 stations, they assessed long term trends using annual values for individual sites and using time series plots that graphically presented summaries across groups of sites. For each group of sites, the 25 th, 50 th, and 75 th percentile across sites for a five-year averaging period were plotted to visually assess presence of trends. 01sen (1989) and Simpson and 01sen (1990) used a similar approach to present trends in annual concentration and deposition for subsets of North American sites. A time series of boxplots are constructed that summarize annual distribution for sets of sites to visually assess changes 
(trends) in distribution over time (see Appendix A for examples). Although this approach summarizes a large amount of data and presents it graphically, it only allows a qualitative assessment of patterns and is likely to be effective in detecting trends when the trends are substantial compared to interannual variation within a site and consistent across sites. The approach does not remove differences in mean level between sites, hence annual distributions reflect this variation.

Another approach to assessing trends, or changes, in annual concentration and deposition for network of sites is to compare the spatial patterns determined for different periods. Likens and Butler (1981) investigated temporal trends in precipitation acidity in eastern North America during 1955 to 1976 . They determined the spatial pattern for three different time periods: 1955-56, 1965-66, and 1975-76 and qualitatively assessed differences among the patterns. Having the data for the three periods collected by three different organizations and having the number and locations of the sites different for each period, limits the ability to assess, even qualitatively, the presence of trends. Using data available from North American networks operating during 1980-1984, Seilkop and Finkelstein (1987) compared changes in annual spatial patterns of sulfate, nitrate, and hydrogen ion concentration and deposition. They used a consistent methodology to calculate annual averages, to determine which sites to include each year, and to estimate and display the spatial pattern for each year. In addition to qualitatively assessing differences in patterns, they developed a method, based on kriging standard errors, to quantitatively determine regions of change between two years. Eynon (1988) completed a similar qualitative comparison across 1979-1983 for eastern North America using data from the UAPSP network. Spatial and temporal trends were estimated and subtracted from the annual values before the correlation structure of the residuals was used to estimate the semi-variogram for the kriging analysis. Bilonick (1985) estimated space-time semi-variograms of sulfate deposition data collected by the USGS during 1965-1979 in New York state and used them to determine the annual sulfate spatial patterns over New York. A qualitative approach was used to assess changes in patterns. 
Trend assessment for multiple sites can also be approached by first completing a trend analysis for each site and then combining the trend results to determine regional or national consistency. Schertz and Hirsch (1985) used this approach to summarize their Kendall seasonal tau analyses of NADP/NTN sites. They tabulated and discussed the number of sites with increasing and decreasing trend estimates and with statistically significant increasing and decreasing trends. 01 sen (1989) and Simpson and 01 sen (1990) used boxplots of trend estimates for all sites and geographic displays of trend estimates to summarize trend analysis results. A qualitative assessment for regional consistency was included. Further research is needed in combining trend results from individual sites, or in determining an alternative approach. 


\subsection{DATA PREPARATION AND ANALYSIS METHODOLOGY}

The purpose of this section is to state the sources of the wet deposition monitoring data, to describe the data quality and summarization procedures, to define the site selection process for spatial and temporal pattern analyses, and to describe the spatial and temporal methodologies that are applied.

\subsection{SOURCES OF WET DEPOSITION DATA}

Federal, state, and local agencies and private industries support networks of sites for the collection and chemical analysis of precipitation samples. The data in this report are from regional and national networks that contribute data to the Acid Deposition System (ADS) (Watson and 01sen 1984) for statistical reporting of North American wet deposition data.

The spatial and temporal pattern analyses include data from six regional networks (Table 2.1):

- The Multi-State Atmospheric Pollution and Power Production Study (MAP3S) initiated the MAP3S precipitation chemistry network (MAP3S/PCN) in 1976 with four sites in the northeastern United States to begin research on the scavenging of pollutants by precipitation. It was the first wet-deposition-only, event sampling network.

- The National Atmospheric Deposition Program (NADP) established, in 1978, a weekly sampling network to monitor trends in precipitation chemistry in the United States. The NADP was created, in cooperation with federal, state, and private agencies, to conduct research on atmospheric deposition and its effects. In 1982, the NADP assumed responsibility for coordinating the operation of the National Trends Network (NTN) of the federally-supported National Acid Precipitation Assessment Program (NAPAP). The merged networks now have the designation NADP/NTN.

- Utility Acid Precipitation Study Program (UAPSP) began in 1978 as a nine site daily sampling research network initiated by the Electric Power Research Institute (originally the EPRI/SURE network) and expanded to 22 sites in 1982 under the Utility Acid Precipitation Study Program, giving 
broader regional coverage. On December 31, 1987, the UAPSP network ceased operation, and most of the same sites or ones near the UAPSP sites, together with a few other sites, began operation as the Operational Evaluation Network (OEN) on January 1, 1988.

- The dafly Canadian federal network, CAPMON, was formed using sites from two previous networks as a base: the Canadian Network for Sampling Actd Prectpitation (CANSAP, 1977-1985) and the Air and Precipitation Monitoring Network (APN, 1978-1985).

- In 1980, Ontario established two networks as part of the Acidic Precipitation in Ontario Study (APIOS). The cumulative network, APIOS-C, with a four-week sampling period is designed to determine the long-term deposition pattern in Ontario. The daily network, APIOS-D, is designed to define the sector of origin of the ion species as well as the frequency and intensity of acidic deposition eptsodes.

A summary of the number of sites operated by each network from 1979 to 1988 is presented in Table 2.2. For the purposes of this table, a site is considered to have operated during a year if one or more samples were collected at some time during the year. Hence sites are included that operated only a portion of the year because they were either terminated or started during the year. The total number of sites increased from 69 in 1979 to 331 in 1988. The implementation of the NTN and expansion of the NADP network is responsible for most of the growth in the United States. The initiation of the APIOS and CAPMON networks in 1980 and 1983 accounts for most of the growth in Canada.

A site is considered to have operated a full year if precipitation (not necessarily precipitation chemistry) is monitored for at least $90 \%$ of the year. Only sites operating a full year can be considered as sites that may provide data for an annual summary. The number of sites operating a full year(Table 2.3) increased from 50 in 1979 to 293 in 1988 . Figure 2.1 gives the location of sites operating a full year in 1988. 
IABLE 2.1. Wet Deposition Monitoring Networks in the United State and Canada that Contributed Data to the ADS

Network

Abbreviation

MAP3S/PCN

NADP/NTN

UAPSP/OEN ${ }^{(b)} \begin{aligned} & \text { Utflity Acid Precipitation } \\ & \text { Study Program/ } \\ & \text { Operational Evaluation Network }\end{aligned}$

UAPSP/OEN ${ }^{(b)} \quad \begin{aligned} & \text { Utility Acid Precipitation } \\ & \text { Study Program/ } \\ & \text { Operational Evaluation Network }\end{aligned}$ Network Name

MAP3S Precipitation Chemistry Network

National Atmospheric Deposition Program/ National Trends Network

CAPMON/APN ${ }^{(a)}$ Canadian Air and

Precipitation Monitoring Network

APIOS-C

Acidic Precipitation

in Ontarto Study -

Cumulative Network

APIOS-D
Acidic Precipitation
in Ontario Study -
Dally Network

\begin{tabular}{|c|c|c|}
\hline $\begin{array}{l}\text { Start } \\
\text { Date } \\
\end{array}$ & $\begin{array}{l}\text { Number } \\
\text { of Sites } \\
\text { in } 1988 \\
\end{array}$ & $\begin{array}{c}\text { Samp 1e } \\
\text { Iype }\end{array}$ \\
\hline 1976 & 9 & $D a f 1 y^{(a)}$ \\
\hline 1978 & 209 & Week1y \\
\hline 197 & 29 & Dafly $y^{(a)}$ \\
\hline
\end{tabular}

1978

28 Datly

1980

$37 \quad$ Monthiy (d)

1980

19 Datly

(a) Dally or duration of precipitation event, whichever is greater.

(b) UAPSP sites prior to 1981 were part of the EPRI/SURE network. The UAPSP network ceased operation on December 31, 1987; on January 1, 1988 most of the same sites or ones near to the present UAPSP sites, together with a few other sites, began operation as the Operational Evaluation Network.

(c) Some CANSAP and APN sites were transferred to CAPMoN during the period 1983 to 1985; before 1983, CANSAP and APN operated as separate networks.

(d) Sampling interval changed from calendar month to 28 days in January 1982. 
IABLE 2.2. Number of Sites Operated by Network, from 1979 to 1988 $\begin{array}{llllllllll}\text { Network } & 1979 \quad 1980 \quad 1981 & 1982 & 1983 & 1984 & 1985 & 1986 & 1987 & 1988\end{array}$ $\begin{array}{lllllllllll}\text { NADP/NTN } & 3 y & 82 & 100 & 113 & 148 & 183 & 195 & 206 & 205 & 209\end{array}$ $\begin{array}{llllllllll}M A P 3 S / P C N & 8 & 8 & 9 & 9 & 9 & 9 & 9 & 9 & 9\end{array}$ $\begin{array}{lllllllllll}\text { UAPSP/OEN } & 18 & 10 & 21 & 22 & 25 & 27 & 26 & 25 & 31 & 29\end{array}$ CAPMON APIOS-D APIOS-C

Total 4

0

$0 \quad 30$

69

144

$\begin{array}{rr}6 & 9 \\ 16 & 16 \\ 35 & 36\end{array}$

18

1924

$\begin{array}{llllll}16 & 17 & 15 & 17 & 15 & 19\end{array}$

$\begin{array}{llllll}38 & 38 & 37 & 38 & 37 & 37\end{array}$

IABLE 2.3. Number of Sites, by Network, that Monitored Precipitation More than 90 Percent of Year from 1979 to 1988

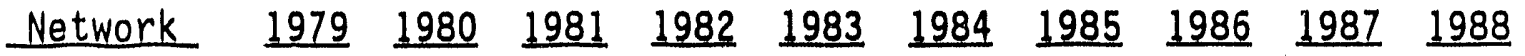

$\begin{array}{lllllllllll}\text { NADP/NTN } & 19 & 36 & 73 & 89 & 102 & 136 & 179 & 187 & 181 & 193\end{array}$

$\begin{array}{llllllllll}M A P 3 S / P C N & 8 & 8 & 9 & 9 & 9 & 9 & 9 & 9 & 9\end{array}$

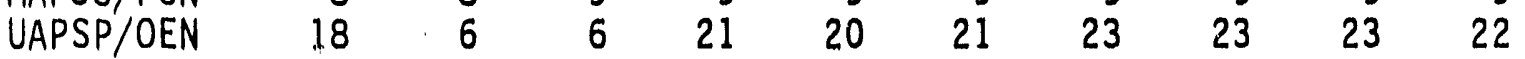

CAPMON

APIOS-D

APIOS - C

Total

$\begin{array}{rrr}3 & 4 & 5 \\ 0 & 0 & 12 \\ 0 & 0 & 29\end{array}$

6

7 17

$18 \quad 20 \quad 21$

$\begin{array}{lllllll}16 & 16 & 15 & 14 & 15 & 14 & 13\end{array}$

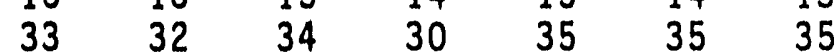

$48 \quad 54 \quad 134$

\subsection{DATA QUALITY AND SUMMARIZATION PROCEDURES}

Each network has its own set of specific protocols for selecting site locations, field operation procedures, laboratory analysis procedures, and data screening procedures. Networks implement these protocols to ensure that the collection, laboratory analysis, and reporting of wet deposition data is consistent and of known quality. Each network included in this report has and implements a quality assurance program. However, even with careful attention, some samples must be declared invalid because of the viciation of some aspect of the protocol that affects the sample's representativeness of the precipitation chemistry. The calculation of concentration and deposition summaries should not use these invalid samples. The current study applies the valid sample criteria discussed in 01 sen et a1. (1990).

The spatial and temporal analyses use precipitation-weighted mean concentration and total wet deposition for an ion species to characterize wet deposition during the period summarized. The periods summarized are annual 


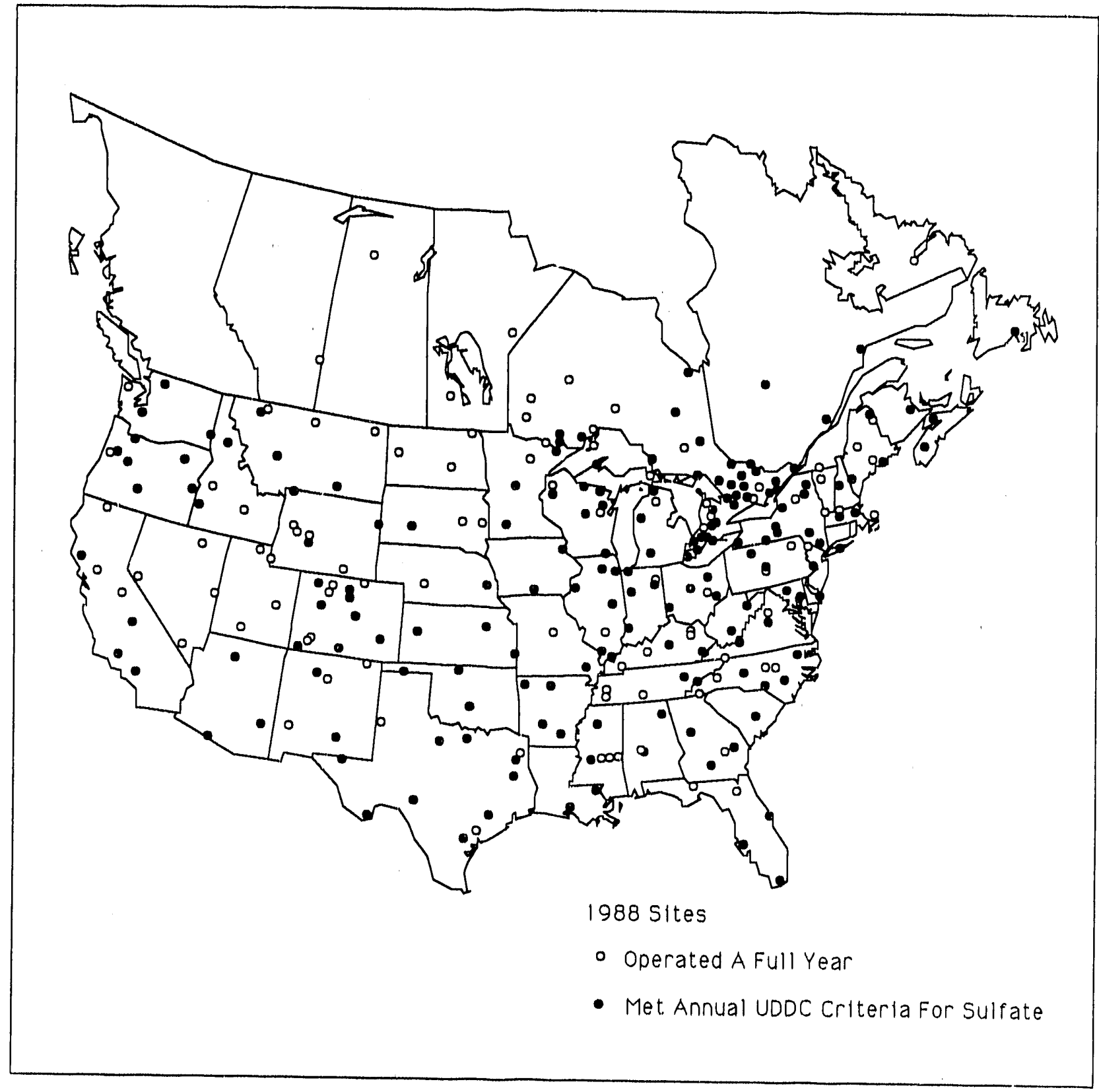

FIGURE 2.1. Geographic Location of Sites in 1988 Operating a Full Year and the Subset of Sites Meeting Annual UDDC Criteria for Sulfate 
and seasonal (three months, December 1 to March 1 for winter and June 1 to September 1 for summer) for spatial analyses and four-weekly and annual for temporal analyses. The precipitation-weighted mean concentration is calculated as a weighted average of the valid sample ion species' concentration with the weight being the corresponding rain gage precipitation depth divided by the sum of rain gage precipitation in valid samples. Total wet deposition is the product of the precipitation-weighted mean concentration and the total precipitation, as determined by the rain gage, during the period. 0lsen et al. (1990) give additional details of the calculation procedures.

Although calculation of an annual, seasonal, or four-weekly summary based on valid data is possible for a site that operated during the summary period, this does not imply that sufficient valid data for the period are present to ensure a meaningful, i.e., representative, summary. The Unified Deposition Database Committee (UDDC) (01sen et a1. 1990) defined five quantitative data completeness measures and assigned thresholds to each of the five criteria. The following questions concerning data completeness and - temporal representativeness motivated the measures: for what portion of the summary period is the occurrence and amount of precipitation known?; what portion of the precipitation volume collected is associated with valid deposition samples?; what percent of the time and what percent of the samples collected are associated with valid samples?; and, what is the ratio of the wet deposition sample volume to the precipitation measured by a standard gage? The application of the measures, and at what threshold, depends on the requirements appropriate for a study.

The ADS 1987 data summary report by Erb, Simpson and 01 sen (1989) discusses the UDDC data completeness measures and criteria. Application of the UDDC criteria significantly reduces the number of sites available for defining the temporal or spatial pattern of wet deposition. Although the UDDC criteria are reasonable in the sense that a site meeting a network's protocol would be expected to exceed them, the criteria are in fact very strict. For example, an annual summary must meet minimum threshold levels for each of the five data completeness measures not only for the entire annual period but also for each of the four quarters within the annual period: The primary 
requirements are that precipitation monitoring cover at least $90 \%$ of the period (annual and each quarter) and that valid chemistry data be available for at least $60 \%(50 \%)$ of the annual (quarterly) precipitation measured.

Table 2.4 lists the number of sites by network that meet the UDDC data completeness criteria for annual summaries of sulfate from 1979 to 1988 . The number of sites meeting the UDDC criteria increased from 39 in 1979 to 191 in 1988. Figure 2.1 shows the location of the subset of sites operating a ful1 year that met the UDDC criteria for 1988 annual sulfate summaries. In 1988, $65 \%$ of sites operating a full year met the UDDC criteria for annual sulfate summaries. This is a reflection of the strictness of the criteria, especially for networks with a weekly or four-weekly sampling period. The number of invalid samples occurring during the first quarter (January 1 to April 1) is the most frequent cause for a site to fail the UDDC criteria, i.e., application of the quarterly criteria for all quarters. It should also be noted that in 1987 a number of sites failed to meet the UDDC criteria for annual sulfate summaries because of a laboratory analysis problem. It is reassuring that the quality assurance programs do indeed work and suspect data is removed. However, this additional loss of data points out one of the difficulties with long-term studies: over a long enough period of time, there will be gaps in the data which make the analysis of the data much more difficult.

TABLE 2.4. Number of Sites, by Network, Meeting the Unified Deposition Database Committee Annual Summary Data Completeness Criteria for Sulfate from 1979 to 1988

\begin{tabular}{|c|c|c|c|c|c|c|c|c|c|c|}
\hline Network & $\underline{1979}$ & $\underline{1980}$ & 1981 & $\underline{1982}$ & 1983 & $\underline{1984}$ & $\underline{1985}$ & $\underline{1986}$ & 1987 & 1988 \\
\hline $\begin{array}{l}\text { NADP/NTN } \\
\text { MAP3S/PCN } \\
\text { UAPSP/OEN } \\
\text { CAPMON } \\
\text { APIOS-D } \\
\text { APIOS-C }\end{array}$ & $\begin{array}{r}16 \\
5 \\
16 \\
2 \\
0 \\
0\end{array}$ & $\begin{array}{r}26 \\
7 \\
6 \\
2 \\
0 \\
0\end{array}$ & $\begin{array}{r}53 \\
8 \\
6 \\
3 \\
0 \\
10\end{array}$ & $\begin{array}{r}60 \\
9 \\
21 \\
4 \\
0 \\
14\end{array}$ & $\begin{array}{r}71 \\
8 \\
20 \\
4 \\
10 \\
22\end{array}$ & $\begin{array}{r}85 \\
9 \\
18 \\
11 \\
10 \\
21\end{array}$ & $\begin{array}{r}101 \\
9 \\
19 \\
11 \\
11 \\
20\end{array}$ & $\begin{array}{r}115 \\
9 \\
21 \\
17 \\
11 \\
22\end{array}$ & $\begin{array}{r}101 \\
9 \\
0 \\
13 \\
10 \\
21\end{array}$ & $\begin{array}{l}13 \\
13 \\
22\end{array}$ \\
\hline Total & 39 & 41 & 80 & 108 & 135 & 154 & 171 & 195 & 154 & 19 \\
\hline
\end{tabular}

The selection of sites for temporal pattern analyses uses a relaxed criteria for selection of a representative summary based on the data 
completeness measures. The criteria are a compromise between ensuring each summary is based on very complete data, i.e., meet the UDDC criteria, and increasing the number of sites available for temporal pattern analysis.

\subsection{SELECTION OF SITES FOR SPATIAL AND TEMPORAL PATTERN ANALYSES}

Site selection is similar for the networks and is based on criteria for regional representativeness. A regionaliy representative site is one at which the precipitation chemistry is free from the influence of local pollution sources. An example of typical criteria specific to NADP/NTN is given by Robertson and Wilson (1985) and Bigelow (1984). A joint United States and Canadian committee, the Unified Deposition Database Committee, consolidated network criteria for regional representativeness into a single set of criteria (01sen et a1. 1990). In an analysis of sites with data in the ADS in 1988, the UDDC rated $39 \%$ of the sites as being regionally representative; $57 \%$ as marginally representative, often because those sites were in regions of high emission density where it is difficult to locate sites sufficiently far from all pollution sources; and $4 \%$ as unrepresentative of regional wet deposition. The current report does not exclude any site solely on the basis of being regionally unrepresentative as defined by the UDDC. For purposes of this report, adherence to individual network siting protocols was deemed a sufficient measure of representativeness.

\subsubsection{Temporal Pattern Sites}

A primary consideration in selecting a site for temporal pattern analysis is the continuous operation of the site for the entire period of the analysis. Preferably, the site would also meet the UDDC data completeness criteria for each year during the period. Applying these criteria severely restricts the number of sites available for temporal pattern analysis covering seven or more years. Since the objective of the data criteria is to aid in identifying sites with good quality data, an alternative approach based on a relaxed criteria applied to multiple years is developed.

The modified Kendall seasoral tau (KST) statistical trend analyses uses the four-weekly summaries and the method allows missing data. Thus a site was only required to operate from 1979 (or 1982) to 1988 for inclusion in the ten 
(or seven) year trend analyses. For the 10-year trend analyses there are 35 sites (Table A.1) and for the 7-year trend analyses there are 137 sites (Table A.2) that have been operating during the respective time periods. The location of the sites in each of the subsets is presented in Figure 2.2. A four-weekly data completeness is applied to each four-weekly summary for each of these sites. The criteria requires precipitation monitoring to cover at least $75 \%$ of the period and at least $60 \%$ of the precipitation measured during the period must be associated with valid data. For the 10-year subset, depending on the ion species, there are generally over 105 four-weekly periods, out of 130 total periods, included in the analyses for 30 of the 35 sites. Davis, California (ADS ID 01009a) had the fewest valid four-weekly summaries, between 77 and 81 , depending on the ion species. The lack of rain in the summer at Davis accounts for many of its "invalid" summaries. A sample with no precipitation can be a valid sample. However, if there is no precipitation over a summary period, it is impossible to calculate a precipitation-weighted concentration and thus the summary is designated "invalid" for this report. For the 7-year subset, depending on the ion species, there are generally 85 or more four-weekly periods, out of 91 total periods, included in the analyses for 120 of the 137 sites.

The temporal pattern analyses al so compare the annual summaries of the sites across years. These comparisons require that the sites have complete data for all the years. Therefore, a site is required to have valid samples in at least 10 four-weekly periods in every year and additionally at least 8 four-weekly periods in every year satisfy the four-weekly data completeness requirement described above. For the 35 ten-year trend sites, 20 sites have annual summaries for all ion species, 11 more sites have annual summaries for most of the ion species, and 4 sites have no annual summaries. For the 137 seven-year trend sites, 78 sites have annual summaries for all ion species, 26 more sites have annual summaries for most of the ion species, and 33 sites have no annual summaries. Tables A.1 and A.2 indicate which ion species for each site had annual summaries, for the 10-year and 7-year subsets, respectively. 

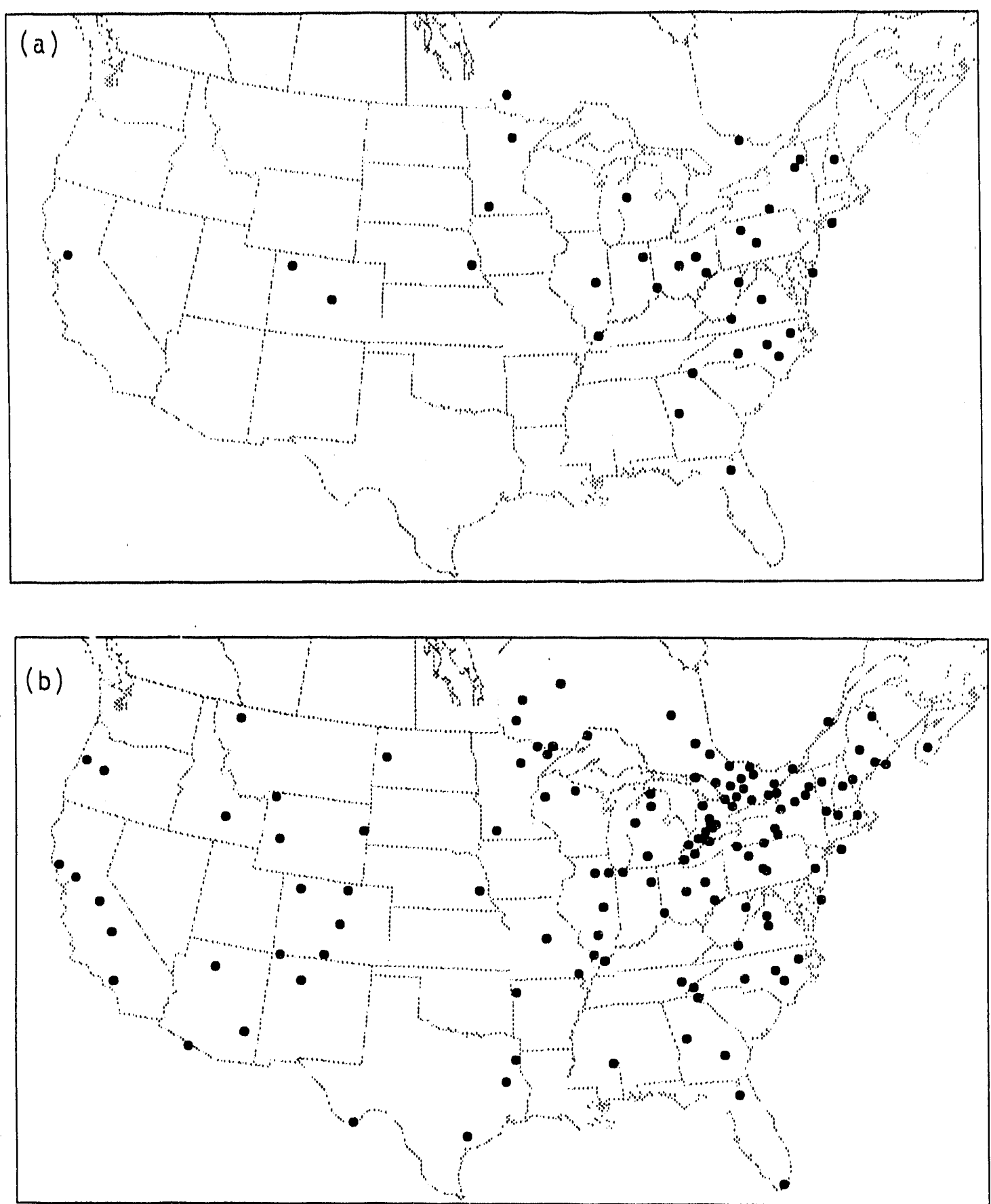

FIGURE 2.2. Locations of Sites Included in Trend Subsets for (a) 1979-1988 and (b) $1982-1988$ 


\subsubsection{Spatial Pattern Sites}

The report presents 30 mosaic maps of hydrogen, sulfate, nitrate, ammonium, and calcium wet deposition spatial patterns for 1988 annual and seasonal (winter and summer) summary periods. For each ion species, maps of both precipitation-weighted concentration and total wet deposition are presented, except hydrogen where precipitation-weighted $\mathrm{pH}$ is presented in $\mathrm{place}$ of concentration. The maps use a separate selection of sites for each ion and summary period based on the UDDC data completeness criteria. As an example, the number of sites used to create the 1988 annual sulfate concentration and deposition mosaic maps is 191 (Table 2.4). Tables A.3 and A. 4 give the number of sites which meet the UDDC data completeness criteria and the frequency distribution percentiles for these sites, by ion species and summary period.

\subsection{SPATIAL ESTIMATION METHODOLOGY}

Mosaic maps illustrate the spatial distribution of precipitationweighted mean concentration (or $\mathrm{pH}$ ) and total wet deposition for the United States and southeastern Canada in 1988. Such maps provide a good visual display of the general features of the spatial distribution, e.g., location of spatial maxima and general orientation of regions with high concentration or deposition. The purpose of the maps is to convey the general features of the spatial pattern; not to interpolate monitoring data to non-monitored site locations. This section provides a description of the methodology used to prepare the maps.

Preparation of mosaic maps involves: (1) selection of sites that meet data completeness criteria, (2) estimation of the spatial surface based on the selected sites, and (3) display of the estimated surface by use of gray-scale shading of hexagons. Using alternative procedures for any of the three steps can result in mosaic maps that differ. For reasonable alternatives, detailed features of the maps will differ but overall general features will remain similar. The maps presented should be viewed with this in mind.

Estimating the spatial distribution of an ion species' concentration or deposition (annual or seasonal) is a problem of estimating a spatial surface 
by interpolation between measurement sites. It is assumed that spatial correlation exists among the sites, thus the estimation technique should take this into consideration. Additionally, it is assumed that the spatial correlation is a function only of the distance between sites. Kriging (a member of a family of geostatistical estimation procedures) is a surface estimation technique that explicitly utilizes this assumption. It uses the relationship between inter-site correlation and distance, modeled from the data, to determine the weights that are applied to measured site values in estimating the surface at any location. It also provides an estimate of the interpolation error, but this is not considered in this report. This application uses simple kriging, i.e., assumes that there is no deterministic drift. It has been used in environmental studies and has been used to analyze spatial patterns in acid precipitation data (Bilonick 1983; Eynon and Switzer 1983; Finkelstein and Seilkop 1981; Finkelstein 1984; 01 sen and Slavich 1986; Vong et al. 1989).

Often kriging uses a "nugget effect" to describe the within-site or short distance variability. This nugget appears as a jump discontinuity at the origin of the variogram, a device used to assess the relationship between inter-site correlation and distance and the overall variability of the phenomenon of interest. The consequence of using the nugget effect is to say that the annual summary at a site is measured without error and the kriging algorithm will interpolate the value at the site to be its annual summary ("exact" interpolation). An alternative approach is to estimate the within-site variability from information at the collocated sites and set the nugget effect to zero. When the within-site variability is used, kriging is no longer an exact interpolator. Thus the interpolated value at a site is not its annual summary. The kriging algorithm now takes into account the within-site variability and the values of nearby sites in interpolating at a location that has an annual summary. The alternative approach is used in this report.

Since western and eastern North America have distinctively different levels of wet deposition for many of the ion species considered, the estimation and display of the surface are done separately for these two regions. The regions are partitioned between Texas and Louisiana, in the 
south, and between the Dakotas and Minnesota, in the north. The variogram model used in simple kriging is estimated using sites only in the appropriate regions. However, the estimates produced by simple kriging used the eight closest sites to the hexagon's center, regardless of the regions.

Mosaic maps display the surface estimated by the kriging procedure. Estimates of the surface are made on a grid of hexagon centers. The hexagons have an area of 2,670 squared kilometers. A lambert conformal conic map projection, that is nearly distance preserving, defines the coordinate system for the grid. The western region consists of 1875 hexagons while the eastern part conststs of 1833 hexagons (1317 within the United States). The gray scale used in the maps is based on the percentiles from the frequency distribution of the estimates associated with the hexagons in the eastern and western regions of the United States.

\subsection{TEMPORAL PATTERN METHODOLOGY}

The intent of the temporal pattern methodology is to determine the year-to-year characteristics of precipitation-weighted mean concentration and total wet deposition temporal patterns from 1979 (or 1982) to 1988. The characteristics apply only to the period studied and do not imply either the presence or absence of any long-term trend. Ten (or seven) years is not a sufficient number of years to address the issue of long-term trends.

The methodology includes two basic, and fundamentally different, approaches: graphical displays of annual data and statistical trend analysis of four-weekly data. Boxplots, defined below, graphically display percentiles of annual data from a subset of trend sites for each year in either the ten or seven year period. Visual inspection of boxplots across years provides a visual assessment of annual temporal patterns during the period. Application of a modified Kendall seasonal tau trend statistical test and Sen's median slope estimation procedure to four-weekly data provide estimates of a general temporal pattern change over the entire period.

As discussed in Section 2.3.2, the statistical estimation procedures allow missing four-weekly summaries for a site, so 35 sites are used in the 1979-1988 period and 137 are used in the 1982-1988 period. However the graphical displays of annual data required complete and representative data 
for all years in the period, thus the number of sites used is reduced and different for each ion species.

Boxplots simultaneously display several features of a set of data. Figure 2.3 illustrates the definition of the boxplot as applied in this report. Each boxplot presents the 5 th (or 10th), 25th, 50th (median), 75th, 95th (or 90th) percentiles of the data from a set of sites. The plots display al1 sites more extreme than either the 5 th (10th) or 95th (90th) percentiles. In some boxplots, very extreme data values are truncated and plotted above the plot boundary. Boxplots for the 1979-1988 period had at most 35 sites, so the 10th and 90th percentiles are shown, while the 1982-1988 period had at least 78 sites, so the 5 th and 95 th percentiles are shown. The boxplots include a shaded rectangle to display the $95 \%$ confidence interval for the median. The upper portion of a boxplot depicts the pattern of high concentration or deposition sites or of sites with most positive (or nearly positive) "trend", depending upon the type of data displayed by the boxplot. The lower portion of a boxplot depicts the pattern of low concentration or deposition sites or of sites with most negative "trend", depending upon the type of data displayed by the boxplot.

Hirsch et al. (1982) developed the Kendall seasonal tau test for trend detection in the presence of constant length cycles or seasonal effects. The test accommodates missing, tied, or limit of detection data values. Furthermore, the validity of the test does not require the data to be normally distributed. The test consists of computing the Mann-Kendall test statistic for year-to-year change separately for each season and combining these seasonal test statistics into a single statistic that can be tested for statistical significance. A limitation of this test is that it assumes that the seasons are independent. Hirsch et al. (1982) showed that when the seasons were not independent the rate of false positive results increased.

Dietz and Killeen (1981) developed a similar multivariate test for monotone trend based on Kendall's tau statistic. They developed a covariance matrix for a multivariate Kendalls tau statistic. The incorporation of the covariance matrix alleviates the problems from dependence. Dietz and Killeen's alternative hypothesis, restated in the context of seasonal trend 


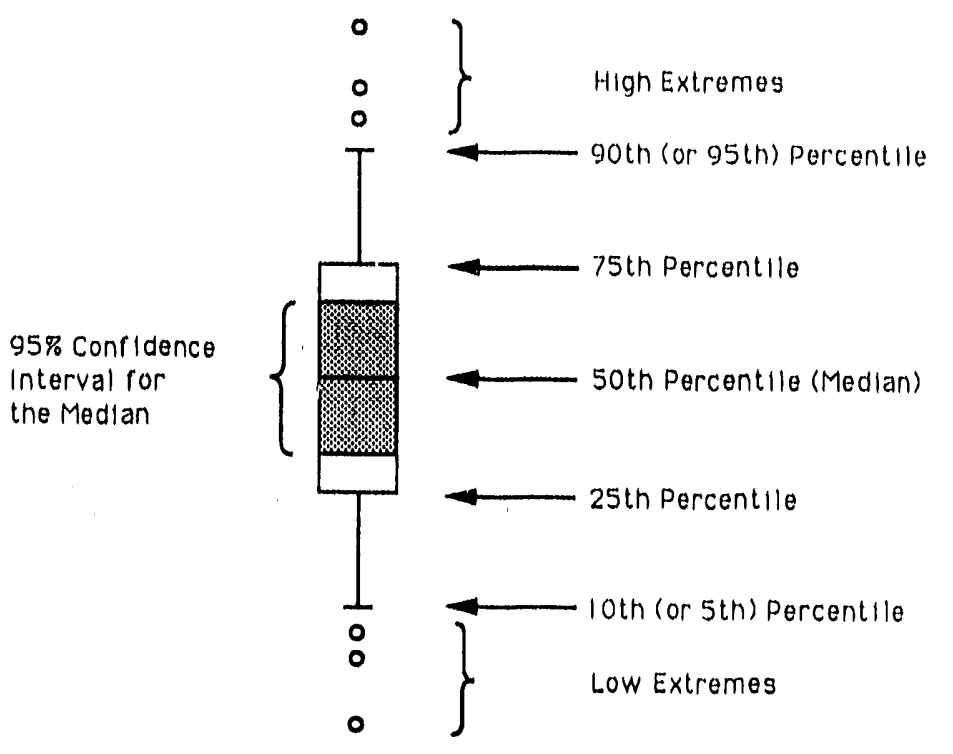

\section{EIGURE 2.3. Definition of Boxplot Display}

analysis, is that one or more seasons have a trend, but the trend need not be in the same direction for all seasons. Although they included ties in thetr statistic, missing values are not incorporated.

Hirsch and Slack (1984) extended the approach of Dietz and Killeen to include missing data. Additionally, their alternative hypothesis is that the trend for all seasons is either monotone increasing or decreasing. This change in alternative hypothesis probably accounts for the increased power that Hirsch and Slack observed for their test when compared to the Dietz and Killeen test. However, in their test, if some seasons are increasing and other seasons are decreasing, then the sum over all seasons would be zero and thus insignificant. The Hirsch and Slack approach is the modified KST test that is used in this report.

The seasons used in the modifled KST test are the 13 four-weekly precipitation-weighted mean concentrations or total wet deposition values potentially available from each year. These periods are chosen to coincide with the four-weekly sampling schedule of the APIOS-C network. The NADP/NTN network sampling schedule is weekly and its week begins on the same day of the week that APIOS-C starts a new sampling period. The other networks are daily. Therefore, the four-weekly summaries are comparable across sites and networks. 
The modifled KST test is still being repeated across a large number of sttes, 35 sites in the 1979-1988 perlod and 137 sites in the 1982-1988 pertod, thus the possibility of false positives is still large. If there is no trend and the tests are independent with a significance level of $5 \%$ ( $5 \%$ chance of a false positive result for one test), then for 35 sites there is a $2.9 \%$ chance of having 5 or more false positives and for 137 sites there is a $82 \%$ chance of having 5 or more false positives.

An estimate of the magnitude of the trend is given by Sen's median slope (Gilbert 1987). The median slope of all possible seasonal pairs of values gives an estimate of the annual change. A nonparametric confidence interval can also be computed using the covariance matrix discussed above. Sen's median slope is related to the KST test, thus a significant median slope usually occurs when the KST test also indicates a significant trend.

Two different approaches summarize the modified KST test and Sen's median slope across sites in each trend period for each ion species. The first approach gives percentile summaries across sites for the slope estimates for an ion species' concentration or deposition analysis. Boxplots display the percentiles. The text discusses sites with extreme slope estimates.

The second approach displays the slope estimate for a site on a map of North America. The angle of a constant length ray is proportional to the magnitude of the slope estimate. A vertical ray represents a zero slope estimate. Positive slopes are represented by rays that point to the right and negative slopes are represented by rays that point to the left. A horizontal ray either to the left or the right represents the minimum or maximum slope depending on which has the largest absolute value. The direction of the rays are scaled to the largest absolute value. The purpose of the map display is to show all the slope estimates relative to their spatial location and to look for consistent regional patterns in temporal pattern changes by locating regions with consistent ray angles for all sites in the region. In addition to displaying the slope estimate, a solid symbol at the base of the ray identifies the sites with a modified KST test result significantly different from zero at the $5 \%$ significance level. 


\subsection{INDIVIDUAL ION SPATIAL AND TEMPORAL PATTERNS}

This section contains descriptive statistical summartes and analyses of wet deposition spatial and temporal patterns for individual fons. For hydrogen, sulfate, nitrate, ammontum, and calcium tons, the description gives an overview of 1988 annual and seasonal (winter and summer) spattal patterns in terms of precipitation-weighted concentration (except hydrogen, where $\mathrm{pH}$ is used) and deposition. Temporal pattern information is presented for nine tons, the five tons above plus chlortde, sodium, potasstum and magnestum. Additionally, the annual total precipitation is considered. This information is presented using graphical displays of annual precipitation-weighted mean concentration and deposition and a statistical analysis based on a modified Kendall seasonal tau trend test. The modified Kendall seasonal tau trend test uses a subset of 35 long-term sites (see Table A.1) over a 10-year (1979-1988) pertod and an expanded subset of 137 sites (see Table A.2) with greater spatial coverage over a 7-year (1982-1988) pertod. The graphical displays of annual summartes use subsets of the sites in the 10-year and 7-year periods. The 10-year pertod represents the longest period with wet deposition monitoring data avallable that has a sufficient number of sites with data of known quality to allow a descriptive summary of annual temporal patterns to be produced. The 7-year period restricts the number of years in order to increase the number of sites avatlable with data of known quality. Section 2 describes the site selection and data summarization procedures, the spatial pattern methodology, and the temporal pattern graphical and statistical analysis methodology.

This section is organized as follows. First, a brief overview of emission trends is presented to provide a context for the interpretation of the deposition temporal patterns. Then the 1988 annual and seasonal spatial patterns for precipitation-weighted concentration and deposition are presented. Finally, the temporal patterns for each of the tons are presented. Patterns that are common to multiple tons are discussed in Section 4.0. Rather than intersperse the many figures and tables used to support the descriptions, most figures and tables for this section appear in Appendix $A$. 


\subsection{EMISSION TEMPORAL PATTERNS 1978-1988}

The temporal pattern of emissions for total suspended particulates (TSP), sulfur oxides, nitrogen oxides and volatile organtc compounds provide a context for the interpretation of wet deposition temporal patterns. Nationwide temporal patterns in emissions indicate whether emissions are generally increasing or decreasing nationally, but give no information on regional differences in emission temporal patterns.

Nationwide TSP emissions (EPA 1990) decreased from approximately 8.9 to 6.9 milliton metric tons per year between 1979 and 1988 (Figure 3.1). This approximately $22 \%$ decrease is primarily from industrial processes and fuel combustion source categories. Sulfur oxide emissions (EPA 1990) decreased from approximately 24.8 to 20.7 million metric tons per year between 1979 and 1988 (Figure 3.2). This approximately 17\% decrease reflects the installation of flue gas desulfurization controls at coal-fired electric generating stations and a reduction in the average iulfur content of fuels consumed. Nitrogen oxide emissions (EPA 1990) decreased from approximately 21.6 to 19.8 million metric tons per year between 1979 and 1988 (Figure 3.3). This approximately $8 \%$ decrease reflects a decrease in vehicle emissions (transportation). Emissions of volatile organic compounds (VOC) (EPA 1990) decreased from approximately 22.4 to 18.6 million metric tons per year between 1979 and 1988 (Figure 3.4). This approximately $17.0 \%$ decrease is primarily from transportation and industrial processes source categories.

The TSP, sulfur oxide, nitrogen oxide and VOC temporal patterns are decreasing. However all these patterns have an increase in 1984 and nitrogen and sulfur oxides increase in 1988. The increase in sulfur and nitrogen oxides emtssions between 1987 and 1988 is due to increased industrial activity.

\section{$3.2 \quad 1988$ SPATIAL PATTERNS}

Mosaic maps, Figures A.1 through A.15, display the surface estimated by the kriging procedure described in Section 2.4. Estimates of the surface are made on a grid of hexagon centers. The hexagons have an area of 2,670 squared 


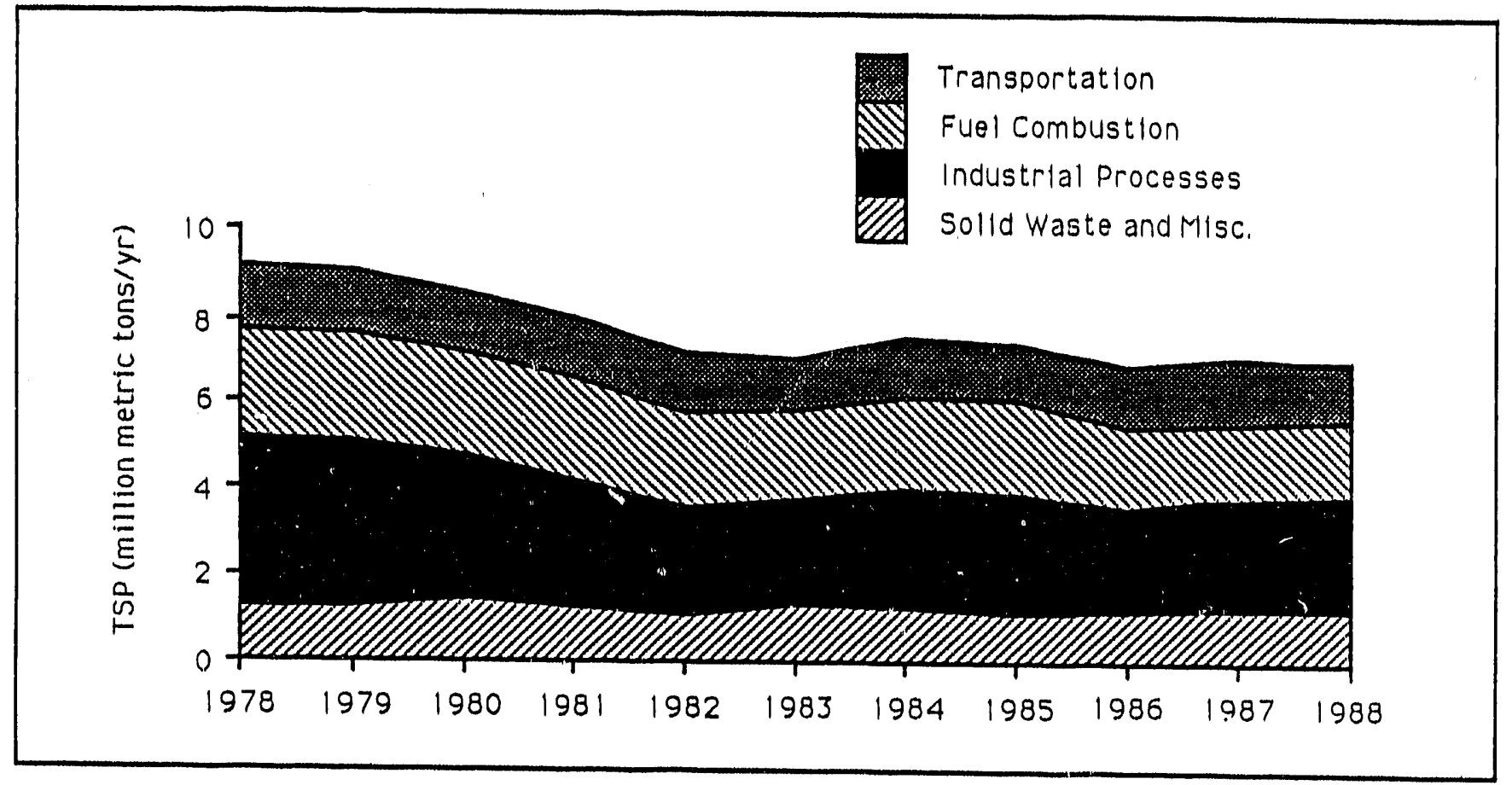

FIGURE 3.1. National Trend in Total Suspended Particulate Emissions, 1978-1988

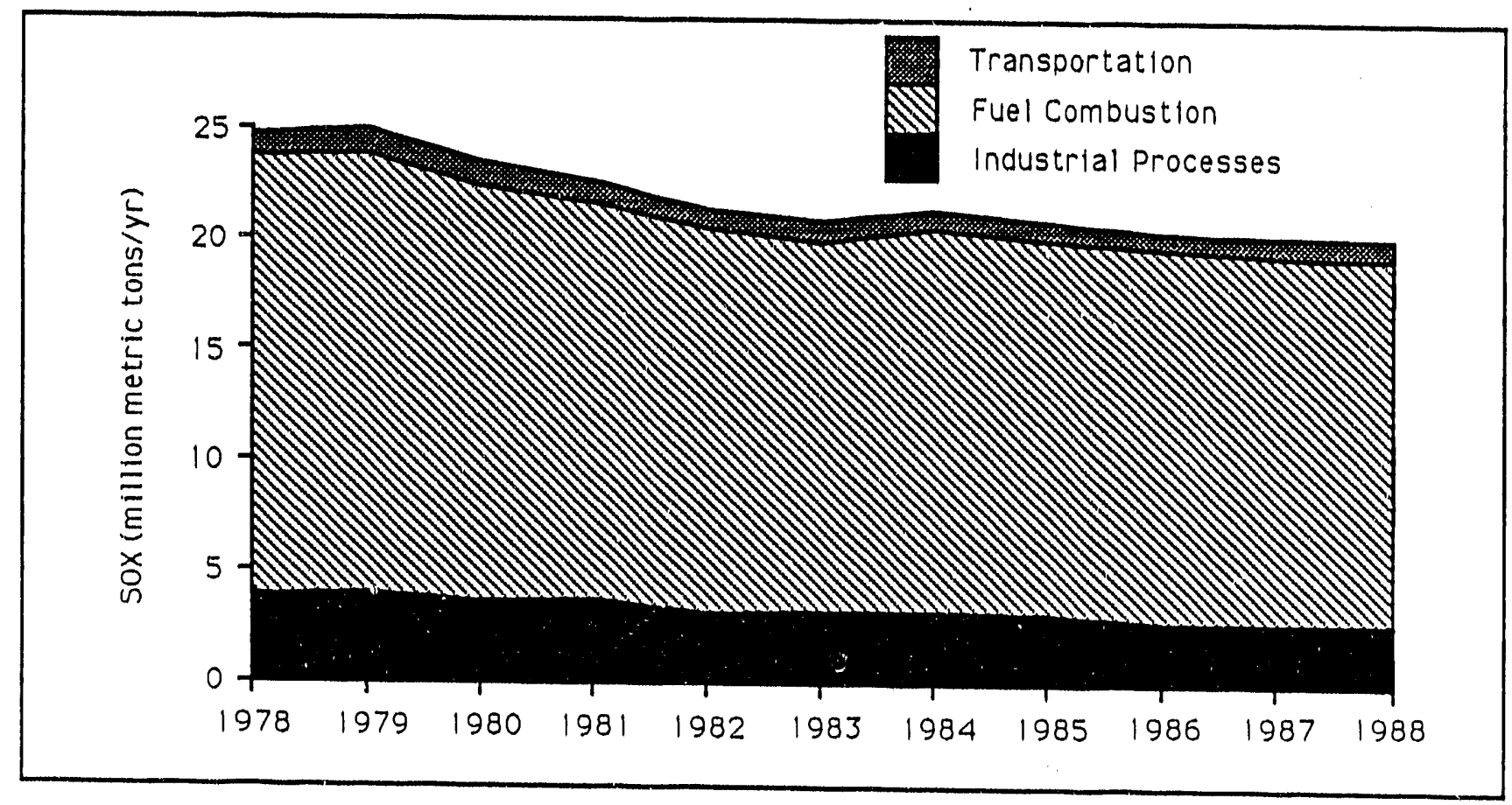

FIGURE 3.2. National Trend in Sulfur Oxide Emissions, 1978-1988 


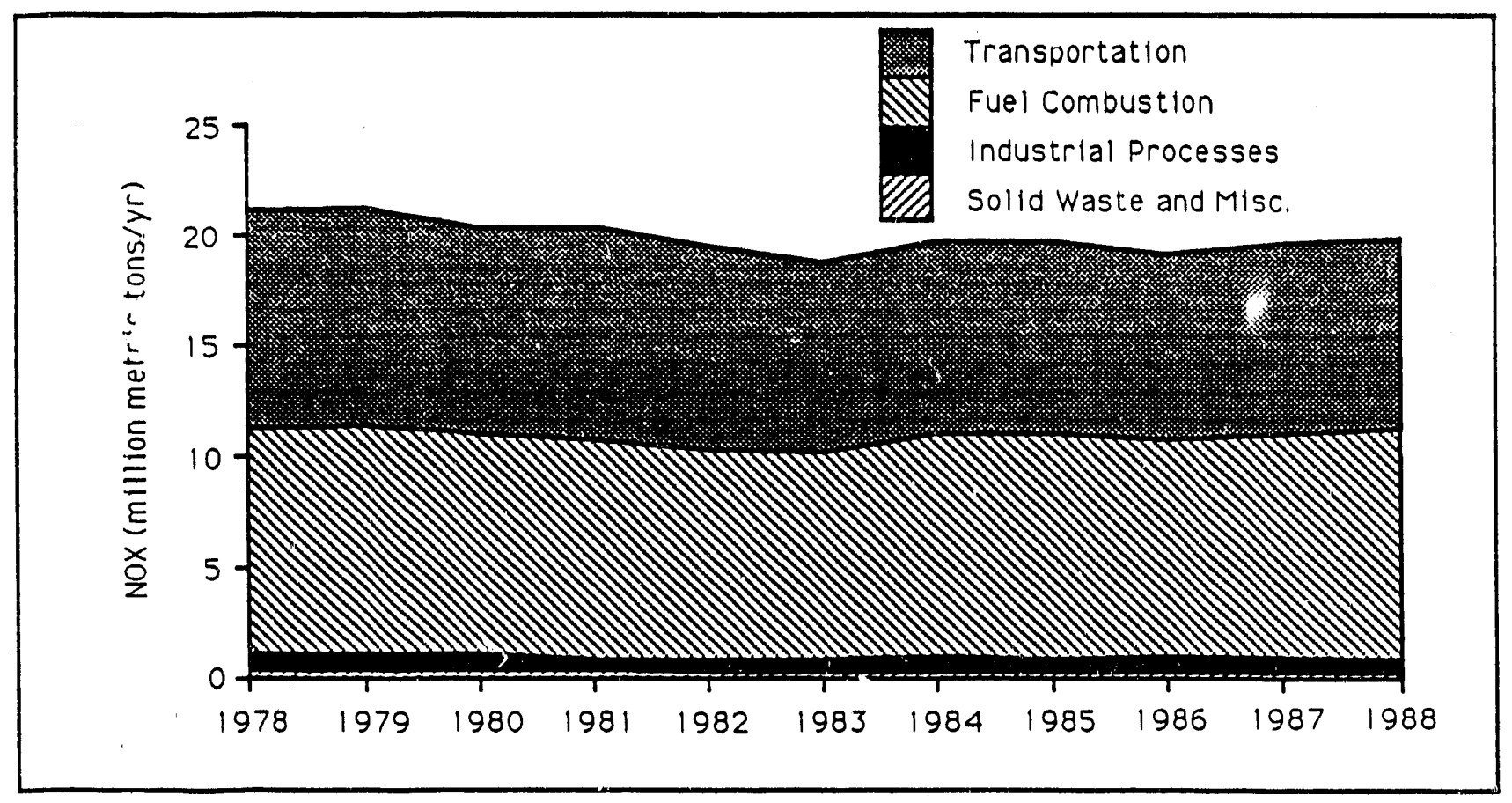

FIGURE 3.3. National Trend in Nitrogen Oxide Emis:ions, 1978-1988

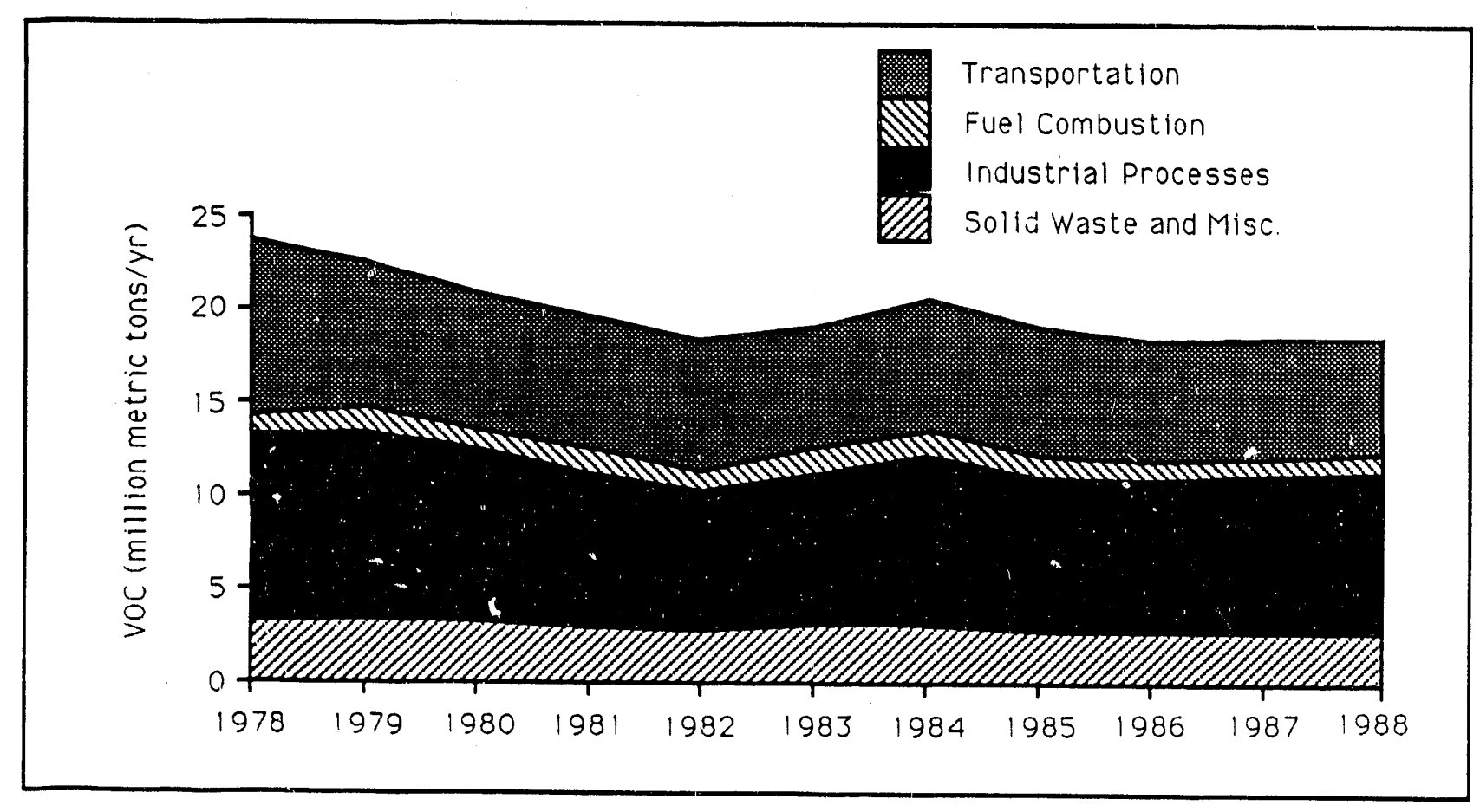

FIGURE 3.4 National Trend in Volatile Organic Compound Emissions, 1978-1988 
kilometers. The eastern and western parts of the maps are estimated and displayed separately because the magnitude of wet deposition is generally much larger in the east. The western part consists of 1875 hexagons while the eastern part consists of 1833 hexagons (1317 within the United States). The gray scale used in the maps are based on the percentiles from the frequency distribution of the estimates for each part.

The 1988 annual and seasonal precipitation-weighted concentrations and total depositions for the sites used to generate the mosaic maps are summarized in Table A.3 and Table A.4, respectively. The frequency distribution percentiles of the estimated precipitation-weighted concentration and total deposition at the center of the hexagons in eastern and western United States are shown in Table A.9 and A.10, respectively. The relevant percentiles are also displayed on the individual mosaic maps. Finally, the location of the sites with the three highest and three lowest values, in the western and eastern United States and southeastern Canada (shown in the figures), are given in Tables A.11 through A.15 for hydrogen, sulfate, nitrate, ammonium and calcium, respectively.

The mosaic maps discussed in this section are based on sites that are assumed to be regionally representative. As seen in Figure 2.1, the regions represented by some sites are quite large. For the maps based on the annual summaries, there are three states in the west (Nevada, Utah, and North Dakota) that have no sites and a number of other states with only one site. The winter and summer seasons have more valid summaries (see Tables A.3 and A.4), but many sites with valid summer summaries do not have valid winter summaries, and vice versa. Therefore, when reading this section or viewing the mosaic maps the following must be kept in mind:

- The smaller the area of a regional extreme, the more likely it is based on the summary of only one site.

- Comparisons between the summer and winter seasons can be misleading since the same sites are not in both seasons. The following discussion points out when this may be the case. 


\subsection{1 pH and Hydrogen}

The estimated (kriged) 1988 annual spatial pattern in the United States and southeastern Canada for $\mathrm{pH}$ (Figure A.1) has a range of 4.19 to 5.42 in the east and a range of 4.59 to 5.69 in the west. Approximately $50 \%$ of the east has $\mathrm{pH}$ values which are lower than the lowest $\mathrm{pH}$ in the west, 4.59 . In the east, the lowest $\mathrm{pH}$ values occur from southeastern Indiana to central Maryland and north to central New York. The highest pH values in the east occur in northern Iowa, Minnesota and western Ontario. In the west, the lowest estimated $\mathrm{pH}$ values occur in two separate regions: eastern Kansas, OKlahoma, and Texas; southeastern Arizona and western New Mexico. The highest pH values in the west occur in one large region: eastern Oregon and northern Nevada to eastern Montana; and several small regions in California, Texas and Colorado.

The estimated 1988 winter spatial pattern in the United States and southeastern Canada for $\mathrm{pH}$ (Figure A.2) has a range of 4.30 to 5.10 in the east and a range of 4.57 to 6.37 in the west. Almost $50 \%$ of the east has $\mathrm{pH}$ values lower than the lowest $\mathrm{pH}$ in the west, 4.57. In the east, the lowest $\mathrm{pH}$ values occur in two regions: western Pennsylvania and eastern Ohio; and southern Ontario and Quebec. The highest $\mathrm{pH}$ values in the east occur on the western and southern boundaries of the region. In the west, the lowest $\mathrm{pH}$ values occur along the eastern boundary of the region, in Texas along the Gulf Coast and two isolated spots in Utah and Arizona. The highest pH values in the west occur in southwestern Texas and southern Idaho.

The estimated 1988 summer spatial pattern in the United States and southeastern Canada for $\mathrm{pH}$ (Figure A.3) has a range of 3.92 to 6.32 in the east and a range of 4.36 to 6.52 in the west. Again, close to $50 \%$ of the pH values in the east are lower than the lowest $\mathrm{pH}$ in the west, 4.36. In the east, the lowest $\mathrm{pH}$ values occur in patches from eastern Indiana and Kentucky to Cape Cod, Massachusetts. The highest $\mathrm{pH}$ values in the east occur in Minnesota and western Ontario. In the west, the lowest $\mathrm{pH}$ values occur in three regions: eastern Kansas and Texas; eastern Arizona and western New Mexico; and southwestern California. The highest $\mathrm{pH}$ values in the west occur in four regions: eastern Idaho and western Utah; southern Nevada; western Kansas and North Dakota. 
In the east, the median summer $\mathrm{pH}$ value, 4.47 , is slilghtly lower than the median winter value, 4.59. The summer has a much larger range of values, 3.92 to 6.32 , than the winter, 4.30 to 5.10 . In the east, the most striking seasonal difference occurs in the region centered in southwestern ohio. During the summer, the $\mathrm{pH}$ is less than 4.07 , while in the winter the $\mathrm{pH}$ is greater than 4.40. This is over a factor of two decrease in hydrogen concentration between summer and winter in this region. In the west, the magnitude of the pH is similar in the summer (5.18 median and range of 4.36 to 6.52 ) and winter (5.28 median and range of 4.57 to 6.37 ). In the west, there is a large local seasonal difference on the southern California coast, where the summer $\mathrm{pH}$ is less than 4.74 and the winter $\mathrm{pH}$ is greater than 5.28 , a factor of 3.5. Additionally, the state of North Dakota changes from a pH of over 5.65 in the summer to a pattern of decreasing $\mathrm{pH}^{\prime} \mathrm{s}$ in the winter, from 5.4 in the west to less than 5.0 in the east. This difference may be due to the presence of only one site in North Dakota in the summer, and no sites in the winter.

The estimated 1988 annual spatial pattern in the United States and southeastern Canada for hydrogen ion deposition (Figure A.1) has a range of $0.02 \mathrm{~kg} / \mathrm{ha}$ to $0.59 \mathrm{~kg} / \mathrm{ha}$ in the east and a range of $0.01 \mathrm{~kg} / \mathrm{ha}$ to $0.24 \mathrm{~kg} / \mathrm{ha}$ in the west. Well over $50 \%$ of the east has hydrogen deposition greater than the maximum value in the west. In the east, the highest deposition occurs in eastern Ohio, Pennsylvania, and southern New York. The lowest deposition in the east occurs in Iowa, Minnesota, Wisconsin and western Ontario. In the west, the highest deposition occurs in eastern Oklahoma and Texas. The lowest deposition in the west is in a number of locations from western Nevada, through Montana and Wyoming and then into western North and South Dakota. The west's spatial pattern appears to be dominated by a large number of local extremes in hydrogen deposition.

The estimated 1988 winter spatial pattern in the United States and southeastern Canada for hydrogen ion deposition (Figure A.2) has a range of $0.004 \mathrm{~kg} / \mathrm{ha}$ to $0.123 \mathrm{~kg} / \mathrm{ha}$ in the east and a range of $0.001 \mathrm{~kg} / \mathrm{ha}$ to 0.066 $\mathrm{kg} / \mathrm{ha}$ in the west, with the median $(0.008 \mathrm{~kg} / \mathrm{ha})$ in the west being almost eight times smaller than the median $(0.059 \mathrm{~kg} / \mathrm{ha})$ in the east. In the east, the highest deposition primarily occurs in southern Ontario, and southern 
Illinois, Indiana and western Kentucky. The lowest deposition in the east occurs in Iowa, Minnesota and Wisconsin. The east's spatial pattern appears to be dominated by a large number of local extremes in hydrogen deposition. In the west, the highest deposition occurs in eastern Oklahoma and Texas, and the Pacific Northwest. The lowest deposition in the west occur from southern Idaho and southern Montana to the western Dakotas and Nebraska.

The estimated 1988 summer spatial pattern in the United States and southeastern Canada for hydrogen ion deposition (Figure A.3) has a range of $0.000 \mathrm{~kg} / \mathrm{ha}$ to $0.260 \mathrm{~kg} / \mathrm{ha}$ in the east and a range of $0.001 \mathrm{~kg} / \mathrm{ha}$ to 0.104 $\mathrm{kg} / \mathrm{ha}$ in the west, with the median $(0.007 \mathrm{~kg} / \mathrm{ha})$ in the west being over 14 times smaller than the median $(0.100 \mathrm{~kg} / \mathrm{ha})$ in the east. In the east, the highest deposition occurs in regions from eastern North Carolina, Virginia, to Pennsylvania and New York with additional high depositions in Ohio and western Florida. The lowest deposition in the east occurs in Iowa, Minnesota, Wisconsin and western Ontario. In the west, the highest deposition orcurs in two regions: eastern Kansas, OKlahoma and Texas; and New Mexico. The lowest deposition in the west occurs primarily in two regions: northern California; and southern Idaho, and central Montana.

In both the east and west there are apparent differences in the summer and winter hydrogen deposition patterns. In the east, almost all of the area in the winter has depositions that are less than the summer median deposition of $0.100 \mathrm{~kg} / \mathrm{ha}$. In the summer, there are large areas from North Carolina to New York and Ohio with depositions greater than $0.205 \mathrm{~kg} / \mathrm{ha}$. In the winter, almost all of this area has depositions less than $0.084 \mathrm{~kg} / \mathrm{ha}$. Additionally, western Florida has decreased from a deposition of over $0.205 \mathrm{~kg} / \mathrm{ha}$ in the summer to less than $0.042 \mathrm{~kg} / \mathrm{ha}$ in the winter. In the west, the magnitude of the depositions do not change markedly from summer to winter. However the location of some of the extremes do change. In the summer, New Mexico has a region with hydrogen deposition over $0.039 \mathrm{~kg} / \mathrm{ha}$ which during the winter has a deposition of less than $0.008 \mathrm{~kg} / \mathrm{ha}$. The Pacific Northwest has a hydrogen deposition of over $0.029 \mathrm{~kg} / \mathrm{ha}$ in the winter and a deposition of less than $0.018 \mathrm{~kg} / \mathrm{ha}$ in the summer.

The estimated spatial patterns of $\mathrm{pH}$ and hydrogen deposition are similar except for a few regional differences. The annual pH pattern has a low point 
in western New Mexico, which has only a median hydrogen deposition. The Pacific Northwest has a high winter hydrogen deposition but only a median $\mathrm{pH}$ in the winter. Eastern Illinois, Indiana and western Kentucky have high winter depositions but only median pHs. North Carolina and western Florida have high summer hydrogen depositions and only median summer $\mathrm{pH}^{\prime} \mathrm{s}$.

\section{2 .2 Sulfate}

The estimated 1988 annual spatial pattern in the United States and southeastern Canada for sulfate ion concentration (Figure A.4) has a range of $0.89 \mathrm{mg} / 1$ to $4.90 \mathrm{mg} / 1$ in the east and a range of $0.23 \mathrm{mg} / 1$ to $2.00 \mathrm{mg} / 1$ in the west, with almost all of the concentrations in the west being smaller than the median concentration in the east $(1.77 \mathrm{mg} / \mathrm{l})$. In the east, the highest concentrations occur in the southern tip of Ontario, eastern Michigan, Ohio and western Pennsylvania. The lowest concentrations in the east occur in three regions: western Ontario and northern Minnesota; Nova Scotia; and Florida. In the west, the highest concentrations occur in two regions: eastern Kansas and Nebraska; and southern Texas. The lowest concentrations in the west occur in northern California, Oregon, and Idaho.

The estimated 1988 winter spatial pattern in the United States and southeastern Canada for sulfate ion concentration (Figure A.5) has a range of $0.68 \mathrm{mg} / 1$ to $2.61 \mathrm{mg} / 1$ in the east and a range of $0.18 \mathrm{mg} / 1$ to $1.93 \mathrm{mg} / 1$ in the west, with over $90 \%$ of the concentrations in the west being smaller than the median concentration in the east $(1.26 \mathrm{mr} / 1)$. In the east, the highest concentrations occur in the southern tip of Ontario, western Pennsylvania, Ohio, eastern Michigan, and central Indiana. The lowest concentrations in the east occur primarily in Minnesota, Wisconsin and western Ontario. In the west, the highest concentrations occur in southern Texas. The lowest concentrations in the west occur in northern California, Oregon and Idaho.

The estimated 1988 summer spatial pattern in the United States and southeastern Canada for sulfate ion concentration (Figure A.6) has a range of $0.88 \mathrm{mg} / 1$ to $12.41 \mathrm{mg} / 1$ in the east and a range of $0.38 \mathrm{mg} / 1$ to $1.79 \mathrm{mg} / 1$ in the west. The large maximum concentration in the east is due to two sites in Ontario, Wilkesport $(15.04 \mathrm{mg} / 1)$ and Alvinston $(12.81 \mathrm{mg} / 1)$, the site with the third highest concentration is Oxford, Ohio with $6.16 \mathrm{mg} / 1$, a factor of two 
less. Almost all of the west is less than the 25 th percentile of the east $(1.65 \mathrm{mg} / 1)$. In the east, the highest concentrations occur in the southern tip of Ontario, Ohio and western Pennsylvania. The lowest concentrations in the east occur in western Ontario and Minnesota. In the west, the highest concentrations occur in eastern Kansas, Oklahoma and Texas. The lowest concentrations in the west occur in Oregon and Washington.

In the east, the magnitude of the summer sulfate concentrations are higher than the winter sulfate concentrations. Almost all of the east has lower winter concentrations than the summer median concentration, $2.19 \mathrm{mg} / 1$. The summer and winter spatial patterns are similar. In the west, the magnitude of the higher concentrations stay the same from summer to winter, however the lower concentrations are two to three times larger in the summer than in the winter (the 25th percentile is $0.96 \mathrm{mg} / 1$ in the summer and only $0.33 \mathrm{mg} / 1$ in the winter). In the winter the highest concentrations are in southern Texas, while in the summer the highest concentrations are in eastern Texas, OKlahoma and Kansas. However, the greatest seasonal changes in the west occur in two areas: southeastern California, southern Nevada and northwestern Arizona; and northern Colorado and southeastern Wyoming; where the summer concentration is over $1.37 \mathrm{mg} / 1$ and the winter concentration is less than $0.56 \mathrm{mg} / 1$.

The estimated 1988 annual spatial pattern in the United States and southeastern Canada for sulfate ion deposition (Figure A.4) has a range of 6.3 $\mathrm{kg} / \mathrm{ha}$ to $32.2 \mathrm{~kg} / \mathrm{ha}$ in the east and a range of $0.8 \mathrm{~kg} / \mathrm{ha}$ to $16.3 \mathrm{~kg} / \mathrm{ha}$ in the west, with the median in the east $(17.1 \mathrm{~kg} / \mathrm{ha})$ over five times larger than the median in the west $(3.4 \mathrm{~kg} / \mathrm{ha})$. In the east, the highest deposition occurs in the southern tip of Ontario, western Pennsylvania, eastern Ohio and northern West Virginia. The lowest deposition in the east occurs in western Ontario, Minnesota, Iowa, and western Wisconsin. In the west, the highest deposition occurs in eastern Kansas, OKlahoma and Texas. The lowest deposition in the west occurs in northern California, eastern Oregon, western Idaho, and Nevada.

The estimated 1988 winter spatial pattern in the United Staties and southeastern Canada for sulfate ion deposition (Figure A.5) has a ranje of $0.36 \mathrm{~kg} / \mathrm{ha}$ to $6.41 \mathrm{~kg} / \mathrm{ha}$ in the east and a range of $0.10 \mathrm{~kg} / \mathrm{ha}$ to $4.00 \mathrm{~kg} / \mathrm{ha}$ in the west, with the median in the east $(2.81 \mathrm{~kg} / \mathrm{ha}$ ) over five times larger 
than the median in the west $(0.47 \mathrm{~kg} / \mathrm{ha})$. In the east, the highest deposition occurs in southern I11inois and Indiana and western Kentucky and Tennessee. The lowest deposition in the east occurs in Iowa, Minnesota, Wisconsin and western Ontario. In the west, the highest deposition occurs in eastern Texas and Oklahoma. The lowest deposition in the west occurs in southern Idaho and southern Montana, northern Wyoming and the eastern Dakotas.

The estimated 1988 summer spatial pattern in the United States and southeastern Canada for sulfate ion deposition (Figure A.6) has a range of $1.56 \mathrm{~kg} / \mathrm{ha}$ to $14.88 \mathrm{~kg} / \mathrm{ha}$ in the east and a range of $0.07 \mathrm{~kg} / \mathrm{ha}$ to $5.60 \mathrm{~kg} / \mathrm{ha}$ in the west, with the median in the east $(5.57 \mathrm{~kg} / \mathrm{ha})$ over four times larger than the median in the west $(1.22 \mathrm{~kg} / \mathrm{ha})$. In the east, the highest deposition occurs in a number of different regions: southern tip of Ontario, New York, Ohio, Virginia and North Carolina. The lowest deposition in the east occurs in two regions: western Ontario and Minnesota; and Arkansas. In the west, the highest deposition occurs in two regions: eastern Nebraska, Kansas, and Texas; and southern New Mexico. The lowest deposition in the west occurs in California, Oregon and southwestern Idaho.

In both the east and west, the magnitude of the sulfate deposition is greater in the summer than in the winter. In the east the median summer deposition is $5.6 \mathrm{~kg} / \mathrm{ha}$ while the winter median deposition is $2.8 \mathrm{~kg} / \mathrm{ha}$. In the west the median summer deposition is $1.2 \mathrm{~kg} / \mathrm{ha}$ while the winter median deposition is only $0.5 \mathrm{~kg} / \mathrm{ha}$. The spatial pattern in the east changes dramatically between the summer and winter. In the summer the sulfate depositions are greater than $10 \mathrm{~kg} / \mathrm{ha}$ from North Carolina north through New York and from Virginia east through Ohio. In the winter, almost all of this region has sulfate depositions less than $3.7 \mathrm{~kg} / \mathrm{ha}$. In the west, New Mexico, with sulfate depositions greater than $2.5 \mathrm{~kg} / \mathrm{ha}$ in the summer, drops to less than $0.8 \mathrm{~kg} / \mathrm{ha}$ in the winter. This difference may be due to the presence of four sites in New Mexico during the summer and only one site, in the northwest, during the winter.

The estimated spatial patterns of sulfate concentration and deposition are similar except for a few regional differences for the annual and summer values. The annual spatial patterns show only minor differences in the Pacific Northwest, southern Texas and Ohio. In summer, the high 
concentrations are in one region centered on Ohio, while the high depositions are in a number of separate regions, from North Carolina to New York. The west has a high deposition in southern New Mexico, but the concentration there is low. Additionally, the concentrations in southern California and Nevada are high while the depositions are low. The winter spatial patterns for concentration and deposition are very different in both the east and west. In the east, the high concentrations occur in ohio and central Indiana while the high depositions occur to the southwest of this region. In the west the concentrations are very low along the coast, but the depositions are high, especially in southern California and the Pacific Northwest.

\subsubsection{Nitrate}

The estimated 1988 annual spatial pattern in the United States and southeastern Canada for nitrate ion concentration (Figure $A .7$ has a range of $0.42 \mathrm{mg} / 1$ to $3.53 \mathrm{mg} / 1$ in the east and a range of $0.15 \mathrm{mg} / 1$ to $1.69 \mathrm{mg} / 1$ in the west. Over $90 \%$ of the nitrate concentrations in the west are less than the median concentration in the east $(1.22 \mathrm{mg} / 1)$. In the east, the highest concentrations occur in southern Ontario and Quebec, and eastern Michigan. The lowest concentrations in the east occur in the south along the Gulf of Mexico from Louisiana through all of Florida. In the west, the highest concentrations occur in eastern South Dakota and Nebraska, through western Kansas and into southeastern Colorado. The lowest concentrations in the west occur in northern California, Oregon, and Washington.

The estimated 1988 winter spatial pattern in the United States and southeastern Canada for nitrate ion concentration (Figure A.8) has a range of $0.28 \mathrm{mg} / 1$ to $3.28 \mathrm{mg} / 1$ in the east and a range of $0.10 \mathrm{mg} / 1$ to $1.61 \mathrm{mg} / 1$ in the west, with the median in the east $(1.30 \mathrm{mg} / 1)$ being over twice the median in the west $(0.59 \mathrm{mg} / 1)$. In the east, the highest concentrations occur in southern Ontario and Quebec. The lowest concentrations in the east occur in the south along the Gulf of Mexico and north through Georgia. In the west, the highest concentrations occur in two regions: the eastern Dakotas, Nebraska and Kansas; and eastern Utah. The lowest concentrations in the west occur in Oregon and Washington. 
The estimated 1988 summer spatial pattern in the United States and southeastern Canada for nitrate ion concentration (Figure A.9) has a range of $0.46 \mathrm{mg} / 1$ to $4.15 \mathrm{mg} / 1$ in the east and a range of $0.00 \mathrm{mg} / 1$ to $3.31 \mathrm{mg} / 1 \mathrm{in}$ the west. The median and upper percentiles in the east and west are simtlar, with only the lower percentiles being markedly smaller in the west. In the east, the highest concentrations occur in southern ontario and Ohto. The lowest concentrations in the east occur in two regions: Ontario and Quebec; and Florida. In the west, the highest concentrations occur in southern California. The lowest concentrations in the west occur in northern California, Oregon, Washington.

In the east, the magnitude of the summer and winter concentrations are about the same. The spatial pattern in the east changes with the seasons. The nitrate concentrations in winter are highest in southern ontario and Quebec, while the highest concentrations in the summer are in ohio and the southern tip of Ontario. The largest change is on the border between ontarto and Quebec, where the winter concentrations are over $2.65 \mathrm{mg} / 1$ while the summer concentrations are less than $1.79 \mathrm{mg} / 1$. The high concentration estimates in Quebec during the winter are due to the high concentrations in Ontario since there are no valid summaries for this region of Quebec during the winter. In the west, the summer concentrations are greater than the winter. The difference in the west is due to the large summer concentrations in southern California, over $2.26 \mathrm{mg} / 1$, while the winter concentrations are less than $0.38 \mathrm{mg} / \mathrm{l}$.

The estimated 1988 annual spatial pattern in the United States and southeastern Canada for nitrate ion deposition (Figure A.7) has a range of 5.7 $\mathrm{kg} / \mathrm{ha}$ to $30.1 \mathrm{~kg} / \mathrm{ha}$ in the east and a range of $0.7 \mathrm{~kg} / \mathrm{ha}$ to $11.2 \mathrm{~kg} / \mathrm{ha}$ in the west, with almost all the deposition in the west less than the loth percentile of the deposition in the east $(7.8 \mathrm{~kg} / \mathrm{ha})$. In the east, the highest deposition occurs in central New York, and southern Ontario. The lowest deposition in the east occurs in two regions: western Minnesota and lowa; and Georgia and the Florida. In the west, the highest deposition occurs in eastern Nebraska, Kansas, OKlahoma and Texas. The lowest deposition in the west occurs in northern California, southern Oregon, southern Idaho, southwestern Montana, and northern Nevada. 
The estimated 1988 winter spatial pattern in the United States and southeastern Canada for nitrate ion deposition (Figure A.8) has a range of $0.48 \mathrm{~kg} / \mathrm{ha}$ to $7.44 \mathrm{~kg} / \mathrm{ha}$ in the east and a range of $0.15 \mathrm{~kg} / \mathrm{ha}$ to $2.29 \mathrm{~kg} / \mathrm{ha}$ in the west, with almost all of the western depositions being less than the median deposition in the east $(2.21 \mathrm{~kg} / \mathrm{ha})$. In the east, the highest deposition occurs in southern Ontario and quebec. The lowest deposition in the east occurs in two regions: Minnesota, Iowa and Wisconsin; and southern Florida. In the west, the highest deposition occurs in eastern Oklahoma and Texas; Colorado; and along the west coast. The lowest deposition in the west occurs in southern Idaho and southeastern Montana.

The estimated 1988 summer spatial pattern in the United States and southeastern Canada for nitrate ion deposition (Figure A.9) has a range of $1.20 \mathrm{~kg} / \mathrm{ha}$ to $6.98 \mathrm{~kg} / \mathrm{ha}$ in the east and a range of $0.00 \mathrm{~kg} / \mathrm{ha}$ to $3.53 \mathrm{~kg} / \mathrm{ha}$ in the west, with almost all of the western depositions being less than the median deposition in the east $(3.2 \mathrm{~kg} / \mathrm{ha})$. In the east, the spatial pattern is dominated by numerous local extremes. The regions with high concentrations occur in Ohio and Michigan and then towards the northeast. The regions with low concentrations are in the northern extent of the map and the southern states. In the west, the highest deposition occurs in two regions: eastern Nebraska, Kansas, Oklahoma and Texas; and southern New Mexico. The lowest deposition in the west occurs in northern Californta, Oregon and Washington.

In both the east and west, the spatial patterns of nitrate deposition appear markedly different between summer and winter. In the east, the winter deposition pattern is dominated from the high depositions in southern Ontario and its border with Quebec. In the summer, Ohto and southern Michigan have depositions greater than $5.4 \mathrm{~kg} / \mathrm{ha}$, while in the winter the depositions are less than $3.8 \mathrm{~kg} / \mathrm{ha}$. In western Florida, the summer deposition is also greater than $5.0 \mathrm{~kg} / \mathrm{ha}$, while in the winter the deposition is less than 1.0 $\mathrm{kg} / \mathrm{ha}$. In the west, the summer deposition in southern New Mexico is greater than $2.3 \mathrm{~kg} / \mathrm{ha}$, while the winter deposition is less than $0.32 \mathrm{~kg} / \mathrm{ha}$. The winter deposition in coastal central Californta and the Pacific Northwest is greater than $0.76 \mathrm{~kg} / \mathrm{ha}$, while the summer depositions are less than $0.2 \mathrm{~kg} / \mathrm{ha}$. As noted previously, during the winter there are no valid site summaries for 
the intertor of Quebec and most of New Mexico. Thus the apparent differences observed in the maps may be artffacts.

The estimated annual spatial patterns for nitrate concentration and deposition are the same for most of the United States and southeastern Canada. The estimated summer and winter spatial patterns for nitrate concentration and deposition are different in both the east and west. In the east, the winter patterns deviate in lowa and Minnesota where the depositions are very low while the concentrations are moderate. In the west, winter patterns deviate in two regions: eastern Oklahoma and Texas; and the Pactfic Northwest. In these regions, the depositions are relatively high while the concentrations are low. In the summer, the eastern spatial pattern for nitrate concentrations is very smooth, while the nitrate deposition pattern is dominated by numerous local extremes. The biggest difference occurs in western Florida with high summer depositions and low suminer concentrations. The summer concentration pattern in the west is dominated by the high values in southern Californita and Nevada, while the depositions in this area are relatively low.

\section{2 .4 Ammontum}

The estimated 1988 annual spatfal pattern in the United States and southeastern Canada for ammonium ion concentration (Figure A.10) has a range of $0.04 \mathrm{mg} / 1$ to $0.81 \mathrm{mg} / 1$ in the east and a range of $0.01 \mathrm{mg} / 1$ to $0.53 \mathrm{mg} / 1 \mathrm{in}$ the west, with the concentrations in the west being less than those in the east. In the east, the highest concentrations occur in two regions: southern Ontario and eastern Michigan; and Iowa. The lowest concentrations in the east occur in two regions: coastal Maine; and Mississippl, Alabama, Georgia, South Carolina, and Florida. In the west, the highest concentrations occur in eastern South Dakota and Nebraska, western Kansas and 0k.1ahoma, and the panhandle of Texas. The lowest concentrations in the west occur primarily in northern California, Oregon, and Washington.

The estimated 1988 winter spatial pattern in the United States and southeastern Canada for ammonium ion concentration (Figure A.11) has a range of $0.03 \mathrm{mg} / 1$ to $0.56 \mathrm{mg} / 1$ in the east and a range of $0.01 \mathrm{mg} / 1$ to $0.52 \mathrm{mg} / 1$ in the west. In the east, the highest concentrations occur in southern ontarto, 
and eastern Michigan. The lowest concentrations in the east occur primarily in New Brunswick, Nova Scotta, Maine, Georgla, Alabama and Flortda. In the west, the highest concentrations occur in eastern Nebraska and Kansas. The lowest concentrations in the west occur in Washington, Oregon, and northern Idaho.

The estimated 1988 summer spatial pattern in the United States and southeastern Canada for ammonium ion concentration (Figure A.12) has a range of $0.02 \mathrm{mg} / 1$ to $1.29 \mathrm{mg} / 1$ in the east and a range of $0.01 \mathrm{mg} / 1$ to $0.59 \mathrm{mg} / 1 \mathrm{in}$ the west, with the concentrations in the west being less than those in the east. In the east, the highest concentrations occur in southern Ontarto, Quebec and eastern Michigan, with a local high in southeastern ohto. The lowest concentrations in the east occur in southern Mississippi, Alabama, and Georgia, and Florida. In the west, the highest concentrations occur in two regions: North Dakota and eastern Montana; and southern California. The lowest concentrations in the west occur in Washington, Oregon, and northern Idaho.

The summer ammonium concentration is greater than the winter concentration, in both the east and the west. The spatial pattern in the east does not appear to change between the winter and summer. The spatial pattern in the west appears to change between the summer and winter due to the different locations of the high concentrations. In the summer, North Dakota and eastern Montana has ammonium concentrations greater than $0.43 \mathrm{mg} / 1$ across almost all of the state, while in the winter the concentration is less than 0.17 across most of the state, decreasing to less than $0.10 \mathrm{mg} / 1$ in the west. As noted previousiy, there are no valid winter summaries in North Dakota, however the site in northeastern Montana has valid summaries during both the summer and winter. Additionally, the summer concentration in coastal southern Caltfornia is also greater than $0.43 \mathrm{mg} / 1$, while in the winter the concentrations are $0.17 \mathrm{mg} / 1$.

The estimated 1988 annual spatial pattern in the United States and southeastern Canada for ammonium ion deposition (Figure A.10) has a range of $0.52 \mathrm{~kg} / \mathrm{ha}$ to $6.91 \mathrm{~kg} / \mathrm{ha}$ in the east and a range of $0.12 \mathrm{~kg} / \mathrm{ha}$ to $2.30 \mathrm{~kg} / \mathrm{ha}$ in the west. Almost all of the west has depositions less than the median deposition in the east, $2.10 \mathrm{~kg} / \mathrm{ha}$. In the east, the highest deposition 
occurs in southern Ontarlo. The lowest depositions in the east occurs in two regtons: Maine; and South Carolina, Florida, Georgia, and Alabama. In the west, the highest deposition occurs in the eastern Dakotas, Nebraska, Kansas and $0 \mathrm{Kl}$ ahoma. The lowest deposition in the west occurs in eastern Oregon, southern Idaho, northern Utah and western Wyoming.

The estimated 1988 winter spatial pattern in the United States and southeastern Canada for ammonium ion deposition (Figure A.11) has a range of $0.04 \mathrm{~kg} / \mathrm{ha}$ to $1.38 \mathrm{~kg} / \mathrm{ha}$ in the east and a range of $0.02 \mathrm{~kg} / \mathrm{ha}$ to $1.11 \mathrm{~kg} / \mathrm{ha}$ in the west, with the median in the east $(0.25 \mathrm{~kg} / \mathrm{ha})$ more than three times the median in the west $(0.08 \mathrm{~kg} / \mathrm{ha})$. In the east, the highest deposition occurs in two regions: southern Ontario and eastern Michigan; and Arkansas and Louisiana. The lowest deposition in the east occurs in numerous small areas in Minnesota, Wisconsin, Iowa, South Carolina, Georgla and Florida. In the west, the highest deposition occurs in two regions: eastern Kansas, OKlahoma and Texas; and the coast of California. The lowest deposition in the west occurs in two regions: central Montana and Wyoming; and New Mexico.

The estimated 1988 summer spatial pattern in the United States and southeastern Canada for ammonium ion deposition (Figure A.12) has a range of $0.10 \mathrm{~kg} / \mathrm{ha}$ to $2.77 \mathrm{~kg} / \mathrm{ha}$ in the east and a range of $0.00 \mathrm{~kg} / \mathrm{ha}$ to $0.93 \mathrm{~kg} / \mathrm{ha}$ in the west, with the median in the east $(0.60 \mathrm{~kg} / \mathrm{ha})$ five times the median in the west $(0.12 \mathrm{~kg} / \mathrm{ha})$. In the east, the highest deposition occurs in two regions: southwestern Ontario; and southeastern Ontario. The lowest deposition in the east occurs in the Arkansas, Mississippi, Alabama, Georgia, and Florida. In the west, the highest deposition occurs in North Dakota, and eastern South Dakota. The lowest deposition in the west occurs in coastal northern California, Oregon and western Washington.

Ammonium deposition is lower in the winter than in the summer. Almost a11 the winter depositions in the east are less than the median summer deposition, $0.60 \mathrm{~kg} / \mathrm{ha}$. The spatial patterns in the east change in two regions: in western Ontario, the winter deposition is less than $0.12 \mathrm{~kg} / \mathrm{ha}$ while the summer deposition is greater than $1.29 \mathrm{~kg} / \mathrm{ha}$; and in Arkansas and Louisiana, where the magnitudes of the depositions stay the same, but in the summer the magnitudes are only moderate compared to the depositions in Ontario. In the west, North Dakota has a summer deposition of over 0.60 
$\mathrm{kg} / \mathrm{ha}$, while it's winter deposition is less than $0.08 \mathrm{~kg} / \mathrm{ha}$, but there are no valid winter summaries in North Dakota to support this estimation. Along the coast of California, the winter depositions are greater than $0.24 \mathrm{~kg} / \mathrm{ha}$, while it's summer depositions are less than $0.02 \mathrm{~kg} / \mathrm{ha}$ in the San Francisco area and less than $0.12 \mathrm{~kg} / \mathrm{ha}$ in the Los Angeles area.

The estimated spatial patterns for ammonium concentration and deposition have regional differences in both the east and west. In the east, the annual concentration has a high point in Iowa, which only has a moderate deposition. In the west, the Pacific Northwest has very low annual concentrations but moderate depositions. In the winter, the east has low depositions in Iowa, Minnesota, and Wisconsin, but the concentrations are moderate. In the west, the winter depositions aiong the Pacific Coast range from very high in California to moderate in Oregon and Washington, while the concentrations range from moderate in California to very low in Oregon and Washington. In the summer, the east's concentrations and depositions appear to have the same spatial pattern. In the west, the summer concentration in coastal southern California is high while the deposition is only moderate.

\section{2 .5 Calcium}

The estimated 1988 annual spatial pattern in the United States and southeastern Canada for calcium ion concentration (Figure A.13) has a range of $0.05 \mathrm{mg} / 1$ to $0.99 \mathrm{mg} / 1$ in the east and a range of $0.03 \mathrm{mg} / 1$ to $0.58 \mathrm{mg} / 1 \mathrm{in}$ the west, with the west having a higher median $(0.24 \mathrm{mg} / 1)$ than the east $(0.17$ $\mathrm{mg} / 1)$. In the east, the highest concentrations occur in three regions: southern Quebec; southern Ontario and eastern Michigan; and Iowa. The lowest concentrations in the east occur in two regions: New Brunswick, Nova Scotia and New England; and the Carolinas, Georgia and Mississippi. In the west, the highest concentrations occur in four regions: western Kansas and southeastern Colorado; Oklahoma; eastern Nebraska; and the junction of Utah, Colorado, New Mexico ard Arizona. The lowest concentrations in the west occur in northern California, western Oregon and Washington.

The estimated 1988 winter spatial pattern in the United States and southeastern Canada fo ${ }^{\prime}$ calcium ion concentration (Figure A.14) has a range of $0.04 \mathrm{mg} / 1$ to $0.63 \mathrm{mg} / 1$ in the east and a range of $0.03 \mathrm{mg} / 1$ to $0.57 \mathrm{mg} / 1 \mathrm{in}$ 
the west. In the east, the highest concentrations occur in two regions: southern Quebec, the southern tip of Ontario, and eastern Michigan; and southern Iowa. The lowest concentrations in the east occur in two regions: New England; and the Carolinas, Georgia and Alabama. In the west, the highest concentrations occur in western Texas. The lowest concentrations in the west occur along the coast of the Pacific Ocean.

The estimated 1988 summer spatial pattern in the United States and southeastern Canada for calcium ion concentration (Figure A.15) has a range of $0.05 \mathrm{mg} / 1$ to $1.21 \mathrm{mg} / 1$ in the east and a range of $0.05 \mathrm{mg} / 1$ to $2.32 \mathrm{mg} / 1$ in the west, with the west having a larger median $(0.31 \mathrm{mg} / 1)$ than the east $(0.16$ $\mathrm{mg} / 1)$. In the east, the highest concentrations occur in two regions: the southern tip of Ontario; and Iowa. The lowest concentrations in the east occur in two regions: New Brunswick, Nova Scotia, Quebec, and New England; and the Carolinas. In the west, the highest concentrations occur in two regions: Oklahoma; and southern Nevada. The lowest concentrations in the west occur in northern California, western Oregon and Washington.

The calcium concentration in the summer is greater than the winter concentration, especially in the west where the percentiles are over a factor of two greater. In the east, the spatial patterns are about the same in both the summer and winter. In the west, the winter calcium concentration is over $0.36 \mathrm{mg} / 1$ in western Texas, while the summer concentration is less than 0.21 $\mathrm{mg} / 1$. In the summer the concentration in southern Nevada and Oklahoma is over $0.77 \mathrm{mg} / 1$, while in the winter the concentration is less than $0.08 \mathrm{mg} / 1$ in southern Nevada and $0.29 \mathrm{mg} / 1$ in Oklahoma. In both Nevada and Oklahoma, one site accounted for the large summer concentrations and those sites did not have valid winter summaries.

The estimated 1988 annual spatial pattern in the United States and southeastern Canada for calcium ion deposition (Figure A.13) has a range of $0.61 \mathrm{~kg} / \mathrm{ha}$ to $6.39 \mathrm{~kg} / \mathrm{ha}$ in the east and a range of $0.23 \mathrm{~kg} / \mathrm{ha}$ to $2.94 \mathrm{~kg} / \mathrm{ha}$ in the west, with the median in the east $(1.55 \mathrm{~kg} / \mathrm{ha})$ larger than the median in the west $(0.97 \mathrm{~kg} / \mathrm{ha})$. In the east, the highest deposition occurs in three regions: southern Ontario; southern Quebec; and eastern Iowa. The lowest deposition in the east occurs in three regions: New Brunswick, Nova Scotia, and New England; the Carolinas; and Alabama. In the west, the highest 
deposition occurs in Oklahoma and eastern Kansas. The lowest deposition in the west occurs in California, southern Oregon and western Nevada.

The estimated 1988 winter spatial pattern in the United States and southeastern Canada for calcium ion deposition (Figure A.14) has a range of $0.03 \mathrm{~kg} / \mathrm{ha}$ to $1.07 \mathrm{~kg} / \mathrm{ha}$ in the east and a range of $0.02 \mathrm{~kg} / \mathrm{ha}$ to $0.40 \mathrm{~kg} / \mathrm{ha}$ in the west. In the east, the highest deposition occurs in southern Ontario and Quebec. The lowest deposition in the east occurs in western Ontario, Minnesota, Wisconsin, and Iowa. The northeast spatial pattern is dominated by numerous local extremes. In the west, the highest deposition occurs in three regions: northeastern Texas and eastern Oklahoma; Colorado; and the Oregon coast. The lowest deposition in the west occurs in two regions: Oregon; and Montana, the Dakotas and northern Nebraska.

The estimated 1988 summer spatial pattern in the United States and southeastern Canada for calcium ion deposition (Figure A.15) has a range of $0.16 \mathrm{~kg} / \mathrm{ha}$ to $1.55 \mathrm{~kg} / \mathrm{ha}$ in the east and a range of $0.03 \mathrm{~kg} / \mathrm{ha}$ to $1.23 \mathrm{~kg} / \mathrm{ha}$ in the west, with the median deposition in the east $(0.44 \mathrm{~kg} / \mathrm{ha})$ greater than the median deposition in the east $(0.34 \mathrm{~kg} / \mathrm{ha})$. In the east, the highest deposition occurs in two regions: southern Ontario; and Iowa. The lowest deposition in the east occurs in three regions: New Brunswick, Nova Scotia, and New England; the Carolinas; and Mississippi. The east spatial pattern is dominated by numerous local extremes. In the west, the highest deposition occurs in Oklahoma. The lowest deposition in the west occurs in northern California, Oregon and southwestern Washington.

The summer calcium depositions are larger than the winter depositions in both the east and west. In the summer, much of Iowa has calcium depositions greater than $0.94 \mathrm{~kg} / \mathrm{ha}$, while the same area in the winter has depositions less than $0.17 \mathrm{~kg} / \mathrm{ha}$. In Iowa, Minnesota, and Wisconsin the summer depositions are greater than $0.66 \mathrm{~kg} / \mathrm{ha}$, while in the winter the depositions are less than $0.12 \mathrm{~kg} / \mathrm{ha}$. In the west, the magnitude of the summer deposition is almost three times that of the winter deposition. In the west the greatest seasonal change occurs in Montana, the Dakotas, and Nebraska, where in the winter the depositions are less than $0.07 \mathrm{~kg} / \mathrm{ha}$, while in the summer the depositions are greater than $0.17 \mathrm{~kg} / \mathrm{ha}$. 
The estimated spatial patterns for calcium concentration and deposition are similar for the annual, summer and winter summaries in the east. However, in the west the concentration and deposition patterns are different for all three summaries. The annual high concentrations in southeastern and southwestern Colorado have only moderate annual depositions. The summer high concentrations in southern Nevada have relatively low summer depositions. In the winter, the very low concentrations on the west coast become moderate depositions.

\subsection{TEMPORAL PATTERNS}

The temporal patterns are examined using two approaches described in Section 2.5. First, the annual temporal patterns are examined using boxplots of the percentiles of the annual summaries for each year in the two trend subsets, 1979-1988 and 1982-1988. Then the temporal changes are examined using rayplots for each of the two trend subsets. The temporal patterns examine both concentration and deposition for nine ion species: hydrogen, sulfate, nitrate, ammonium, calcium, chloride, sodium, potassium and magnesium. $\mathrm{pH}$ and precipitation are also examined.

The boxplots that are examined for annual temporal patterns include $95 \%$ confidence intervals for the median. These boxplots and confidence intervals measure the variability for the entire region that the trend subsets cover, thus they are not sensitive indicators of a temporal trend. Additionally, the confidence intervals were developed one-at-a-time, thus it is not valid to infer a statistical significance when the confidence intervals do not overlap. Thus the few annual temporal patterns which are noted in this section are only subjective.

The interpretation of the rayplots in this section is simplified by the fact that most of the ion species and precipitation have only a small number of sites with significant trend estimates. As discussed in Section 2.5, with the number of sites being tested, a small number of sites with significant trends would be expected even if no trend actually existed. If these few sites with significant trend estimates are also widely dispersed across the United States and southern Canada, then the rayplots are consistent with the hypothesis that there is no trend over a large geographic area. 


\subsubsection{Hydrogen, $\mathrm{pH}$ and Precipitation}

\subsubsection{Annual Temporal Patterns}

The 31 site 1979-1988 trend subset for annual total precipitation (Table A. 6 and Figure A.16) has a maximum median in 1979 of $117.3 \mathrm{~cm}$ and minimum median of $89.4 \mathrm{~cm}$ in 1988 . The 103 site 1982-1988 trend subset for annual total precipitation (Table A.8 and Figure A.17) has a maximum median of 100.2 $\mathrm{cm}$ in 1985 and a minimum median of $85.6 \mathrm{~cm}$ in 1988 . While the 10-year subset has inter-annual variation that suggests an almost cyclic appearance, the 7 -year subset has no distinctive inter-annual pattern.

The 23 site 1979-1988 trend subset for annual pH (Table A.5 and Figure A.16) has approximately equal maximum medians in 1982 and 1983 of 4.48 .1980 has the lowest median pH of 4.33. The 92 site 1982-1988 trend subset for annual $\mathrm{pH}$ (Table A.7 and Figure A.17) has a maximum median $\mathrm{pH}$ of 4.46 in 1983 and a minimum median $\mathrm{pH}$ of 4.33 in 1982.

The annual hydrogen concentration for the 1979-1988 trend subset (Table A. 5 and Figure A.18) has a minimum median of $33.00 \mu \mathrm{g} / 1$ in 1983 and a maximum median of $46.42 \mu \mathrm{g} / 1$ in 1980 . The $1982-1988$ trend subset (Table A.7 and Figure A.19) has a minimum median of $34.76 \mu \mathrm{g} / 1$ in 1983 and a maximum median of $46.24 \mu \mathrm{g} / 1$ in 1982 .

The annual hydrogen deposition (Table A.6 and Figure A.18) has approximately equal minimum medians in 1979 and 1986 of $0.35 \mathrm{~kg} / \mathrm{ha} .1980$ and 1981 have the highest annual hydrogen median depositions of $0.45 \mathrm{~kg} / \mathrm{ha}$. The annual hydrogen deposition (Table A.8 and Figure A.19) has a maximum median of $0.43 \mathrm{~kg} / \mathrm{ha}$ in 1982 and a minimum median of $0.33 \mathrm{~kg} / \mathrm{ha}$ in 1988 .

\subsubsection{Temporal Change Analysis}

Based on the modified KST test, five of the 35 1979-1988 trend sites (Figure A.20) exhibit a significantly $(p<0.05)$ decreasing trend for total annual precipitation: Coweeta, NC $(-7.1 \mathrm{~cm} /$ year $)$; Delaware, OH $(-3.8$ $\mathrm{cm} /$ year $), \mathrm{Cl}$ inton Station, $\mathrm{NC}(-2.9 \mathrm{~cm} /$ ye $\mathrm{ir})$; Wooster, $\mathrm{OH}(-1.7 \mathrm{~cm} /$ year $)$ and Manitou, CO (-1.4 cm/year). Eleven of the 137 1982-1988 trend sites (Figure A.21) have significantly decreasing trends: Coweeta, NC $(-11.9 \mathrm{~cm} /$ year); 
H. J. Andrews, OR $(-10.5 \mathrm{~cm} /$ year $)$; Great Smoky Mts, TN $(-9.7 \mathrm{~cm} /$ year $)$; Ashland, MO $(-6.5 \mathrm{~cm} /$ year $)$; Salem, IL $(-5.0 \mathrm{~cm} /$ year $)$ Indiana Dunes, IN $(-4.9$ $\mathrm{cm} /$ year); Trout Lake, WI $(-4.7 \mathrm{~cm} /$ year $)$; Parsons, WV $(-4.7 \mathrm{~cm} /$ year $)$; Craters of Moon, ID $(-4.5 \mathrm{~cm} /$ year); Wooster, $\mathrm{OH}(-4.4 \mathrm{~cm} /$ year); and Hopland (Ukiah), CA $(-0.7 \mathrm{~cm} /$ year $)$. With the number of sites being tested, a sma11 number of sites with significant trends would be expected even if no trend actually existed. The lack of significant trends for precipitation is not surprising when the cyclic nature of the precipitation (see Figure A.16) is considered.

Two of the 35 1979-1988 trend sites exhibit a significantly $(p<0.05)$ increasing trend in $\mathrm{pH}$ : I thaca, NY $(0.014 \mathrm{pH}$ units/year); and Fort Wayne, IN (0.013 pH units/year), while one site has a significantly decreasing trend: Bradford Forest, FL (-0.034 pH units/year). Three of the 137 1982-1988 trend sites exhibit significantly increasing trends for pH: Ear Falls, ON $(0.082 \mathrm{pH}$ units/year); Killarney, ON (0.036 pH units/year); and Shallow Lake, ON (0.030 $\mathrm{pH}$ units/year), and three sites have significantly decreasing trends:

Manitou, CO (-0.031 pH units/year); Sand Spring, CO (-0.030 pH units/year); and Dixon Springs, IL $(-0.020 \mathrm{pH}$ units/year). With the number of sites being tested, a small number of sites with significant trends would be expected even if no trend actually existed. Figure A.20 and Figure A.21 display the trend estimates for the 1979-1988 and 1982-1988 trend subsets, respectively.

Since $\mathrm{pH}$ is a transformation of hydrogen concentration, the same sites have significant hydrogen concentrations trends (with a change of direction):

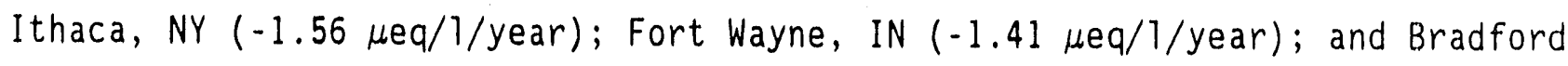
Forest, FL (1.04 $\mu \mathrm{eq} / 1 /$ year), in the 1979-1988 trend subset; and Ear Fal1s, ON $(-1.38 \mu \mathrm{eq} / 1 /$ year $)$; Killarney, ON $(-4.44 \mu \mathrm{eq} / 1 /$ year $)$; Shallow Lake, ON $(-2.84$

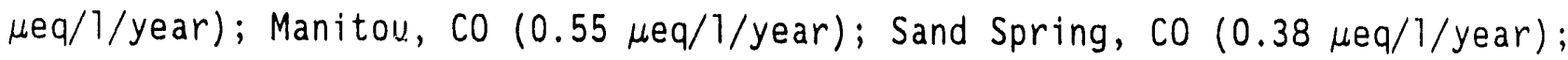
and Dixon Springs, IL $(1.67 \mu \mathrm{eq} / 1 /$ year $)$, in the $1982-1988$ trend subset. With the number of sites being tested, a small number of sites with significant trends would be expected even if no trend actually existed. Figure A.22 and Figure A.23 display the trend estimates for the 1979-1988 and 1982-1988 trend subsets, respectively.

For 1979-1988 trend sites, only one site has a significant hydrogen deposition decrease: Ithaca, NY $\left(-2.29 \mathrm{meq} / \mathrm{m}^{2} /\right.$ year $)$; and one site has a significant increase: Bradford Forest, FL $\left(1.43 \mathrm{meq} / \mathrm{m}^{2} /\right.$ year $)$. For $1982-1988$ 
trend sites, significant hydrogen deposition decreases occur at ten sites: Killarney, ON (-5.23 meq/m²/year); Quabbin Reservoir, MA (-3.94 meq/m²/year); Wellesley, ON (-3.46 meq $/ \mathrm{m}^{2} /$ year); Melbourne, ON (-3.37 meq/m²/year); Coldwater, ON (-3.12 meq $/ \mathrm{m}^{2} /$ year); Wellston, MI $\left(-1.64 \mathrm{meq} / \mathrm{m}^{2} /\right.$ year $)$; Forest Seed Ctr, TX (-1.48 meq/ $\mathrm{m}^{2} /$ year); Al sea, OR $\left(-0.27 \mathrm{meq} / \mathrm{m}^{2} /\right.$ year $) ;$ Lamberton, MN $\left(-0.20 \mathrm{meq} / \mathrm{m}^{2} /\right.$ year $)$; and Teddy Roosevelt NP, ND $\left(-0.20 \mathrm{meq} / \mathrm{m}^{2} /\right.$ year $)$. With the number of sites being tested, a small number of sites with significant trends would be expected even if no trend actually existed. Figure A.22 and Figure A.23 display the trend estimates for the 1979-1988 and 1982-1988 trend subsets, respectively.

A11 of the raygraphs in this section, Figure A.20 through A.24, are consistent with the hypothesis that there is no trend over a large geographic area.

\section{3 .2 Sulfate}

\subsubsection{Annual Temporal Patterns}

The 30 site 1979-1988 trend subset for annual sulfate concentration (Table A.5 and Figure A.24) has maximum medians in $1980(2.62 \mathrm{mg} / 1$ ) and 1981 $(2.65 \mathrm{mg} / 1)$. 1987 has the lowest median, $1.90 \mathrm{mg} / 1$. The annual sulfate deposition (Table A.6 and Figure A.24) has a maximum median in 1981 of 25.63 $\mathrm{kg} / \mathrm{ha}$ and a minimum median in 1988 of $20.44 \mathrm{~kg} / \mathrm{ha}$. The median annual concentrations appear to have inter-annual variation that is opposite the variation of precipitation amount, while the deposition appears to decrease consistently.

The 100 site 1982-1988 trend subset for annual sulfate concentration (Table A.7 and Figure A.25) has maximum medians of $2.52 \mathrm{mg} / 1$ in 1982 and 2.51 $\mathrm{mg} / 1$ in 1987 and minimum median of $2.08 \mathrm{mg} / 1$ in 1983 . The annual sulfate deposition (Table A.8 and Figure A.25) has a maximum median in 1982 of 24.07 $\mathrm{kg} / \mathrm{ha}$ and a minimum median of $20.99 \mathrm{~kg} / \mathrm{ha}$ in 1988.

\subsubsection{Temporal Change Analys is}

Based on the modified KST test, six of the 35 1979-1988 trend sites exhibit a significantly $(p<0.05)$ decreasing trend in sulfate concentration:

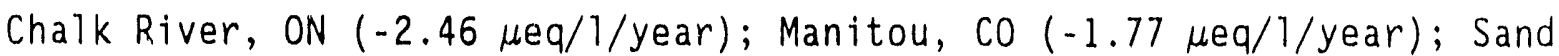




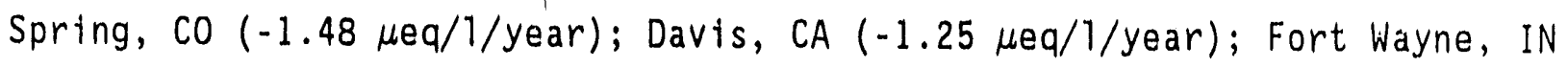
$(-1.20 \mu \mathrm{eq} / 1 /$ year $)$; and I11lnois, IL $(-1.18 \mu \mathrm{eq} / 1 /$ year $)$. Figure A.26 displays the trend estimates for all 35 sites. The rayplot shows little evidence of a trend over a large geographic area.

For 1982-1988 trend sites (Figure A.27), only three sites exhibit significantly decreasing trend in sulfate concentration: Wilkesport, ON

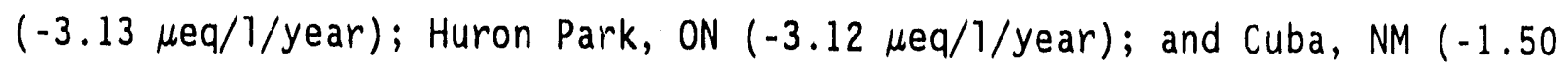
$\mu \mathrm{eq} / 1 /$ year); and one site has a significantly increasing trend, Delaware, $\mathrm{OH}$ $(2.99 \mu \mathrm{eq} / 1 /$ year). With the number of sites being tested, a small number of sites with significant trends would be expected even if no trend actually existed. The rayplot is consistent with the hypothesis of no trend over a large geographic area.

For" 1979-1988 trend sites (Figure A.26), significant sulfate deposition decreases occur at ten sites: Coweeta, NC $\left(-2.61 \mathrm{meq} / \mathrm{m}^{2} /\right.$ year $)$; Piedmont Station, NC (-2.47 meq/m²/year); Delaware, OH $\left(-2.17 \mathrm{meq} / \mathrm{m}^{2} /\right.$ year $) ; \mathrm{Chalk}$ River, ON (-1.99 meq $/ \mathrm{m}^{2} /$ year $)$; Hubbard Brook, $N H\left(-1.76 \mathrm{meq} / \mathrm{m}^{2} /\right.$ year $)$; Lamberton, MN (-1.18 meq $/ \mathrm{m}^{2} /$ year); Georgia Station, GA $\left(-1.03 \mathrm{meq} / \mathrm{m}^{2} /\right.$ year $)$; ELA (b), ON (-0.79 meq/m²/year); Marce11, MN $\left(-0.67 \mathrm{meq} / \mathrm{m}^{2} /\right.$ year $) ;$ and Manitou, CO $\left(-0.44 \mathrm{meq} / \mathrm{m}^{2} /\right.$ year $)$. The sites with significant trend estimates are located across the entire region.

For 1982-1988 trend sites (Figure A.27), significant sulfate deposition decreases occur at 14 sites: Quabbin Reservoir, MA $\left(-3.53 \mathrm{meq} / \mathrm{m}^{2} /\right.$ year $)$; Oxford, $\mathrm{OH}\left(-2.84 \mathrm{meq} / \mathrm{m}^{2} /\right.$ year); I1linois, IL $\left(-2.33 \mathrm{meq} / \mathrm{m}^{2} /\right.$ year $) ;$ Penn State, PA $\left(-2.12 \mathrm{meq} / \mathrm{m}^{2} /\right.$ year $)$; Tanbark Flat, CA $\left(-1.97 \mathrm{meq} / \mathrm{m}^{2} /\right.$ year $)$; Forest Seed $\mathrm{Ctr}$, TX (-1.97 meq/m²/year); ELA (b), ON $\left(-1.21 \mathrm{meq} / \mathrm{m}^{2} /\right.$ year $) ;$ Sequoia National Park, CA $\left(-1.08 \mathrm{meq} / \mathrm{m}^{2} /\right.$ year); 01iver Knoll, AZ $\left(-0.95 \mathrm{meq} / \mathrm{m}^{2} /\right.$ year $) ; A 1 \mathrm{sea}$, OR $\left(-0.89 \mathrm{meq} / \mathrm{m}^{2} /\right.$ year $\left.)\right)$; Pinedale, WY $9\left(-0.70 \mathrm{meq} / \mathrm{m}^{2} /\right.$ year $)$; Grand Canyon, $A Z$ $\left(-0.62 \mathrm{meq} / \mathrm{m}^{2} /\right.$ year $)$; Craters of Moon, ID $\left(-0.56 \mathrm{meq} / \mathrm{m}^{2} /\right.$ year $)$; and $A 1$ amosa, co $\left(-0.39 \mathrm{meq} / \mathrm{m}^{2} /\right.$ year $)$. While the west has far fewer sites, it has the largest number of significant sites. The significant sites in the east are not located in any one area. 


\subsubsection{Nitrate}

\subsubsection{Annual Temporal Patterns}

The 31 site 1979-1988 trend subset for annual nitrate concentration (Table A.5 and Figure A.28) has maximum median in 1980 of $1.75 \mathrm{mg} / 1$. The lowest median is $1.18 \mathrm{mg} / 1$ in 1983 . The annual nitrate deposition (Table A.6 and Figure A.28) has a maximum median in 1985 of $14.62 \mathrm{~kg} / \mathrm{ha}$ and a minimum median in 1988 of $12.29 \mathrm{~kg} / \mathrm{ha}$.

The 103 site 1982-1988 trend subset for annual nitrate concentration (Table A.7 and Figure A.29) has a maximum medians in 1987 of $1.55 \mathrm{mg} / 1$ and 1988 of $1.57 \mathrm{mg} / 1$. The lowest medians are $1.35 \mathrm{mg} / 1$ in 1982 and $1.33 \mathrm{mg} / 1$ in 1983. The annual nitrate deposition (Table A.8 and Figure A.29) has a maximum median in 1984 of $14.91 \mathrm{~kg} / \mathrm{ha}$ and a minimum median in 1988 of $13.14 \mathrm{~kg} / \mathrm{ha}$.

\subsubsection{Temmoral Change Analys is}

Based on the modified KST test, one of the 35 1979-1988 trend sites exhibits a significantly $(p<0.05)$ decreasing trend in nitrate concentration: Manitou, CO ( $-0.73 \mu \mathrm{eq} / 1 /$ year); and one site has a significantly increasing trend: Lewes, DE $(0.43 \mu \mathrm{eq} / 1 /$ year $)$. With the number of sites being tested, a small number of sites with significant trends would be expected even if no trend actually existed. Figure A.30 displays the trend estimates for all 35 sites.

There are 12 sites in the 1982-1988 trend subset that have significantly

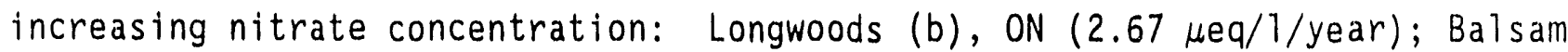

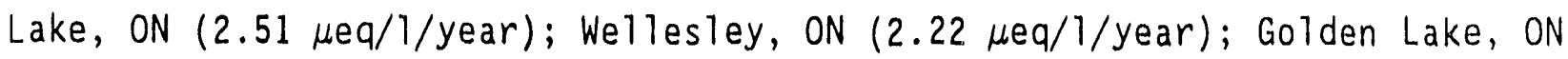

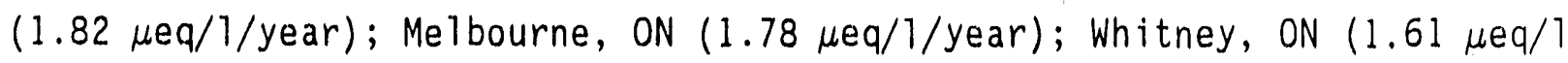

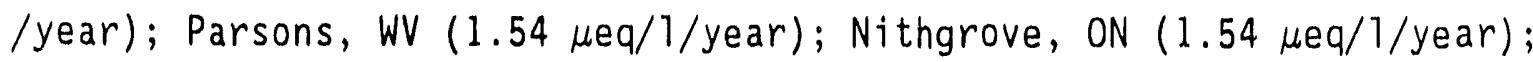
Bennett Bridge, NY $(1.23 \mu \mathrm{eq} / 1 /$ year $)$; Horton's Station, VA $(1.11 \mu \mathrm{eq} / 1 /$ year $)$; Lewes, DE $(0.72 \mu \mathrm{eq} / 1 /$ year $)$; and Bradford Forest, FL $(0.40 \mu \mathrm{eq} / 1 /$ year $)$. Additionally, there are two sites with significantly decreasing trends:

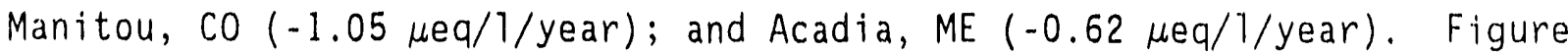
A.31 displays the trend estimates for a11 137 sites. Most of the sites with significant increasing trends are in the southern tip of Ontario. 
For 1979-1988 trend sites (Figure A.30), significant nitrate deposition decreases occur at three sites: Hubbard Brook, $\mathrm{NH}\left(-0.65 \mathrm{meq} / \mathrm{m}^{2} /\right.$ year $)$; Coweeta, NC $\left(-0.76 \mathrm{meq} / \mathrm{m}^{2} /\right.$ year $)$; and $\mathrm{Caldwe} 11$, OH $\left(-0.50 \mathrm{meq} / \mathrm{m}^{2} /\right.$ year $)$. With the number of sites being tested, a small number of sites with significant trends would be expected even if no trend actually existed.

Five of 1982-1988 trend sites have significantly decreasing nitrate deposition: Quabbin Reservoir, MA $\left(-2.61 \mathrm{meq} / \mathrm{m}^{2} /\right.$ year $)$; Fort Wayne IN $(-1.36$ $\mathrm{meq} / \mathrm{m}^{2} /$ year $)$; Forest Seed Ctr, TX $\left(-0.97 \mathrm{meq} / \mathrm{m}^{2} /\right.$ year $) ; H$. J. Andrews, OR $\left(-0.52 \mathrm{meq} / \mathrm{m}^{2} /\right.$ year $)$; and Alamosa, CO $\left(-0.18 \mathrm{meq} / \mathrm{m}^{2} /\right.$ year $)$. Three of the sites have significantly increasing trends: Bennett Bridge, NY $\left(2.00 \mathrm{meq} / \mathrm{m}^{2} /\right.$ year $)$; Mattawa, ON (1.67 meq/ $\mathrm{m}^{2} /$ year); and Balsam Lake, ON (1.50 meq $/ \mathrm{m}^{2} /$ year). With the number of sites being tested, a small number of sites with significant trends would be expected even if no trend actually existed. Figure A.31 displays the trend estimates for al1 137 sites. Except for the nitrate concentrations in the southern tip of Ontario in the 1982-1988 trend subset, the rayplots are all consistent with the hypothesis of no trend over a 1 arge geographic area.

\subsubsection{Ammonium}

\subsubsection{Annual Temporal Patterns}

The 31 site 1979-1988 trend subset for annual ammontum concentration (Table A.5 and Figure A.32) has approximately equal maximum medians in 1980 and 1981 of $0.29 \mathrm{mg} / 1.1979$ and 1985 has approximately equal lowest medians, $0.25 \mathrm{mg} / 1$. The annual ammonium deposition (Table A.6 and Figure A.32) has a maximum median in 1983 of $2.99 \mathrm{~kg} / \mathrm{ha}$ and a minimum median in 1988 of 2.09 $\mathrm{kg} / \mathrm{ha}$.

The 103 site 1982-1988 trend subset for annual ammonium concentration (Table A.7 and Figure A.33) has maximum medians of $0.33 \mathrm{mg} / 1$ in 1987 and 1988 and minimum medians of $0.29 \mathrm{mg} / 1$ in 1983,1985 and 1986 . The annual ammonium deposition (Table A.8 and Figure A.33) has a maximum median of $3.06 \mathrm{~kg} / \mathrm{ha}$ in 1984 and a minimum median of $2.58 \mathrm{~kg} / \mathrm{ha}$ in 1986 . 


\subsubsection{Temporal Change Analys is}

Based on the modifted KST test, three of the 35 1979.1988 trend sites exhtbit a significantly $(p<0.05)$ decreasing trend in ammontum concentration:

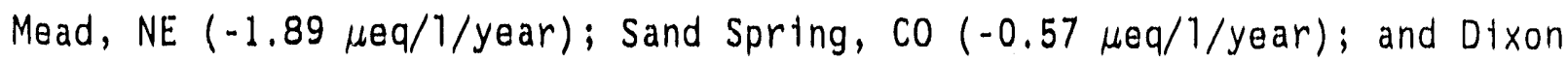
Springs, IL $(-0.50 \mu \mathrm{eq} / 1 /$ year $)$. With the number of sites being tested, a smal1 number of sites with significant trends would be expected even if no trend actually existed. Figure A.34 displays the trend estimates for all 35 sites.

The 1982-1988 trend sites have nine sites with significantly decreasing

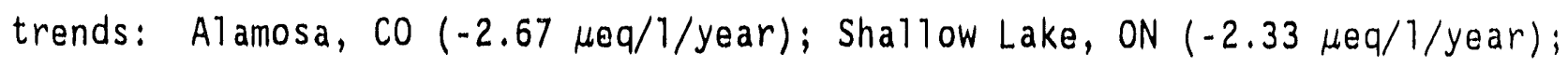

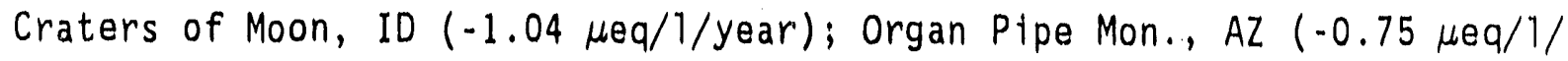

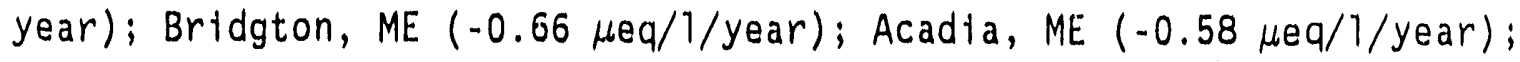
Victorta, TX $(-0.50 \mu \mathrm{eq} / 1 /$ year $)$; Everglades National Park, FL $(-0.33 \mu \mathrm{eq} / 1 /$ year); and Grand Canyon, AZ $(-0.30 \mu \mathrm{eq} / 1 /$ year). Seven sites have

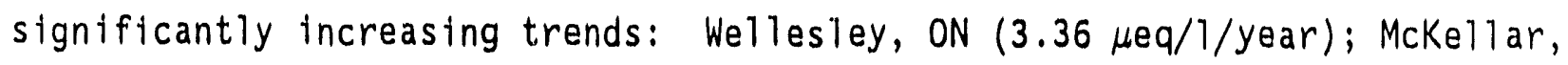
ON $(2.33 \mu \mathrm{eq} / 1 /$ year $)$; North Easthope, ON $(2.33 \mu \mathrm{eq} / 1 /$ year $)$; Longwoods (b), ON

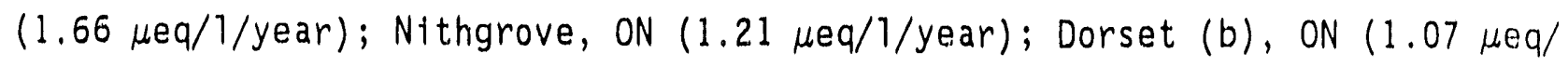
$1 /$ year); and Whiteface, NY $(0.68 \mu \mathrm{eq} / 1 /$ year $)$. With the number of sites being tested, a small number of sites with significant trends would be expected even if no trend actualiy existed. Figure A.35 displays the trend estimates for a11 137 sites.

For 1979-1988 trend sites (Figure A.34), significant ammonium deposition decreases occur at four sites: Dixon Springs IL $\left(-0.81 \mathrm{meq} / \mathrm{m}^{2} /\right.$ year $)$; Georgia Station, GA (-0.44 meq $/ \mathrm{m}^{2} /$ year $)$; Marce 11 , MN $\left(-0.30 \mathrm{meq} / \mathrm{m}^{2} /\right.$ year $)$; and Sand Spring, CO $\left(-0.18 \mathrm{meq} / \mathrm{m}^{2} /\right.$ year $)$. There are two sites with significant increasing trends: Virginia, VA $\left(0.46 \mathrm{meq} / \mathrm{m}^{2} /\right.$ year $)$; and Whiteface, NY $(0.40$ $\mathrm{meq} / \mathrm{m}^{2} /$ year). With the number of sites being tested, a small number of sites with significant trends would be expected even if no trend actually existed.

The 1982-1988 trend sites have 13 sites with significantly decreasing trends: Dixon Springs, IL $\left(-1.25 \mathrm{meq} / \mathrm{m}^{2} /\right.$ year $)$; Piedmont Station, NC $(-1.05$ meq $/ \mathrm{m}^{2} /$ year $)$; Wel1ston, MI $\left(-1.03 \mathrm{meq} / \mathrm{m}^{2} /\right.$ year $)$; Great Smoky Mts, TN $(-0.98$ $\mathrm{meq} / \mathrm{m}^{2} /$ year $)$; Georgia Station, GA $\left(-0.76 \mathrm{meq} / \mathrm{m}^{2} /\right.$ year $)$; Bridgton, ME $(-0.72$ 
meq $/ \mathrm{m}^{2} /$ year); Fernberg, MN $\left(-0.69 \mathrm{meq} / \mathrm{m}^{2} /\right.$ year $)$; Craters of Moon, ID $(-0.60$ $\mathrm{meq} / \mathrm{m}^{2} /$ year); Newcastle, WY $\left(-0.39 \mathrm{meq} / \mathrm{m}^{2} /\right.$ year $)$; Al amosa, CO $(-0.36 \mathrm{meq} /$ $\mathrm{m}^{2} /$ year); Hubbard Brook, $\mathrm{NH}\left(-0.36 \mathrm{meq} / \mathrm{m}^{2} /\right.$ year $)$; Big Bend Nattonal Park, TX $\left(-0.36 \mathrm{meq} / \mathrm{m}^{2} /\right.$ year $)$; and Sand Spring, CO $\left(-0.30 \mathrm{meq} / \mathrm{m}^{2} /\right.$ year $)$; and one ste with a significantly increasing trend: Whiteface, NY $\left(0.87 \mathrm{meq} / \mathrm{m}^{2} /\right.$ year $)$. Figure A.35 displays the trend estimates for all 137 sites.

The rayplots for the 1979-1988 trend subset are consistent with the hypothesis that there is no trend over a large geographic area. While the 1982-1988 trend subset had a number of sites with signiffcant trends, there is little evidence of a trend over a large area.

\section{3 .5 Calctum Patterns}

\subsubsection{Annual Temporal Patterns}

The 31 site 1979-1988 trend subset for annual calctum concentration (Table A.5 and Figure A.36) has a maximum medtan in 1980 of $0.21 \mathrm{mg} / 1.1985$ has the lowest median, $0.12 \mathrm{mg} / 1$. The annual calcium deposition (Table A.6 and Figure A.36) has a maximum median in 1984 of $1.75 \mathrm{~kg} / \mathrm{ha}$ and a mintmum median in 1987 of $1.00 \mathrm{~kg} / \mathrm{ha}$.

The 98 site 1982-1988 trend subset for annual calctum concentration (Table A.7 and Figure A.37) has maximum medians in 1984 and 1988 of $0.21 \mathrm{mg} / 1$ and a minimum median of $0.16 \mathrm{mg} / 1$ in 1986 . The calcium deposition (Table A.8 and Figure A.37) has a maximum median in 1984 of $1.89 \mathrm{~kg} / \mathrm{ha}$ and a minimum median of $1.29 \mathrm{~kg} / \mathrm{ha}$ in 1987 .

\subsubsection{Temporal Change Analys is}

Based on the modified KST test, six of the 35 1979-1988 trend sites exhibits a significantly $(p<0.05)$ decreasing trend in calcium concentration:

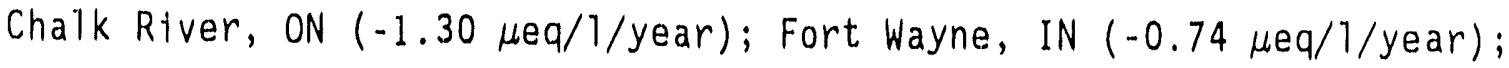
Manitou, CO $(-0.50 \mu \mathrm{eq} / 1 /$ year $)$; Caldwe11, OH $(-0.61 \mu \mathrm{eq} / 1 /$ year $)$; Huntington, NY $(-0.27 \mu \mathrm{eq} / 1 /$ year $)$; and Lewiston, NC $(-0.24 \mu \mathrm{eq} / 1 /$ year $)$. Figure A.38 displays the trend estimates for all 35 sites.

The 1982-1988 trend sites have two sites with significantly decreasing concentrations: Lewiston, NC $(-0.33 \mu \mathrm{eq} / 1 /$ year $)$; and East, MA $(-0.30 \mu \mathrm{eq} / 1 /$ 
year). There are also six sites with significantly increasing concentrations:

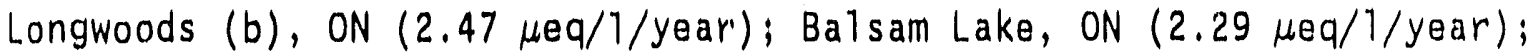

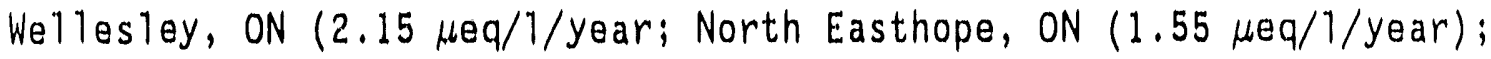

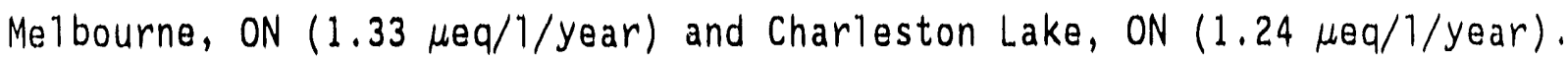
Figure A.39 displays the trend estimates for all 137 sttes.

For 1979-1988 trend sites (Figure A.38), significant calctum deposition decreases occur at 17 sites: Chalk River, ON $\left(-1.18 \mathrm{meq} / \mathrm{m}^{2} /\right.$ year $)$; Dixon Springs, IL $\left(-0.86 \mathrm{meq} / \mathrm{m}^{2} /\right.$ year $)$; Fort Wayne, IN $\left(-0.56 \mathrm{meq} / \mathrm{m}^{2} /\right.$ year $) ;$ Caldwel1, $\mathrm{OH}\left(-0.54 \mathrm{meq} / \mathrm{m}^{2} /\right.$ year $)$; Delaware, $\mathrm{OH}\left(-0.44 \mathrm{meq} / \mathrm{m}^{2} /\right.$ year $)$; Wooster, $\mathrm{OH}(-0.39$ $\mathrm{meq} / \mathrm{m}^{2} /$ year); Clinton Station, NC $\left(-0.37 \mathrm{meq} / \mathrm{m}^{2} /\right.$ year $)$; Penn State, PA $(-0.36$ $\mathrm{meq} / \mathrm{m}^{2} /$ year $)$; Coweeta, NC $\left(-0.34 \mathrm{meq} / \mathrm{m}^{2} /\right.$ year $)$; Piedmont Station, NC $(-0.34$ $\mathrm{meq} / \mathrm{m}^{2} /$ year); Bradford Forest, FL $\left(-0.26 \mathrm{meq} / \mathrm{m}^{2} /\right.$ year $)$; Sand Spring, CO $(-0.26$ $\mathrm{meq} / \mathrm{m}^{2} /$ year $)$; Davis, CA $\left(-0.25 \mathrm{meq} / \mathrm{m}^{2} /\right.$ year $)$; Lewiston, NC $\left(-0.22 \mathrm{meq} / \mathrm{m}^{2} /\right.$ year $)$; Manttou, CO $\left(-0.20 \mathrm{meq} / \mathrm{m}^{2} /\right.$ year $)$; Oxford, $\mathrm{OH}\left(-0.20 \mathrm{meq} / \mathrm{m}^{2} /\right.$ year $)$; and $\mathrm{F} i n$ ley (A), NC $\left(-0.18 \mathrm{meq} / \mathrm{m}^{2} /\right.$ year $)$.

The 1982-1988 trend sites have 18 sites with significantly decreasing trends: Merlin, ON $\left(-1.63 \mathrm{meq} / \mathrm{m}^{2} /\right.$ year $)$; Dixon Springs, IL $\left(-1.21 \mathrm{meq} / \mathrm{m}^{2}\right)$ year); Walker Branch, TN $\left(-0.94 \mathrm{meq} / \mathrm{m}^{2} /\right.$ year); University Forest, MO $(-0.81$ $\mathrm{meq} / \mathrm{m}^{2} /$ year $)$; Forest Seed Center, TX $\left(-0.60 \mathrm{meq} / \mathrm{m}^{2} /\right.$ year $) ;$ Caldwe11, OH $(-0.59$ $\mathrm{meq} / \mathrm{m}^{2} /$ year $)$; Oak Ridge, TN $\left(-0.55 \mathrm{meq} / \mathrm{m}^{2} /\right.$ year $) ;$ Victorla, TX $\left(-0.49 \mathrm{meq} / \mathrm{m}^{2} /\right.$ year); Tanbark Flat, CA $\left(-0.48 \mathrm{meq} / \mathrm{m}^{2} /\right.$ year $)$; Cuba, NM $\left(-0.44 \mathrm{meq} / \mathrm{m}^{2} /\right.$ year $)$; Grand Canyon, AZ ( $-0.41 \mathrm{meq} / \mathrm{m}^{2} /$ year $)$; East, $M A\left(-0.39 \mathrm{meq} / \mathrm{m}^{2} /\right.$ year $)$; Huntington, NY $\left(-0.34 \mathrm{meq} / \mathrm{m}^{2} /\right.$ year $)$; Alsea, OR $\left(-0.33 \mathrm{meq} / \mathrm{m}^{2} /\right.$ year $) ;$ Davis, CA $\left(-0.33 \mathrm{meq} / \mathrm{m}^{2} /\right.$ year $)$; Greenville Station, ME $\left(-0.32 \mathrm{meq} / \mathrm{m}^{2} /\right.$ year $) ; A 1$ amosa, CO $\left(-0.26 \mathrm{meq} / \mathrm{m}^{2} /\right.$ year $)$; and Pickle Lake, ON $\left(-0.26 \mathrm{meq} / \mathrm{m}^{2} /\right.$ year $)$. There are also four sites with significantly increasing trends: Balsam Lake, ON (1.72 meq/ $\mathrm{m}^{2} /$ year); North Easthope, ON (1.66 meq/m²/year); Charleston Lake, ON (0.97 $\mathrm{meq} / \mathrm{m}^{2} /$ year); and Bear Island, ON $\left(0.63 \mathrm{meq} / \mathrm{m}^{2} /\right.$ year $)$. Figure A.39 displays the trend estimates for a11 137 sites.

The rayplots of calcium concentration for both trend subsets are consistent with the hypothesis of no trend over a large geographical area. The rayplot of calcium deposition for the 1979-1988 subset show two areas with 
significantly decreasing trends, North Carolina and Ohto. The calctum depositions for the 1982-1988 subset show 1:ttle evidence of a trend over a large area.

\section{3 .6 Chloride}

\subsubsection{Annual Temporal Patterns}

The 29 site 1979-1988 trend subset for annual chloride concentration (Table A.5 and Figure A.40) has approximately equal maximum medtans in 1979 and 1980 of $0.23 \mathrm{mg} / 1 . \quad 1983$ and 1986 have the lowest medians, $0.17 \mathrm{mg} / 1$. The 1980 and 1983 medians are significantly different. The annual chloride deposition (Table A.6 and Figure A.40) has a maximum median in 1979 of 2.90 $\mathrm{kg} / \mathrm{ha}$ and a minimum median in 1983 of $1.85 \mathrm{~kg} / \mathrm{ha}$. The distribution of both the concentration and deposition are highiy skewed and, except for 1981 and 1988, there are extremely large values that are not included on Figure A.40.

The 99 site 1982-1988 trend subset for annual chloride concentration (Table A.7 and Figure A.41) has approximately equal maximum medtans in 1982, 1984 , and 1988 of $0.18 \mathrm{mg} / 1.1983$ and 1986 have approximately equal minimum medians of $0.15 \mathrm{mg} / 1$. The 1983 and 1984 medtans are significantly different. The annual chloride deposition (Table A.8 and Figure A.41) has a maximum medtan of $1.72 \mathrm{~kg} / \mathrm{ha}$ in 1984 and a mintmum median of $1.35 \mathrm{~kg} / \mathrm{ha}$ in 1986 . As with the 1979-1988 trend subset, the concentration and deposition are highly skewed with extremely large values that are not included on Figure A.41.

\subsubsection{Temporal Change Analys is}

Based on the modified KST test, nine of the 35 1979-1988 trend sites exhibit a significantly $(p<0.05)$ decreasing trend in chloride concentration:

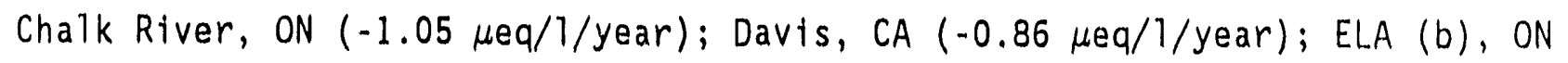
$(-0.76 \mu \mathrm{eq} / 1 /$ year $)$; Brookhaven, NY $(-0.56 \mu \mathrm{eq} / 1 /$ year $)$; Ptedmont Station, NC $(-0.34 \mu \mathrm{eq} / \mathrm{l} /$ year); Dixon Springs, IL $(-0.31 \mu \mathrm{eq} / 1 /$ year $)$; Mead, NE $(-0.24 \mu \mathrm{eq} /$ $1 /$ year); Fort Wayne, IN $(-0.19 \mu \mathrm{eq} / 1 /$ year $)$; and Wellston, MI $(-0.18 \mu \mathrm{eq} / 1 /$ year). Additionally, one site has a significantly increasing trend: Ithaca, NY $(0.40 \mu \mathrm{eq} / 1 /$ year $)$. Figure A.42 displays the trend estimates for all 35 sites. 
The 1982-1988 trend subset has two sites with significantly decreasing

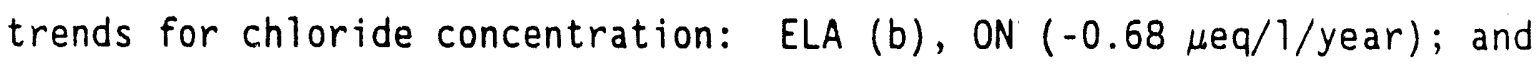
Yellowstone, WY $(-0.34 \mu \mathrm{eq} / 1 /$ year $)$. There are also seven sites with significantly increasing trends: Ithaca, NY $(0.72 \mu \mathrm{eq} / 1 /$ year $)$; Longwoods (b), ON $(-0.56 \mu \mathrm{eq} / 1 /$ year $)$; Whiteface, NY $(0.46 \mu \mathrm{eq} / 1 /$ year $)$; Oak Ridge, TN $(-0.39$ $\mu e q / 1 /$ year); Wellesley, ON $(-0.34 \mu \mathrm{eq} / 1 /$ year $)$; Melbourne, ON $(-0.31 \mu \mathrm{eq} / 1 /$ year); and Dorion, ON ( $0.28 \mu \mathrm{eq} / 1 /$ year $)$. With the number of sites being tested, a small number of sites with significant trends would be expected even if no trend actually existed. Figure A.43 displays the trend estimates for all 137 sites.

For 1979-1988 trend sites (Figure A.42), significant chloride 1979-1988 trend sites occur at 12 sites: Chalk River ON $\left(-0.84 \mathrm{meq} / \mathrm{m}^{2} /\right.$ year $)$; Piedmont Station, NC $\left(0.45 \mathrm{meq} / \mathrm{m}^{2} /\right.$ year $)$; Coweeta, NC $\left(-0.39 \mathrm{meq} / \mathrm{m}^{2} /\right.$ year $)$; ELA (b), ON $\left(-0.37 \mathrm{meq} / \mathrm{m}^{2} /\right.$ year $)$; Georgia Station, GA $(-0.30)$; Hubbard Brook, NH $(-0.25$ $\mathrm{meq} / \mathrm{m}^{2} /$ yearl; Caldwell, $\mathrm{OH}\left(-0.18 \mathrm{meq} / \mathrm{m}^{2} /\right.$ year $)$; Mead, NE $\left(-0.15 \mathrm{meq} / \mathrm{m}^{2} /\right.$ year $)$; Wellston, $\mathrm{hi}\left(-0.14 \mathrm{meq} / \mathrm{m}^{2} /\right.$ year $)$; Delaware, $\mathrm{OH}\left(-0.13 \mathrm{meq} / \mathrm{m}^{2} /\right.$ year $)$; Lamberton, $\operatorname{MN}\left(-0.12 \mathrm{meq} / \mathrm{m}^{2} /\right.$ year $)$; and Manitou, CO $\left(-0.06 \mathrm{meq} / \mathrm{m}^{2} /\right.$ year $)$. One site has a significantly increasing trend: Whiteface, NY $\left(0.24 \mathrm{meq} / \mathrm{m}^{2} /\right.$ y ar $)$.

The 1982-1988 trend sites have 12 sites with significantly decreasing trends for chloride deposition: Hopland (Ukiah), CA $\left(-2.01 \mathrm{meq} / \mathrm{m}^{2} /\right.$ year); Victoria, TX $\left(-1.71 \mathrm{meq} / \mathrm{m}^{2} /\right.$ year $)$; Forest Seed Center, $\operatorname{TX}\left(-1.57 \mathrm{meq} / \mathrm{m}^{2} /\right.$ year $)$; Tanbark Flat, CA $\left(-0.70 \mathrm{meq} / \mathrm{m}^{2} /\right.$ year $)$; Sequoia National Park, CA $\left(-0.67 \mathrm{meq} / \mathrm{m}^{2} /\right.$ year); ELA (b), ON (-0.43 meq/ $\mathrm{m}^{2} /$ year); Argonne, IL (-0.32 meq $/ \mathrm{m}^{2} /$ year); Craters of Moon, ID $\left(-0.18 \mathrm{meq} / \mathrm{m}^{2} /\right.$ year $)$; Underhill Center, VT $\left(-0.15 \mathrm{meq} / \mathrm{m}^{2} /\right.$ year); Fernberg, MN $\left(-0.11 \mathrm{meq} / \mathrm{m}^{2} /\right.$ year $)$; 01 iver Knoll, AZ $\left(-0.10 \mathrm{meq} / \mathrm{m}^{2} /\right.$ year $)$; and Newcastle, WY $\left(-0.09 \mathrm{meq} / \mathrm{m}^{2} /\right.$ year $)$. There are also two sites with a significantly increasing trend: Ithaca, NY $\left(0.58 \mathrm{meq} / \mathrm{m}^{2} /\right.$ year $)$; and Whiteface, NY $\left(0.44 \mathrm{meq} / \mathrm{m}^{2} /\right.$ year $)$. Figure $A .43$ displays the trend estimates for all 137 sites.

The rayplots of chloride concentration and deposition for both subsets show little evidence of a trend over a large area. 


\subsubsection{Sodium}

\subsubsection{Annual Temporal Patterns}

The 29 site 1979-1988 trend subset for annual sodium concentration (Table A.5 and Figure A.44) has a maximum median in 1979 of $0.25 \mathrm{mg} / 1.1985$ and 1986 has the lowest median, $0.06 \mathrm{mg} / 1$. The annual sodium deposition (Table A.6 and Figure A.44) has a maximum median in 1979 of $2.83 \mathrm{~kg} / \mathrm{ha}$ and a minimum median in 1987 of $0.56 \mathrm{~kg} / \mathrm{ha}$. The median concentration and deposition decreased dramatically between 1980 and 1981 and has continued to decrease since then, but at a slower pace. The distribution of both the concentration and deposition are highly skewed and there are extremely large values that are not included on Figure A.44.

The 95 site 1982-1988 trend subset for annual sodium concentration (Table A.7 and Figure A.45) has maximum medians in 1982, 1984, and 1988 of $0.08 \mathrm{mg} / 1$ and minimum median concentrations of $0.06 \mathrm{mg} / 1$ in 1985 and 1986 . The annual sodium deposition (Table A.8 and Figure A.45) has maximum medians of $0.73 \mathrm{~kg} / \mathrm{ha}$ in 1984 and $0.72 \mathrm{~kg} / \mathrm{ha}$ in 1982 and a minimum median of 0.53 $\mathrm{kg} / \mathrm{ha}$ in 1987 and $0.54 \mathrm{~kg} / \mathrm{ha}$ in 1986. As with the 1979-1988 trend subset, the concentration and deposition are highly skewed with extremely large values that are not included on Figure A.45.

\subsubsection{Temporal Change Analysis}

Based on the modified KST test, 16 of the 35 1979-1988 trend sites exhibit a significantly $(p<0.05)$ decreasing trend in sodium concentration:

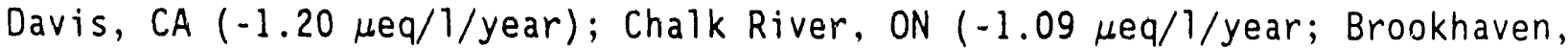
NY $(-0.91 \mu \mathrm{eq} / 1 /$ year $)$; Clinton Station, NC $(-0.80 \mu \mathrm{eq} / 1 /$ year $) ; E L A(b), O N$

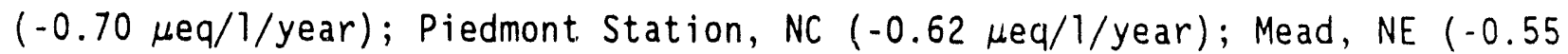
$\mu e q / 1 /$ year); Horton's Station, VA $(-0.45 \mu \mathrm{eq} / 1 /$ year); Georgia Station, $G A$

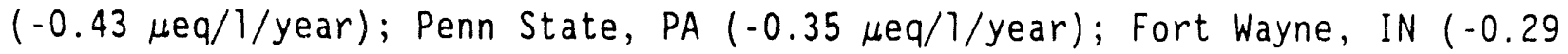

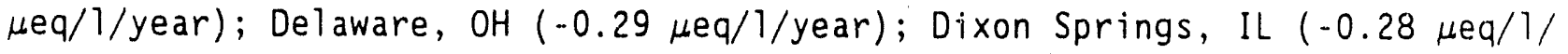

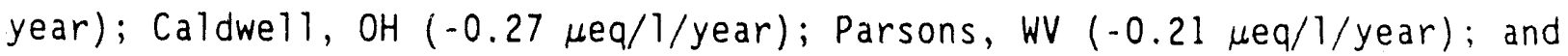
Whiteface, NY $(-0.07 \mu \mathrm{eq} / 1 /$ year $)$. Figure $\mathrm{A} .46$ displays the trend estimates for all 35 sites. 
Only two of the 137 1982-1988 trend sites have significantly decreasing trends for sodium concentration: Brookhaven, NY (-1.76 $\mu \mathrm{eq} / 1 /$ year $)$; and Dixon Springs, IL $(-0.38 \mu \mathrm{eq} / \mathrm{l} /$ year $)$. Additionally, two of the sites have a

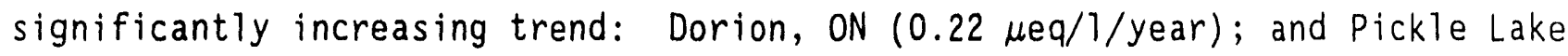
$(0.16 \mu \mathrm{eq} / 1 /$ year $)$. With the number of sites being tested, a sma11 number of sites with significant trends would be expected even if no trend actually existed. Figure A.47 displays the trend estimates for all 137 sites.

For 1979-1988 trend sites (Figure A.46), significant sodium deposition decreases occur at 20 sites: Davis, CA $\left(-1.15 \mathrm{meq} / \mathrm{m}^{2} /\right.$ year $)$; Chalk River, ON $\left(-1.01 \mathrm{meq} / \mathrm{m}^{2} /\right.$ year $) ; C l i n t o n$ Station, NC $\left(-0.78 \mathrm{meq} / \mathrm{m}^{2} /\right.$ year $) ;$ Coweeta, NC $\left(-0.74 \mathrm{meq} / \mathrm{m}^{2} /\right.$ year $)$; Piedmont Station, NC (-0.66 meq $/ \mathrm{m}^{2} /$ year); Georgia Station, GA (-0.58 meq $/ \mathrm{m}^{2} /$ year); Horton's Station, VA $\left(-0.48 \mathrm{meq} / \mathrm{m}^{2} /\right.$ year $)$; Hubbard Brook, NH (-0.44 meq/m²/year); ELA (b), ON (-0.41 meq $/ \mathrm{m}^{2} /$ year); Mead, NE $\left(-0.30 \mathrm{meq} / \mathrm{m}^{2} /\right.$ year $)$; Delaware, OH $\left(-0.29 \mathrm{meq} / \mathrm{m}^{2} /\right.$ year $) ; \mathrm{Caldwe} 11$, OH $(-0.28$ $\mathrm{meq} / \mathrm{m}^{2} /$ year); Wooster, $\mathrm{OH}\left(-0.28 \mathrm{meq} / \mathrm{m}^{2} /\right.$ year $)$; Penn State, PA $\left(-0.28 \mathrm{meq} / \mathrm{m}^{2} /\right.$ year); Kane, PA (-0.26 meq/ $\mathrm{m}^{2} /$ year); Lamberton, MN (-0.24 meq $/ \mathrm{m}^{2} /$ year $)$; Fort Wayne, IN (-0.18 meq $/ \mathrm{m}^{2} /$ year); Huntington, NY $\left(-0.16 \mathrm{meq} / \mathrm{m}^{2} /\right.$ year $)$; Manitou, CO $\left(-0.14 \mathrm{meq} / \mathrm{m}^{2} /\right.$ year $)$; and Sand Spring, CO $\left(-0.12 \mathrm{meq} / \mathrm{m}^{2} /\right.$ year $)$.

The 1982-1988 trend sites have nine sites with significantly decreasing trends for sodium deposition: Hopland (Ukiah), CA (-1.48 meq $/ \mathrm{m}^{2} /$ year); Forest Seed Center, TX (-1.26 meq/m²/year); Sequoia National Park, CA $\left(-0.64 \mathrm{meq} / \mathrm{m}^{2} /\right.$ year); Ashland, MO ( $-0.45 \mathrm{meq} / \mathrm{m}^{2} /$ year); Pinedale, WY $\left(-0.35 \mathrm{meq} / \mathrm{m}^{2} /\right.$ year $)$; Penn State, PA (-0.34 meq $/ \mathrm{m}^{2} /$ year); Argonne, IL ( $-0.27 \mathrm{meq} / \mathrm{m}^{2} /$ year); ELA (b), ON $\left(-0.25 \mathrm{meq} / \mathrm{m}^{2} /\right.$ year $)$; and Fernberg, $M N\left(-0.10 \mathrm{meq} / \mathrm{m}^{2} /\right.$ year $)$. Figure $A .47$ displays the trend estimates for all 137 sites.

The rayplots for the 1982-1988 subset are consistent with the hypothesis that there is no trend over a large geographical area. The 1979-1988 subset has a relatively large number of sites with significant concentration and deposition trends. However, these sites are generally located close to sites whose trends are not significantly different from zero. Thus there is no distinct area of significant trends. 


\subsubsection{Potassium}

\subsubsection{Annual Temporal Patterns}

The 31 site 1979-1988 trend subset for annual potassium concentration (Table A.5 and Figure A.48) has approximately equal maximum medians in 1979, and 1980 of $0.04 \mathrm{mg} / 1$. The lowest median, $0.02 \mathrm{mg} / 1$, occurs in 1988. The annual potassium deposition (Table A.6 and Figure A.48) has a maximum median in 1979 of $0.51 \mathrm{~kg} / \mathrm{ha}$ and a minimum median in 1988 of $0.19 \mathrm{~kg} / \mathrm{ha}$. The large number of high potassium concentrations and depositions in 1987 and 1988 are primarily from network, MAP3S.

The 95 site 1982-1988 trend subset for annual potassium concentration (Table A.7 and Figure A.49) has approximately equal medians for all the years of $0.03 \mathrm{mg} / 1$. The annual potassium deposition (Table A.8 and Figure A.49) has the largest median in 1983, $0.36 \mathrm{~kg} / \mathrm{ha}$ and the smallest median, $0.22 \mathrm{~kg} / \mathrm{ha}$, in 1987. The large number of high potassium concentrations and depositions in 1097 and 1988 are primarily from network, MAP3S.

\subsubsection{Temporal Change Analysis}

Based on the modified KST test, 14 of the 35 1979-1988 trend sites exhibit a significantly $(p<0.05)$ decreasing trend in potassium

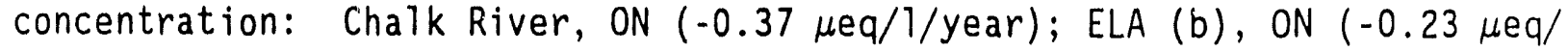

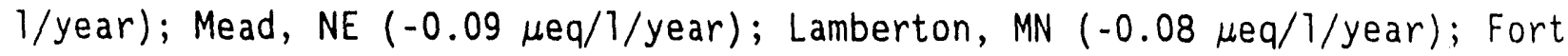

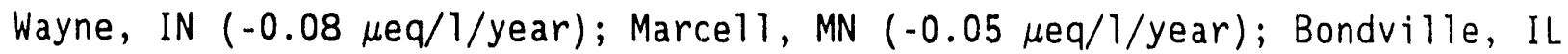

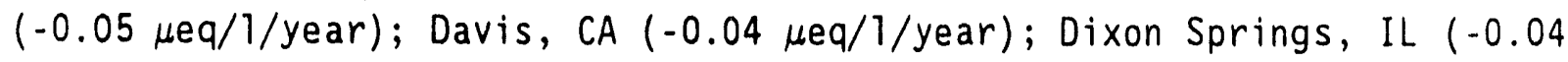

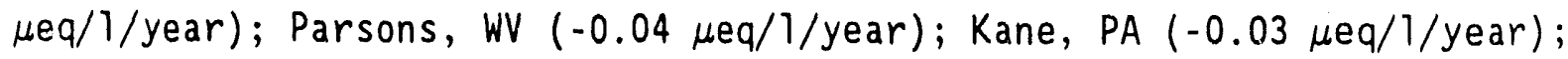

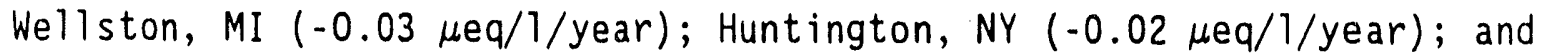
Hubbard Brook, NH $(-0.02 \mu \mathrm{eq} / 1 /$ year $)$. Figure $A .50$ displays the trend estimates for all 35 sites. Most of the sites with significant trends occur in the midwest region.

The 1982-1988 trend sites have 24 significantly decreasing trends for potassium concentration: Chalk River, ON (-0.18 $\mu \mathrm{eq} / \mathrm{l} /$ year); ELA (b), ON $(-0.17 \mu \mathrm{eq} / 1 /$ year $)$; Cuba, NM $(-0.13 \mu \mathrm{eq} / 1 /$ year $) ; \operatorname{Kejimkujik~(b),~NS~(-0.12~}$

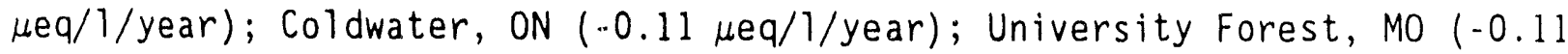

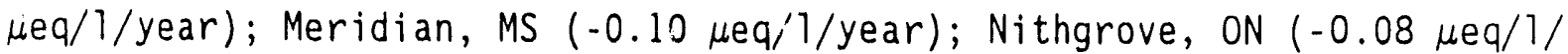




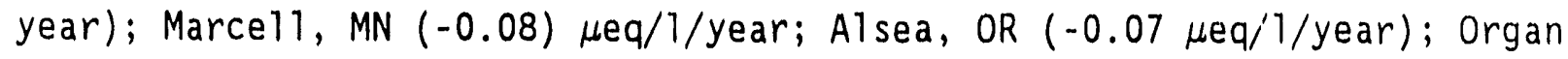

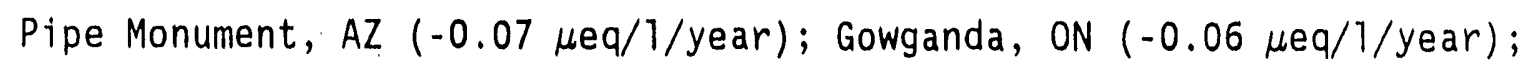
Piedmont Station, NC $(-0.06 \mu \mathrm{eq} / 1 /$ year $)$; Georgia Station, GA $(-0.06 \mu \mathrm{eq} / 1 /$ year); Douglas Lake, MI $(-0.06 \mu$ eq/1/year); We11ston, MI $(-0.05 \mu$ eq/1/year; Aurora, NY $(-0.05 \mu \mathrm{eq} / 1 /$ year $)$; Huntington, NY $(-0.05 \mu \mathrm{eq} / 1 /$ year $)$; Fort Wayne, IN $(-0.05 \mu \mathrm{eq} / 1 /$ year $)$; Dixon Springs, IL $(-0.05 \mu \mathrm{eq} / 1 /$ year $)$; Bondville, IL $(-0.05 \mu \mathrm{eq} / 1 /$ year $)$; Shabbona, IL $(-0.04 \mu \mathrm{eq} / 1 /$ year $)$; Greenville Station, ME $(-0.04 \mu \mathrm{eq} / 1 /$ year $)$; and Trout Lake, WI $(-0.03 \mu \mathrm{eq} / 1 /$ year $)$. There are also six sites with significantly increasing trends: Virginia, VA $(0.43 \mu \mathrm{eq} / 1 /$ year $)$; Oxford, $\mathrm{OH}(0.29 \mu \mathrm{eq} / 1 /$ year $)$; Whiteface, NY $(0.26 \mu \mathrm{eq} / 1 /$ year $)$; I thaca, NY $(0.22 \mu \mathrm{eq} / 1 /$ year $)$; Oak Ridge, TN $(0.15 \mu \mathrm{eq} / 1 /$ year $)$; and Uvalda, GA $(0.11 \mu \mathrm{eq} /$ $1 /$ year). Of the 11 largest increasing trends for potassium concentration, 9 of them are from the MAP3S network. Figure A.51 displays the spatial pattern for the potassium concentration. The sites with significant trends do not occur in any clearly defined area.

For 1979-1988 trend sites (Figure A.50), significant potassium deposition decreases occur at 13 sites: Chalk River, ON $\left(-0.32 \mathrm{meq} / \mathrm{m}^{2} /\right.$ year $)$; ELA (b), ON (-0.11 meq $/ \mathrm{m}^{2} /$ year); Parsons, WV (-0.06 meq $/ \mathrm{m}^{2} /$ year); Lamberton, MN (-0.06 meq $/ \mathrm{m}^{2} /$ year $)$; Mead, NE $\left(-0.05 \mathrm{meq} / \mathrm{m}^{2} /\right.$ year $)$; Fort Wayne, IN (-0.05 $\mathrm{meq} / \mathrm{m}^{2} /$ year $)$; Georgia Station, GA $\left(-0.05 \mathrm{meq} / \mathrm{m}^{2} /\right.$ year $)$; Kane, PA $\left(-0.04 \mathrm{meq} / \mathrm{m}^{2} /\right.$ year); Marce11, MN (-0.03 meq $/ \mathrm{m}^{2} /$ year $)$; Bondville, IL $\left(-0.03 \mathrm{meq} / \mathrm{m}^{2} /\right.$ year $)$; Hubbard Brook, NH $\left(-0.03 \mathrm{meq} / \mathrm{m}^{2} /\right.$ year $)$; Delaware, $\mathrm{OH}\left(-0.03 \mathrm{meq} / \mathrm{m}^{2} /\right.$ year $)$; and Manitou, CO $\left(-0.02 \mathrm{meq} / \mathrm{m}^{2} /\right.$ year $)$. The sites with significant trend estimates do not occur in any clearly defined region.

There are 40 sites in the 1982-1988 trend site with significantly decreasing potassium deposition trends: Chalk River, ON $\left(-0.17 \mathrm{meq} / \mathrm{m}^{2} /\right.$ year $)$; Kejimkujik (b), NS $\left(-0.15 \mathrm{meq} / \mathrm{m}^{2} /\right.$ year); Pickle Lake, ON $\left(-0.12 \mathrm{meq} / \mathrm{m}^{2} /\right.$ year $)$; North Easthope, ON $\left(-0.11 \mathrm{meq} / \mathrm{m}^{2} /\right.$ year $)$; University Forest, MO $\left(-0.10 \mathrm{meq} / \mathrm{m}^{2} /\right.$ year); Ashland, MO (-0.10 meq $/ \mathrm{m}^{2} /$ year); ELA (b), ON $\left(-0.09 \mathrm{meq} / \mathrm{m}^{2} /\right.$ year $)$; Salem, IL (-0.09 meq/ $/ \mathrm{m}^{2} /$ year); Walker Branch, TN $\left(-0.08 \mathrm{meq} / \mathrm{m}^{2} /\right.$ year $)$; Georgia Station, GA $\left(-0.08 \mathrm{meq} / \mathrm{m}^{2} /\right.$ year $)$; Southern $111 \mathrm{U}, \mathrm{IL}\left(-0.08 \mathrm{meq} / \mathrm{m}^{2} /\right.$ year $)$; Davis, CA $\left(-0.08 \mathrm{meq} / \mathrm{m}^{2} /\right.$ year $)$; Tanbark Flat, CA $\left(-0.08 \mathrm{meq} / \mathrm{m}^{2} /\right.$ year $)$; Leading Ridge, PA $\left(-0.08 \mathrm{meq} / \mathrm{m}^{2} /\right.$ year $)$; Coldwater, ON $\left(-0.08 \mathrm{meq} / \mathrm{m}^{2} /\right.$ year $)$; Dorset (b), ON (-0.08 $\mathrm{mrq} / \mathrm{m}^{2} /$ year); Alsea, OR $\left(-0.07 \mathrm{meq} / \mathrm{m}^{2} /\right.$ year $)$; Dixon Springs, IL 
$\left(-0.07 \mathrm{meq} / \mathrm{m}^{2} /\right.$ year); Shenandoah Nat'1, VA $\left(-0.07 \mathrm{meq} / \mathrm{m}^{2} /\right.$ year $)$; Washington Xing, $\mathrm{NJ}\left(-0.06 \mathrm{meq} / \mathrm{m}^{2} /\right.$ year $)$; Argonne, IL $\left(-0.06 \mathrm{meq} / \mathrm{m}^{2} /\right.$ year $) ;$ Kane, PA $(-0.06$ $\mathrm{meq} / \mathrm{m}^{2} /$ year $)$; Wel1ston, MI $\left(-0.05 \mathrm{meq} / \mathrm{m}^{2} /\right.$ year $)$; Bondvi11e, IL $\left(-0.05 \mathrm{meq} / \mathrm{m}^{2} /\right.$ year); Huntington, NY $\left(-0.05 \mathrm{mec} / \mathrm{m}^{2} / \mathrm{gear}\right)$; Quabbin Reservoir, MA $(-0.05 \mathrm{meq} /$ $\mathrm{m}^{2} /$ year $) ; H . J$. Andrews, OR $\left(-0,05 \mathrm{~s} / \mathrm{meq} / \mathrm{m}^{2} /\right.$ year $)$; Fort Wayne, IN $\left(-0.05 \mathrm{meq} / \mathrm{m}^{2}\right)$ year); Delaware, OH (-0.04 meq/mear); Indiana Dunes, IN $\left(-0.04 \mathrm{meq} / \mathrm{m}^{2}\right)$ year); Trout Lake, WI $\left(-0.04 \mathrm{meq} / \mathrm{m}^{2} /\right.$ year $)$; Cuba, NM $\left(-0.04 \mathrm{meq} / \mathrm{m}^{2} /\right.$ year $)$; Fernberg, MN (-0.03 meq $/ \mathrm{m}^{2} /$ year); Caribou (a), ME (-0.03 meq $/ \mathrm{m}^{2} /$ year); Criters of Moon, ID (-0.03 meq $/ \mathrm{m}^{2} /$ year $)$; 01tver Knol1, AZ $\left(-0.03 \mathrm{meq} / \mathrm{m}^{2} /\right.$ year $)$; Mesa Verde, CO (-0.03 meq $/ \mathrm{m}^{2} /$ year $)$; Alamosa, CO (-0.03 meq $/ \mathrm{m}^{2} /$ year $)$; Organ Pipe Mon., AZ $\left(-0.02 \mathrm{meq} / \mathrm{m}^{2} /\right.$ year $)$; and Newcastle, WY $\left(-0.02 \mathrm{meq} / \mathrm{m}^{2} /\right.$ year $)$. Additionally, there are four sites with significantly increasing potassiuil deposition: Virginia, VA $\left(0.37 \mathrm{meq} / \mathrm{m}^{2} /\right.$ year $)$; Whiteface, NY $\left(0.23 \mathrm{meq} / \mathrm{m}^{2}\right)$ year); Oxford, $\mathrm{OH}\left(0.20 \mathrm{meq} / \mathrm{m}^{2} /\right.$ year $)$; and I thaca, NY $\left(0.20 \mathrm{meq} / \mathrm{m}^{2} /\right.$ year $)$. Of the 10 largest increasing trends for potassium concentration, 9 of them are from the MAP3S network. Figure A.51 displays the spatial pattern for the potassium concentration. Although there are a large number of sites with significant trends, there are no large areas with consistent (either increasing or decreasing) significant trend estimates.

\subsubsection{Magnesium}

\subsubsection{Annual Temporal Patterns}

The 31 site 1979-1988 trend subset for annual magnesium concentration (Table A.5 and Figure A.52) has a maximum median in 1981 of $0.05 \mathrm{mg} / 1$. 1985, 1986, 1987 and 1988 have approximately equal lowest medians, $0.03 \mathrm{mg} / 1$. The annual magnesium deposition (Table A.6 and Figure A.52) has a maximum median in 1981 of $0.43 \mathrm{~kg} / \mathrm{ha}$ and a minimum median in 1987 of $0.24 \mathrm{~kg} / \mathrm{ha}$.

The 95 site $1982-1988$ trend subset for annual magnesium concentration (Table A.7 and Figure A.53) has the smallest medians in 1986, 1987 and 1988. The annual magnesium deposition (Table A.8 and Figure A.53) has a maximum median of $0.41 \mathrm{~kg} / \mathrm{ha}$ in 1984 and minimum medians of $0.27 \mathrm{~kg} / \mathrm{ha}$ in 1986 and 1987. 


\subsubsection{Temporal Change Analys is}

Based on the modified KST test, nine of the 35 1979-1988 trend sites exhibits a significantly $(p<0.05)$ decreasing trend in magnesium concentration: Sand Spring, CO $(-0.33 \mu \mathrm{eq} / 1 /$ year $)$; Chalk River, ON $(-0.31$ $\mu \mathrm{eq} / 1 /$ year); Fort Wayne, IN $(-0.26 \mu \mathrm{eq} / 1 /$ year $)$; Clinton Station, NC $(-0.23$ $\mu \mathrm{eq} / 1 /$ year $)$; Brookhaven, NY $(-0.20 \mu \mathrm{eq} / 1 /$ year $)$; Caldwe11, OH $(-0.19) \mu \mathrm{eq} / 1 /$ year; Lewiston, NC $(-0.19 \mu \mathrm{eq} / 1 /$ year $)$; Hubbard Brook, NH $(-0.15 \mu \mathrm{eq} / 1 /$ year $)$; and Huntington, NY $(-0.08 \mu \mathrm{eq} / 1 /$ year $)$. Figure A.54 displays the trend estimates for al1 35 sites.

There are nine 1982-1988 trend sites with significantly decreasing magnesium concentration trends: Clinton Station, NC $(-0.35 \mu \mathrm{eq} / 1 /$ year $)$; University Forest, MO $(-0.34 \mu \mathrm{eq} / 1 /$ year $)$; Georgia Station, GA $(-0.29 \mu \mathrm{eq} / 1 /$ year); East, MA $(-0.25 \mu \mathrm{eq} / 1 /$ year $)$; Chalk Creek, ON $(-0.22 \mu \mathrm{eq} / 1 /$ year $)$; Golden Lake, ON $(-0.21 \mu \mathrm{eq} / 1 /$ year $)$; Piedmont Station, NC $(-0.20 \mu \mathrm{eq} / 1 /$ year $)$; Walker Branch, TN $(-(.18 \mu \mathrm{eq} / 1 /$ year $)$; and Huntington, NY $(-0.17 \mu \mathrm{eq} / 1 /$ year $)$. There are also two ites with a significantly increasing trend: Longwoods (b), ON $(0.46 \mu \mathrm{eq} / 1 / \mathrm{y}(\mathrm{ar})$; and $0 x$ ford, $\mathrm{OH}(0.13 \mu \mathrm{eq} / 1 /$ year $)$. Figure A.55 displays the spatial pattel $n$ for the magnesium concentration trend estimates.

For 197:-1988 trend sites (Figure A.54), significant magnesium deposition decreases occur at ten sites: Chalk River, ON $\left(-0.33 \mathrm{~m}^{2} /\right.$ year $)$; Clinton Staticn, NC $\left(-0.24 \mathrm{meq} / \mathrm{m}^{2} /\right.$ year $)$; Fort Wayne, IN $\left(-0.22 \mathrm{meq} / \mathrm{m}^{2} /\right.$ year $)$; Piedmont Station, NC $\left(-0.20 \mathrm{meq} / \mathrm{m}^{2} /\right.$ year $)$; Caldwe 11 , OH $\left(-0.20 \mathrm{meq} / \mathrm{m}^{2} /\right.$ year $)$; Georgia Staticn, GA $\left(-0.18 \mathrm{meq} / \mathrm{m}^{2} /\right.$ year $)$; Delaware, $\mathrm{OH}\left(-0.18 \mathrm{meq} / \mathrm{m}^{2} /\right.$ year $)$; Hubbard Brook, NH $\left(-0.17 \mathrm{meq} / \mathrm{m}^{2} /\right.$ year $)$; Coweeta, NC $\left(-0.16 \mathrm{meq} / \mathrm{m}^{2} /\right.$ year $)$; and Manitou, CO ( $0.06 \mathrm{meq} / \mathrm{m}^{2} /$ year $)$.

There are 28 sites in the 1982-1988 trend subset with significantly decreasing magnesium deposition trends: Merlin, ON $\left(-0.66 \mathrm{meq} / \mathrm{m}^{2} /\right.$ year $)$; Victoria, TX (-0.43 meq $/ \mathrm{m}^{2} /$ year $)$; Forest Seed Ctr, TX $\left(-0.46 \mathrm{meq} / \mathrm{m}^{2} /\right.$ year $)$; University Forest, MO $\left(-0.43 \mathrm{meq} / \mathrm{m}^{2} /\right.$ year); Hopland (Ukiah), CA $(-0.42 \mathrm{meq} /$ $\mathrm{m}^{2} /$ year $)$; Davis, CA $\left(-0.38 \mathrm{meq} / \mathrm{m}^{2} /\right.$ year $)$; Alsea, OR $\left(-0.35 \mathrm{meq} / \mathrm{m}^{2} /\right.$ year $)$; Shenandoah National Park, VA $\left(-0.33 \mathrm{meq} / \mathrm{m}^{2} /\right.$ year $)$; Meridian, MS $(-0.33$ $\mathrm{meq} / \mathrm{m}^{2} /$ year $)$; Washington Xing, NJ $\left(-0.32 \mathrm{meq} / \mathrm{m}^{2} /\right.$ year $)$; Ashland, MO $(-0.30$ $\mathrm{meq} / \mathrm{m}^{2} /$ year); Walker Branch, TN $\left(-0.28 \mathrm{meq} / \mathrm{m}^{2} /\right.$ year $)$; Coweeta, NC (-0.24 meq/ 
$\mathrm{m}^{2} /$ year); Sequoia Nat. Park, CA $\left(-0.22 \mathrm{meq} / \mathrm{m}^{2} /\right.$ year $)$; Greenville Station, ME $\left(-0.22 \mathrm{meq} / \mathrm{m}^{2} /\right.$ year $) ; \mathrm{Ca}$ (dwe $11, \mathrm{OH}\left(-0.22 \mathrm{meq} / \mathrm{m}^{2} /\right.$ year $)$; Huntington, NY $(-0.19)$ $\mathrm{meq} / \mathrm{m}^{2} /$ year; Glacier Nat'1 Park, MT $\left(-0.16 \mathrm{meq} / \mathrm{m}^{2} /\right.$ year $)$; Great Smoky Mts, TN $\left(-0.15 \mathrm{meq} / \mathrm{m}^{2} /\right.$ year $) ;$ Fernberg, MN $\left(-0.14 \mathrm{meq} / \mathrm{m}^{2} /\right.$ year $) ;$ Spooner, WI $(-0.14$ $\mathrm{meq} / \mathrm{m}^{2} /$ year); Cuba, NM $\left(-0.13 \mathrm{meq} / \mathrm{m}^{2} /\right.$ year $)$; Organ Pipe Mon., AZ (-0.12 meq/ $\mathrm{m}^{2} /$ year); 01iver Knol1, AZ (-0.11 meq/m²/year); Sand Spring, CO $(-0.11 \mathrm{meq} /$ $\mathrm{m}^{2} /$ year); Alamosa, CO $\left(-0.11 \mathrm{meq} / \mathrm{m}^{2} /\right.$ year $)$; Newcastle, W' $\left(-0.11 \mathrm{meq} / \mathrm{m}^{2} /\right.$ year $)$; and Pickle Lake, ON $\left(-0.05 \mathrm{meq} / \mathrm{m}^{2} /\right.$ year $)$. There are also two sites with a significantly increasing trend: Wilkesport, ON $\left(0.38 \mathrm{meq} / \mathrm{m}^{2} /\right.$ year $)$; and Ithaca, NY $\left(0.14 \mathrm{meq} / \mathrm{m}^{2} /\right.$ year $)$. Figure A.55 displays the spatial pattern for the magnesium concentration trend estimates.

The rayplots of concentration and deposition trend estimates for both subsets show little evidence of a trend over a large area. 


\subsection{MULTIVARIATE TEMPORAL PATTERNS}

Section 3 discusses the temporal patterns observed for each individual wet deposition ion species. The results suggest the sites have one or more ion species that either have similar increasing temporal patterns or have similar decreasing temporal patterns. Previous studies on wet deposition trends also support this view. The purpose of this section is to discuss the multivariate aspects of the temporal patterns observed in wet deposition for the 1979-1988 and 1982-1988 trend stte subsets.

\subsection{MULTIVARIATE TEMPORAL PATTERN CONSISTENCY ACROSS ION SPECIES}

This section simultaneously considers the nine ion species: hydrogen, sulfate, nitrate, ammonium, calcium, chloride, sodium, potassium, and magnesium. To facilitate the simultaneous use of nine ions, the units used are in terms of equivalents instead of grams. The equivalents are obtained by dividing the number of grams by the formula weight and multiplying by the valence. The approach will be first to discuss the multivariate temporal patterns for concentration and then to discuss deposition. The discussion begins with an overview of the estimated 1988 annual concentrations for the ion species observed at the sites. This is followed by a comparison across the ion species of Sen's median slope, a trend estimate associated with the modified Kendall seasonal tau test. The trend estimate is then discussed in terms of percent change during the period. The reference is the estimated (using kriging) 1988 annual concentration for an ion species at a site. The estimated annual concentration is used because not all the sites have annual summaries, due to missing or invalid samples during a significant portion of at least one season. The magnitude of the percent change depends on the reference base at those sites with increasing or decreasing temporal patterns for an ion species. For example, using 1988 rather than 1982 as the reference, results in greater percent changes for cations at most sites, since the cations have decreased markedly over that period of time. All tables and figures appear at the end of Section 4. 


\subsubsection{Concentration Multivariate Patterns}

Boxplots in Figure 4.1 give the distribution summaries of the estimated 1988 annual precipitation-weighted concentrations of a11 the fons for the 1979-1988 and 1982-1988 trend sites. Note that the boxplots use the 10th and 90th percentile for the 1979-1988 subset and the 5th and 95th percentile for the 1982-1988 subset. Sulfate has the largest estimated relative concentration in precipitation, with medians of $48.9 \mu \mathrm{eq} / 1$ for the 1979-1988 trend sites and $44.5 \mu \mathrm{eq} / 1$ for the 1982-1988 trend sites. Hydrogen was a slightly smaller median concentration than sulfate, $42.3 \mu \mathrm{eq} / 1$ for the 1979-1988 trend sites and $35.8 \mu \mathrm{eq} / 1$ for the $1982-1988$ trend sites. Nitrate has a median concentration leve 1 of $22 \mu \mathrm{eq} / 1$ and ammonium median level is 14 $\mu$ eq/ 1 , approximately. The median concentration for the other ion species are below $10 \mu \mathrm{eq} / 1$. Sodium and chloride have a skewed distribution due to large concentrations at several coastal sites that have their precipitation chemistry influenced by sea salt. Calcium, potassium and magnesium also have skewed distributions, due to a number of sites with relatively high concentrations.

\subsubsection{Trend Estimates}

The distribution of Sen's median slope trend estimates for each ion species concentration are presented as boxplot displays in Figure 4.2 and the percentiles are shown in Tables 4.1 and 4.2 for the 1979-1988 trend set and the 1982-1988 trends sets, respectively. For the 1979-1988 subset only hydrogen and nitrate have slightly more than $50 \%$ of the slope estimates greater than zero (increasing trends). Ammonium has slightly less than $50 \%$ of the slope estimates greater than zero. All the other ions in the 1979-1988 subset have more than $75 \%$ of the slope estimates less than zero (decreasing trends), with all the sodium trends decreasing. For the 1982-1988 subset the percentage of negative slope estimates are reduced for all the ions, except hydrogen and ammonium. The most striking differences are nitrate, with over $75 \%$ of the trends increasing, and sodium with a1most $50 \%$ of the trends increasing. 
The shift toward more positive slope estimates is not necessartly due to the additional sites in the 1982-1988 subset. For example, of the 35 sites in 1979-1988 subset, only two sites have more negative sulfate slope estimates, one site has the same slope and the remaining 32 sites have more positive sulfate slopes during the 1982-1988 time pertod as compared to the 1979-1988 time pertod. Only six sites have increasing sulfate trends over the 10 year pertod, while over the seven year pertod, 18 of the 35 sites have increasing trends. That $\mathrm{is}, 12$ of the 35 sites have decreasing slopes over the ten year pertod and increasing slopes over the seven year pertod. None of these 12 sites have significantly increasing or decreasing slopes during etther time pertod. This change in trend is consistent with the national trend in sulfur oxide emissions shown in Figure 3.2. The 1979 sulfur oxide emissions decreased from 24.8 mt1lion metric tons/year in 1979 to 21.4 milliton metric tons/year in 1982, a 13.7 percent decrease (4.6 percent decrease per year). In 1988 the sulfur oxide emissions where 20.7 million metric tons/year, only a 3.3 percent decrease since 1982 ( 0.5 percent decrease per year) as compared to a 16.5 percent decrease since 1979 ( 1.8 percent decrease per year). Thus, since the 1979-1982 time pertod is when most of the decreases in sulfur oxide emmissions occured, on'y the subset which includes this time period will reflect this decrease.

In addition to providing Sen's median slope estimate, the modified Kendall seasonal tau provides a test of the significance for the temporal pattern. A significance level of $p<0.05$ is used as one way to summarize the test results. For each ton species in the two trend subsets, Table 4.3 summarizes the number and percent of the trend estimates that are significant, either decreasing or increasing. For the 1979-1988 trend sites, hydrogen, nitrate and chloride concentration each have one site with a significant increasing trend (a different site for each ion). All the ion species have one or more sites with significant decreasing trends. However, because there are 35 sites being tested simultaneously, it is not unusual for a small number of sites to be significant even when there is no trend (false positive). Assuming the tests are independent, for 35 simultaneous tests three or less significant results occur $90.4 \%$ of the time, while five or more significant results occur only $2.9 \%$ of the time when there is no trend. Therefore the 
number of significant decreasing slopes for sulfate, calctum, chloride, sodium, potassium and magnestum are greater than what would be expected if there is no trend.

For the 1982-1988 trend sttes, there is a lower percentage of significant decreasing trends and a higher percentage of significant increasing trends. For 137 simultaneous tests five or more significant results occur $82 \%$ of the time when there is no trend, nine or more significant results occur $32 \%$ of the time when there is no trend and 12 or more significant results occur on 1 y $4.2 \%$ of the time when there is no trend. Therefore, only the number of significantly increasing slopes for nitrate and decreasing slopes for potassium are greater than what would be expected if there is no trend.

For hydrogen, sulfate and ammonium none of the sites which have significant trends in the 1979-1988 subset have significant trends in the 1982-1988 subset. For calcium only one site that has a significant trend for 1979-1988 also has a significant trend for 1982-1988. For nitrate, chloride and sodium, the two sites that have significant trends for 1979-1988 also have significant trends for 1982-1988. For magnesium, only three sites with significant trends for the 1979-1988 subset have significant trends for the 1982-1988 subset. For potassium, eight sites with significant trends for the 1979-1988 subset have significant trends for the 1982-1988 subset. This coincides with the observation that potassium is the only ion that has a significantly large number of sites with decreasing trends in both the $1979-1988$ and 1982-1988 subset.

Table 4.4 gives the ranks, by individual ton, of the concentration trend estimates for the 1979-1988 trend sites, ordered by the average rank of the nine ions. The rank of the precipitation trend estimate is also included. A11 the ions, except hydrogen behave in a somewhat consistent fashion within the sites. None of the trend estimates for the ion concentration appear to behave like the trend estimate for total precipitation.

\subsubsection{Percent Change}

The concentration trend estimates may also be e.pressed in terms of percent chanje per year during the period. The reference for the percent 
change is the estimated 1983 annual concentration for an fon spectes at a stte. Table 4.5, Table 4.6 and Figure 4.3 summartze the concentration percent change results. The boxplots in Figure 4.3 al so show the $95 \%$ one-at-a-time confidence intervals for the medians. The percent changes discussed below all have confidence intervals that do not include zero. However, since a number of confidence intervals are being examined simultaneousiy, the significance level of these percent changes may not be as sma11 at 5\%. For the 1979-1988 trend subset, sodium has the 1 argest median percent change, $-7.0 \%$ per year. Extrapolating this change back to 1979, the 1979 median sodium concentration is $70 \%$ larger in 1979 than in 1988 . Potassium (-4.0\% per year), magnesium (-3.6\% per year), calcium (-3.2\% per year), chloride $(-2.3 \%$ per year) and sulfate $(-1.7 \%$ per year) also have relatively large medtan percent changes. For the 1982-1988 trend subset, the median percent changes are approximately the same as the 1979-1988 trend subset for only potassium (-4.8\% per year) and magnesium $(-3.0 \%$ per year). While the median percent change for potassium is about the same for the two trend subsets, the 1982-1988 subset has a numbir of sites with large percent increases. A11 of these sites are from one network, MAP3S. The nine MAP3S sites in this study are included in the eleven sites with the largest percent increases for potassium.

\subsubsection{Deposition Multivartate Patterns}

Boxplots in Figure 4.4 give the distribution summaries of the estimated 1988 annual total deposition of all the ions for the 1979-1988 and 1982-1988 trend sites. Sulfate has a median deposition of approximately $42 \mathrm{meq} / \mathrm{m}^{2}$. Hydrogen has a median deposition of approximately $35 \mathrm{meq} / \mathrm{m}^{2}$. Nitrate has a medtan deposition level of $19 \mathrm{meq} / \mathrm{m}^{2}$ and ammonium has a median deposition level of $12 \mathrm{meq} / \mathrm{m}^{2}$, approximately. The median deposition for the other ion species are below $10 \mathrm{meq} / \mathrm{m}^{2}$. Sodium and chloride have a skewed distribution due to high deposition at several coastal sites that have their precipitation chemistry influenced by sea salt. Calcium, potassium and magnesium also have skewed distributions, due to a number of sites with relatively high deposition.

\subsubsection{Irend Estimates}

The distribution of Sen's median slope trend estimates for each ion species total deposition are presented as boxplot displays in Figure 4.5 and 
the percentiles are shown in Table 4.7 and Table 4.8 for the 1979-1988 and the 1982-1988 trend subsets, respectively. For the 1979-1988 subset a11 the fons have at least approximately $75 \%$ of the slope estimates less than zero (decreasing trend). A11 the sodfum trends are negative (decreasing trends), and over $90 \%$ of the sulfate and calctum trends are negative. For the 1982-1988 subset, a11 the lons have more than $50 \%$ of the slope estlmates less than zero. Over $75 \%$ of the trend estimates for hydrogen, sulfate, sodium, potassium and magnesium are negative. Unlike the trend estimates for the concentration (see Section 4.1.1.1), the interquartile ranges do not change markedly between the two trend subsets.

Table 4.9 summarizes the number of sites with significantly decreasing or increasing deposition trend estimates. As discussed in Section 4.1.1.1, because a large number of sites are being tested simultaneously, a few significant trends can be expected even when there is no change in the trend. However, for the 1979-1988 subset, sulfate, calcium, chloride, sodium, potassium and magnesium a 11 have more significant decreasing trends than chance alone would explain. For the 1982-1988 subset, sulfate, ammonium, calcium, potassium and magnesium al1 have more significant decreasing trends than chance alone would explain. Additionally, hydrogen has ten sites with decreasing trends and no sites with increasing trends. While ten or more significant trends can occur $18 \%$ of the time when there is no trend, these significant trends would be expected to be both negative and positive if there is no trend. Thus the decreasing hydrogen deposition trend also appears to be signtficant.

For hydrogen and nitrate none of the sites which have significant trends in the 1979-1988 subset have significant trends in the 1982-1988 subset. For sulfate, chloride and sodtum only one site that has a significant trend for 1979-1988 also has a significant trend for 1982-1988. Calcium has only three sites that have a significant trend for both 1979-1988 and 1982-1988. Four of the six sites with significant ammonium trends for 1979-1988 also have a significant trend for 1982-1988. Six of the 13 sites with significant potassium trends for 1979-1988 also have a significant trend for 1982-1988. This is consistent with the observations made for the concentrations. 
Table 4.10 gives the ranks, by individual ion, of the deposition trend estimates for the 1979-1988 trend sites, ordered by the average rank of the nine ions. The rank of the precipitation trend estimate is also included. The trends for the different ions are relatively consistent within the sites, especially for hydrogen, sulfate and nitrate. Additionally, the total precipitation trend estimate does appear to be consistent, within sites, with the deposition trends, which was not the case with the concentration trend estimates. The greater the precipitation is, the greater the deposition. Consequentiy, the ordering of the sites by the average rank of the deposition trends appears to be unrelated to the ordering of the sites by the average rank of the concentration trends (see Table 4.4).

\subsubsection{Percent Change}

The deposition trend estimates may also be expressed in terms of percent change during the period. The reference for the percent change is the estimated 1988 annual deposition for an ion species at a site. Table 4.11, Table 4.12 and Figure 4.6 summarize the deposition percent change results. For the 1979-1988 trend subset, sodium has the largest median percent change, $-8.3 \%$ per year. Extrapolating this change back to 1979, the 1979 median sodium concentration is $83 \%$ larger in 1979 than in 1988 . Magnesium $(-4.9 \%$ per year), potassium $(-4.5 \%$ per year), calcium $(-4.3 \%$ per year $)$, chloride $(-3.8 \%$ per year) and sulfate (-2.9\% per year) also have relatively large median percent changes. For the 1982-1988 trend subset, the median percent changes are larger (more negative) than the median percent changes in the 1979-1988 subset for most ions. Sodium has a large increase (less negative) in the median percent change, to only $-3.2 \%$ per year in the 1982-1988 subset. Hydrogen, potassium and magnesium have decreases in the median percent change. Like the potassium concentration trends, nine of the ten largest percent increases for potassium deposition are MAP3S sites. 

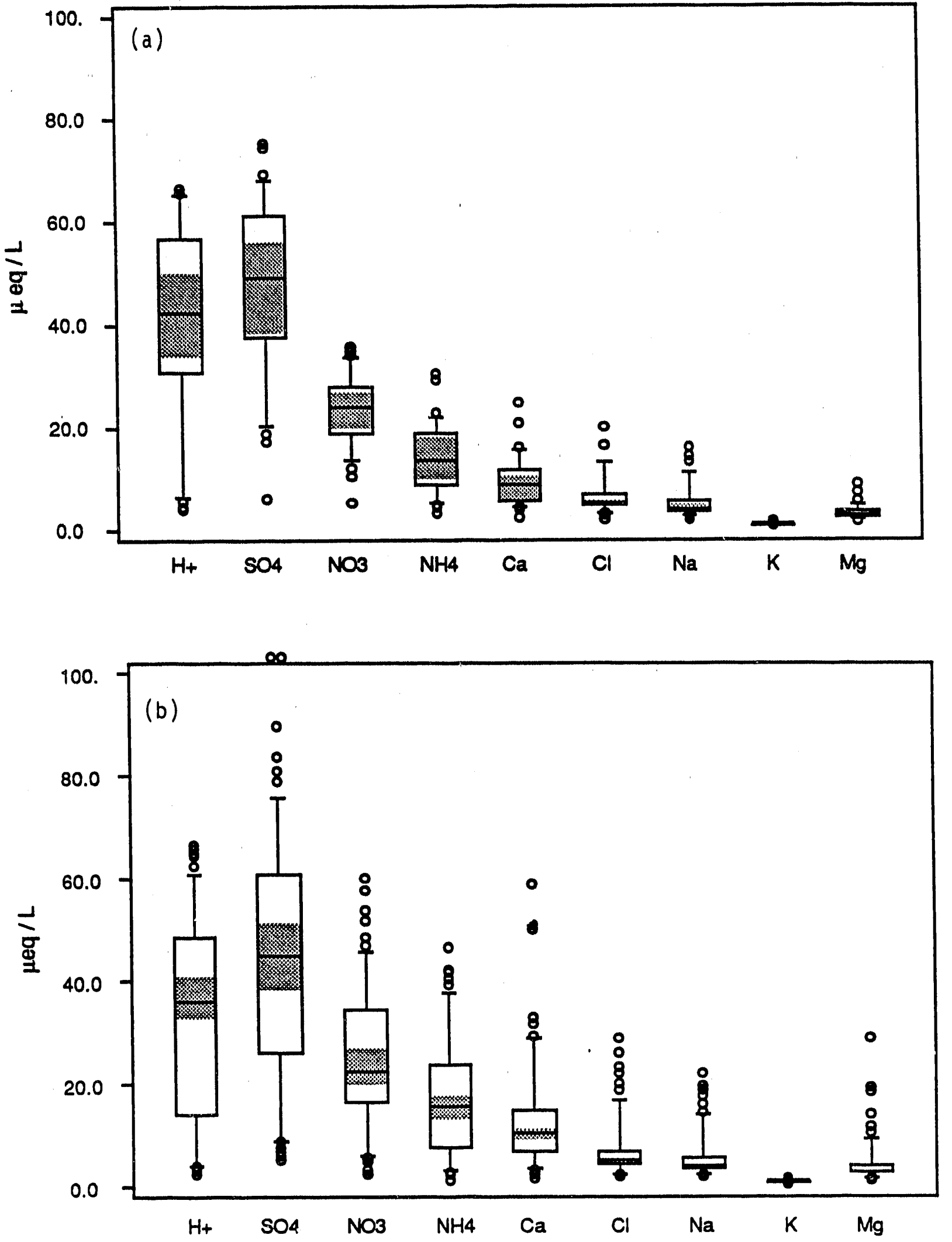

FIGURE 4.1 Estimated 1988 Ion Species Concentration for (a) 1979-1988 Trend Sites and (b) 1982-1988 Trend Sites 

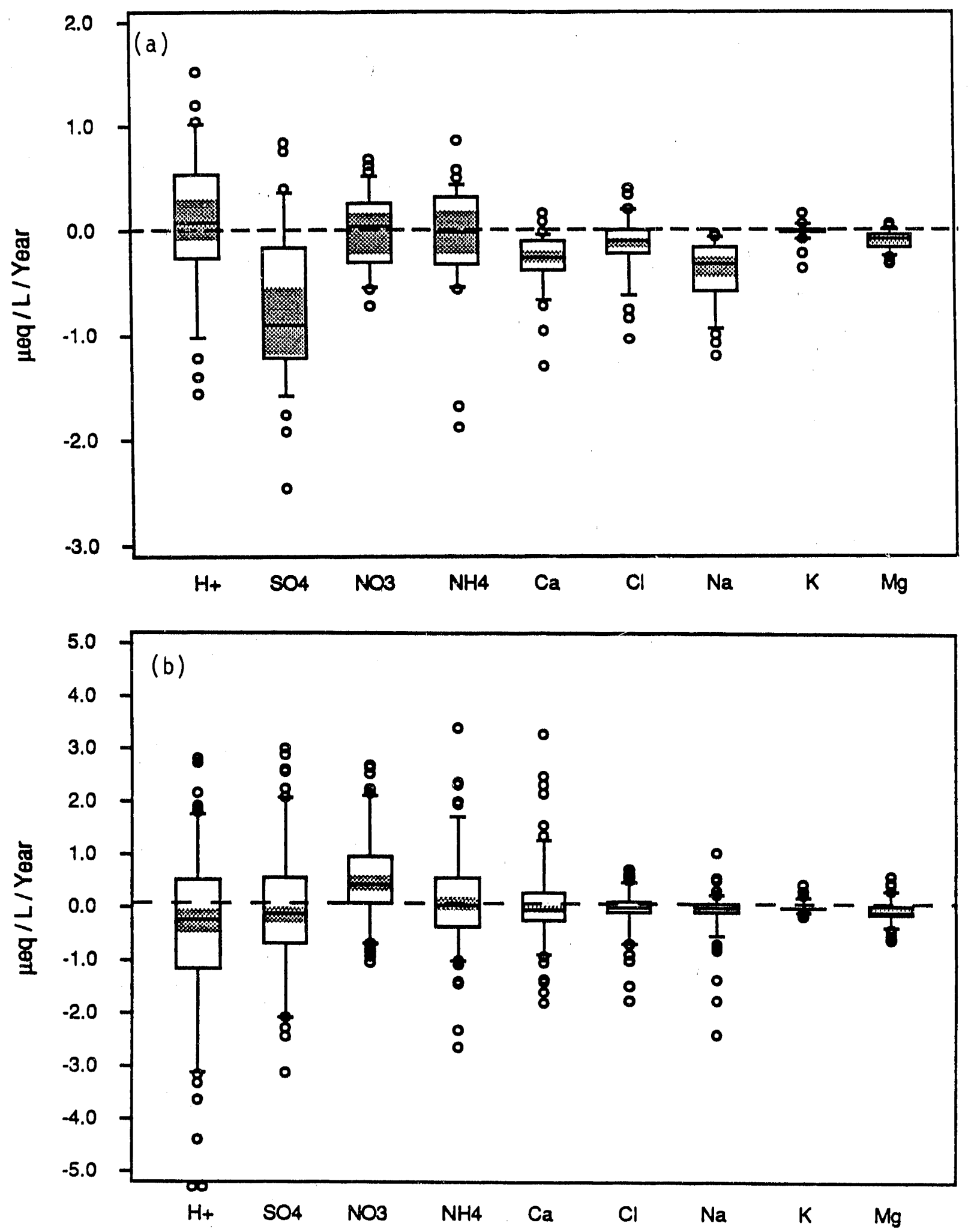

FIGURE 4.2 Ion Species Concentration Trend Estimates for (a) 1979-1988 Trend Sites and (b) 1982-1988 Trend Sites 

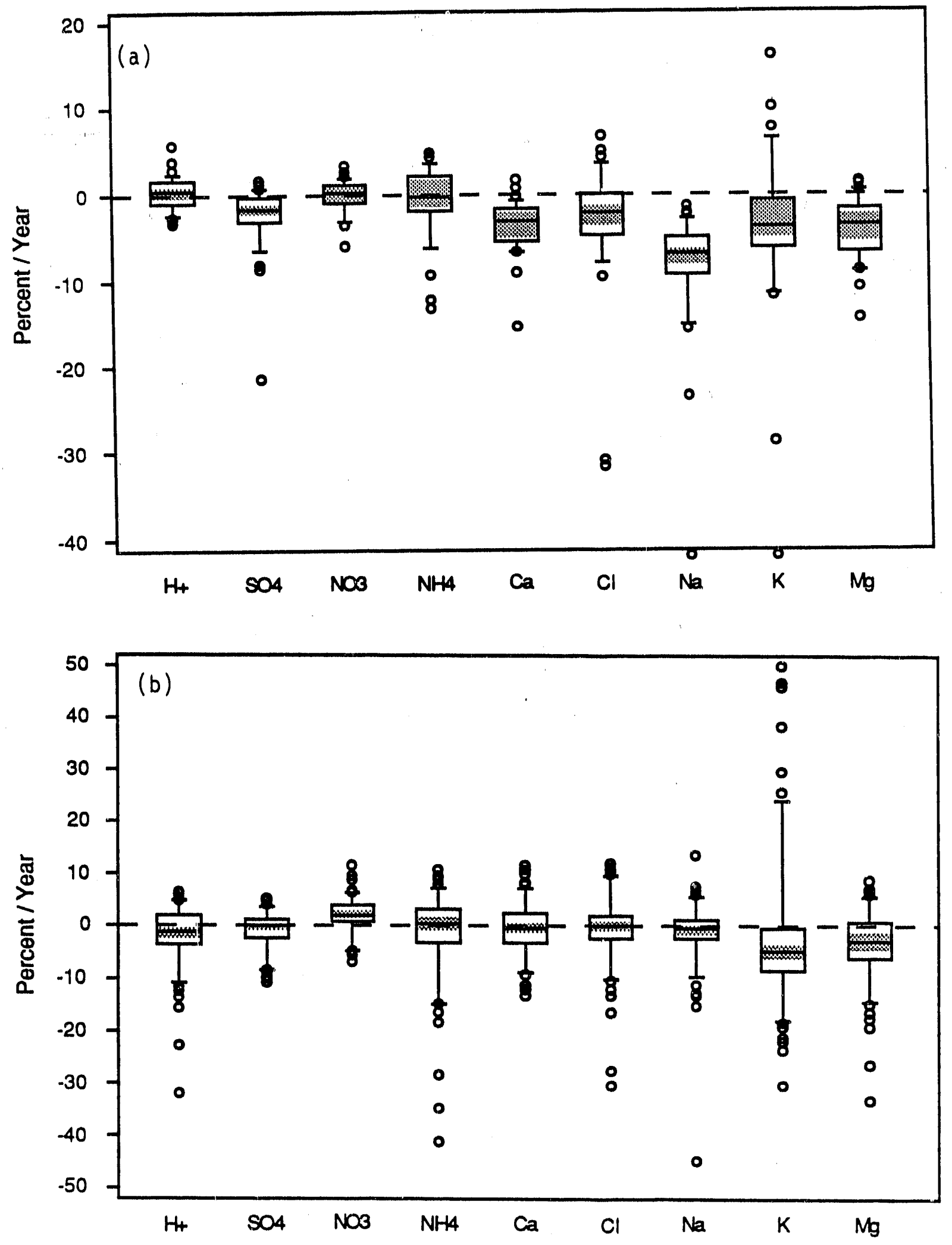

FIGURE 4.3 Distribution of Ion Species Concentration Trend Estimates as Percent of Estimated 1988 Annual Concentration for (a) 19791988 Trend Sites and (b) 1982-1988 Trend Sites 

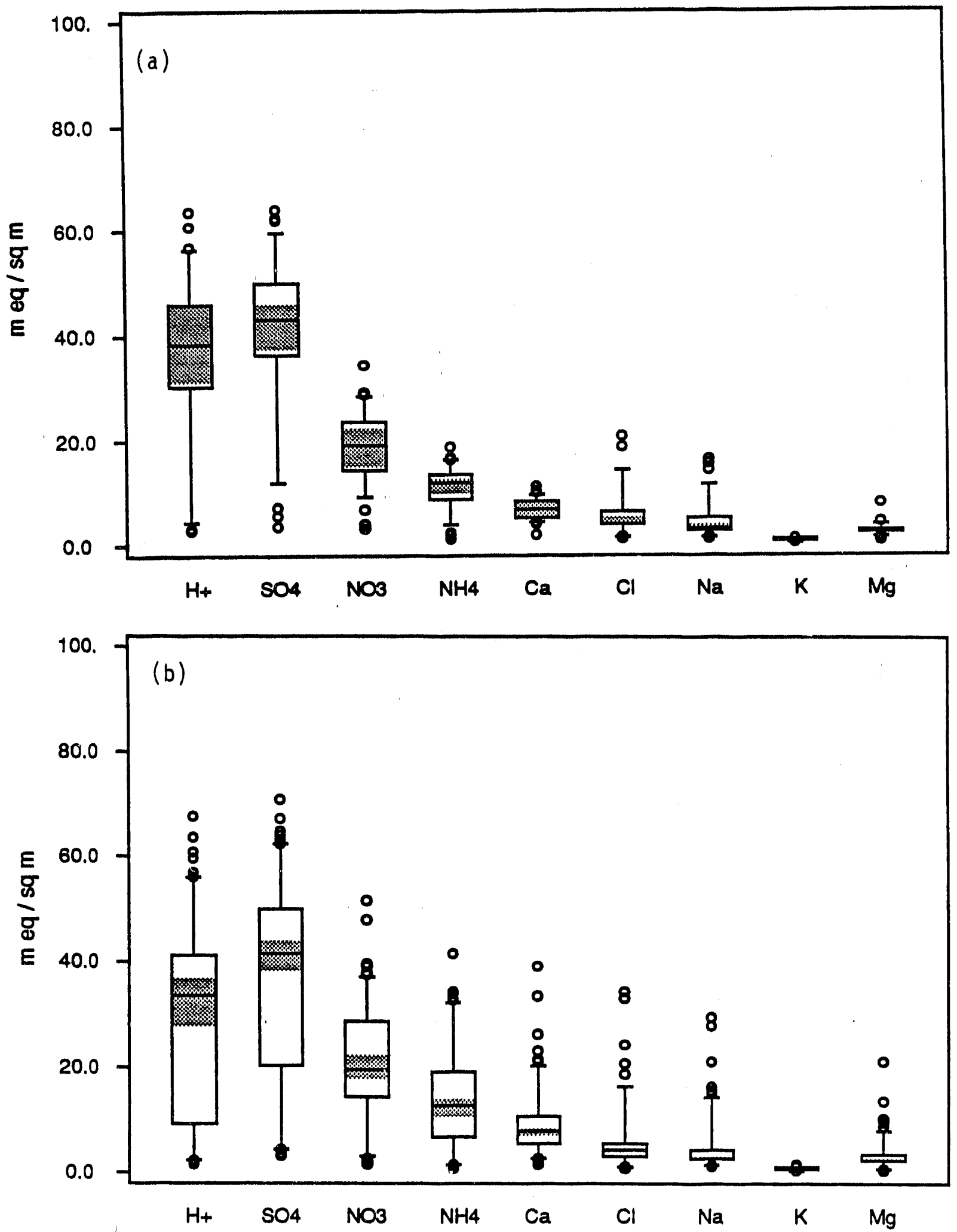

FIGURE 4.4 Estimated 1988 Ion Species Deposition for (a) 1979-1988 Trend Sites and (b) 1982-1988 Trend Sites 

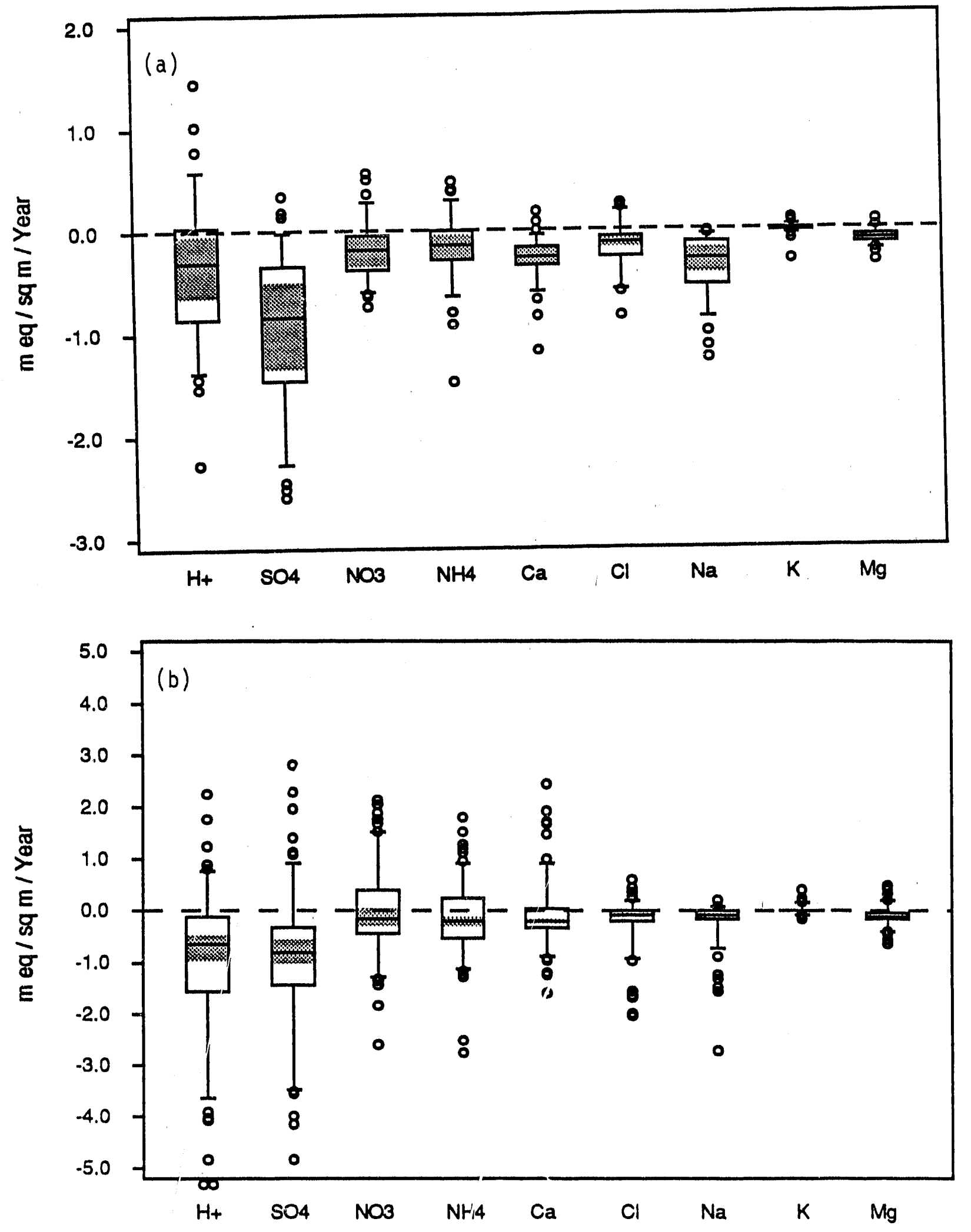

FIGURE 4.5 Ion Species Deposition Trend Estimates for (a) 1979-1988 Trend Sites and (b) 1982-1988 Trend Sites 

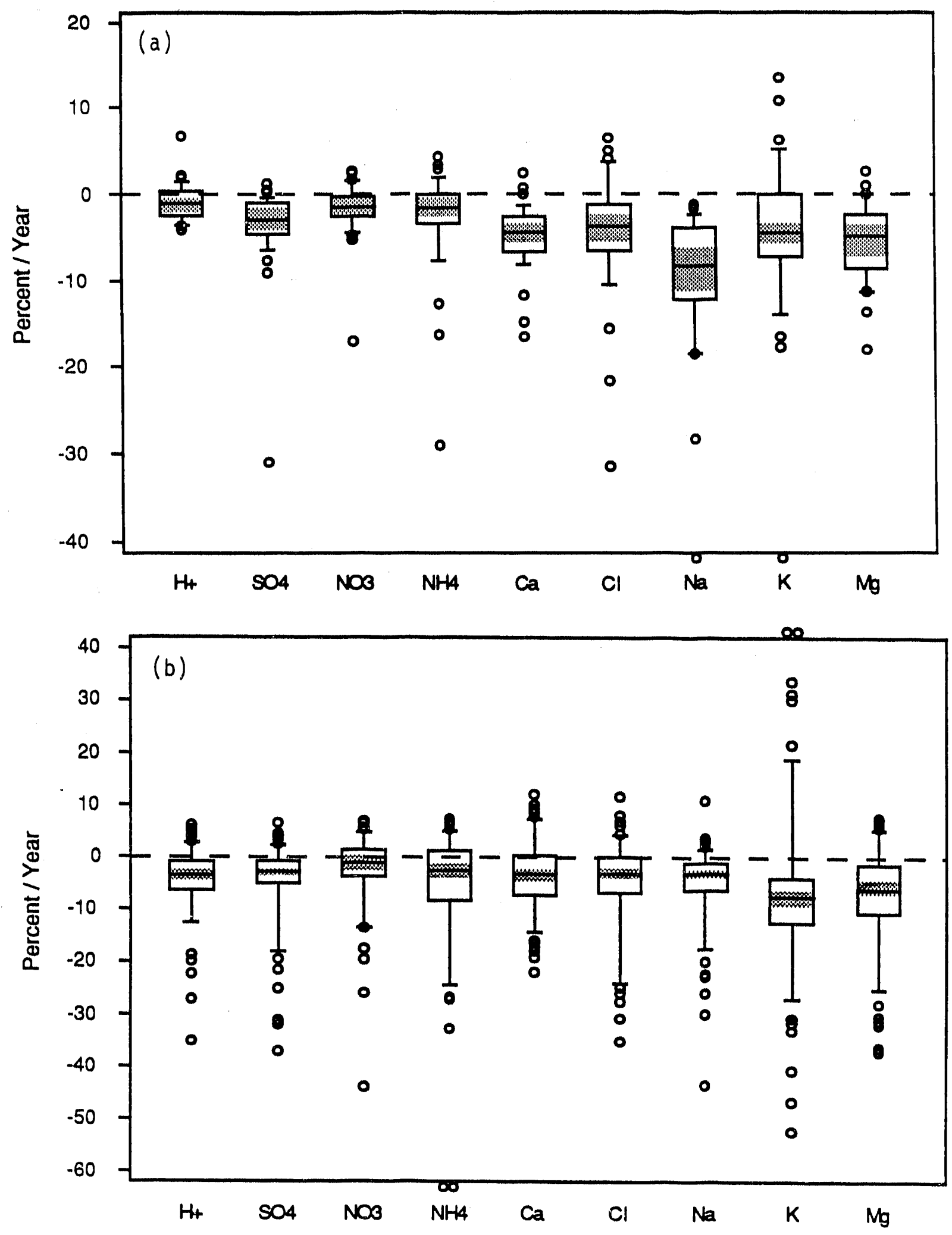

EIGURE 4.6 Distribution of Ion Species Deposition Trend Estimates as Percent of Estimated 1988 Annual Deposition for (a) 1979-1988 Trend Sites and (b) 1982-1988 Trend Sites. 
IABLE 4.1. Change per Year ( $\mu$ eq/1/year) of Precipitation-weighted Annual Mean Concentration for 1979-1988 Trend Sites $(n=35)$

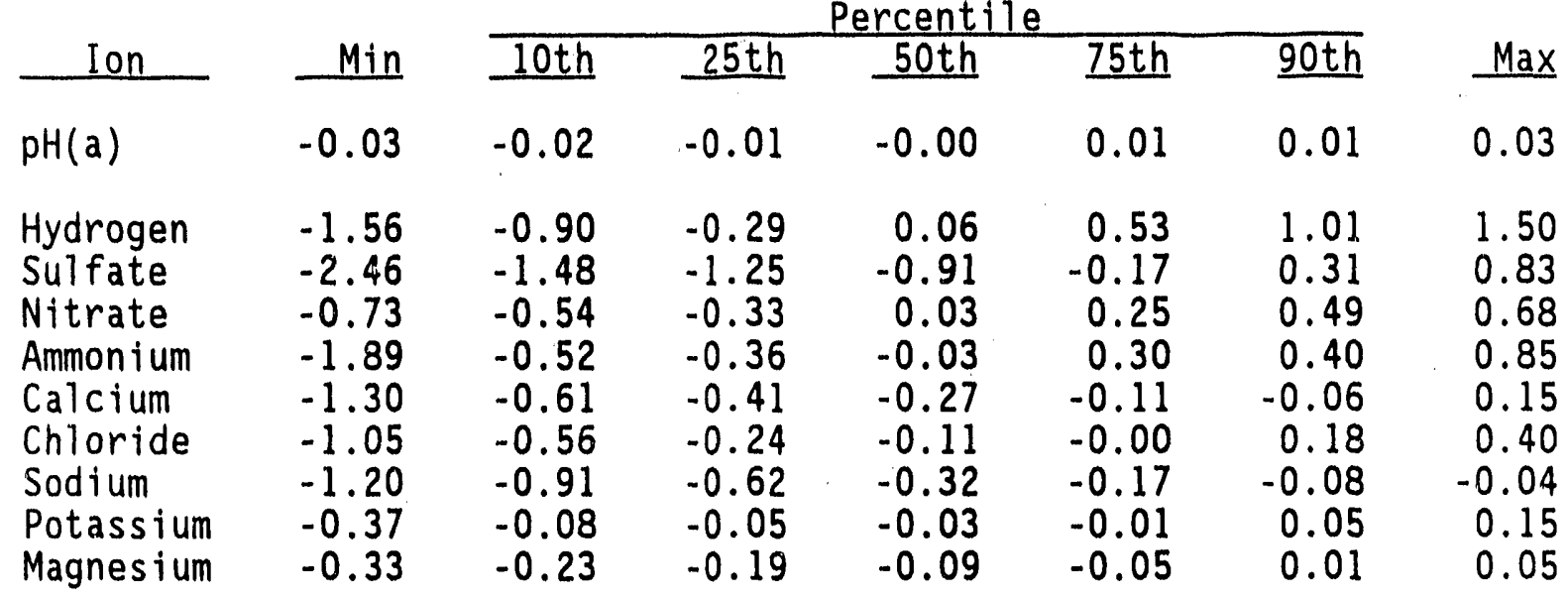

(a) pH units

IABLE 4.2. Change per Year ( $\mu$ eq/1/year) of Precipitation-weighted Annual Mean Concentration for 1982-1988 Trend Sites $(n=137)$

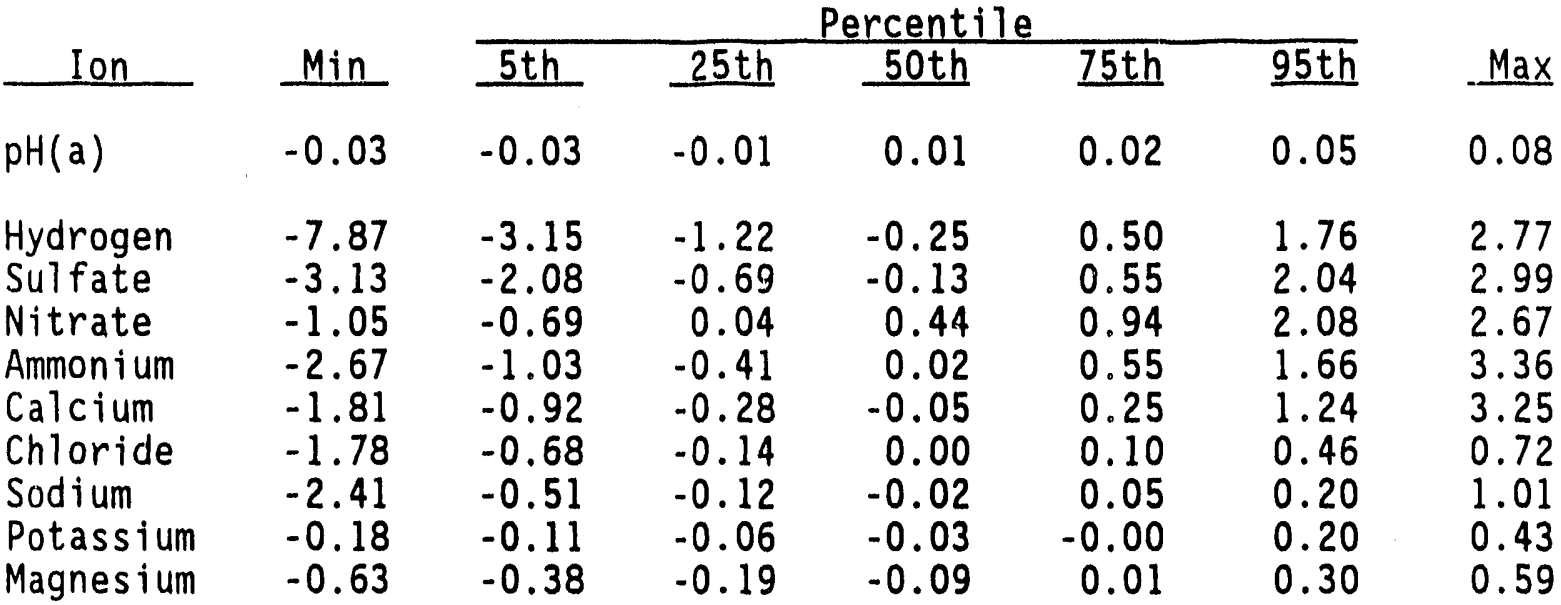

(a) $\mathrm{pH}$ units 
TABLE 4.3. Number and Percent of Significantly $(p<0.05)$ Decreasing and Increasing Trend Estimates by Ion Species for Concentration at 1979-1988 and 1982-1988 Trend Sites

Ion Species

1979-1988 Trend Sites

$\frac{\text { Decrease }}{\%} \quad \frac{\text { None }}{\mathrm{N}} \frac{\text { Increase }}{\mathrm{N}} \%$

$\mathrm{pH}$

Hydrogen

Sulfate

Nitrate

Ammonium

Calcium

Chloride

Sodium

Potassium

Magnesium

$\begin{array}{lllll}3 & 1 & 32 & 2 & 6\end{array}$

$\begin{array}{lllll}6 & 2 & 32 & 1 & 3\end{array}$

$\begin{array}{lllll}17 & 6 & 29 & 0 & 0\end{array}$

$\begin{array}{lllll}3 & 1 & 33 & 1 & 3\end{array}$

$\begin{array}{lllll}9 & 3 & 32 & 0 & 0\end{array}$

$\begin{array}{lllll}17 & 6 & 29 & 0 & 0\end{array}$

$26 \quad 9$

25

$\begin{array}{lllll}46 & 16 & 19 & 0 & 0\end{array}$

$\begin{array}{lllll}40 & 14 & 21 & 0 & 0\end{array}$

$\begin{array}{lllll}26 & 9 & 26 & 0 & 0\end{array}$
1982-1988 Trend Sites

$\frac{\text { Decrease }}{\%} \quad \frac{\text { None }}{N} \quad \frac{\text { Increase }}{N} \frac{1}{\%}$

$\begin{array}{lllll}2 & 3 & 131 & 3 & 2\end{array}$

$\begin{array}{lllll}2 & 3 & 131 & 3 & 2\end{array}$

$\begin{array}{lllll}2 & 3 & 133 & 1 & 1\end{array}$

$\begin{array}{lllll}1 & 2 & 123 & 12 & 9\end{array}$

$\begin{array}{lllll}7 & 9 & 121 & 7 & 5\end{array}$

$\begin{array}{lllll}1 & 2 & 129 & 6 & 4\end{array}$

$\begin{array}{lllll}1 & 2 & 128 & 7 & 5\end{array}$

$\begin{array}{lllll}1 & 2 & 133 & 2 & 1\end{array}$

$\begin{array}{lllll}18 & 24 & 107 & 6 & 4\end{array}$

$\begin{array}{lllll}7 & 9 & 126 & 2 & 1\end{array}$ 
IABLE 4.4. Ranks by Ion of Annual Concentration Temporal Change for 1979-1988 Trend Sites (Ordered by Average Rank)

\begin{tabular}{|c|c|c|c|c|c|c|c|c|c|c|c|}
\hline SITENAME & Precip & $\underline{H}$ & $\underline{\mathrm{SO} 4}$ & $\underline{\mathrm{NO} 3}$ & $\underline{C L}$ & $\mathrm{NH4}$ & NA & $K$ & $\underline{C A}$ & $M G$ & $\begin{array}{l}\text { Ave } \\
\text { Rank }\end{array}$ \\
\hline alk River & 19 & 34 & 1 & 11 & 1 & 9 & 2 & 1 & 1 & 2 & 6.9 \\
\hline ort Wayne & 20 & 2 & 10 & 3 & 10 & 11 & 20 & 5 & 3 & 3 & 7.4 \\
\hline ead & 28 & 14 & 2 & 6 & 9 & $i$ & 10 & 3 & 8 & 18 & 7.9 \\
\hline avis & 25.5 & 13 & 9 & 10 & 2 & 7 & 1 & 10 & 23 & 5 & 8.9 \\
\hline anitoul & 12 & 24 & 3 & 1 & 16 & 4 & 14 & 6 & 6 & 10 & 9.3 \\
\hline and spring & 25.5 & 18 & 4 & 4 & 18 & 3 & 16 & 23 & 2 & 1 & 9.9 \\
\hline xon fiprings & 3 & 9 & 8 & 12 & 7 & 5 & 22 & 11 & 10 & 15 & 11.0 \\
\hline rookhaven & 33 & 8 & 18 & 21 & 4 & 13 & 4 & 16 & 19 & 6 & 12.1 \\
\hline ambertion & 16 & 16 & 7 & 13 & 13 & 2 & 15 & 4 & 13 & 28.5 & 12.4 \\
\hline$A(b)$ & 29 & 19 & 11 & 16 & 3 & 29 & 7 & 2 & 5 & 21 & 12.6 \\
\hline arcelli & 21 & 10 & 20 & 7 & 15 & 8 & 30 & 7 & 9 & 16 & 13.6 \\
\hline bband Brook & 6 & 11 & 17 & 8 & 12 & 18 & 21 & 20.5 & 18 & 12 & 15.3 \\
\hline edmont Station & 4 & 21 & 16 & 26 & 6 & 22 & 9 & 13 & 14 & 11 & 15.3 \\
\hline radford Forest & 34 & 33 & 25 & 23 & 8 & 16 & 5 & 8 & 20 & 7 & 16.1 \\
\hline Ilston & 32 & 6 & 5 & 9 & 11 & 12 & 31 & 15 & 33 & 27 & 16.6 \\
\hline $1 \mathrm{dwel} 11$ & 10 & 17 & 21 & 5 & 20 & 30 & 23 & 22 & 4 & 9 & 16.8 \\
\hline untirigton & 30 & 15 & 6 & 17 & 17 & 14 & 28 & 20.5 & 16 & 19 & 16.9 \\
\hline andville & 23 & 20 & 19 & 2 & 24 & 6 & 32 & 9 & 26 & 25.5 & 18.2 \\
\hline Georgla Station & 17 & 30 & 26 & 20 & 14 & 10 & 13 & 14 & 28 & 13 & 18.7 \\
\hline Lewiston & 18 & 23 & 24 & 22 & 19 & 20 & 8 & 25 & 21 & 8 & 18.9 \\
\hline Wooster & 9 & 12 & 12 & 25 & 21.5 & 34 & 24 & 17 & 11 & 14 & 18.9 \\
\hline Parsons & 7 & 26 & 23 & 19 & 25 & 19 & 25 & 12 & 7 & 17 & 19.2 \\
\hline linton Station & 5 & 29 & 32 & 31 & 5 & 27 & 6 & 18 & 25 & 4 & 19.7 \\
\hline Illinois & 27 & 7 & 13 & 14 & 30 & 23 & 26 & 27.5 & 17 & 20 & 19.7 \\
\hline$x$ ford & 31 & 4 & 14 & 15 & 31 & 17 & 29 & 32 & 15 & 28.5 & 20.6 \\
\hline Coweeta & 1 & 28 & 28 & 24 & 23 & 21 & 18 & 27.5 & 30 & 23 & 24,7 \\
\hline 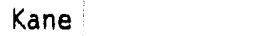 & 14 & 32 & 31 & 28 & 27.5 & 15 & 33 & 19 & 22 & 22 & 25.5 \\
\hline hiteface & 35 & 3 & 22 & 18 & 33 & 26 & 34 & 33.5 & 29 & 31 & 25.5 \\
\hline owes & 11 & 22 & 33 & 30 & 29 & 25 & 3 & 24 & 31 & 33 & 25.6 \\
\hline Penn State & 13 & 25 & 27 & 33 & 32 & 31 & 17 & 30 & 12 & 24 & 25.7 \\
\hline Finley (A) & 15 & 31 & 29 & 27 & 26 & 24 & 11 & 31 & 27 & 30 & 26.2 \\
\hline Delaware & 2 & 27 & 30 & 29 & 21.5 & 35 & 19 & 26 & 24 & 25.5 & 26.3 \\
\hline Ithaca & 22 & 1 & 15 & 32 & 35 & 28 & 35 & 33.5 & 34 & 34 & 27.5 \\
\hline Horton's Station & 24 & 35 & 35 & 35 & 27.5 & 32 & 12 & 29 & 32 & 32 & 29.9 \\
\hline Virginia & 8 & 5 & 34 & 34 & 34 & 33 & 27 & 35 & 35 & 35 & 30.2 \\
\hline
\end{tabular}


TABLE 4.5. Percent Change per Year of Precipitation-weighted Annual Mean Concentration for 1979-1988 Trend Sites $(n=35)$

\begin{tabular}{|c|c|c|c|c|c|c|c|}
\hline \multirow[b]{2}{*}{ Ion } & \multirow[b]{2}{*}{ Min } & \multicolumn{5}{|c|}{ Percentile } & \multirow[b]{2}{*}{$\operatorname{Max}$} \\
\hline & & 10th & $25 t_{h}$ & $50 t h$ & 75th & 90th & \\
\hline $\mathrm{pH}$ & -0.72 & -0.38 & -0.14 & -0.05 & 0.16 & 0.27 & 0.59 \\
\hline $\begin{array}{l}\text { Hydrogen } \\
\text { Sulfate } \\
\text { Nitrate } \\
\text { Ammonium } \\
\text { Calcium } \\
\text { Chloride } \\
\text { Sodium } \\
\text { Potassium } \\
\text { Magnesium }\end{array}$ & $\begin{array}{l}-3.45 \\
-21.41 \\
-6.05 \\
-13.14 \\
-15.31 \\
-31.68 \\
-59.59 \\
-50.24 \\
-14.41\end{array}$ & $\begin{array}{l}-2.52 \\
-6.48 \\
-3.05 \\
-6.31 \\
-6.71 \\
-8.05 \\
-15.25 \\
-11.51 \\
-8.97\end{array}$ & $\begin{array}{l}-1.32 \\
-3.46 \\
-1.32 \\
-2.17 \\
-5.73 \\
-4.97 \\
-9.70 \\
-6.59 \\
-6.97\end{array}$ & $\begin{array}{r}0.44 \\
-1.73 \\
0.16 \\
-0.24 \\
-3.23 \\
-2.28 \\
-6.97 \\
-3.99 \\
-3.60\end{array}$ & $\begin{array}{r}1.65 \\
-0.29 \\
1.09 \\
2.01 \\
-1.76 \\
-0.05 \\
-5.07 \\
-0.73 \\
-1.76\end{array}$ & $\begin{array}{r}2.37 \\
0.78 \\
1.98 \\
3.68 \\
-0.68 \\
3.51 \\
-2.82 \\
6.35 \\
0.36\end{array}$ & $\begin{array}{r}5.71 \\
1.60 \\
3.43 \\
4.73 \\
1.58 \\
6.58 \\
-1.38 \\
15.94 \\
1.46\end{array}$ \\
\hline
\end{tabular}

TABLE 4.6. Percent Change per Year of Precipitation-weighted Annual Mean Concentration for 1982-1988 Trend Sites $(n=137)$

\begin{tabular}{|c|c|c|c|c|c|c|c|}
\hline & \multirow[b]{2}{*}{ Min } & \multicolumn{5}{|c|}{ Percentile } & \multirow[b]{2}{*}{$\operatorname{Max}$} \\
\hline & & 5 th & $25 \mathrm{th}$ & 50 th & 75 th & 95 th & \\
\hline $\mathrm{pH}$ & -0.73 & -0.63 & -0.20 & 0.16 & 0.42 & 1.00 & 1.53 \\
\hline $\begin{array}{l}\text { Hydrogen } \\
\text { Sulfate } \\
\text { Nitrate } \\
\text { Ammonium } \\
\text { Calcium } \\
\text { Chloride } \\
\text { Sodium } \\
\text { Potassium } \\
\text { Magnesium }\end{array}$ & $\begin{array}{r}-32.22 \\
-10.96 \\
-6.95 \\
-41.57 \\
-13.27 \\
-30.66 \\
-45.06 \\
-30.51 \\
-33.47\end{array}$ & $\begin{array}{r}-10.82 \\
-8.40 \\
-4.94 \\
-14.93 \\
-8.88 \\
-10.17 \\
-9.66 \\
-18.12 \\
-14.68\end{array}$ & $\begin{array}{r}-4.00 \\
-2.92 \\
0.21 \\
-3.78 \\
-3.83 \\
-2.98 \\
-3.04 \\
-8.86 \\
-6.74\end{array}$ & $\begin{array}{r}-1.48 \\
-0.35 \\
1.97 \\
0.09 \\
-0.53 \\
0.00 \\
-0.77 \\
-4.84 \\
-3.03\end{array}$ & $\begin{array}{r}1.65 \\
1.16 \\
3.80 \\
2.82 \\
2.16 \\
1.95 \\
1.14 \\
-0.45 \\
0.52\end{array}$ & $\begin{array}{r}4.49 \\
3.42 \\
6.13 \\
6.94 \\
6.90 \\
9.23 \\
5.45 \\
23.65 \\
5.60\end{array}$ & $\begin{array}{r}6.28 \\
5.00 \\
11.34 \\
10.42 \\
11.44 \\
11.86 \\
13.45 \\
49.93 \\
8.70\end{array}$ \\
\hline
\end{tabular}


TABLE 4.7. Change per Year (meq/ $\mathrm{m}^{2} /$ year) of Annual Deposition for $1979-1988$ Trend Sites $(n=35)$

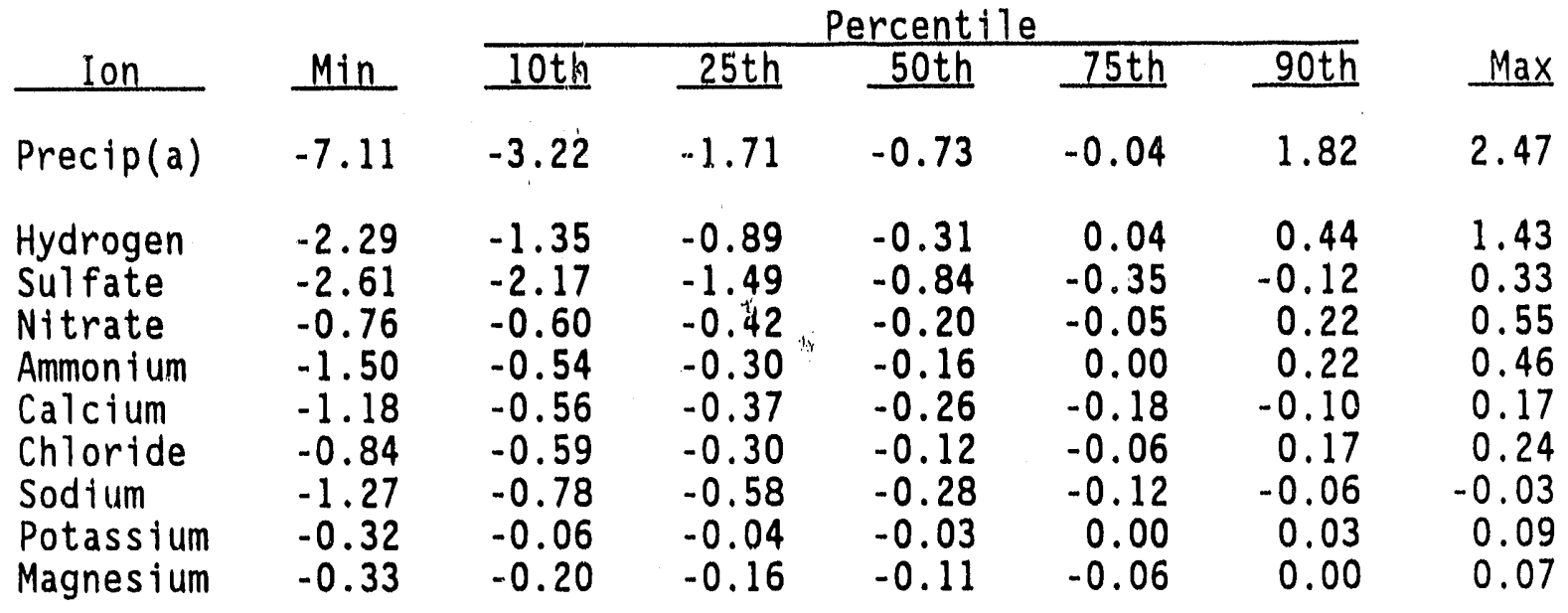

(a) Annual precipitation (cm)

IABLE 4.8. Change per Year (meq/m²/year) of Annual Deposition for $1982-1988$ Trend Sites $(n=137)$

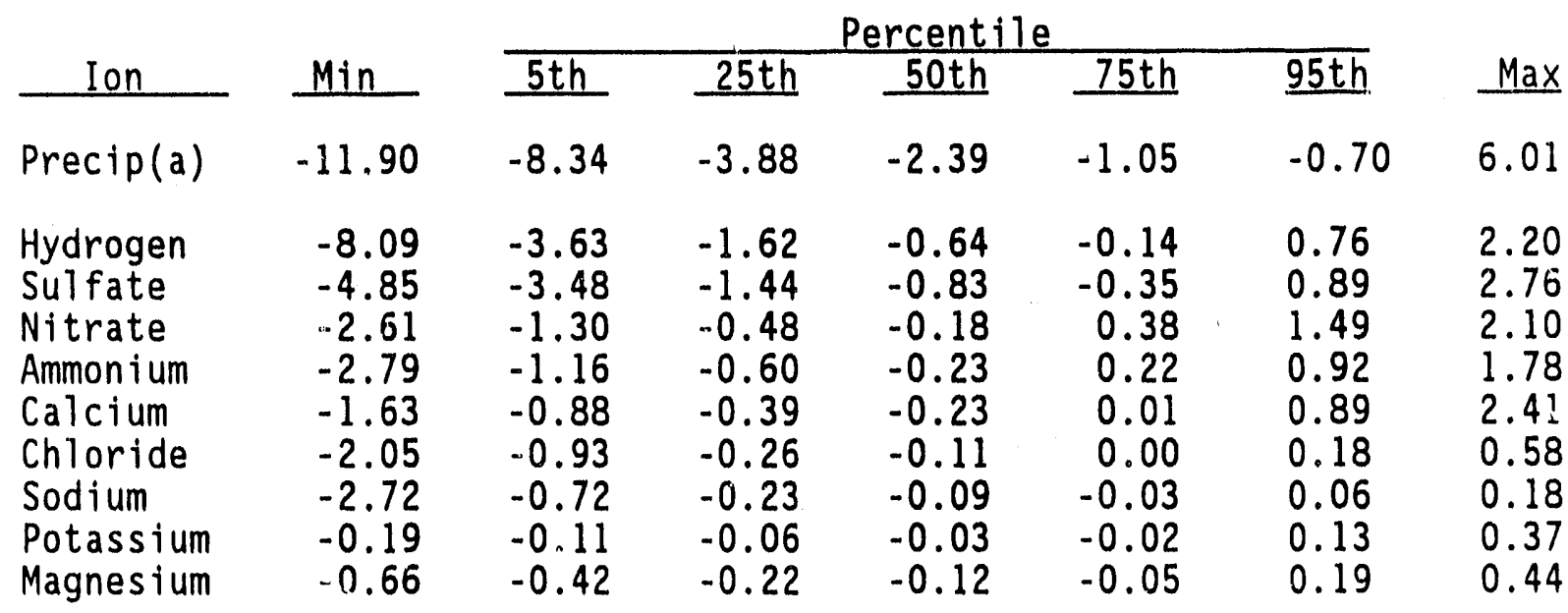

(a) Annual precipitation (cm) 
TABLE 4.9. Number and Percent of Significantly $(p<0.05)$ Decreasing and Increasing Trend Estimates by Ion Speciés for Deposition at 1979-1988 and 1982-1988 Trend Sites

\begin{tabular}{|c|c|c|c|c|c|c|c|c|c|c|}
\hline \multirow[b]{3}{*}{ Ion Species } & \multicolumn{5}{|c|}{ 1979-1988 Trend Sites } & \multicolumn{5}{|c|}{ 1982-1988 Trend Sites } \\
\hline & \multicolumn{2}{|c|}{ Decrease } & \multirow{2}{*}{$\frac{\text { None }}{N}$} & \multicolumn{2}{|c|}{ Increase } & \multirow{2}{*}{\multicolumn{2}{|c|}{ Decrease }} & \multirow{2}{*}{$\frac{\text { None }}{N}$} & \multirow{2}{*}{\multicolumn{2}{|c|}{$\frac{\text { Increase }}{\mathrm{N}}$}} \\
\hline & & $\bar{N}$ & & $\bar{N}$ & $\%$ & & & & & \\
\hline Precipitation & 14 & 5 & 30 & 0 & 0 & 8 & 11 & 126 & 0 & 0 \\
\hline Hydrogen & 3 & 1 & 33 & 1 & 3 & 7 & 10 & 127 & 0 & 0 \\
\hline Sulfate & 29 & 10 & 25 & 0 & 0 & 10 & 14 & 123 & 0 & 0 \\
\hline Nitrate & a & 3 & 32 & 0 & 0 & 4 & 5 & 129 & 3 & 2 \\
\hline Ammonium & 11 & 4 & 29 & 2 & 6 & 9 & 13 & 123 & 1 & 1 \\
\hline Calcium & 49 & 17 & 22 & 0 & 0 & 13 & 18 & 115 & 4 & 3 \\
\hline Chloride & 34 & 12 & 22 & 1 & 3 & 9 & 12 & 123 & 2 & 1 \\
\hline Sodium & 57 & 20 & 15 & 0 & 0 & 7 & 9 & 128 & 0 & 0 \\
\hline Potassium & 37 & 13 & 22 & 0 & 0 & 29 & 40 & 93 & 4 & 3 \\
\hline Magnesium & 29 & 10 & 25 & 0 & 0 & 20 & 28 & 107 & 2 & 1 \\
\hline
\end{tabular}



TABLE 4.10. Ranks by Ion of Annual Deposition Temporal Change for 1979-1988
Trend Sites (Ordered by Average Rank)

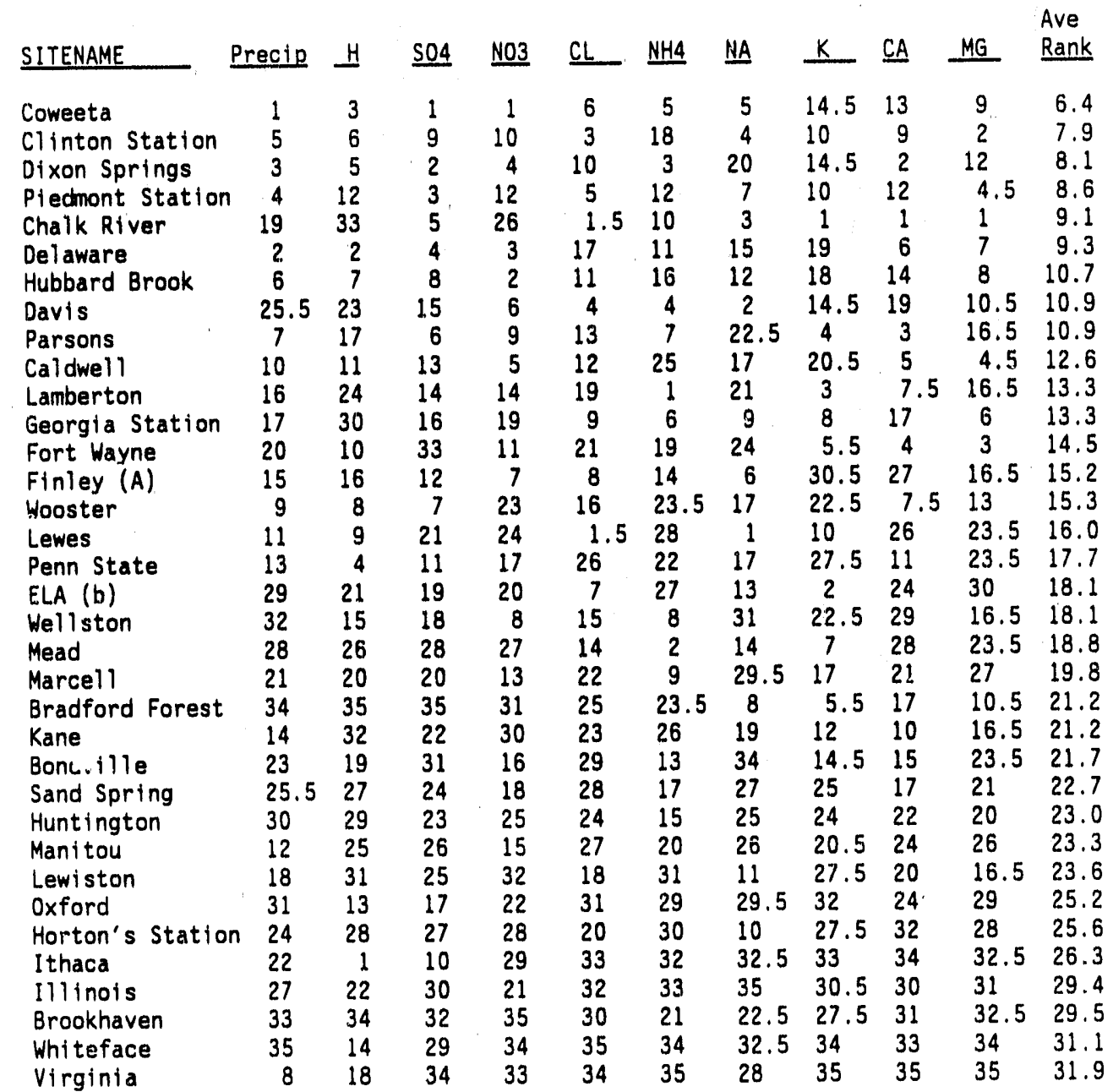


TABLE 4.11. Percent Change per Year of Annual Deposition for 1979-1988 Trend Sites $(n=35)$

\begin{tabular}{|c|c|c|c|c|c|c|c|}
\hline \multirow[b]{2}{*}{ Ion } & \multirow[b]{2}{*}{ Min } & \multicolumn{5}{|c|}{ Percentile } & \multirow[b]{2}{*}{ Max } \\
\hline & & 10 th & $25 t h$ & 50 th & $75 \mathrm{th}$ & $90 t h$ & \\
\hline Frecip & -5.57 & -3.58 & -2.32 & -0.72 & 0.06 & 1.38 & 2.51 \\
\hline $\begin{array}{l}\text { Hydrogen } \\
\text { Sulfate } \\
\text { Nitrate } \\
\text { Ammonium } \\
\text { Calcium } \\
\text { Chloride } \\
\text { Sodium } \\
\text { Potassium } \\
\text { Magnesium }\end{array}$ & $\begin{array}{l}-4.03 \\
-30.94 \\
-17.12 \\
-29.02 \\
-16.64 \\
-31.52 \\
-68.56 \\
-51.53 \\
-18.12\end{array}$ & $\begin{array}{r}-3.40 \\
-6.33 \\
-4.29 \\
-7.77 \\
-8.13 \\
-10.30 \\
-18.49 \\
-13.95 \\
-11.29\end{array}$ & $\begin{array}{r}-2.39 \\
-4.57 \\
-2.63 \\
-3.23 \\
-6.67 \\
-6.51 \\
-12.06 \\
-7.08 \\
-8.68\end{array}$ & $\begin{array}{l}-1.06 \\
-2.86 \\
-1.50 \\
-1.63 \\
-4.33 \\
-3.81 \\
-8.26 \\
-4.47 \\
-4.88\end{array}$ & $\begin{array}{r}0.27 \\
-0.95 \\
-0.19 \\
0.00 \\
-2.42 \\
-1.10 \\
-3.95 \\
0.00 \\
-2.22\end{array}$ & $\begin{array}{r}1.48 \\
-0.28 \\
1.54 \\
1.94 \\
-1.27 \\
3.75 \\
-2.19 \\
5.11 \\
0.00\end{array}$ & $\begin{array}{r}6.58 \\
1.15 \\
2.56 \\
4.19 \\
2.36 \\
6.41 \\
-1.31 \\
13.43 \\
2.70\end{array}$ \\
\hline
\end{tabular}

IABLE 4.12. Percent Change per Year of Annual Deposition for 1982-1988 Trend Sites $(n=137)$

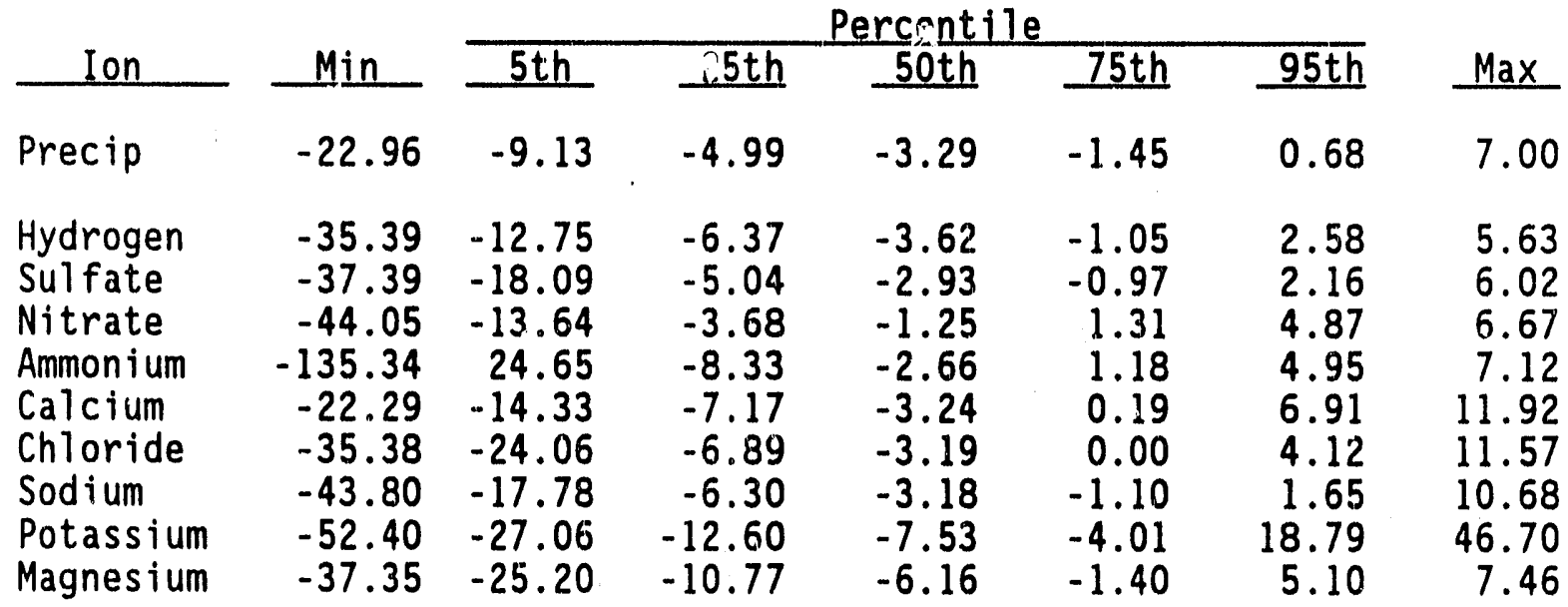




\subsection{REFERENCES}

Barchet, W. R. 1987. "Acidic Deposition and its Gaseous Precursors." Chapter 5 in NAPAP Interim Assessment, The Causes and Effects of Acidic Deposition, Vol III: Atmospheric Processes and Deposition. U.S. Government Printing Office, Washington, DC.

Barchet, W. R., A. R. 01 sen, D. S. Daly, and D. B. Carr. 1987a. "Temporal Changes in Wet Deposition for Eastern North America from 1980 Through 1984." Proceedings of EMEP Workshop on Data Analys is and Presentation. Cologne, Federal Republic of Germany, June 15-17, 1987. Norwegian Institute for Air Research, Lillestrom, Norway.

Barchet, W. R., A. R. 01 sen, and D. W. Enge1. 1987b. "Spatial Patterns in Wet Deposition for Eastern North America: A 1980-1984 Composite." Proceedings of EMEP Workshop on Data Analys is and Presentation. Cologne, Federal Republic of Germany, June 15-17, 1987. Norwegian Institute for Air Research, Lillestrom, Norway.

Barrie, L. A., and J. M. Hales. 1984. "The Spatial Distribution of Precipitation Acidity and Major Ions: Wet Deposition in North America During 1980." Tellus 36B:333-355.

Bigelow, D. S. 1984. NADP Instruction Manual: NADP/NTN Site Selection and Installation. Natural Resource Ecology Laboratory, Colorado State University, Fort Collins, Colorado.

Bilonick, R. A. 1983. "Risk Qualified Maps of Hydrogen Ion Concentration for the New York State Area for 1966-1978." Atmos. Environ. 17:2513-2524.

Bilonick, R. A. 1985. "The Space-time Distribution of Sulfate Deposition in the Northeastern United States." Atmos. Environ. 19:1829-1845.

Bilonick, R., and D. Nichols. 1983. "Temporal Variations in Acid Precipitation over New York State." Atmos. Environ. 17:1062-1072.

Burrough, P. A. 1986. Principles of Geographic Information Systems for Land Regime Assessment. Glarenden Press, Oxford.

Clark, I. 1979. Practical Geostatistics. Applied Science Publishers, London.

Cogbi11, C. V., and G. E. Likens. 1974. "Acid Precipitation in the Northeastern United States." Water Resources Research 10:1133-1137.

Creutio, J. D., and C. Obled. 1982. "Objective Analyses and Mapping Techniques for Rainfall Fields: An Objective Comparison." Water Resources Research 18:413-431. 
Dana, M. T., and R. C. Easter. 1987. "Statistical Summary and Analyses of Event Precipitation Chemistry from the MAP3S Network." Atmos. Environ. $21: 113-128$.

David, M. 1977. Geostatistical Ore Reserve Estimation. Elsevier, New York.

Dietz, E. J., and T. J. Killeen. 1981. "A Nonparametric Multivariate Test for Monotone Trend with Pharmaceutical Applications." $\mathrm{J}$. of the American Statistical Association 76(373)169-174.

Endlich, R. M., B. P. Eynon, R. J. Ferek, A. D. Valdes, and C. Maxwell. 1986. Statistical Analys is of Precipitation Chemistry Measurements Over the Ecosystem United States. UAPSP-112, Electric Power Research Institute, Paln A1 to, CA.

Endlich, R. M., B. P. Eynon, R. J. Ferek, A. D. Valdes, and C. Maxwell. 1988. "Statistical Analysis of Precipitation Chemistry Measurements Over the Eastern United States. Part I: Seasonal and Regional Patterns and Correlations." Applied Meteor. 27:1322-1333.

Environmental Protection Agency (EPA). 1990. National Air Quality and Emissions Trends Report, 1988. EPA/450/4/90/002, U.S. Environmental Protection Agency, Research Triangle Park, North Carolina.

Erb, T. A., J. C. Simpson, and A. R. 01 sen. 1989. 1987 Annual and Seasonal Data Summaries from Acid Deposition System Data Base. EPA/600/4-90/018, U. S. Environmental Protection Agency, Washington, D.C.

Eynon, B. P. 1988. "Statistical Analysis of Precipitation Chemistry Measurements Over the Eastern United States. Part II: Kriging Analysis of Regional Patterns and Trends." J.Applied Meteor. 27:1334-1343.

Eynon, B., and P. Switzer. 1983. "The Variability of Rainfall Acidity." Canadian Journal of Statistics 11:11-24.

Finkelstein, P. L. 1984. "The Spatial Analysis of Acid Precipitation Data." J. of Climate and Applied Meteor. 23:52-62.

Finkelstein, P. L., and S. K. Seilkop. 1981. "Interpolation Error and the Spatial Variability of Acid Precipitation." Proceedings of the Seventh Conference on Probability and Statistics in Atmospheric Sciences, pp. 206-212. Amer. Meteor. Soc., Boston.

Galloway, J. N., and D. M. Whelpdale. 1980. "An Atmospheric Sulfur Budget for Eastern North America." Atmos. Environ. 14:409-417.

Gandin, L. S. 1965. Objective Analysis of Meteorological Fields. Translated from Russian by R. Hardin, p. 242, Israel Program for Scientific Translation, Jerusalem. 
Gatz, D. F., and D. G. Naiman. 1980. "Spatial Variability in Rainwater Impurities in Mesoscale Events." Paper presented at Symposium on Intermediate Range Atmospheric Transport Processes and Technology Assessment, October 1-3, 1980, Gatlinburg, Tennessee.

Gilbert, R. 0. 1987. Statistical Methods for Environmental Pollution Monitoring. Van Nostrand Reinhold Company Inc., New York.

Granat, L. 1978. "Sulfate in Precipitation as Observed by the European Atmospheric Chemistry Network." Atmos. Environ. 12:413-424.

Guertin, K., J-P. Villeneuve, S. Deschenes, and G. Jacques. 1988. "The Choice of Working Variables in the Geostatistical Estimation of the Spatial Distribution of Ion Concentration from Acid Precipitation." Atmos. Environ. $22: 2787-2801$.

Hidy, G. M., D. A. Hansen, R. C. Henry, K. Ganesan, and J. Collins. 1984. "Trends in Historical Acid Precursor Emissions and Their Airborne and Precipitation Products." J.Air Poll. Control Assoc. 31:333-354.

Hirsch, R. M., J. R. Slack, and R. A. Smith. 1982. "Techniques of Trend Analysis for Monthly Water-quality Data." Water Resources Research $18(1): 107-121$.

Hirsch, R. M., and J. R. Slack. 1984. "A Nonparametric Trend Tesí for Seasonal Data with Serial Dependence." Water Resources Research $20(6): 727-732$.

Journel, A. G., and Ch. Huijbregts. 1978. Mining Geostatistics. Academic Press, New York.

Lenton, R. L., and I. Rodriquez-Iturbe. 1977. "Rainfall Network Systems Analysis: The Optimal Estimation of Total Aerial Storm Depth." Water Resources Research 13:825-836.

Likens, G. E., F. H. Bormann, R. S. Pierce, J. S. Eaton, and R. E. Munn. 1984. "Long Term Trends in Precipitation Chemistry at Hubbard Brook, New Hampshire." Atmos. Environ. 18:2641-2647.

Likens, G. E., and T. J. Butler. 1981. "Recent Acidification of Precipitation in North America." Atmos. Environ. 15:1103-1109.

Matheron, G. 1971. The Theory of Regionalized Variables and its Applications. Ecole Des Mines, Fontainebleau, France.

McArthur, G. R., ed. 1983. The SCD Graphics Utilities. National Center for Atmospheric Research (NCAR), Boulder, Colorado.

Munger, J. W., and S. J. Eisenreich. 1983. "Continental-scale Variations in Precipitation Chemistry." Environ. Sci. Tech. 17(1):32A-42A. 
NADP. 1991. NADP/NTN Annual Data Summary--Precipitation Chemistry in the United States, 1990. Natural Resource Ecology Laboratory, Colorado State University, Fort Collins, Colorado.

National Research Council. 1986. Acjd Deposition Long Term Trends. National Academy Press, Washington, D.C.

Oehlert, G. W. 1984. A Statistical Analysis of the Trends in the Hubbard Brook Bulk Precipitation Chemistry Data Base. Tech. Report No 260, Series 2, Department of Statistics, Princeton University.

Oehlert, G. W. 1985. "Statistical Aspects of Acidification Trends." Ninth Conference on Probability and Statistics in Atmospheric Sciences, pp. 48-54. Amer. Meteor. Soc., Boston.

01 ea, R. A. 1975. Optimum Mapping Techniques Using Regionalized Variable Theory. Series on Spatial Analysis, No. 2, Kansas Geological Survey, Lawrence, Kansas.

01 sen, A. R. 1989. 1986 Wet Deposition Temporal and Spatial Patterns in North America. PNL-6933, Pacific Northwest Laboratory, Richland, Washington.

01 sen, A. R., E. C. Voldner, D. S. Bigelow, W. H. Chan, T. L. Clark, M. A. Lusis, P. K. Misra, and R. J. Vet. 1990. "Unified Wet Deposition Data Summaries for North America: Data Summary Procedures and Results for 1980 1986." Atmospheric Environment 3:661-672.

01 sen, A. R., and A. L. Slavich. 1985. Acid Precipitation in North America: 1983 Annual Data Summary from Acid Deposition System Data Base. EPA/600/4-85/061, U.S. Environmental Protection Agency, Research Triangle Park, NC.

01 sen, A. R., and A. L. Slavich. 1986. Acid Precipitation in North America: 1984 Annual Data Summary frnm Acid Deposition System Data Base. EPA/600/4-86/033, U.S. Environmental Protection Agency, Research Triangle Park, North Carolina.

01 sen, A. R., and C. R. Watson. 1984. Acid Precipitation in North America: 1980, 1981 and 1982 Annual Data Summaries Based on Acid Deposition System Data Base. EPA/600/7-84/097, U.S. Environmental Protection Agency, Research Triangle Park, NC.

Pack, D. H, 1980. "Precipitation Chemistry Patterns: A Two-network Data Set." Science 208:1143-1145.

Peters, N. E., and J. E. Bonelli. 1982. Chemical Composition of Bulk Precipitation in the North-central and Northeastern United States, December 1980 Through February 1981. U.S. Geological Survey Circular 874, U.S. Government Printing Office, Washington D.C.

Ripley, B. D. 1981. Spatial Statistics. John Wiley and Sons, New York. 
Robertson, J. K., and J.W. Wilson. 1985. Design of the National Trends Network for Monitoring the Chemistry of Atmospheric Precipitation. U.S. Geological Survey Circular 694, U.S. Government Printing Office, Washington D.C.

Rodriquez-Iturbe, I., and J. M. Mejia. 1974. "The Design of Rainfall Networks in Time and Space." Water Resources Research 10:713-728.

Rodhe, H., and L. Granat. 1984. "An Evaluation of Sulfate in European Precipitation 1955-1982." Atmos. Environ. 18:2627-2639.

Schertz, T. L., and R. M. Hirsch. 1985. Trend Analys is of Weekly Acid Rain Data - 1978-83. U.S. Geological Survey water Resources Investigations Report 85-4211, U.S. Geological Survey, Denver.

Seilkop, S. K., and P. L. Finkelstein. 1987. "Acid Precipitation Patterns and Trends in Eastern North America, 1980-1984." J. Climate and Applied Meteor. 26:980-994.

Simpson, J. C., and A. R. 01 sen. 1990. Uncertainty in North American Wet Deposition I sopleth Maps: Effect of Site Selection and Valid Sample Criteria. EPA/600/4-90/005, U. S. Environmental Protection Agency, Research Triangle Park, North Carolina.

Simpson, J. C., and A. R. 01 sen. 1990. 1987 Wet Deposition Temporal and Spatial Patterns in North America. PNL-7208, Pacific Northwest Laboratory, Richland, Washington.

Stensland, G. J., and R. G. Semonin. 1982. "Another Interpretation of the pH Trend in the United States." Bull. Amer. Met. Soc. 63:1277-84.

Sweeney, J. K., and A. R. 01 sen. 1987. Acid Precipitation in North America: 1985 Annual and Seasonal Data Summaries from Acid Deposition System Data Base. EPA/600/4-87/035, U.S. Environmental Protection Agency, Research Triangle Park, North Carolina.

Sweeney, J. K., and A. R. 01 sen. 1989. Acid Precipitation in North Arierica: 1986 Annual and Seasonal Data Summaries from Acid Deposition System Data Base. EPA/600/4-89/005, U.S. Environmental Protection Agency, Research Triangle Park, North Carolina.

Venkatram, A. 1988. "On the Use of Kriging in the Spatial Analysis of Acid Precipitation Data. Atmos. Environ. 22:1963-1975.

Venkatram, A. 1989. The Incorporation of Semi-empirical Lonq-Range Transport Models into the Spatial Analys is of Acid Precipitation Data. ENSR Doc. No. 2460-007-100, ENSR Consulting and Engineering, Camarillo, Cal ifornia.

Vong, R., S. Cline, G. Reams, J. Bernert, D. Charles, J. Gibson, T. Haas, J. Moore, R. Husar, A. Olsen, J. Simpson, and S. Seilkop. 1989. Regional Analys is of Wet Deposition for Effects Research. EPA/600/3-89/030, U.S. Environmental Protection Agency, Research Triangle Park, North Carolina. 
Wampler, S. J., and A. R. 01 sen. 1987. "Spatial Estimation of Annual Wet Acid Deposition Using Supplemental Precipitation Data." Tenth Conference on Probability and Statistics, pp. 248-251. Amer. Meteor. Soc.

Watson, C. R., and A. R. 01 sen. 1984. Acid Deposition System (ADS) for Statistical Reporting. System Design and User's Code Manual.

EPA-600/8-84/023, U.S. Environmenta1 Protection Agency, Research Triangle Park, North Carolina.

World Meteorological Organization. 1970. The Planning of Meteorological Station Networks. Tech Note 111, Geneva.

Zemba, S. G., D. Golomb, and J. A. Fay. 1988. "Wet Sulfate and Nitrate Deposition Patterns in Eastern North America." Atmos. Environ. 22:2751-2761. 


\section{APPENDIX A}

TABLES AND FIGURES FOR SPATIAL AND TEMPORAL ANALYSIS OF CONCENTRATION AND PEPOSITION 

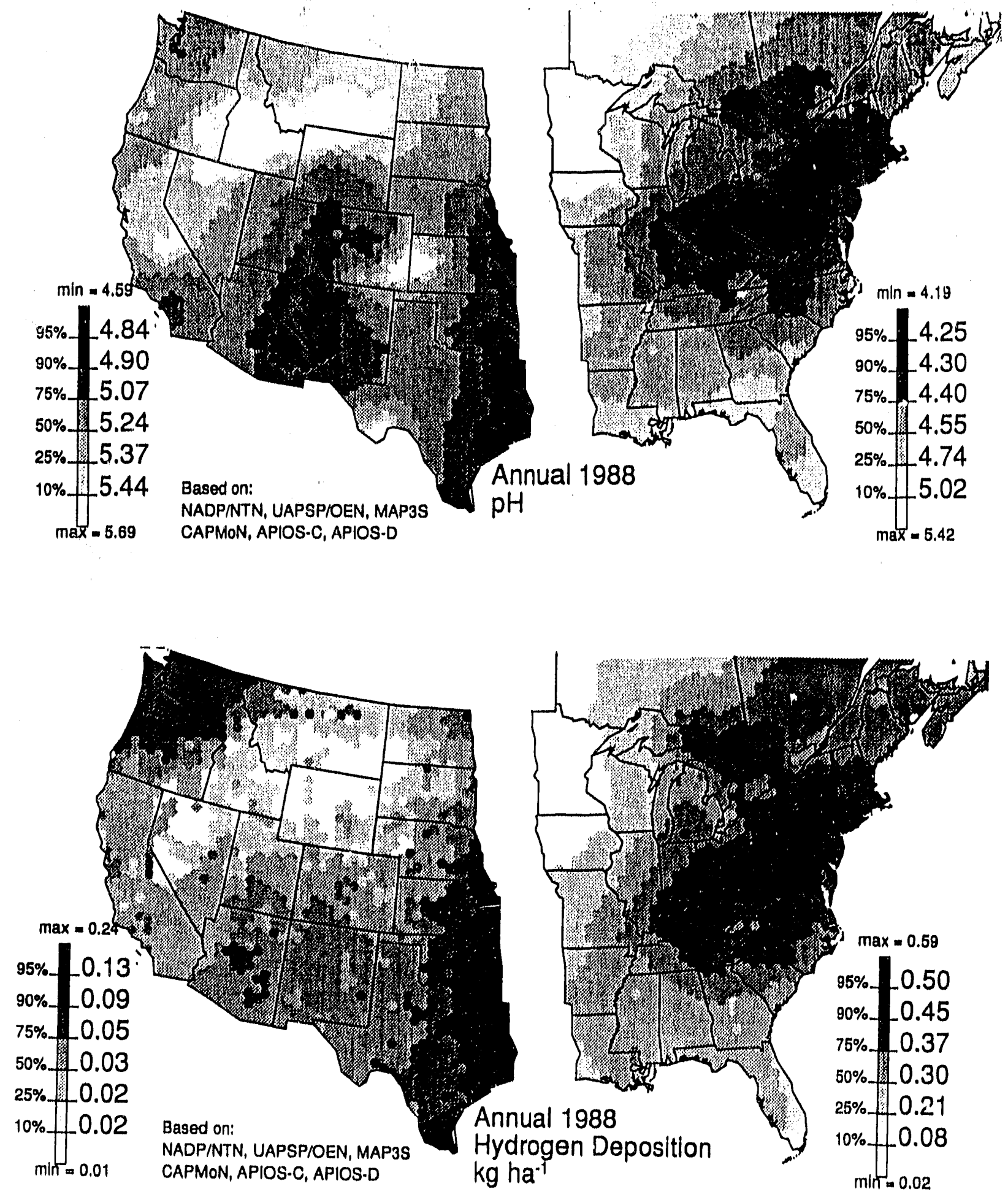

FIGURE A.1. Annual 1988 Spatial Distribution of Precipitation-weighted $\mathrm{pH}$ and Hydrogen Ion Deposition

\section{A.1}



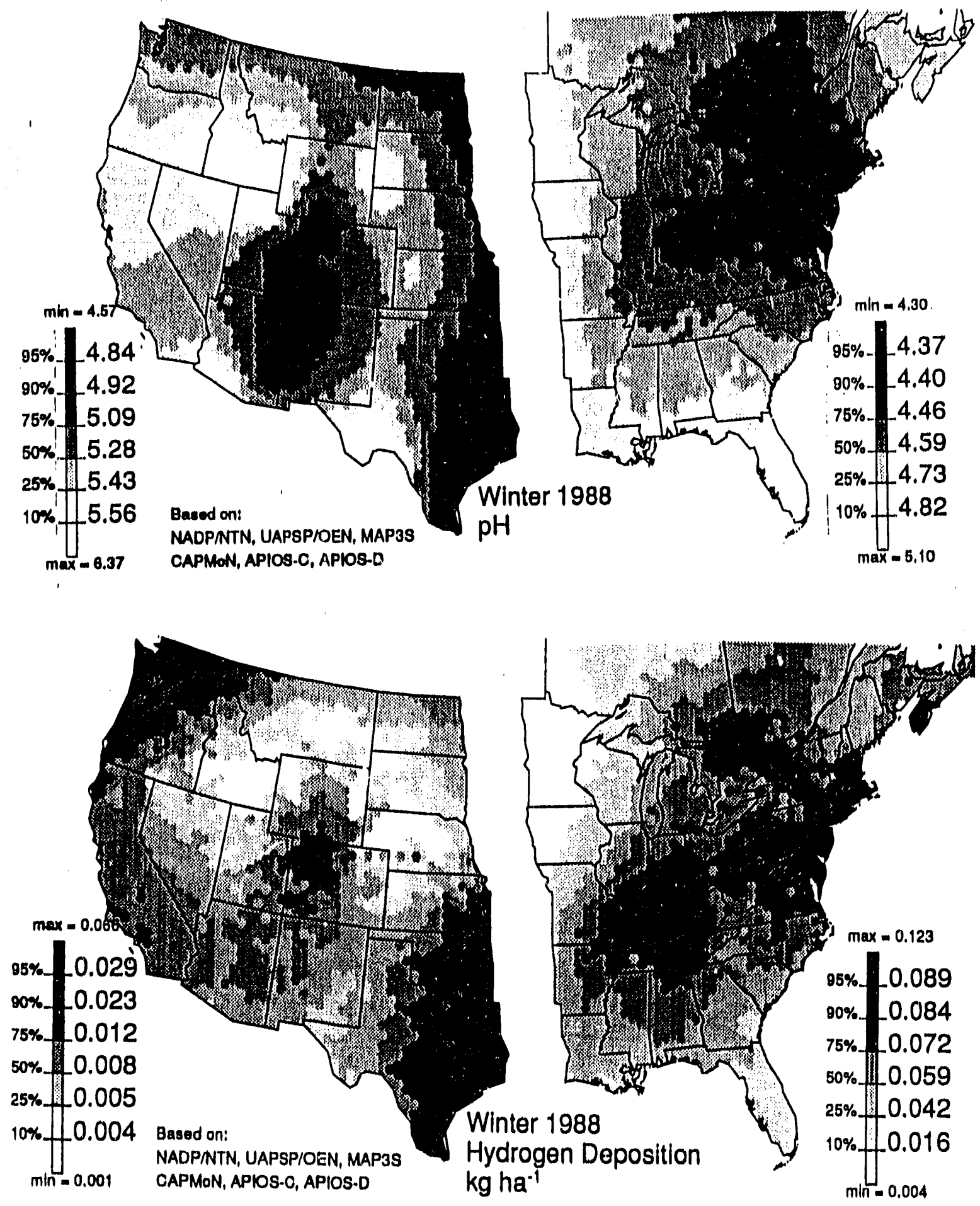

FIGURE A.2. Winter 1988 Spatial Distribution of Precipitation-weighted pH and Hydrogen Ion Deposition 

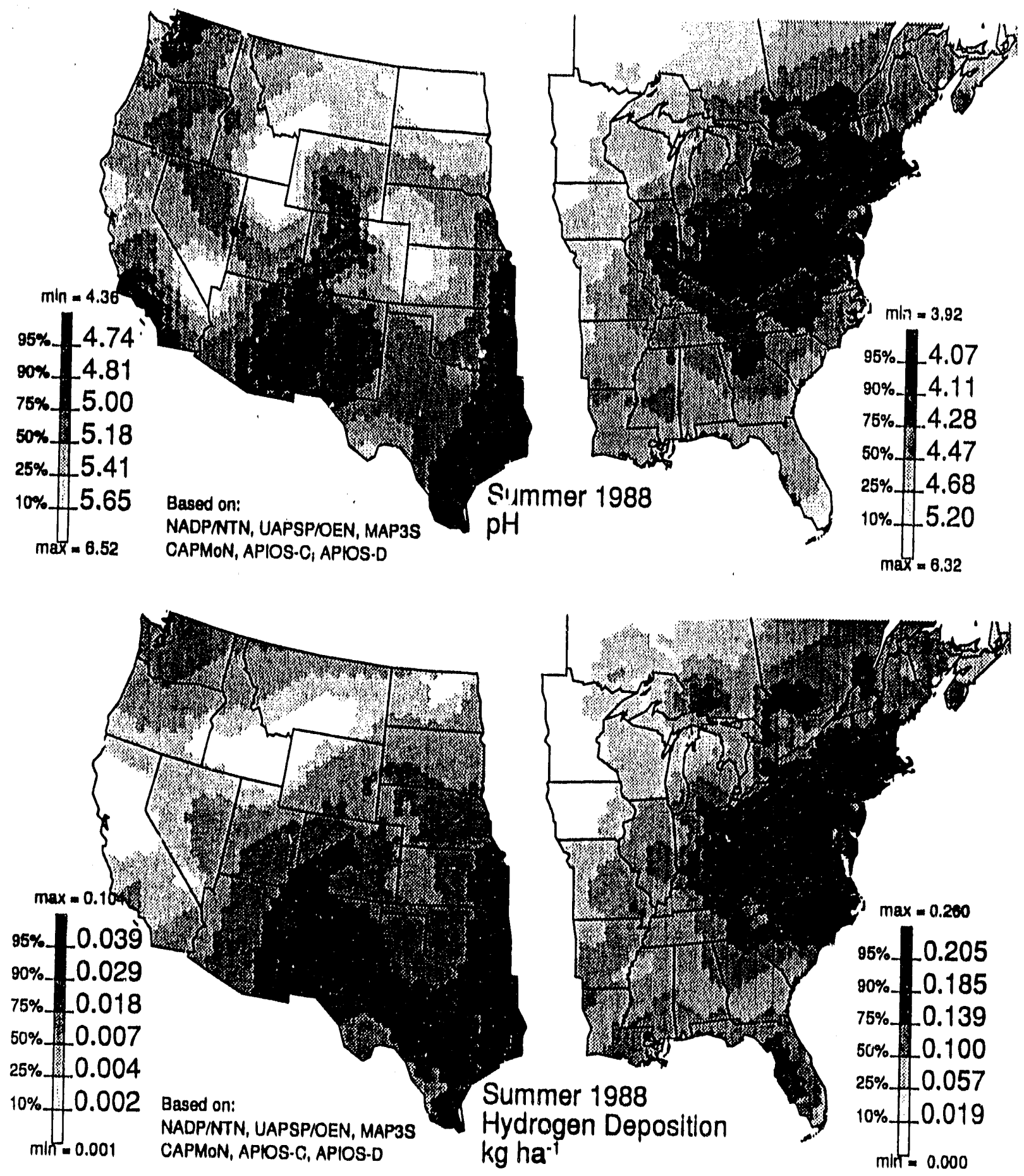

FIGURE A.3. Summer 1988 Spatial Distribution of Precipitation-weighted $\mathrm{pH}$ and Hydrogen Ion Deposition 

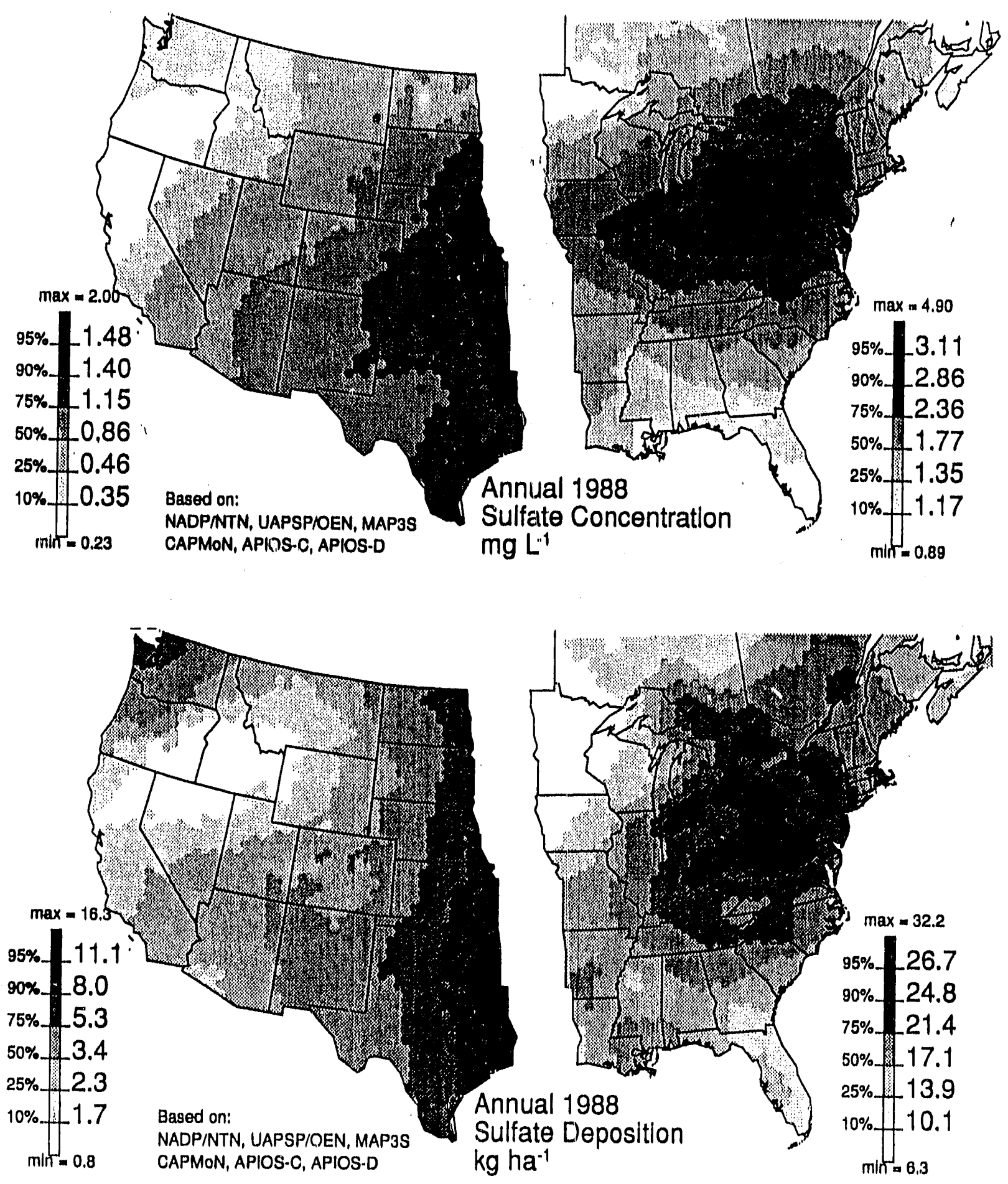

FIGURE A.4. Annual 1988 Spatial Distribution of Sulfate Precipitationweighted Concentration and Deposition 

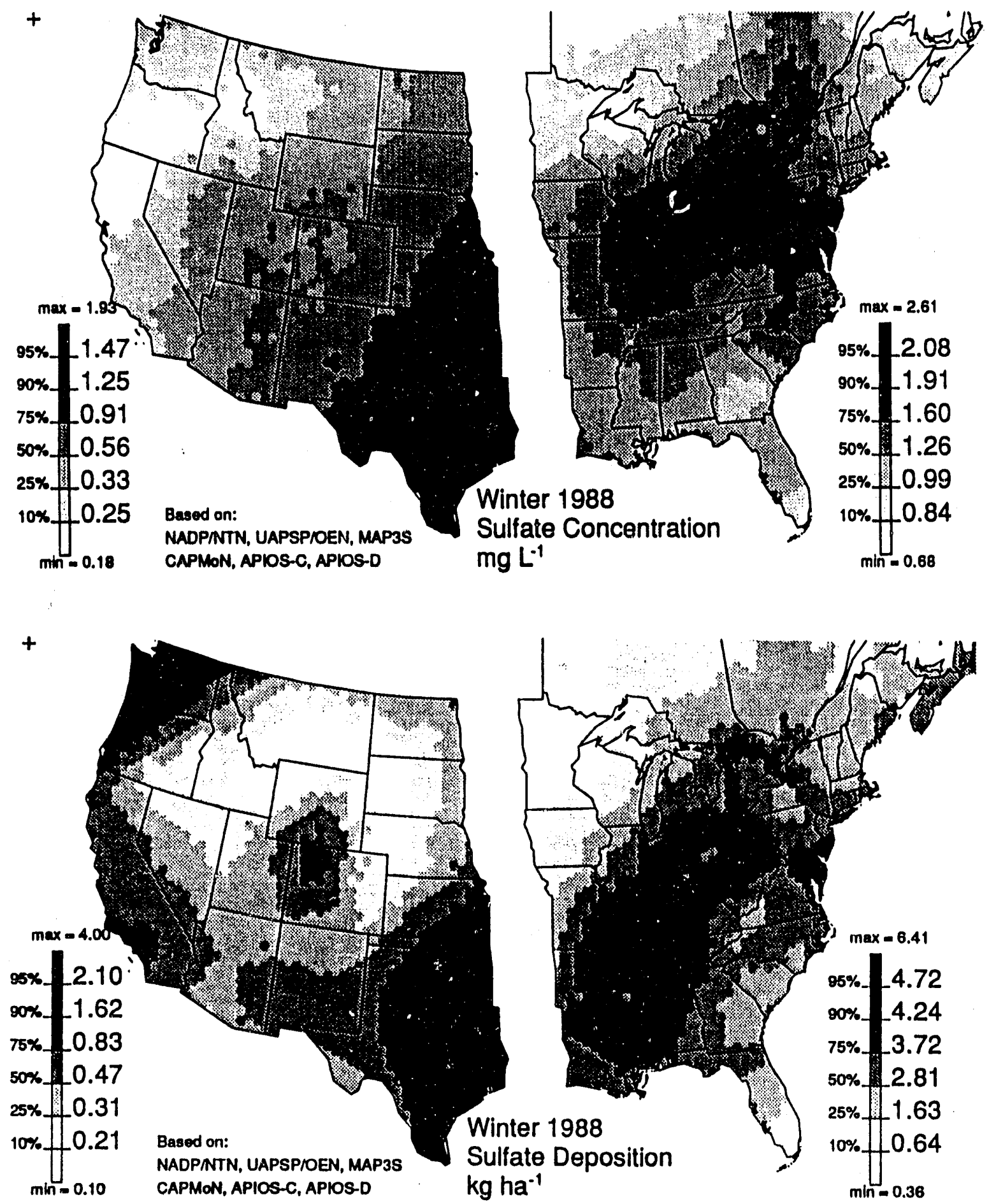

FIGURE A.5. Winter 1988 Spatial Distribution of Sulfate Precipitationweighted Concentration Deposition 


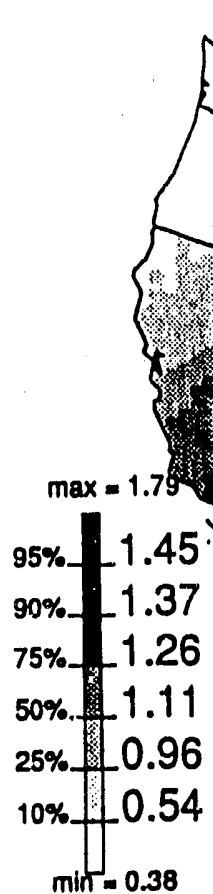

Based on:

NADPNTN, UAPSPNOEN, MAP3S

CAPMON, APIOS-C, APIOS-D

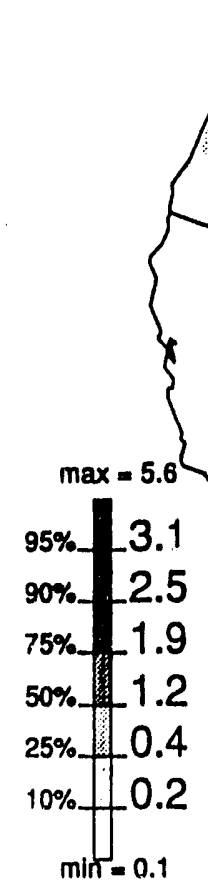

NADPNTN, UAPSPIOEN, MAP3S

CAPMON, APIOS-C, APIOS-D

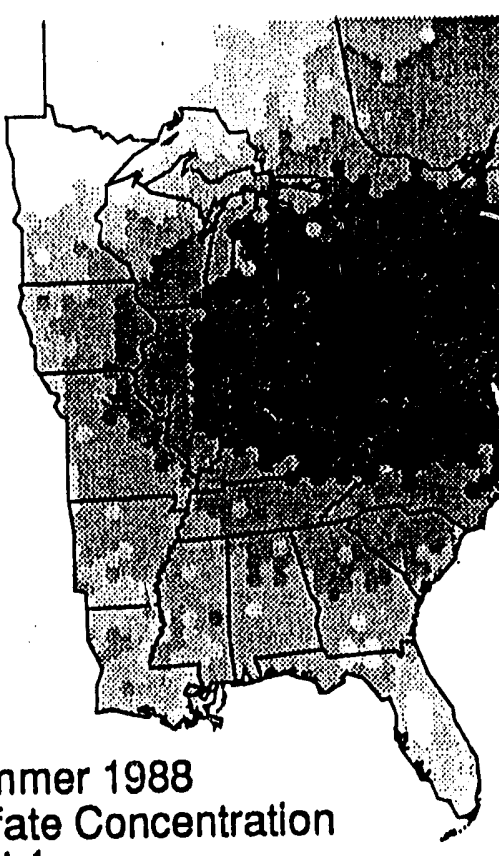

Sulfate Concentration $\mathrm{mg} \mathrm{L}^{-1}$
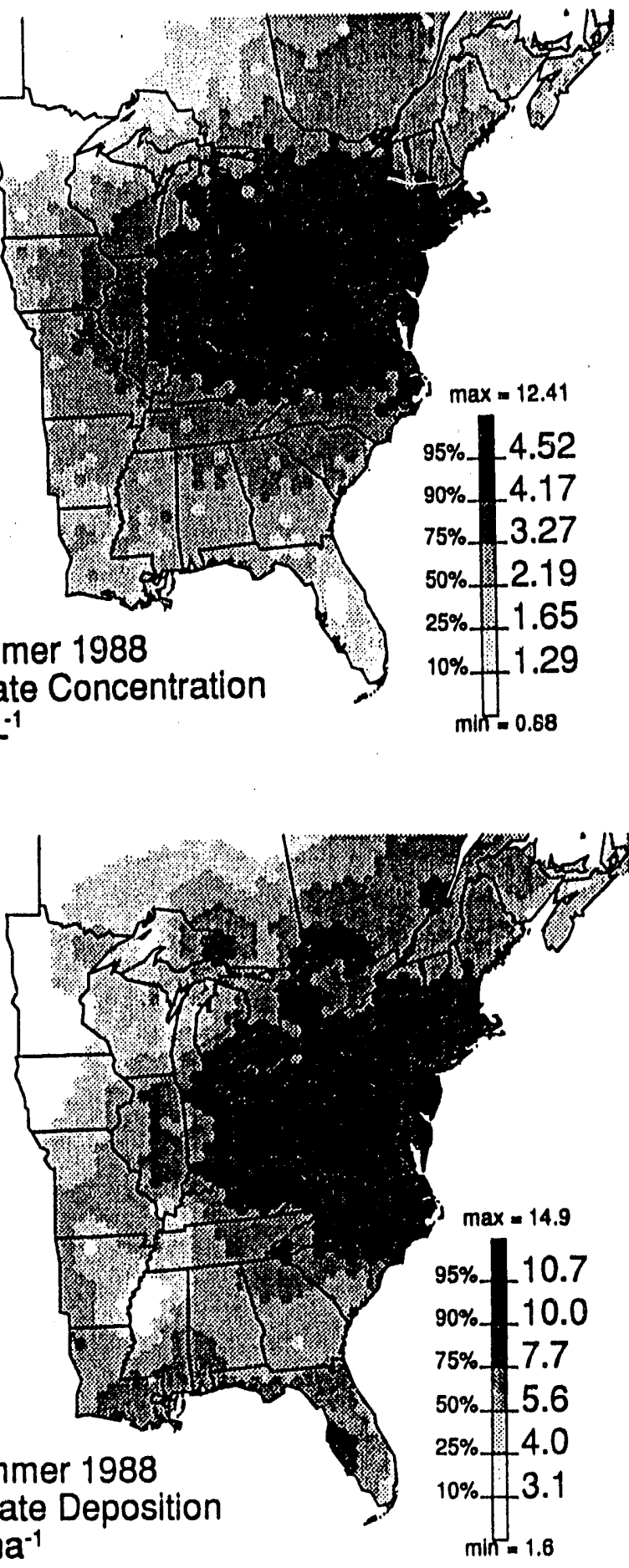

FIGURE A.6. Summer 1988 Spatial Distribution of Sulfate Precipitationweighted Concentration and Deposition 


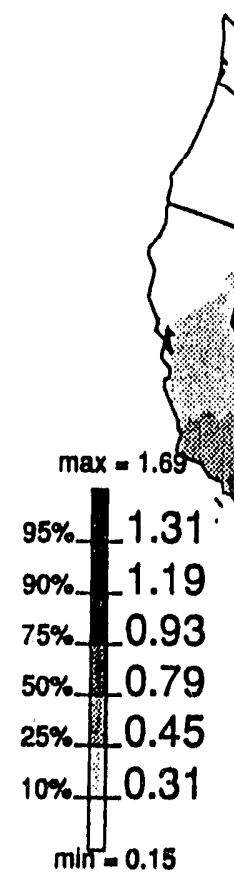

Based on: NADPNTN, UAPSPIOEN, MAPJS CAPMON, APIOS-C, APIOS-D

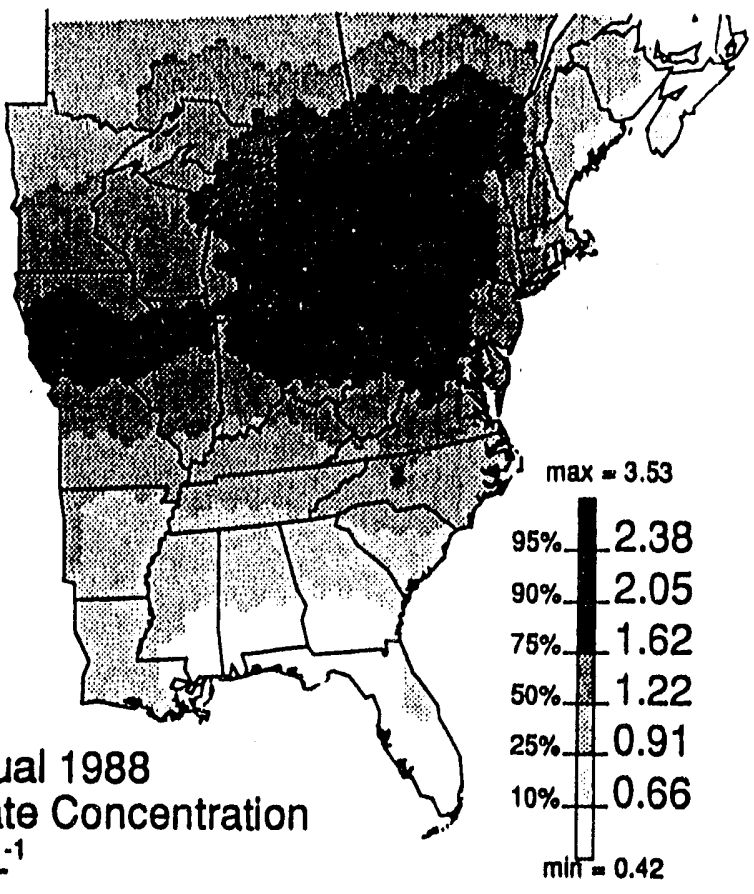

$\mathrm{mg} \mathrm{L}^{-1}$

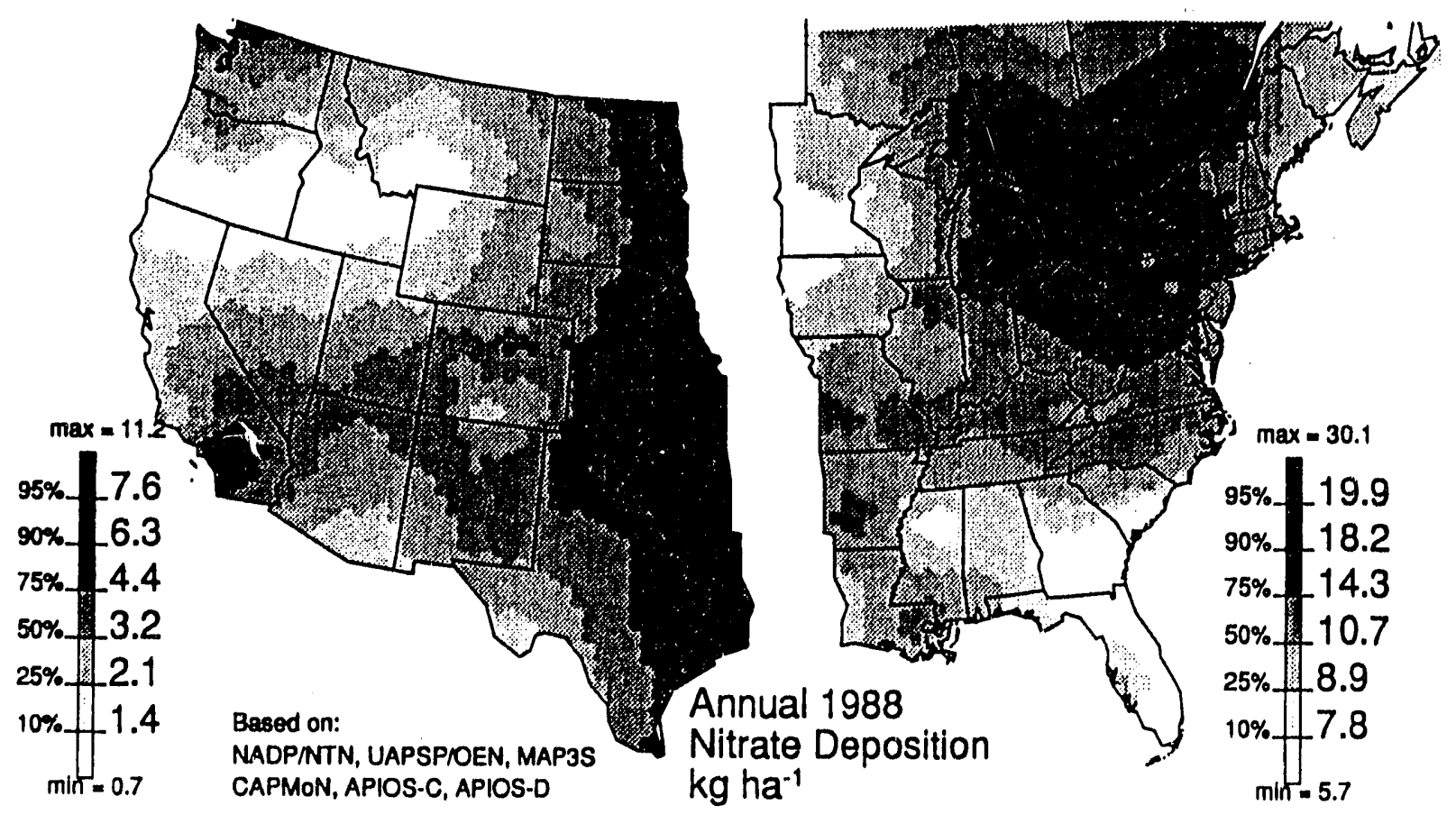

FIGURE A.7. Annual 1988 Spatial Distribution of Nitrate Precipitationweighted Concentration and Deposition 

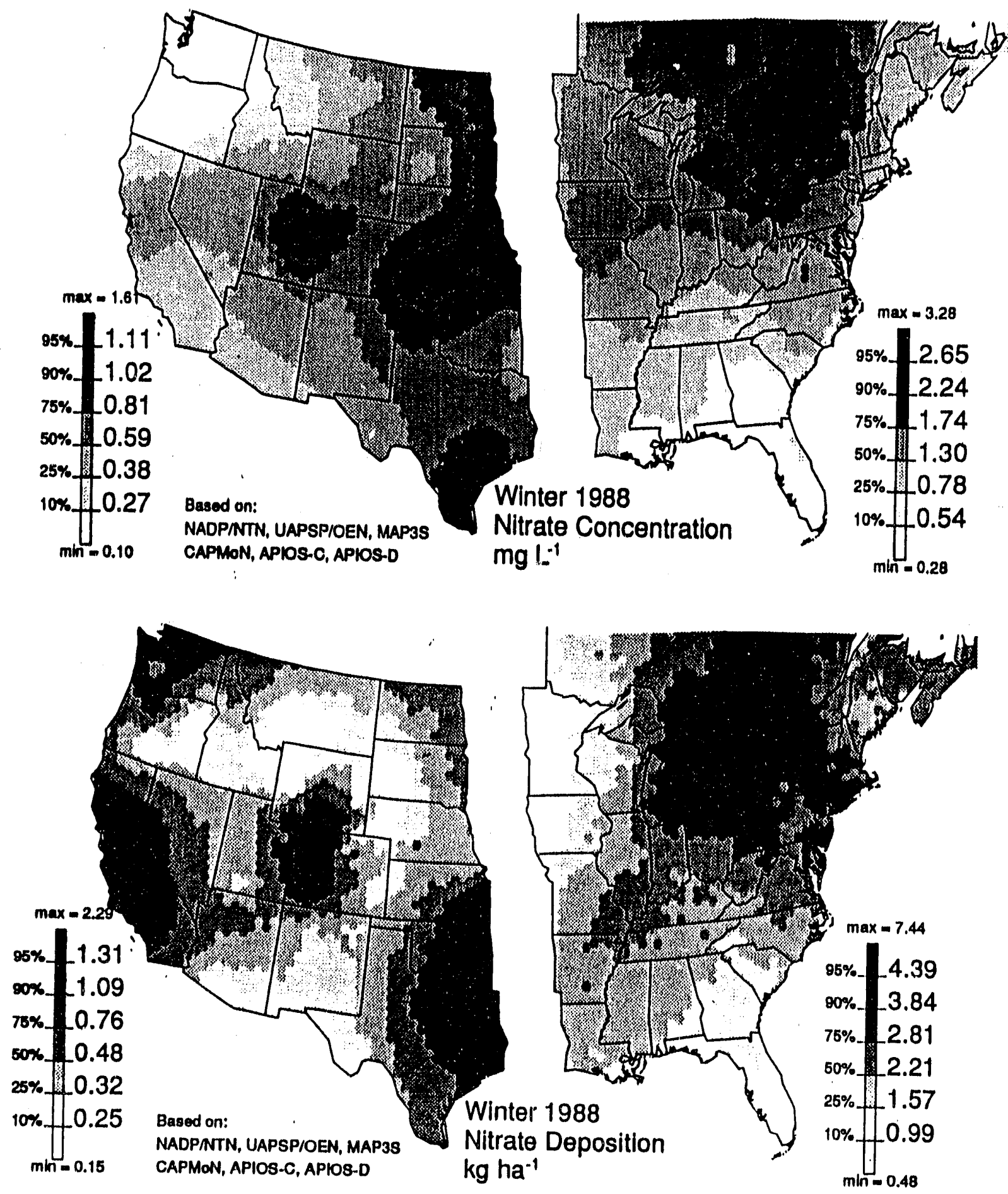

FIGURE A.8. Winter 1988 Spatial Distribution of Nitrate Precipitationweighted Concentration and Deposition 


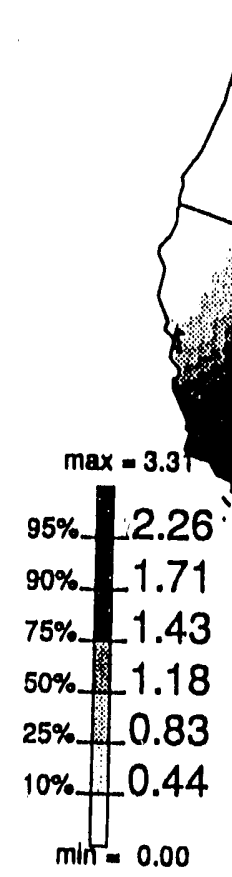

$\min =0.00$
Based on:

NADP/NTN, UAPSPIOEN, MAP3S CAPMON, APIOS-C, APIOS-D
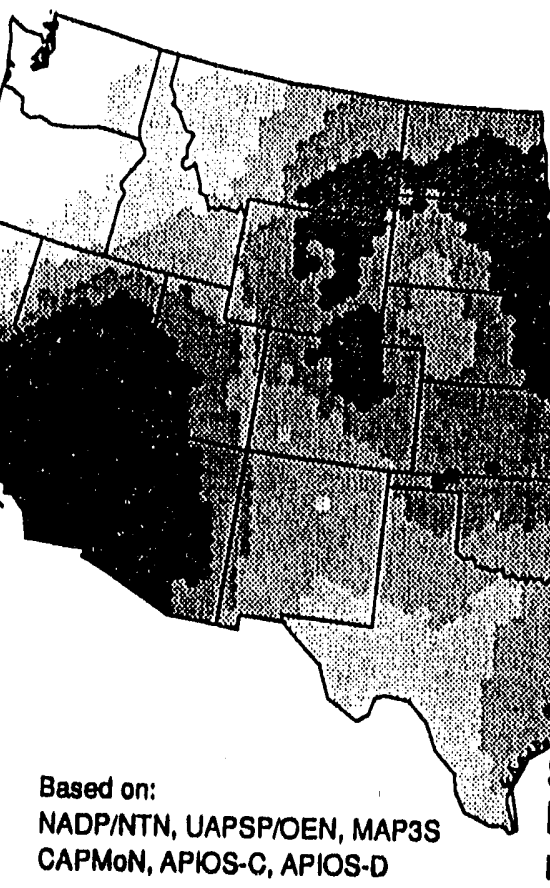

\%
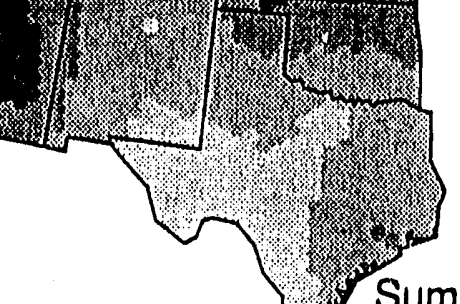

Summer 1988

Nitrate Concentration $\mathrm{mg} \mathrm{L}^{-1}$
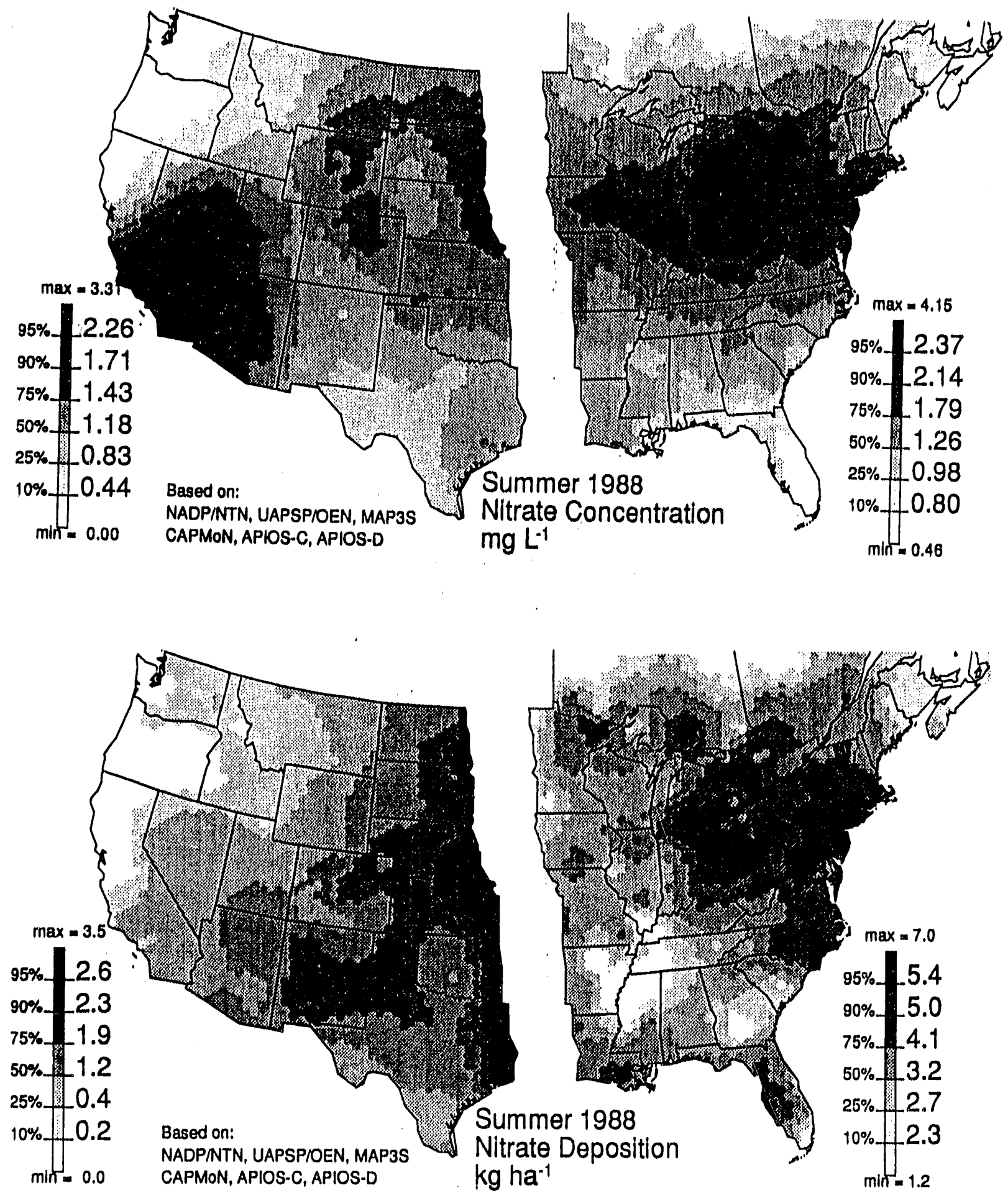

Based on:

NADPINTN, UAPSP/OEN, MAP3S

CAPMON, APIOS-C, APIOS-D
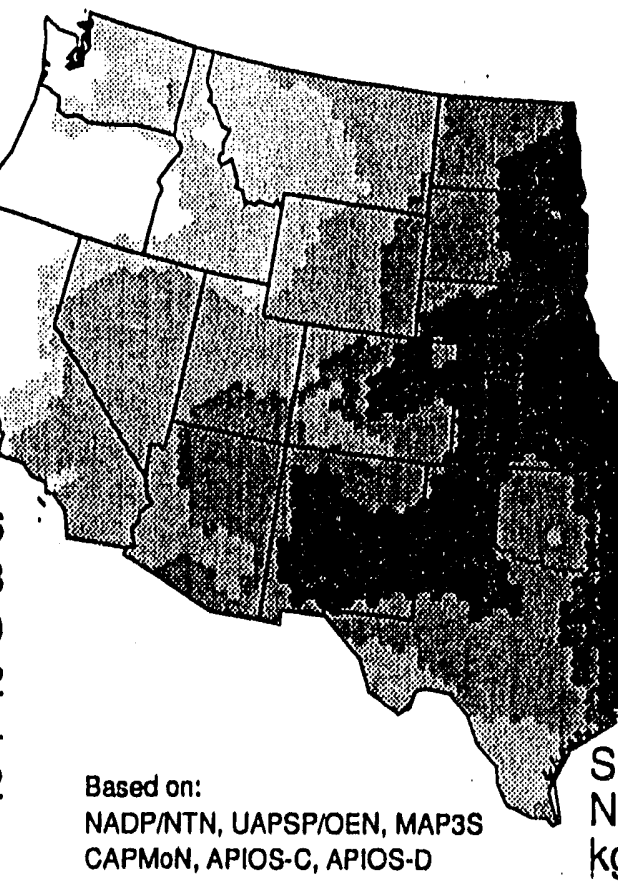


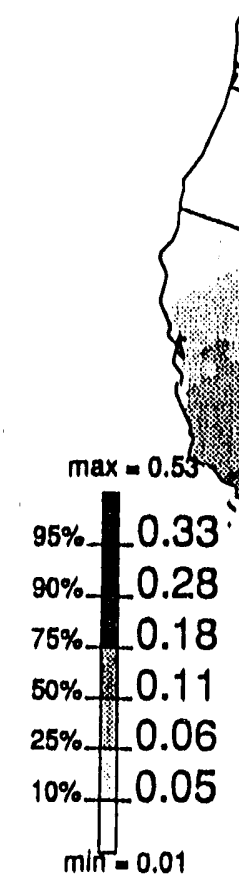

NADP/NTN, UAPSPIOEN, MAP3S CAPMON, APIOS C, APIOS-D

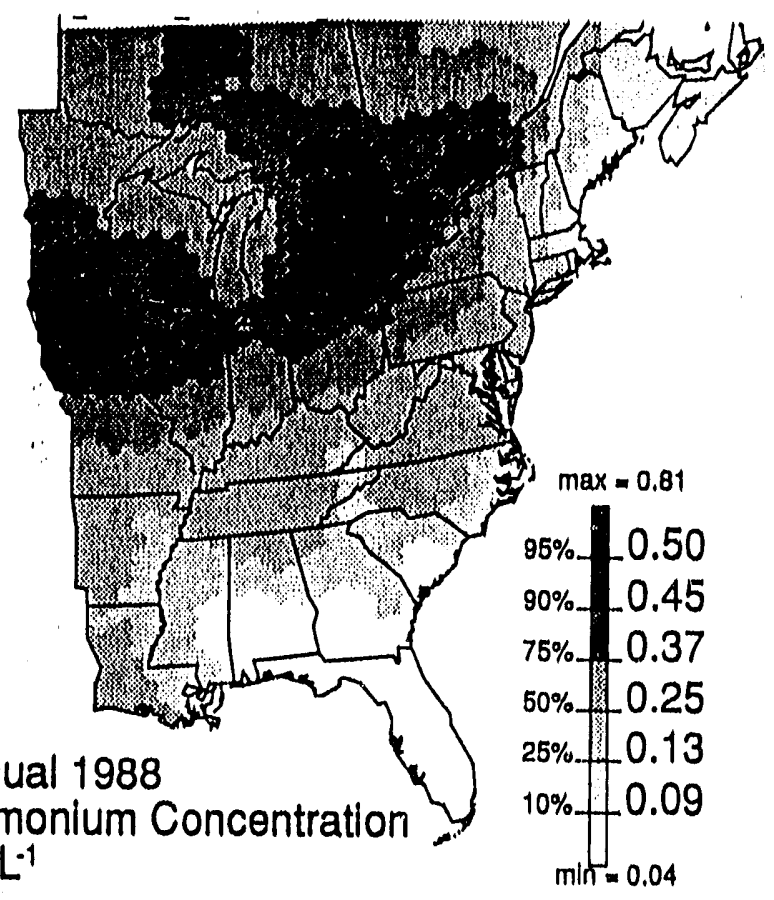

$\mathrm{mg} \mathrm{L}^{-1}$

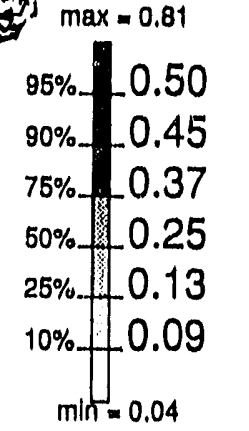

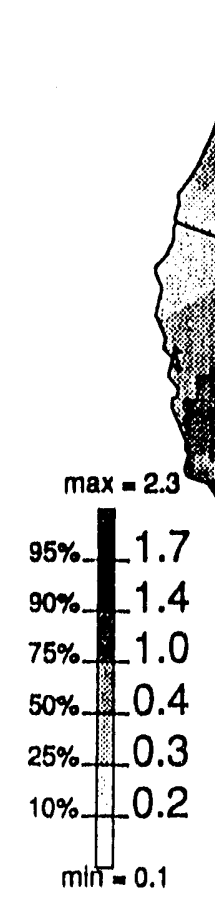

Based on

NADP/NTN, UAPSP/OEN, MAP'SS

CAPMON, APIOS-C, APIOS-D

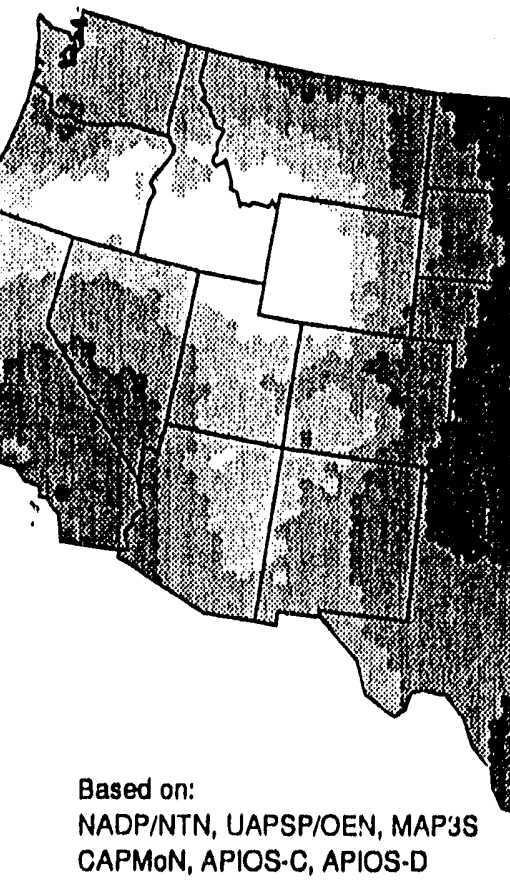

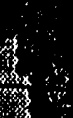
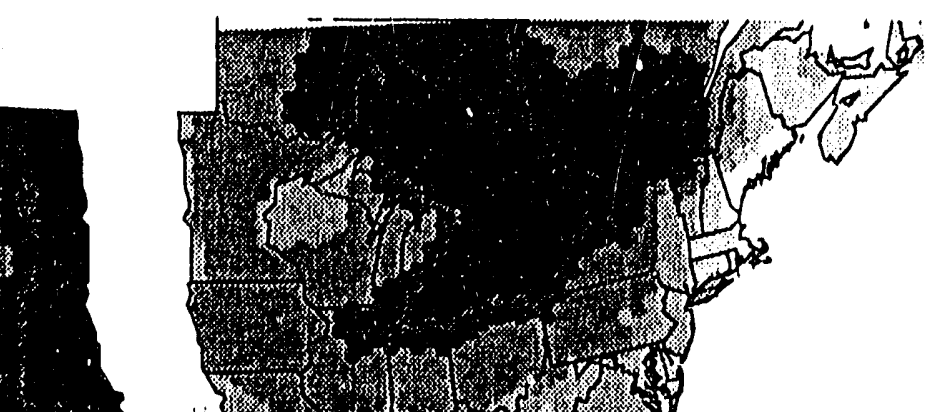

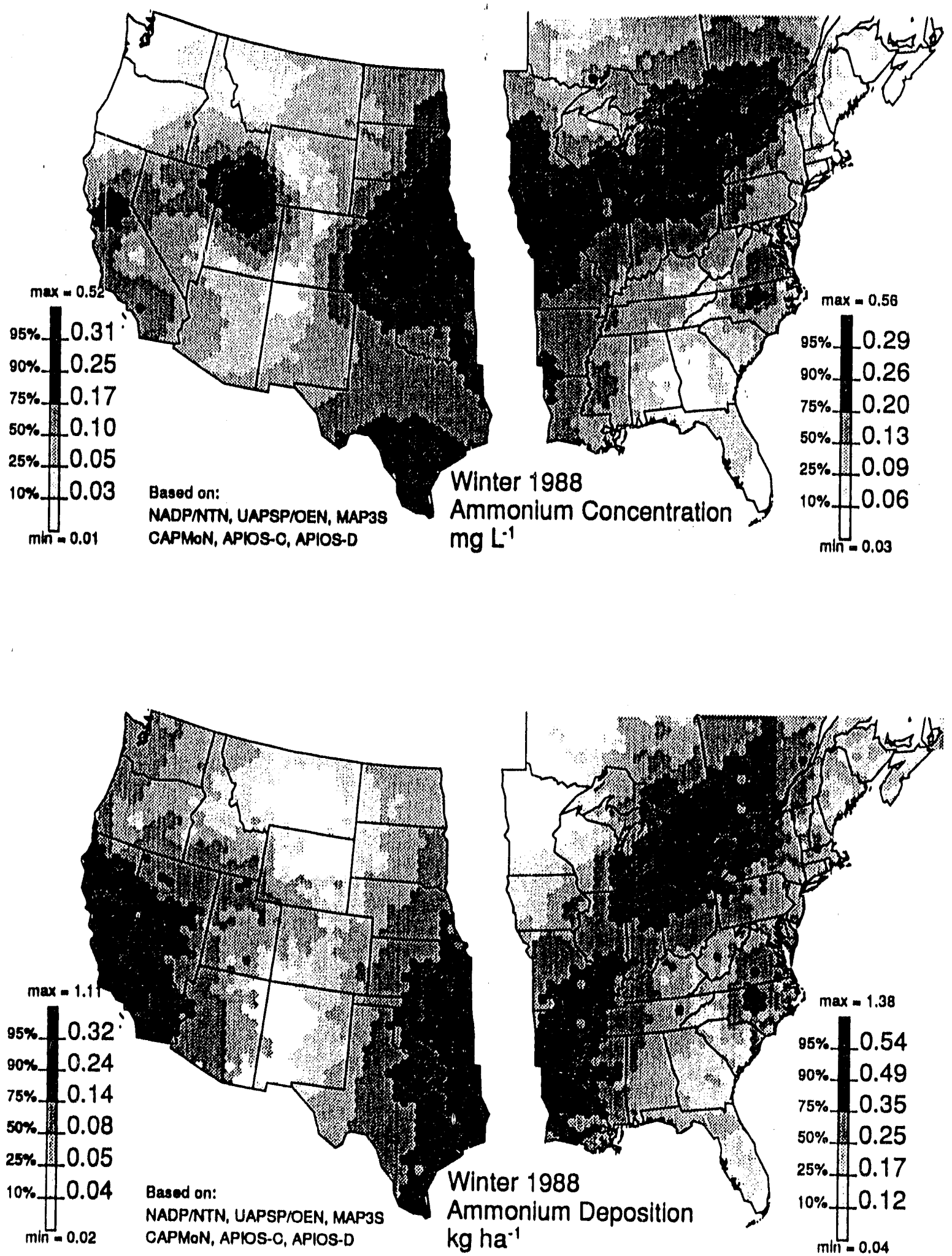

FIGURE A.11 Winter 1988 Spatial Distribution of Ammonium Precipitationweighted Concentration and Deposition

A. 11 

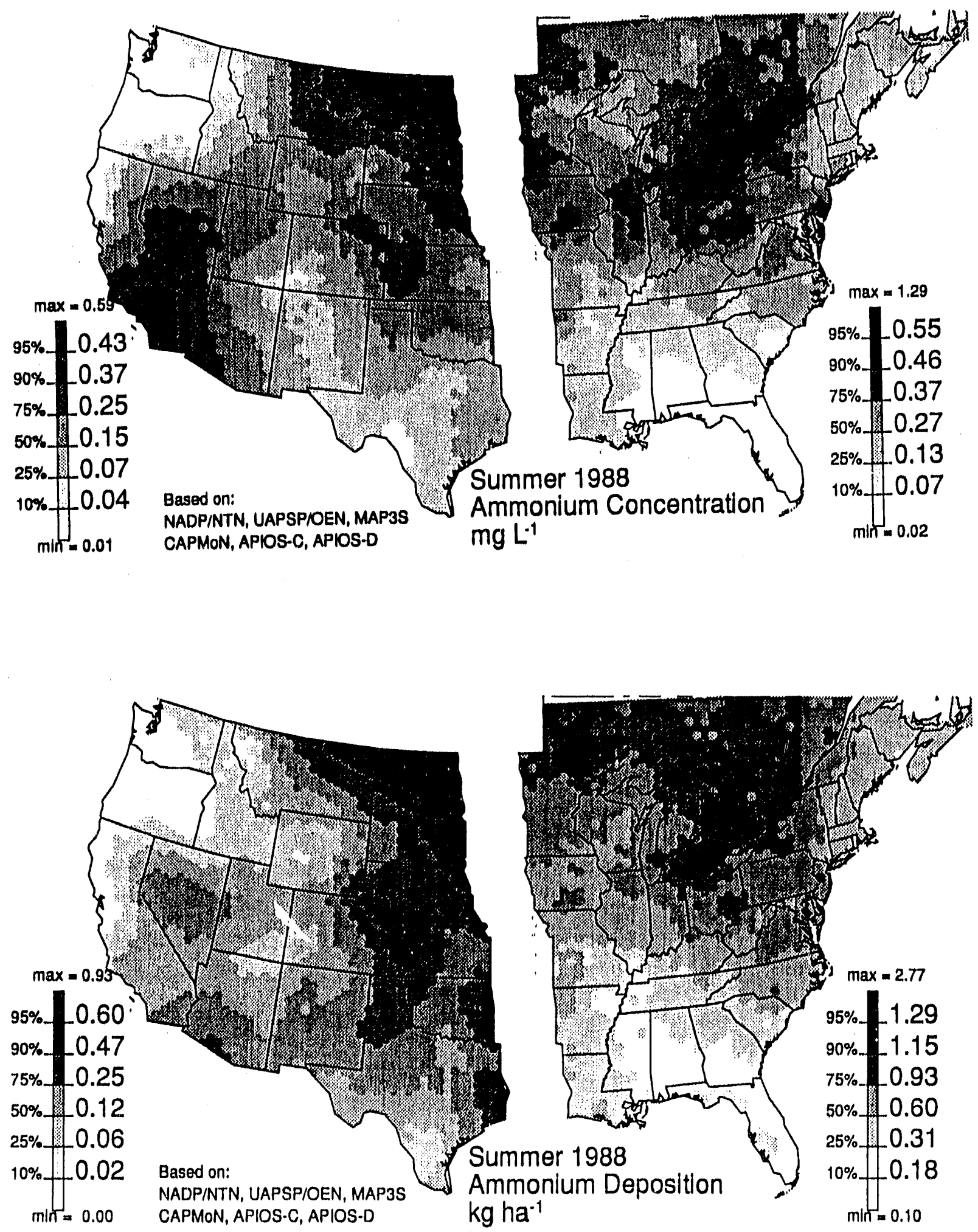

FIGURE A.12 Surmer 1988 Spatial Distribution of Ammonium Precipitationweighted Concentration and Deposition

\section{A. 12}



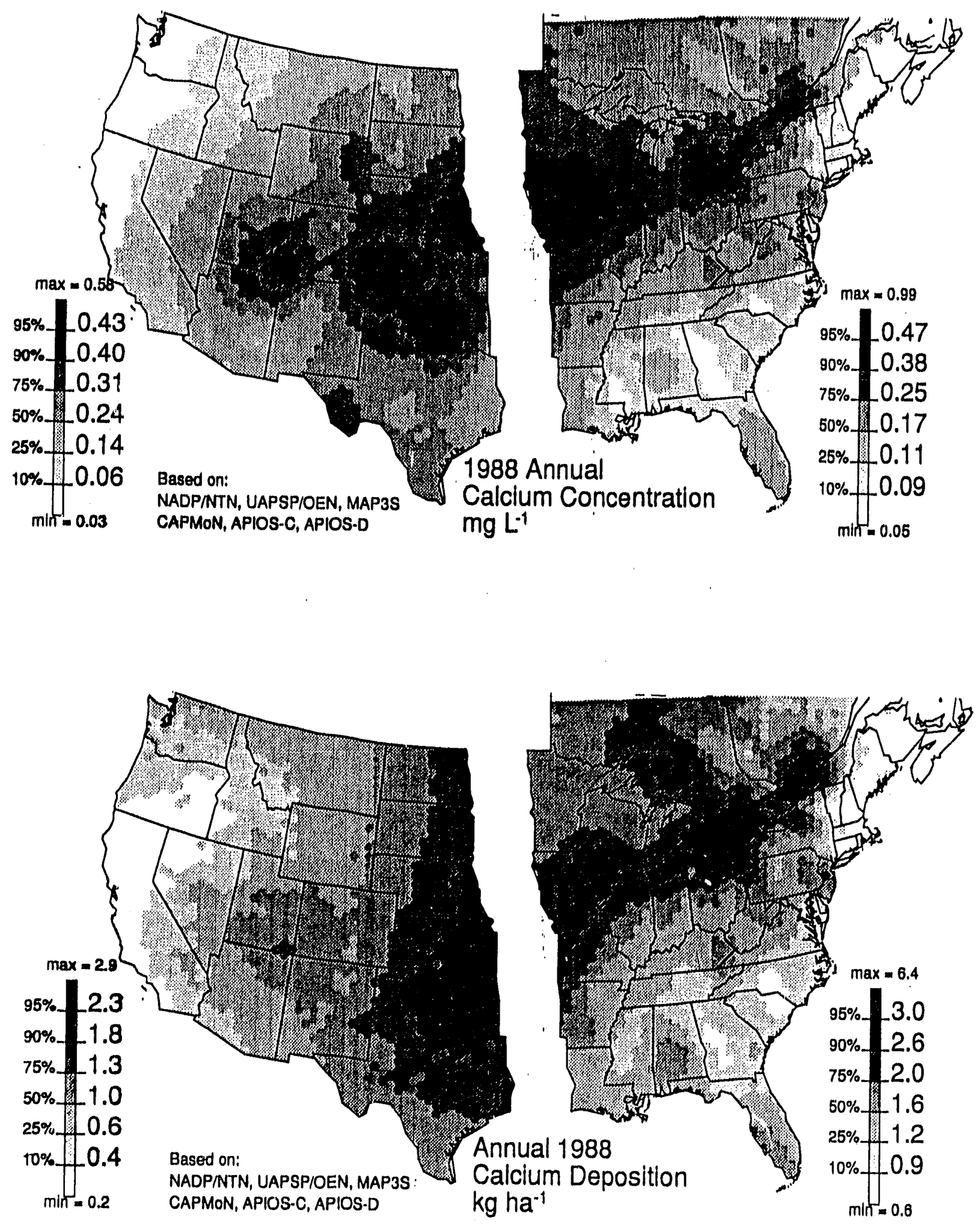

FIGURE A.13 Annual 1988 Spatial Distribution of Calcium Precipitationweighted Concentration and Deposition

\section{A. 13}



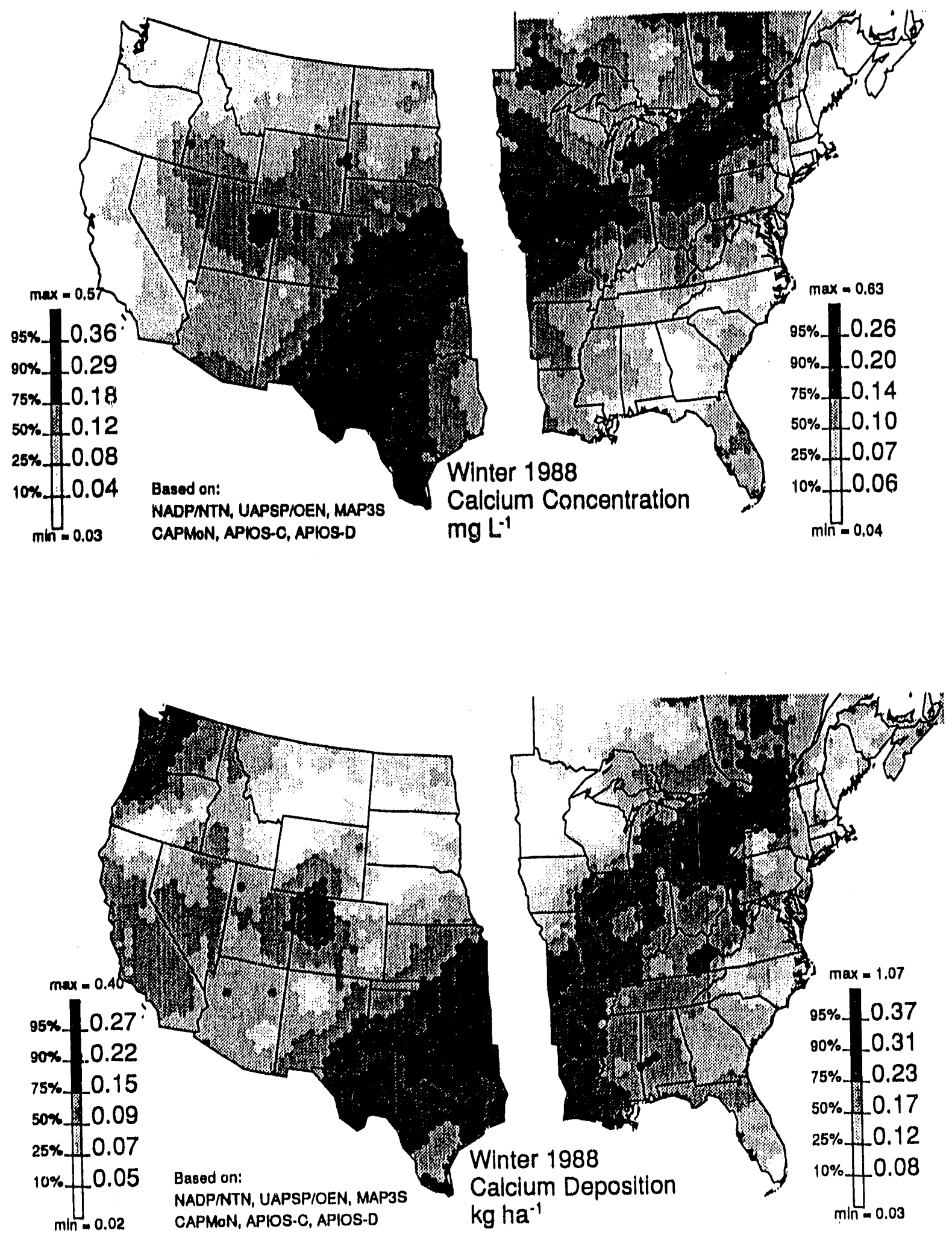

FIGURE A.14 Winter 1988 Spatial Distribution of Calcium Precipitationweighted Concentration and Deposition

\section{A. 14}



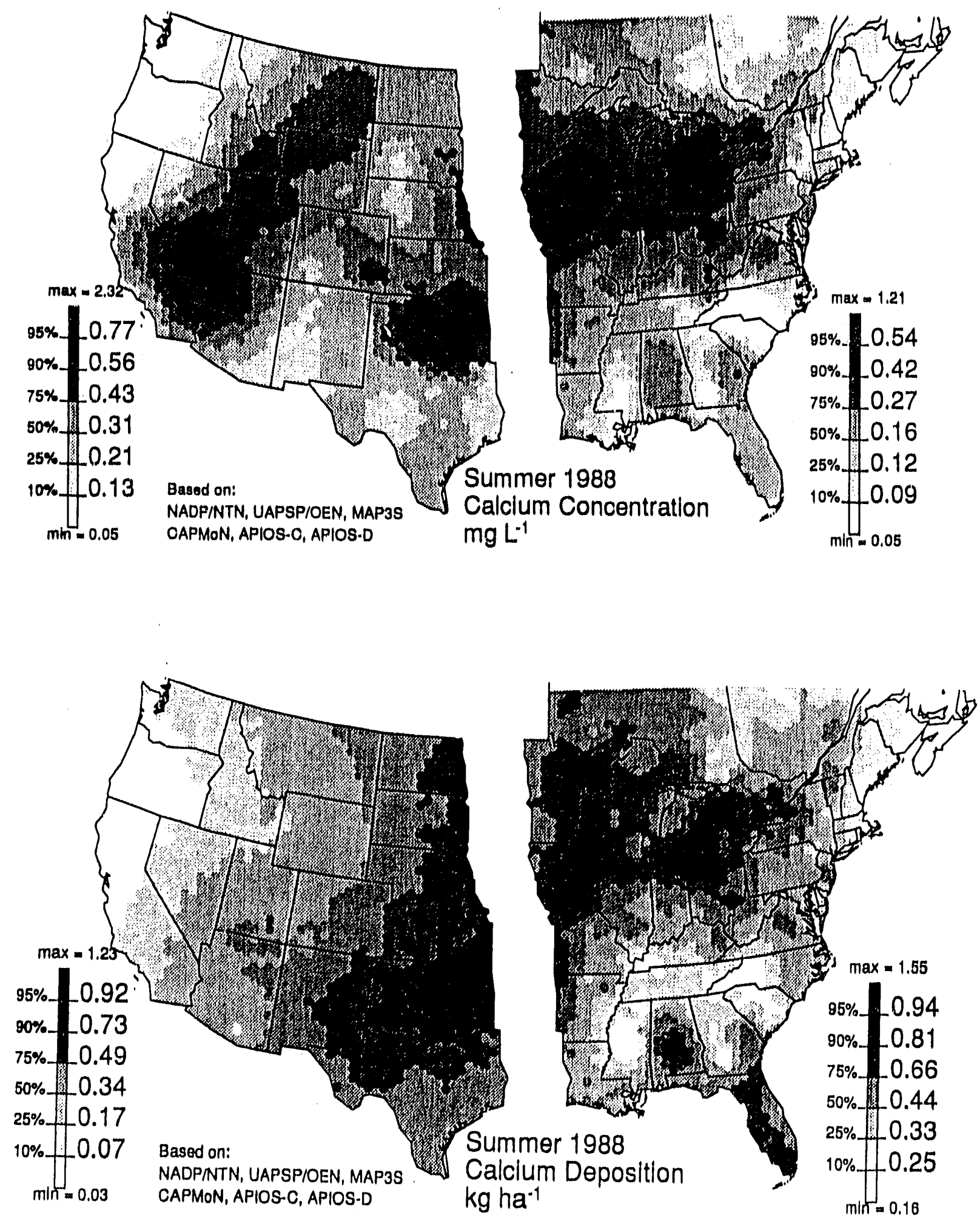

FIGURE A.15 Summer 1988 Spatial Distribution of Calcium Precipitationweighted Concentration and Deposition

A. 15 


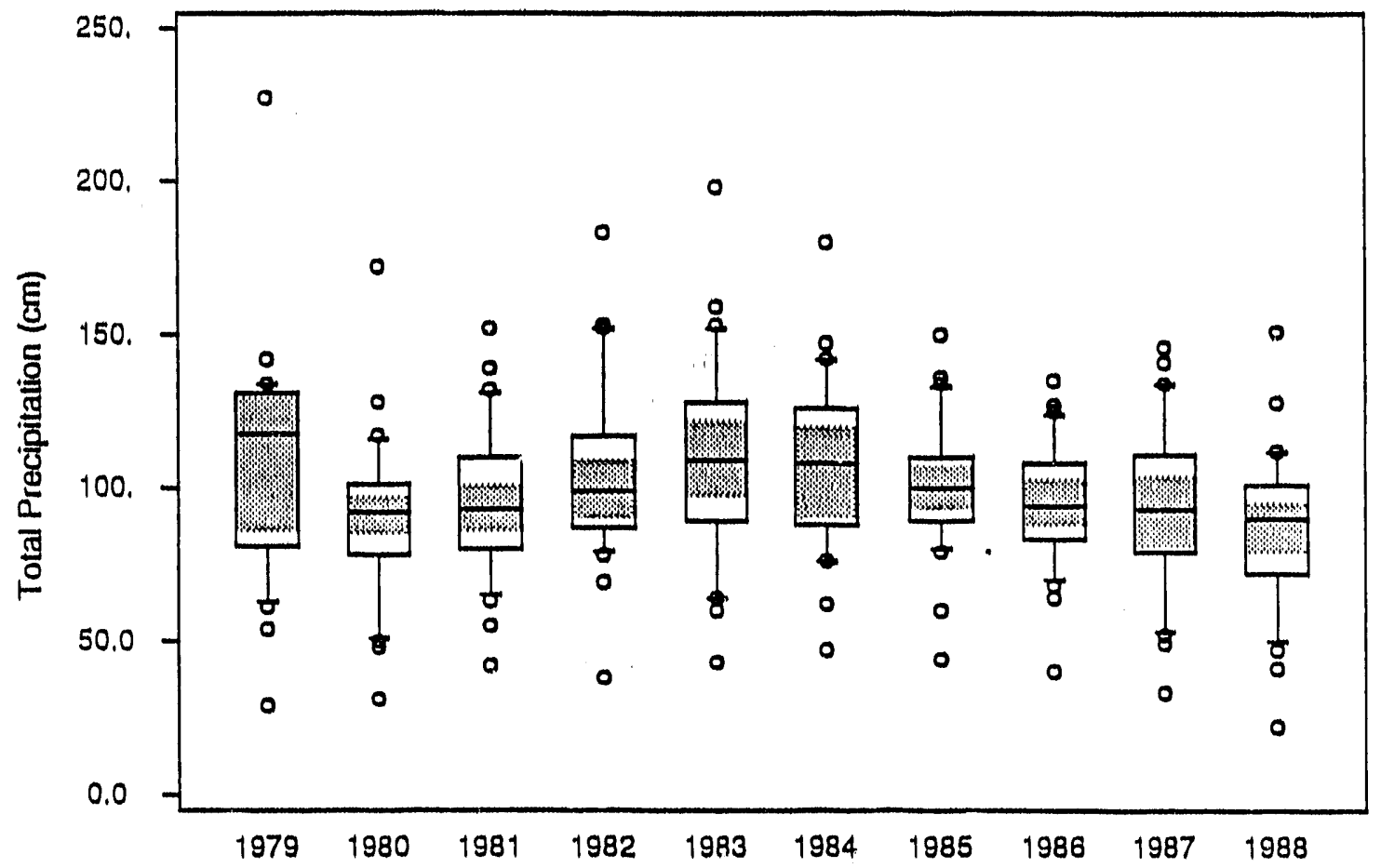

FIGURE A.16a. Temporal Pattern of Annual Precipitation. Boxplots are the 10th, 25th, 50th, 75th and 90th Percentiles of Sites in the 1979-88 Trend Subset.

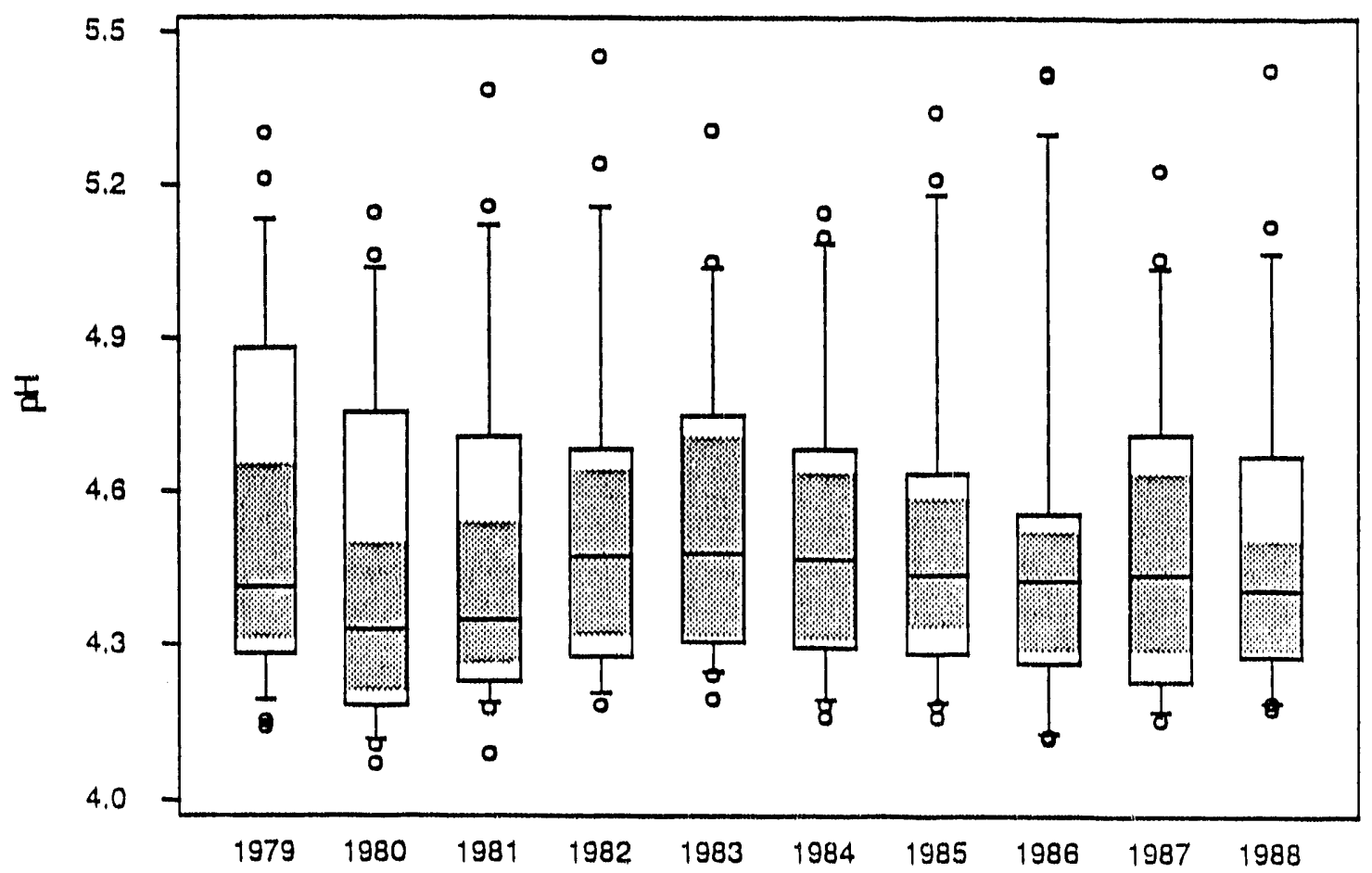

EIGURE A.16b. Temporal Pattern of Annual Precipitation-weighted pH. Boxplots are the 10th, 25th, 50th, 75th and 90th Percentiles of Sites in the 1979-88 Trend Subset. 


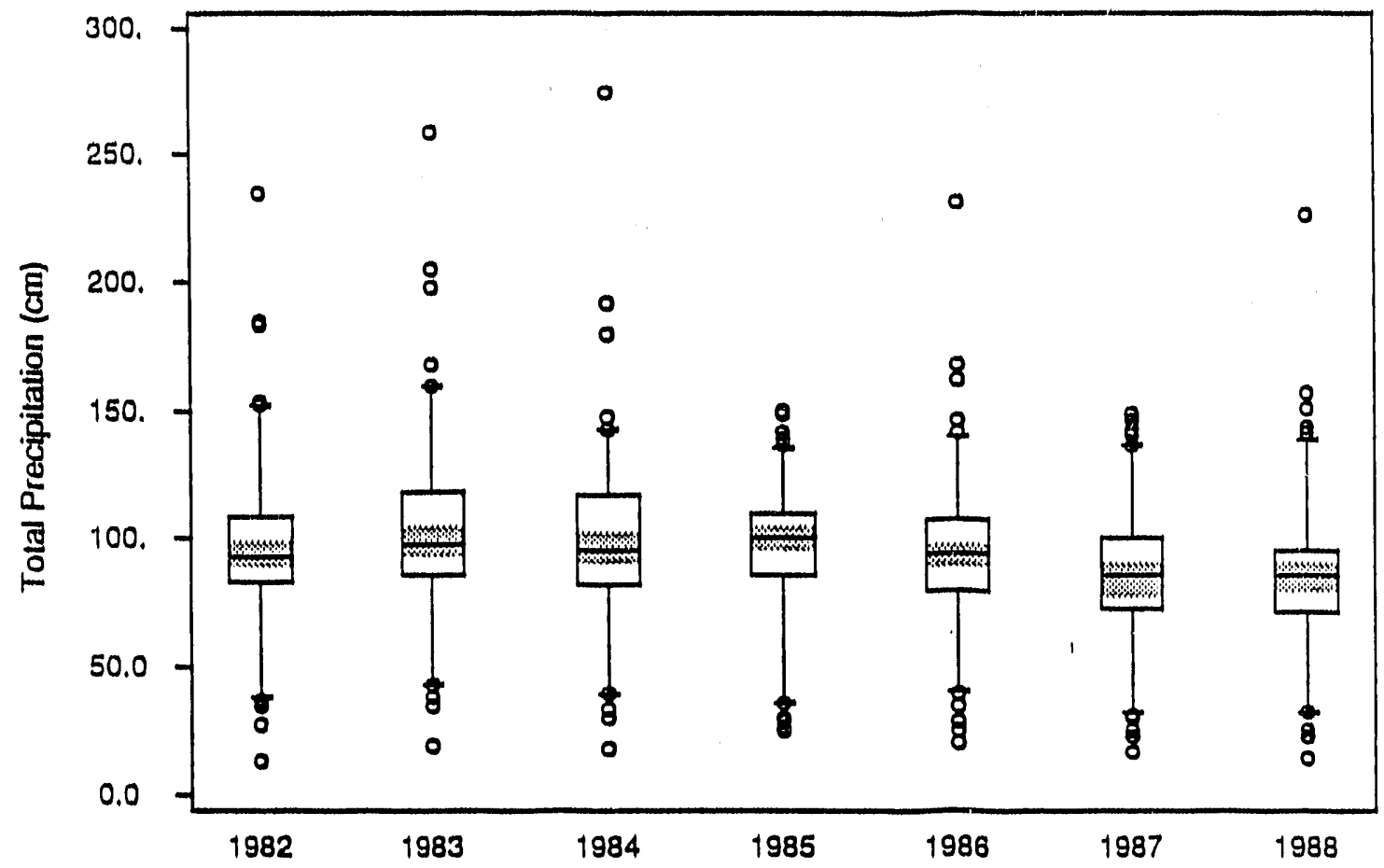

EIGURE A.17a. Temporal Pattern of Annual Precipitation. Boxplots are the 5 th, 25th, 50th, 75th and 95th Percentiles of Sites in the 1982-88 Trend Subset.

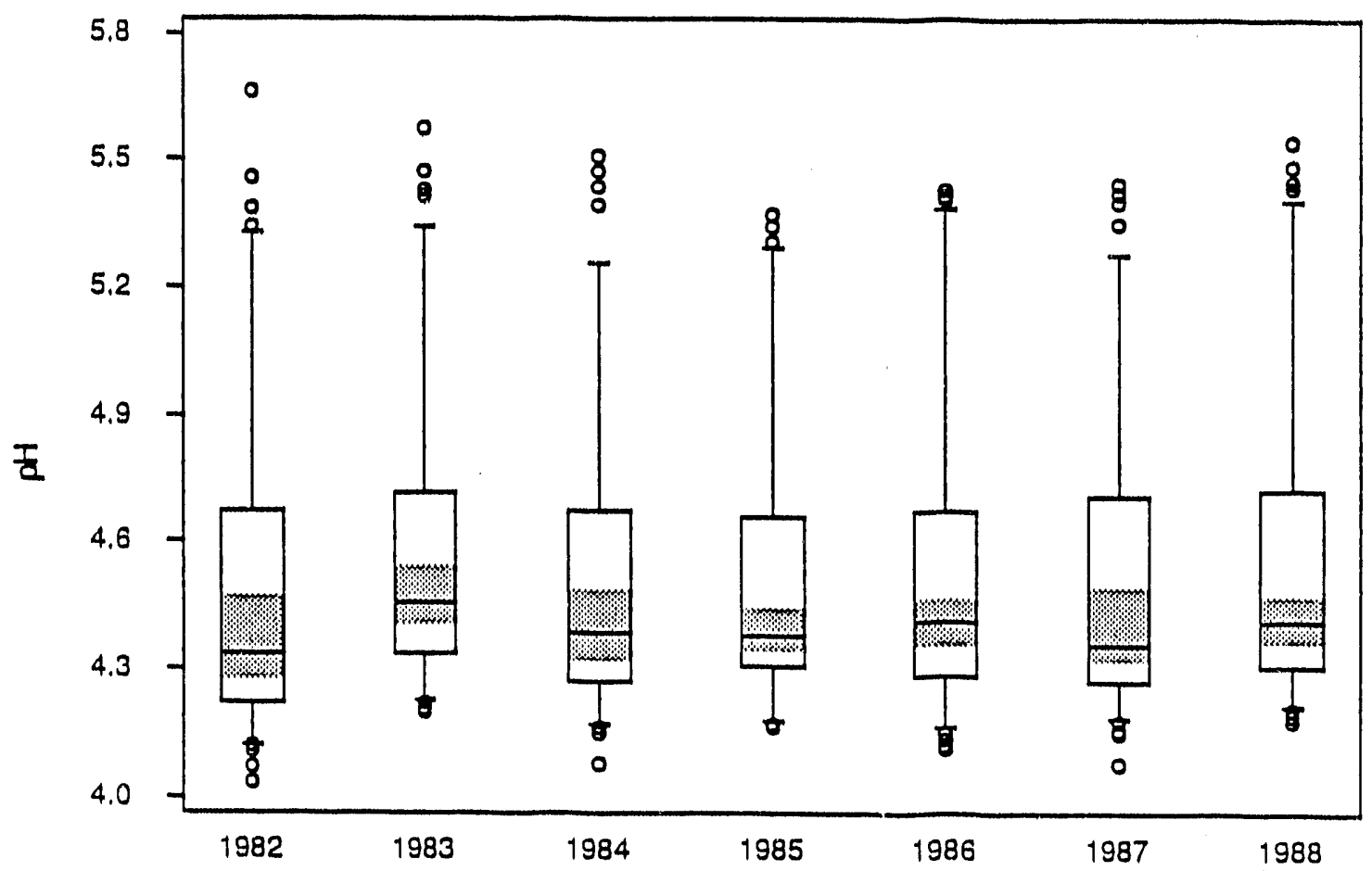

FIGURE A.17b. Temporal Pattern of Annual Precipitation-weighted pH. Boxplots are the 5th, 25th, 50th, 75th and 95th Percentfles of Sites in the 1982-88 Trend Subset. 


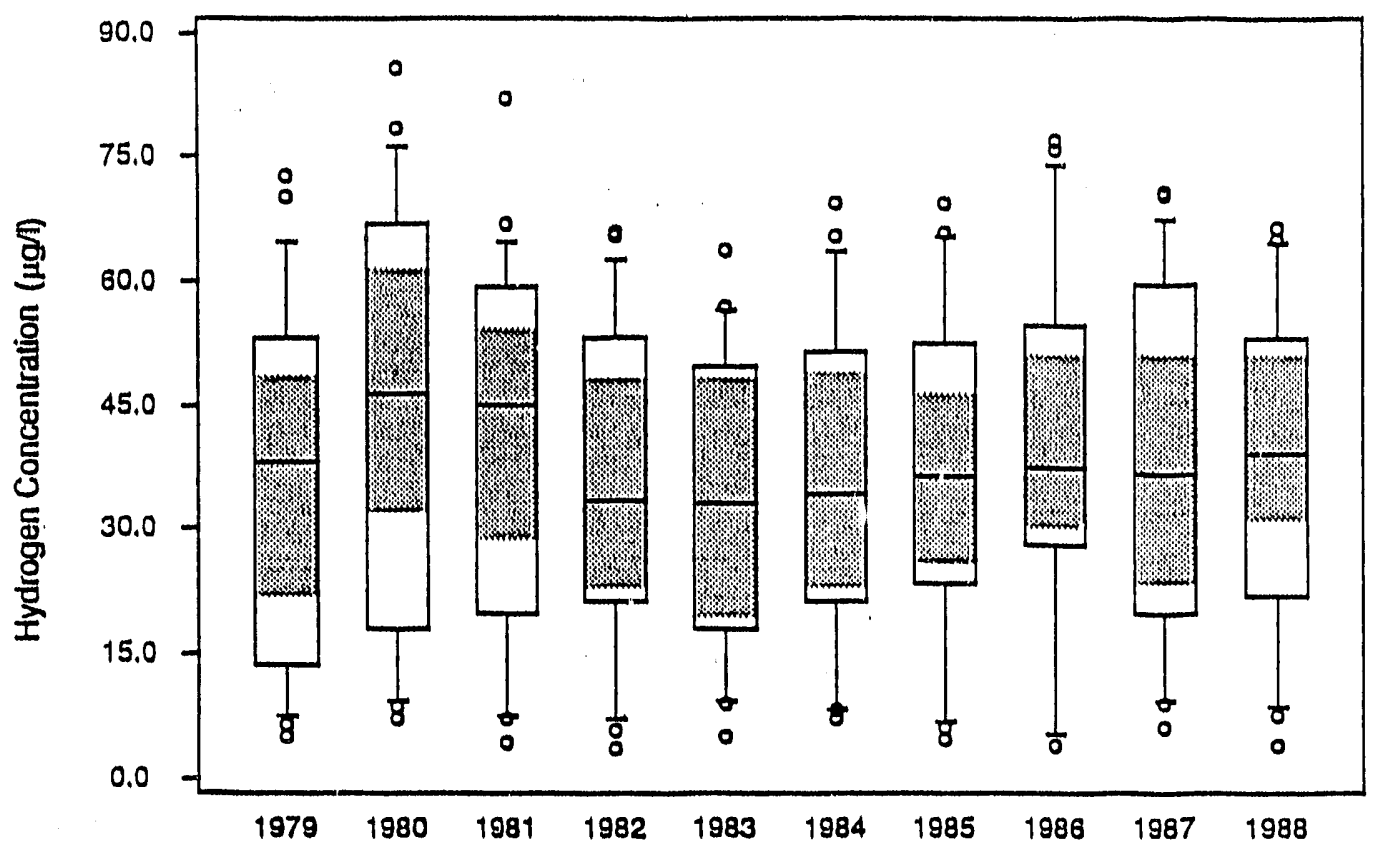

FIGURE A.18a. Temporal Pattern of Annual Precipitation-weighted Hydrogen Ion Concentration. Boxplots are the 10th, 25th, 50th, 75th and 90th Percentiles of Sites in the 1979-88 Trend Subset.

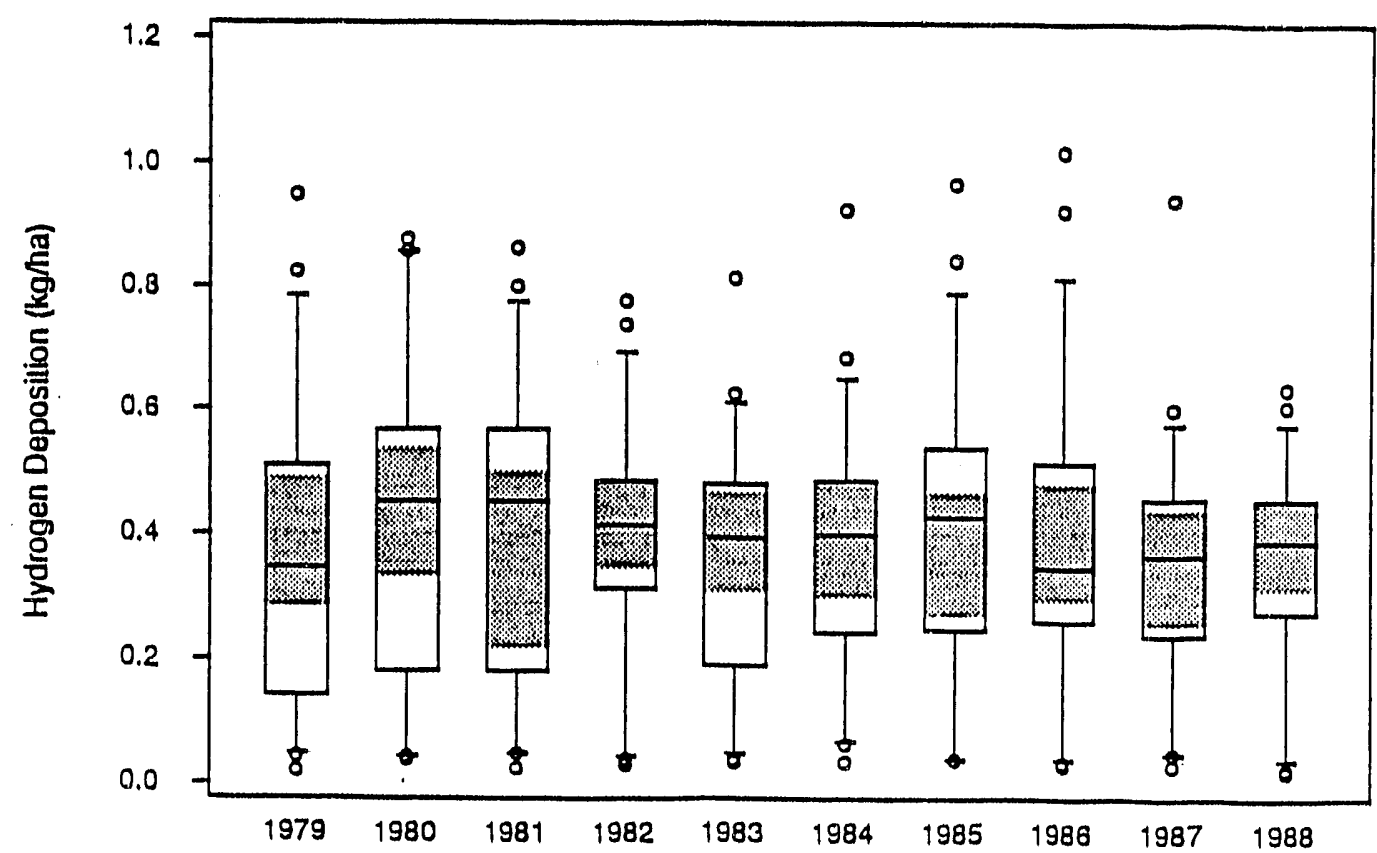

FIGURE A.18b. Temporal Pattern of Annual Precipitation-weighted Hydrogen Ion Wet Deposition. Boxplots are the 10th, 25th, 50th, 75th and 90th Percentiles of Sites in the 1979-88 Trend Subset.

\section{A. 18}




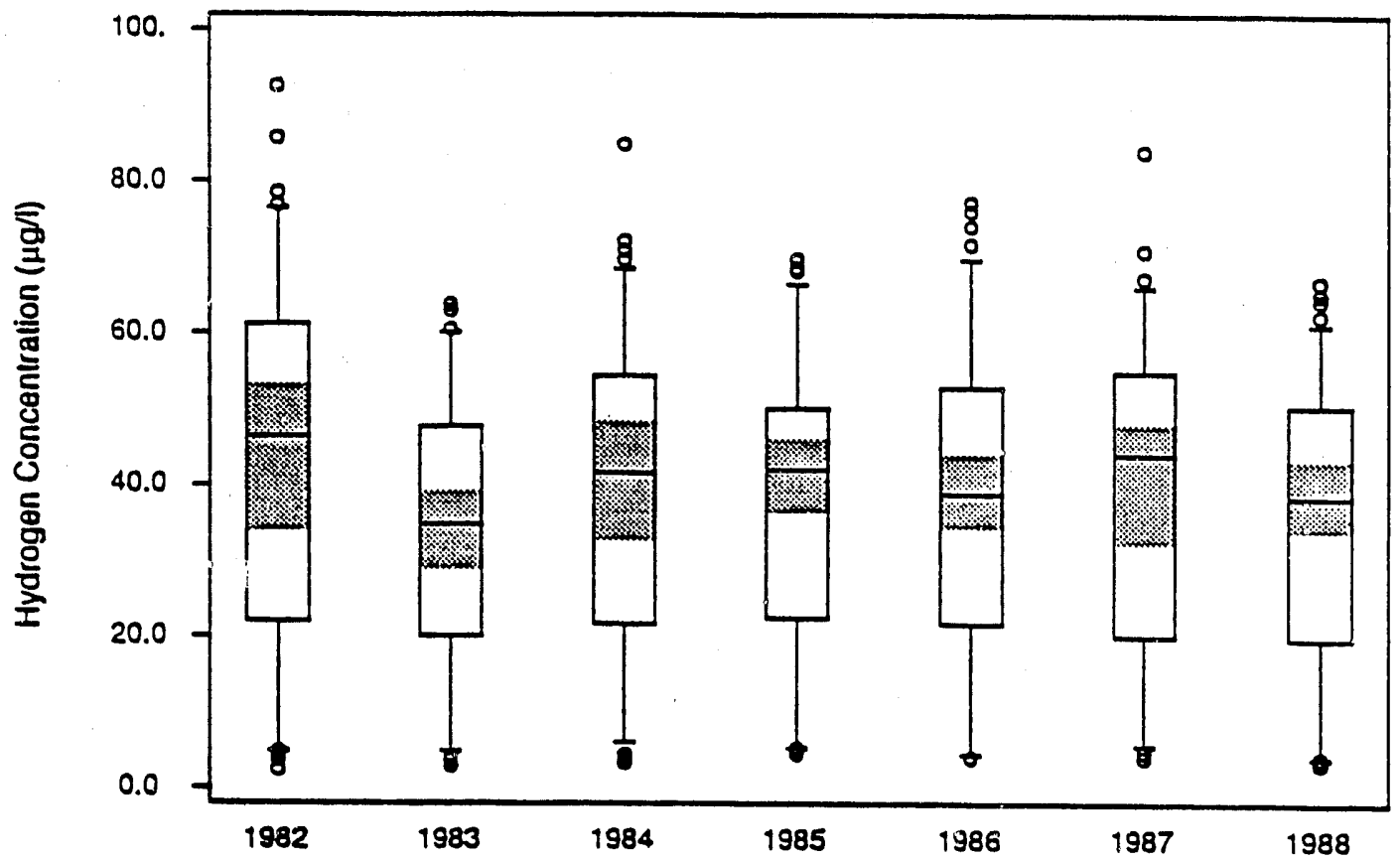

FIGURE A.19a. Temporal Pattern of Annual Precipitation-weighted Hydrogen Ion Concentration. Boxplots are the 5th, 25th, 50th, 75th and 95th Percentiles of Sites in the 1982-88 Trend Subset.

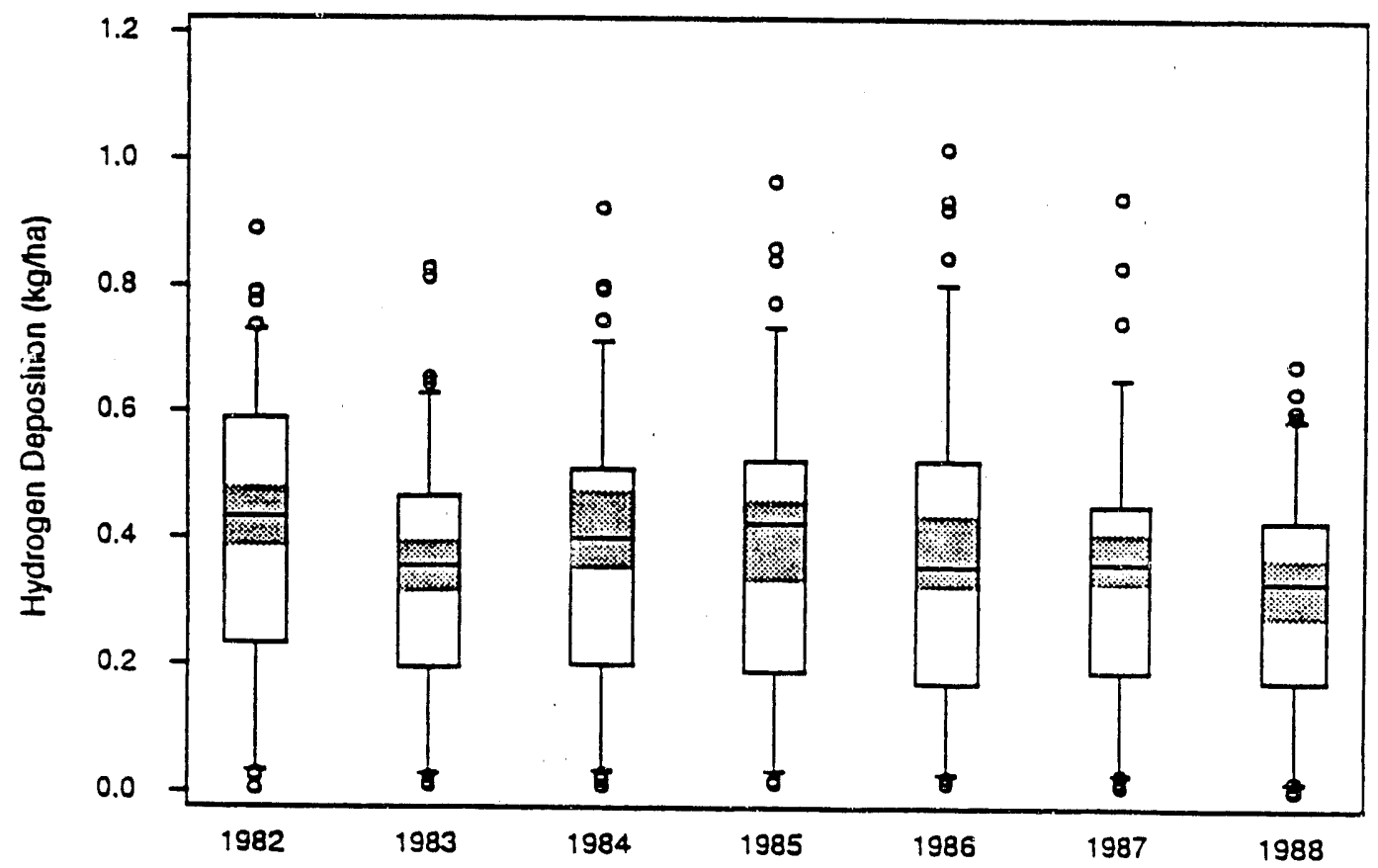

FIGURE A.19b. Temporal Pattern of Annual Hydrogen Ion Wet Depostion. Boxplots are the 5th, 25th, 50th, 75th and 95th Percentiles of Sites in the 1982-88 Trend Subset. 


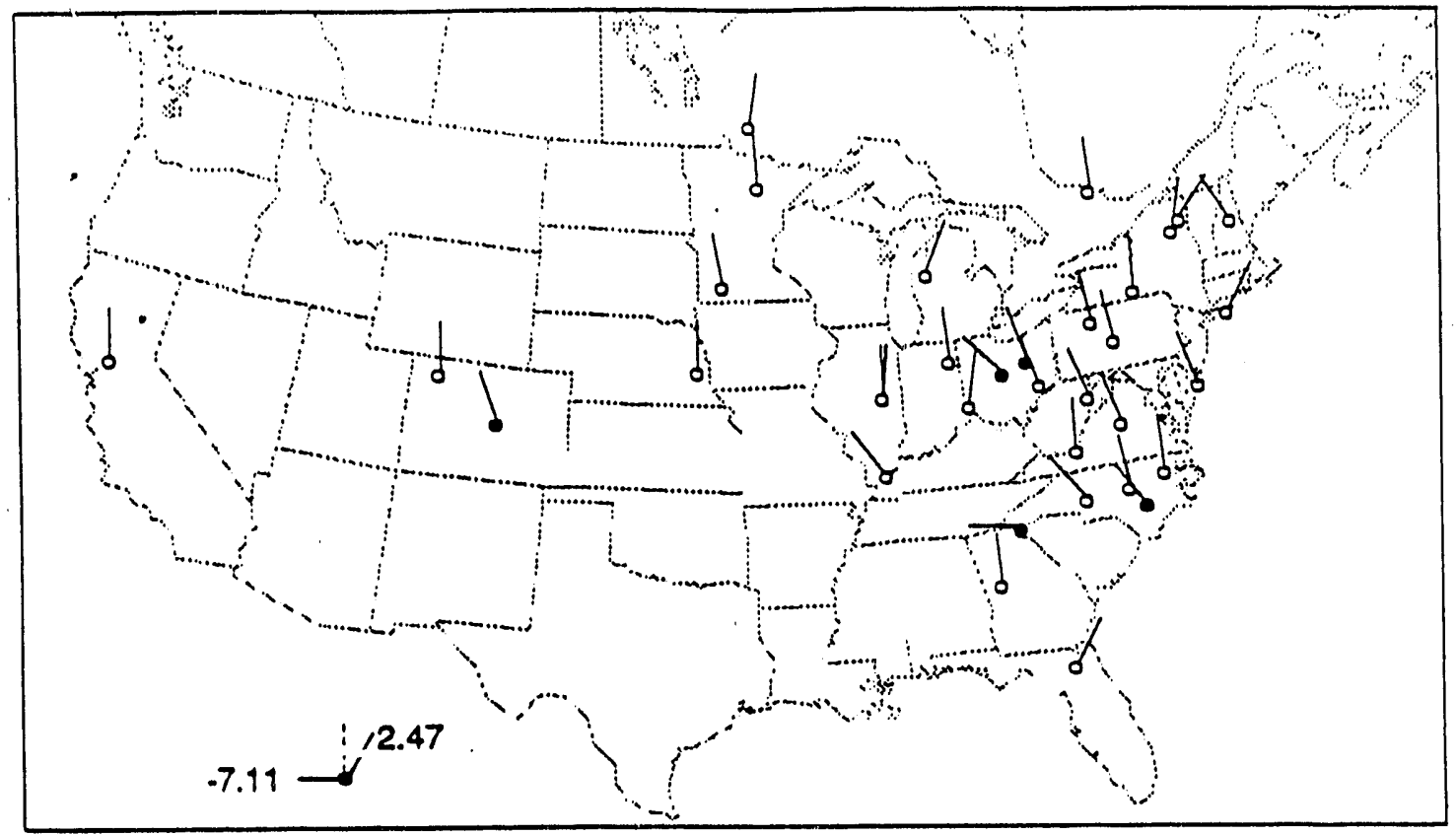

FIGURE A.20a. Total Precipitation (cm) Trend Estimates for 1979-88 Trend Subset. Ray Angle Proportional to Trend Estimate. Solid Symbol Indicates Significant Trend $(p<0.05)$.

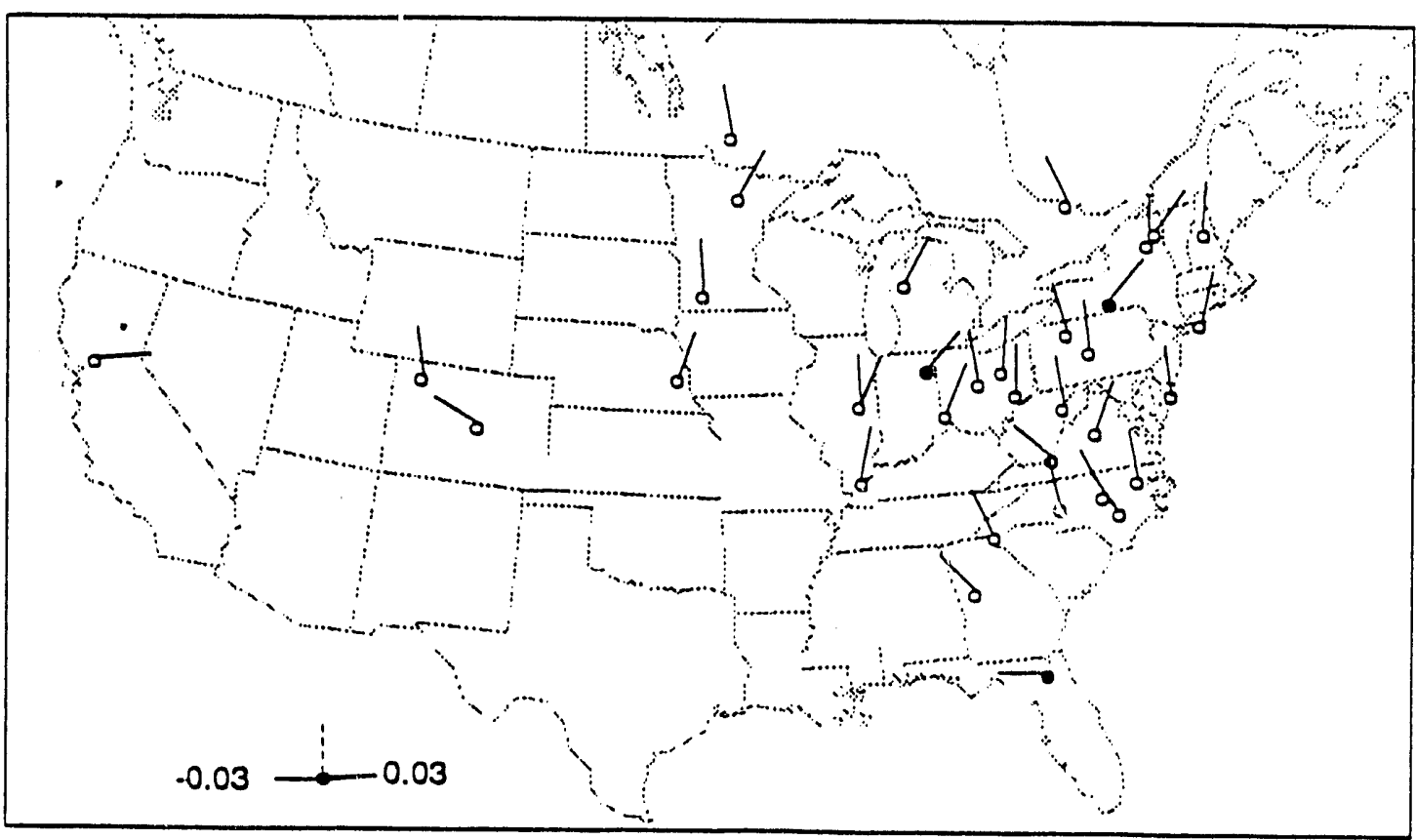

FIGURE A.20b. pH Trend Estimates for 1979-88 Trend Subset. Ray Angle Proportional to Trend Estimate. Solid Symbol Indicates Significant Trend $(p<0.05)$. 


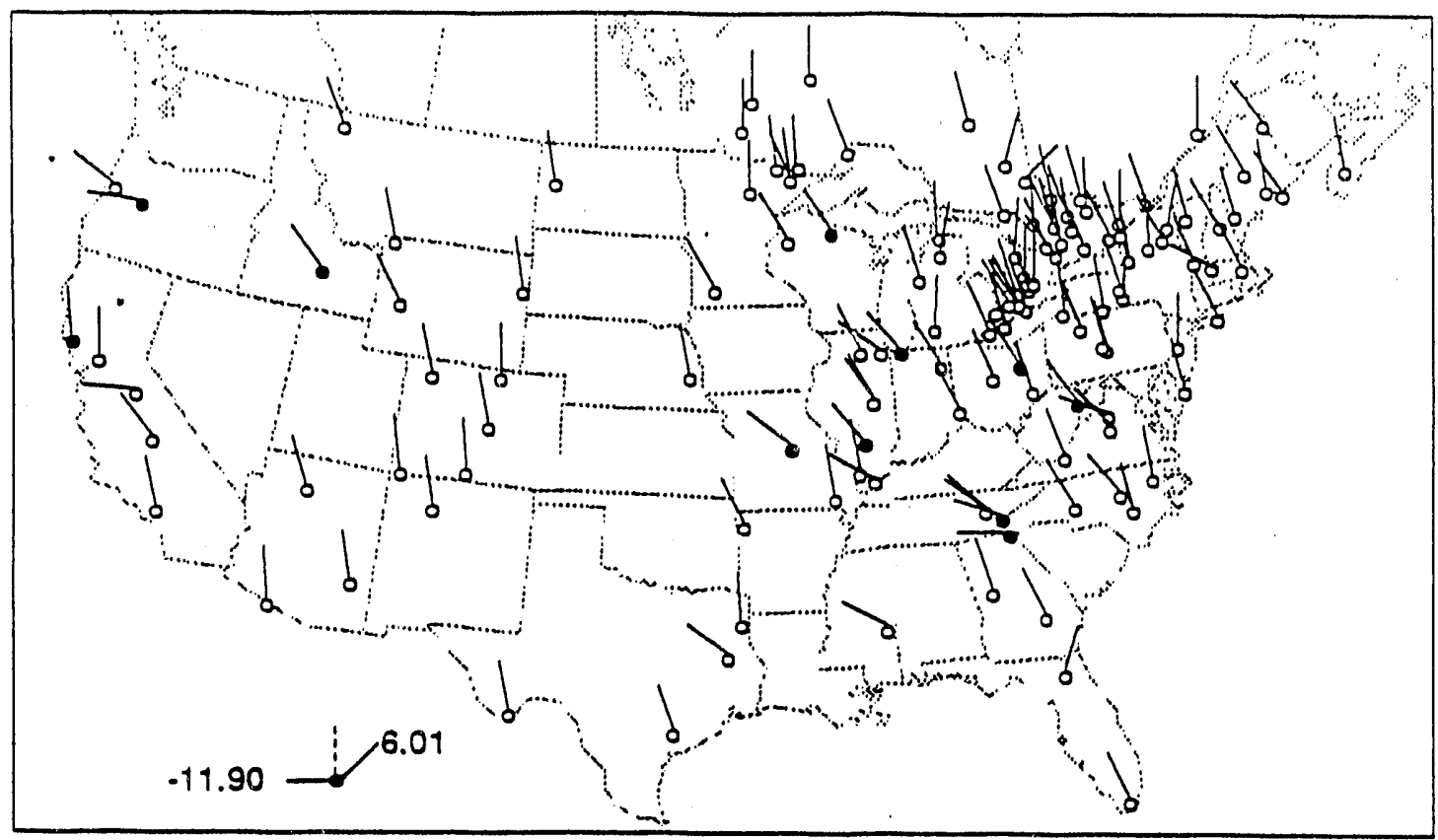

FIGURE A.2la. Total Precipitation (cm) Trend Estimates for 1982-88 Trend Subset. Ray Angle Proportional to Trend Estimate. Solid Symbol Indicates Significant Trend $(p<0.05)$.

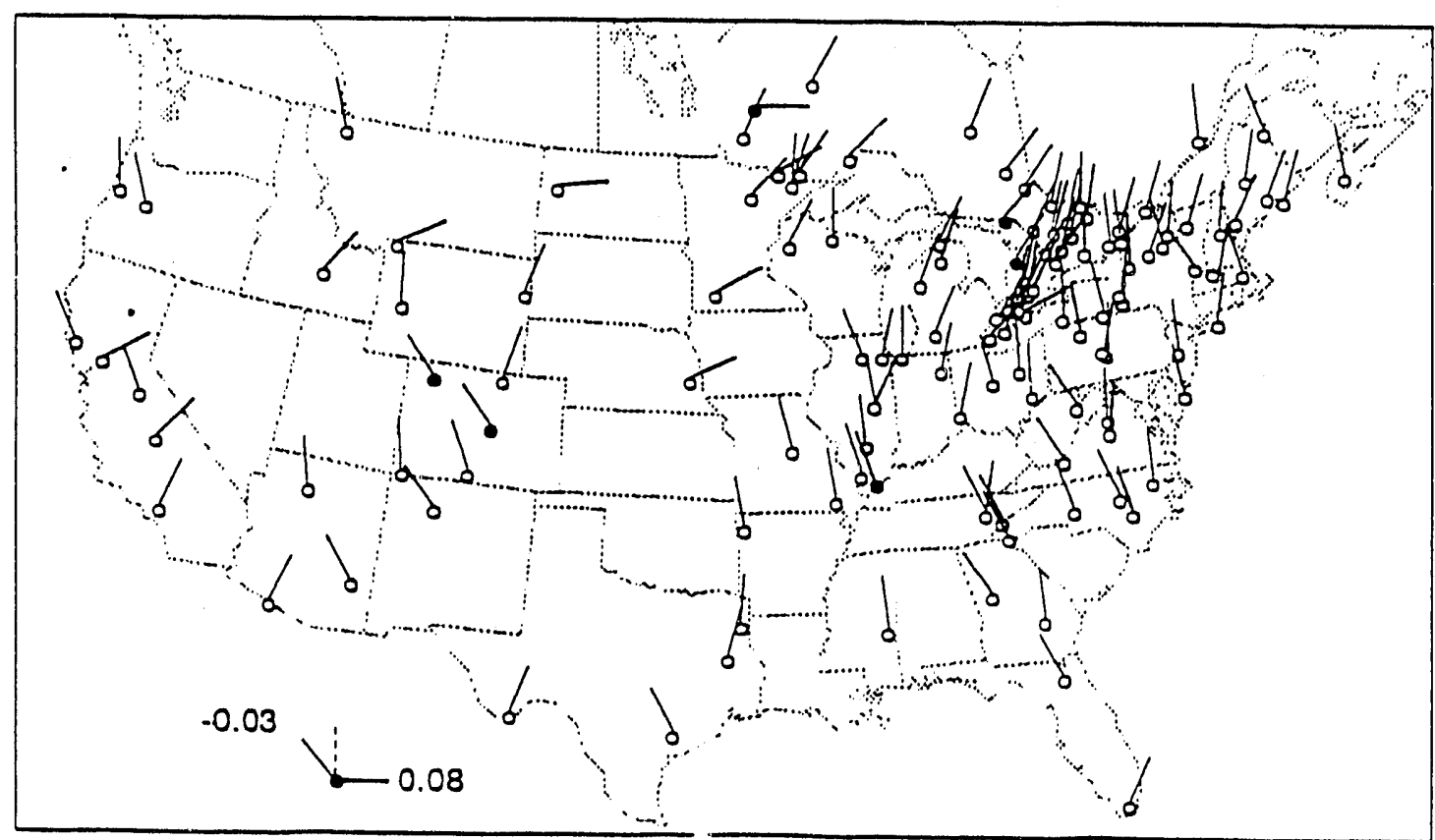

FIGURE A.21b. pH Trend Estimates for 1982-88 Trend Subset. Ray Angle Proportional to Trend Estimate. Solid Symbol Indicates Significant Trend $(p<0.05)$. 


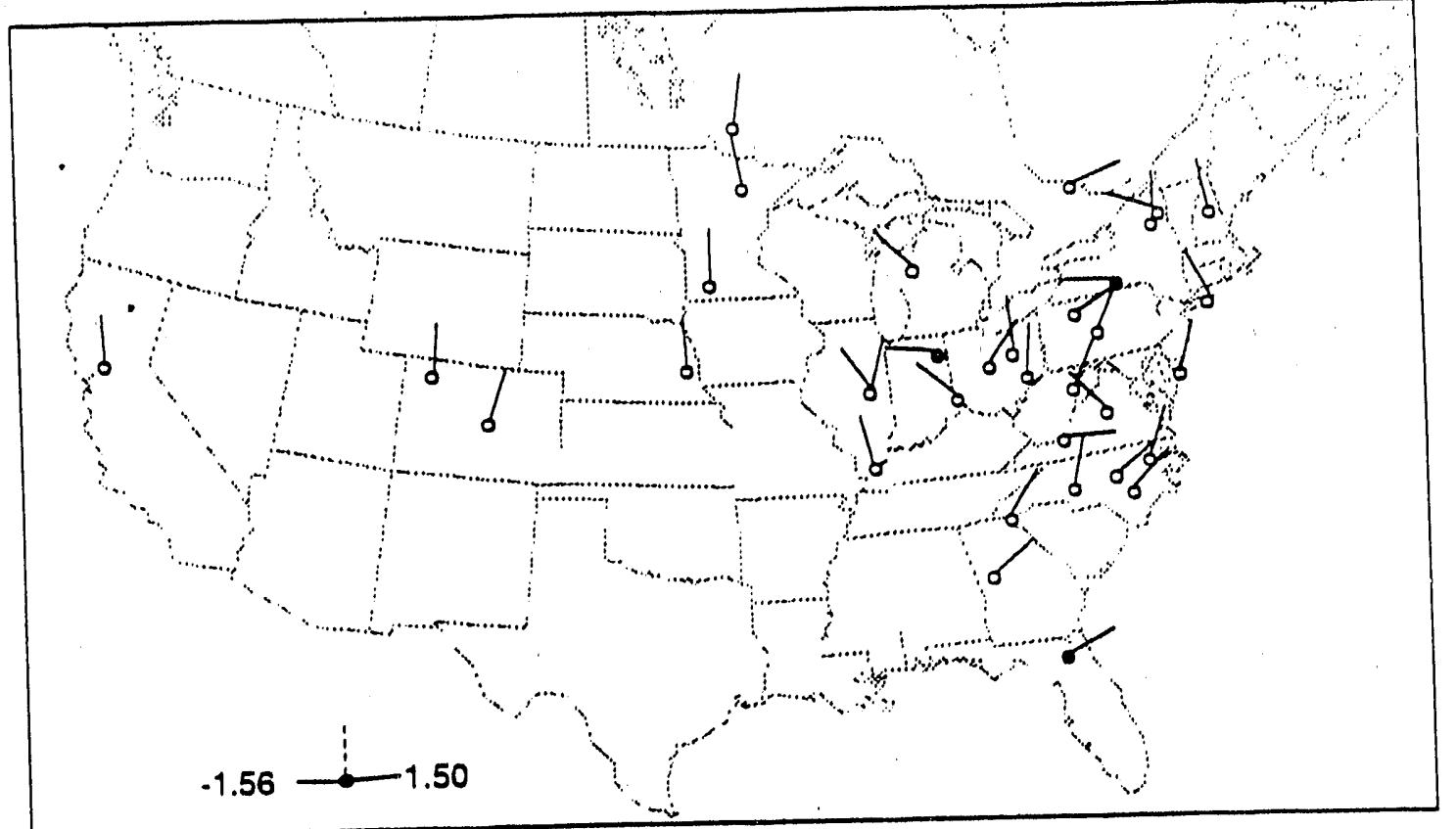

FIGURE A.22a. Hydrogen Concentration ( $\mu \mathrm{eq} / 1$ ) Trend Estimates for 1979-88 Trend Subset. Ray Angle Proportional to Trend Estimate. Solid Symbol Indicates Significant Trend $(p<0.05)$.

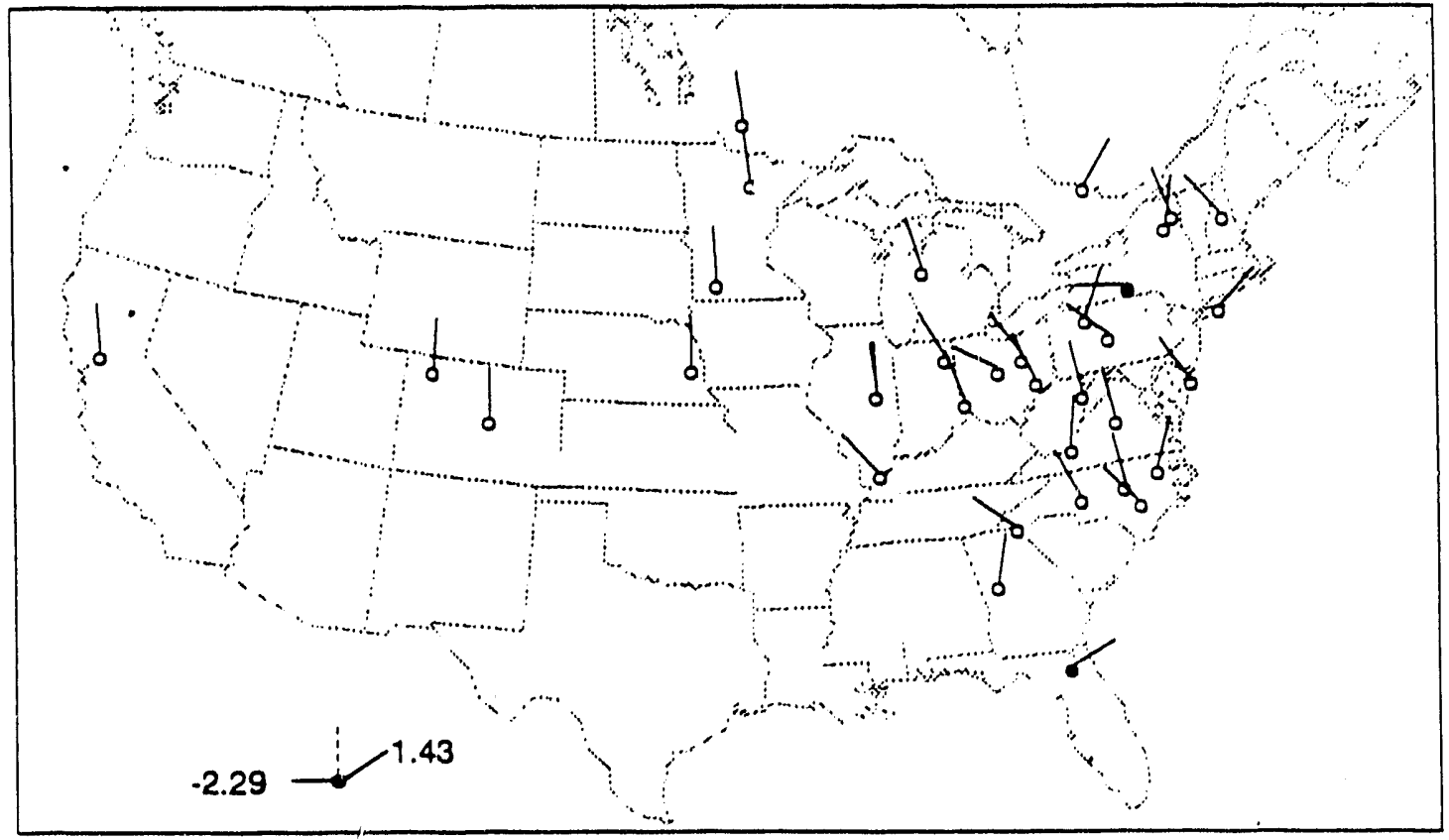

FIGURE A.22b. Hydrogen Deposition (meq/ $\mathrm{m}^{2}$ ) Trend Estimates for 1979-88 Trend Subset. Ray Angle Proportional to Trend Estimate. Solid Symbol Indicates Significant Trend $(p<0.05)$. 


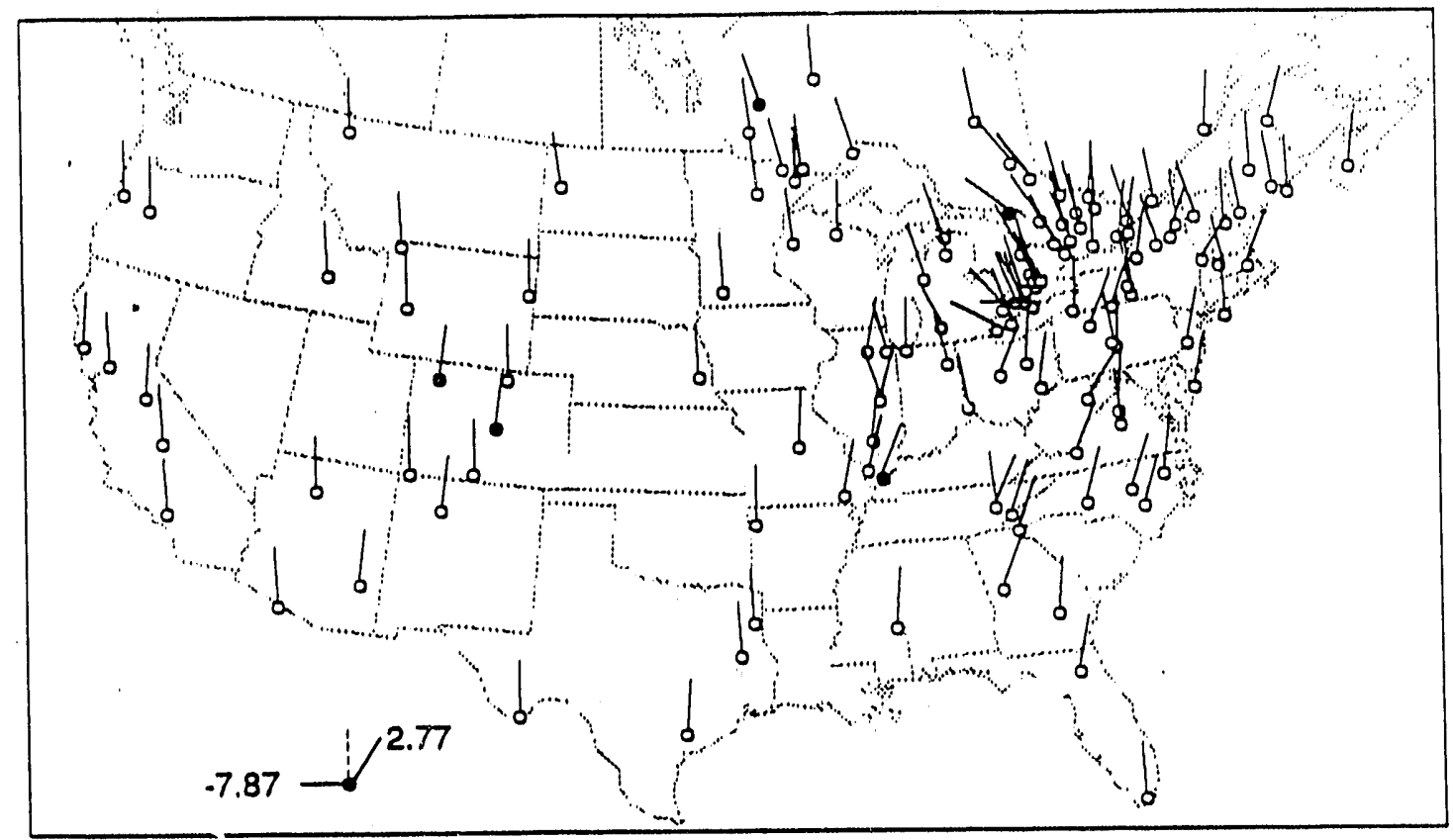

FIGURE A.23a. Hydrogen Concentration ( $\mu \mathrm{eq} / 1)$ Trend Estimates for 1982-88 Trend Subset. Ray Angle Proportional to Trend Estimate. Sol id Symbol Indicates Significant Trend $(p<0.05)$.

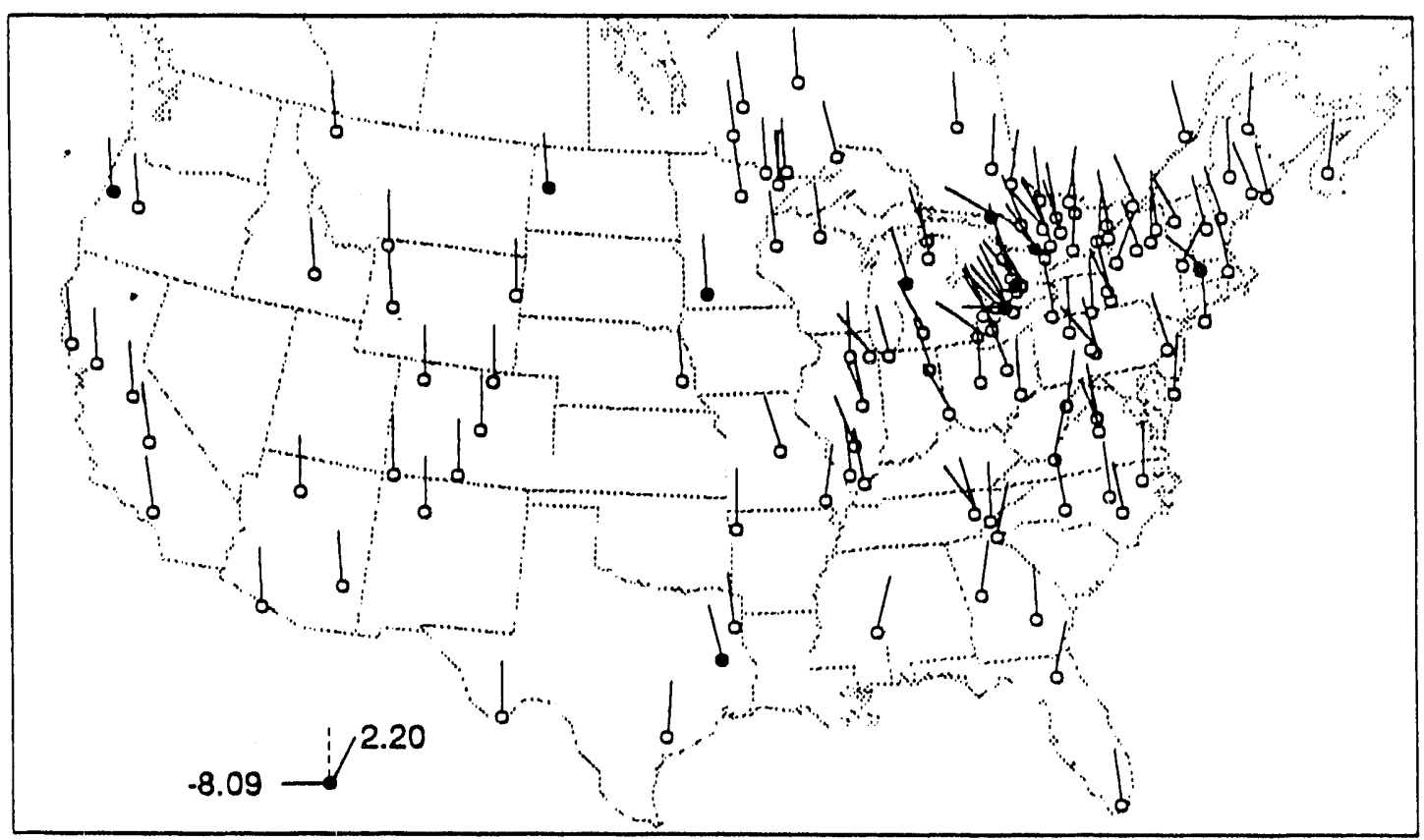

FIGURE A.23b. Hydrogen Deposition (meq/ $\mathrm{m}^{2}$ ) Trend Estimates for 1982-88

Trend Subset. Ray Angle Proportional to Trend Estimate. Solid Symbol Indicates Significant Trend $(p<0.05)$. 


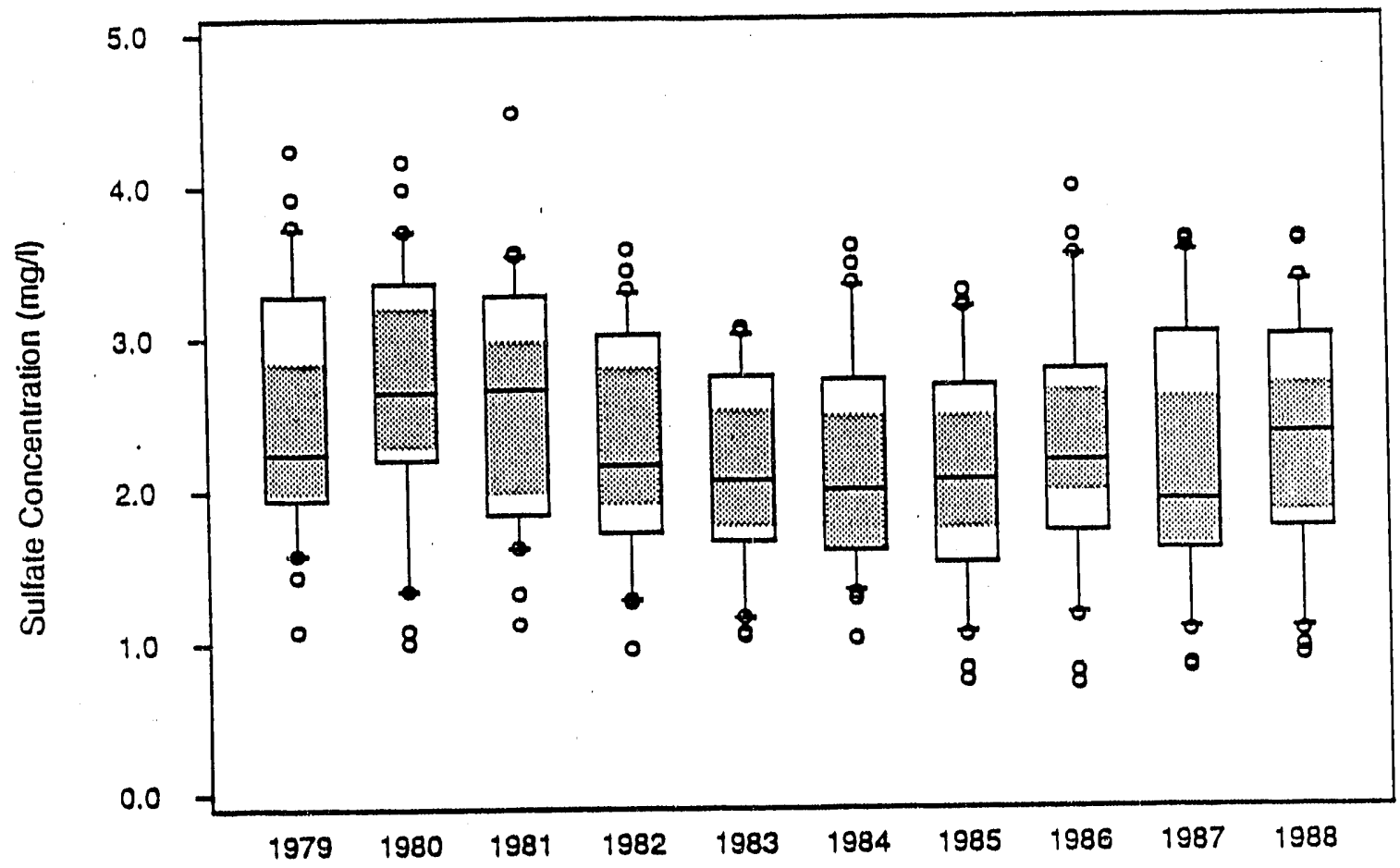

FIGIJRE A.24a. Temporal Pattern of Annual Precipitation-weighted Sulfate Ion Concentration. Boxplots are the 10th, 25th, 50th, 75th and 90th Percentiles of Sites in the 1979-88 Trend Subset.

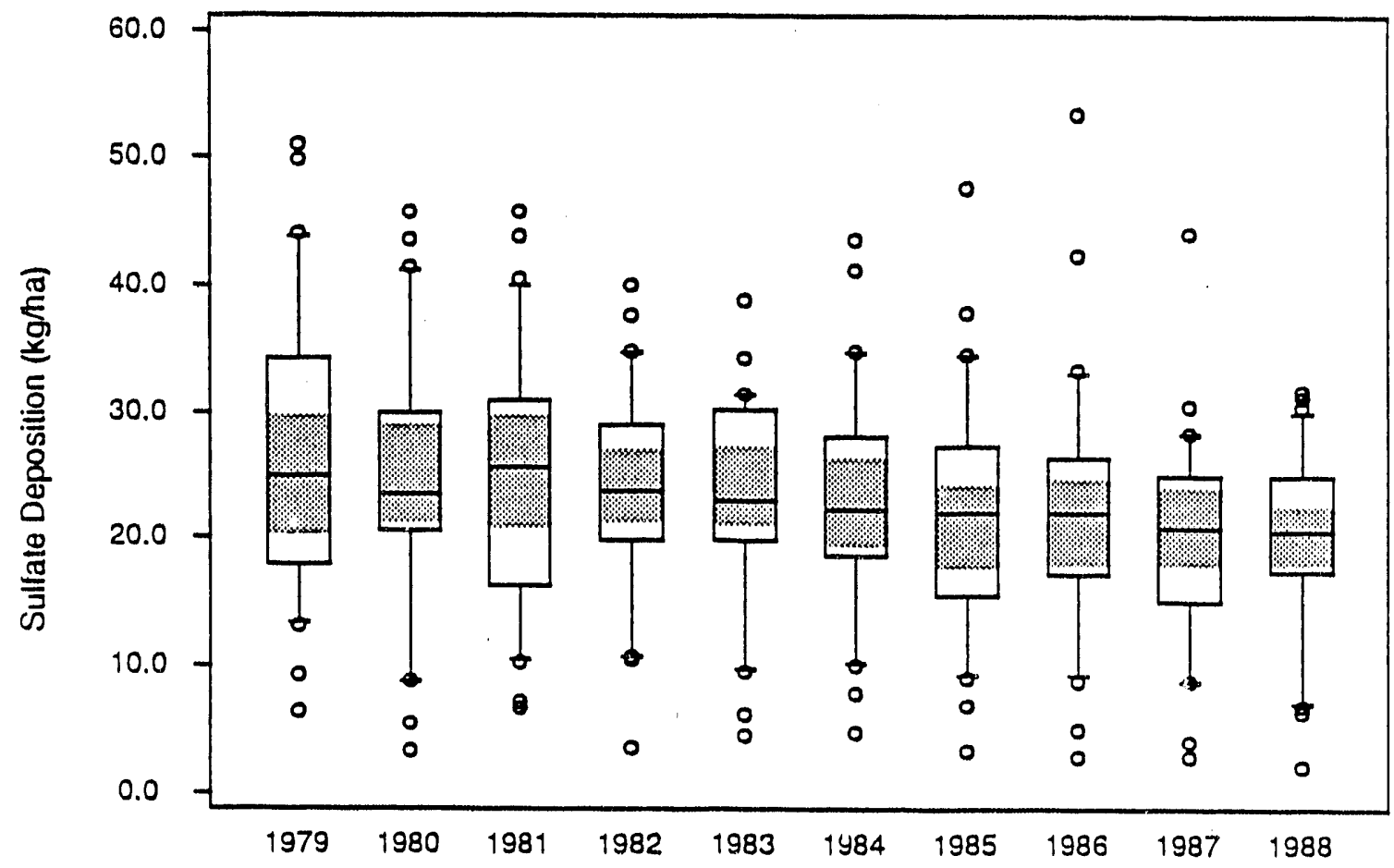

FIGURE A.24b. Temporal Pattern of Annual Sulfate Ion Wet Depositon. Boxplots are the 10th, 25th, 50th, 75th and 90th Percentiles of Sites in the 1979-88 Trend Subset. 


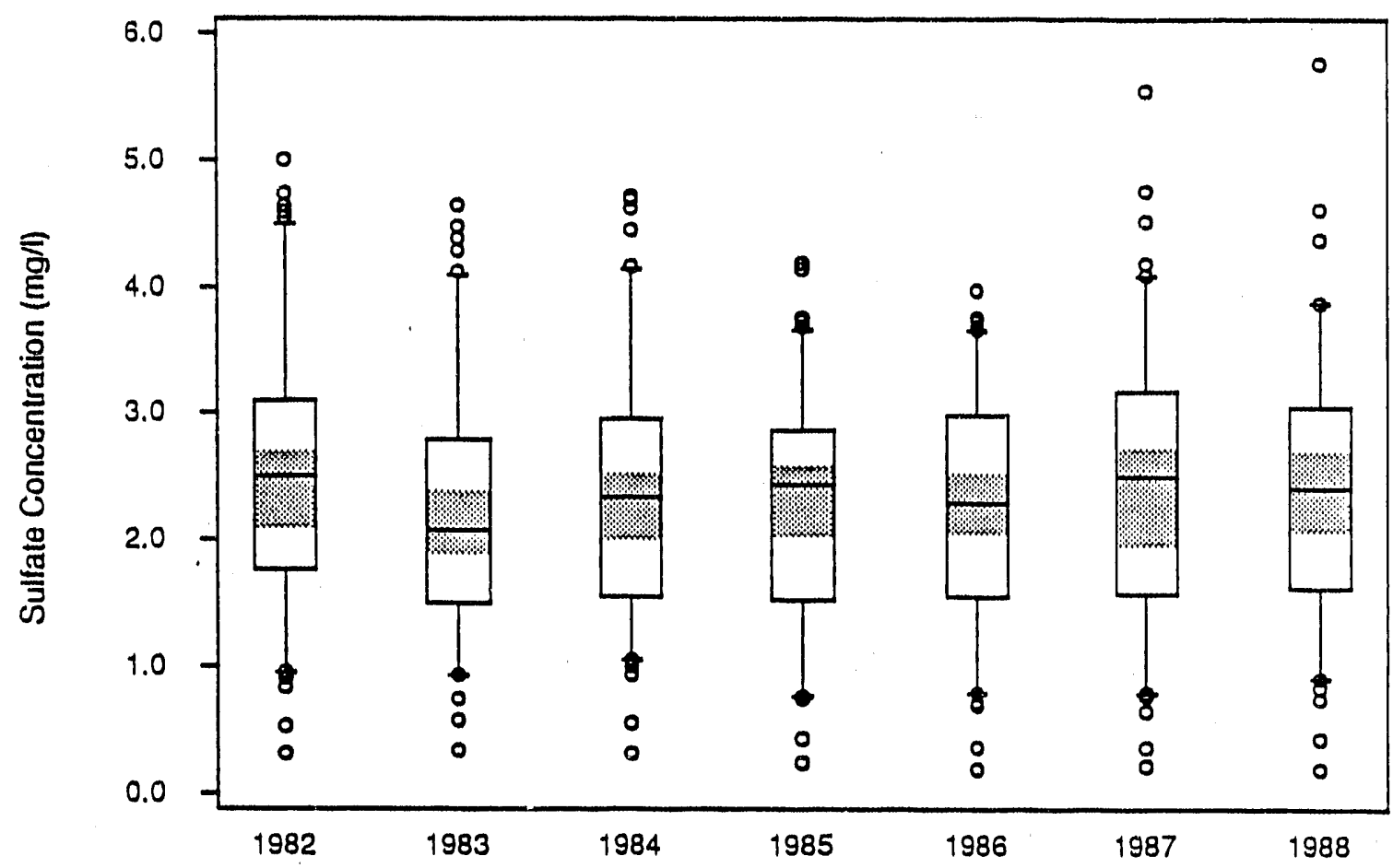

FIGURE A.25a Temporal Pattern of Annual Precipitation-weighted Sulfate Ion Concentration. Boxplots are the 5th, 25th, 50th, 75th and 95th Percentiles of Sites in the 1982-88 Trend Subset.

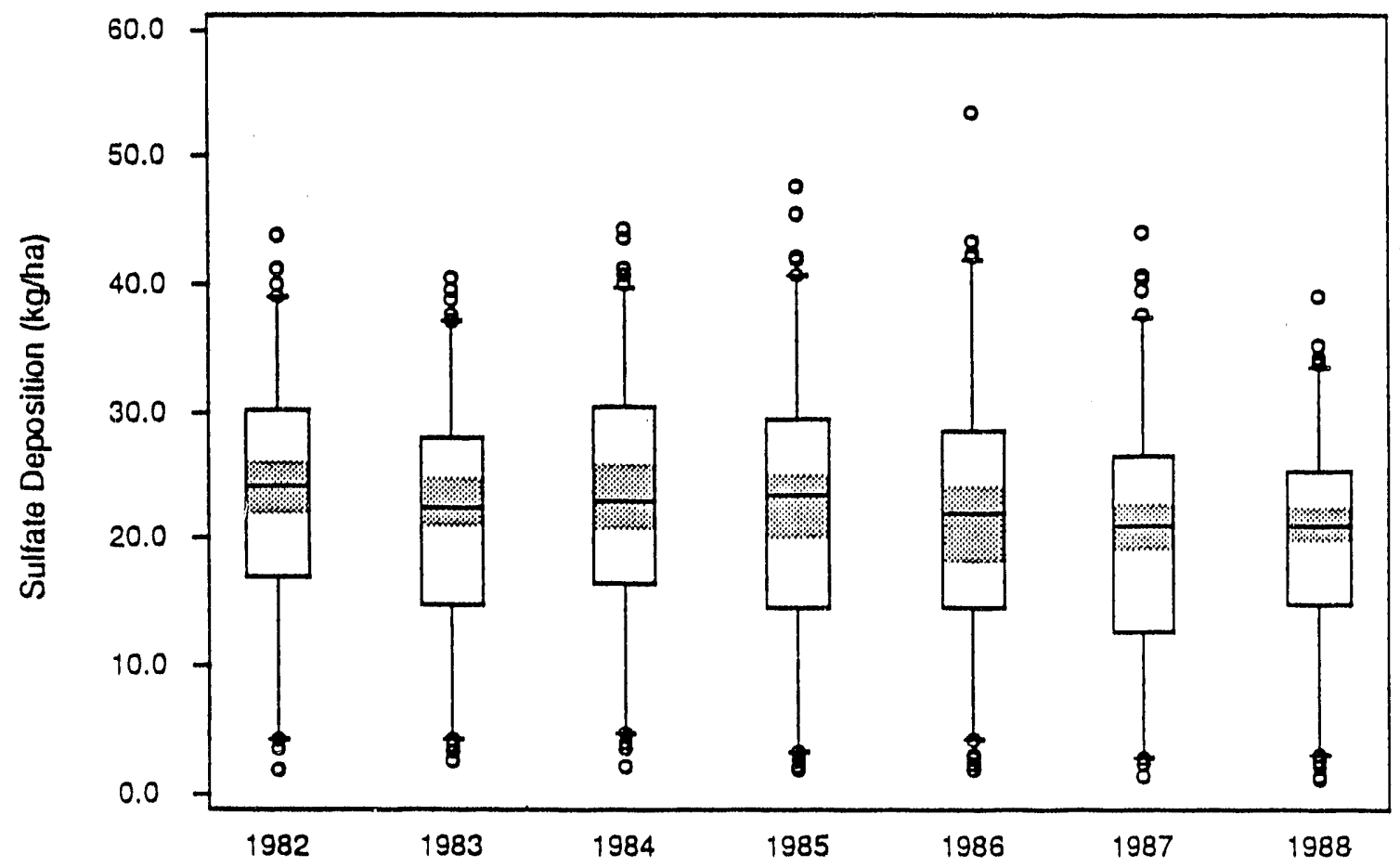

FIGURE A.25b. Temporal Pattern of Annual Sulfate Ion Wet Deposition. Boxplots are the 5 th, 25 th, 50th, 75th and 95 th Percentiles of Sites in the 1982-88 Trend Subset. 


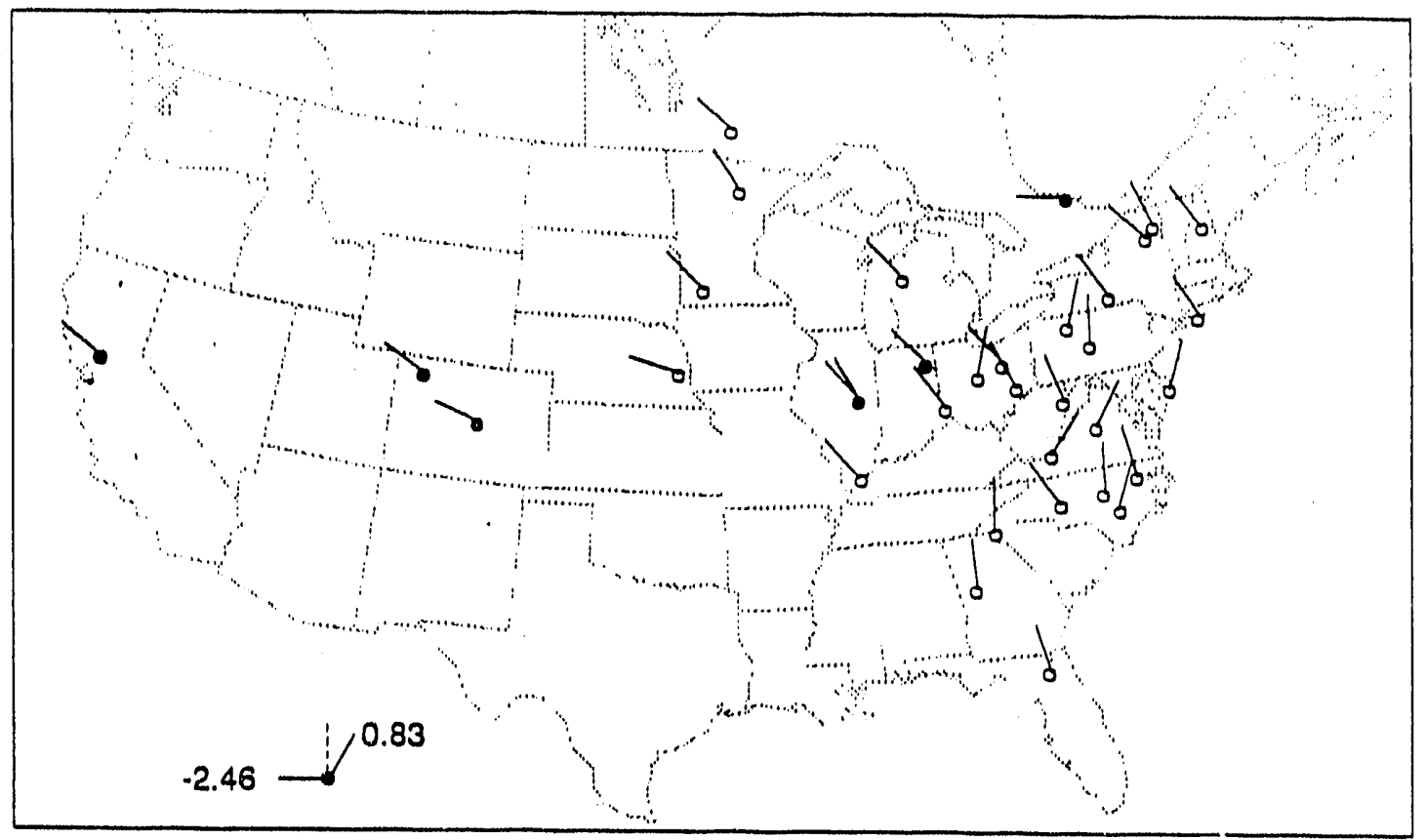

FIGURE A.26a. Sulfate Concentration ( $\mu$ eq/1) Trend Estimates for 1979-88 Trend Subset. Ray Angle Proportional to Trend Estimate. Solid Symbol Indicates Significant Trend $(p<0.05)$.

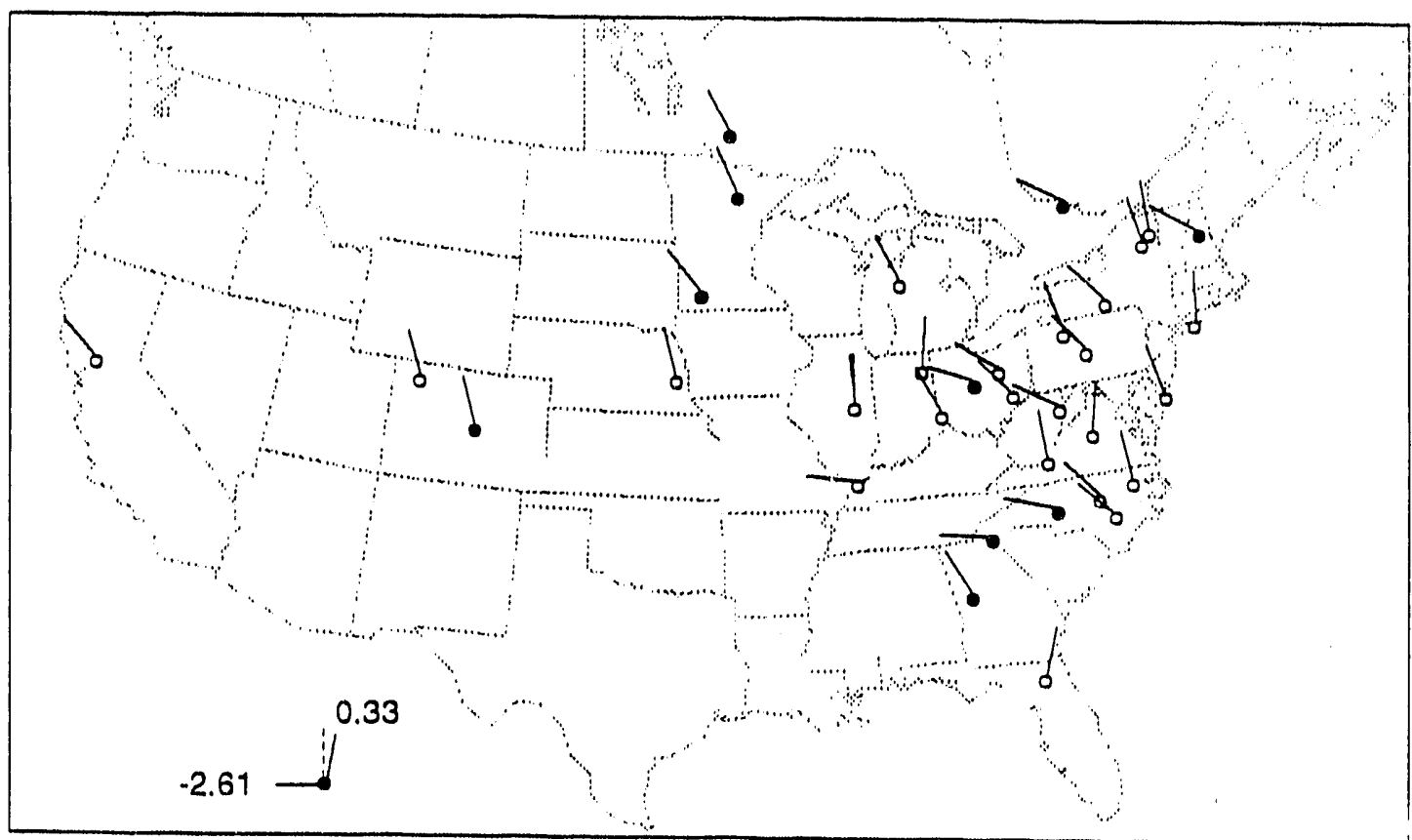

FIGURE A.26b. Sulfate Depostion (meq/ $\mathrm{m}^{2}$ ) Trend Estimates for 1979-88 Trend Subset. Ray Angle Proportional to Trend Estimate. Solid Symbol Indicates Significant Trend $(p<0.05)$. 


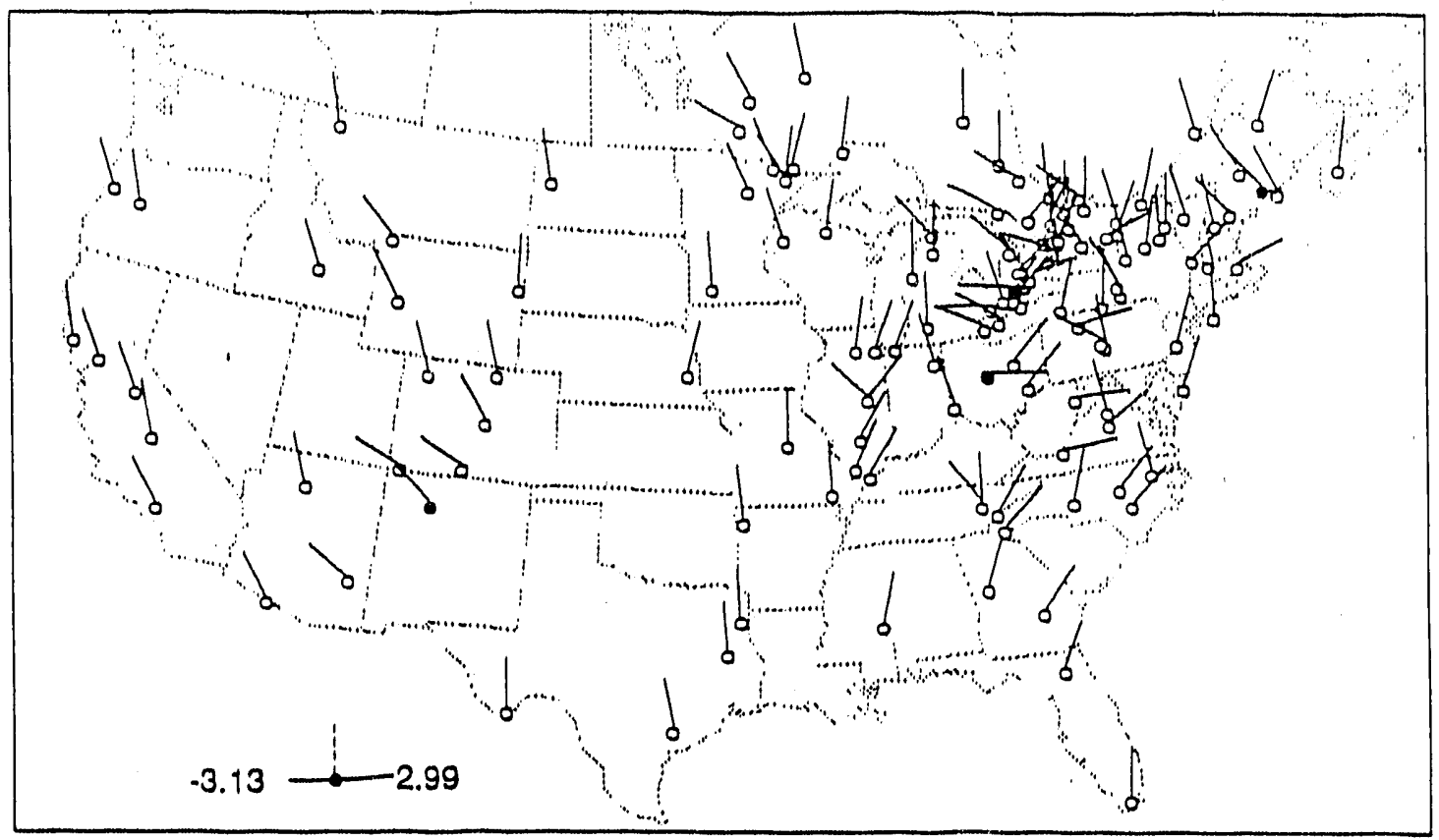

FIGURE A.27a. Sulfate Concentration ( $\mu$ eq/1) Trend Estimates for 1982-88 Trend Subset. Ray Angle Proportional to Trend Estimate. Sol id Symbol Indicates Significant Trend $(p<0.05)$.

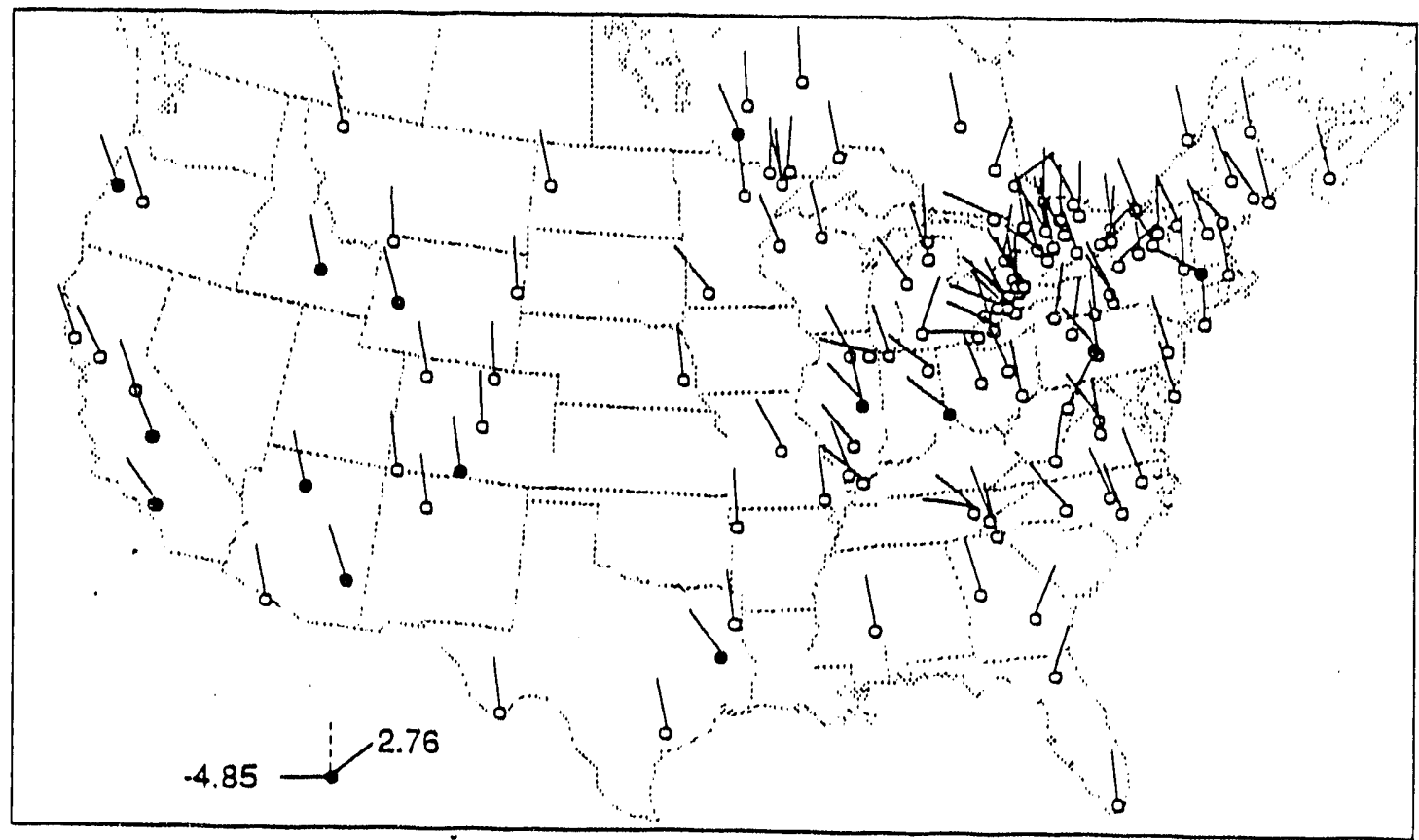

FIGURE A.27b. Sulfate Depostion (meq/ $\mathrm{m}^{2}$ ) Trend Estimates for 1982-88 Trend Subset. Ray Angle Proportional to Trend Estimate. Solid Symbol Indicates Significant Trend $(p<0.05)$. 


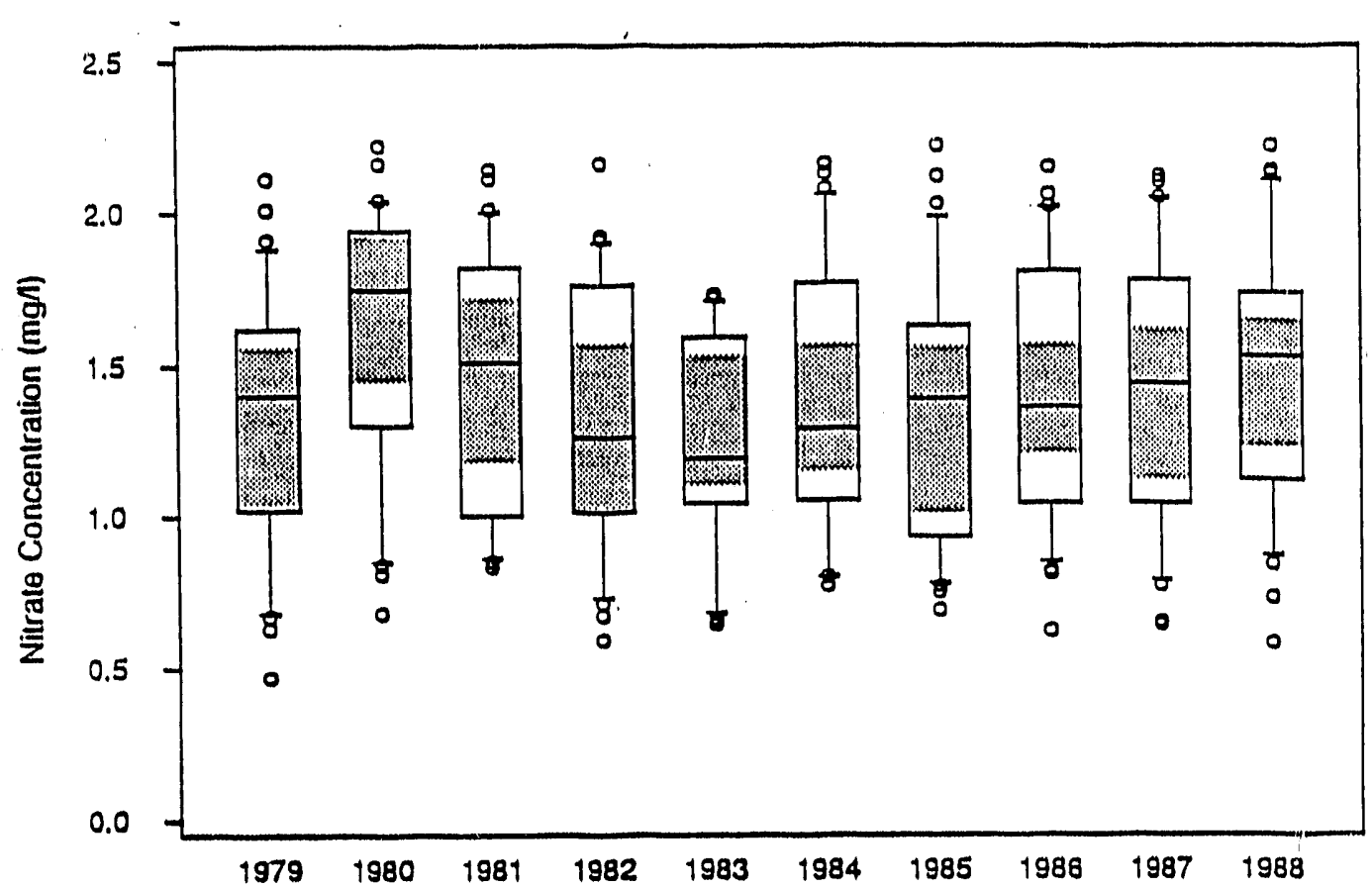

FIGURE A.28a. Temporal Pattern of Annual Precipitation-weighted Nitrate Ion Concentration. Boxplots are the 10th, 25th, 50th, 75th and 90th Precentiles of Sites in the 1979-88 Trend Subset.

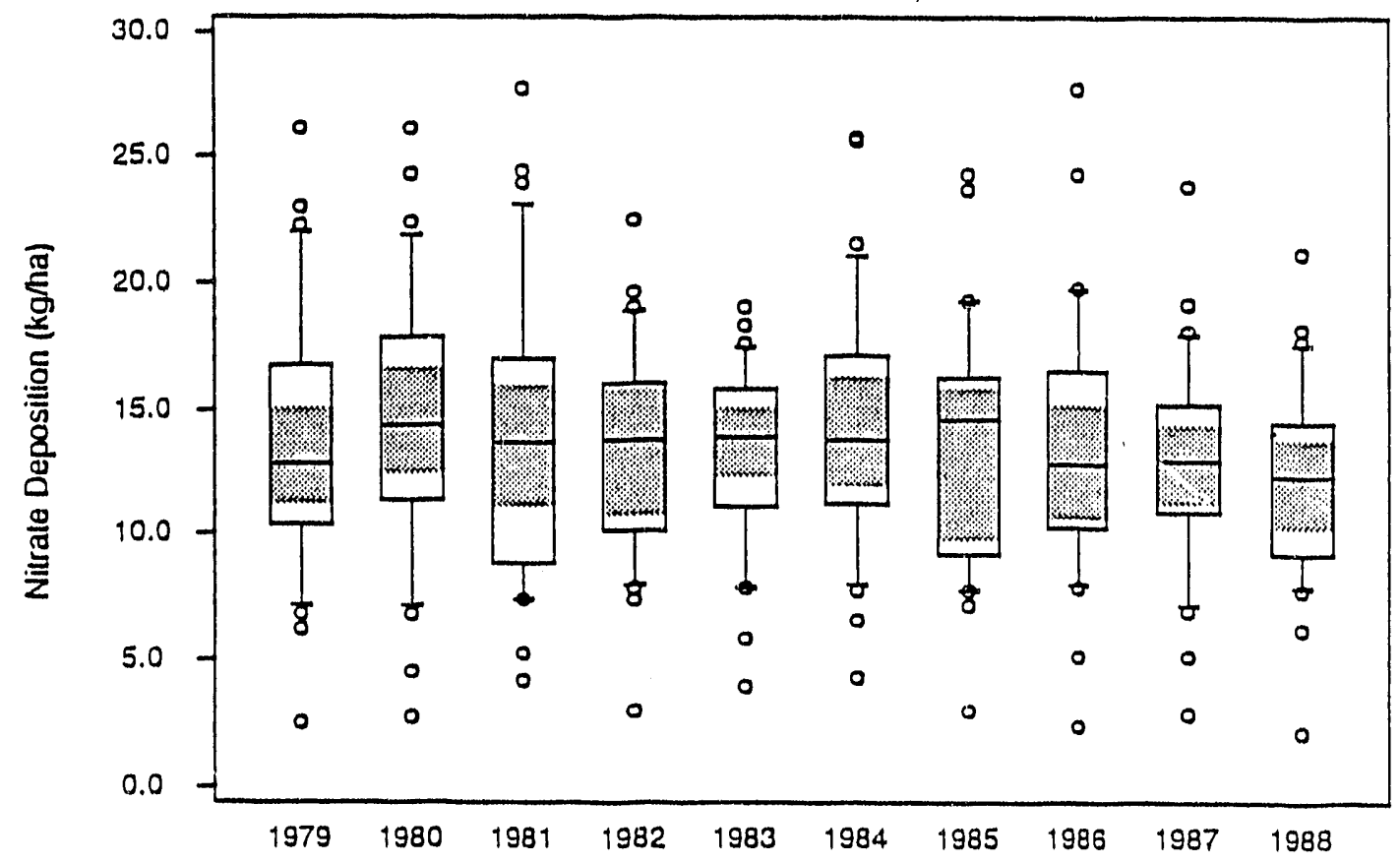

FIGURE A.28b. Temporal Pattern of Annual Nitrate Ion Wet Deposition. Boxplots are the 10th, 25th, 50th, 75th and 90th Percentiles of Sites in 1979-88 Trend Subset. 


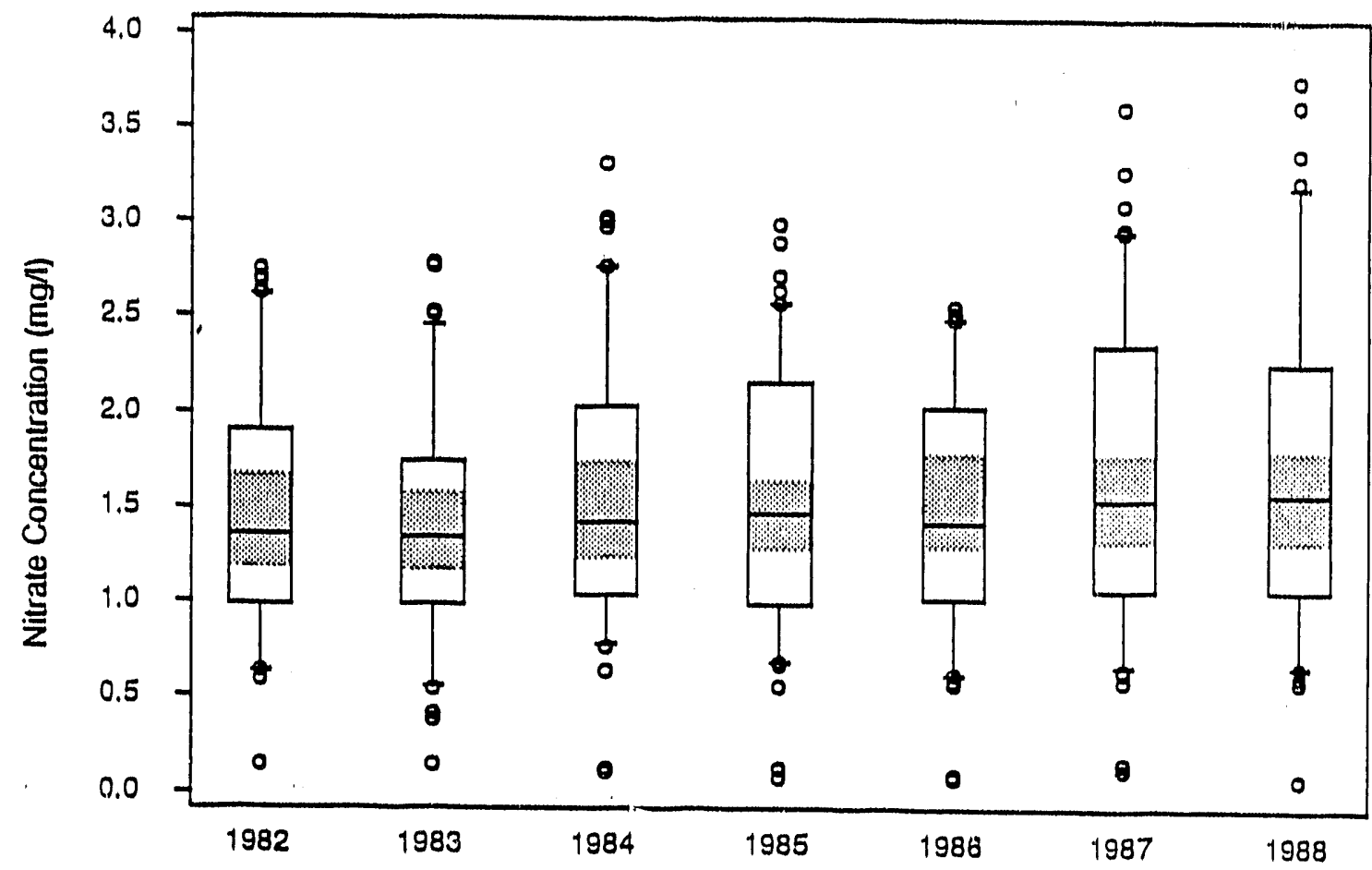

FIGURE A.29a. Temporal Pattern of Annual Precipitation-weighted Nitrate Ion Concentration. Boxplots are the 5th, 25th, 50th, 75th and 95th Percentiles of Sites in the 1982-88 Trend Subset.

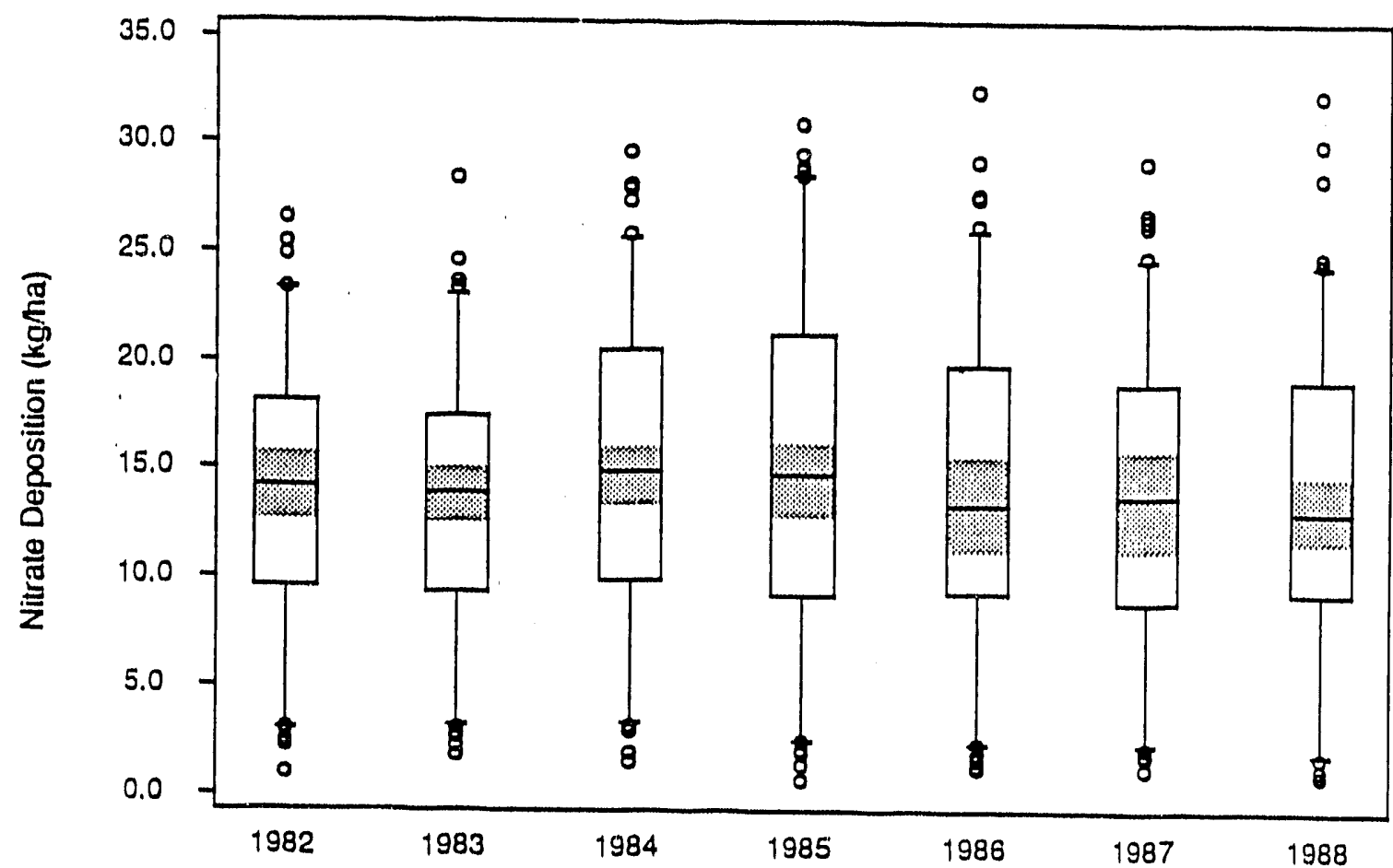

FIGURE A.29b. Temporal Pattern of Annual Nitrate Ion Wet Depostion. Boxplots are the 5th, 25th, 25th, 50th and 95th Percentfles of Sites in the 1982-88 Trend Subset. 


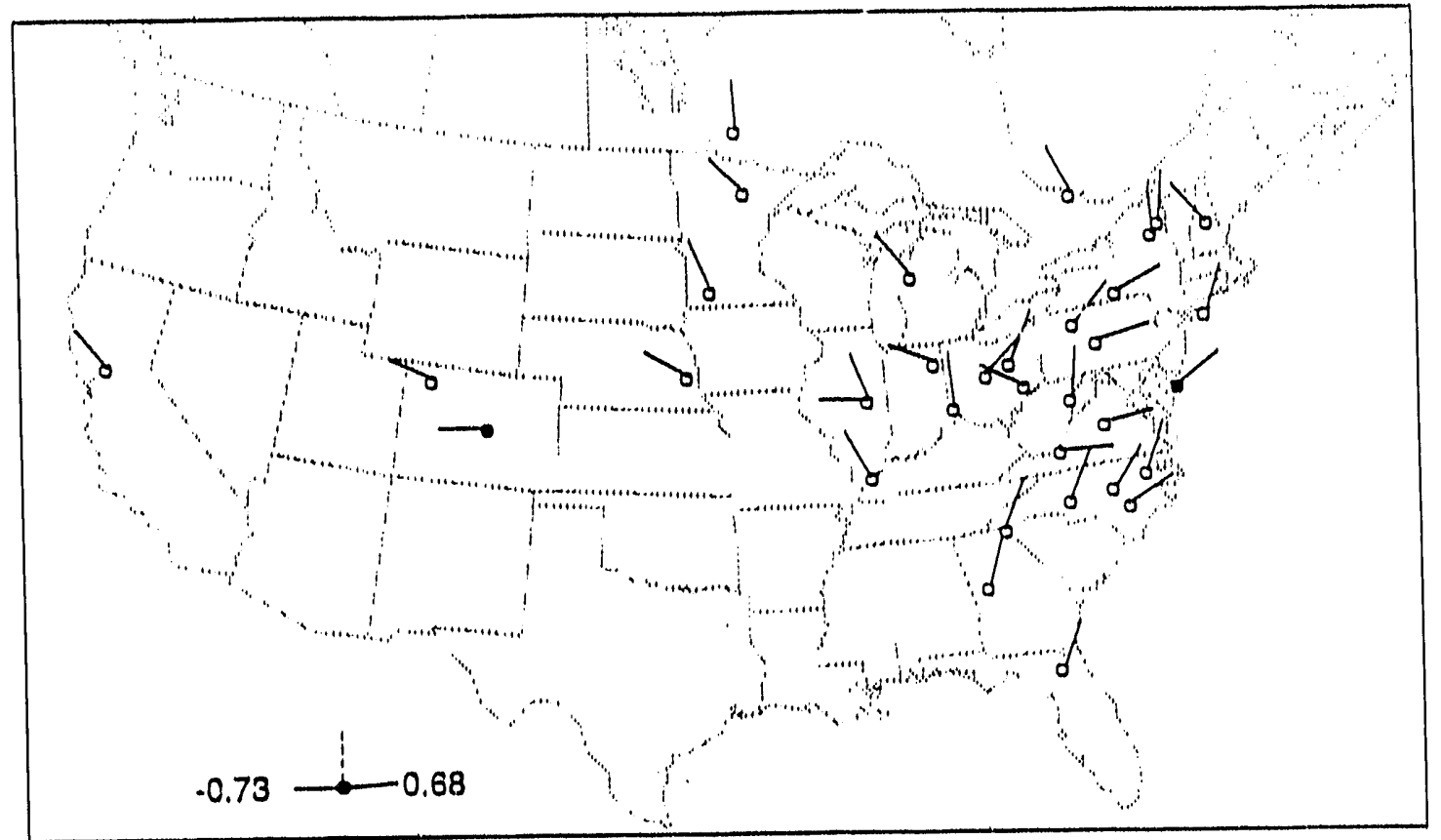

EIGURE A.30a. Nitrate Concentration ( $\mu$ eq/ 1 ) Trend Estimates for 1979-88 Trend Subset. Ray Angle Proportional to Trend Estimate. Soltd Symbol Indicates Significant Trend $(p<0.05)$.

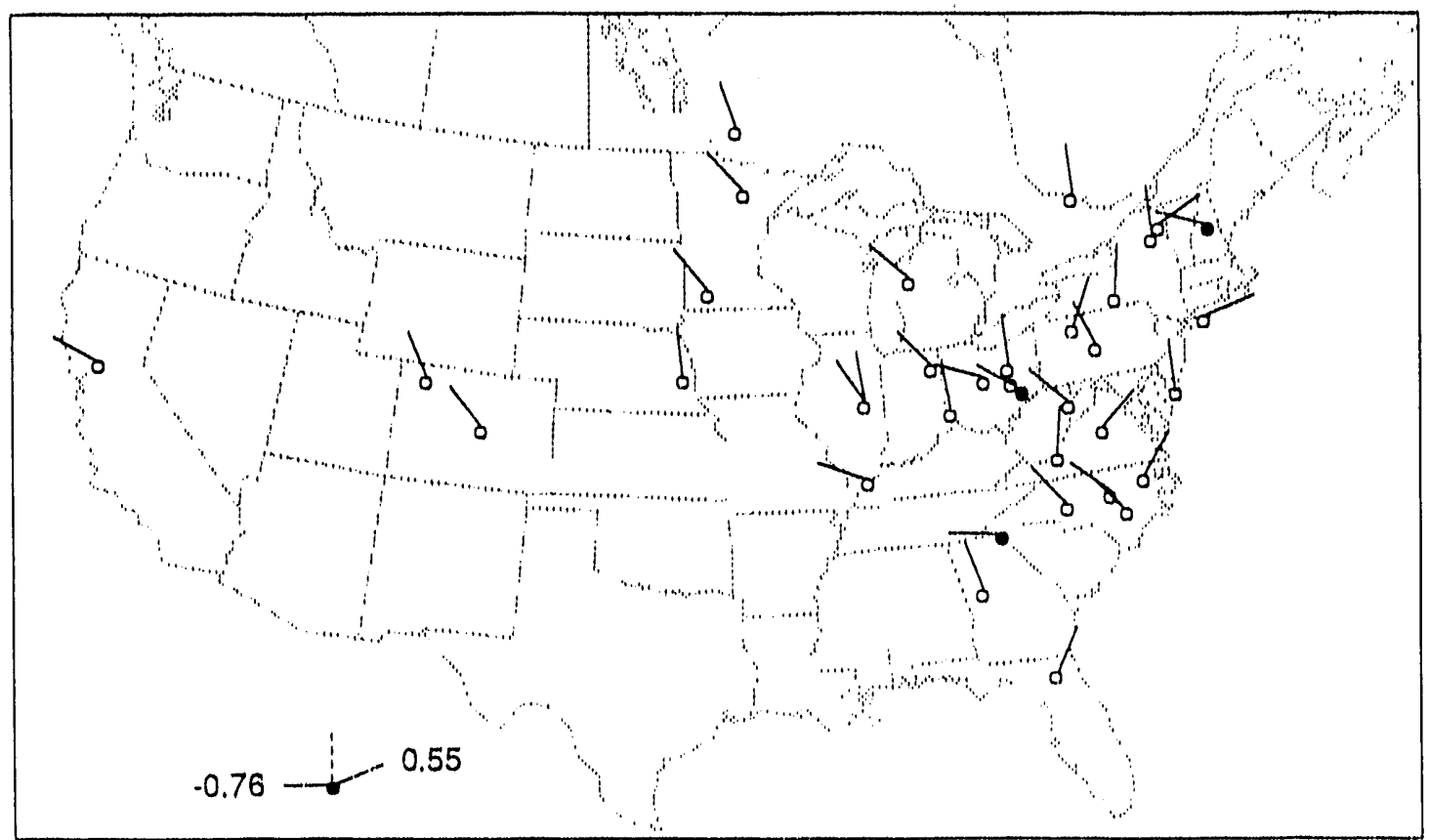

FIGURE A.30b. Nitrate Deposition $\left(\mathrm{meq} / \mathrm{m}^{2}\right)$ Trend Estimates for 1979-88 Trend Subset. Ray Angle Proportional to Trend Estimate. Solid Symbol Indicates significant Trend $(p<0.05)$. 


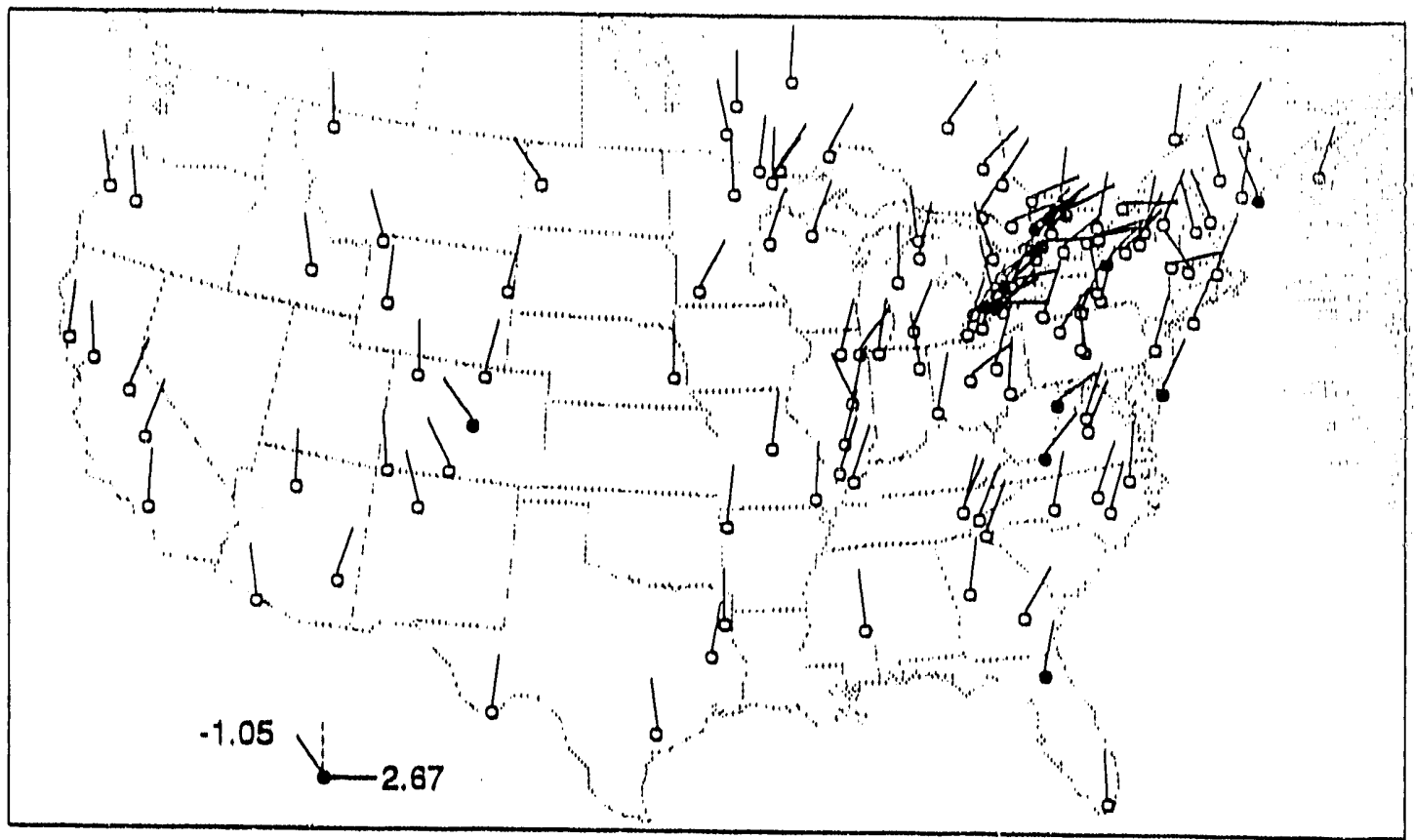

EIGURE A.31a. Nitrate Concentration ( $\mu$ eq/1) Trend Estimates for 1982-88 Trend Subset. Map Ray Angle Proportional to Trend Estimate. Solid Symbol Indicates Significant Trend $(p<0.05)$.

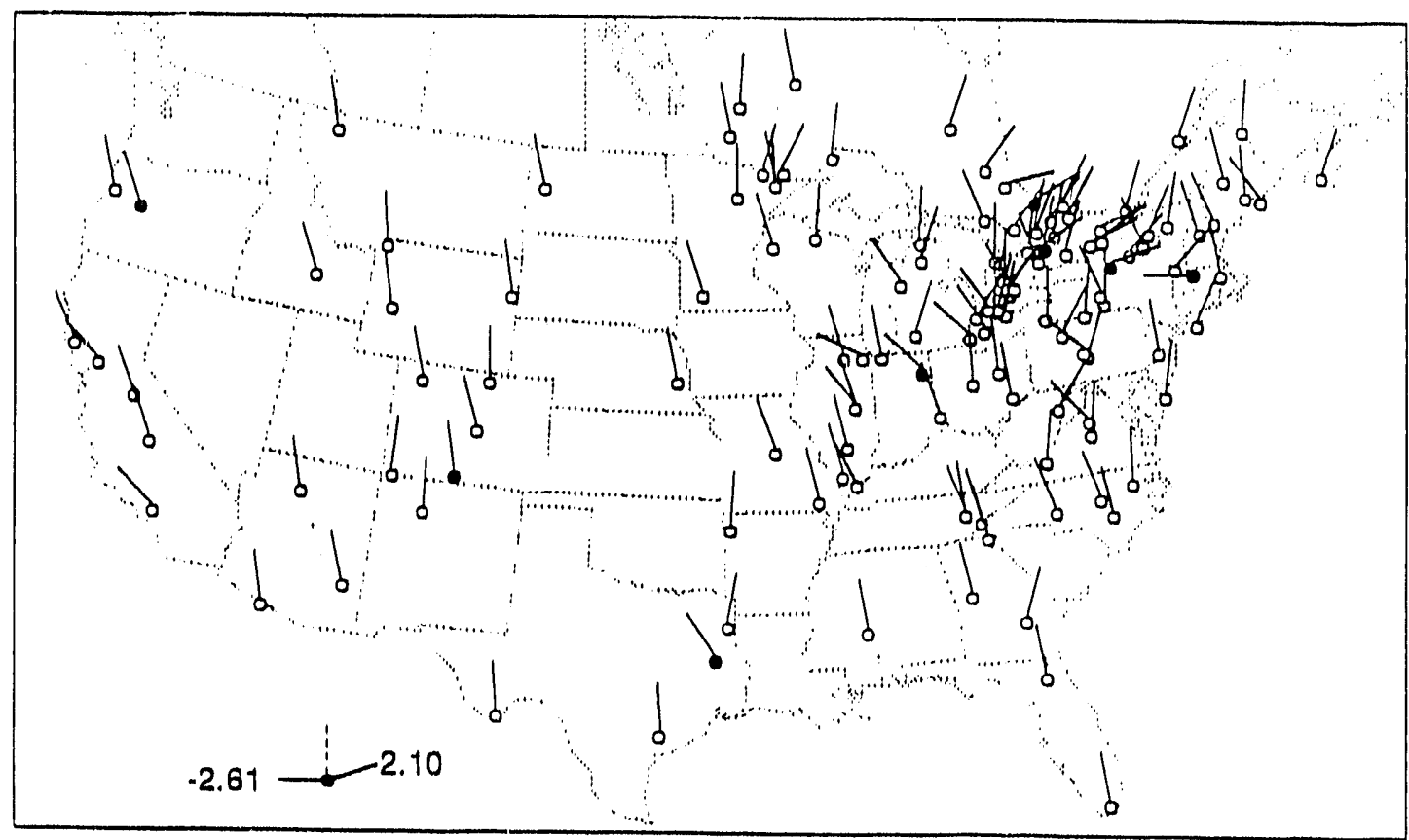

FIGURE A.31b. Nitrate Deposition (meq/ $\mathrm{m}^{2}$ ) Trend Estimates for 1982-88 Trend Subset. Ray Angle Proportional to Trend Estimate, Solld Symbol Indicates Significant Trend $(p<0.05)$. 


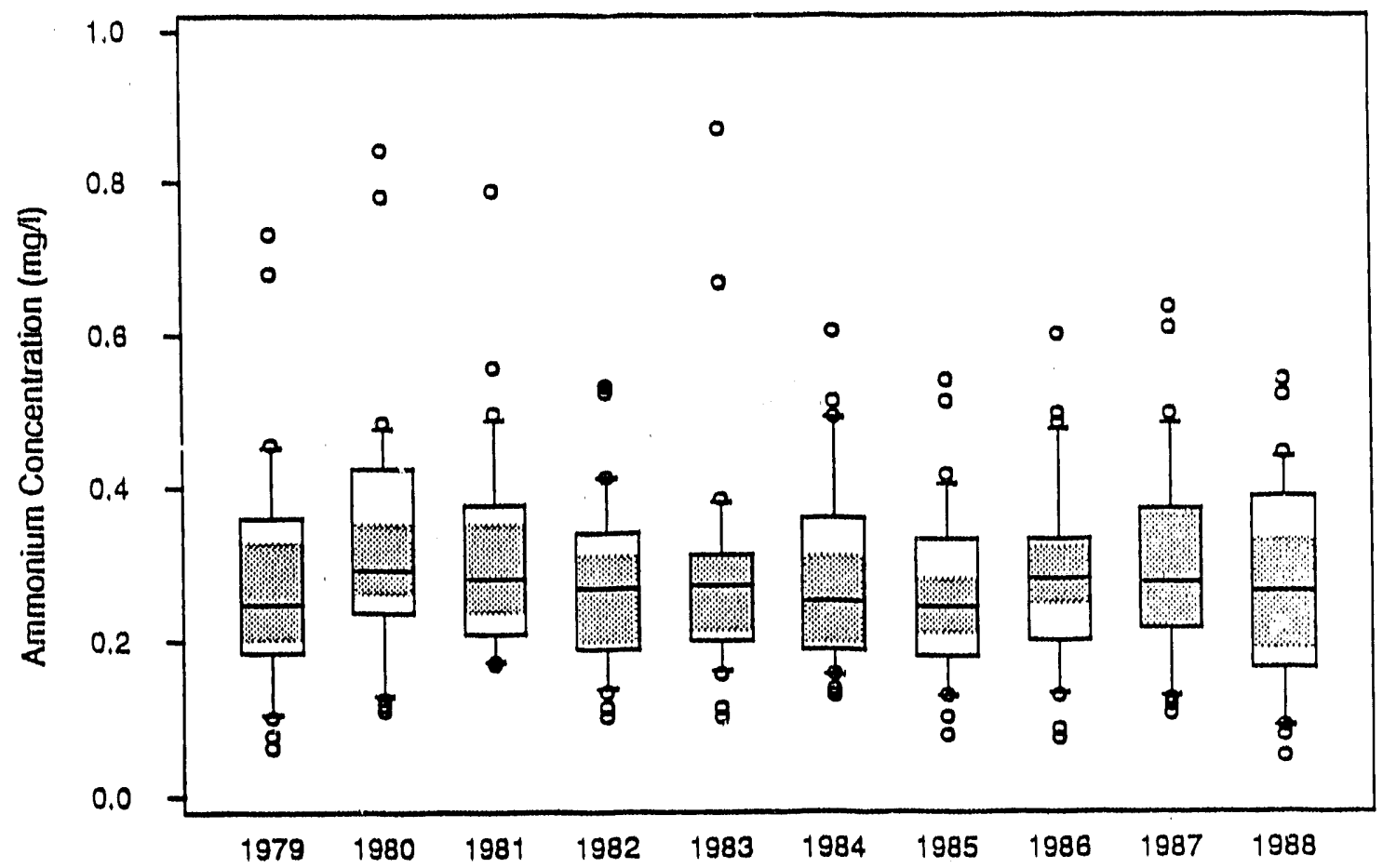

EIGURE A.32a. Temporal Pattern of Annual Precipitation-weighted Ammonium Ion Concentration. Boxplots are the 10th, 25th, 50th, 75th and 90th Percentiles of Sites in the 1979-88 Trend Subset.

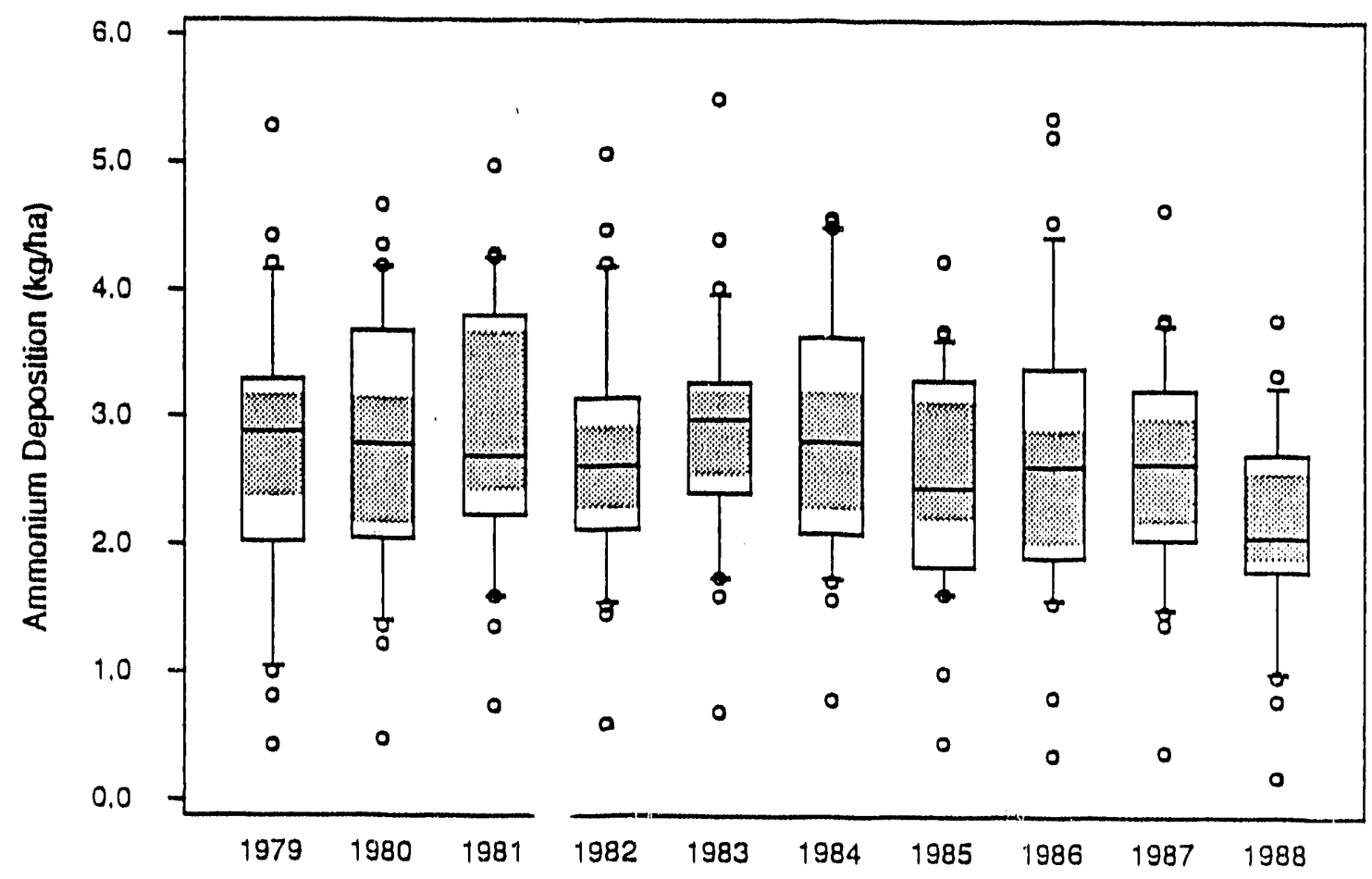

FIGURE A.32b. Temporal Pattern of Annual Ammontum Ion Wet Depostion. Boxplots are the 10th, 25th, 50th, 75th and 90th Percentiles of Sites in the 1979-88 Trend Subset. 


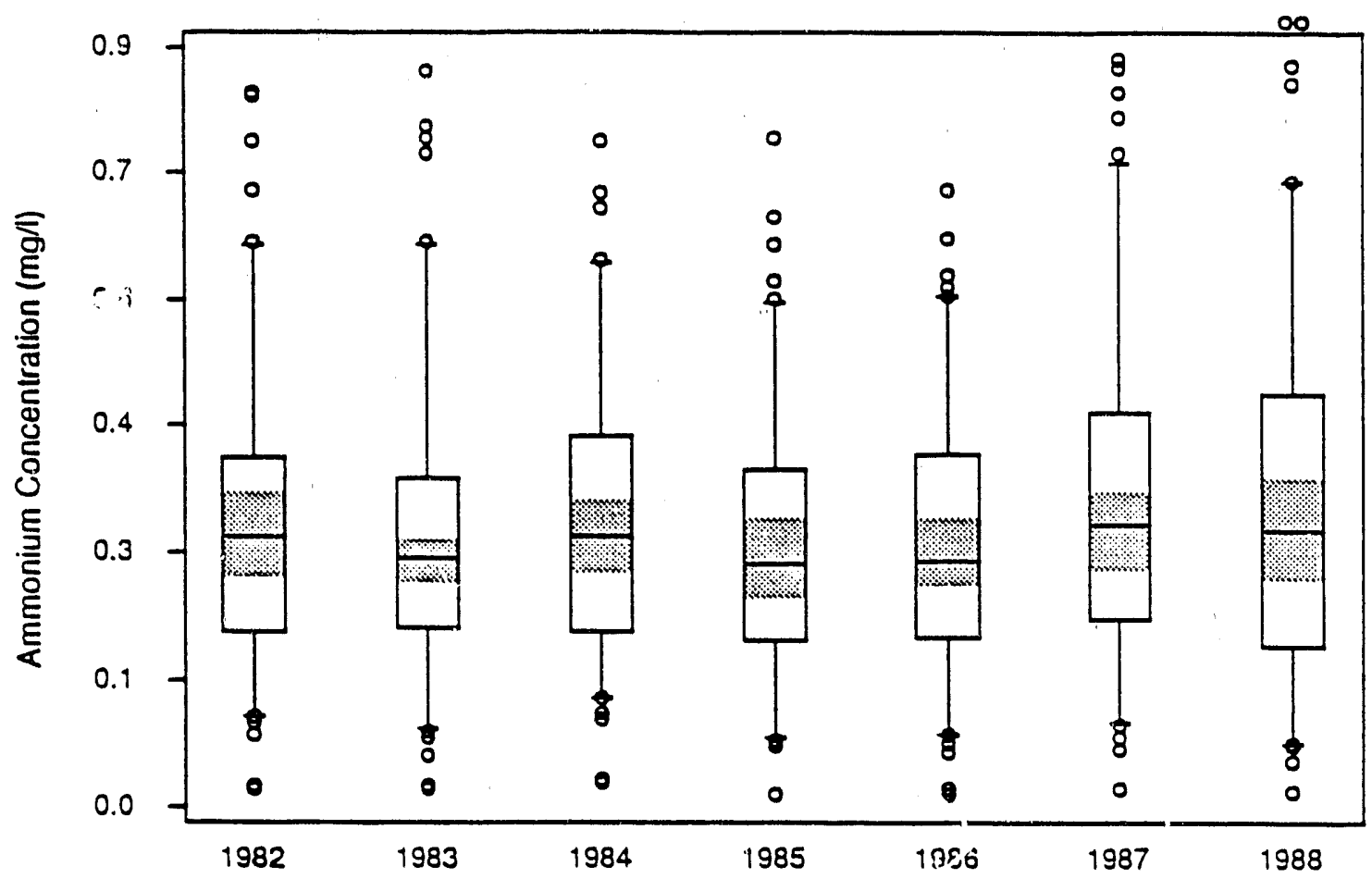

FIGURE A.33a. Temporal Pattern of Annual Precipitation-weighted Ammonium Ion Concentration. Boxplots are the 5th, 25th, 50th, 75th and 95th Percentiles of Sites in the 1982-88 Trend Subset.

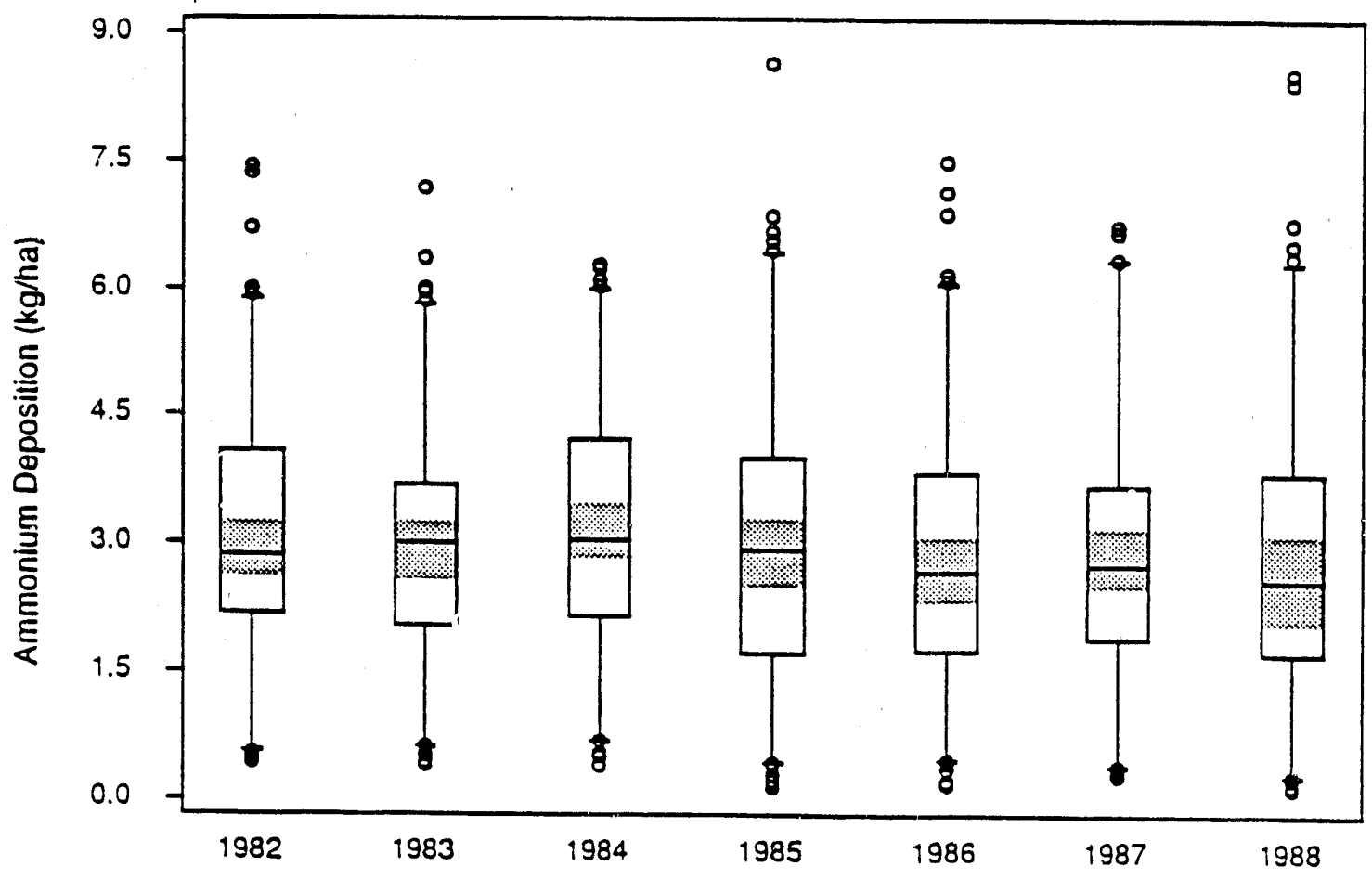

FIGURE A.33b. Temporal Pattern of Annual Ammonium Ion Wet Depostion. Boxplots are the 5th, 25th, 50th, 75th and 95th Percentiles of Sites in the 1982-88 Trend Subset. 


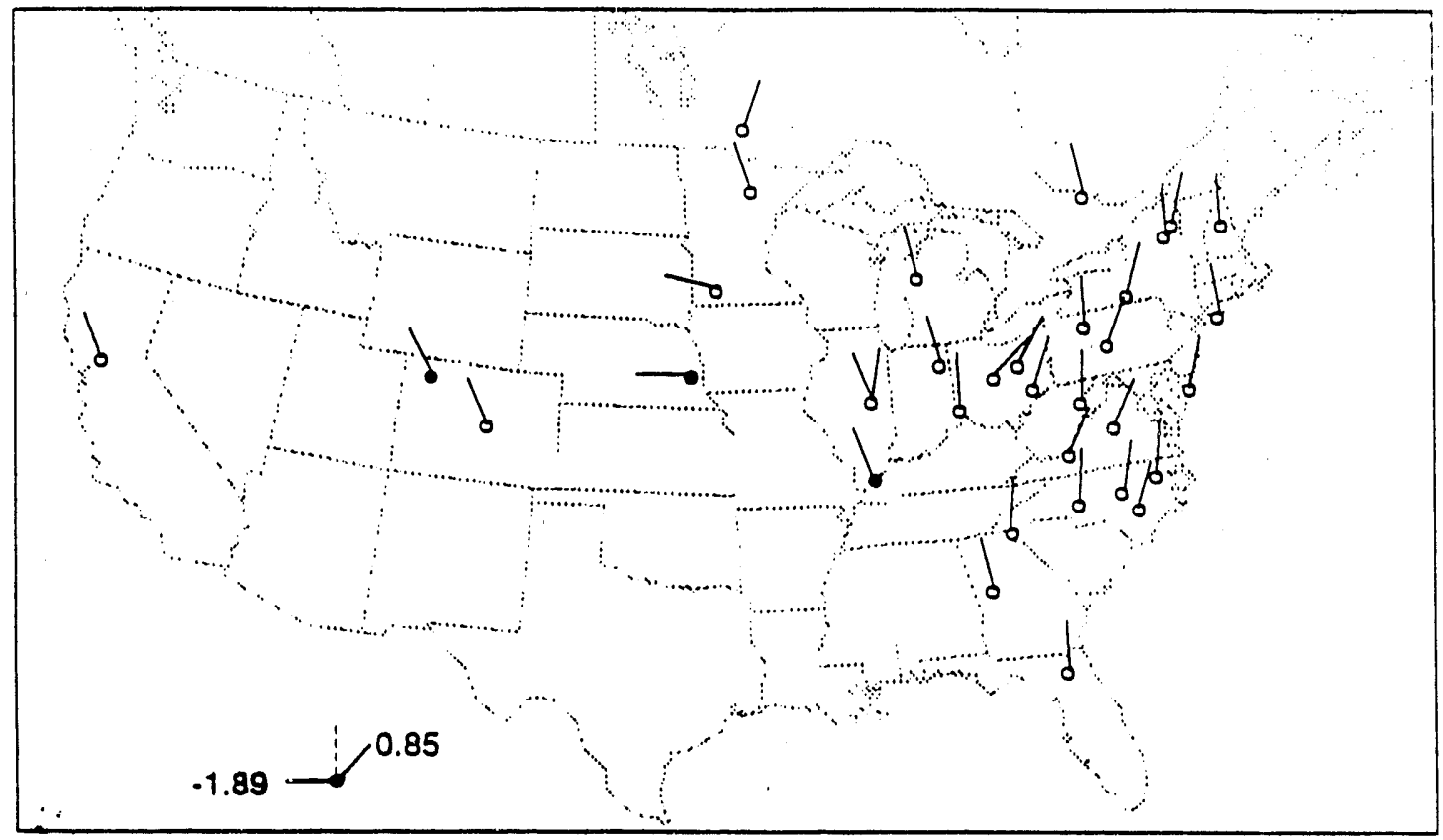

FIGURE A.34a. Ammonium Concentration ( $\mu \mathrm{eq} / 1$ ) Trend Estimates for 1979-88 Trend Subset. Ray Angle Proportional to Trend Estimate. Solid Symbol Indicates Significant Trend $(p<0.05)$.

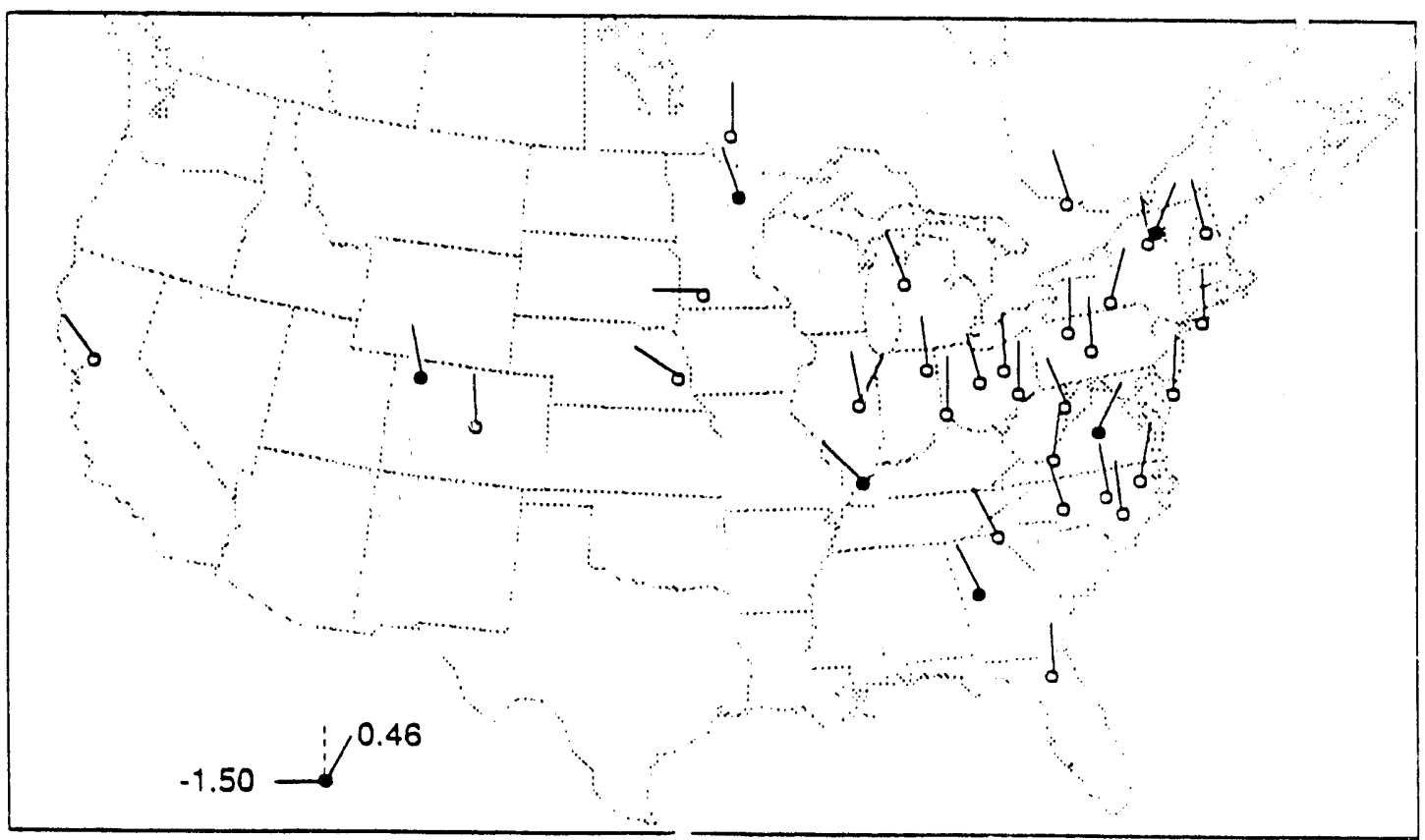

FIGURE A.34b. Ammonium Deposition (meq/ $\mathrm{m}^{2}$ ) Trend Estimates for 1979-88 Trend Subset. Ray Angle Proportional to Trend Estimate. Solid Symbol Indicates Significant. Trend $(p<0.05)$. 


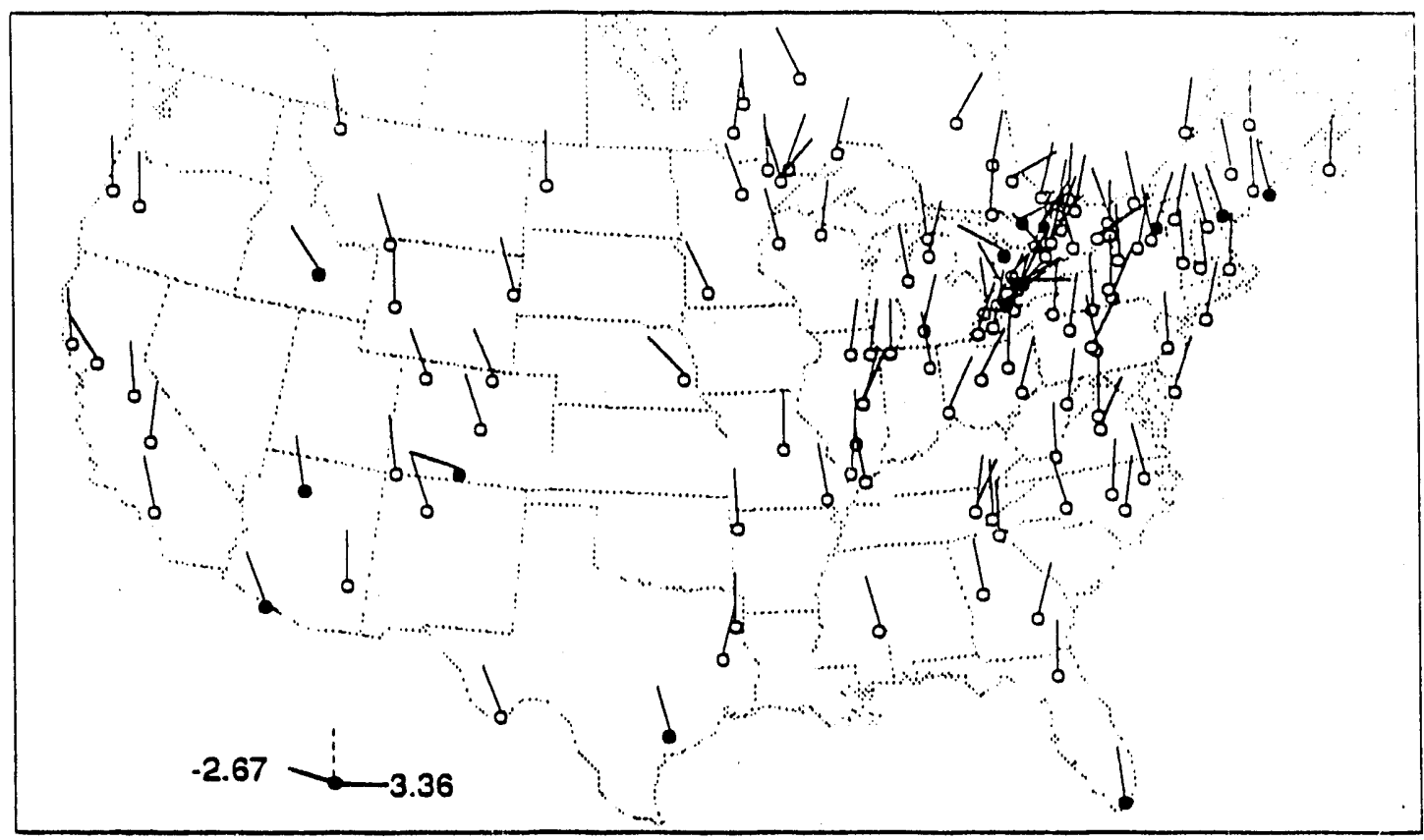

FIGURE A.35a. Ammonium Concentration ( $\mu \mathrm{eq} / 1$ ) Trend Estimates for 1982-88 Trend Subset. Ray Angle Proportional to Trend Estimate. Solid Symbol Indicates Significant Trend $(p<0.05)$.

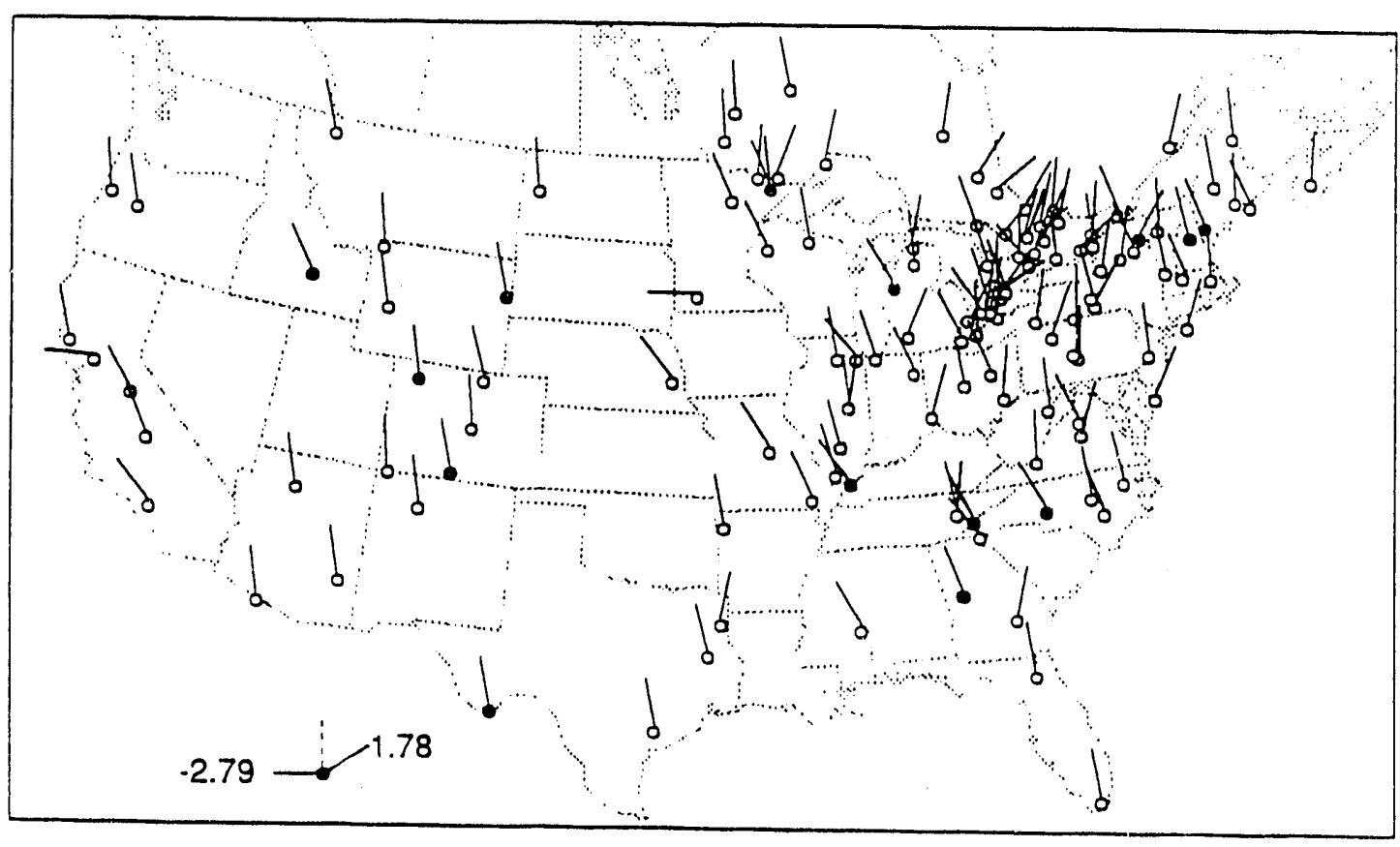

FIGURE A.35b. Ammonium Deposition (meq $/ \mathrm{m}^{2}$ ) Trend Estimates for 1982-88

Trend Subset. Ray Angle Proportional to Trend Estimate. Solid Symbol Indicates Significant Trend $(p<0.05)$.

\section{$\bar{A} .35$}




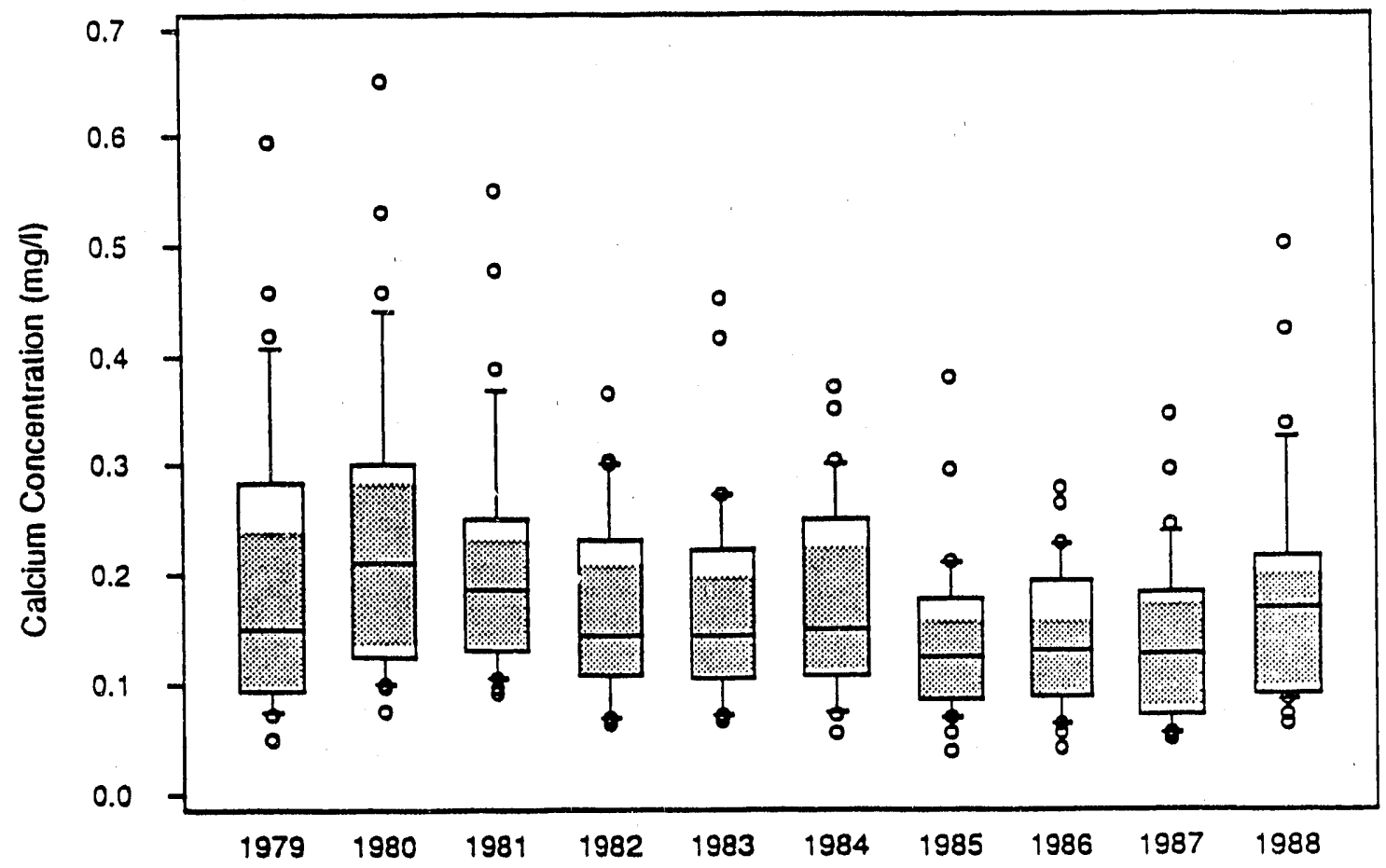

FIGURE A.36a. Temporal Pattern of Annual Precipitation-weighted Calcium Ion Concentration. Boxplots are the 10th, 25th, 50th, 75th and 90th Percentiles of Sites in the 1979-88 Trend Subset.

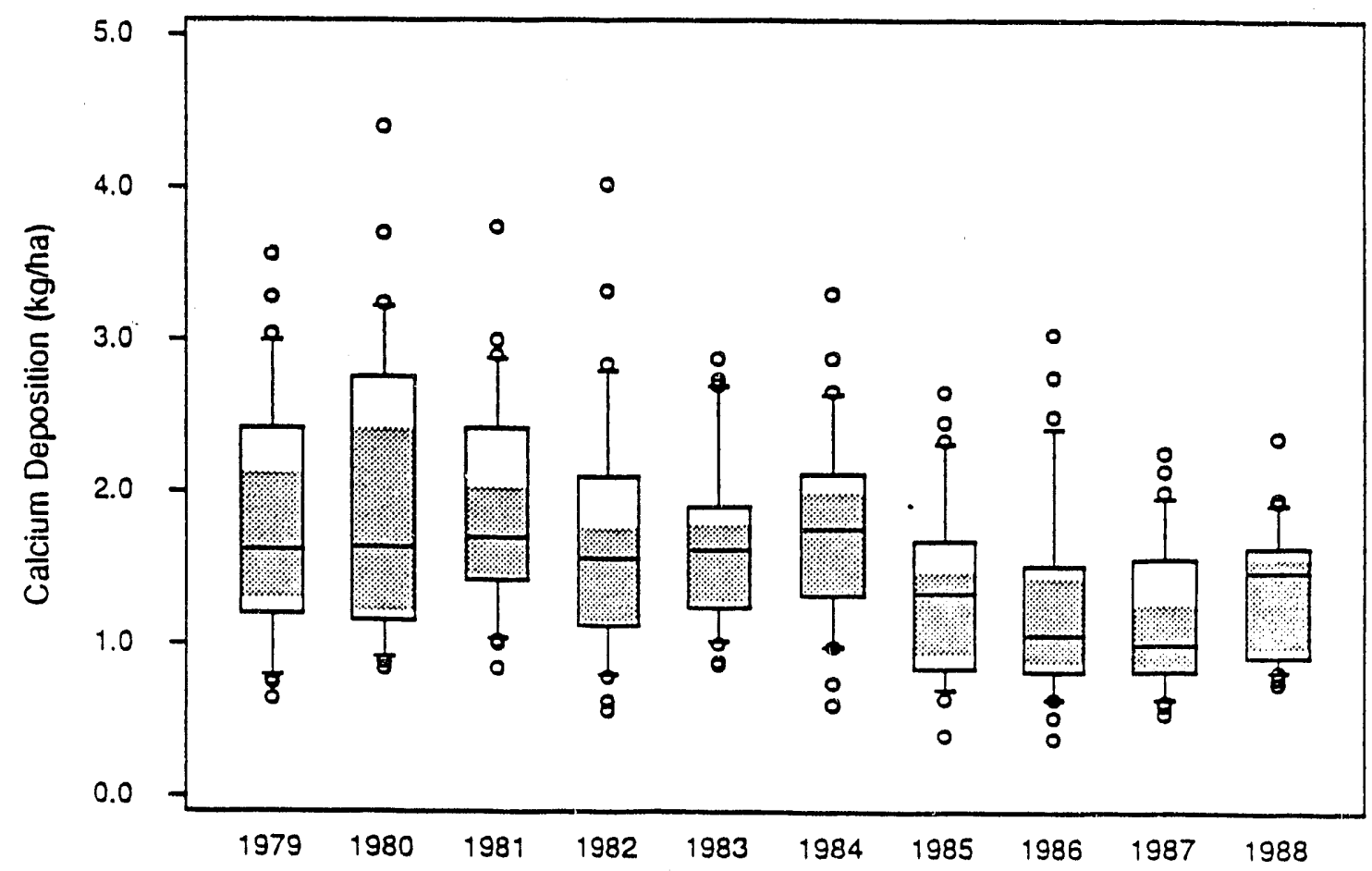

FIGURE A.36b. Temporal Pattern of Annual Calcium Ion Wet Deposition. Boxplots are the 10th, 25th, 50th, 75th and 90th Percentiles of Sites in the 1979-88 Trend Subset.

\section{A. 36}




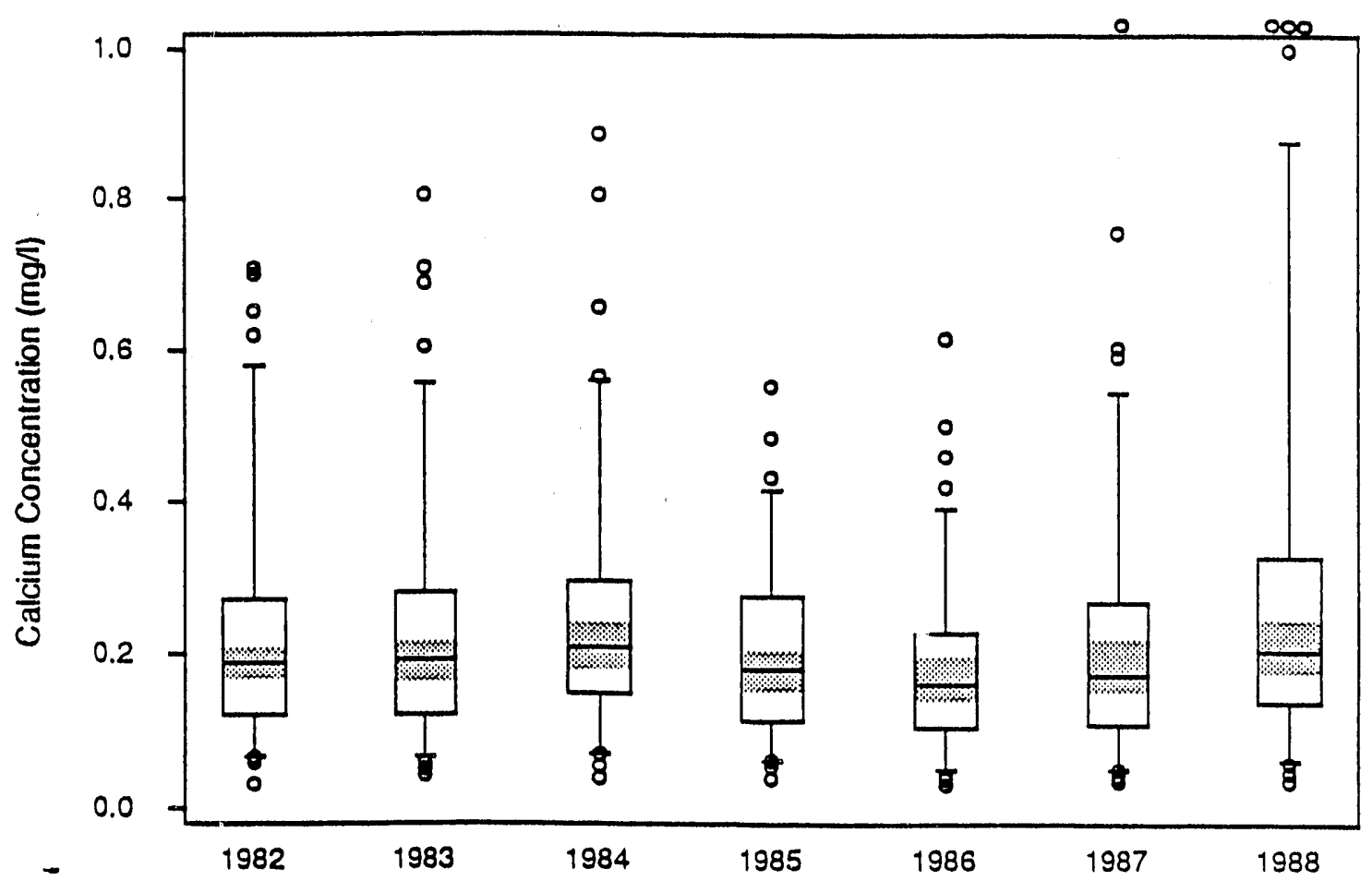

FIGURE A.37a. Temporal Pattern of Annual Precipitation-weighted Calcium Ion Concentration. Boxplots are the 5th, 25th, 50th, 75th and 95th Percentiles of Sites in the 1982-88 Trend Subset.

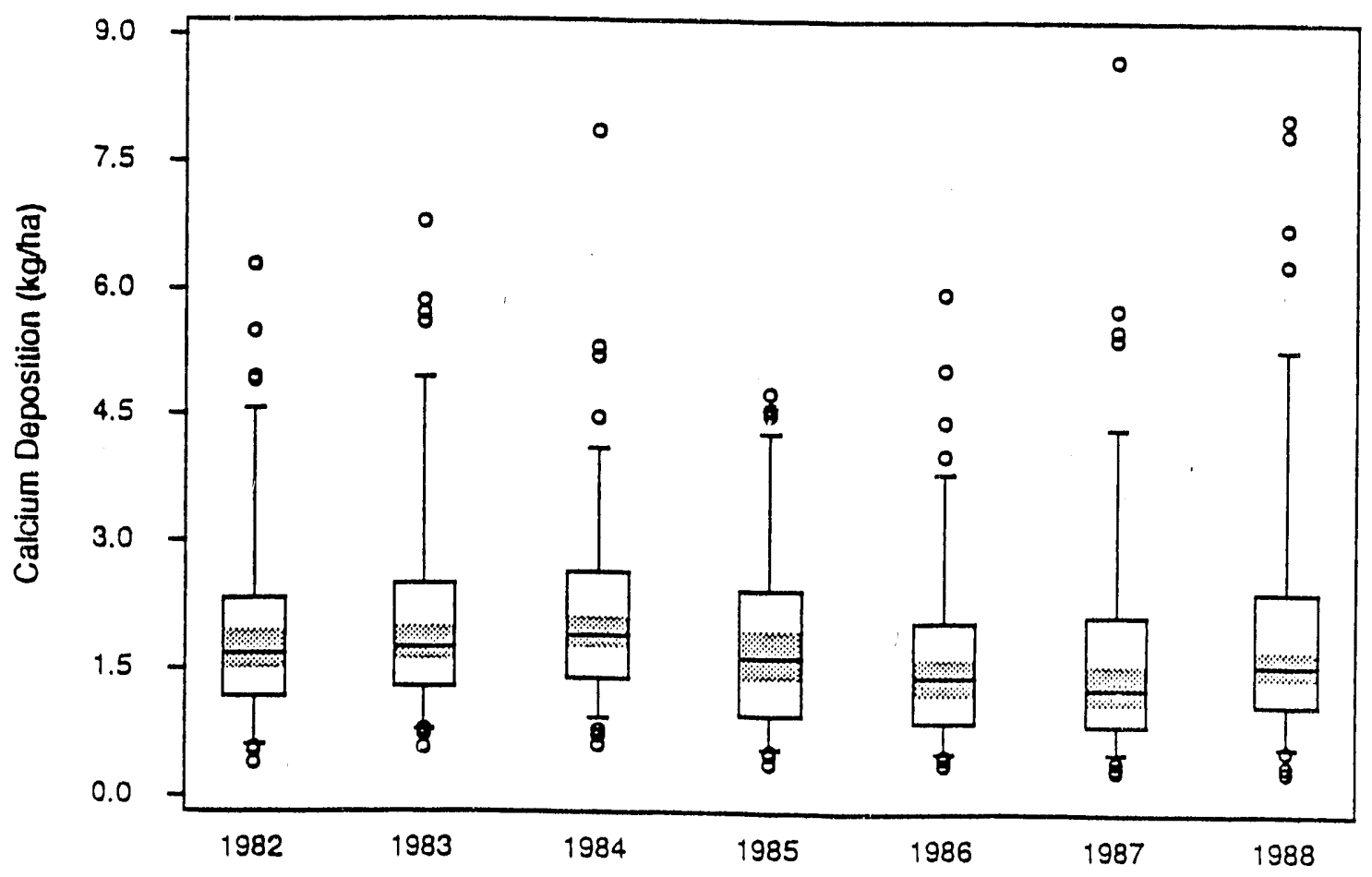

FIGURE A.37b. Temporal Pattern of Annual Calcium Ion Wet Deposition. Boxplots are the 5th, 25th, 50th, 75th and 95th Percentiles of Sites in the 1982-88 Trend Subset. 


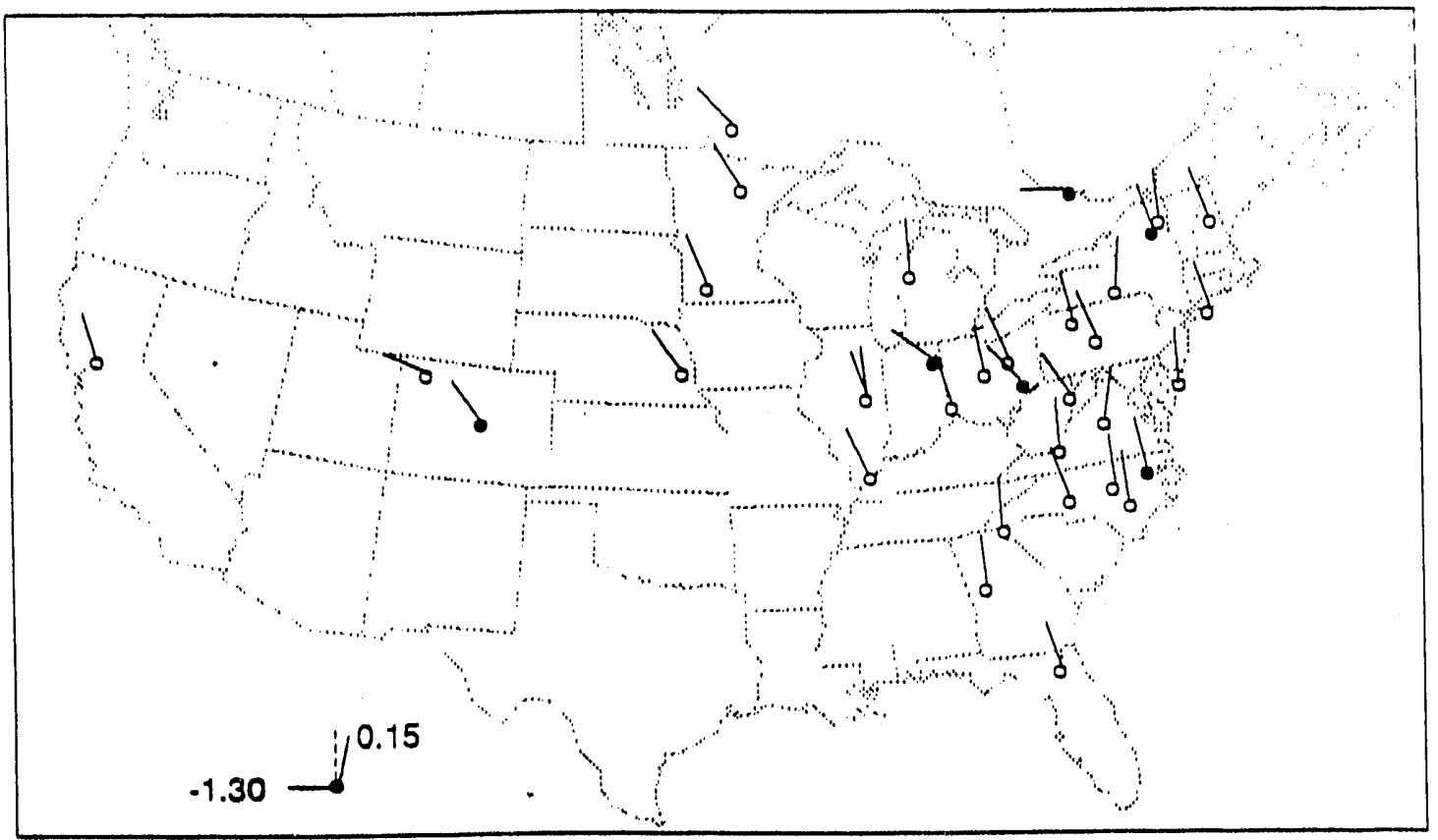

FIGURE A.38a. Calcium Concentration ( $\mu$ eq/1) Trend Estimates for 1979-88 Trend Subset. Ray Angle Proportional to Trend Estimate. Solid Symbol Indicates Significant Trend $(p<0.05)$.

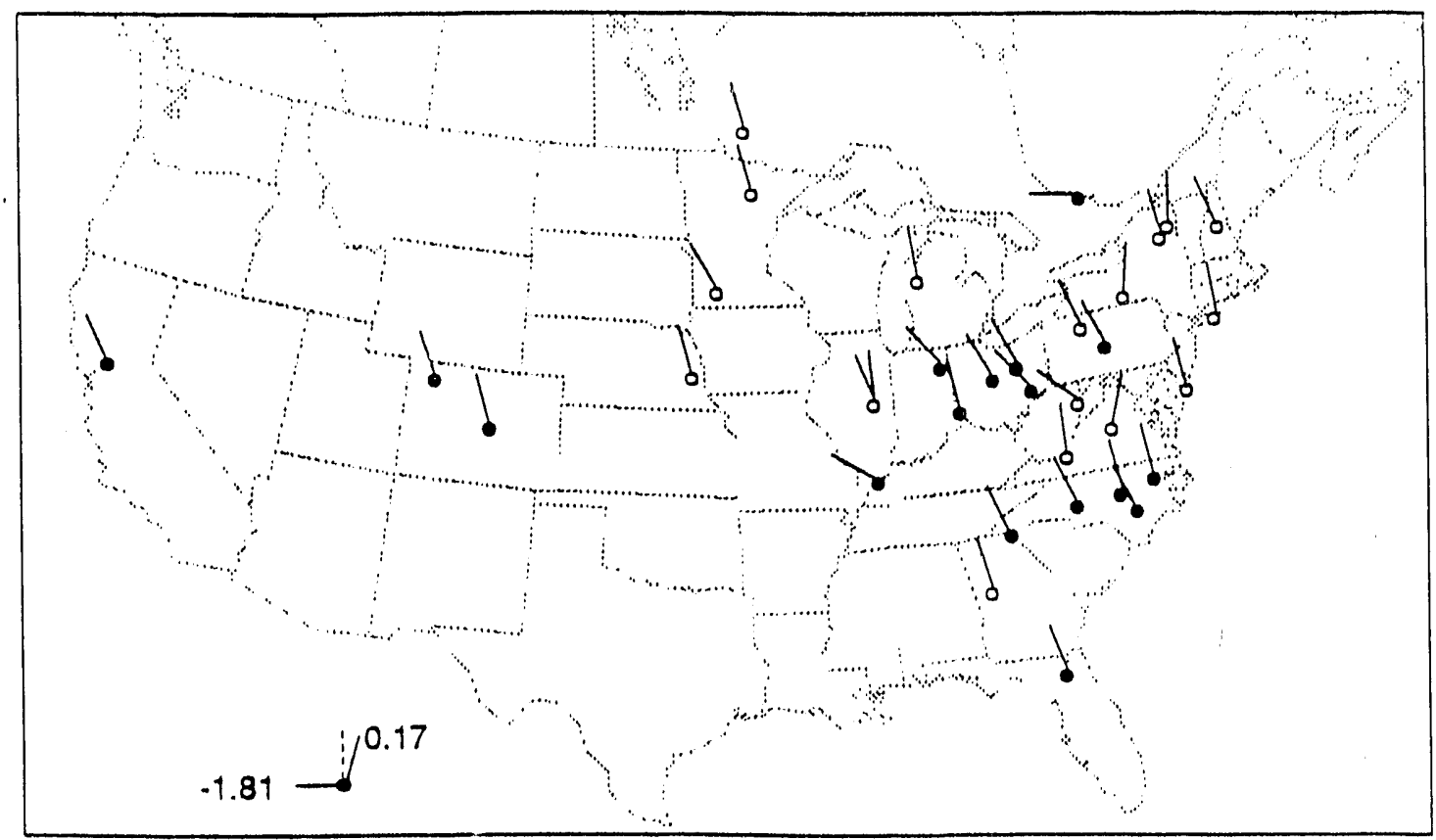

FIGURE A.38b. Calcium Deposition (meq/ $\mathrm{m}^{2}$ ) Trend Estimates for 1979-88 Trend Sites. Ray Angle Proportional to Trend Estimate. Solid Symbol Indicates Significant Trend $(p<0.05)$. 


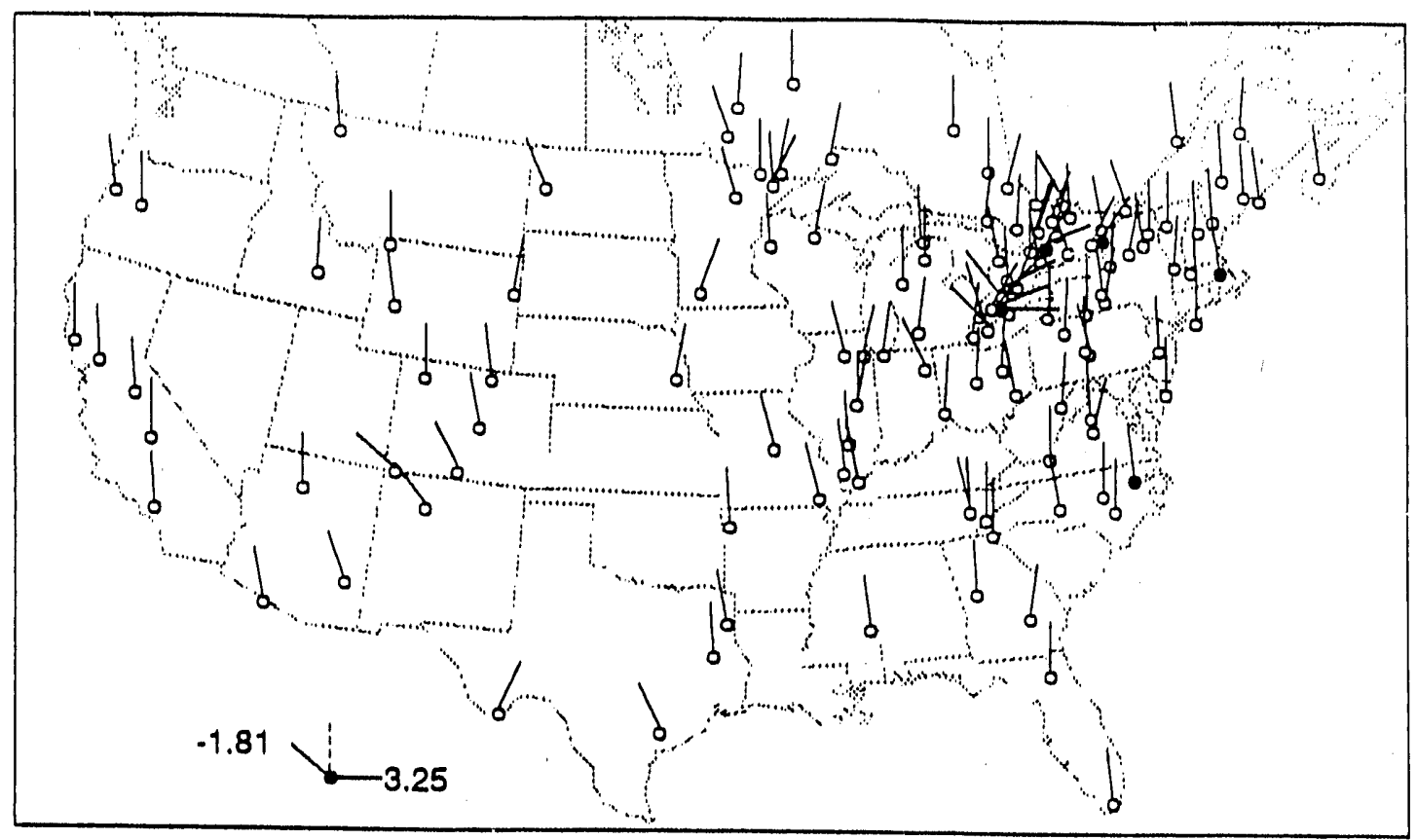

FIGURE A.39a. Calcium Concentration ( $\mu \mathrm{eq} / 1$ ) Trend Estimates for 1982-88

Trend Subset. Ray Angle Proportional to Trend Estimate. Solid Symbol Indicates Significant Trend $(p<0.05)$.

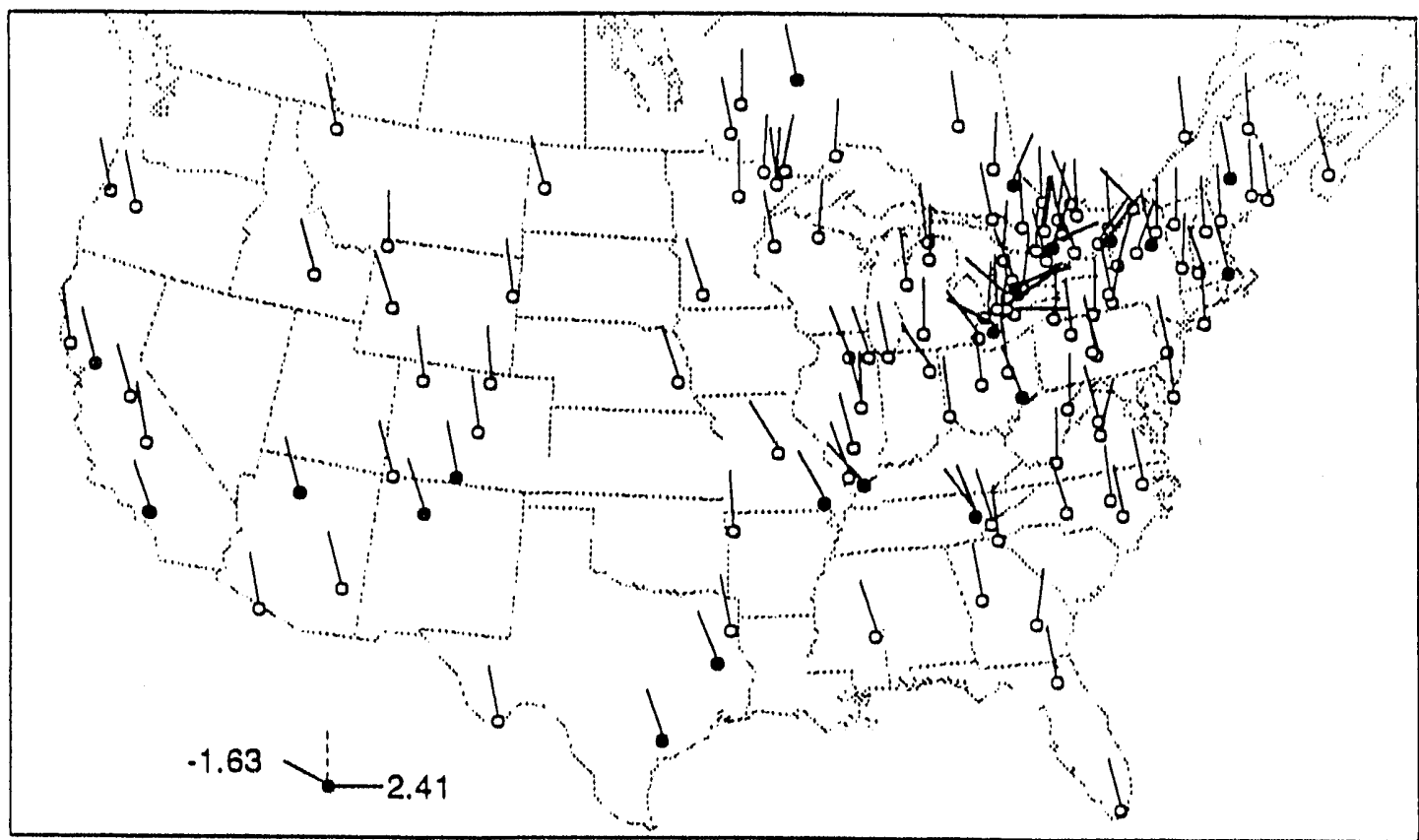

FIGURE A.39b. Calcium Deposition (meq $/ \mathrm{m}^{2}$ ) Trend Estimates for 1982-88 Trend Subset. Ray Angle Proportional to Trend Estimate. Solid Symbol Indicates Significant Trend $(p<0.05)$. 


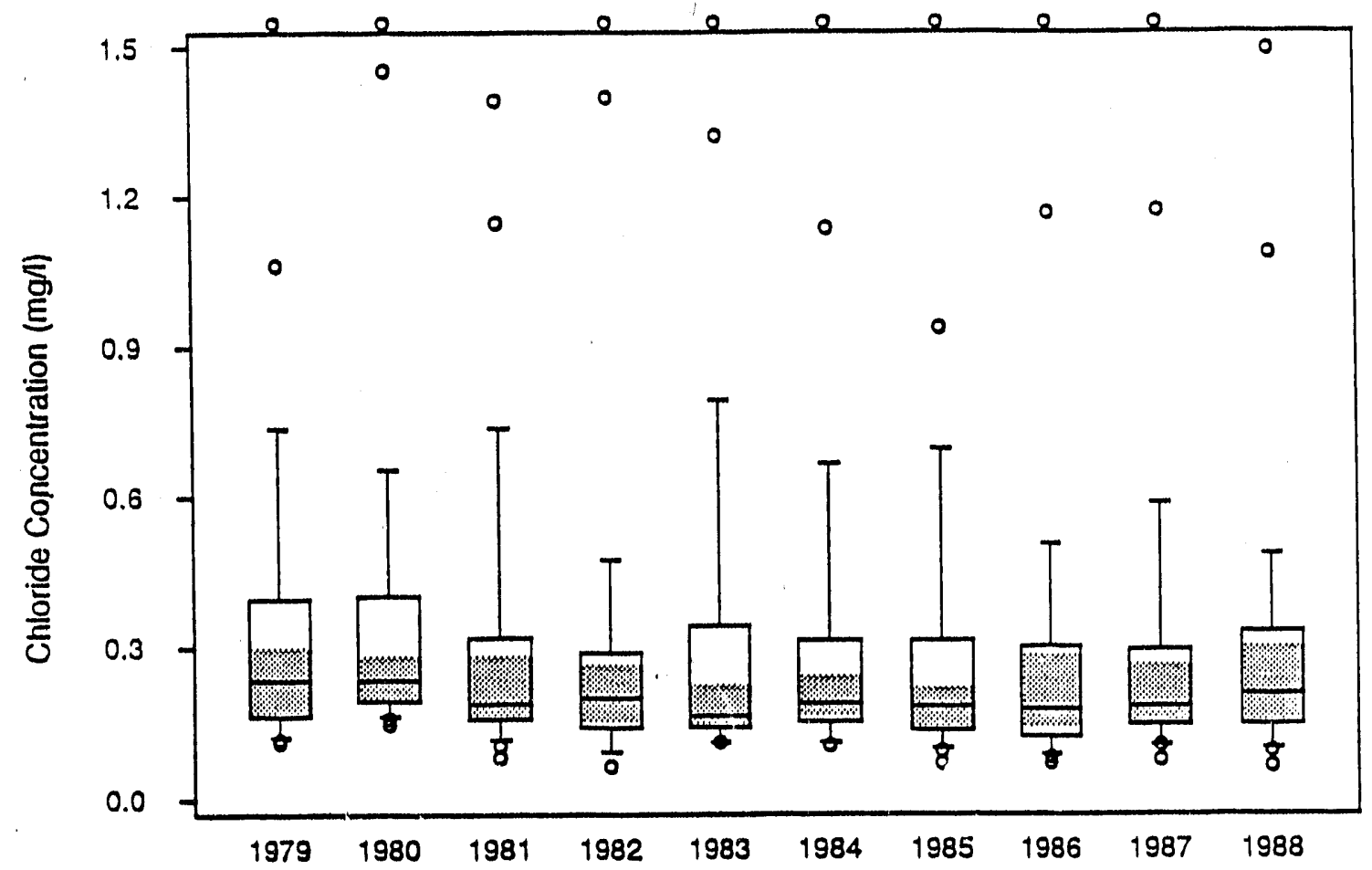

FIGURE A.40a. Temporal Pattern of Annual Precipitation-weighted Chloride Ion Concentration. Boxplots are the 10th, 25th, 50th, 75th and 90th Percentiles of Sites in the 1979-88 Trend Subset.

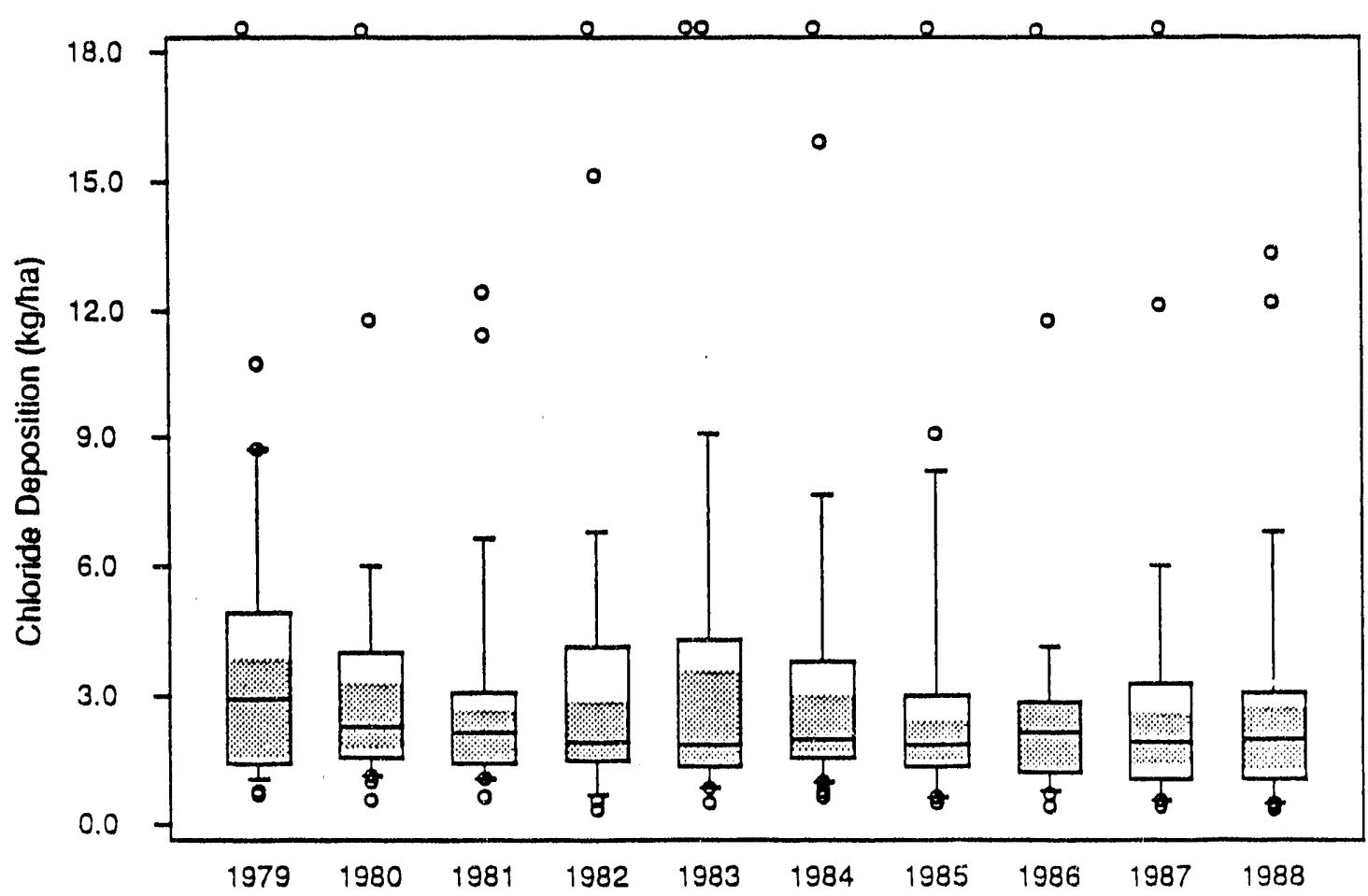

FIGURE A.40b. Temporal Pattern of Annual Chloride Ion Wet Deposition. Boxplots are the 10th, 25th, 50th, 75th and 90th Percentiles of Sites in the 1979-88 Trend Subset. 


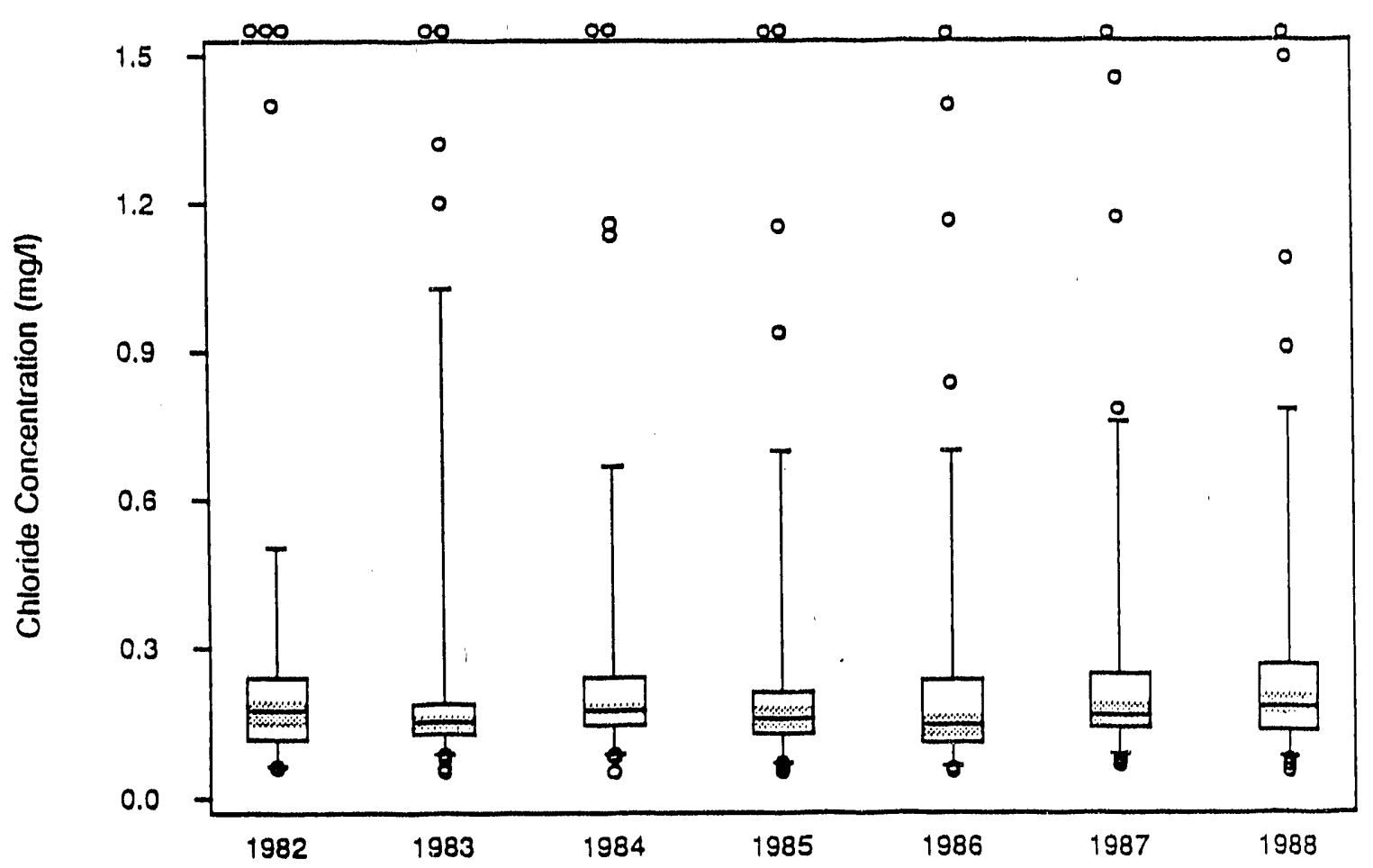

FIGURE A.41a. Temporal Pattern of Annual Precipitation-weighted Chloride Ion Concentration. Boxplots are the 5th, 25th, 50, 75th and 95th Percentiles of Sites in the 1982-88 Trend Subset.

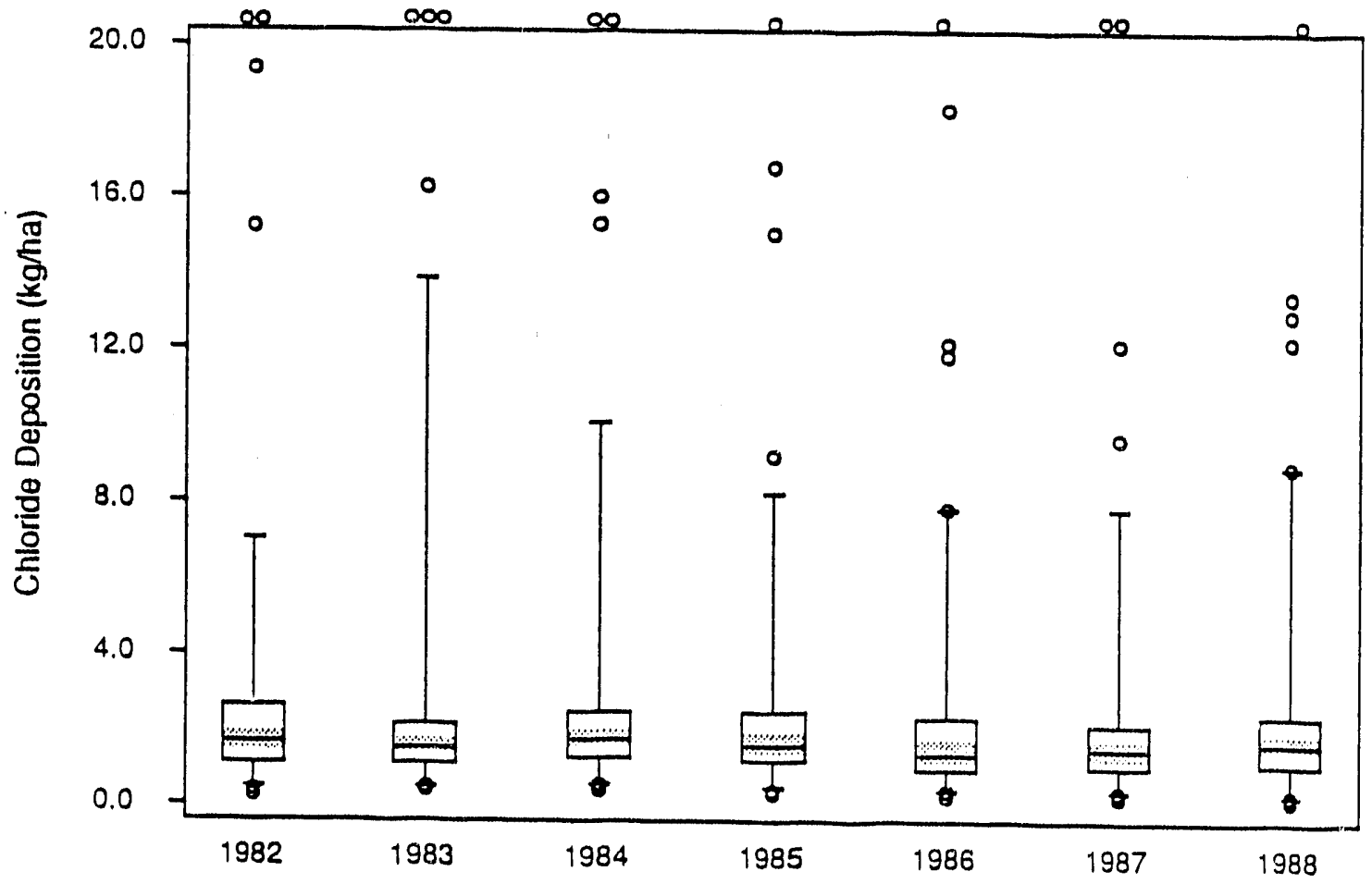

FIGURE A.41b. Temporal Pattern of Annual Chloride Ion Wet Deposition. Boxplots are the 5th, 25th, 50th, 75th and 95th Percentiles of Sites in the 1982-88 Trend Subset.

\section{A. 41}




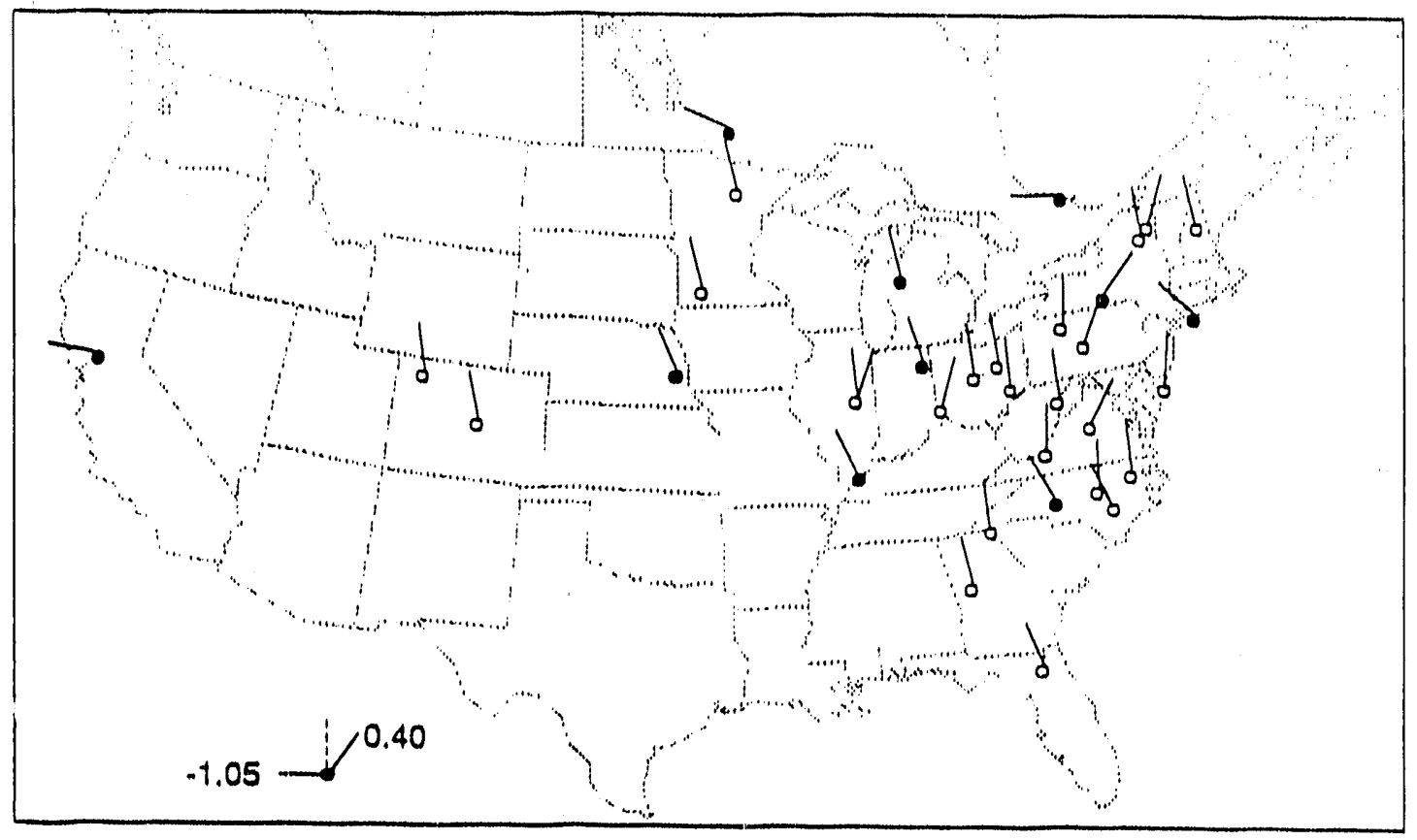

FIGURE A.42a. Chloride Concentration ( $\mu$ eq/1) Trend Estimates for 1979-88 Trend Subset. Ray Angle Proportional to Trend Estimate. Solid Symbol Indicates Significant Trend $(p<0.05)$.

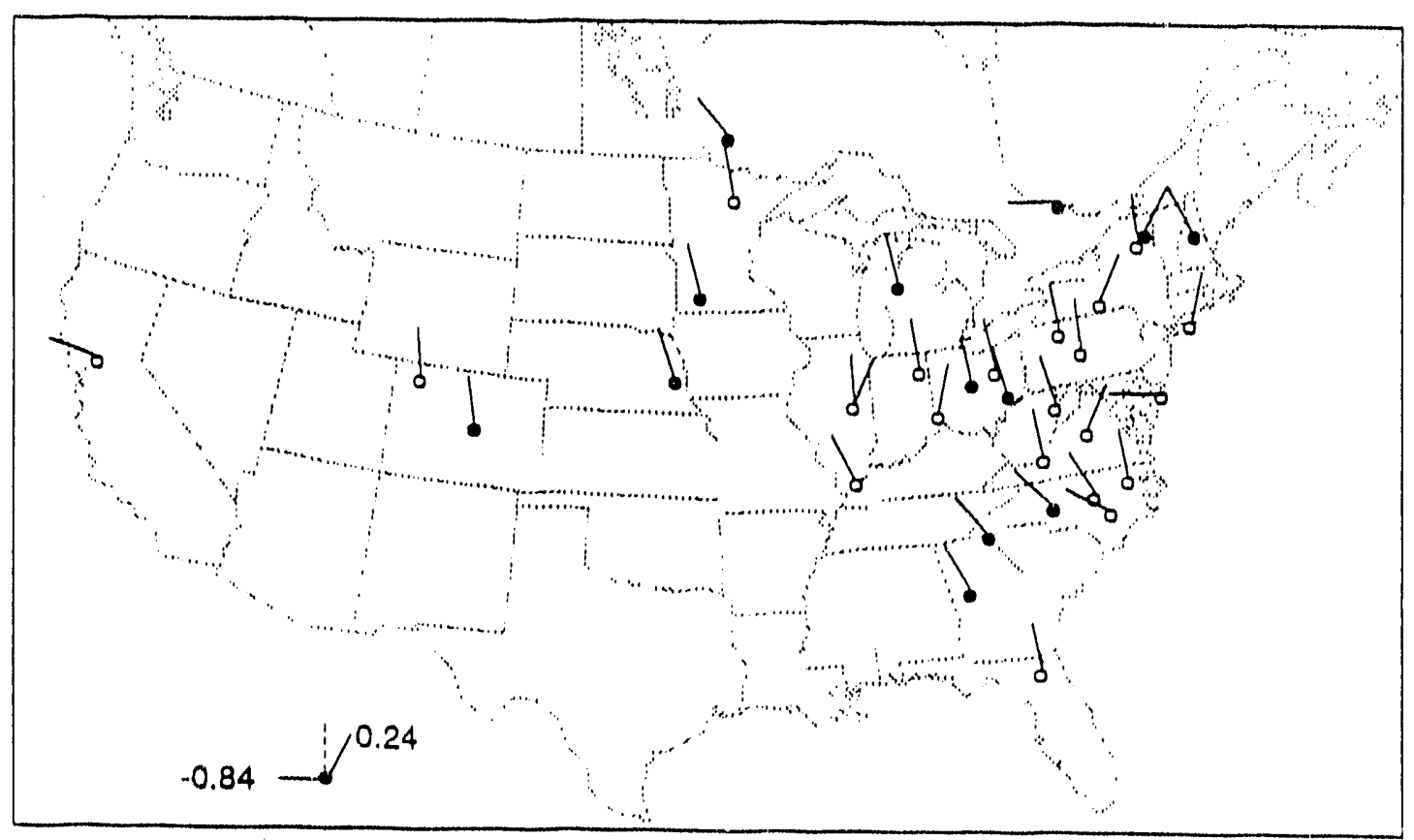

FIGURE A.42b. Chloride Deposition (meq/ $\mathrm{m}^{2}$ ) Trend Estimates for 1979-88 Trend Subset. Ray Angle Proportional to Trend Estimate. Solid Symbol Indicates Significant Trend $(p<0.05)$. 


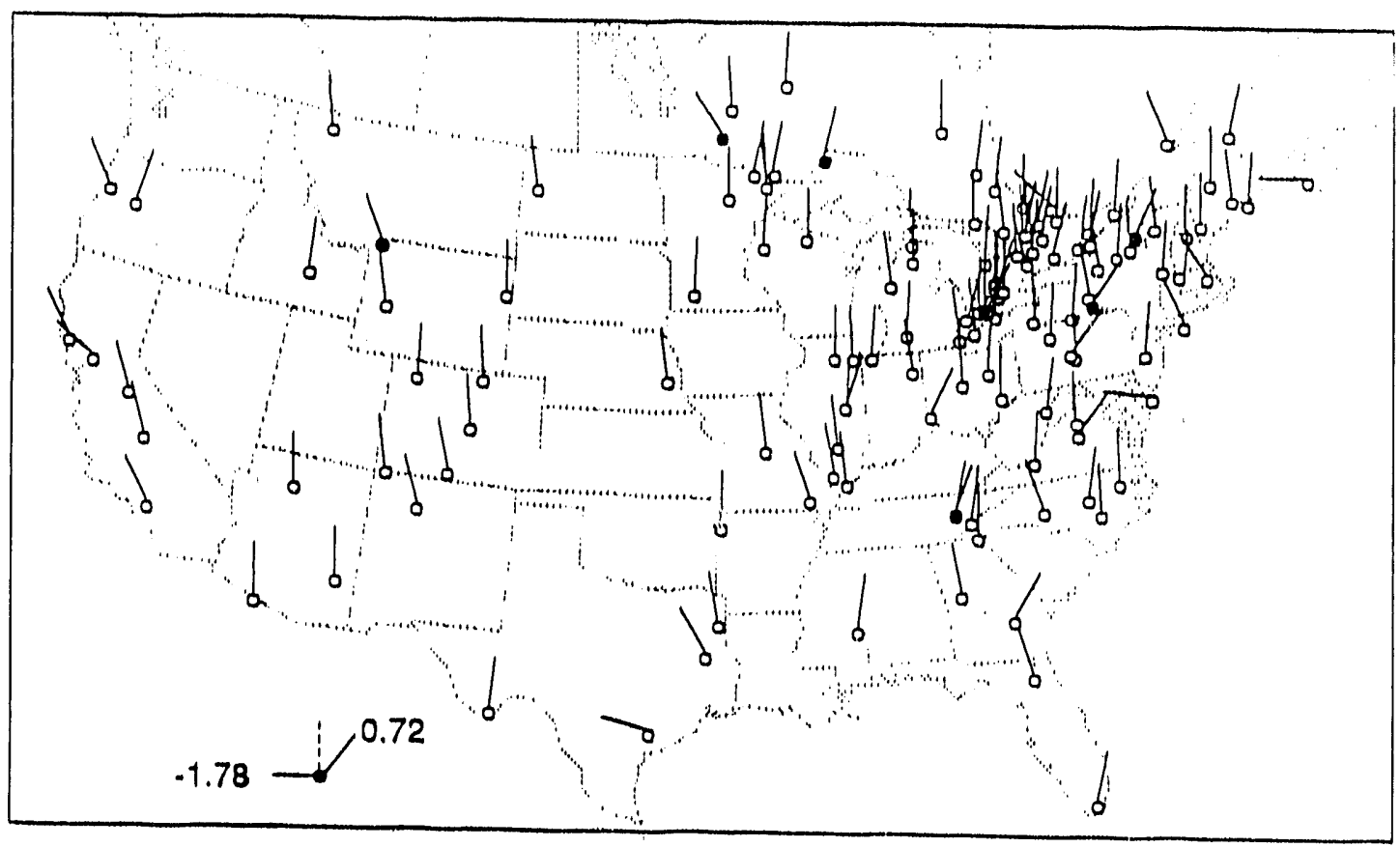

FIGURE A.43a. Chloride Concentration ( $\mu \mathrm{eq} / 1$ ) Trend Estimates for $1982 . .88$ Trend Subset. Angle Proportional to Trend Estimate. Solid Symbol Indicates Significant Trend $(p<0.05)$.

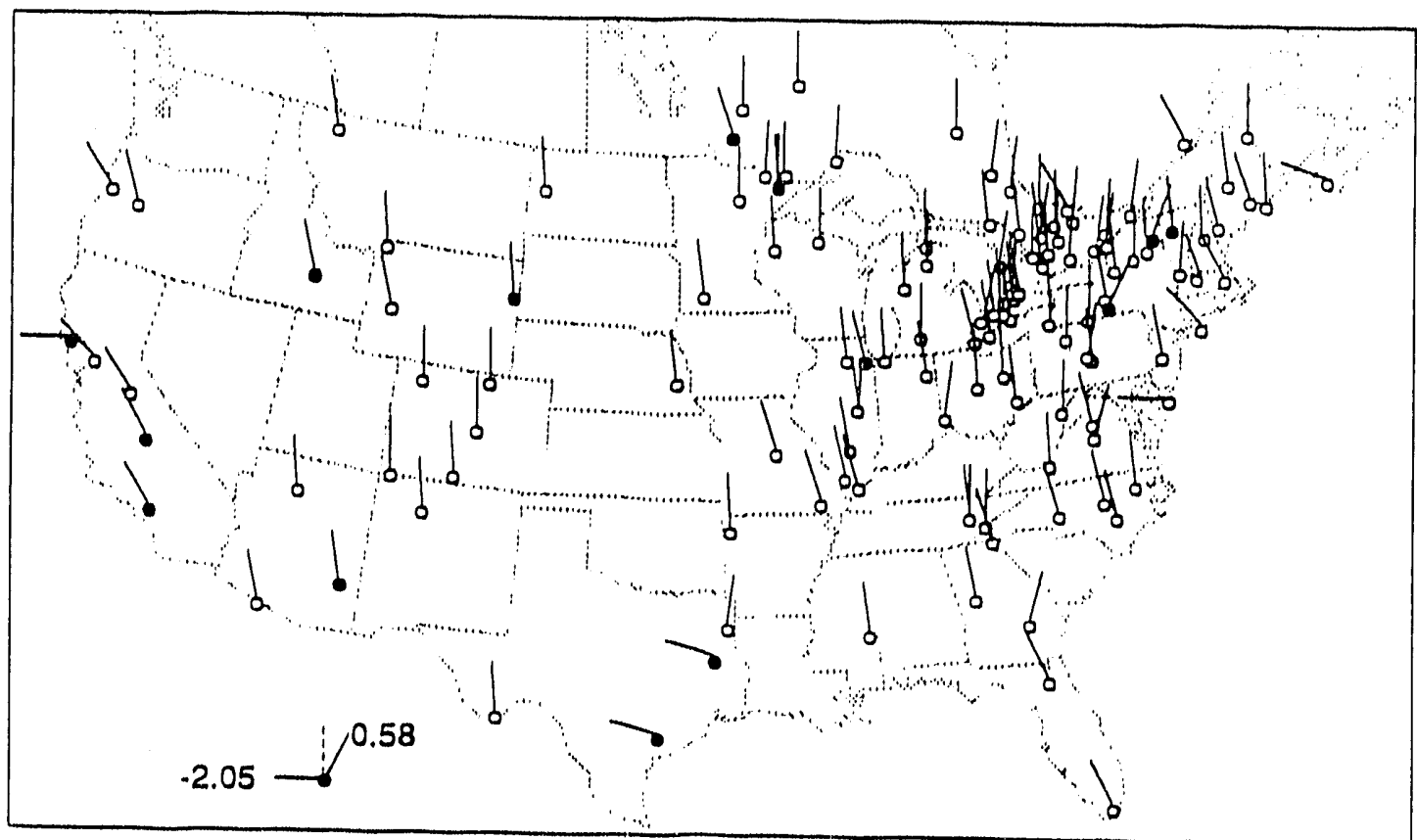

FIGURE A.43b. Chloride Deposition (meq/ $\mathrm{m}^{2}$ ) Trend Estimates for 1982-88 Trend Subset. Ray Angle Proportiunal to Trend Estimate. Solid Symbol Indicates Significant Trend $(p<0.05)$. 


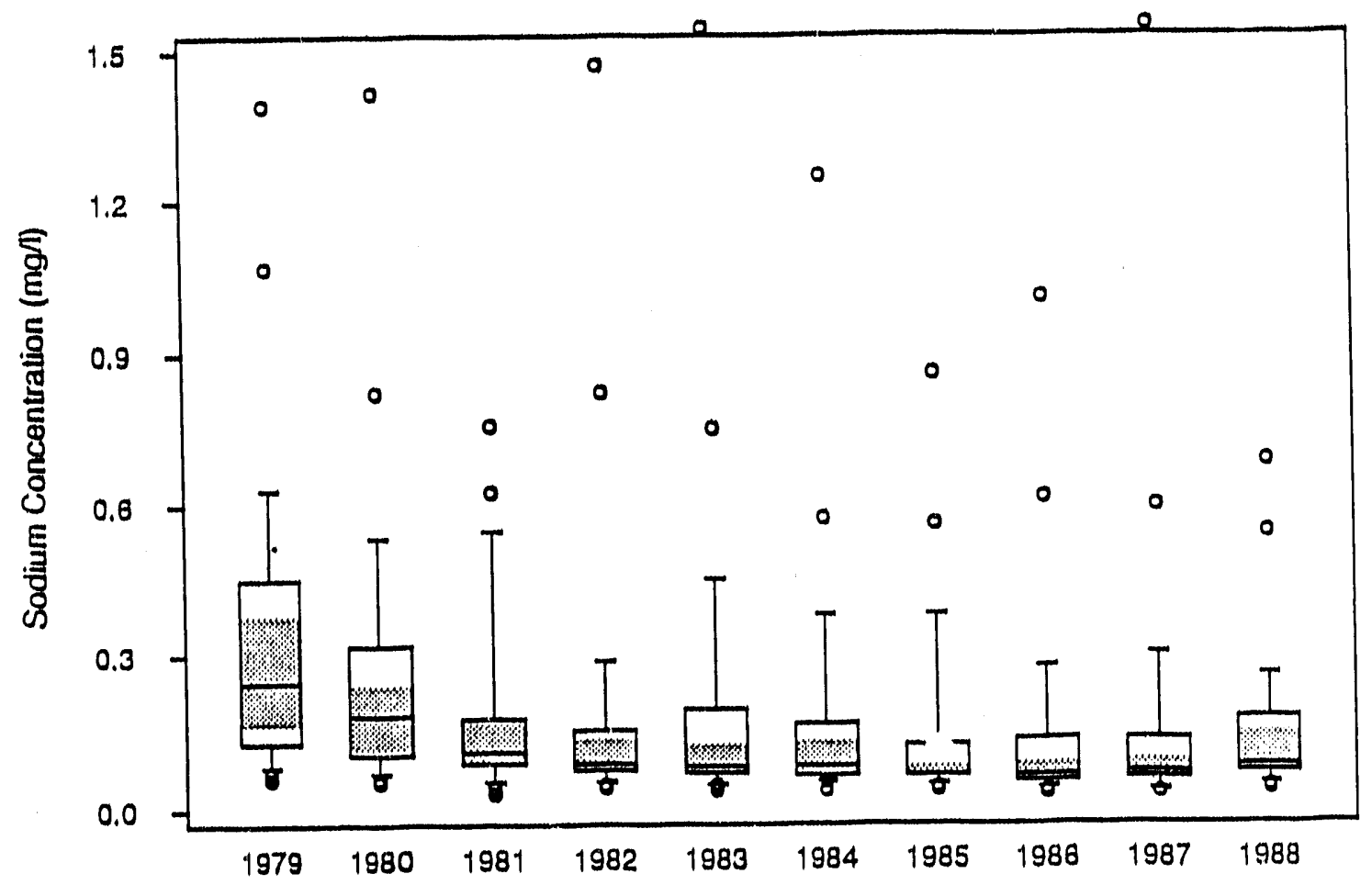

FIGURE A.44a. Temporal Pattern of Annual Precipitation-weighted Sodium Ion Concentration. Boxplots are the 10th, 25th, 50th, 75th and goth Percentiles of Sites in the 1979-88 Trend Subset.

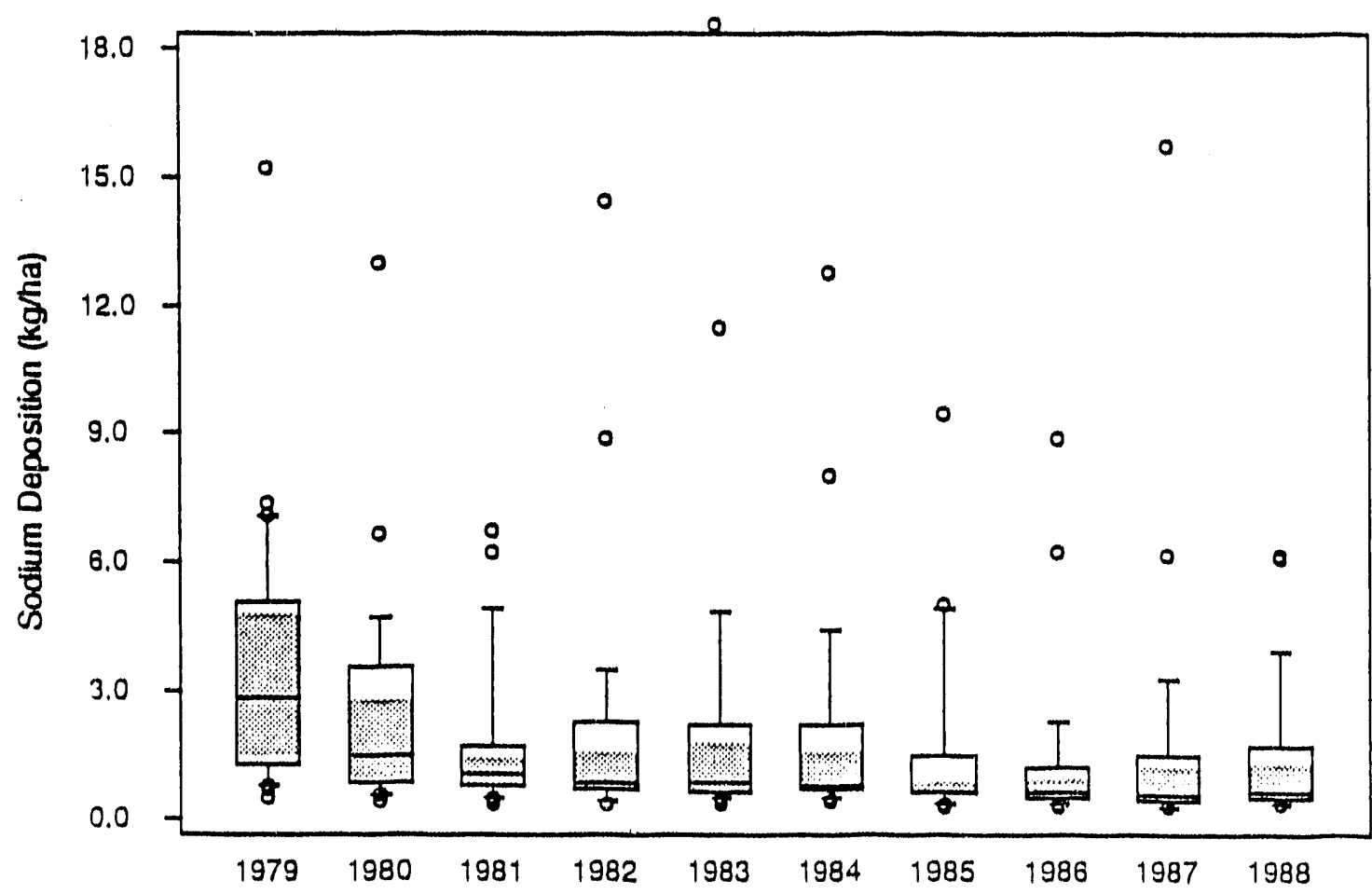

EIGURE A.44b. Temporal Pattern of Annuar Sodium Ion Wet Deposition. Boxplots are the 10th, 25th, 50th, 75th and 90th Percentiles of Sites in the 1979-88 Trend Sibset.

\section{A. 44}




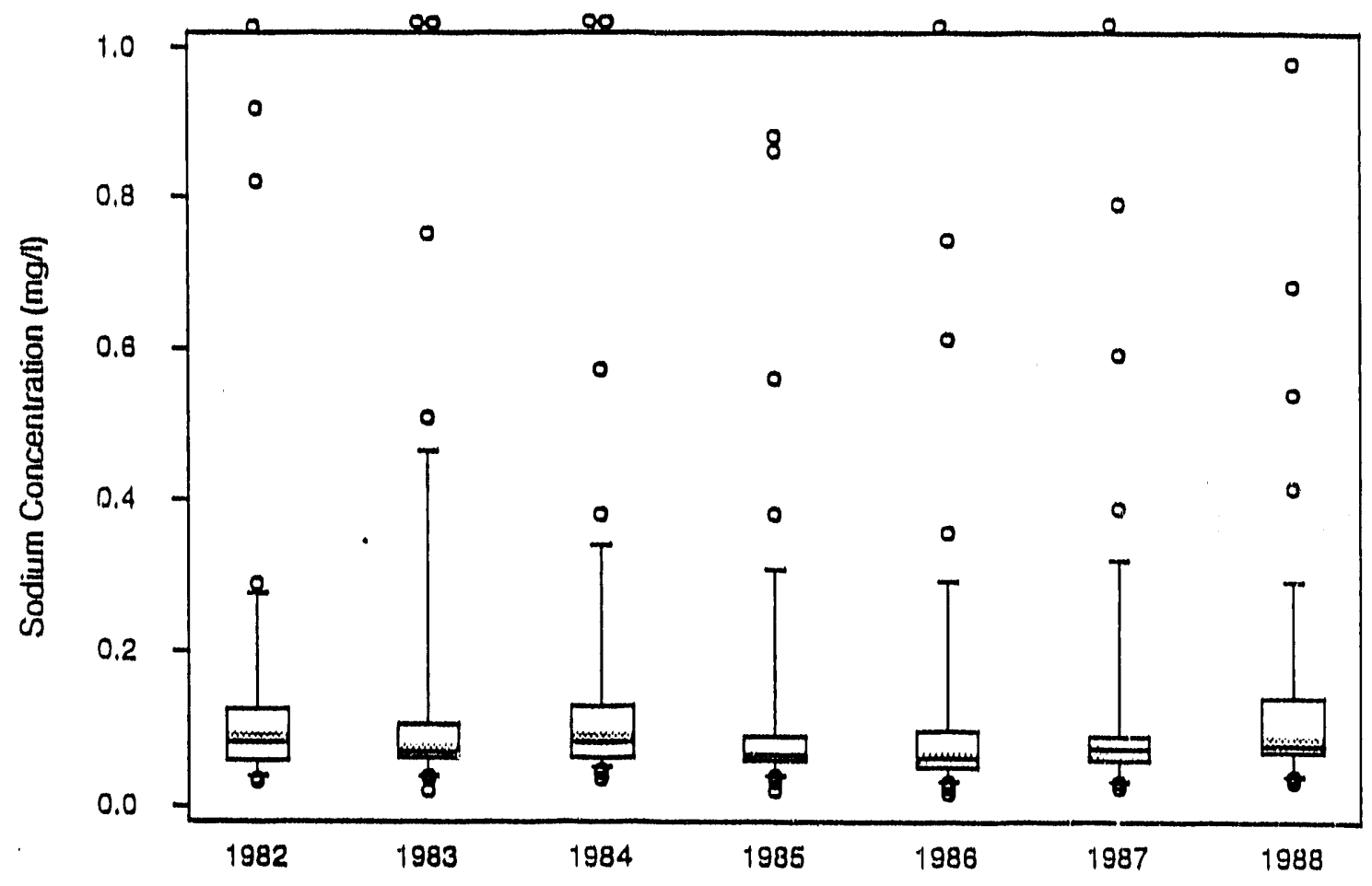

EIGURE A.45a. Temporal Pattern of Annual Precipitation-weighted Sodium Ion Concentration. Boxplots are the 5th, 25th, 50th, 75th and 95th Percentiles of Sites in the 1982-88 Trend Subset.

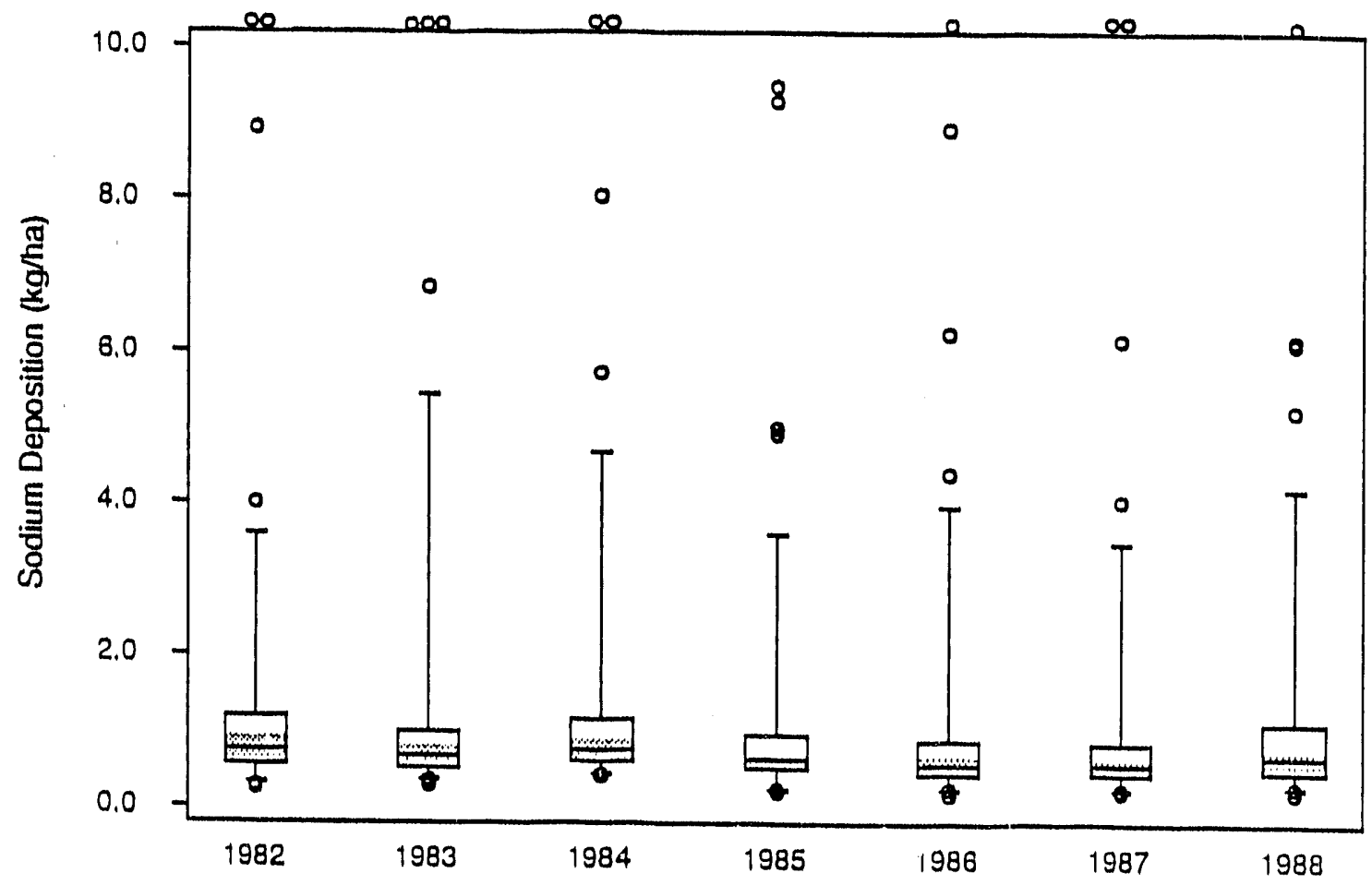

EIGURE A.45a. Temporal Pattern of Annual Sodium Ion Wet Deposition. Boxplots are the 5th, 25th, 50th, 75th and 95th Percentlles of Sites in the 1982-88 Trend Subset. 


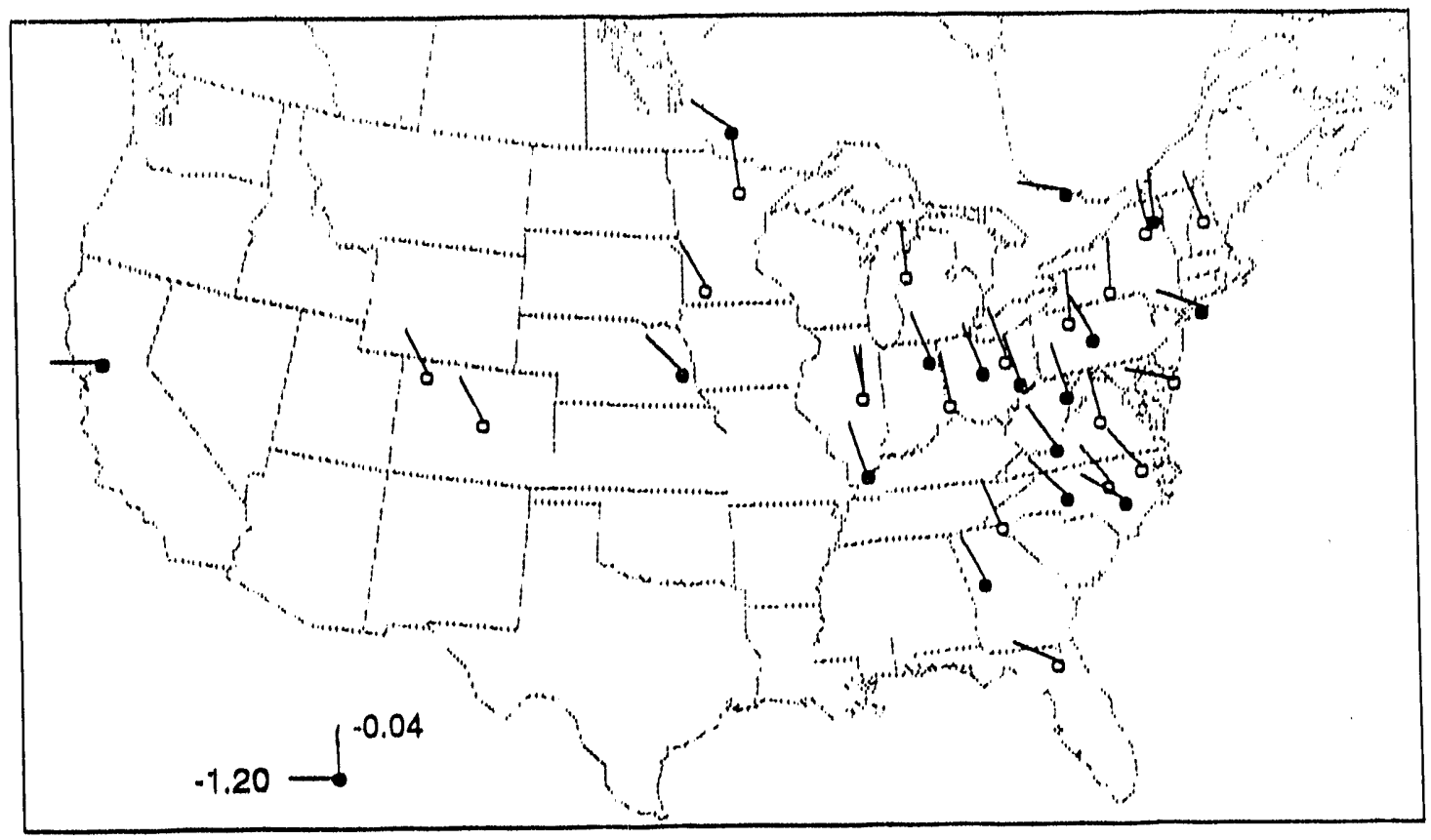

FIGURE A.46a. Sodium Concentration ( $\mu$ eq/1) Trend Estimates for 1979-88 Trend Subset. Ray Angle Proportional to Trend Estimate. Solid Symbol Indicates Significant Trend $(p<0.05)$.

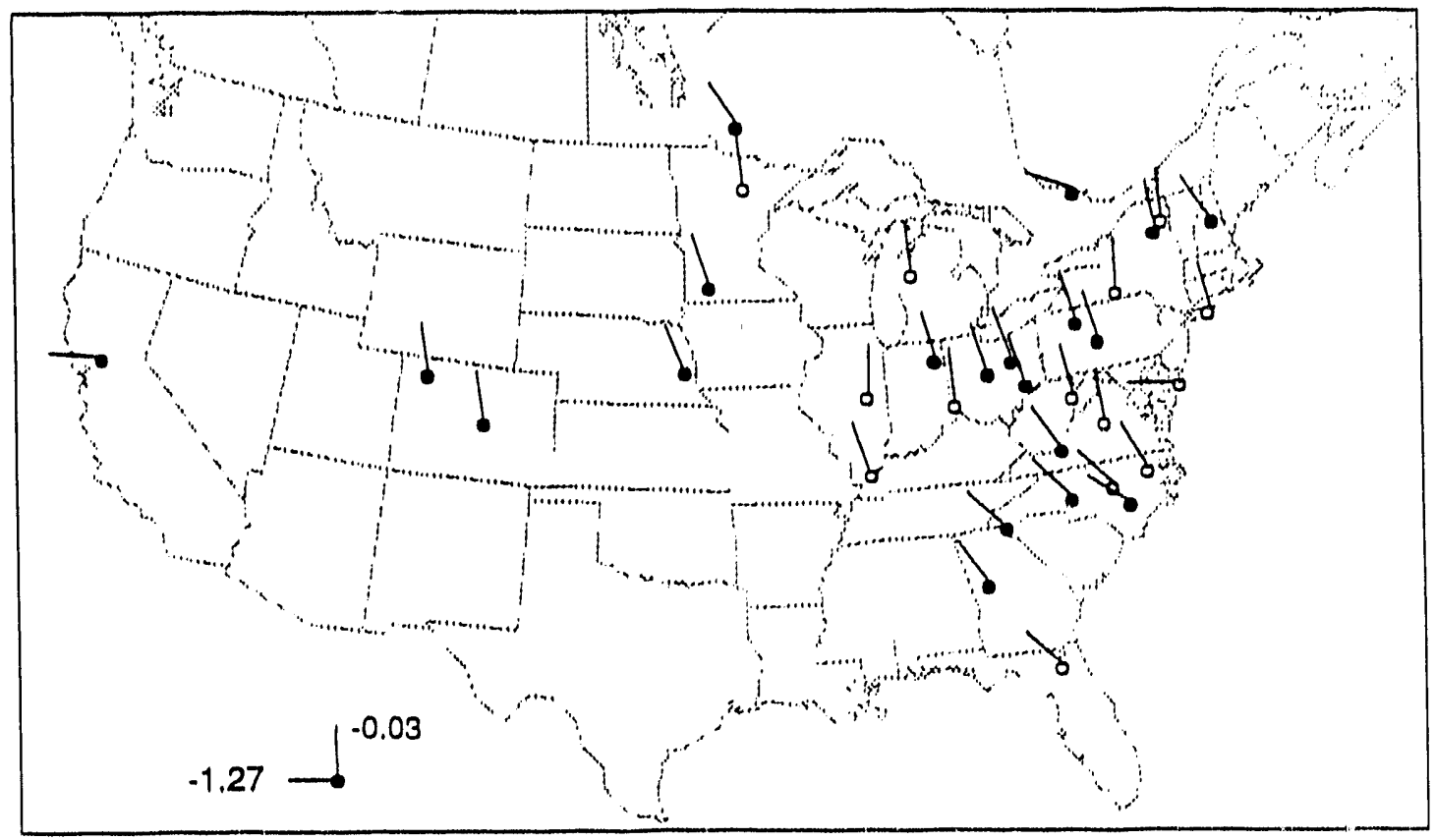

FIGURE A.46b. Sodium Deposition (meq/m²) Trend Estimates for 1979-88 Trend Su'bset. Ray Angle Proportional to Trend Estimate. Solid Symbol Indicates Significant Trend $(p<0.05)$. 


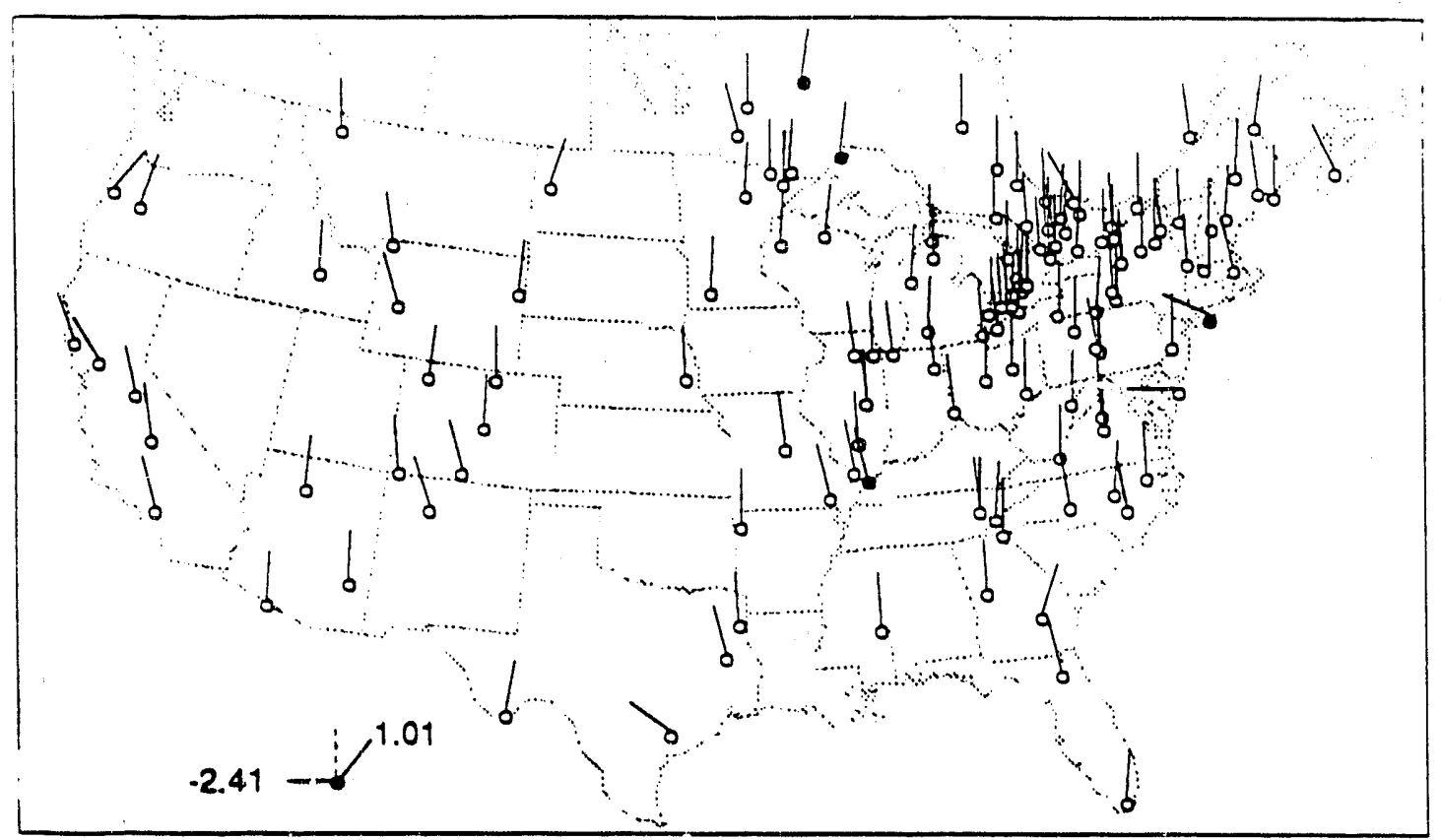

FIGURE A.47a. Sodium Concentrations ( $\mu \mathrm{eq} / 1$ ) Trend Estimates for 1982-88 Trend Subset. Ray Angle Proportional to Trend Estimate. Solid Symbol Indicates Significant Trend $(p<0.05)$.

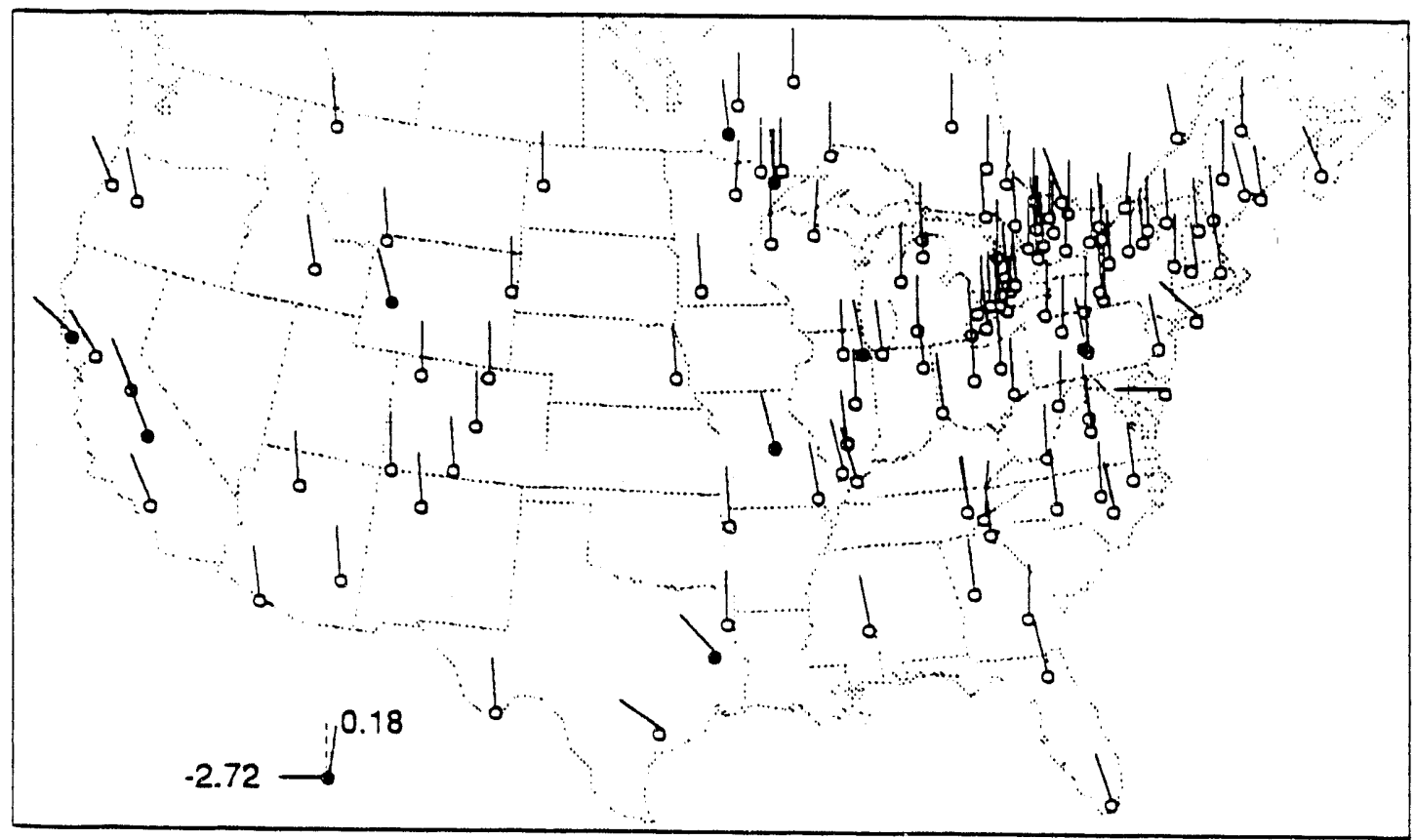

FIGURE A.47b. Sodium Deposition (meq/ $\mathrm{m}^{2}$ ) Trend Estimates for 1982-88 Trend Subset. Ray Angle Proportional to Trend Estimate. Solid Symbol Indicates Significant Trend $(n<0,05)$ : 


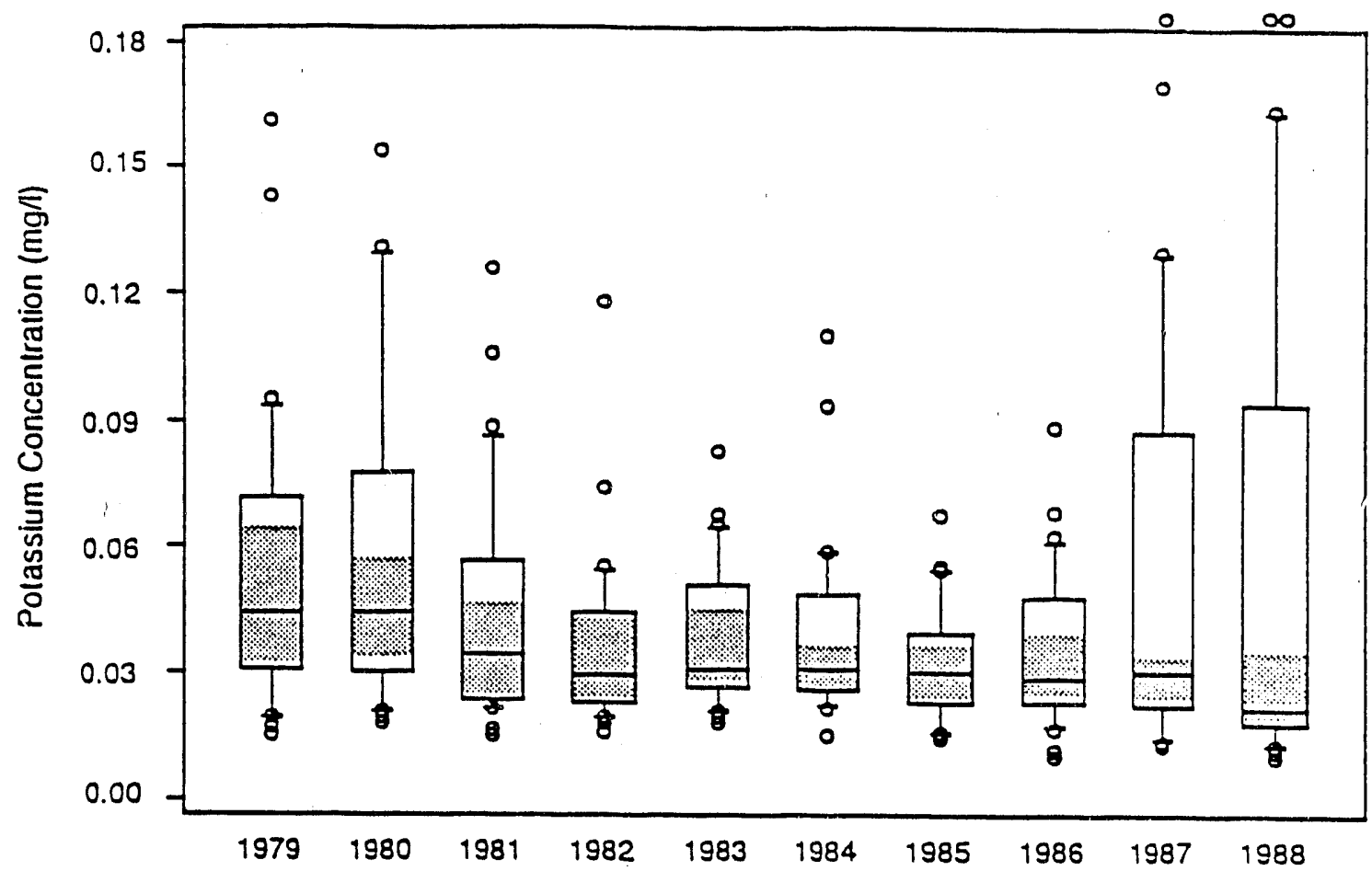

FIGURE A.48a. Temporal Pattern of Annual Precipitation-weighted Potassium Ion Concentration. Boxplots are the 5th, 25th, 50th, 75th and 95th Percentiles of Sites in the 1979-88 Trend Subset.

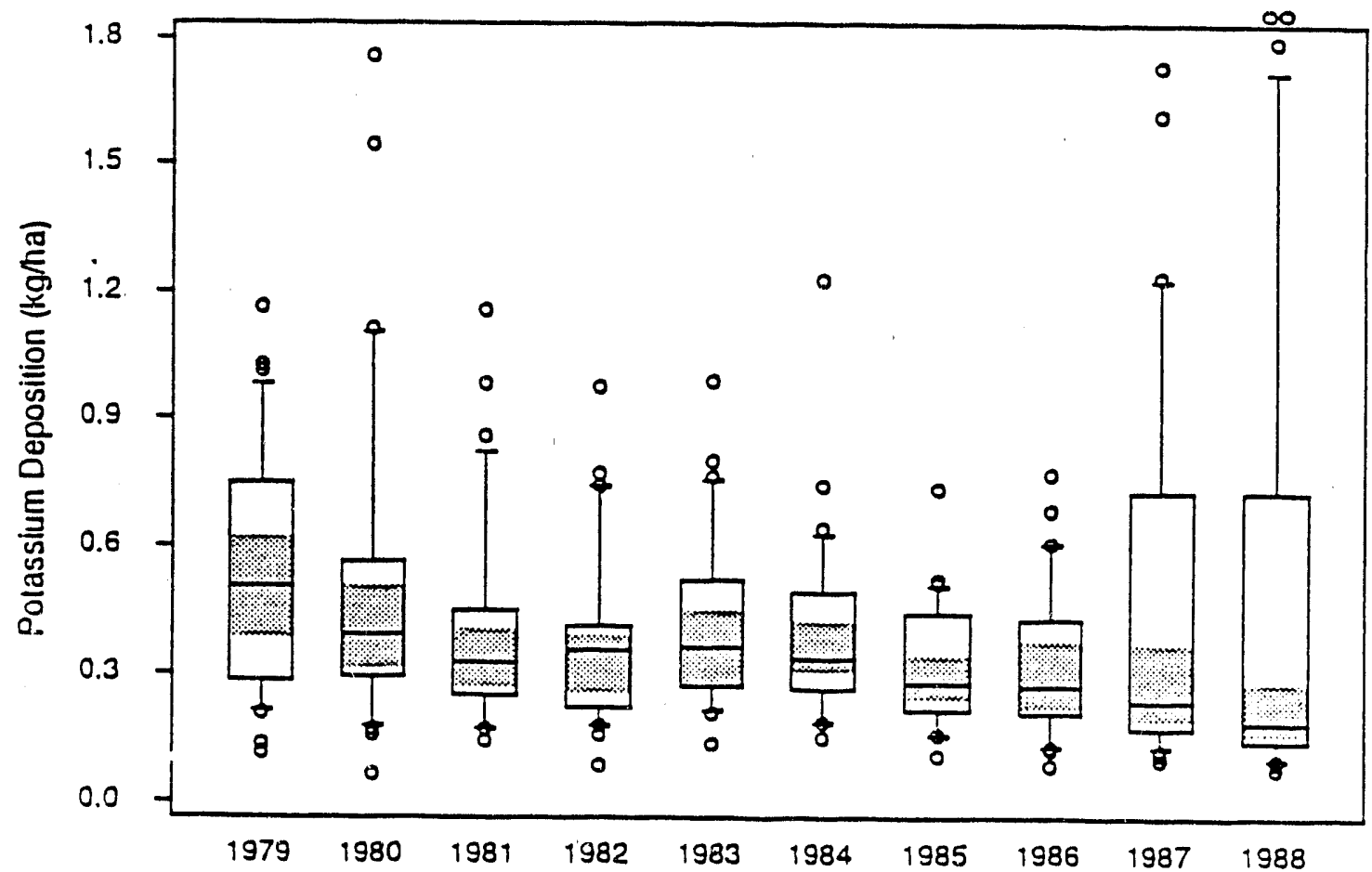

FIGURE A.48b. Temporal Pattern of Annual Potassium Ion Wet Deposition. Boxplots are the 10th, 25th, 50th, 75th and 90th Percentiles of Sites in the 1979-88 Trend Subset. 


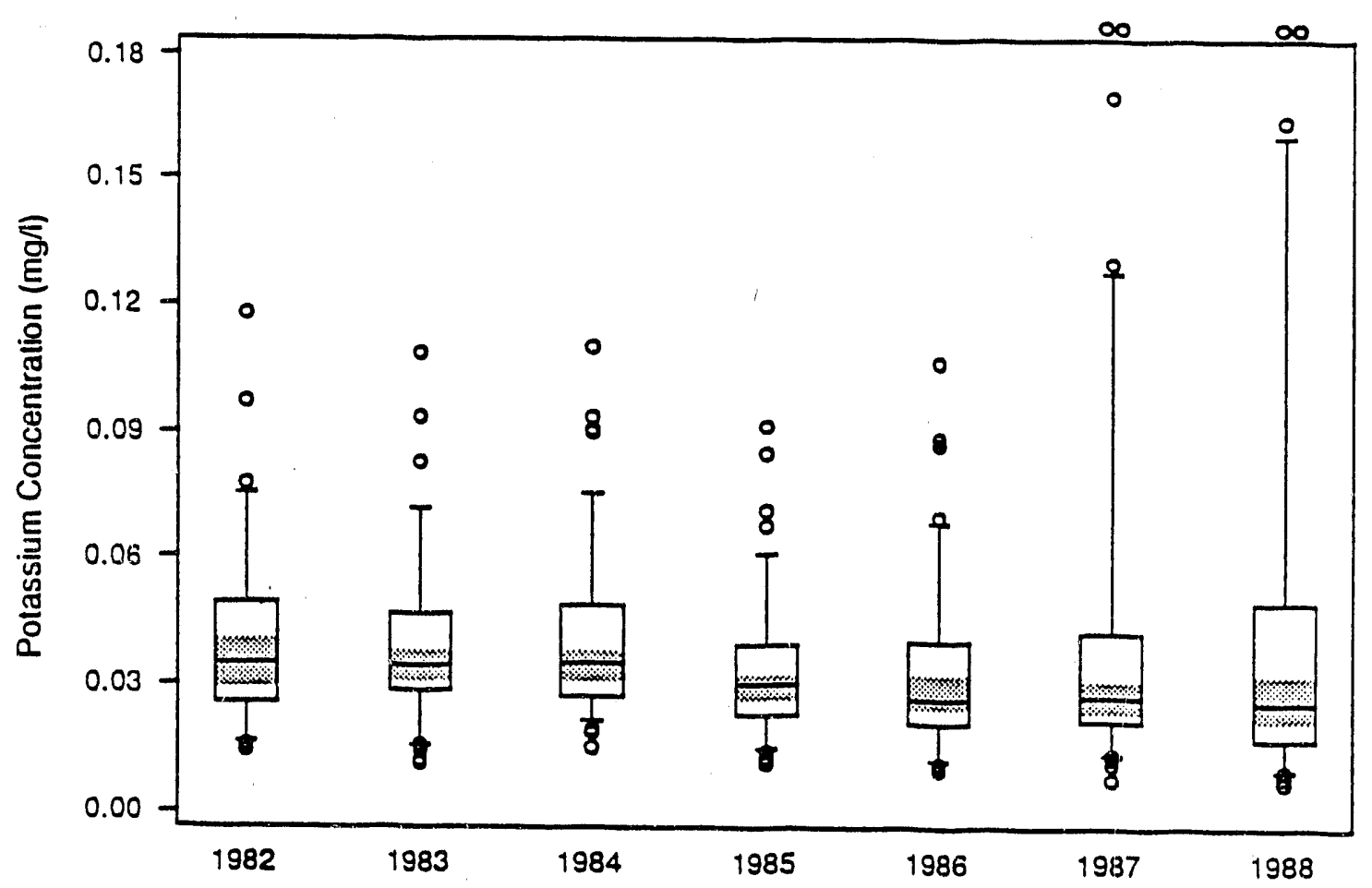

FIGURE A.49a. Temporal Pattern of Annual Precipitation-weighted Potassium Ion Concentration. Boxplots are the 5th, 25th, 50th, 75th and 95th Percentiles of Sites in the 1982-88 Trend Subset.

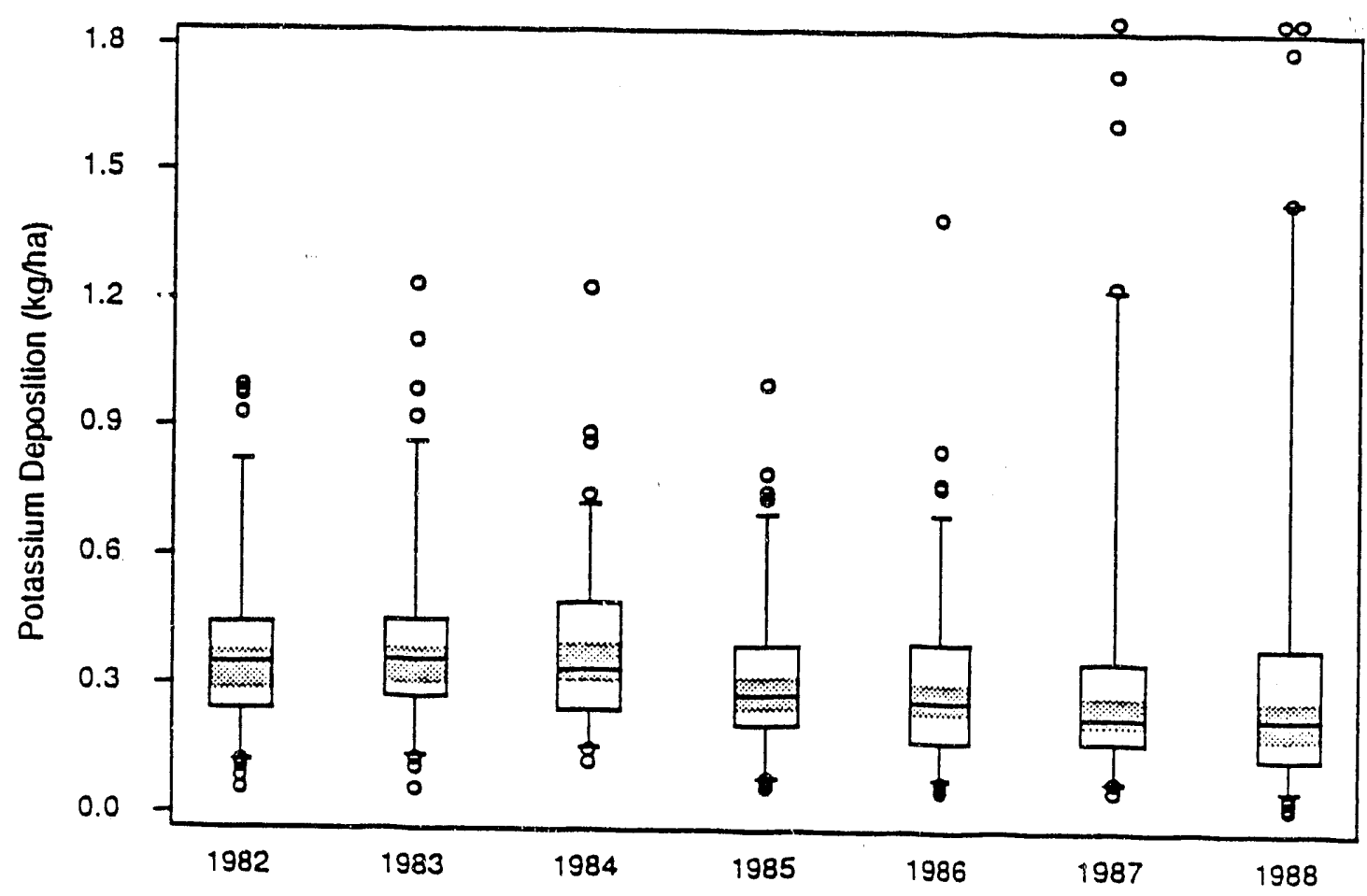

FIGURE A.49b. Temporal Pattern of Annual Potassium Ion Wet Deposition. Boxplots are the 5th, 25th, 50th, 75th and 95th Percentiles of Sites in the 1982-88 Trend Subset. 


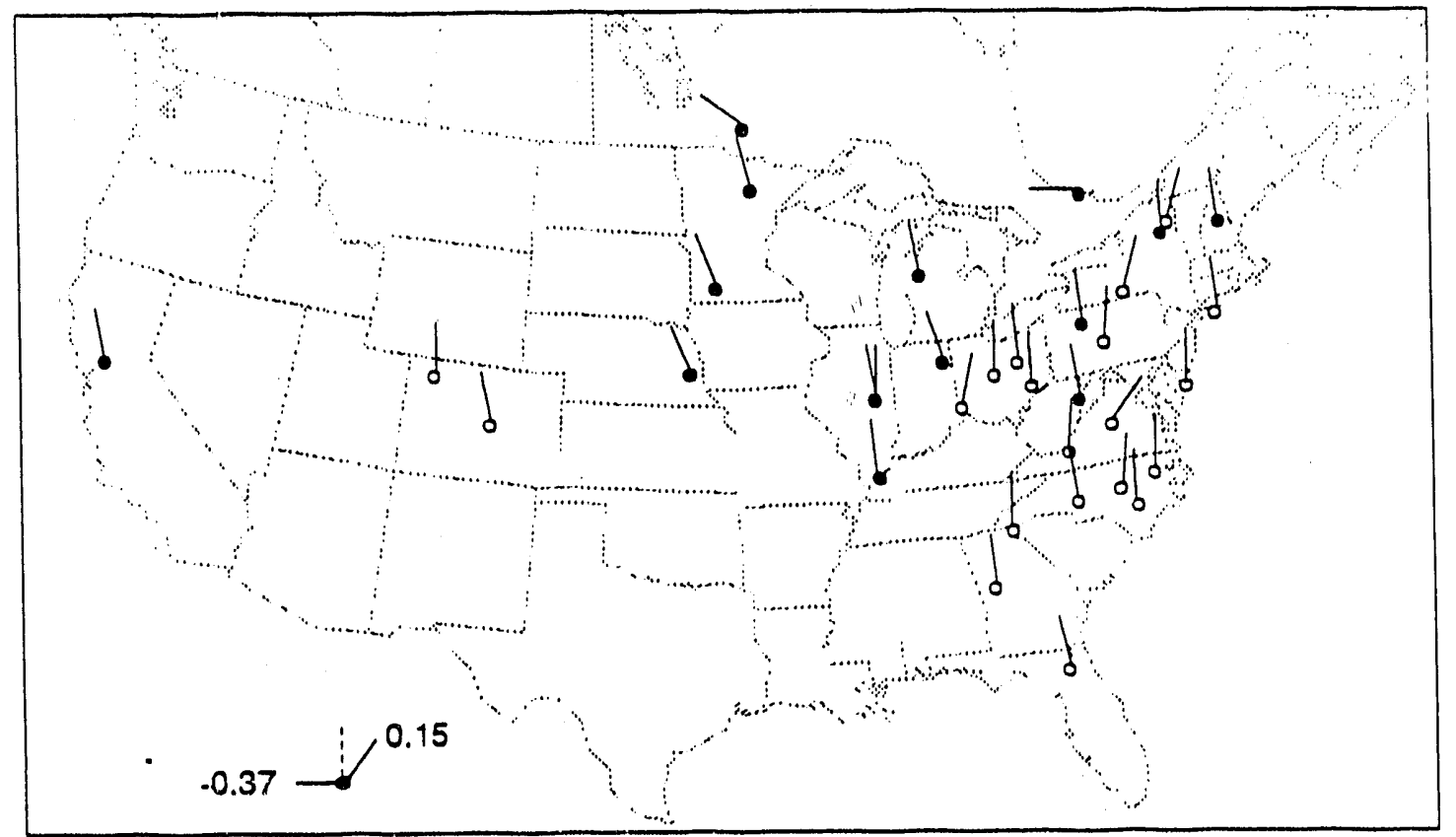

FIGURE A.50a. Potassium Concentration ( $\mu \mathrm{eq} / 1$ ) Trend Estimates for 1979-88 Trend Sites. Ray Angle Proportional to Trend Estimate. Solid Symbol Indicates Significant Trend $(p<0.05)$.

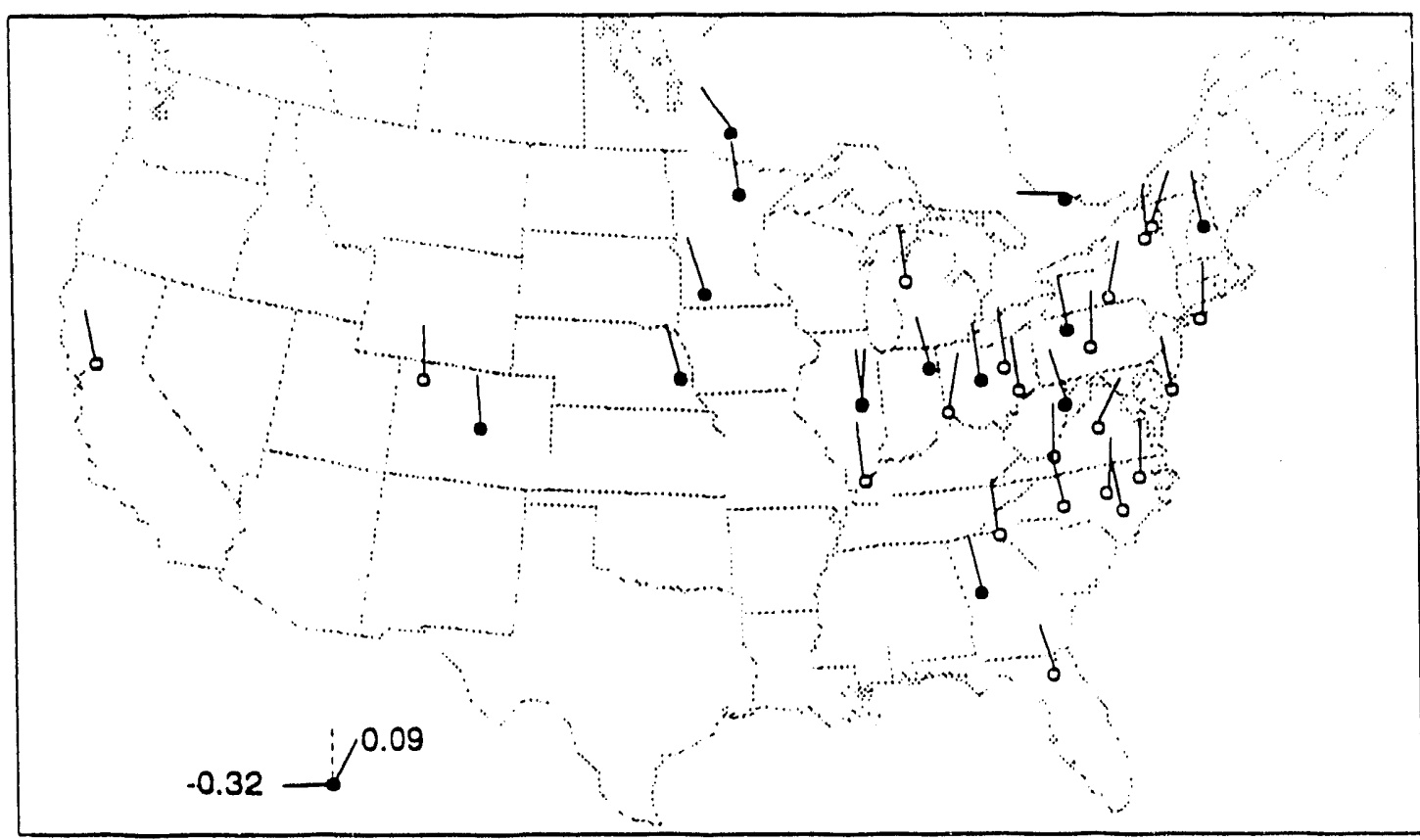

FIGURE A.50b. Potassium Deposition (meq $/ \mathrm{m}^{2}$ ) Trend Estimates for 1979-88 Trend Subset. Ray Angle Proportional to Trend Estimate. Solid Symbol Indicates Significant Trend $(p<0.05)$. 


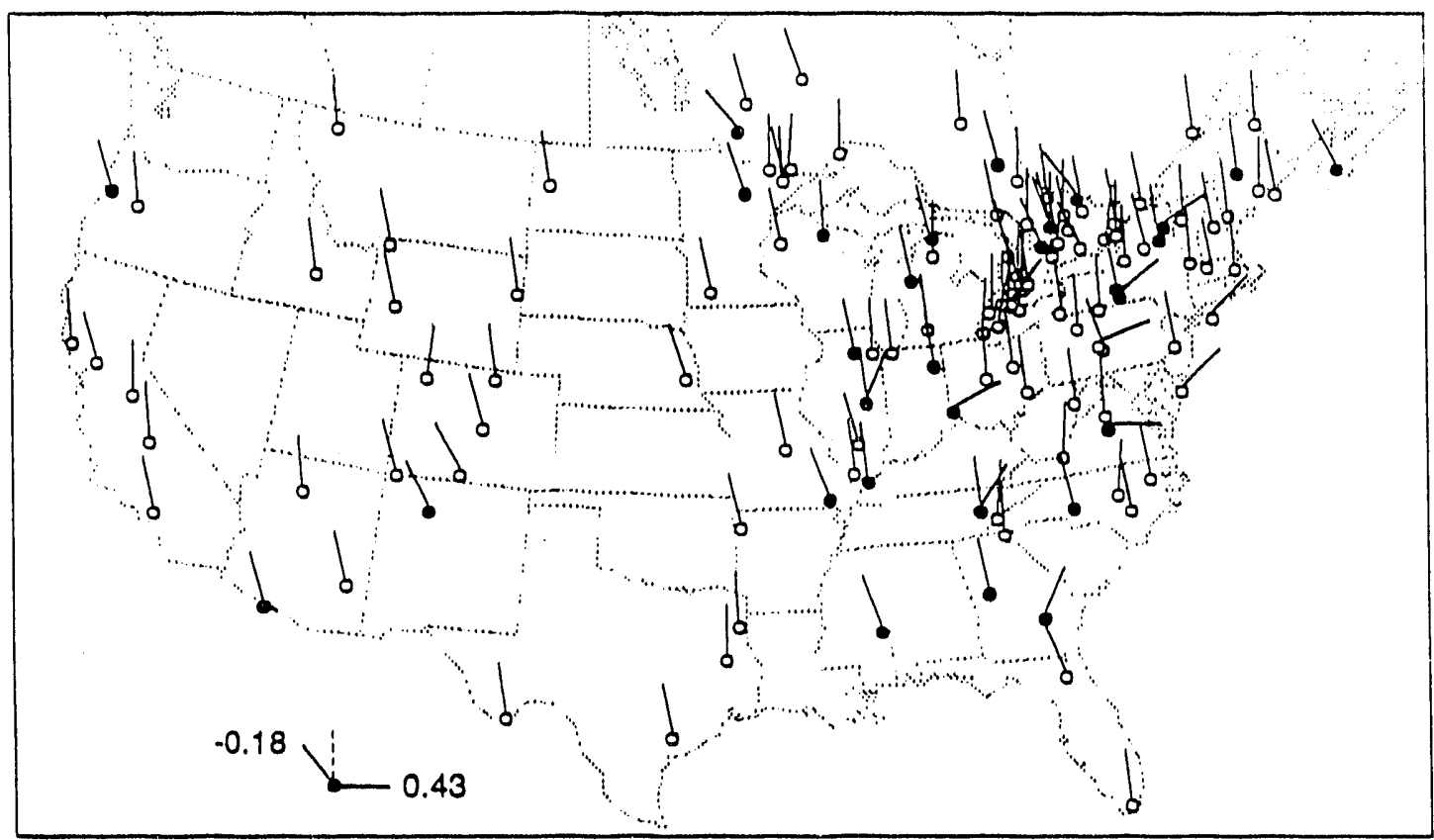

FIGURE A.51a. Potassium Concentration ( $\mu$ eq/1) Trend Estimates for 1982-88 Trend Subset. Ray Angle Proportional to Trend Estimate. Solid Symbol Indicates Significant Trend $(p<0.05)$.

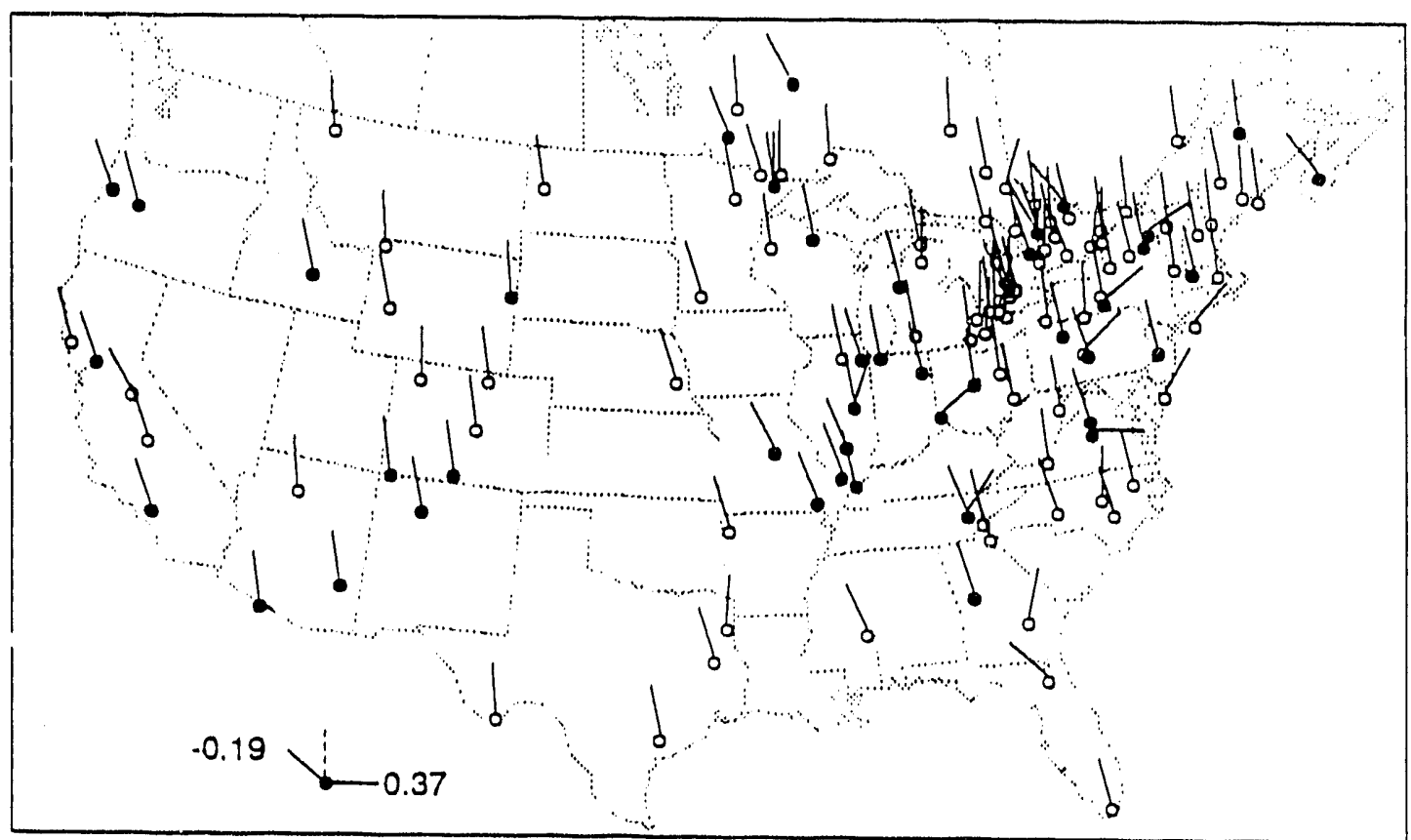

FIGURE A.51b. Potassium Deposition (meq/ $\mathrm{m}^{2}$ ) Trend Estimates for 1982-88 Trend Subset. Ray Angle Proportional to Trend Estimate. Solid Symbol Indicates Significant Trend $(p<0.05)$. 


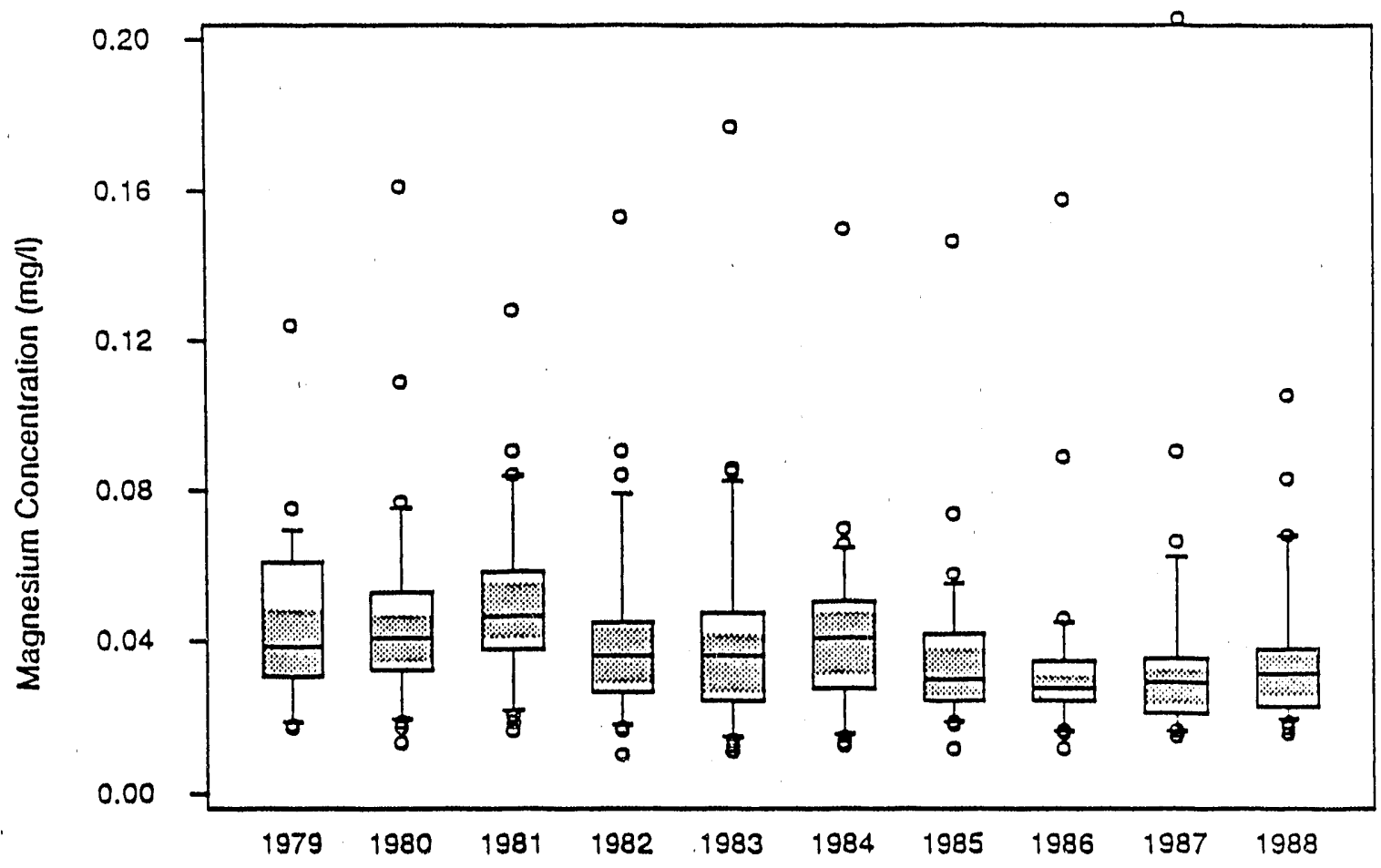

FIGURE A.52a. Temporal Pattern of Annual Precipitation-weighted Magnesium Ion Concentration. Boxplots are the 10th, $25 \mathrm{th}, 50 \mathrm{th}, 75 \mathrm{th}$ and 90th Percentiles of Sites in the 1979-88 Trend Subset.

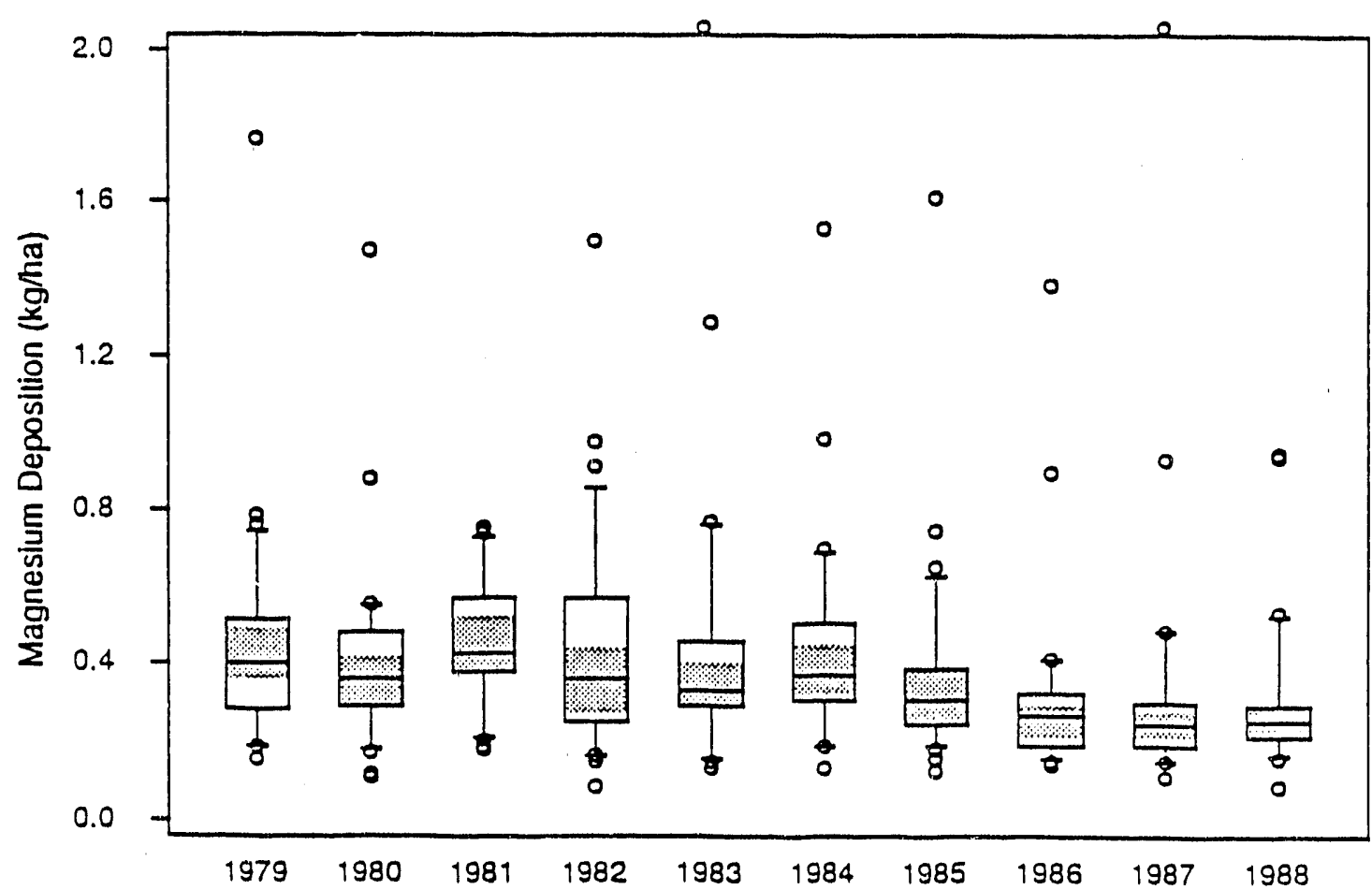

FIGURE A.52b. Temporal Pattern of Annual Precipitation-weighted Magnesium Ion Concentration. Boxplots are the 10th, 25th, 50th, 75th and 90th Percentiles of Sites in the 1979-88 Trend Subset.

A. 52 


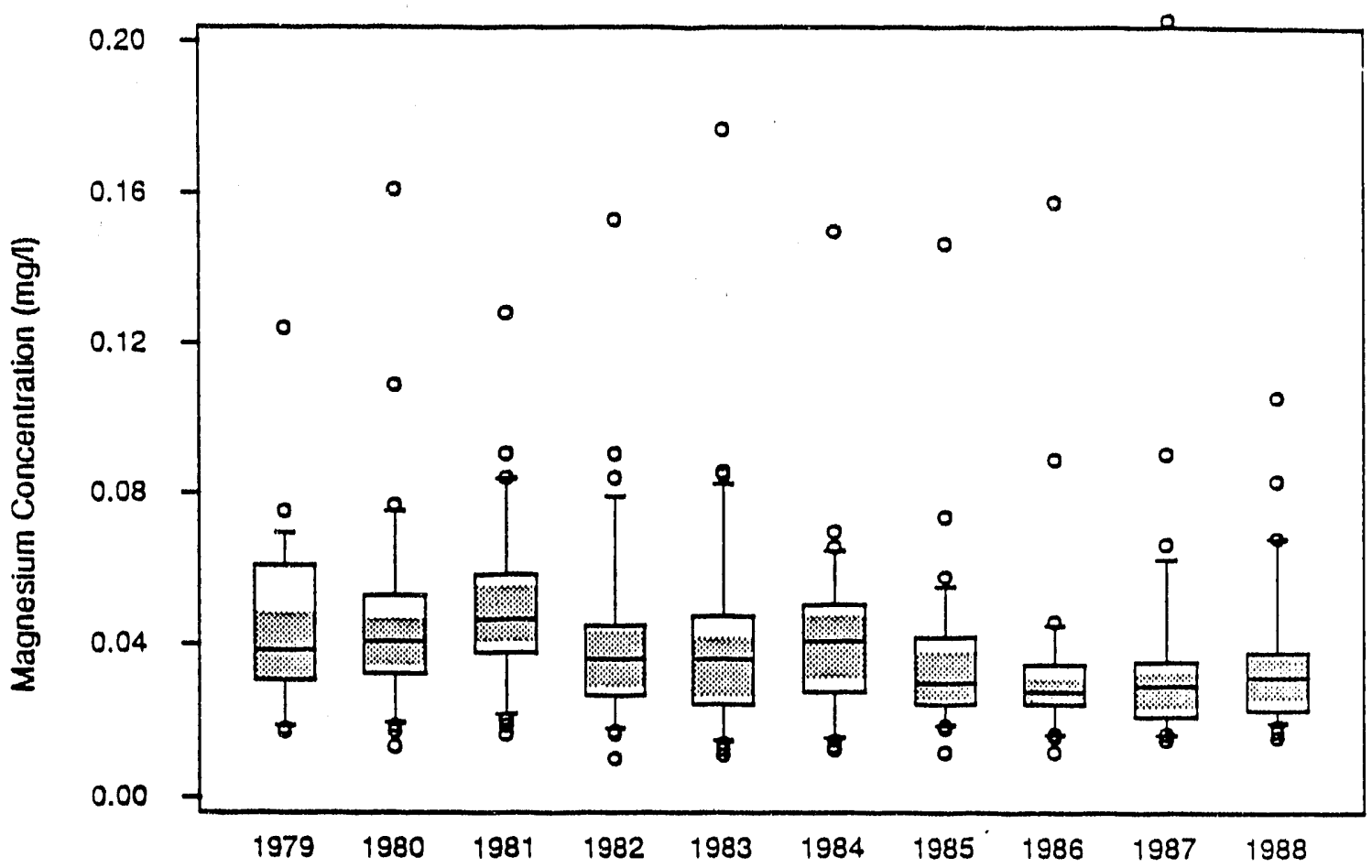

FIGURE A.53a. Temporal Pattern of Annual Precipitation-weighted Magnesium Ion Concentration. Boxplots are the 5th, 25th, 50th, 75th and 95th Percentiles of Sites in the 1982-88 Trend Subset.

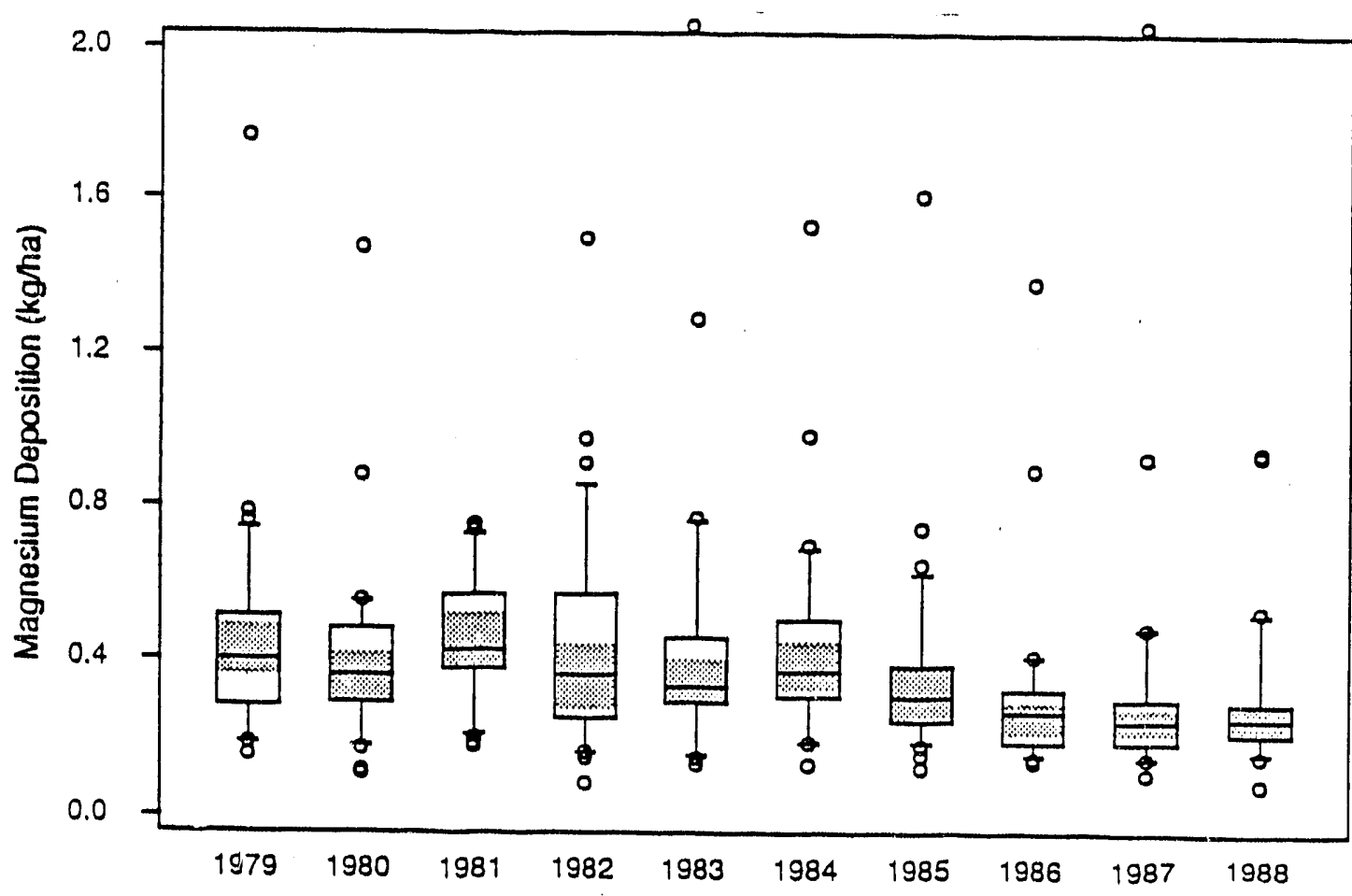

FIGURE A.53b. Temporal Pattern of Annual Magnesium Ion Wet Deposition. Boxplots are the 5th, 25th, 50th, 75th and 95th Percentiles of Sites in the 1982-88 Trend Subset. 


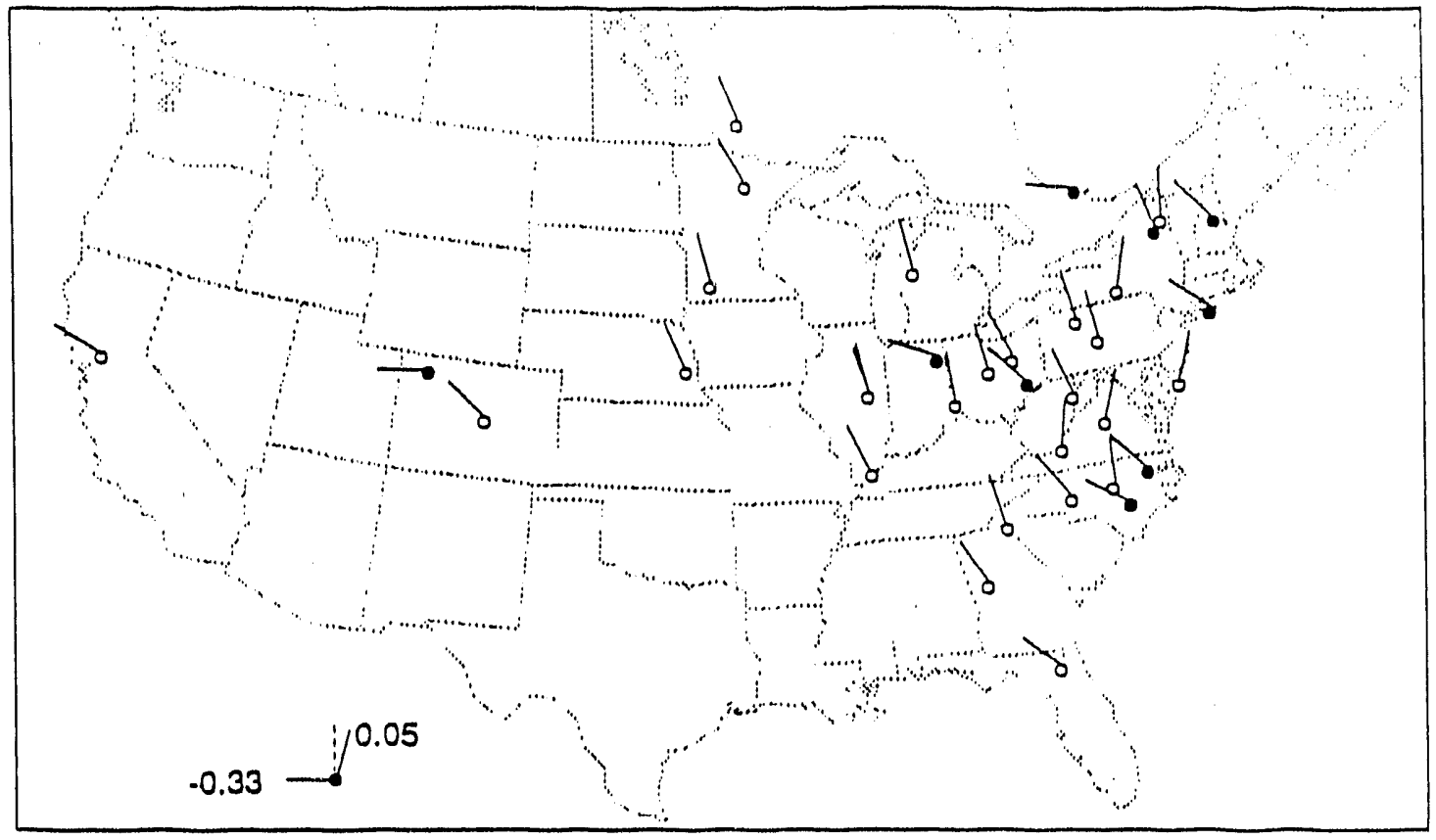

FIGURE A.54a. Magnesium Concentration ( $\mu \mathrm{eq} / 1$ ) Trend Estimates for 1979-88 Trend Sites Map Ray Angle Proportional to Trend Estimate. Solid Symbol Indicates Significant Trend $(p<0.05)$.

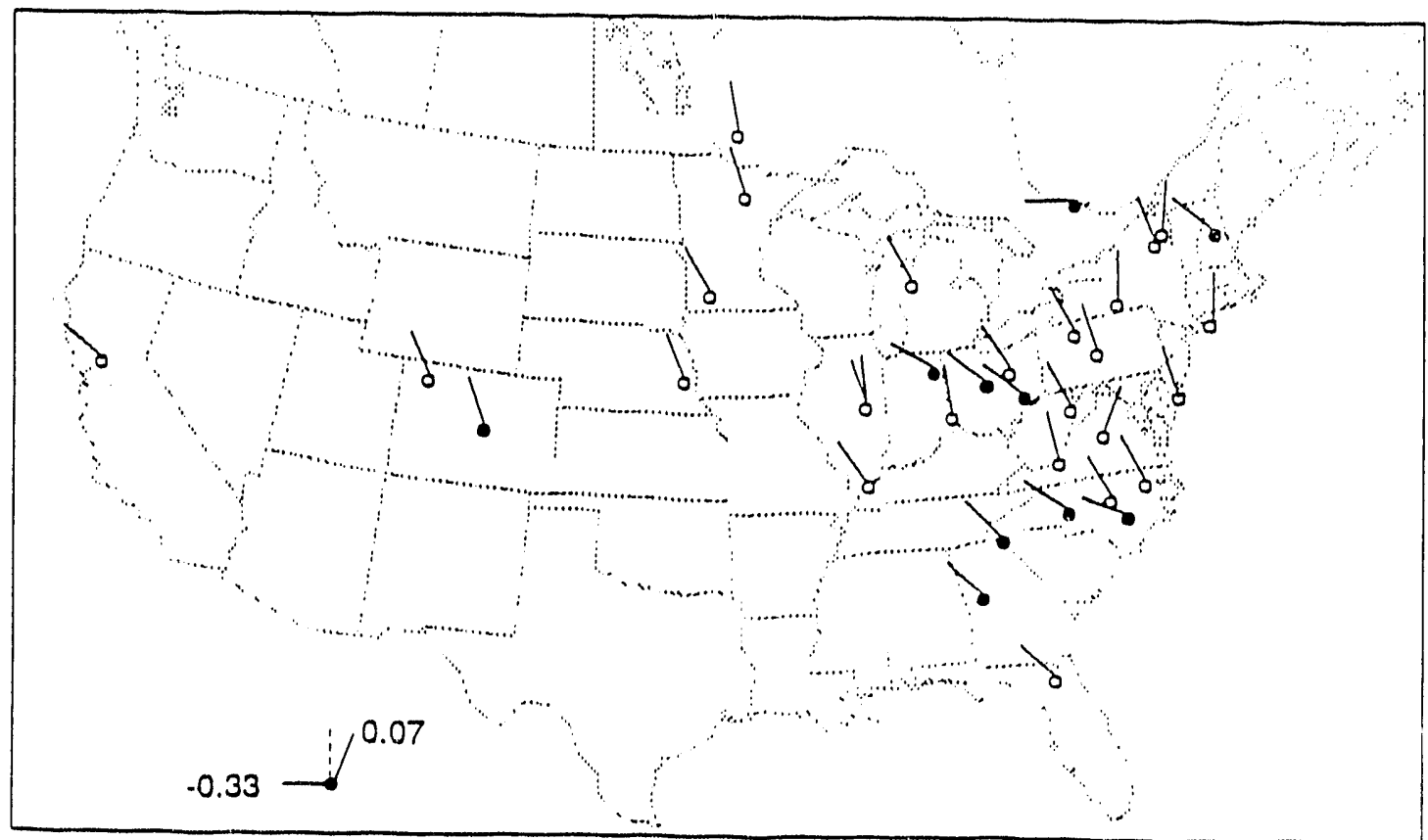

FIGURE A.54b. Magnesium Deposition (meq/ $\left.\mathrm{m}^{2}\right)$. Trend Estimates for 1979-88 Trend Sites. Map Ray Angle Proportional to Trend Estimate. Solid Symbol Indicates Significant Trend $(p<0.05)$. 


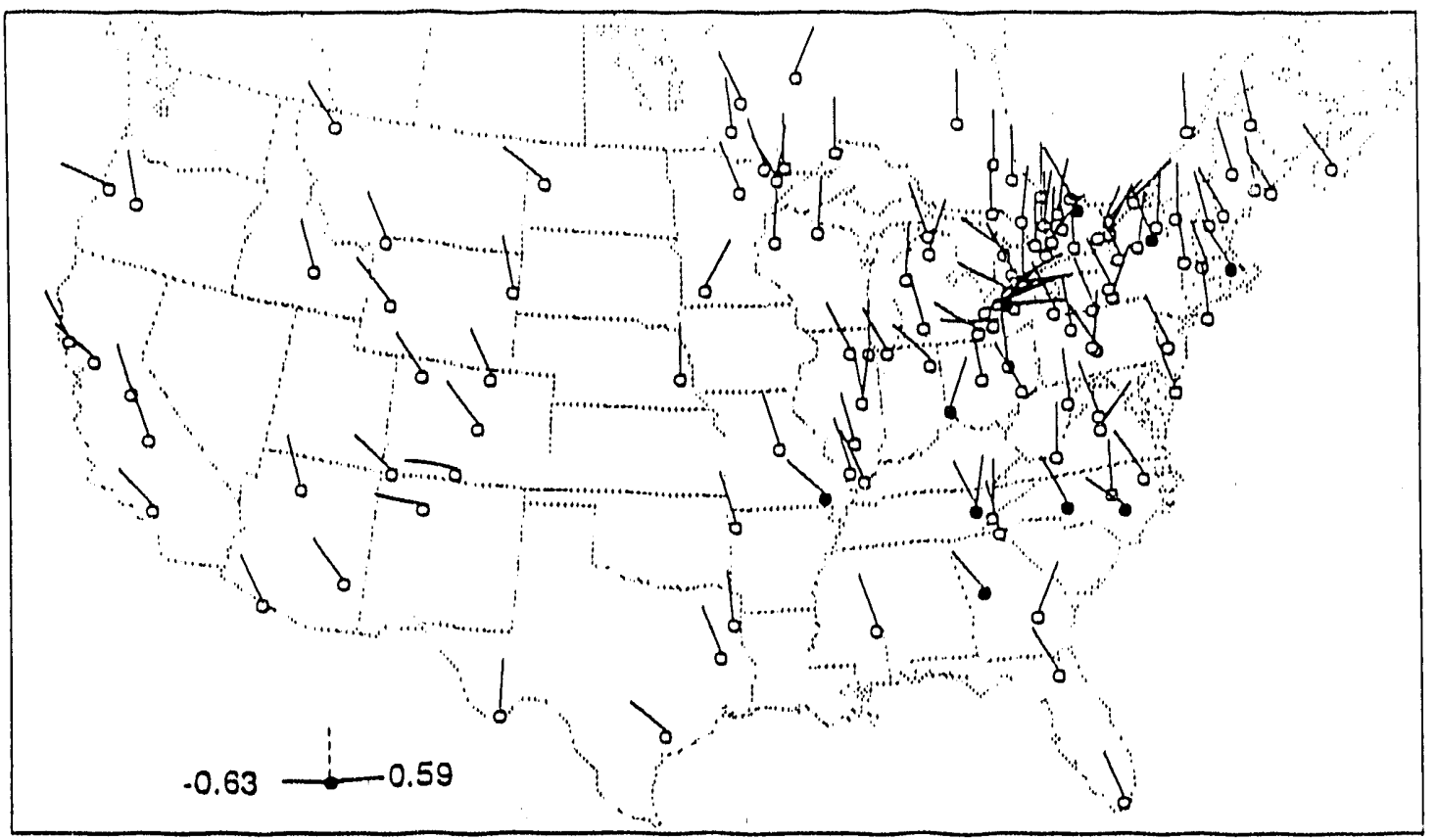

FIGURE A.55a. Mangesium Concentration ( $\mu$ eq/1) Trend Estimates for 1982-88 Trend Sites Map Ray Angle Proportional to Trend Estimate. Solid Symbol Indicates Significant Trend $(p<0.05)$.

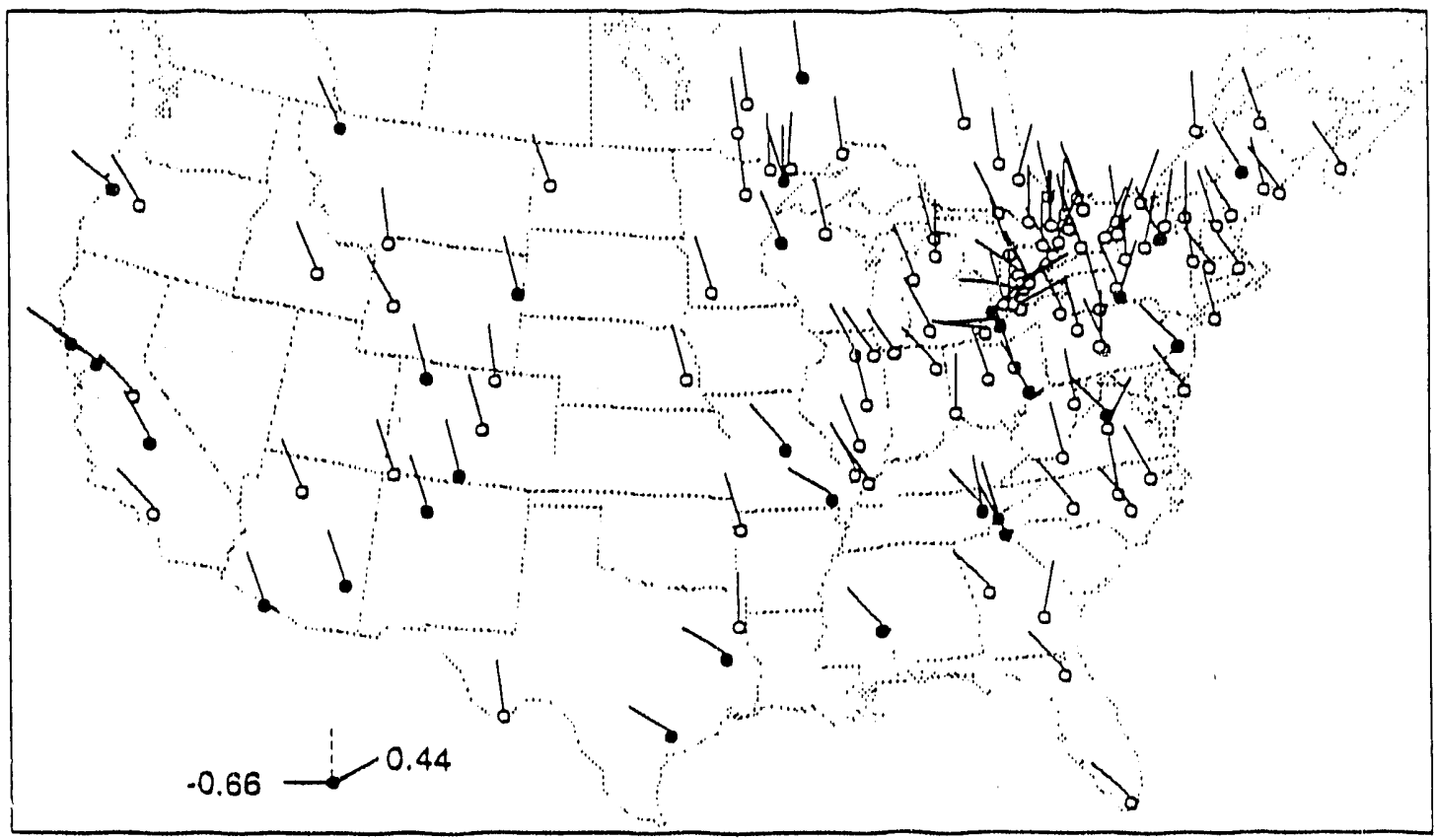

FIGURE A.55b. Magnesium Deposition (meq/ $\mathrm{m}^{2}$ ) Trend Estimates for 1982-88 Trend Sites. Map Ray Angle Proportional to Trend Estimate. Solid Symbol Indicates Significant Trend $(p<0.05)$. 
IABLE A.1. 1979-1988 Trend Sites Ordered by Sitename

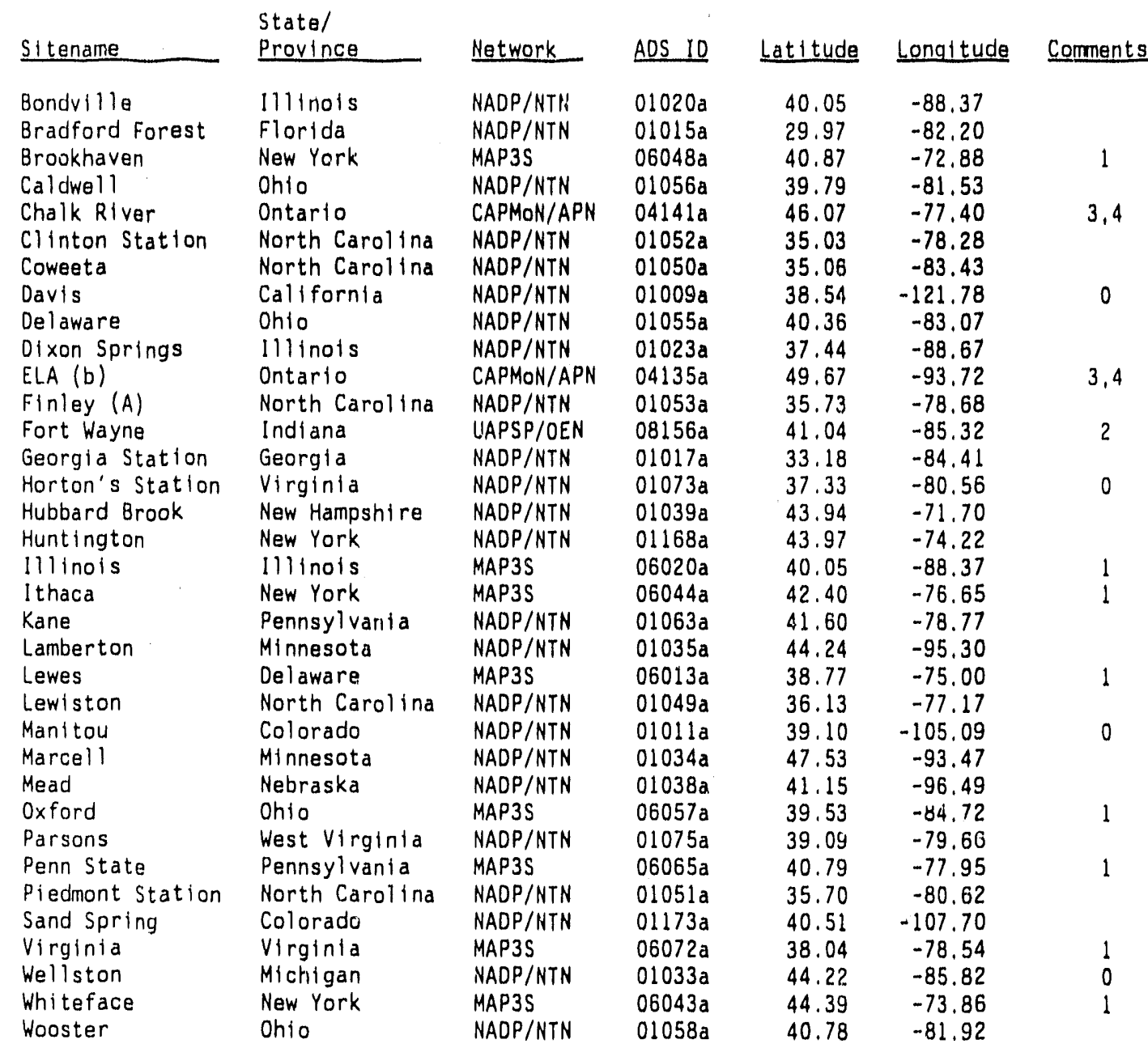

Comments:

O No annual average

1 No annual average for hydrogen

2 No annual average for sulfate

3 No annual average for chloride

4 No annual average for sodium 
IABLE A,2. 1982-1988 Trend Sites Ordered by Siterlame

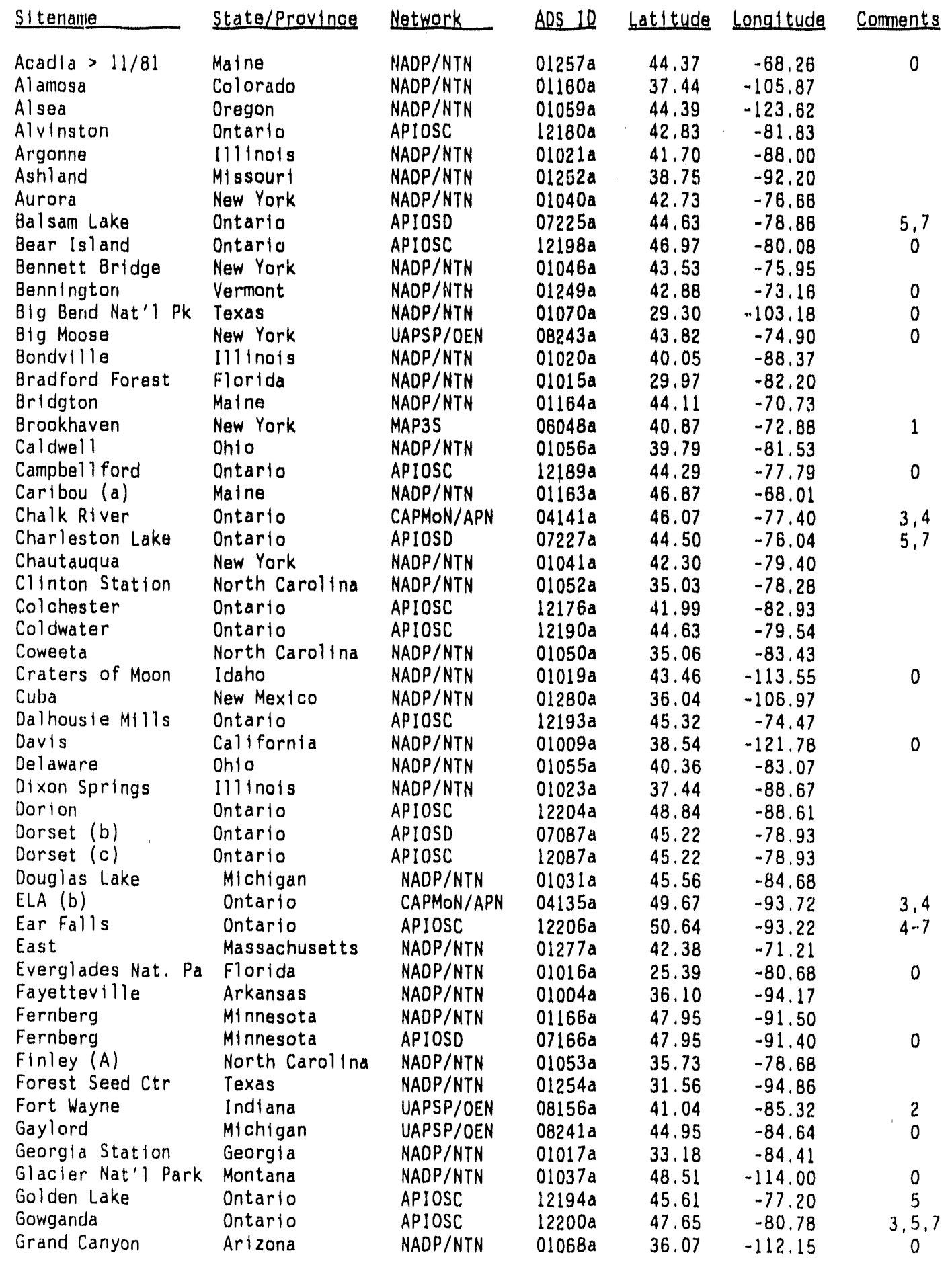

Comments :

- No annual averages

2 No annual average for sulfate

4 No annual average for sodium

6 No annual average for calctum

1 No annual average for hydrogen
3 No annual average for chloride
5 No annual average for potassium
7 No annual average for magnesium 
IABLE A.2. 1982-1988 Trend Sites Ordered by Sitename (Contd.)

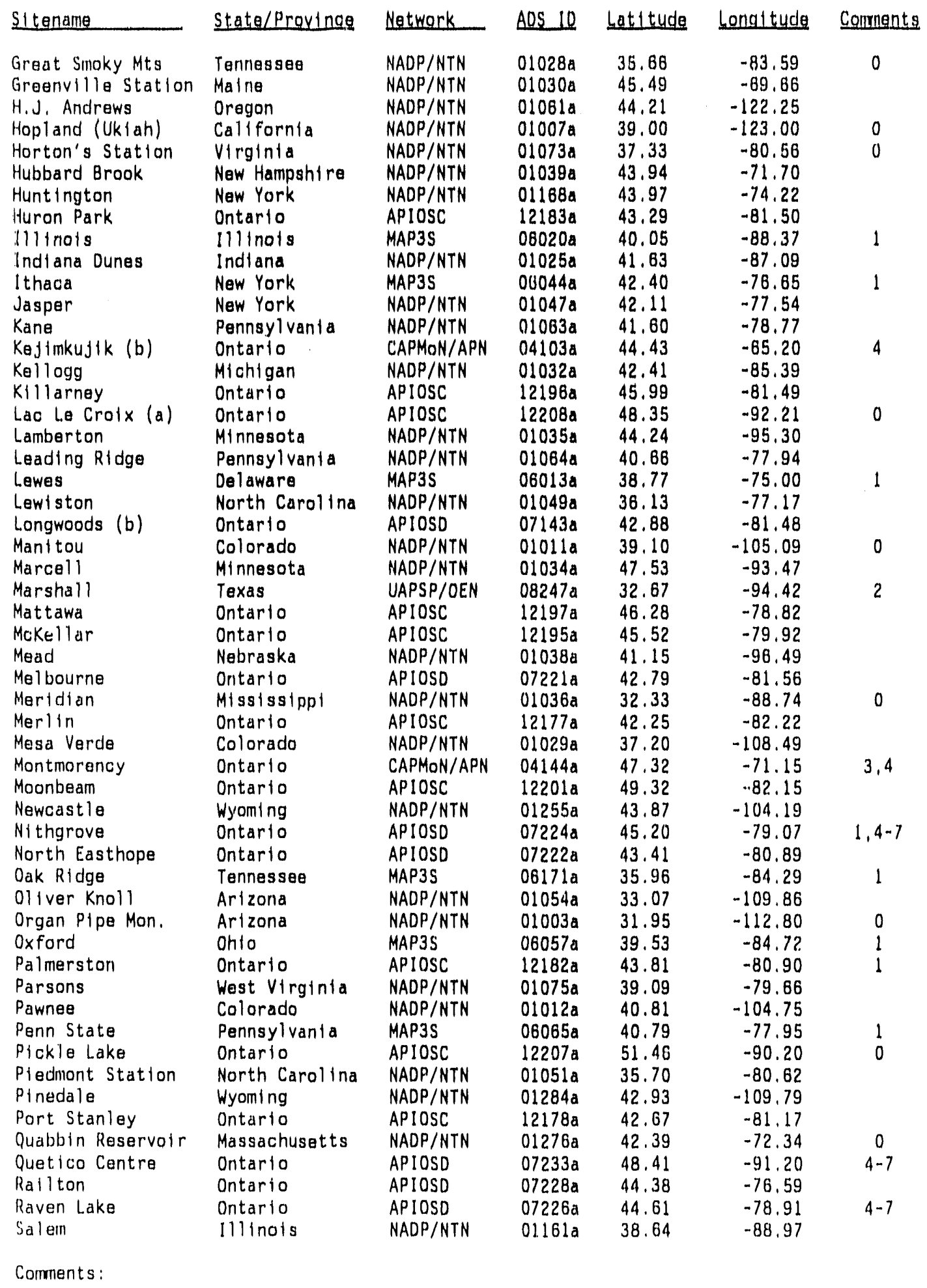

0 No annual averages

2 No annual average for sulfate

4 No annual average for sodium

6) No annual average for calctum

1 No annual average for hydrogen

3 No annual average for chloride

5 No annual average for potassium

7 No annual average for magnestum 
IABLE A.2. 1982-1988 Trend Sites Ordered by Sitename (Contd.)

\begin{tabular}{|c|c|c|c|c|c|c|}
\hline Sitaname & State/Proylinoe & Network & ADS 10 & Lat fude & Longlt tude & Comments \\
\hline $\begin{array}{l}\text { Sand Spring } \\
\text { Sequola Nat. Park } \\
\text { Shabbona } \\
\text { Shallow Lake } \\
\text { Shenarloah Nat'l } \\
\text { Smith's Falls } \\
\text { Southern } 111 \text { U } \\
\text { Spooner } \\
\text { Tanbark Flat } \\
\text { Teddy Roosevelt NP } \\
\text { Trout Lake } \\
\text { Underhlll Center } \\
\text { Universtty Forest } \\
\text { Uvalda } \\
\text { Uxbrldge } \\
\text { Vlatoria } \\
\text { Virglnla } \\
\text { Walker Branoh } \\
\text { Washington Xing } \\
\text { Waterloo } \\
\text { Wellesley } \\
\text { Wellston } \\
\text { Whiteface } \\
\text { Whitney } \\
\text { Wilberforce } \\
\text { Wilkesport } \\
\text { Winterport } \\
\text { Wooster } \\
\text { Yellowstone } \\
\text { Yosemite }\end{array}$ & 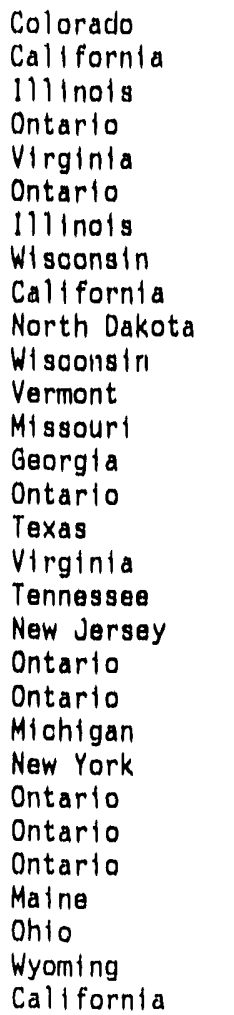 & $\begin{array}{l}\text { NADP/NTN } \\
\text { NADP/NTN } \\
\text { NADP/NTN } \\
\text { APIOSC } \\
\text { NADP/NTN } \\
\text { APIOSC } \\
\text { NADP/NTN } \\
\text { NADP/NTN } \\
\text { NADP/NTN } \\
\text { NADP/NTN } \\
\text { NADP/NTN } \\
\text { UAPSP/OEN } \\
\text { NADP/NTN } \\
\text { UAPSP/OEN } \\
\text { APIOSC } \\
\text { NADP/NTN } \\
\text { MAP3S } \\
\text { NADP/NTN } \\
\text { NADP/NTN } \\
\text { APIOSC } \\
\text { APIOSD } \\
\text { NADP/NTN } \\
\text { MAP3S } \\
\text { APIOSC } \\
\text { APIOSC } \\
\text { APIOSC } \\
\text { UAPSP/OEN } \\
\text { NADP/NTN } \\
\text { NADP/NTN } \\
\text { NADP/NTN }\end{array}$ & $\begin{array}{l}01173 a \\
01008 a \\
01024 a \\
12181 a \\
01250 a \\
12192 a \\
01022 a \\
01077 a \\
01270 a \\
01062 a \\
01076 a \\
08248 a \\
01253 a \\
08237 a \\
12187 a \\
01071 a \\
06072 a \\
01171 a \\
01285 a \\
12184 a \\
07223 a \\
01033 a \\
06043 a \\
12203 a \\
12188 a \\
12179 a \\
08240 a \\
01058 a \\
010 \% \\
01157 a\end{array}$ & $\begin{array}{r}40.51 \\
36.57 \\
41.84 \\
44.58 \\
38.52 \\
44.94 \\
37.71 \\
45.82 \\
34.21 \\
47.60 \\
46.05 \\
44.53 \\
36.91 \\
32.06 \\
44.21 \\
28.85 \\
38.04 \\
35.96 \\
40.31 \\
43.48 \\
43.47 \\
44.22 \\
44.39 \\
45.54 \\
45.01 \\
2.70 \\
44.62 \\
40.78 \\
44.92 \\
37.80\end{array}$ & $\begin{array}{r}-107.70 \\
-118.78 \\
-88.85 \\
-81.09 \\
-78.44 \\
-75.96 \\
-89.27 \\
-91.87 \\
-117.76 \\
-103.20 \\
-89.65 \\
-72.87 \\
-90.32 \\
-82.47 \\
-79.21 \\
-96.92 \\
-78.54 \\
-84.29 \\
-74.85 \\
-80.59 \\
-80.76 \\
-85.82 \\
-73.86 \\
-78.26 \\
-78.22 \\
-82.35 \\
-68.97 \\
-81.92 \\
-110.42 \\
-119.86\end{array}$ & $\begin{array}{l}? \\
0 \\
0 \\
0 \\
1\end{array}$ \\
\hline
\end{tabular}

Comments:

0 No alinual averages

2 No annual average for sulfate

4 No annual average for sodium

6 No annual average for calclum

1 No annual average for hydrogen
3 No annual average for chloride
5 No annual average for potassium
7 No annual average for magnesium 
IABLE_A.3. 1988 Frequency Distribution Percentlles for Annual and Seasonal Ion Spectes Precipłtation-weighted Concentration

\begin{tabular}{|c|c|c|c|c|c|c|c|c|c|c|c|}
\hline & & Number of & & & & & Percen & & & & \\
\hline & & S1tes & $\mathrm{Min}$ & 5 th & 10th & $25 t h$ & 50th & 25 th & 90th & 95th & $\operatorname{Max}$ \\
\hline & $\begin{array}{l}\text { Annual } \\
\text { Winter } \\
\text { Spring } \\
\text { Summer } \\
\text { Fall }\end{array}$ & $\begin{array}{l}193 \\
229 \\
251 \\
243 \\
247\end{array}$ & $\begin{array}{l}4.161 \\
4.219 \\
4.073 \\
3.906 \\
4.198\end{array}$ & $\begin{array}{l}4.217 \\
4.293 \\
4.208 \\
4.044 \\
4.297\end{array}$ & $\begin{array}{l}4.260 \\
4.335 \\
4.276 \\
4.097 \\
4.328\end{array}$ & $\begin{array}{l}4.343 \\
4.406 \\
4.378 \\
4.250 \\
4.450\end{array}$ & $\begin{array}{l}4.557 \\
4.578 \\
4.609 \\
4.567 \\
4.685\end{array}$ & $\begin{array}{l}4.947 \\
4.842 \\
5.182 \\
5.070 \\
5.043\end{array}$ & $\begin{array}{l}5.343 \\
5.408 \\
5.605 \\
5.338 \\
5.433\end{array}$ & $\begin{array}{l}5.468 \\
5.540 \\
5.799 \\
5.582 \\
5.538\end{array}$ & $\begin{array}{l}5.740 \\
6.446 \\
6.762 \\
6.587 \\
6.711\end{array}$ \\
\hline $\begin{array}{l}\text { Sulfate } \\
(\mathrm{mg} / 1)\end{array}$ & $\begin{array}{l}\text { Annual } \\
\text { Winter } \\
\text { Spring } \\
\text { Summer } \\
\text { Fall }\end{array}$ & $\begin{array}{l}191 \\
207 \\
235 \\
241 \\
248\end{array}$ & $\begin{array}{l}0.187 \\
0.063 \\
0.260 \\
0.181 \\
0.074\end{array}$ & $\begin{array}{l}0.370 \\
0.230 \\
0.387 \\
0.515 \\
0.270\end{array}$ & $\begin{array}{l}0.622 \\
0.307 \\
0.564 \\
0.662 \\
0.458\end{array}$ & $\begin{array}{l}1.111 \\
0.724 \\
1.208 \\
1.065 \\
0.890\end{array}$ & $\begin{array}{l}1.782 \\
1.250 \\
2.141 \\
1.737 \\
1.347\end{array}$ & $\begin{array}{l}2.685 \\
1.780 \\
3.026 \\
3.422 \\
1.950\end{array}$ & $\begin{array}{l}3.159 \\
2.252 \\
3.545 \\
4.445 \\
2.520\end{array}$ & $\begin{array}{l}3.429 \\
2.405 \\
4.329 \\
5.057 \\
2.770\end{array}$ & $\begin{array}{r}6.191 \\
3.133 \\
6.091 \\
15.038 \\
4.038\end{array}$ \\
\hline $\begin{array}{l}\text { Nitrate } \\
(\mathrm{mg} / 1)\end{array}$ & $\begin{array}{l}\text { Annual } \\
\text { Winter } \\
\text { Spring } \\
\text { Summer } \\
\text { Fall }\end{array}$ & $\begin{array}{l}189 \\
223 \\
249 \\
242 \\
245\end{array}$ & $\begin{array}{l}0.021 \\
0.015 \\
0.034 \\
0.015 \\
0.023\end{array}$ & $\begin{array}{l}0.272 \\
0.221 \\
0.258 \\
0.238 \\
0.131\end{array}$ & $\begin{array}{l}0.427 \\
0.346 \\
0.432 \\
0.538 \\
0.235\end{array}$ & $\begin{array}{l}0.802 \\
0.643 \\
0.830 \\
0.880 \\
0.535\end{array}$ & $\begin{array}{l}1.217 \\
1.134 \\
1.476 \\
1.332 \\
0.881\end{array}$ & $\begin{array}{l}1.758 \\
1.736 \\
2.186 \\
1.906 \\
1.418\end{array}$ & $\begin{array}{l}2.481 \\
2.592 \\
2.986 \\
2.521 \\
1.885\end{array}$ & $\begin{array}{l}2.688 \\
2.808 \\
3.713 \\
2.697 \\
2.030\end{array}$ & $\begin{array}{l}3.760 \\
3.664 \\
5.215 \\
5.264 \\
2.974\end{array}$ \\
\hline $\begin{array}{l}\text { Arrmon i um } \\
(\mathrm{mg} / 1)\end{array}$ & $\begin{array}{l}\text { Annual } \\
\text { Winter } \\
\text { Spring } \\
\text { Summer } \\
\text { Fall }\end{array}$ & $\begin{array}{l}195 \\
232 \\
253 \\
245 \\
246\end{array}$ & $\begin{array}{l}0.010 \\
0.010 \\
0.010 \\
0.010 \\
7.010\end{array}$ & $\begin{array}{l}0.033 \\
0.018 \\
0.032 \\
0.011 \\
0.013\end{array}$ & $\begin{array}{l}0.080 \\
0.028 \\
0.060 \\
0.021 \\
0.032\end{array}$ & $\begin{array}{l}0.103 \\
0.061 \\
0.160 \\
0.074 \\
0.067\end{array}$ & $\begin{array}{l}0.212 \\
0.119 \\
0.302 \\
0.195 \\
0.164\end{array}$ & $\begin{array}{l}0.388 \\
0.224 \\
0.533 \\
0.406 \\
0.305\end{array}$ & $\begin{array}{l}0.537 \\
0.354 \\
0.803 \\
0.588 \\
0.420\end{array}$ & $\begin{array}{l}0.667 \\
0.402 \\
1.105 \\
0.730 \\
0.534\end{array}$ & $\begin{array}{l}1.002 \\
0.671 \\
1.854 \\
1.916 \\
1.146\end{array}$ \\
\hline $\begin{array}{l}\text { Calctum } \\
(\mathrm{mg} / 1)\end{array}$ & $\begin{array}{l}\text { Annual } \\
\text { Winter } \\
\text { Spring } \\
\text { Summer } \\
\text { Fall }\end{array}$ & $\begin{array}{l}190 \\
219 \\
248 \\
242 \\
244\end{array}$ & $\begin{array}{l}0.016 \\
0.006 \\
0.021 \\
0.007 \\
0.013\end{array}$ & $\begin{array}{l}0.052 \\
0.039 \\
0.064 \\
0.064 \\
0.032\end{array}$ & $\begin{array}{l}0.074 \\
0.049 \\
0.089 \\
0.081 \\
0.037\end{array}$ & $\begin{array}{l}0.104 \\
0.066 \\
0.111 \\
0.120 \\
0.064\end{array}$ & $\begin{array}{l}0.191 \\
0.099 \\
0.243 \\
0.213 \\
0.121\end{array}$ & $\begin{array}{l}0.290 \\
0.161 \\
0.430 \\
0.344 \\
0.219\end{array}$ & $\begin{array}{l}0.447 \\
0.329 \\
0.666 \\
0.470 \\
0.336\end{array}$ & $\begin{array}{l}0.577 \\
0.401 \\
0.911 \\
0.562 \\
0.411\end{array}$ & $\begin{array}{l}1.177 \\
0.964 \\
2.585 \\
3.024 \\
2.961\end{array}$ \\
\hline
\end{tabular}


TABLE A.4. 1988 Frequency Distribution Percentiles for Annual and Seasonal Ion Species Deposition

\begin{tabular}{|c|c|c|c|c|c|c|c|c|c|c|c|}
\hline \multirow{3}{*}{$\begin{array}{l}\text { Hydrogen } \\
\text { (kg/ha) }\end{array}$} & & \multirow{2}{*}{$\begin{array}{l}\text { Number of } \\
\text { Sites }\end{array}$} & \multirow[b]{2}{*}{ Min } & \multicolumn{7}{|c|}{ Percentile } & \multirow[b]{2}{*}{$\operatorname{Max}$} \\
\hline & & & & 5 th & $10 t h$ & 25th & 50 th & $75 \mathrm{th}$ & 90th & 95 th & \\
\hline & $\begin{array}{l}\text { Annual } \\
\text { Winter } \\
\text { Spring } \\
\text { Summer } \\
\text { Fall }\end{array}$ & $\begin{array}{l}193 \\
229 \\
251 \\
243 \\
247\end{array}$ & $\begin{array}{l}0.003 \\
0.000 \\
0.000 \\
0.000 \\
0.000\end{array}$ & $\begin{array}{l}0.013 \\
0.001 \\
0.001 \\
0.001 \\
0.002\end{array}$ & $\begin{array}{l}0.023 \\
0.004 \\
0.002 \\
0.003 \\
0.003\end{array}$ & $\begin{array}{l}0.066 \\
0.016 \\
0.010 \\
0.012 \\
0.016\end{array}$ & $\begin{array}{l}0.268 \\
0.051 \\
0.045 \\
0.061 \\
0.067\end{array}$ & $\begin{array}{l}0.395 \\
0.078 \\
0.081 \\
0.130 \\
0.100\end{array}$ & $\begin{array}{l}0.487 \\
0.099 \\
0.110 \\
0.189 \\
0.138\end{array}$ & $\begin{array}{l}0.559 \\
0.120 \\
0.138 \\
0.219 \\
0.160\end{array}$ & $\begin{array}{l}0.679 \\
0.176 \\
0.206 \\
0.271 \\
0.216\end{array}$ \\
\hline $\begin{array}{l}\text { Sulfate } \\
(\mathrm{kg} / \mathrm{ha})\end{array}$ & $\begin{array}{l}\text { Annual } \\
\text { Winter } \\
\text { Spring } \\
\text { Summer } \\
\text { Fall }\end{array}$ & $\begin{array}{l}191 \\
207 \\
235 \\
241 \\
248\end{array}$ & $\begin{array}{l}0.566 \\
0.039 \\
0.089 \\
0.032 \\
0.020\end{array}$ & $\begin{array}{l}1.695 \\
0.157 \\
0.411 \\
0.244 \\
0.211\end{array}$ & $\begin{array}{l}2.761 \\
0.313 \\
0.669 \\
0.437 \\
0.352\end{array}$ & $\begin{array}{l}7.801 \\
0.723 \\
1.999 \\
1.640 \\
1.430\end{array}$ & $\begin{array}{c}16.55 \\
2.485 \\
3.831 \\
4.236 \\
3.524\end{array}$ & $\begin{array}{r}22.47 \\
3.81 \\
5.51 \\
7.52 \\
5.41\end{array}$ & $\begin{array}{r}27.47 \\
4.79 \\
6.90 \\
10.37 \\
7.37\end{array}$ & $\begin{array}{r}30.25 \\
5.59 \\
7.88 \\
11.82 \\
8.52\end{array}$ & $\begin{array}{r}39.11 \\
7.23 \\
10.19 \\
19.85 \\
11.83\end{array}$ \\
\hline $\begin{array}{l}\text { Nitrate } \\
\text { (kg/ha) }\end{array}$ & $\begin{array}{l}\text { Annual } \\
\text { Winter } \\
\text { Spring } \\
\text { Summer } \\
\text { Fall }\end{array}$ & $\begin{array}{l}189 \\
223 \\
249 \\
242 \\
245\end{array}$ & $\begin{array}{l}0.362 \\
0.025 \\
0.066 \\
0.001 \\
0.015\end{array}$ & $\begin{array}{l}1.243 \\
0.193 \\
0.304 \\
0.156 \\
0.167\end{array}$ & $\begin{array}{l}2.114 \\
0.294 \\
0.431 \\
0.353 \\
0.277\end{array}$ & $\begin{array}{l}6.107 \\
0.905 \\
1.253 \\
1.546 \\
0.944\end{array}$ & $\begin{array}{r}10.61 \\
1.99 \\
2.62 \\
2.78 \\
2.16\end{array}$ & $\begin{array}{r}14.69 \\
2.95 \\
3.82 \\
4.05 \\
3.53\end{array}$ & $\begin{array}{r}20.79 \\
5.01 \\
5.64 \\
5.52 \\
5.28\end{array}$ & $\begin{array}{r}22.95 \\
6.01 \\
6.57 \\
6.22 \\
6.45\end{array}$ & $\begin{array}{r}32.29 \\
10.89 \\
8.22 \\
8.16 \\
9.92\end{array}$ \\
\hline $\begin{array}{l}\text { Ammon i um } \\
(\mathrm{kg} / \mathrm{ha})\end{array}$ & $\begin{array}{l}\text { Annual } \\
\text { Winter } \\
\text { Spring } \\
\text { Summer } \\
\text { Fall }\end{array}$ & $\begin{array}{l}195 \\
232 \\
253 \\
245 \\
246\end{array}$ & $\begin{array}{l}0.044 \\
0.003 \\
0.006 \\
0.001 \\
0.002\end{array}$ & $\begin{array}{l}0.175 \\
0.017 \\
0.039 \\
0.010 \\
0.024\end{array}$ & $\begin{array}{l}0.265 \\
0.036 \\
0.080 \\
0.028 \\
0.043\end{array}$ & $\begin{array}{l}0.820 \\
0.084 \\
0.217 \\
0.109 \\
0.138\end{array}$ & $\begin{array}{l}1.838 \\
0.202 \\
0.562 \\
0.425 \\
0.371\end{array}$ & $\begin{array}{l}2.964 \\
0.408 \\
0.872 \\
0.795 \\
0.686\end{array}$ & $\begin{array}{l}4.377 \\
0.612 \\
1.370 \\
1.396 \\
1.109\end{array}$ & $\begin{array}{l}4.856 \\
0.826 \\
1.910 \\
1.673 \\
1.415\end{array}$ & $\begin{array}{l}8.433 \\
1.863 \\
2.982 \\
3.656 \\
3.358\end{array}$ \\
\hline $\begin{array}{l}\text { Calcium } \\
(\mathrm{kg} / \mathrm{ha})\end{array}$ & $\begin{array}{l}\text { Arnual } \\
\text { Wirter } \\
\text { Spring } \\
\text { Summer } \\
\text { Fall }\end{array}$ & $\begin{array}{l}190 \\
219 \\
248 \\
242 \\
244\end{array}$ & $\begin{array}{l}0.063 \\
0.013 \\
0.018 \\
0.004 \\
0.005\end{array}$ & $\begin{array}{l}0.373 \\
0.035 \\
0.116 \\
0.051 \\
0.045\end{array}$ & $\begin{array}{l}0.606 \\
0.062 \\
0.155 \\
0.107 \\
0.085\end{array}$ & $\begin{array}{l}0.924 \\
0.106 \\
0.285 \\
0.239 \\
0.142\end{array}$ & $\begin{array}{l}1.449 \\
0.170 \\
0.420 \\
0.371 \\
0.265\end{array}$ & $\begin{array}{l}2.027 \\
0.291 \\
0.633 \\
0.630 \\
0.436\end{array}$ & $\begin{array}{l}3.224 \\
0.514 \\
0.926 \\
0.895 \\
0.665\end{array}$ & $\begin{array}{l}3.916 \\
0.836 \\
1.302 \\
1.124 \\
0.855\end{array}$ & $\begin{array}{l}7.852 \\
1.725 \\
3.945 \\
3.194 \\
3.991\end{array}$ \\
\hline
\end{tabular}


TABLE A.5. Summary of 1979-1988 Trend Sites Annual Precipitation-weighted Concentration by Year

\begin{tabular}{|c|c|c|c|c|c|c|c|c|c|c|c|c|c|}
\hline & & & & & & & & & ent & & & & \\
\hline & Year & N & Mean & $\begin{array}{l}\text { sto } \\
\text { Dev }\end{array}$ & Min & $\underline{5 t h}$ & 10th & 25th & 50th & 75th & 90th & 95th & Max \\
\hline$y$ & & & & & & & & & & & & & \\
\hline & 1979 & 23 & 4.57 & 0.34 & 4.14 & 4.15 & 4.2 .5 & 4.28 & 4.42 & 4.88 & 5.03 & 5.21 & 5.30 \\
\hline & 1980 & 23 & 4.45 & 0.33 & 4.07 & 4.11 & 4.14 & 4.17 & 4.33 & 4.76 & 5.01 & $5.0 \%$ & 5.15 \\
\hline & 1981 & 23 & 4.52 & 0.36 & 4.09 & 4.18 & 4.21 & 4.23 & 4.35 & 4.71 & 5.07 & 5.16 & 5.39 \\
\hline & 1982 & 23 & 4.54 & 0.35 & 4.18 & 4.18 & 4.23 & 4.27 & 4.48 & 4.69 & 5.03 & 5.24 & 5.4 \\
\hline & 1983 & 23 & 4.56 & 0.30 & 4.20 & 4.25 & 4.25 & 4.30 & 4.48 & 4.76 & 5.03 & 5.05 & 5.3 \\
\hline & 1984 & 23 & 4.55 & 0.31 & 4.16 & 4.19 & 4.22 & 4.29 & 4.47 & 4.69 & 5.07 & 5.10 & 5.1 \\
\hline & 1985 & 23 & 4.54 & 0.36 & 4.16 & 4.18 & 4.19 & 4.28 & 4.44 & 4.64 & 5.14 & 5.21 & 5.3 \\
\hline & 1986 & 23 & 4.52 & 0.39 & 4.11 & 4.12 & 4.15 & 4.26 & 4.43 & 4.56 & 5.14 & 5.42 & 5.43 \\
\hline & 1987 & 23 & 4.52 & 0.32 & 4.15 & 4.15 & 4.20 & 4.22 & 4.44 & 4.72 & 5.02 & 5.06 & 5.24 \\
\hline & 1988 & 23 & 4.51 & 0.34 & 4.1 & 4.19 & 4.1 & 4.27 & 4.41 & 4.67 & 4.99 & 5.13 & 5.43 \\
\hline Hydrogen & & & & & & & & & & & & & \\
\hline (ug) & 1979 & 23 & 34.16 & 20.66 & 4.98 & 6.13 & 9.42 & 13.04 & 38.05 & 52.92 & 56.17 & 70.15 & 2.53 \\
\hline & 1980 & 23 & 44.29 & 24.38 & 7.10 & 8.57 & 9. & 17.45 & 46.42 & 66 & 72 & 6 & .6 \\
\hline & 1981 & 23 & 38.74 & 22.04 & 4.10 & 6.91 & 8.50 & 19.40 & 44.71 & 59.37 & 61.97 & 65 & 1.7 \\
\hline & 1982 & 23 & 35.78 & 19.20 & 3.49 & 5.71 & 9.23 & 20.63 & 33.24 & 53.26 & 58.27 & 65.45 & 65.64 \\
\hline & 1983 & 23 & 32.97 & 17.48 & 4.91 & 8.90 & 9.43 & 17.56 & 33.00 & 49.60 & 55.93 & 56.79 & 63.57 \\
\hline & 1984 & 23 & 34.56 & 19.54 & 7.08 & 7.92 & 8.44 & 20.63 & 34.03 & 51.19 & 60.86 & 65.23 & 69.21 \\
\hline & 1985 & 23 & 36.62 & 20.56 & 4.51 & 6.10 & 7.19 & 23.00 & 36.28 & 52.40 & 64.41 & 65.66 & 69.43 \\
\hline & 1986 & 23 & 39.14 & 21.91 & 3.74 & 3.84 & 7.26 & 27.49 & 37.11 & 6 & 71.32 & 75.67 & 76.8 \\
\hline & 1987 & 23 & 37.10 & 20.90 & 5.82 & 8.77 & 9.52 & 19.22 & 36.39 & 59 & 63 & 70 & 70.61 \\
\hline & 1988 & 23 & 38.28 & 19.61 & 3.68 & 7.47 & 10.1 & 21.26 & 39.01 & 53.10 & 64.13 & 64.89 & 66.4 \\
\hline & & & & & & & & & & & & & \\
\hline & 1979 & 30 & 2.48 & 0.82 & 1.07 & 1.43 & 1.6 & 1.94 & 2.23 & 3.2 & 3.6 & 3.91 & 4.2 \\
\hline & 1980 & 30 & 2.65 & 0.85 & 0.9 & 1. & 1. & 2.25 & 2.62 & 3. & & 3. & 4.1 \\
\hline & 1981 & 30 & 2.55 & 0.80 & 1.12 & 1.32 & 1.65 & 1.82 & $? .65$ & 3.27 & 3 . & 3.55 & 4.4 \\
\hline & 1982 & 30 & 2.29 & 0.76 & 0.95 & 1.26 & 1.27 & 1.73 & 2.15 & 3.00 & 3.27 & 3.43 & 3.5 \\
\hline & 1983 & 30 & 2.08 & 0.64 & 1.02 & 1.05 & 1.19 & 1.64 & 2.05 & 2.71 & 2.94 & 3.03 & 3.05 \\
\hline & 1984 & 30 & 2.14 & 0.73 & 1.00 & 1.27 & 1.35 & 1.57 & 1.99 & 2.70 & 3.26 & 3.46 & 3.59 \\
\hline & 1985 & 30 & 2.09 & 0.75 & 0.72 & 0.81 & 1.10 & 1.52 & 2.04 & 2.65 & 3.19 & 3.22 & 3.29 \\
\hline & 1986 & 30 & 2.28 & 0.82 & 0. & 0.79 & 1.25 & 1.72 & 2.16 & 2. & 3. & 3.65 & 3.96 \\
\hline & 1987 & 30 & 2.18 & 0.86 & 0. & 0.83 & 1. & 1.56 & 1.90 & 2.99 & 3.43 & 3.6 & 3.64 \\
\hline & & 30 & 2.29 & 0.79 & 0.8 & 0.94 & 1 & 1.74 & 23 & 2 & 3.30 & 3.62 & 3.6 \\
\hline & & & & & & & & & & & & & \\
\hline & 1979 & 31 & 1.32 & 0.43 & 0.47 & 0.62 & 0.7 & 1.01 & 1.40 & 1.62 & 1.77 & 2.00 & 2.10 \\
\hline & 1980 & 31 & 1.60 & 0.45 & 0.68 & 0.81 & 0.8 & 1.28 & 1.75 & 1.93 & 2.02 & 2.16 & 2.2 \\
\hline & 1981 & 31 & 1.44 & 0.42 & 0.83 & 0.84 & 0.88 & 0.99 & 1.50 & 1.82 & 1.95 & 2.10 & 2.1 \\
\hline & 1982 & 31 & 1.31 & 0.42 & 0.59 & 0.66 & 0.80 & 1.00 & 1.26 & 1.75 & 1.89 & 1.91 & 2.1 \\
\hline & 1983 & 31 & 1.26 & 0.34 & 0.63 & 0.65 & 0.78 & 1.02 & 1.18 & 1.59 & 1.69 & 1.73 & 1.7 \\
\hline & 1984 & 31 & 1.37 & 0.44 & 0.76 & 0.79 & 0.80 & 1.03 & 1.28 & 1.77 & 1.99 & 2.12 & 2.15 \\
\hline & 1985 & 31 & 1.33 & 0.43 & 0.68 & 0.74 & 0.80 & 0.91 & 1.38 & 1.62 & 1.82 & 2.11 & 2.2 \\
\hline & 1986 & 31 & 1.40 & 0.42 & 0.61 & 0.80 & 0.93 & 1.03 & 1.35 & 1.80 & 2.00 & 2.06 & 2.14 \\
\hline & 198 & 31 & 1.41 & 0.45 & 0.64 & 0.65 & 0.8 & 1.02 & 1.43 & 1.78 & 2.01 & 2.10 & 2.12 \\
\hline & 1988 & 31 & 1.45 & 0.42 & 0.58 & 0.72 & 0.98 & 1.11 & 1.52 & 1.74 & 2.04 & 2.13 & 2.22 \\
\hline
\end{tabular}


TABLE A.5. Summary of 1979-1988 Trend Sites Annual Precipitation-weighted Concentration by Year (Cont'd)

Percentile

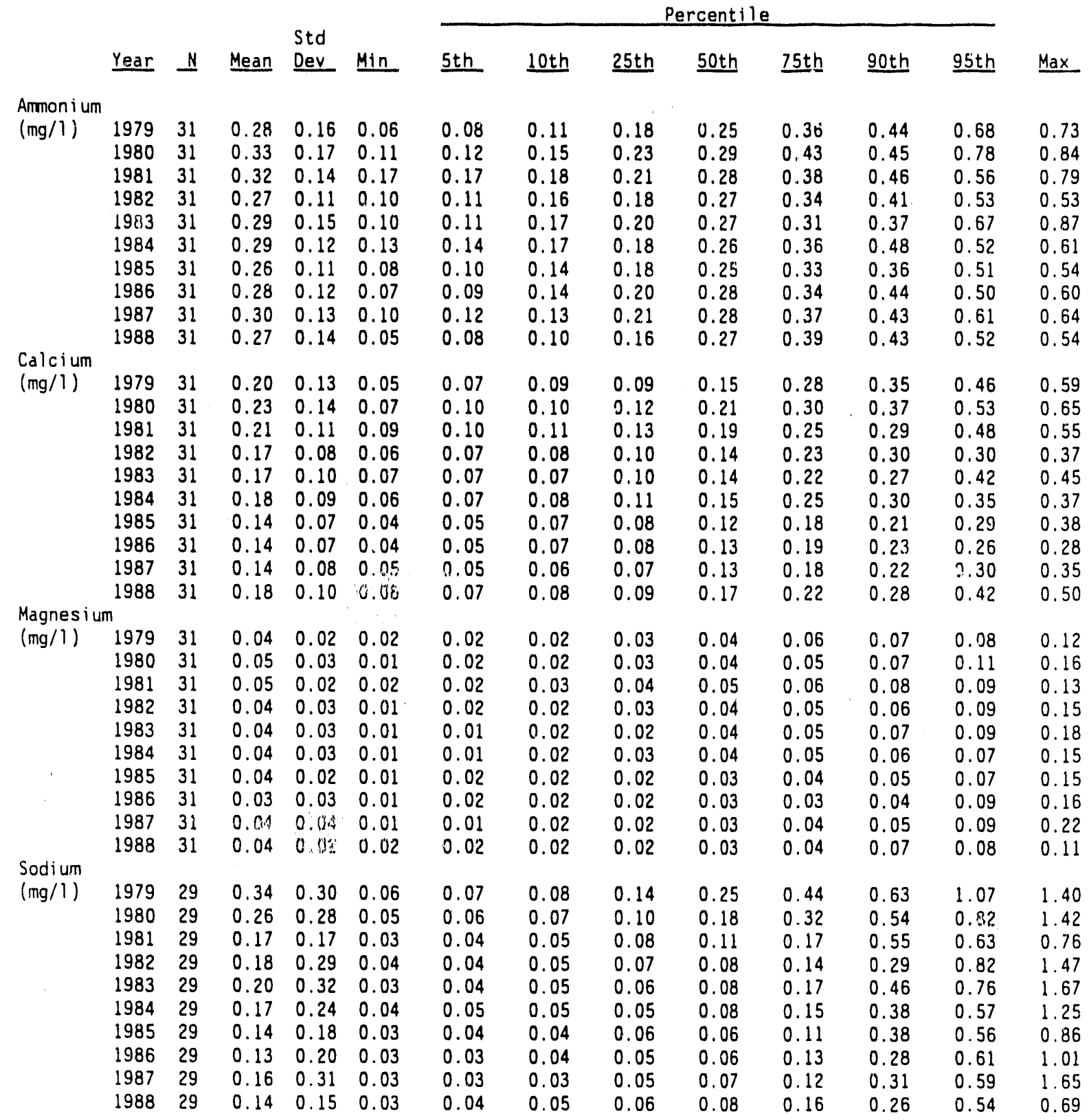


TABLE A.5. Summary of 1979-1988 Trend Sites Annual Precipitation-weighted Concentration by Year (Cont'd)

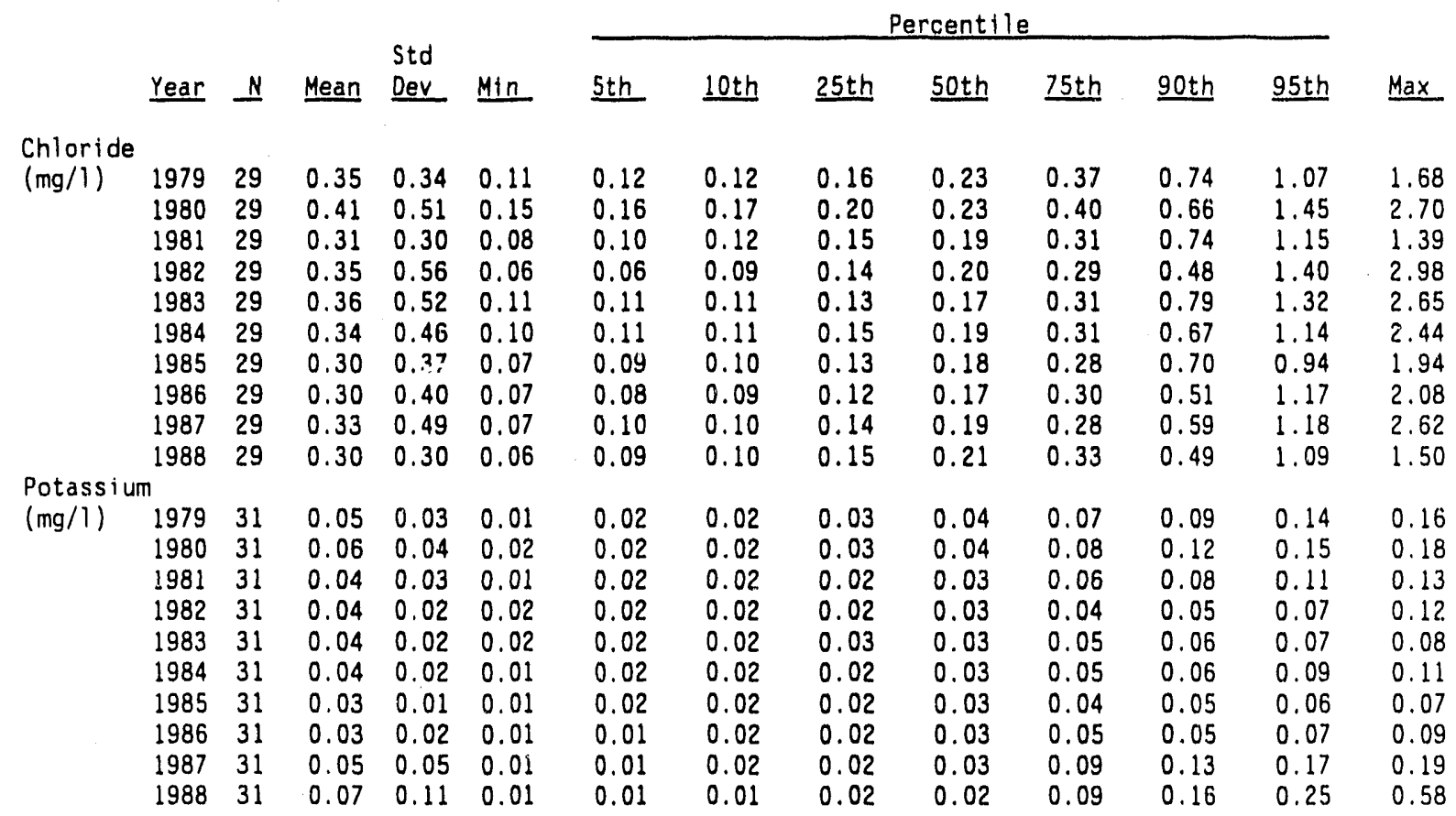


TABLE A.6. Summary of 1979-1988 Trend Sites Annual Deposition by Year

\begin{tabular}{|c|c|c|c|c|c|c|c|c|c|c|c|c|c|}
\hline & & & & & & & & & reent & & & & \\
\hline & Year & $\underline{N}$ & Mean & Dev & Min & 5 th & 10 th & 25th & 50th & 75 th & 90th & 95th & $\operatorname{Max}$ \\
\hline & & & & & & & & & & & & & \\
\hline & 79 & 31 & 107.1 & 36.26 & 28.16 & 53.84 & 72.08 & 79.29 & 117.3 & 130.5 & 131.6 & 141.7 & 226.5 \\
\hline & 1980 & 31 & 89.8 & 25.82 & 30.65 & 47.20 & 55.02 & 76.62 & 91.5 & 100.4 & 112.6 & 128.0 & 171.4 \\
\hline & 1981 & 31 & 95.1 & 23.98 & 41.75 & 54.34 & 71.86 & 78.85 & 92.9 & 110.0 & 129.4 & 138.4 & 151.5 \\
\hline & 1982 & 31 & 103.4 & 28.65 & 37.17 & 68.95 & 81.43 & 85.12 & 98.1 & 116.4 & 150.4 & 152.7 & 182.6 \\
\hline & 1983 & 31 & 109.9 & 32.86 & 42.70 & 59.30 & 65.94 & 87.77 & 108.5 & 127.9 & 146.5 & 158.7 & 197.5 \\
\hline & 1984 & 31 & 106.7 & 28.36 & 46.34 & 61.77 & 75.35 & 86.22 & 107.1 & 125.5 & 140.3 & 146.7 & 179.8 \\
\hline & 1985 & 31 & 100.7 & 21.71 & 43.78 & 59.73 & 81.94 & 87.59 & 99.8 & 109.7 & 130.3 & 135.6 & 149.8 \\
\hline & 1986 & 31 & 94.6 & 19.86 & 39.18 & 63.83 & 76.69 & 81.93 & 93.4 & 107.3 & 120.3 & 126.4 & 134.6 \\
\hline & 1987 & 31 & 92.9 & 26.55 & 32.31 & 48.75 & 57.86 & 77.26 & 92.7 & 110.5 & 133.5 & 140.3 & 145.8 \\
\hline & 1988 & 31 & 86.2 & 25.08 & 21.81 & 40.14 & 61.65 & 70.60 & 89.4 & 100.2 & 109.0 & 127.6 & 150.3 \\
\hline ydrogen & & & & & & & & & & & & & \\
\hline$(\mathrm{kg} /$ & 1979 & 23 & 0.38 & 0.25 & 0.02 & 0.04 & 0.06 & 0.14 & 0.35 & 0.51 & 0.72 & 0.82 & 0.95 \\
\hline & 1980 & 23 & 0.43 & 0.27 & 0.04 & 0.04 & 0.05 & 0.18 & 0.45 & 0.57 & 0.86 & 0.86 & 0.88 \\
\hline & 1981 & 23 & 0.40 & 0.26 & 0.02 & 0.05 & 0.05 & 0.17 & 0.45 & 0.57 & 0.74 & 0.80 & 0.86 \\
\hline & 1982 & 23 & 0.39 & 0.21 & 0.03 & 0.03 & 0.05 & 0.31 & 0.42 & 0.49 & 0.63 & 0.74 & 0.77 \\
\hline & 1983 & 23 & 0.36 & 0.20 & 0.03 & 0.04 & 0.06 & 0.18 & 0.40 & 0.48 & 0.59 & 0.63 & 0.81 \\
\hline & 1984 & 23 & 0.38 & 0.22 & 0.03 & 0.06 & 0.07 & 0.24 & 0.40 & 0.49 & 0.61 & 0.68 & 0.93 \\
\hline & 1985 & 23 & 0.39 & 0.25 & 0.04 & 0.04 & 0.04 & 0.24 & 0.43 & 0.54 & 0.71 & 0.84 & 0.96 \\
\hline & 1986 & 23 & 0.39 & 0.26 & 0.03 & 0.03 & 0.04 & 0.26 & 0.35 & 0.52 & 0.65 & 0.92 & 1.02 \\
\hline & 1987 & 23 & 0.35 & 0.21 & 0.03 & 0.04 & 0.05 & 0.23 & 0.37 & 0.46 & 0.54 & 0.60 & 0.94 \\
\hline & 1988 & 23 & 0.34 & 0.1 & 0.01 & 0.02 & 0.06 & 0.27 & 0.39 & 0.46 & 0.54 & 0.61 & 0.64 \\
\hline Sulfate & & & & & & & & & & & & & \\
\hline$(\mathrm{kg})$ & 1979 & 30 & 26.41 & 11.20 & 6.42 & 9.24 & 13.57 & 17.66 & 24.79 & 33.86 & 42.27 & 49.68 & 51.03 \\
\hline & 1980 & 30 & 24.38 & 10.65 & 3.27 & 5.45 & 9.69 & 20.40 & 23.43 & 29.79 & 40.25 & 43.67 & 45.61 \\
\hline & 1981 & 30 & 24.72 & 10.37 & 6.68 & 7.00 & 10.62 & 16.63 & 25.63 & 30.52 & 38.46 & 43.74 & 45.81 \\
\hline & 1982 & 30 & 23.37 & 8.37 & 3.53 & 10.43 & 10.73 & $19.8 ?$ & 23.75 & 28.94 & 33.87 & 37.56 & 40.05 \\
\hline & 1983 & 30 & 22.88 & 8.22 & 4.37 & 6.21 & 10.48 & 19.89 & 23.00 & 30.17 & 31.11 & 34.21 & 38.78 \\
\hline & 1984 & 30 & 22.95 & 8.98 & 4.64 & 7.84 & 10.95 & 18.42 & 22.31 & 27.20 & 34.61 & 41.17 & 43.59 \\
\hline & 1985 & 30 & 21.57 & 9.70 & 3.17 & 6.84 & 9.20 & 15.60 & 21.86 & 26.85 & 34.15 & 37.82 & 47.63 \\
\hline & 1986 & 30 & 22.13 & 10.06 & 2.80 & 5.03 & 10.66 & 17.14 & 22.06 & 25.61 & 32.08 & 42.45 & 53.31 \\
\hline & 1987 & 30 & 20.14 & 8.30 & 2.69 & 3.91 & 8.74 & 14.84 & 20.85 & 24.80 & 28.07 & 30.37 & 44.02 \\
\hline & & 30 & 19.72 & 7.30 & 2.06 & 6.40 & 7.58 & 17.24 & 20.44 & 24.65 & 28.63 & 31.02 & 31.55 \\
\hline Nitr & & & & & & & & & & & & & \\
\hline$(\mathrm{kg} / \mathrm{ha})$ & 1979 & 31 & 13.60 & 5.19 & 2.51 & 6.15 & 8.56 & 10.23 & 12.79 & 16.75 & 20.94 & 23.02 & 26.12 \\
\hline & 1980 & 31 & 14.29 & 5.30 & 2.72 & 4.46 & 8.31 & 11.19 & 14.40 & 17.82 & 2.0 .20 & 24.31 & 26.07 \\
\hline & 1981 & 31 & 13.81 & 5.68 & 4.10 & 5.26 & 7.51 & 8.76 & 13.66 & 16.96 & 19.89 & 24.42 & 27.60 \\
\hline & 1982 & 31 & 13.14 & 4.19 & 2.99 & 7.36 & 8.65 & 9.99 & 13.70 & 15.98 & 18.34 & 19.64 & 22.46 \\
\hline & 1983 & 31 & 13.27 & 3.62 & 3.88 & 5.80 & 8.20 & 10.95 & 13.86 & 15.81 & 17.12 & 18.34 & 19.02 \\
\hline & 1984 & 31 & 14.32 & 4.97 & 4.24 & 6.58 & 8.77 & 11.14 & 13.72 & 17.08 & 19.24 & 25.57 & 25.80 \\
\hline & 1985 & 31 & 13.39 & 4.93 & 2.98 & 7.12 & 7.96 & 9.06 & 14.62 & 16.26 & 19.02 & 23.67 & 24.34 \\
\hline & 1986 & 31 & 13.43 & 5.16 & 2.40 & 5.13 & 8.67 & $10.2 \mathrm{C}$ & 12.83 & 16.44 & 19.37 & 24.28 & 27.68 \\
\hline & 1987 & 31 & 12.68 & 4.31 & 2.81 & 5.07 & 7.99 & 10.71 & 12.87 & 15.13 & 17.75 & 19.09 & 23.81 \\
\hline & 1988 & 31 & 12.08 & 3.93 & 2.14 & 6.17 & 8.14 & 9.05 & 12.29 & 14.48 & 17.19 & 18.13 & 21.22 \\
\hline
\end{tabular}


TABLE A.6. Summary of 1979-1988 Trend Sites Annual Deposition by Year (Cont'd)

\begin{tabular}{|c|c|c|c|c|c|c|c|c|c|c|c|c|c|}
\hline & \multirow[b]{2}{*}{ Year } & \multirow[b]{2}{*}{$N$} & \multirow[b]{2}{*}{ Mean } & \multirow[b]{2}{*}{$\begin{array}{l}\text { Std } \\
\text { Dev } \\
\end{array}$} & \multirow[b]{2}{*}{ Min } & \multicolumn{7}{|c|}{ Percentlle } & \multirow[b]{2}{*}{ Max } \\
\hline & & & & & & Sttit & Len & 25th & 50th & 75th & goth & 95th & \\
\hline \multirow{10}{*}{$\begin{array}{l}\text { Ammoni um } \\
(\mathrm{kg} / \mathrm{ha})\end{array}$} & 1979 & 31 & 2.71 & 1.11 & 0.41 & 0.8 & 1.25 & 2,01 & 2.88 & 3.29 & 3.96 & 4.42 & 5. \\
\hline & 1980 & 31 & 2.74 & 1.04 & 0.46 & 1.20 & 1.51 & 2.04 & 2.79 & 3.68 & 4.14 & 4.35 & 4.67 \\
\hline & 1981 & 31 & 2.91 & 1.03 & 0.73 & 1.34 & 1.63 & 2.22 & 2.71 & 3.79 & 4.23 & 4.29 & 4.97 \\
\hline & 1982 & 31 & 2.70 & 0.95 & 0.60 & 1.45 & 1.64 & 2.09 & 2.62 & 3.15 & 4.08 & 4.48 & 5.08 \\
\hline & 1983 & 31 & 2.87 & 0.90 & 0.68 & 1.60 & 1.75 & 2.39 & 2.99 & 3.28 & 3.81 & 4.41 & 5.51 \\
\hline & 1984 & 31 & 2.89 & 1.00 & 0.79 & 1.58 & 1.75 & 2.08 & 2.82 & 3.64 & 4.47 & 4.56 & . \\
\hline & 1985 & 31 & 2,52 & 0.86 & 0.44 & 1.01 & 1.64 & 1.82 & 2.47 & 3.30 & 3.40 & 3.69 & 4.23 \\
\hline & 1986 & 31 & 2.66 & 1.14 & 0.34 & 0.80 & 1.65 & 1.88 & 2.64 & 3.38 & 3.88 & 5.21 & 5.36 \\
\hline & 1987 & 31 & 2.61 & 0.86 & 0.38 & 1.37 & 1.68 & 2.02 & 2.65 & 3.22 & 3.69 & 3.79 & 4.63 \\
\hline & 1988 & 31 & 2.12 & 0.81 & 0.17 & 0.78 & 1.04 & 1.79 & 2.09 & 2.71 & 2.90 & 3.35 & 3.77 \\
\hline \multirow{10}{*}{$\begin{array}{l}\text { Calcium } \\
\text { (kg/ha) }\end{array}$} & & & & & & & & & & & & & \\
\hline & 1979 & 31 & 1.80 & 0.79 & 0.63 & 0.73 & 0.91 & 1.17 & 1.60 & 2.41 & & & \\
\hline & 1980 & 31 & 1.91 & $\begin{array}{l}0.95 \\
0.69\end{array}$ & 0.82 & 0.86 & 1.01 & $\begin{array}{l}1.12 \\
1.39\end{array}$ & 1.62 & 2.75 & & & $\begin{array}{l}4.39 \\
3.73\end{array}$ \\
\hline & $\begin{array}{l}1981 \\
1982\end{array}$ & $\begin{array}{l}31 \\
31\end{array}$ & $\begin{array}{l}1.84 \\
1.66\end{array}$ & $\begin{array}{l}0.69 \\
0.79\end{array}$ & $\begin{array}{l}0.84 \\
0.54\end{array}$ & $\begin{array}{l}0.98 \\
0.61\end{array}$ & $\begin{array}{l}1.07 \\
0.90\end{array}$ & $\begin{array}{l}1.39 \\
1.09\end{array}$ & $\begin{array}{l}1.69 \\
1.55\end{array}$ & $\begin{array}{l}2.41 \\
2.10\end{array}$ & 2.63 & $\begin{array}{l}2.98 \\
3.31\end{array}$ & $\begin{array}{l}3.73 \\
4.01\end{array}$ \\
\hline & 1983 & 31 & 1.66 & 0.59 & 0.86 & 0.87 & 1.05 & 1.22 & 1.61 & 1.89 & 2.63 & 2.74 & 2.87 \\
\hline & 1984 & 31 & 1.74 & 0.64 & 0.60 & 0.73 & 0.99 & 1.28 & 1.75 & 2.12 & 2.56 & 2.87 & 3.2 \\
\hline & 1985 & 31 & 1.31 & 0.59 & 0.39 & 0.64 & 0.70 & 0.82 & 1.33 & 1.67 & 2.27 & 2.45 & 2.6 \\
\hline & 1986 & 31 & 1.27 & 0.66 & 0.36 & 0.51 & 0.65 & 0.78 & 1.05 & 1.52 & 2. & 2.76 & 3.0 \\
\hline & 1987 & 31 & 1.15 & 0.48 & 0.54 & 0.60 & 0.71 & 0.78 & 1.00 & 1. & 1.78 & 2.13 & 2.2 \\
\hline & 1988 & 31 & 1.34 & 0. & 0.73 & 0.78 & 0.82 & 0.90 & 1.6 & 1. & 1.84 & 1.5 & 2.3 \\
\hline \multicolumn{14}{|c|}{ Magnesium } \\
\hline \multirow[t]{10}{*}{$(\mathrm{kg} / \mathrm{ha})$} & 1979 & 31 & 0.45 & 0.29 & 0.16 & 0.19 & 0.19 & 0.27 & 0.40 & 0.51 & 0.69 & 0.79 & 1.7 \\
\hline & 1980 & 31 & 0.40 & 0.25 & 0.11 & 0.12 & 0.18 & 0.29 & 0.36 & 0.49 & 0.54 & 0.89 & 1.4 \\
\hline & 1981 & 31 & 0.46 & 0.17 & 0.18 & 0.19 & 0.23 & 0.37 & 0.43 & 0.57 & 0.70 & 0.74 & 0.7 \\
\hline & 1982 & 31 & 0.43 & 0.29 & 0.08 & 0.15 & 0.16 & 0.24 & 0.36 & 0.57 & 0.65 & 0.98 & 1.5 \\
\hline & 1983 & 31 & 0.47 & 0.46 & 0.13 & 0.13 & 0.19 & 0.28 & 0.33 & 0.46 & 0.76 & 1.29 & 2.5 \\
\hline & 1984 & 31 & 0.44 & 0.27 & 0.13 & 0.13 & 0.19 & 0.30 & 0.37 & 0.51 & 0.67 & 0.98 & 1.5 \\
\hline & 1985 & 31 & 0.36 & 0.27 & 0.12 & 0.16 & 0.20 & 0.23 & 0.31 & 0.39 & 0.52 & 0.75 & 1.6 \\
\hline & 1986 & 31 & 0.31 & 0.24 & 0.14 & 0.14 & 0.16 & 0.18 & 0.27 & 0.32 & 0.39 & 0.90 & 1.3 \\
\hline & 1987 & 31 & 0.33 & 0.37 & 0.11 & 0.14 & 0.15 & 0.18 & 0.24 & 0.30 & 0.47 & 0.93 & 2.1 \\
\hline & 1988 & 31 & 0.30 & 0.19 & 0.08 & 0.15 & 0.18 & 0.20 & 0.25 & 0.30 & 0.51 & 0.94 & 0.9 \\
\hline \multirow{10}{*}{$\begin{array}{l}\text { Sodium } \\
(\mathrm{kg} / \mathrm{ha})\end{array}$} & & & & & & & & & & & & & \\
\hline & $19 \% 9$ & 29 & 3.57 & 3.05 & $\begin{array}{l}0.47 \\
0.38\end{array}$ & 0.68 & 0.73 & 1.26 & 2.83 & 5.03 & 7.10 & 7.40 & \\
\hline & $\begin{array}{l}1980 \\
1981\end{array}$ & $\begin{array}{l}29 \\
29\end{array}$ & $\begin{array}{r}2.40 \\
1.60\end{array}$ & $\begin{array}{l}2.58 \\
1.62\end{array}$ & $\begin{array}{l}0.38 \\
0.30\end{array}$ & 0.41 & 0.54 & $\begin{array}{l}0.83 \\
0.74\end{array}$ & & & & 6.68 & \\
\hline & $\begin{array}{l}1981 \\
1982\end{array}$ & $\begin{array}{l}29 \\
29\end{array}$ & $\begin{array}{l}1.60 \\
1.96\end{array}$ & $\begin{array}{l}1.62 \\
2.94\end{array}$ & $\begin{array}{l}0.30 \\
0.29\end{array}$ & $\begin{array}{l}0.37 \\
0.34\end{array}$ & $\begin{array}{l}0.49 \\
0.37\end{array}$ & $\begin{array}{l}0.74 \\
0.65\end{array}$ & 1.03 & $\begin{array}{l}1.58 \\
2.20\end{array}$ & 4.93 & $\begin{array}{l}6.22 \\
8.89\end{array}$ & $\begin{array}{r}6 . \\
14 .\end{array}$ \\
\hline & $\begin{array}{l}1986 \\
1983\end{array}$ & 29 & $\begin{array}{l}1.96 \\
2.54\end{array}$ & $\begin{array}{l}2.94 \\
4.76\end{array}$ & $\begin{array}{l}0.29 \\
0.35\end{array}$ & $\begin{array}{l}0.34 \\
0.36\end{array}$ & $\begin{array}{l}0.37 \\
0.44\end{array}$ & $\begin{array}{l}0.65 \\
0.56\end{array}$ & 0.81 & $\begin{array}{l}2.20 \\
2.08\end{array}$ & $\begin{array}{l}3.46 \\
4.85\end{array}$ & $\begin{array}{r}8.89 \\
11.50\end{array}$ & 24.2 \\
\hline & 1984 & 29 & 1.90 & 2.68 & 0.42 & 0.44 & 0.45 & 0.59 & 0.73 & 2.02 & 4.39 & 8.02 & 12.8 \\
\hline & 1980 & 29 & 1.43 & 1.97 & 0.27 & 0.28 & 0.35 & 0.54 & 0.64 & 1.46 & 4.91 & 4.97 & 9.4 \\
\hline & 1986 & 29 & 1.26 & 1.85 & 0.27 & 0.31 & 0.35 & 0.46 & 0.59 & 1.22 & 2.29 & 6.20 & 8.8 \\
\hline & 1987 & 29 & 1.63 & 3.01 & 0.24 & 0.26 & 0.28 & 0.35 & 0.56 & 1.32 & 3.31 & 6.13 & 15.7 \\
\hline & 1988 & 29 & 1.34 & 1.56 & 0.29 & 0.33 & 0.36 & 0.40 & 0.64 & 1.68 & 3.94 & 6.08 & 6.1 \\
\hline
\end{tabular}


IABLE A.6. Summary of 1979-1988 Trend Sites Annual Deposition by Year (Cont'd)

Percentile

Std

$\lambda$

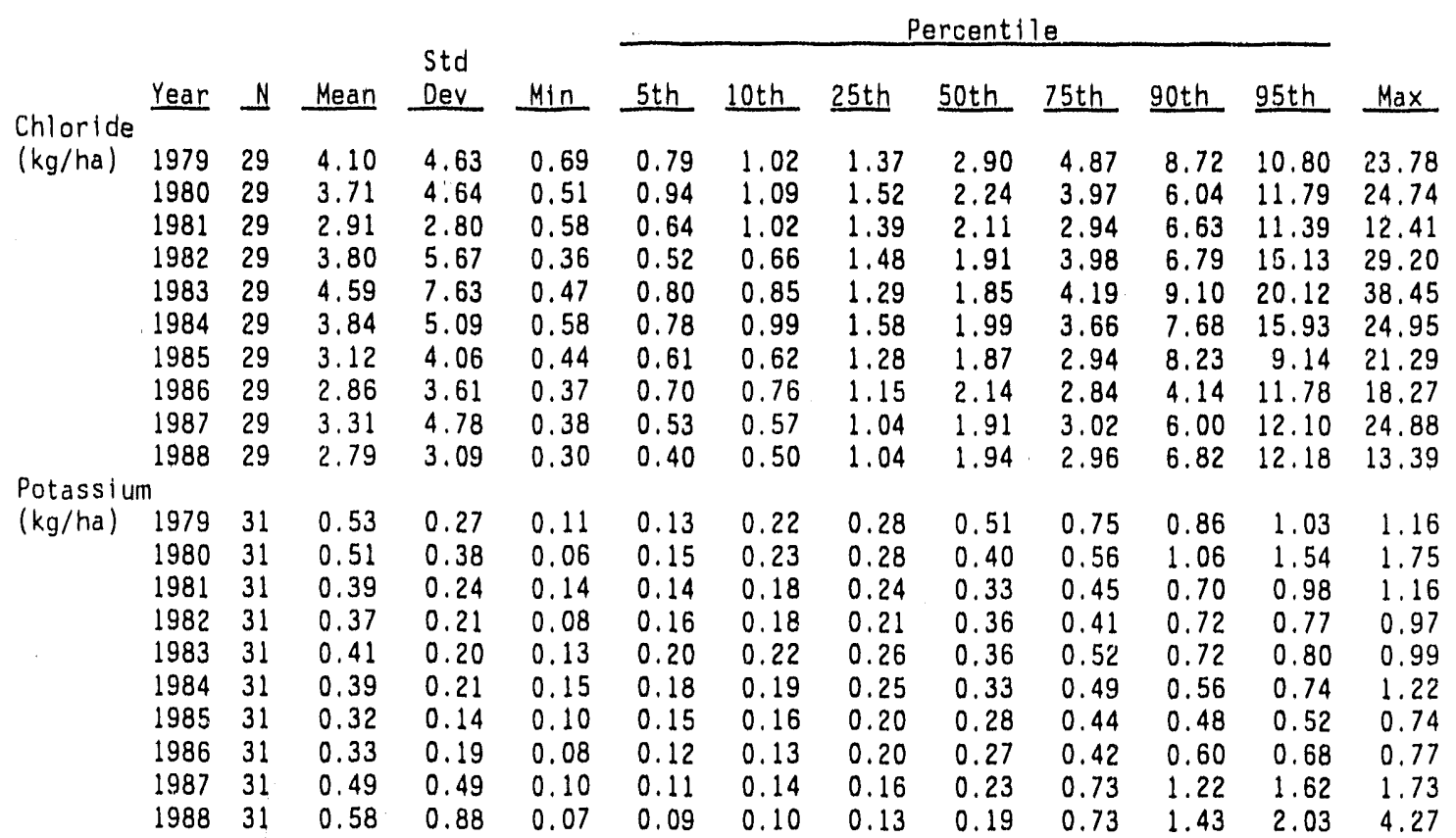


TABLE A.7. Summary of 1982-1988 Trend Sites Annual Precipitation-weighted Concentration by Year

\begin{tabular}{|c|c|c|c|c|c|c|c|c|c|c|c|c|c|}
\hline & & & & & & & & & Perc & & & & \\
\hline & Year & $\underline{N}$ & Mean & $\begin{array}{l}\text { Std } \\
\text { Dev }\end{array}$ & Min & 5th & 10th & 25th & 50th & 75th & 90th & 95th & Max \\
\hline & & & & & & & & & & & & & \\
\hline & $\begin{array}{l}1982 \\
1983 \\
1984 \\
1985 \\
1986 \\
1987 \\
1988\end{array}$ & $\begin{array}{l}92 \\
92 \\
92 \\
92 \\
92 \\
92 \\
92\end{array}$ & $\begin{array}{l}4.48 \\
4.57 \\
4.52 \\
4.52 \\
4.53 \\
4.51 \\
4.55\end{array}$ & $\begin{array}{l}0.37 \\
0.32 \\
0.34 \\
0.34 \\
0.35 \\
0.34 \\
0.35\end{array}$ & $\begin{array}{l}4.03 \\
4.20 \\
4.07 \\
4.16 \\
4.11 \\
4.08 \\
4.18\end{array}$ & $\begin{array}{l}4.12 \\
4.23 \\
4.17 \\
4.18 \\
4.16 \\
4.19 \\
4.22\end{array}$ & $\begin{array}{l}4.16 \\
4.25 \\
4.20 \\
4.20 \\
4.22 \\
4.20 \\
4.25\end{array}$ & $\begin{array}{l}4.21 \\
4.33 \\
4.27 \\
4.30 \\
4.28 \\
4.26 \\
4.30\end{array}$ & $\begin{array}{l}4.33 \\
4.46 \\
4.38 \\
4.38 \\
4.41 \\
4.36 \\
4.42\end{array}$ & $\begin{array}{l}4.67 \\
4.71 \\
4.67 \\
4.66 \\
4.66 \\
4.71 \\
4.70\end{array}$ & $\begin{array}{l}5.03 \\
5.02 \\
5.02 \\
5.14 \\
5.05 \\
5.06 \\
5.11\end{array}$ & $\begin{array}{l}5.33 \\
5.31 \\
5.18 \\
5.29 \\
5.38 \\
5.24 \\
5.39\end{array}$ & $\begin{array}{l}5.66 \\
5.57 \\
5.51 \\
5.37 \\
5.43 \\
5.44 \\
5.55\end{array}$ \\
\hline Hydrogen & & & & & & & & & & & & & \\
\hline & $\begin{array}{l}1982 \\
1983 \\
1984 \\
1985 \\
1986 \\
1987 \\
1988\end{array}$ & $\begin{array}{l}92 \\
92 \\
92 \\
92 \\
92 \\
92 \\
92\end{array}$ & $\begin{array}{l}42.22 \\
33.03 \\
37.92 \\
37.34 \\
37.21 \\
38.56 \\
35.27\end{array}$ & $\begin{array}{l}22.98 \\
16.73 \\
20.22 \\
19.15 \\
19.64 \\
20.30 \\
17.82\end{array}$ & $\begin{array}{l}2.19 \\
2.67 \\
3.09 \\
4.22 \\
3.72 \\
3.62 \\
2.83\end{array}$ & $\begin{array}{l}4.72 \\
4.91 \\
6.57 \\
5.16 \\
4.18 \\
5.82 \\
4.03\end{array}$ & $\begin{array}{l}9.23 \\
9.61 \\
9.46 \\
7.19 \\
8.82 \\
8.77 \\
7.68\end{array}$ & $\begin{array}{l}21.39 \\
19.50 \\
21.33 \\
22.01 \\
22.08 \\
19.47 \\
19.78\end{array}$ & $\begin{array}{l}46.24 \\
34.76 \\
41.43 \\
41.95 \\
38.79 \\
43.93 \\
38.39\end{array}$ & $\begin{array}{l}61.05 \\
47.10 \\
54.21 \\
49.82 \\
52.31 \\
54.61 \\
50.03\end{array}$ & $\begin{array}{l}69.12 \\
55.82 \\
63.36 \\
63.06 \\
60.16 \\
63.29 \\
56.67\end{array}$ & $\begin{array}{l}76.19 \\
59.32 \\
67.65 \\
65.66 \\
68.39 \\
64.81 \\
60.65\end{array}$ & $\begin{array}{l}92.35 \\
63.57 \\
84.48 \\
69.43 \\
76.84 \\
83.97 \\
66.47\end{array}$ \\
\hline $\begin{array}{l}\text { Sulfate } \\
(m g / 1)\end{array}$ & $\begin{array}{l}1982 \\
1983 \\
1984 \\
1985 \\
1986 \\
1987 \\
1988\end{array}$ & $\begin{array}{l}100 \\
100 \\
100 \\
100 \\
100 \\
100 \\
100\end{array}$ & $\begin{array}{l}2.44 \\
2.16 \\
2.34 \\
2.23 \\
2.25 \\
2.35 \\
2.38\end{array}$ & $\begin{array}{l}0.97 \\
0.90 \\
0.95 \\
0.89 \\
0.91 \\
1.06 \\
1.06\end{array}$ & $\begin{array}{l}0.29 \\
0.32 \\
0.31 \\
0.24 \\
0.18 \\
0.21 \\
0.19\end{array}$ & $\begin{array}{l}0.99 \\
0.94 \\
1.08 \\
0.75 \\
0.79 \\
0.79 \\
0.90\end{array}$ & $\begin{array}{l}1.24 \\
1.04 \\
1.27 \\
0.98 \\
0.98 \\
1.03 \\
1.02\end{array}$ & $\begin{array}{l}1.75 \\
1.51 \\
1.53 \\
1.52 \\
1.53 \\
1.55 \\
1.60\end{array}$ & $\begin{array}{l}2.52 \\
2.08 \\
2.35 \\
2.43 \\
2.29 \\
2.51 \\
2.41\end{array}$ & $\begin{array}{l}3.09 \\
2.78 \\
2.97 \\
2.86 \\
2.98 \\
3.19 \\
3.05\end{array}$ & $\begin{array}{l}3.63 \\
3.12 \\
3.60 \\
3.25 \\
3.50 \\
3.63 \\
3.51\end{array}$ & $\begin{array}{l}4.17 \\
3.94 \\
4.05 \\
3.63 \\
3.64 \\
4.08 \\
3.84\end{array}$ & $\begin{array}{l}5.00 \\
4.64 \\
4.72 \\
4.20 \\
3.96 \\
5.55 \\
6.19\end{array}$ \\
\hline $\begin{array}{l}\text { Nitrogen } \\
(\mathrm{mg} / \mathrm{l})\end{array}$ & $\begin{array}{l}1982 \\
1983 \\
1984 \\
1985 \\
1986 \\
1987 \\
1988\end{array}$ & $\begin{array}{l}103 \\
103 \\
103 \\
103 \\
103 \\
103 \\
103\end{array}$ & $\begin{array}{l}1.48 \\
1.37 \\
1.55 \\
1.53 \\
1.49 \\
1.68 \\
1.69\end{array}$ & $\begin{array}{l}0.61 \\
0.57 \\
0.66 \\
0.65 \\
0.60 \\
0.77 \\
0.77\end{array}$ & $\begin{array}{l}0.14 \\
0.13 \\
0.10 \\
0.07 \\
0.07 \\
0.13 \\
0.07\end{array}$ & $\begin{array}{l}0.64 \\
0.58 \\
0.79 \\
0.68 \\
0.66 \\
0.71 \\
0.72\end{array}$ & $\begin{array}{l}0.78 \\
0.65 \\
0.81 \\
0.75 \\
0.78 \\
0.77 \\
0.84\end{array}$ & $\begin{array}{l}0.97 \\
0.97 \\
1.01 \\
0.97 \\
1.00 \\
1.05 \\
1.05\end{array}$ & $\begin{array}{l}1.35 \\
1.33 \\
1.42 \\
1.47 \\
1.42 \\
1.55 \\
1.57\end{array}$ & $\begin{array}{l}1.90 \\
1.74 \\
2.03 \\
2.15 \\
2.02 \\
2.37 \\
2.27\end{array}$ & $\begin{array}{l}2.38 \\
2.14 \\
2.46 \\
2.39 \\
2.25 \\
2.71 \\
2.71\end{array}$ & $\begin{array}{l}2.61 \\
2.32 \\
2.73 \\
2.53 \\
2.46 \\
2.95 \\
3.01\end{array}$ & $\begin{array}{l}2.75 \\
2.78 \\
3.30 \\
2.99 \\
2.55 \\
3.6 . \\
3.76\end{array}$ \\
\hline $\begin{array}{l}\text { Ammon i um } \\
(\mathrm{mg} / 1)\end{array}$ & $\begin{array}{l}1982 \\
1983 \\
1984 \\
1985 \\
1986 \\
1987 \\
1988\end{array}$ & $\begin{array}{l}103 \\
103 \\
103 \\
103 \\
103 \\
103 \\
103\end{array}$ & $\begin{array}{l}0.33 \\
0.32 \\
0.34 \\
0.31 \\
0.31 \\
0.36 \\
0.35\end{array}$ & $\begin{array}{l}0.17 \\
0.17 \\
0.16 \\
0.15 \\
0.16 \\
0.20 \\
0.23\end{array}$ & $\begin{array}{l}0.02 \\
0.02 \\
0.03 \\
0.01 \\
0.01 \\
0.02 \\
0.01\end{array}$ & $\begin{array}{l}0.11 \\
0.10 \\
0.13 \\
0.10 \\
0.09 \\
0.10 \\
0.07\end{array}$ & $\begin{array}{l}0.13 \\
0.12 \\
0.16 \\
0.14 \\
0.11 \\
0.13 \\
0.10\end{array}$ & $\begin{array}{l}0.20 \\
0.21 \\
0.20 \\
0.19 \\
0.20 \\
0.22 \\
0.19\end{array}$ & $\begin{array}{l}0.32 \\
0.29 \\
0.32 \\
0.29 \\
0.29 \\
0.33 \\
0.33\end{array}$ & $\begin{array}{l}0.41 \\
0.39 \\
0.44 \\
0.40 \\
0.41 \\
0.47 \\
0.49\end{array}$ & $\begin{array}{l}0.54 \\
0.54 \\
0.60 \\
0.51 \\
0.53 \\
0.65 \\
0.68\end{array}$ & $\begin{array}{l}0.65 \\
0.64 \\
0.64 \\
0.58 \\
0.60 \\
0.71 \\
0.73\end{array}$ & $\begin{array}{l}0.85 \\
0.87 \\
0.79 \\
0.79 \\
0.73 \\
0.89 \\
1.16\end{array}$ \\
\hline
\end{tabular}




\section{TABLE A.7. Summary of 1982-1988 Trend Sites Annual Precipitation-weighted Concentration by Year (Cont'd)}

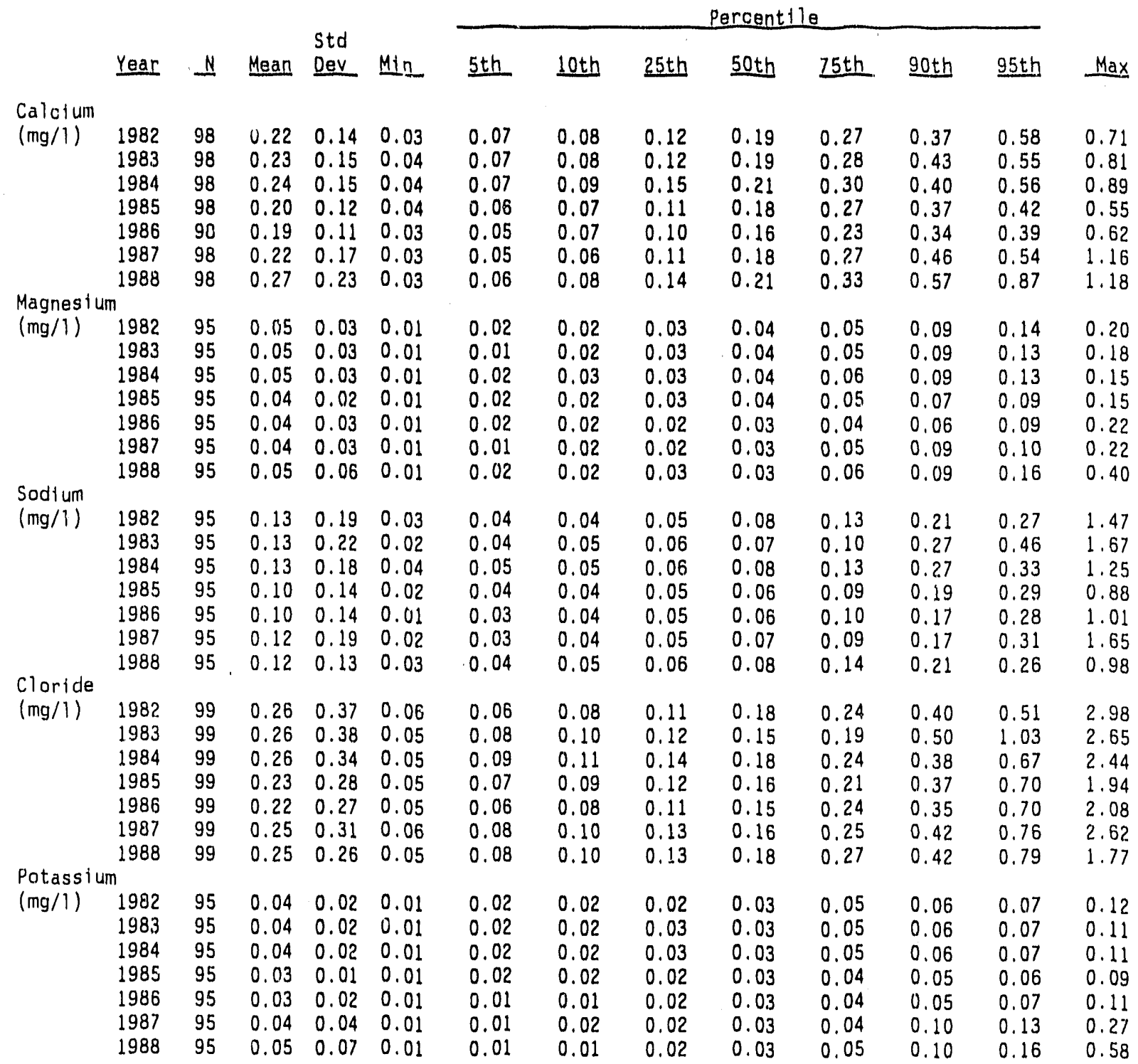


TABLE A.8. Summary of 1982-1988 Trend Sites Annual Deposition by Year

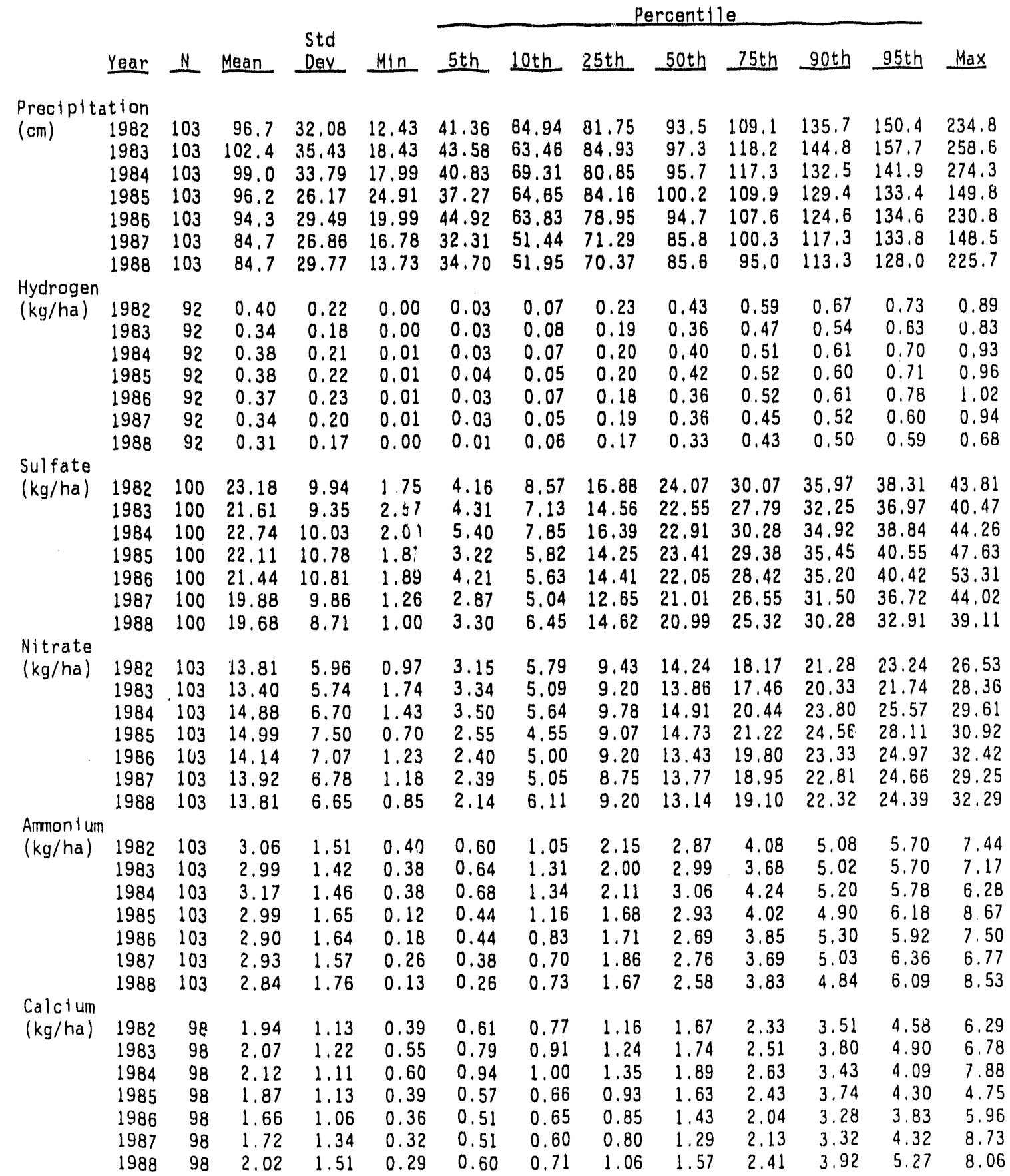


IABLE A.8. Summary of 1982-1988 Trend Sites Annual Deposition by Year (Cont'd)

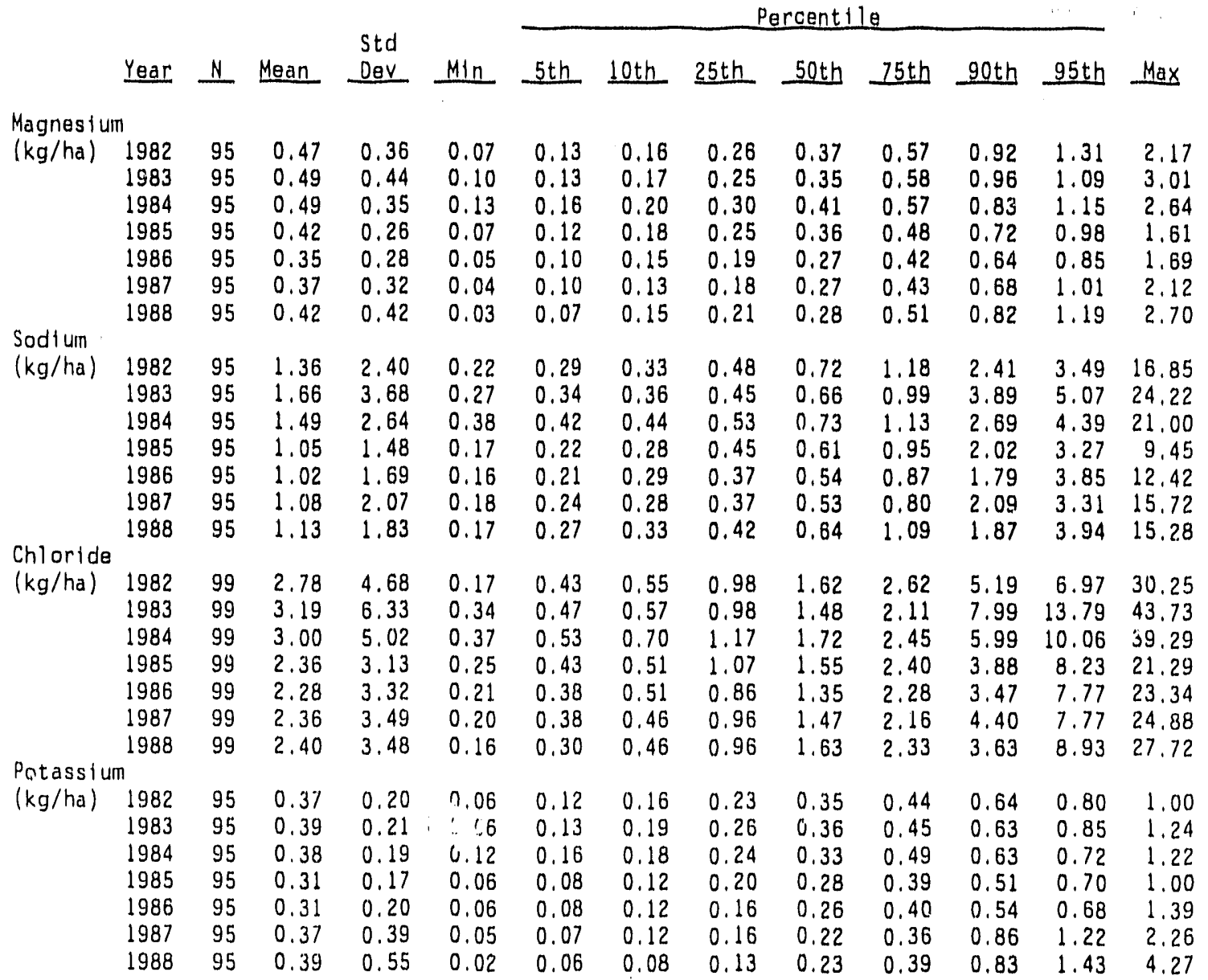


IABLE A.9. Frequency Distribution Percentiles of Estimated Concentrations (mg/1) at the Center of 2670 Squared Kilometer Hexagons in Eastern North America $(n=1833)$ and Western Untted States $(n=1875)$

\begin{tabular}{|c|c|c|c|c|c|c|c|c|c|c|c|c|c|}
\hline & & & & & & & & cent & & & & & \\
\hline & & & MIN & $I$ & .5 & 10 & 35 & 50 & 75 & 90 & 95 & 99 & MAX \\
\hline $\mathrm{pH}$ & Eastern & $\begin{array}{l}\text { Annual } \\
\text { Winter } \\
\text { Summer }\end{array}$ & $\begin{array}{l}4.19 \\
4.30 \\
3.92\end{array}$ & $\begin{array}{l}4.20 \\
4.34 \\
4.03\end{array}$ & $\begin{array}{l}4.25 \\
4.37 \\
4.07\end{array}$ & $\begin{array}{l}4.30 \\
4.40 \\
4.11\end{array}$ & $\begin{array}{l}4.40 \\
4.46 \\
4.28\end{array}$ & $\begin{array}{l}4.55 \\
4.59 \\
4.47\end{array}$ & $\begin{array}{l}4.74 \\
4.73 \\
4.87\end{array}$ & $\begin{array}{l}5.01 \\
4.82 \\
5.20\end{array}$ & $\begin{array}{l}5.25 \\
4.89 \\
5.47\end{array}$ & $\begin{array}{l}5.39 \\
4.99 \\
5.96\end{array}$ & $\begin{array}{l}5.42 \\
5.10 \\
6.32\end{array}$ \\
\hline & Western & $\begin{array}{l}\text { Annual } \\
\text { Winter } \\
\text { Sumner }\end{array}$ & $\begin{array}{l}4.59 \\
4.57 \\
4.36\end{array}$ & $\begin{array}{l}4.74 \\
4.66 \\
4.59\end{array}$ & $\begin{array}{l}4.83 \\
4.83 \\
4.74\end{array}$ & $\begin{array}{l}4.89 \\
4.92 \\
4.81\end{array}$ & $\begin{array}{l}5.06 \\
5.09 \\
5.00\end{array}$ & $\begin{array}{l}5.24 \\
5.28 \\
5.18\end{array}$ & $\begin{array}{l}5.37 \\
5.43 \\
5.41\end{array}$ & $\begin{array}{l}5.44 \\
5.56 \\
5.64\end{array}$ & $\begin{array}{l}5.48 \\
5.66 \\
5.77\end{array}$ & $\begin{array}{l}5.57 \\
5.90 \\
6.00\end{array}$ & $\begin{array}{l}5.69 \\
0.37 \\
6.52\end{array}$ \\
\hline Sulfate & Eastern & $\begin{array}{l}\text { Annual } \\
\text { Winter } \\
\text { Summer }\end{array}$ & $\begin{array}{l}0.89 \\
0.88 \\
0.88\end{array}$ & $\begin{array}{l}1.03 \\
0.73 \\
0.94\end{array}$ & $\begin{array}{l}1.10 \\
0.79 \\
1.03\end{array}$ & $\begin{array}{l}1.17 \\
0.84 \\
1.29\end{array}$ & $\begin{array}{l}1.35 \\
0.99 \\
1.65\end{array}$ & $\begin{array}{l}1.78 \\
1.26 \\
2.19\end{array}$ & $\begin{array}{l}2.36 \\
1.60 \\
3.28\end{array}$ & $\begin{array}{l}2.87 \\
1.91 \\
4.17\end{array}$ & $\begin{array}{l}3.11 \\
2.08 \\
4.52\end{array}$ & $\begin{array}{l}3.63 \\
2.36 \\
4.96\end{array}$ & $\begin{array}{r}4.90 \\
2.61 \\
12.41\end{array}$ \\
\hline & Western & $\begin{array}{l}\text { Annual } \\
\text { Winter } \\
\text { Surmer }\end{array}$ & $\begin{array}{l}0.23 \\
0.18 \\
0.39\end{array}$ & $\begin{array}{l}0.26 \\
0.20 \\
0.44\end{array}$ & $\begin{array}{l}0.30 \\
0.23 \\
0.49\end{array}$ & $\begin{array}{l}0.35 \\
0.25 \\
0.54\end{array}$ & $\begin{array}{l}0.47 \\
0.33 \\
0.96\end{array}$ & $\begin{array}{l}0.86 \\
0.56 \\
1.11\end{array}$ & $\begin{array}{l}1.15 \\
0.91 \\
1.26\end{array}$ & $\begin{array}{l}1.40 \\
1.25 \\
1.37\end{array}$ & $\begin{array}{l}1.48 \\
1.47 \\
1.45\end{array}$ & $\begin{array}{l}1.77 \\
1.74 \\
1.67\end{array}$ & $\begin{array}{l}2.00 \\
1.93 \\
1.79\end{array}$ \\
\hline Nitrate & Eastern & $\begin{array}{l}\text { Annual } \\
\text { Winter } \\
\text { Sunmer }\end{array}$ & $\begin{array}{l}0.42 \\
0.28 \\
0.46\end{array}$ & $\begin{array}{l}0.54 \\
0.41 \\
0.68\end{array}$ & $\begin{array}{l}0.61 \\
0.48 \\
0.76\end{array}$ & $\begin{array}{l}0.66 \\
0.54 \\
0.80\end{array}$ & $\begin{array}{l}0.91 \\
0.78 \\
0.98\end{array}$ & $\begin{array}{l}1.22 \\
1.30 \\
1.26\end{array}$ & $\begin{array}{l}1.62 \\
1.74 \\
1.80\end{array}$ & $\begin{array}{l}2.05 \\
2.24 \\
2.14\end{array}$ & $\begin{array}{l}2.38 \\
2.66 \\
2.37\end{array}$ & $\begin{array}{l}2.79 \\
3.05 \\
2.86\end{array}$ & $\begin{array}{l}3.53 \\
3.28 \\
4.15\end{array}$ \\
\hline & Western & $\begin{array}{l}\text { Annual } \\
\text { Winter } \\
\text { Summer }\end{array}$ & $\begin{array}{l}0.15 \\
0.10 \\
0.00\end{array}$ & $\begin{array}{l}0.19 \\
0.14 \\
0.14\end{array}$ & $\begin{array}{l}0.24 \\
0.19 \\
0.27\end{array}$ & $\begin{array}{l}0.31 \\
0.27 \\
0.44\end{array}$ & $\begin{array}{l}0.46 \\
0.38 \\
0.83\end{array}$ & $\begin{array}{l}0.79 \\
0.59 \\
1.19\end{array}$ & $\begin{array}{l}0.93 \\
0.81 \\
1.43\end{array}$ & $\begin{array}{l}1.19 \\
1.02 \\
1.72\end{array}$ & $\begin{array}{l}1.32 \\
1.11 \\
2.27\end{array}$ & $\begin{array}{l}1.50 \\
1.28 \\
2.94\end{array}$ & $\begin{array}{l}1.69 \\
1.61 \\
3.31\end{array}$ \\
\hline Ammoni um & Eastern & $\begin{array}{l}\text { Annual } \\
\text { Winter } \\
\text { Surmer }\end{array}$ & $\begin{array}{l}0.04 \\
0.03 \\
0.02\end{array}$ & $\begin{array}{l}0.06 \\
0.05 \\
0.03\end{array}$ & $\begin{array}{l}0.08 \\
0.05 \\
0.05\end{array}$ & $\begin{array}{l}0.09 \\
0.06 \\
0.07\end{array}$ & $\begin{array}{l}0.13 \\
0.09 \\
0.13\end{array}$ & $\begin{array}{l}0.25 \\
0.13 \\
0.27\end{array}$ & $\begin{array}{l}0.37 \\
0.20 \\
0.37\end{array}$ & $\begin{array}{l}0.45 \\
0.26 \\
0.46\end{array}$ & $\begin{array}{l}0.50 \\
0.29 \\
0.55\end{array}$ & $\begin{array}{l}0.62 \\
0.37 \\
0.78\end{array}$ & $\begin{array}{l}0.81 \\
0.56 \\
1.29\end{array}$ \\
\hline & Western & $\begin{array}{l}\text { Annual } \\
\text { Winter } \\
\text { Summer }\end{array}$ & $\begin{array}{l}0.01 \\
0.01 \\
0.01\end{array}$ & $\begin{array}{l}0.02 \\
0.02 \\
0.01\end{array}$ & $\begin{array}{l}0.03 \\
0.03 \\
0.02\end{array}$ & $\begin{array}{l}0.05 \\
0.03 \\
0.04\end{array}$ & $\begin{array}{l}0.06 \\
0.05 \\
0.07\end{array}$ & $\begin{array}{l}0.11 \\
0.10 \\
0.15\end{array}$ & $\begin{array}{l}0.18 \\
0.17 \\
0.25\end{array}$ & $\begin{array}{l}0.28 \\
0.25 \\
0.37\end{array}$ & $\begin{array}{l}0.33 \\
0.31 \\
0.43\end{array}$ & $\begin{array}{l}0.44 \\
0.40 \\
0.52\end{array}$ & $\begin{array}{l}0.53 \\
0.52 \\
0.59\end{array}$ \\
\hline Calc & Eastern & $\begin{array}{l}\text { Annual } \\
\text { Winter } \\
\text { Surmer }\end{array}$ & $\begin{array}{l}0.05 \\
0.04 \\
0.05\end{array}$ & $\begin{array}{l}0.05 \\
0.04 \\
0.06\end{array}$ & $\begin{array}{l}0.07 \\
0.05 \\
0.08\end{array}$ & $\begin{array}{l}0.09 \\
0.06 \\
0.09\end{array}$ & $\begin{array}{l}0.11 \\
0.07 \\
0.12\end{array}$ & $\begin{array}{l}0.17 \\
0.10 \\
0.16\end{array}$ & $\begin{array}{l}0.25 \\
0.14 \\
0.27\end{array}$ & $\begin{array}{l}0.38 \\
0.20 \\
0.42\end{array}$ & $\begin{array}{l}0.47 \\
0.26 \\
0.54\end{array}$ & $\begin{array}{l}0.60 \\
0.41 \\
0.73\end{array}$ & $\begin{array}{l}0.99 \\
0.63 \\
1.21\end{array}$ \\
\hline & Western & $\begin{array}{l}\text { Annual } \\
\text { Winter } \\
\text { Summer }\end{array}$ & $\begin{array}{l}0.03 \\
0.03 \\
0.05\end{array}$ & $\begin{array}{l}0.04 \\
0.04 \\
0.06\end{array}$ & $\begin{array}{l}0.05 \\
0.04 \\
0.08\end{array}$ & $\begin{array}{l}0.06 \\
0.04 \\
0.13\end{array}$ & $\begin{array}{l}0.14 \\
0.08 \\
0.21\end{array}$ & $\begin{array}{l}0.24 \\
0.12 \\
0.31\end{array}$ & $\begin{array}{l}0.31 \\
0.18 \\
0.43\end{array}$ & $\begin{array}{l}0.40 \\
0.29 \\
0.56\end{array}$ & $\begin{array}{l}0.43 \\
0.36 \\
0.78\end{array}$ & $\begin{array}{l}0.49 \\
0.45 \\
1.33\end{array}$ & $\begin{array}{l}0.58 \\
0.57 \\
2.32\end{array}$ \\
\hline
\end{tabular}


IABLE A,10. Frequency Distribution Percentiles of Estimated Deposition $(\mathrm{kg} / \mathrm{ha})$ at the Cen er of 2670 Squared Kilometer Hexagons in Eastern North America $(n=1833)$ and Western United States $(n=1875)$.

\begin{tabular}{|c|c|c|c|c|c|c|c|c|c|c|c|c|c|}
\hline & & & & & & & & 10 & & & & & \\
\hline & & & MIN & & 5 & 10 & 25 & 50 & 75 & 90 & 95 & 99 & MAX \\
\hline ydrogen & Eastern & $\begin{array}{l}\text { Anriual } \\
\text { Winter } \\
\text { Summer }\end{array}$ & $\begin{array}{l}0.02 \\
0.00 \\
0.00\end{array}$ & $\begin{array}{l}0.03 \\
0.01 \\
0.00\end{array}$ & $\begin{array}{l}0.05 \\
0.01 \\
0.01\end{array}$ & $\begin{array}{l}0.08 \\
0.02 \\
0.02\end{array}$ & $\begin{array}{l}0.21 \\
0.04 \\
0.06\end{array}$ & $\begin{array}{l}0.30 \\
0.06 \\
0.10\end{array}$ & $\begin{array}{l}0.37 \\
0.07 \\
0.14\end{array}$ & $\begin{array}{l}0.45 \\
0.08 \\
0.19\end{array}$ & $\begin{array}{l}0.50 \\
0.09 \\
0.20\end{array}$ & $\begin{array}{l}0.55 \\
0.10 \\
0.23\end{array}$ & $\begin{array}{l}0.59 \\
0.12 \\
0.26\end{array}$ \\
\hline & Western & $\begin{array}{l}\text { Annual } \\
\text { Winter } \\
\text { Surmer }\end{array}$ & $\begin{array}{l}0.01 \\
0.00 \\
0.00\end{array}$ & $\begin{array}{l}0.01 \\
0.00 \\
0.00\end{array}$ & $\begin{array}{l}0.02 \\
0.00 \\
0.00\end{array}$ & $\begin{array}{l}0.02 \\
0.00 \\
0.00\end{array}$ & $\begin{array}{l}0.02 \\
0.01 \\
0.00\end{array}$ & $\begin{array}{l}0.03 \\
0.01 \\
0.01\end{array}$ & $\begin{array}{l}0.05 \\
0.01 \\
0.02\end{array}$ & $\begin{array}{l}0.09 \\
0.02 \\
0.03\end{array}$ & $\begin{array}{l}0.13 \\
0.03 \\
0.04\end{array}$ & $\begin{array}{l}0.19 \\
0.05 \\
0.08\end{array}$ & $\begin{array}{l}0.24 \\
0.07 \\
0.10\end{array}$ \\
\hline Sulfate & Eastern & $\begin{array}{l}\text { Annual } \\
\text { Winter } \\
\text { Summer }\end{array}$ & $\begin{array}{l}6.35 \\
0.36 \\
1.56\end{array}$ & $\begin{array}{l}7.02 \\
0.44 \\
1.97\end{array}$ & $\begin{array}{l}8.48 \\
0.51 \\
2.67\end{array}$ & $\begin{array}{r}10.18 \\
0.64 \\
3.14\end{array}$ & $\begin{array}{r}13.91 \\
1.63 \\
3.99\end{array}$ & $\begin{array}{r}17.10 \\
2.81 \\
5.57\end{array}$ & $\begin{array}{r}21.38 \\
3.72 \\
7.73\end{array}$ & $\begin{array}{r}24.78 \\
4.24 \\
10.01\end{array}$ & $\begin{array}{r}26.72 \\
4.73 \\
10.67\end{array}$ & $\begin{array}{r}29.42 \\
5.83 \\
11.71\end{array}$ & $\begin{array}{r}32.17 \\
6.41 \\
14.88\end{array}$ \\
\hline & Western & $\begin{array}{l}\text { Annual } \\
\text { Winter } \\
\text { Summer }\end{array}$ & $\begin{array}{l}0.84 \\
0.10 \\
0.07\end{array}$ & $\begin{array}{l}1.17 \\
0.13 \\
0.12\end{array}$ & $\begin{array}{l}1.47 \\
0.18 \\
0.19\end{array}$ & $\begin{array}{l}1.67 \\
0.21 \\
0.25\end{array}$ & $\begin{array}{l}2.35 \\
0.31 \\
0.44\end{array}$ & $\begin{array}{l}3.39 \\
0.48 \\
1.22\end{array}$ & $\begin{array}{l}5.35 \\
0.84 \\
1.86\end{array}$ & $\begin{array}{l}8.08 \\
1.63 \\
2.53\end{array}$ & $\begin{array}{r}11.07 \\
2.10 \\
3.07\end{array}$ & $\begin{array}{r}14.35 \\
3.28 \\
4.46\end{array}$ & $\begin{array}{r}16.33 \\
4.00 \\
5.60\end{array}$ \\
\hline Nitrate & Eastern & $\begin{array}{l}\text { Annual } \\
\text { Winter } \\
\text { Surmer }\end{array}$ & $\begin{array}{l}5.72 \\
0.48 \\
1.20\end{array}$ & $\begin{array}{l}6.45 \\
0.69 \\
1.79\end{array}$ & $\begin{array}{l}7.23 \\
0.82 \\
2.14\end{array}$ & $\begin{array}{l}7.79 \\
0.99 \\
2.31\end{array}$ & $\begin{array}{l}8.87 \\
1.57 \\
2.71\end{array}$ & $\begin{array}{l}10.67 \\
2.21 \\
3.16\end{array}$ & $\begin{array}{r}14.34 \\
2.81 \\
4.10\end{array}$ & $\begin{array}{r}18.19 \\
3.84 \\
4.97\end{array}$ & $\begin{array}{r}19.95 \\
4.39 \\
5.47\end{array}$ & $\begin{array}{r}23.52 \\
5.69 \\
6.11\end{array}$ & $\begin{array}{r}30.05 \\
7.44 \\
6.98\end{array}$ \\
\hline & Western & $\begin{array}{l}\text { Annual } \\
\text { Winter } \\
\text { Summer }\end{array}$ & $\begin{array}{l}0.65 \\
0.15 \\
0.00\end{array}$ & $\begin{array}{l}0.82 \\
0.18 \\
0.03\end{array}$ & $\begin{array}{l}1.18 \\
0.23 \\
0.13\end{array}$ & $\begin{array}{l}1.39 \\
0.25 \\
0.24\end{array}$ & $\begin{array}{l}2.08 \\
0.32 \\
0.43\end{array}$ & $\begin{array}{l}3.20 \\
0.48 \\
1.24\end{array}$ & $\begin{array}{l}4.38 \\
0.76 \\
1.91\end{array}$ & $\begin{array}{l}6.29 \\
1.09 \\
2.27\end{array}$ & $\begin{array}{l}7.60 \\
1.31 \\
2.59\end{array}$ & $\begin{array}{l}9.70 \\
1.78 \\
3.13\end{array}$ & $\begin{array}{r}11.23 \\
2.29 \\
3.53\end{array}$ \\
\hline Am & Eastern & $\begin{array}{l}\text { Annual } \\
\text { Winter } \\
\text { Summer }\end{array}$ & $\begin{array}{l}0.52 \\
0.04 \\
0.10\end{array}$ & $\begin{array}{l}0.69 \\
0.06 \\
0.13\end{array}$ & $\begin{array}{l}0.95 \\
0.08 \\
0.16\end{array}$ & $\begin{array}{l}1.10 \\
0.12 \\
0.18\end{array}$ & $\begin{array}{l}1.48 \\
0.17 \\
0.31\end{array}$ & $\begin{array}{l}2.10 \\
0.25 \\
0.60\end{array}$ & $\begin{array}{l}2.86 \\
0.35 \\
0.93\end{array}$ & $\begin{array}{l}3.67 \\
0.49 \\
1.15\end{array}$ & $\begin{array}{l}4.17 \\
0.54 \\
1.29\end{array}$ & $\begin{array}{l}5.56 \\
0.74 \\
1.64\end{array}$ & $\begin{array}{l}6.91 \\
1.38 \\
2.77\end{array}$ \\
\hline & Western & $\begin{array}{l}\text { Annual } \\
\text { Winter } \\
\text { Summer }\end{array}$ & $\begin{array}{l}0.12 \\
0.02 \\
0.00\end{array}$ & $\begin{array}{l}0.15 \\
0.03 \\
0.00\end{array}$ & $\begin{array}{l}0.18 \\
0.03 \\
0.01\end{array}$ & $\begin{array}{l}0.21 \\
0.04 \\
0.02\end{array}$ & $\begin{array}{l}0.27 \\
0.05 \\
0.06\end{array}$ & $\begin{array}{l}0.43 \\
0.08 \\
0.12\end{array}$ & $\begin{array}{l}0.98 \\
0.14 \\
0.25\end{array}$ & $\begin{array}{l}1.41 \\
0.24 \\
0.47\end{array}$ & $\begin{array}{l}1.74 \\
0.32 \\
0.60\end{array}$ & $\begin{array}{l}2.09 \\
0.51 \\
0.76\end{array}$ & $\begin{array}{l}2.30 \\
1.11 \\
0.93\end{array}$ \\
\hline Calcium & Eastern & $\begin{array}{l}\text { Annual } \\
\text { Winter } \\
\text { Surmer }\end{array}$ & $\begin{array}{l}0.61 \\
0.03 \\
0.16\end{array}$ & $\begin{array}{l}0.67 \\
0.06 \\
0.17\end{array}$ & $\begin{array}{l}0.76 \\
0.07 \\
0.22\end{array}$ & $\begin{array}{l}0.89 \\
0.08 \\
0.25\end{array}$ & $\begin{array}{l}1.19 \\
0.13 \\
0.33\end{array}$ & $\begin{array}{l}1.55 \\
0.17 \\
0.44\end{array}$ & $\begin{array}{l}1.98 \\
0.23 \\
0.66\end{array}$ & $\begin{array}{l}2.64 \\
0.31 \\
0.81\end{array}$ & $\begin{array}{l}2.98 \\
0.37 \\
0.94\end{array}$ & $\begin{array}{l}3.99 \\
0.73 \\
1.22\end{array}$ & $\begin{array}{l}6.39 \\
1.07 \\
1.55\end{array}$ \\
\hline & Western & $\begin{array}{l}\text { Annual } \\
\text { Winter } \\
\text { Surmer }\end{array}$ & $\begin{array}{l}0.23 \\
0.02 \\
0.03\end{array}$ & $\begin{array}{l}0.31 \\
0.04 \\
0.04\end{array}$ & $\begin{array}{l}0.36 \\
0.04 \\
0.05\end{array}$ & $\begin{array}{l}0.42 \\
0.05 \\
0.07\end{array}$ & $\begin{array}{l}0.58 \\
0.07 \\
0.17\end{array}$ & $\begin{array}{l}0.97 \\
0.09 \\
0.34\end{array}$ & $\begin{array}{l}1.32 \\
0.15 \\
0.49\end{array}$ & $\begin{array}{l}1.35 \\
0.22 \\
0.73\end{array}$ & $\begin{array}{l}2.32 \\
0.27 \\
0.92\end{array}$ & $\begin{array}{l}2.68 \\
0.32 \\
1.08\end{array}$ & $\begin{array}{l}2.94 \\
0.40 \\
1.23\end{array}$ \\
\hline
\end{tabular}


IABLE A.11. Mintmum and Maxtmum Anrual, Winter, and Summer Prectpitationweighted $\mathrm{pH}$ and Total Hydrogen Deposttion Observed at ADS

Sites in 1988 by Region.

pH

\begin{tabular}{|c|c|c|c|c|c|c|c|c|c|}
\hline & \multicolumn{3}{|c|}{ Western Untted States } & \multicolumn{3}{|c|}{ Eastern United States } & \multicolumn{3}{|c|}{ Southeastern Canada } \\
\hline & Sittename & State & $\mathrm{pH}$ & Sitename & tate & $\mathrm{pH}$ & Sit tename & Prov & $\mathrm{pH}$ \\
\hline NUAL & $\begin{array}{l}\text { Longview } \\
\text { oliver Knoll } \\
\text { Farlington }\end{array}$ & $\begin{array}{l}T X \\
A Z \\
\text { KS }\end{array}$ & $\begin{array}{l}4.52 \\
4.74 \\
4.75\end{array}$ & $\begin{array}{l}\text { Oxford } \\
\text { I thaoa } \\
\text { Kano }\end{array}$ & $\begin{array}{l}\text { OH } \\
N Y \\
P A\end{array}$ & $\begin{array}{l}4.16 \\
4.18 \\
4.18\end{array}$ & $\begin{array}{l}\text { W1 lberforoe } \\
\text { Melbourne } \\
\text { Klllarney }\end{array}$ & $\begin{array}{l}\text { ON } \\
\text { ON } \\
\text { ON }\end{array}$ & $\begin{array}{l}4.24 \\
4.24 \\
4.26\end{array}$ \\
\hline & $\begin{array}{l}\text { Big Bend Nat Park } \\
\text { Yellowstone } \\
\text { Vines Hill }\end{array}$ & $\begin{array}{l}T X \\
W Y \\
O R\end{array}$ & $\begin{array}{l}5.69 \\
5.71 \\
5.74\end{array}$ & $\begin{array}{l}\text { Fernberg } \\
\text { Camp RIpley } \\
\text { Lamberton }\end{array}$ & $\begin{array}{l}\text { MN } \\
M N \\
M N\end{array}$ & $\begin{array}{l}5.14 \\
5.29 \\
5.43\end{array}$ & $\begin{array}{l}\text { Dawson Creek } \\
\text { Quetico Centre } \\
\text { Ear Falls }\end{array}$ & $\begin{array}{l}\text { ON } \\
\text { ON } \\
\text { ON }\end{array}$ & $\begin{array}{l}4.30 \\
5.05 \\
5.39\end{array}$ \\
\hline WINTER & $\begin{array}{l}\text { Beeville } \\
\text { Victorla } \\
\text { Forest Seed Ctr }\end{array}$ & $\begin{array}{l}T X \\
T X \\
T X\end{array}$ & $\begin{array}{l}4.55 \\
4.57 \\
4.61\end{array}$ & $\begin{array}{l}\text { Kane } \\
\text { Wooster } \\
\text { White Rock }\end{array}$ & $\begin{array}{l}P A \\
O H \\
M D\end{array}$ & $\begin{array}{l}4.22 \\
4.27 \\
4.27\end{array}$ & $\begin{array}{l}\text { MoKellar } \\
\text { Mattawa } \\
\text { Dalhousle Mills }\end{array}$ & $\begin{array}{l}\text { ON } \\
\text { ON } \\
\text { ON }\end{array}$ & $\begin{array}{l}4.23 \\
4.24 \\
4.26\end{array}$ \\
\hline & $\begin{array}{l}\text { Organ Plpe Mon. } \\
\text { Logan } \\
\text { Big Bend Nat Park }\end{array}$ & $\begin{array}{l}A Z \\
\text { UT } \\
\text { TX }\end{array}$ & $\begin{array}{l}5.86 \\
6.06 \\
6.45\end{array}$ & $\begin{array}{l}\text { Fayettavilla } \\
\text { Iberla } \\
\text { Everglades Nat, Park }\end{array}$ & $\begin{array}{l}\text { AR } \\
\text { LA } \\
F L\end{array}$ & $\begin{array}{l}4.97 \\
5.05 \\
5.30\end{array}$ & $\begin{array}{l}\text { Jackson } \\
\text { Plokle Lake } \\
\text { Bay d'Espotr }\end{array}$ & $\begin{array}{l}\text { NS } \\
\text { ON } \\
\text { NF }\end{array}$ & $\begin{array}{l}4.80 \\
4.84 \\
5.07\end{array}$ \\
\hline MMER & $\begin{array}{l}\text { Longview } \\
\text { Ollver Knoll } \\
\text { Tanbark Flat }\end{array}$ & $\begin{array}{l}T X \\
A Z \\
C A\end{array}$ & $\begin{array}{l}4.31 \\
4.48 \\
4.55\end{array}$ & $\begin{array}{l}\text { Oxford } \\
\text { Oxford } \\
\text { White Rock }\end{array}$ & $\begin{array}{l}\mathrm{OH} \\
\mathrm{OH} \\
\mathrm{MD}\end{array}$ & $\begin{array}{l}3.91 \\
3.91 \\
3.98\end{array}$ & $\begin{array}{l}\text { Merlin } \\
\text { Oalhousie Mills } \\
\text { Melbourne }\end{array}$ & $\begin{array}{l}\text { ON } \\
\text { ON } \\
\text { ON }\end{array}$ & $\begin{array}{l}4.04 \\
4.04 \\
4.07\end{array}$ \\
\hline & $\begin{array}{l}\text { Woodworth } \\
\text { Red Rock Canyon } \\
\text { Logan }\end{array}$ & $\begin{array}{l}\text { ND } \\
\text { NV } \\
\text { UT }\end{array}$ & $\begin{array}{l}6.09 \\
6.40 \\
6.59\end{array}$ & $\begin{array}{l}\text { Fernberg } \\
\text { Lamberton } \\
\text { E) Verde }\end{array}$ & $\begin{array}{l}M N \\
M N \\
R Q\end{array}$ & $\begin{array}{l}5.33 \\
5.43 \\
5.58\end{array}$ & $\begin{array}{l}\text { Dawson Creek } \\
\text { Expt. Lake Area } \\
\text { Ear Falls }\end{array}$ & $\begin{array}{l}\text { ON } \\
\text { ON } \\
\text { ON }\end{array}$ & $\begin{array}{l}5.34 \\
5.85 \\
6.36\end{array}$ \\
\hline
\end{tabular}

Deposition

\begin{tabular}{|c|c|c|c|c|c|c|c|c|c|}
\hline & $\begin{array}{l}\text { Western United } \\
\text { Sitename }\end{array}$ & $\begin{array}{l}\text { States } \\
\text { State }\end{array}$ & $\mathrm{kg} / \mathrm{ha}$ & $\begin{array}{l}\text { Eastern United S } \\
\text { Sitename }\end{array}$ & $\begin{array}{l}\text { ates } \\
\text { ate }\end{array}$ & $\mathrm{kg} / \mathrm{ha}$ & $\begin{array}{l}\text { Southeastern } \\
\text { Sitename }\end{array}$ & $\begin{array}{l}\text { Canada } \\
\text { Prov }\end{array}$ & $\mathrm{kg} / \mathrm{ha}$ \\
\hline \multirow[t]{2}{*}{ ANNUAL } & $\begin{array}{l}\text { Vines Hill } \\
\text { Alamosa } \\
\text { Las Animas }\end{array}$ & $\begin{array}{l}\text { OR } \\
\text { CO } \\
\text { CO }\end{array}$ & $\begin{array}{l}0.0027 \\
0.0045 \\
0.0050\end{array}$ & $\begin{array}{l}\text { Lamberton } \\
\text { Camp Rtpley } \\
\text { Big Springs Fish H }\end{array}$ & $\begin{array}{l}M N \\
M N \\
\text { IA }\end{array}$ & $\begin{array}{l}0.0148 \\
0.0359 \\
0.0544\end{array}$ & $\begin{array}{l}\text { Ear Falls } \\
\text { Quetico Centre } \\
\text { Dawson Creak }\end{array}$ & $\begin{array}{l}\text { ON } \\
\text { ON } \\
\text { ON }\end{array}$ & $\begin{array}{l}0.0265 \\
0.0813 \\
0.0867\end{array}$ \\
\hline & $\begin{array}{l}\text { Marblemount } \\
\text { Farl ington } \\
\text { Long̣view }\end{array}$ & $\begin{array}{l}\text { WA } \\
\text { KS } \\
\text { TX }\end{array}$ & $\begin{array}{l}0.1818 \\
0.1973 \\
0.2957\end{array}$ & $\begin{array}{l}\text { Blscult Brook } \\
\text { Kane } \\
\text { Bennett Bridge }\end{array}$ & $\begin{array}{l}\text { NY } \\
\text { PA } \\
\text { NY }\end{array}$ & $\begin{array}{l}0.6170 \\
0.6360 \\
0.6791\end{array}$ & $\begin{array}{l}\text { Wllberforce } \\
\text { Turkey Lake } \\
\text { McKellar }\end{array}$ & $\begin{array}{l}\text { ON } \\
\text { ON } \\
\text { ON }\end{array}$ & $\begin{array}{l}0.4952 \\
0.5528 \\
0.5969\end{array}$ \\
\hline WIITER & $\begin{array}{l}\text { Blg Bend Nat Park } \\
\text { Lugan } \\
\text { Newcastle }\end{array}$ & $\begin{array}{l}\text { TX } \\
\text { UT } \\
W Y\end{array}$ & $\begin{array}{l}0.0001 \\
0.0004 \\
0.0006\end{array}$ & $\begin{array}{l}\text { Everglades Nat Park } \\
\text { Fernberg } \\
\text { Camp Ripley }\end{array}$ & $\begin{array}{l}T X \\
M N \\
M N\end{array}$ & $\begin{array}{l}0.0049 \\
0.0060 \\
0.0079\end{array}$ & $\begin{array}{l}\text { Quetico Centre } \\
\text { Plakle Lake } \\
\text { Lac Le Croix(a) }\end{array}$ & $\begin{array}{l}\text { ON } \\
O N \\
O N\end{array}$ & $\begin{array}{l}0.0103 \\
0.0108 \\
0.0112\end{array}$ \\
\hline & $\begin{array}{l}\text { Marblemount } \\
\text { Marshall } \\
\text { Longview }\end{array}$ & $\begin{array}{l}\text { WA } \\
\text { TX } \\
T X\end{array}$ & $\begin{array}{l}0.0509 \\
0.0704 \\
0.0783\end{array}$ & $\begin{array}{l}\text { Kane } \\
\text { Warwick } \\
\text { Bunnett Bridge }\end{array}$ & $\begin{array}{l}P A \\
M A \\
N Y\end{array}$ & $\begin{array}{l}0.1398 \\
0.1689 \\
0.1760\end{array}$ & $\begin{array}{l}\text { Warsaw Caves } \\
\text { Dorset (c) } \\
\text { McKellar }\end{array}$ & $\begin{array}{l}\text { ON } \\
\text { ON } \\
\text { ON }\end{array}$ & $\begin{array}{l}0.1177 \\
0.1281 \\
0.1641\end{array}$ \\
\hline SUMMER & $\begin{array}{l}\text { Logan } \\
\text { Red Rock Canyon } \\
\text { Hopland (Ukiah) }\end{array}$ & $\begin{array}{l}\text { UT } \\
\text { NV } \\
\text { CA }\end{array}$ & $\begin{array}{l}0.0001 \\
0.0001 \\
0.0003\end{array}$ & $\begin{array}{l}\text { Lamberton } \\
\text { McNay Research Sta } \\
\text { Camp Ripley }\end{array}$ & $\begin{array}{l}M N \\
\text { IA } \\
M N\end{array}$ & $\begin{array}{l}0.005 / \\
0.0130 \\
0.0138\end{array}$ & $\begin{array}{l}\text { Ear Falls } \\
\text { Expt. Lake Area } \\
\text { Dawson Creek }\end{array}$ & $\begin{array}{l}O N \\
O N \\
O N\end{array}$ & $\begin{array}{l}0.0012 \\
0.0041 \\
0.0159\end{array}$ \\
\hline & $\begin{array}{l}\text { Glla Cliff Dwelling } \\
\text { Farlington } \\
\text { Longview }\end{array}$ & $\begin{array}{l}\text { NM } \\
\text { KS } \\
\text { TX }\end{array}$ & $\begin{array}{l}0.0511 \\
0.0526 \\
0.1411\end{array}$ & $\begin{array}{l}\text { White Rock } \\
\text { I thaca } \\
\text { Biscuit Brook }\end{array}$ & $\begin{array}{l}\text { MD } \\
\text { NY } \\
\text { NY }\end{array}$ & $\begin{array}{l}0.2636 \\
0.2654 \\
0.2706\end{array}$ & $\begin{array}{l}\text { Waterloo } \\
\text { Mattawa } \\
\text { Turkey lake }\end{array}$ & $\begin{array}{l}O N \\
O N \\
O N\end{array}$ & $\begin{array}{l}0.1893 \\
0.2148 \\
0.2364\end{array}$ \\
\hline
\end{tabular}


TABLE A.12. Minimum and Maximum Annual, Winter, and Summer Sulfate Precipitation-weighted Concentrations and Total Deposition observed at ADS Sites in 1988 by Region

Concentration

\begin{tabular}{|c|c|c|c|c|c|c|c|c|c|}
\hline \multirow{3}{*}{ ANNUAL } & \multicolumn{3}{|c|}{ Western United States } & \multicolumn{3}{|c|}{ Eastern United States } & \multicolumn{3}{|c|}{ Southeastern Canada } \\
\hline & Sitename & tate & $\mathrm{mg} / \mathrm{l}$ & Sitename & State & $\mathrm{mg} / 1$ & Sitename & Prov & $\mathrm{mg} / \mathrm{l}$ \\
\hline & $\begin{array}{l}\text { H.J. Andrews } \\
\text { Starkey Experiment } \\
\text { Headquarters }\end{array}$ & $\begin{array}{l}O R \\
O R \\
I D\end{array}$ & $\begin{array}{l}0.19 \\
0.20 \\
0.24\end{array}$ & $\begin{array}{l}\text { Everglades Nat Park } \\
\text { Fernberg } \\
\text { Fernberg }\end{array}$ & $\begin{array}{l}F L \\
M N \\
M N\end{array}$ & $\begin{array}{l}0.76 \\
0.91 \\
0.91\end{array}$ & $\begin{array}{l}\text { Jackson } \\
\text { Quetico Centre } \\
\text { Bonner Lake }\end{array}$ & $\begin{array}{l}\text { NS } \\
\text { ON } \\
\text { ON }\end{array}$ & $\begin{array}{l}0.83 \\
0.92 \\
1.05\end{array}$ \\
\hline & $\begin{array}{l}\text { Beeville } \\
\text { Longview } \\
\text { Mead }\end{array}$ & $\begin{array}{l}\text { TX } \\
\text { TX } \\
\text { NE }\end{array}$ & $\begin{array}{l}1.75 \\
1.80 \\
2.03\end{array}$ & $\begin{array}{l}\text { Wooster } \\
\text { Oxford } \\
\text { Caldwell }\end{array}$ & $\begin{array}{l}\mathrm{OH} \\
\mathrm{OH} \\
\mathrm{OH}\end{array}$ & $\begin{array}{l}3.62 \\
3.62 \\
3.63\end{array}$ & $\begin{array}{l}\text { Port Stanley } \\
\text { Alvinston } \\
\text { Wilkesport }\end{array}$ & $\begin{array}{l}\text { ON } \\
\text { ON } \\
\text { ON }\end{array}$ & $\begin{array}{l}4.38 \\
5.77 \\
6.19\end{array}$ \\
\hline WINTER & $\begin{array}{l}\text { Starkey Experiment } \\
\text { Sequota Nat Park } \\
\text { Montague }\end{array}$ & $\begin{array}{l}\text { OR } \\
C A \\
C A\end{array}$ & $\begin{array}{l}0.09 \\
0.12 \\
0.13\end{array}$ & $\begin{array}{l}\text { Everglades Nat Park } \\
\text { Trout Lake } \\
\text { Fernberg }\end{array}$ & $\begin{array}{l}F L \\
W I \\
M N\end{array}$ & $\begin{array}{l}0.52 \\
0.56 \\
0.59\end{array}$ & $\begin{array}{l}\text { Port Cartier } \\
\text { Plckle Lake } \\
\text { Harcourt }\end{array}$ & $\begin{array}{l}\text { PQ } \\
\text { ON } \\
\text { NB }\end{array}$ & $\begin{array}{l}0.40 \\
0.66 \\
0.88\end{array}$ \\
\hline & $\begin{array}{l}\text { Attwater Prairie C } \\
\text { Beeville } \\
\text { Victoria }\end{array}$ & $\begin{array}{l}T X \\
T X \\
T X\end{array}$ & $\begin{array}{l}1.70 \\
2.13 \\
2.53\end{array}$ & $\begin{array}{l}\text { Kane } \\
\text { Caldwell } \\
\text { Wooster }\end{array}$ & $\begin{array}{l}\mathrm{PA} \\
\mathrm{OH} \\
\mathrm{OH}\end{array}$ & $\begin{array}{l}2.41 \\
2.57 \\
2.65\end{array}$ & $\begin{array}{l}\text { Palmerston } \\
\text { Port Staniey } \\
\text { Wilikesport }\end{array}$ & $\begin{array}{l}\text { ON } \\
\text { ON } \\
\text { ON }\end{array}$ & $\begin{array}{l}4.11 \\
4.26 \\
5.19\end{array}$ \\
\hline JMMER & $\begin{array}{l}\text { H.J. Andrews } \\
\text { Hopland (Ukiah) } \\
\text { Vines Hill }\end{array}$ & $\begin{array}{l}O R \\
C A \\
O R\end{array}$ & $\begin{array}{l}0.18 \\
0.34 \\
0.34\end{array}$ & $\begin{array}{l}\text { El Verde } \\
\text { Everglades Nat Park } \\
\text { Fernberg }\end{array}$ & $\begin{array}{l}\text { RQ } \\
\mathrm{FL} \\
\mathrm{MN}\end{array}$ & $\begin{array}{l}0.65 \\
0.68 \\
0.86\end{array}$ & $\begin{array}{l}\text { Quetico Centre } \\
\text { Lac Le Croixla } \\
\text { Bonner Lake }\end{array}$ & $\begin{array}{l}\text { ON } \\
\text { ON } \\
\text { ON }\end{array}$ & $\begin{array}{l}0.74 \\
0.85 \\
0.92\end{array}$ \\
\hline & $\begin{array}{l}\text { Nash Fork } \\
\text { ol iver Knoll } \\
\text { Longview }\end{array}$ & $\begin{array}{l}W Y \\
A Z \\
T X\end{array}$ & $\begin{array}{l}1.87 \\
1.90 \\
2.48\end{array}$ & $\begin{array}{l}\text { Huntington } \\
\text { oxford } \\
\text { Oxford }\end{array}$ & $\begin{array}{l}\text { IN } \\
\mathrm{OH} \\
\mathrm{OH}\end{array}$ & $\begin{array}{l}5.27 \\
5.55 \\
6.16\end{array}$ & $\begin{array}{l}\text { Merlin } \\
\text { Alvinston } \\
\text { Wilkesport }\end{array}$ & $\begin{array}{l}\text { ON } \\
\text { ON } \\
\text { ON }\end{array}$ & $\begin{array}{r}5.68 \\
12.81 \\
15.04\end{array}$ \\
\hline
\end{tabular}

Deposition

Western United States

Eastern United States

Sitename

ANNUAL Vines Hill

Reynolds Creek

State $\mathrm{mg} / \mathrm{l}$

0.57

0.60 Fernberg

Lamberton

Spooner

Great Plains Apiar OK

Longview

Farlington

WINTER

Cottonwood
Pinedale
Yellowstone

Alsea

Forest Seed Ctr

Longview

SUMMER Hopland (Ukiah)

Reynolds Creek

Vines $\mathrm{Hill}$

Mayhill

Farlington

Longview
10.44

17.73

18.38

Kane

Parsons

Bennett Bridge

0.06

0.09

0.09

Fernberg

Fernberg

Camp Ripley

2.33 Salem

2.55 Univ Forest

4.77 Southwest Purdue

0.03 Lamberton

0.06 Coffeeville

0.06 Isle Royale Nat

3.73 Piedmont Station

4.40 Virginia

7.09 Wooster

$\begin{array}{lrlrr}\text { State } & m g / 1 & \text { Sitename } & \text { Prov } & \mathrm{mg} / 1 \\ \text { MN } & 6.40 & \text { Quetico Ctr } & \text { ON } & 8.45 \\ \text { MN } & 7.80 & \text { Quetico Ctr } & \text { ON } & 10.49 \\ \text { WI } & 7.88 & \text { Dawson Creek } & \text { ON } & 10.76 \\ & & & & \\ \text { PA } & 31.02 & \text { Wilkesport } & \text { ON } & 32.16 \\ \text { WV } & 31.55 & \text { McKeliar } & \text { ON } & 35.08 \\ \text { NY } & 33.65 & \text { Alvinston } & \text { ON } & 39.11 \\ & & & & \\ \text { MN } & 0.20 & \text { Dawson Creek } & \text { ON } & 0.59 \\ \text { MN } & 0.38 & \text { Pickle Lake } & \text { ON } & 0.84 \\ \text { MN } & 0.41 & \text { Port Cartier } & \text { PQ } & 0.94 \\ & & & & \\ \text { IL } & 6.33 & \text { Port Stanley } & \text { ON } & 13.48 \\ \text { MO } & 6.67 & \text { Shallow Lake } & \text { ON } & 14.23 \\ \text { IN } & 7.23 & \text { McKellar } & \text { ON } & 16.00 \\ & & & & \\ \text { MN } & 1.79 & \text { Moosonee } & \text { ON } & 2.10 \\ \text { MS } & 2.20 & \text { Expt Lake Area ON } & 2.91 \\ \text { MI } & 2.49 & \text { Ear Falls } & \text { ON } & 3.04 \\ \text { NC } & 12.86 & \text { Coldwater } & \text { ON } & 12.50 \\ \text { VA } & 12.99 & \text { Wilkesport } & \text { ON } & 16.84 \\ \text { OH } & 13.21 & \text { Alvinston } & \text { ON } & 19.85\end{array}$




\section{TABLE A.13. Minimum and Maximum Annual, Winter, and Summer Nitrate Precipitation-weighted Concentrations and Total Deposition Observed at ADS Sites in 1988 by Region}

Concentration

\begin{tabular}{|c|c|c|c|c|c|c|c|c|c|}
\hline & \multicolumn{3}{|c|}{ Western United States } & \multicolumn{3}{|c|}{ Eastern United States } & \multicolumn{3}{|c|}{ Southeastern Canada } \\
\hline & Sitename & tate & $\mathrm{mg} / \mathrm{l}$ & Sitename & State & $\mathrm{mg} / \mathrm{l}$ & Sitename & Prov & $\mathrm{mg} / 1$ \\
\hline \multirow[t]{2}{*}{ ANNUAL } & $\begin{array}{l}\text { H.J. Andrews } \\
\text { Srarkey Experiment } \\
\text { Hyslop Farm }\end{array}$ & $\begin{array}{l}O R \\
O R \\
O R\end{array}$ & $\begin{array}{l}0.08 \\
0.18 \\
0.20\end{array}$ & $\begin{array}{l}\text { Everglades Nat Park } \\
\text { Tifton, ARS } \\
\text { Southeast }\end{array}$ & $\begin{array}{l}F L \\
G A \\
L A\end{array}$ & $\begin{array}{l}0.41 \\
0.51 \\
0.59\end{array}$ & $\begin{array}{l}\text { Jackson } \\
\text { Kejimkujik(b) } \\
\text { Port Cartier }\end{array}$ & $\begin{array}{l}\text { NS } \\
\text { NS } \\
\text { PO }\end{array}$ & $\begin{array}{l}0.51 \\
0.72 \\
0.78\end{array}$ \\
\hline & $\begin{array}{l}\text { Goodwell Research } \\
\text { Manitou } \\
\text { Mead }\end{array}$ & $\begin{array}{l}\text { OK } \\
\text { CO } \\
\text { NE }\end{array}$ & $\begin{array}{l}1.39 \\
1.45 \\
1.74\end{array}$ & $\begin{array}{l}\text { Ithaca } \\
\text { Kane } \\
\text { Bennett Bridge }\end{array}$ & $\begin{array}{l}\text { NY } \\
\text { PA } \\
\text { NY }\end{array}$ & $\begin{array}{l}2.12 \\
2.22 \\
2.35\end{array}$ & $\begin{array}{l}\text { Port Stanley } \\
\text { Alvinston } \\
\text { Wilkesport }\end{array}$ & $\begin{array}{l}\text { ON } \\
\text { ON } \\
\text { ON }\end{array}$ & $\begin{array}{l}3.37 \\
3.62 \\
3.76\end{array}$ \\
\hline \multirow[t]{2}{*}{ WINTER } & $\begin{array}{l}\text { Al sea } \\
\text { H.J. Andrews } \\
\text { Starkey Experiment }\end{array}$ & $\begin{array}{l}O R \\
O R \\
O R\end{array}$ & $\begin{array}{l}0.06 \\
0.08 \\
0.10\end{array}$ & $\begin{array}{l}\text { Everglades Nat Park } \\
\text { Tifton, ARS } \\
\text { Bellville }\end{array}$ & $\begin{array}{l}F L \\
G A \\
G A\end{array}$ & $\begin{array}{l}0.25 \\
0.34 \\
0.36\end{array}$ & $\begin{array}{l}\text { Kejimkujik(b) } \\
\text { Kejimkujik } 2 \\
\text { Port Cartier }\end{array}$ & $\begin{array}{l}\text { NS } \\
\text { NS } \\
P Q\end{array}$ & $\begin{array}{l}0.72 \\
0.75 \\
0.89\end{array}$ \\
\hline & $\begin{array}{l}\text { Scott Lake } \\
\text { Green River } \\
\text { Lancaster }\end{array}$ & $\begin{array}{l}\text { KS } \\
\text { UT } \\
\text { KS }\end{array}$ & $\begin{array}{l}1.28 \\
1.74 \\
1.83\end{array}$ & $\begin{array}{l}\text { Big Moose } \\
\text { Underhill } \\
\text { Bennett Bridge }\end{array}$ & $\begin{array}{l}\text { NY } \\
\text { VT } \\
\text { NY }\end{array}$ & $\begin{array}{l}2.49 \\
2.51 \\
2.93\end{array}$ & $\begin{array}{l}\text { Port Stanley } \\
\text { Dalhousie Mills } \\
\text { Wilkesport }\end{array}$ & $\begin{array}{l}\text { ON } \\
\text { ON } \\
\text { ON }\end{array}$ & $\begin{array}{l}3.93 \\
4.25 \\
4.94\end{array}$ \\
\hline \multirow[t]{2}{*}{ SUMMER } & $\begin{array}{l}\text { Davis } \\
\text { Hopland (Ukiah) } \\
\text { Alsea }\end{array}$ & $\begin{array}{l}C A \\
C A \\
O R\end{array}$ & $\begin{array}{l}0.01 \\
0.01 \\
0.02\end{array}$ & $\begin{array}{l}\text { El Verde } \\
\text { Everglades Nat Park } \\
\text { Tifton. ARS }\end{array}$ & $\begin{array}{l}\text { RQ } \\
\text { FL } \\
\text { GA }\end{array}$ & $\begin{array}{l}0.08 \\
0.31 \\
0.61\end{array}$ & $\begin{array}{l}\text { Quetico Centre } \\
\text { Chapais } \\
\text { Bonner Lake }\end{array}$ & $\begin{array}{l}O N \\
P Q \\
O N\end{array}$ & $\begin{array}{l}0.42 \\
0.57 \\
0.60\end{array}$ \\
\hline & $\begin{array}{l}\text { Chuchupate } \\
\text { Red Rock Canyon } \\
\text { Tanbark Flat }\end{array}$ & $\begin{array}{l}\text { CA } \\
N V \\
\text { CA }\end{array}$ & $\begin{array}{l}2.56 \\
2.95 \\
4.09\end{array}$ & $\begin{array}{l}\text { Caldwell } \\
\text { Oxford } \\
\text { Brookhaven }\end{array}$ & $\begin{array}{l}O H \\
O H \\
N Y\end{array}$ & $\begin{array}{l}2.65 \\
2.71 \\
2.78\end{array}$ & $\begin{array}{l}\text { Wellesley } \\
\text { Wilkesport } \\
\text { Alvinston }\end{array}$ & $\begin{array}{l}\text { ON } \\
\text { ON } \\
\text { ON }\end{array}$ & $\begin{array}{l}3.18 \\
5.11 \\
5.26\end{array}$ \\
\hline
\end{tabular}

Deposition

Western United States

Sitename State $\mathrm{kg} / \mathrm{ha}$

ANNUAL Silver Lake Ranger.

Yellowstone

Vines $\mathrm{HIll}$

Mead

Longview

Farlington

WINTER Cottonwood

Organ Pipe Mon

Si Tver Lake Ranger

\section{Longview \\ Marshall}

Dry Lake

SUMMER Hopland (Ukiah)

Davis

Al sea

Manitou

Farlington

Longview

$\begin{array}{lrl}\text { OR } & 0.483 & \text { Everglades Nat Park } \\ \text { WY } & 0.773 & \text { Lamberton } \\ \text { OR } & 0.777 & \text { Tifton. ARS } \\ & & \\ \text { NE } & 8.136 & \text { Kellogg } \\ \text { TX } & 8.785 & \text { Kane } \\ \text { KS } & 12.167 & \text { Bennett Bridge } \\ & & \\ \text { SO } & 0.098 & \text { Everglades Nat Park } \\ \text { AZ } & 0.108 & \text { Fernberg } \\ \text { OR } & 0.108 & \text { Lake Dubay } \\ & & \\ \text { TX } & 2.235 & \text { Big Moose } \\ \text { TX } & 2.498 & \text { Warwick } \\ \text { CO } & 2.761 & \text { Bennett Bridge } \\ & & \\ \text { CA } & 0.001 & \text { El Verde } \\ \text { CA } & 0.003 & \text { Coffeeville } \\ \text { OR } & 0.010 & \text { Tifton. ARS } \\ & & \\ \text { CO } & 3.376 & \text { White Rock } \\ \text { KS } & 3.391 & \text { Wooster } \\ \text { TX } & 3.568 & \text { Kellogg }\end{array}$

\section{Eastern United States}

State $\mathrm{kg} / \mathrm{ha}$ Sitename Prov $\mathrm{kg} / \mathrm{ha}$

FL

MN

GA

PI

NY

FL $\quad 0.246$ Dawson Creek ON 1.208

MN 0.471 Port Cartier PQ 2.088

WI $\quad 0.598$ Expt Lake Area ON 2.530

NY 6.535 Shallow Lake ON 14.550

MA 6.972 Dorset (c) ON 15.222

NY 10.887 McKellar ON 18.442

RQ $\quad 0.976$ Moosonee ON 1.439

MS 1.113 Port Cartier PQ 1.788

GA $\quad 1.600$ Chapais $\quad P Q \quad 1.835$

MD 6.401 Longwoods (b) ON 6.444

$\mathrm{OH} \quad 6.807$ Shallow Lake ON 6.857

MI $\quad 7.712$ Alvinston ON 8.160 
TABLE A.14. Minimum and Maximum Annual, Winter, and Summer Ammonium Precipitation-weighted Concentrations and Total Deposition Observed at ADS Sites in 1988 by Region

Concentration

0.010

0.010

Scott Lake

Mead

Logan

SUMMER Bull Run

Davis

Hopl and (Ukiah)

$\begin{array}{ll}\text { WA } & 0.010 \\ \text { OR } & 0.010\end{array}$

Everglades Nat Park

Perryutlle

$\begin{array}{lll}\text { KS } & 0.418 & \text { Camp Ripley } \\ \text { NE } & 0.539 & \text { Finley (A) }\end{array}$

Greenville Station

Camp Ripley

UT 0.568 Shawano

Huron Well Field

Tanbark Flat

Woodworth

$\begin{array}{lll}\text { OR } & 0.010 & \text { El Verde } \\ \text { CA } & 0.010 & \text { Everglades Nat Park } \\ \text { CA } & 0.010 & \text { Blackbelt }\end{array}$

IA $\quad 0.499$

IL $\quad 0.511$

MN 0.521

FL $\quad 0.022$

KY $\quad 0.026$

ME $\quad 0.028$

MN 0.295

NC $\quad 0.367$

WI 0.397

RQ $\quad 0.010$

FL $\quad 0.010$

AL $\quad 0.020$

\section{SO 0.532 Illinois}

CA $\quad 0.550$ oxford

NO 0.568 Caldwell

Deposition

Western United States

Si tename

State

ANNUAL

Silver Lake Ranger $O R$

Starkey Experiment $O R$

South Pass City

Goodwell Research

Farlington

Mead

OK

KS

NE

OR 0.06

0.063

0.088

0.092

1.646
2.293

2.545

\section{Eastern United States}

State $\mathrm{mg} / \mathrm{l}$

$\begin{array}{ll}\text { Everglades Nat Park } & F L \\ \text { Santee National Wi } & \text { SC }\end{array}$

Kennedy Space Center FL.

0.541

0.617

0.844

\begin{tabular}{lll}
\multicolumn{2}{c}{$\begin{array}{l}\text { Southeastern } \\
\text { Sitename }\end{array}$} & $\begin{array}{c}\text { Canada } \\
\text { Prov }\end{array}$ \\
Jackson & NS & 0.084 \\
Kejimkujik(b) & NS & 0.098 \\
Port Cartier & PQ & 0.100 \\
Wellesiey & ON & 0.739 \\
Wilkesport & ON & 0.854 \\
Alvinston & ON & 1.002 \\
& & \\
Port Cartier & PQ & 0.035 \\
Pickle Lake & ON & 0.037 \\
Jackson & NS & 0.037 \\
& & \\
Dalhousie Mills & ON & 0.894 \\
Palmerston & ON & 1.196 \\
Wilkesport & ON & 1.236 \\
& & \\
Jackson & NS & 0.121 \\
Port Cartier & PQ & 0.139 \\
Kejimkujik (b) & NS & 0.140 \\
& & \\
Wellesley & ON & 0.933 \\
McKellar & ON & 1.374 \\
Alvinston & ON & 1.916 \\
& &
\end{tabular}

WINTER

$\downarrow$

\begin{tabular}{|c|c|c|c|c|}
\hline & $\begin{array}{l}\text { Pinedale } \\
\text { Silver lake Ranger } \\
\text { Clancy }\end{array}$ & $\begin{array}{l}W Y \\
\text { OR } \\
\text { MT }\end{array}$ & $\begin{array}{l}0.007 \\
0.012 \\
0.013\end{array}$ & $\begin{array}{l}\text { Everglades Nat Park } \\
\text { Trout Lake } \\
\text { Fernberg }\end{array}$ \\
\hline & $\begin{array}{l}\text { Tanbark Flat } \\
\text { Davis } \\
\text { Marshall }\end{array}$ & $\begin{array}{l}C A \\
C A \\
T X\end{array}$ & $\begin{array}{l}0.509 \\
0.589 \\
1.863\end{array}$ & $\begin{array}{l}\text { Pittsboro } \\
\text { Warwick } \\
\text { Bennett Bridge }\end{array}$ \\
\hline SUMMER & $\begin{array}{l}\text { Hopland (Ukiah) } \\
\text { Reynolds Creek } \\
\text { Davis }\end{array}$ & $\begin{array}{l}C A \\
I D \\
C A\end{array}$ & $\begin{array}{l}0.001 \\
0.001 \\
0.002\end{array}$ & $\begin{array}{l}\text { Buffalo River } \\
\text { Tifton, ARS } \\
\text { Southern IL U }\end{array}$ \\
\hline & $\begin{array}{l}\text { Pawnee } \\
\text { Woodworth } \\
\text { Scott Lake }\end{array}$ & $\begin{array}{l}\text { CO } \\
\text { ND } \\
\text { KS }\end{array}$ & $\begin{array}{l}0.629 \\
0.740 \\
0.759\end{array}$ & $\begin{array}{l}\text { Kellogg } \\
\text { Caldwel } \\
\text { Fernberg }\end{array}$ \\
\hline
\end{tabular}

\begin{tabular}{|c|c|c|c|c|}
\hline & $\begin{array}{l}\text { Pinedale } \\
\text { Silver lake Ranger } \\
\text { Clancy }\end{array}$ & $\begin{array}{l}W Y \\
\text { OR } \\
\text { MT }\end{array}$ & $\begin{array}{l}0.007 \\
0.012 \\
0.013\end{array}$ & $\begin{array}{l}\text { Everglades Nat Park } \\
\text { Trout Lake } \\
\text { Fernberg }\end{array}$ \\
\hline & $\begin{array}{l}\text { Tanbark Flat } \\
\text { Davis } \\
\text { Marshall }\end{array}$ & $\begin{array}{l}C A \\
C A \\
T X\end{array}$ & $\begin{array}{l}0.509 \\
0.589 \\
1.863\end{array}$ & $\begin{array}{l}\text { Pittsboro } \\
\text { Warwick } \\
\text { Bennett Bridge }\end{array}$ \\
\hline SUMMER & $\begin{array}{l}\text { Hopland (Ukiah) } \\
\text { Reynolds Creek } \\
\text { Davis }\end{array}$ & $\begin{array}{l}C A \\
I D \\
C A\end{array}$ & $\begin{array}{l}0.001 \\
0.001 \\
0.002\end{array}$ & $\begin{array}{l}\text { Buffalo River } \\
\text { Tifton. ARS } \\
\text { Southern IL U }\end{array}$ \\
\hline & $\begin{array}{l}\text { Pawnee } \\
\text { Woodworth } \\
\text { Scott Lake }\end{array}$ & $\begin{array}{l}\text { CO } \\
\text { ND } \\
\text { KS }\end{array}$ & $\begin{array}{l}0.629 \\
0.740 \\
0.759\end{array}$ & $\begin{array}{l}\text { Kellogg } \\
\text { Caldwel } \\
\text { Fernberg }\end{array}$ \\
\hline
\end{tabular}

\begin{tabular}{|c|c|c|c|c|}
\hline $\begin{array}{l}\text { tes } \\
\text { tate }\end{array}$ & $\mathrm{mg} / \mathrm{l}$ & $\begin{array}{l}\text { Southeastern } \\
\text { Sitename }\end{array}$ & $\begin{array}{l}\text { Canada } \\
\text { Prov }\end{array}$ & $\mathrm{mg} / \mathrm{l}$ \\
\hline SC & $\begin{array}{l}0.444 \\
0.523 \\
0.642\end{array}$ & $\begin{array}{l}\text { Port Cartier } \\
\text { Jackson } \\
\text { Kejimkujik (b) }\end{array}$ & $\begin{array}{l}\text { PQ } \\
\text { NS } \\
\text { NS }\end{array}$ & $\begin{array}{l}1.218 \\
1.286 \\
1.400\end{array}$ \\
\hline $\begin{array}{l}H \\
L \\
I\end{array}$ & $\begin{array}{l}3.772 \\
3.829 \\
4.556\end{array}$ & $\begin{array}{l}\text { Alvinston } \\
\text { Turkey Lake } \\
\text { McKellar }\end{array}$ & $\begin{array}{l}\text { ON } \\
\text { ON } \\
\text { ON }\end{array}$ & $\begin{array}{l}6.789 \\
6.942 \\
8.433\end{array}$ \\
\hline 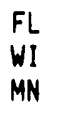 & $\begin{array}{l}0.021 \\
0.024 \\
0.036\end{array}$ & $\begin{array}{l}\text { Pickle Lake } \\
\text { Port Cartier } \\
\text { Dawson Creek }\end{array}$ & $\begin{array}{l}\text { ON } \\
P Q \\
\text { ON }\end{array}$ & $\begin{array}{l}0.047 \\
0.083 \\
0.141\end{array}$ \\
\hline & $\begin{array}{l}0.772 \\
0.814 \\
0.857\end{array}$ & $\begin{array}{l}\text { Turkey Lake } \\
\text { McKellar } \\
\text { Palmerston }\end{array}$ & $\begin{array}{l}\text { ON } \\
\text { ON } \\
\text { ON }\end{array}$ & $\begin{array}{l}3.269 \\
3.533 \\
3.583\end{array}$ \\
\hline L & $\begin{array}{l}0.043 \\
0.060 \\
0.066\end{array}$ & $\begin{array}{l}\text { Jackson } \\
\text { Port Cartier } \\
\text { Moosonee }\end{array}$ & $\begin{array}{l}N S \\
P Q \\
\text { ON }\end{array}$ & $\begin{array}{l}0.384 \\
0.388 \\
0.432\end{array}$ \\
\hline $\mathrm{OH}$ & $\begin{array}{l}1.528 \\
1.799 \\
2.252\end{array}$ & $\begin{array}{l}\text { Lac Le Croix(a) } \\
\text { Alvinston } \\
\text { McKellar }\end{array}$ & $\begin{array}{l}\text { ON } \\
\text { ON } \\
\text { ON }\end{array}$ & $\begin{array}{l}2.791 \\
2.970 \\
3.656\end{array}$ \\
\hline
\end{tabular}


TABLE A,15. Minimum and Maximum Annual, Winter, and Summer Calcium Precipitation-weighted Concentrations and Total Deposition Observed at ADS Sites in 1988 by Region

Concentration

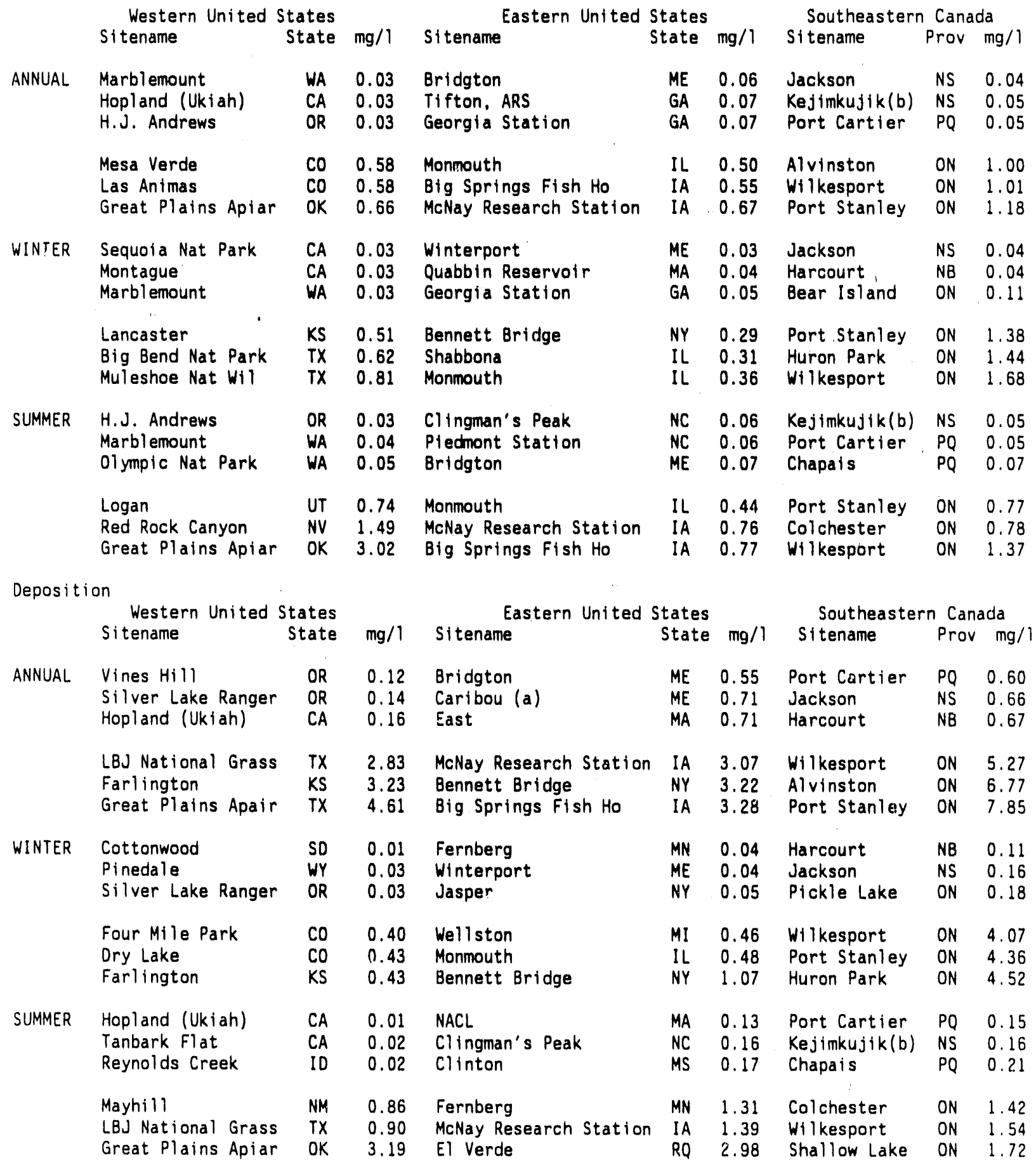


PNL -8049

UC -402

\section{DISTRIBUTION}

No. of

Copies

OFFSITE

James A. Reagan

Atmospheric Research and Exposure Assessment Laboratory

U.S. Environmental Protection Agency

Research Triangle Park, NC 27711

12 DOE/Office of Scientific and Technical Information

D. Beecy

U.S. Department of Energy

Office of Planning and Environment

FE-13, Room C-176 (GTN)

Washington, DC 20545

G. Jordy

U.S. Department of Energy

Office of Program Analysis

MS ER-30, GTN

Washington, DC 20545

D. H. Slade

U.S. Department of Energy

ER-74, GTN

Washington, DC 20545

D. Winstanley

U.S. Department of Energy

Office of Energy Research

MS-G226, ER-32

Washington, DC 20545
No. of

Copies

OFFSITE

M. A. Allan

Energy Analysis and Environment Division

Electric Power Research Institute

P.0. Box 10412

Palo Alto, CA 94303

D. S. Bigelow

Natural Resource Ecology Laboratory

Colorado State University

Fort Collins, CO 80523

v. C. Bowersox

Central Analytical Laboratory

Illinois State Water Survey

2204 Griffith Drive

Champaign, IL 61820

S. Bromberg

Atmospheric Research and Exposure Assessment Laboratory, MD-75

U.S. Environmental Protection Agency

Research Triangle Park, NC 27711

R. Dennis

Atmospheric Research and Exposure Assessment Laboratory, MD-80

U.S. Environmental Protection Agency

Research Triangle Park, NC 27711 
No. of

Copies

J. H. Gibson

Natural Research Ecology Laboratory

Colorado State University

Fort Collins, CO $\mathbf{8 0 5 2 3}$

B. B. Hicks

NOAA - Air Resources Laboratory

Atmospheric Turbulence and

Diffusion Division

$456 \mathrm{~S}$. IIl inois Avenue

Oak Ridge, TN 37830

F. P. Kapinos

U.S. Geological Survey

414 National Center

Reston, VA 22092

W. W. Knapp

Department of Agronomy

1111 Bradfield Hall

Cornell University

Ithaca, NY 14853

\section{$J$. Mahoney}

Director of Research

NAPAP Office of the Director

722 Jackson Place, NW

Washington, DC 20503

J. M. Miller

NOAA - Air Resources Laboratory

6010 Executive Boulevard

Rockville, MD 20852

V. A. Mohnen

Earth Sciences Building, Room 324

State University of New York at Albany

1400 Washington Avenue

Albany, NY 12222
No. of

Copies

P. K. Muller

Environmental Assessment

Department

Electric Power Research Institute

P.0. Box 10412

Palo Alto, CA 94303

National Wildlife Federation Toxics and Pollution Program 1412 16th Street NW

Washington, DC 20036

B. L. Niemann

Office of Air and Radiation (OAR-455)

U.S. Environmental Protection Agency

Washington, DC 20460

Anthony R. 01 sen

Environmental Research Laboratory

U.S. Environmental Protection Agency

Corvallis, OR 97333

J. Pickering

U.S. Geological Survey, MS 416

412 National Center

Reston, VA 22092

D. Renne

NAPAP Office of the Director

722 Jackson $\mathrm{Place}$, NW

Washington, DC 20503

F. Schiermeier

Atmospheric Research and Expos'iie Assessment Labiratory, MD-80

U.S. Elvironmental Protection Agency

Research iriangle Park, NC 27711 
No. of

Copies

D. Sheiman

Natural Resources Defense

Council

1350 New York, NW

Washington, DC 20005

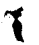

D. Sisterson

Argonne National Laboratory

9700 South Cass Avenue

Argonne, IL 60439

G. J. Stensland

Ill inois State Water Survey

2204 Griffith Drive

Champaign, IL 61820

R. J. Vong

U.S. Environmental Protection Agency

200 SW 35th Street

Corvallis, OR 97333

D. Winters

Office of Air and Radiation (OAR-455)

U.S. Environmental Protection Agency

Washington, DC 20460

\section{FOREIGN}

L. A. Barrie

Atmospheric Environment Service

4905 Dufferin Street

Downsview, Ontario M3H 5 T4

CANADA

H. Dovland

Norwegian Institute for

Air Research

P.B. 130, N-2001 Lillestrom

Elvegt. 52

NORWAY
No. of

Copies

\author{
L. Granat \\ Department of Meteorology \\ University of Stockholm \\ Arrhenius Laboratory S-106 91 \\ Stockholm \\ SWEDEN
}

M. A. Lusis

Air Resources Branch

Ontario Ministry of the Environment

880 Bay Street

Toronto, Ontario M5S 178

CANADA

J. Schaug

Norwegian Institute for Air Research

P.B. 130, N-2001 Lillestrom

Elvegt. 52

NORWAY

P. W. Summers

Atmospheric Environment Service 4905 Dufferin Street

Downsview, Ontario M3H 5T4

CANADA

R. J. Vet

Atmospheric Environment Service 4905 Dufferin Street

Downsview, Ontario M3H 5T4

CANADA

E. Voldner

Atmospheric Environment Service 4905 Dufferin Street

Downsview, Ontario M3H 5T4

CANADA

D. M. Whelpdale Atmospheric Environment Service 4905 Dufferin Street

Downsview, Ontario M3H 5T4

CANADA 
No. of

Copies

J. V. Zidek

University of British Columbia

2021 West Mall

Vancouver, BC V6T 1W5

CANADA

\section{ONSITE}

16 Pacific Northwest Laboratory

W. R. Barchet

E. A. Bittner

M. T. Dana

J. M. Hales

E. W. Pearson

J. C. Simpson (5)

Publishing Coordination

Technical Report Files (5)

Distr. 4 

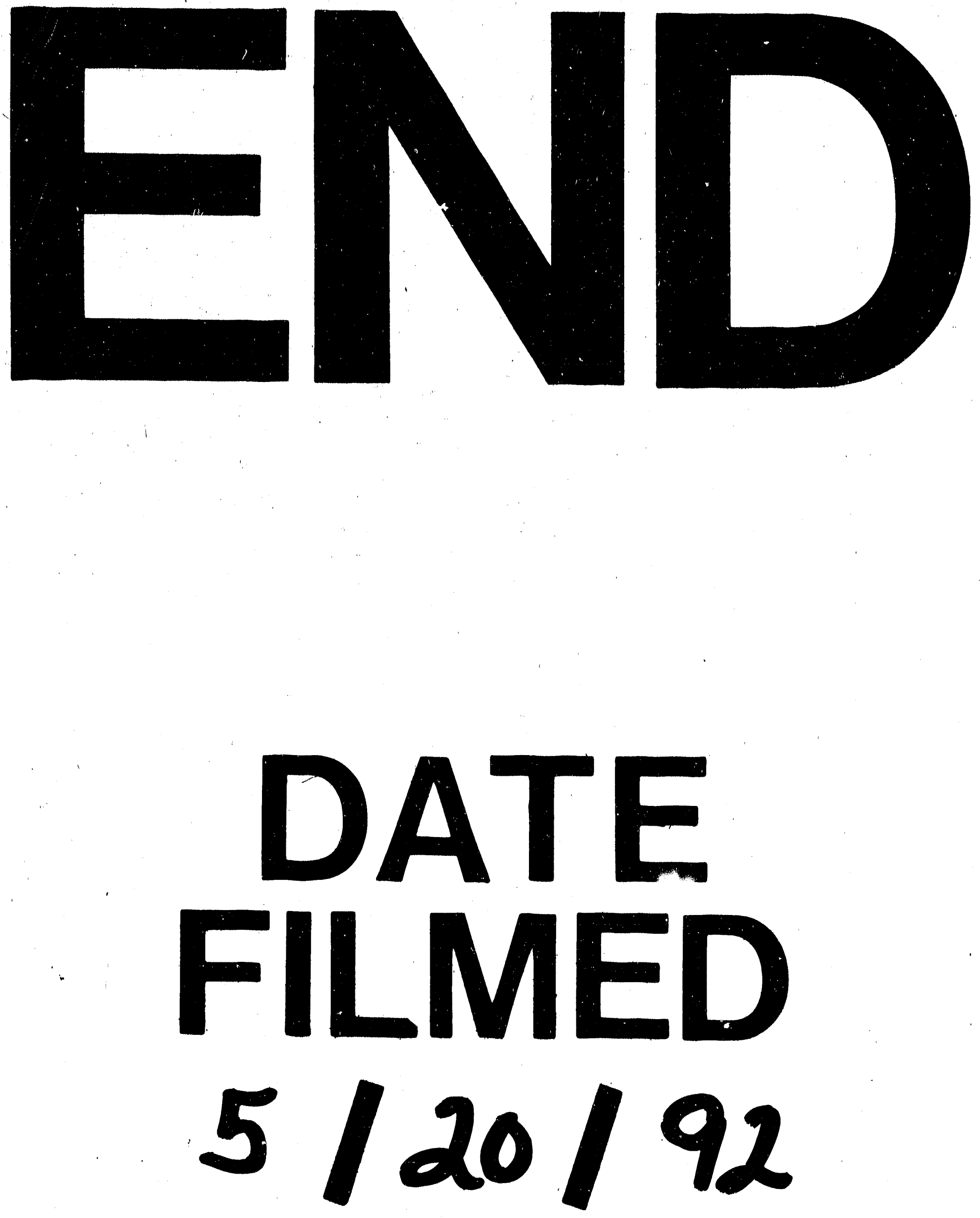
